


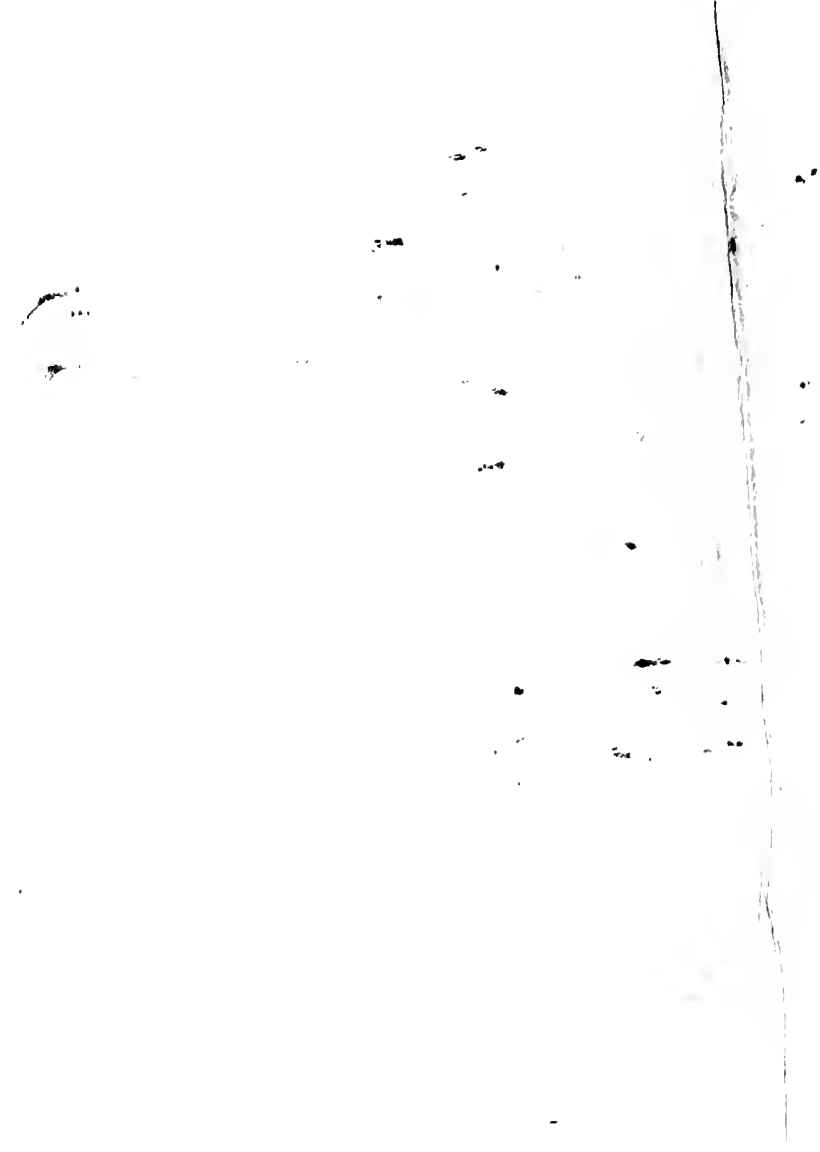




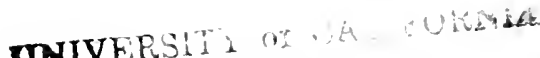

ONIVERSI i is

LOS ANGLLES 



\title{
ETOLUTION OF LAW:
}

SELECT READINGS ON THE ORIGIN AND DEVELOPMENT OF LEGAL INSTITUTIONS

\section{PRIMITIVE AND ANCIENT LEGAL INSTITUTIONS}

\author{
COMPILED BY \\ ALBERT KOCOUREK \\ PROFESSOR OF JCRISPRCDENCE IN NORTHWESTERN LNIVERSITY \\ $A \times D$ \\ JOHN H. WIGMORE \\ PROFESSOR OF LAW IN NORTIWESTERN CYIVERSITY
}

BOSTON

LITTLE, BROWN, AND COMPANY 
Copyright, 1915,

By Little, Brown, and Company.

All rights reserved.

Published, June, 1915.

Set op and electrotyped by J. S. Cushing Co., Norwood, Mass., U.S.A.

Presswork by S. J. Parkhill \& Co., Boston, Mass., U.S.A. 


\section{PREFACE}

THE relation of the present volume to the preceding one and the volume which is to follow is shown in the Preface to Volume I. The first two volumes should be used together. The selection of materials is such that they are intended to complement each other. For the student, the best results will be gotten by attempting first to master the raw materials of the first volume, in analogy to the case-method; that is to say, by making an effort to reconstruct for himself, from topic to topic, the state of development of the legal institutions among primitive and ancient peoples. The easier and less profitable way will be to commence with the second volume, referring for illustrative materials to the first, from subject to sulject. Nothing further is here tendered as suggestive of a methorl of attack. Something should be left to the imagination and the industry of the reader or teacher.

In view of the statement as to the purpose of this compilation already made in the Preface to Volume I, it perhaps need not be declared that these volumes are not intended for the specialist in historical jurisprudence. But it needs again to be emphasized that a study of the laws, customs, and usages of inferior peoples does not exhaust its mission simply in tracing out the connections between the past and the present. The greatest productive value of an inquiry into the juridical life of remote ages and of arrested developments lies in providing an indispensable standard by which the processes of human reason, so far as they enter the sphere of legal evolution, are guided and corrected. Such an inquiry should result in a clearer estimate of the present, and should provide to a degree a calculus to measure the quality of the irresistible pressure of the future by which all juridical institutions are constantly and progressively modified.

Any work on the evolution of law which makes any professions of furnishing a survey of legal institutions necessarily must render account of the ancient substitute for criminal law, of the five main divisions of private law - family, suctession, 
persons, property, and obligations - of commeree in the field of special law, and lastly, procedure. The legal categories of the aneient world were exhausted by sins, rituals, and family. We have sought to unite a developed elassification of legal ideas with the legal life of the first stages of legal development without, however, seeking to indicate the relative order of evolution of legal ideas. Within the more or less prescribed limits of a manageable volume, an undertaking so pretentious as to embrace the whole seale of legal ideas must, in compensation for its range, omit to sound the overtones. It is elear that a book which aims to be a survey of legal institutions must, to aceomplish its mission, shum the choice of detailed treatment. In other words, length and breadth are only rarely found in combination, and of these alternatives, we have put the emphasis on the one suitable for our purpose.

It was not possible to restrict these readings, as had been planned in the beginning, to materials already available in English, and in order to fill in what seemed to us to be important gaps in an organic outline of the law, we have inserted a number of original translations which now appear for the first time in English.

For valuable suggestions in the volumes now published, the editors acknowledge their indebtedness to Edward Lindsey, Esq., of the Pemnylvania bar, who has been one of the first in this eountry, among professional lawyers at least, to urge the large importance of the studies here represented.

A. K.

J. H. W.

Northwesters Universitx,

Circago, November, 1914. 


\section{TABLE OF CONTENTS}

\section{INTRODUCTION}

Section 1. Evolution of Law

By Josef Foller.

Section 2. Ethyological Jurisprudence . . . . . 10

By Albert H. Post.

Section 3. The Origin of Legal Institutions . . . . 36

1. The Imitation Theory . . . . . 36

By Gabriel Tarie.

2. Criticism of the Imitation Theory . . . 55

By Paul Frédéric Girard.

Section 4. Universal Comparative Law . . . . . 61

By Georgio Del Vecchio.

\section{PART I \\ LAW AND THE STATE}

CIIAP'TER I

Forms of Social Organization . . . . . . . . . . 73

By J. W. Powell.

\section{CHAPTER II}

Evolution of the State . . . . . . . . . . . . . 88

By Josef hohler.

CHAP'TER III

Onnipotence of the Axcient State . . . . . . . . 92

By Fustel de Coulanges.

\section{CIIAPTER IV}

Chieftainti and Kingsin

Section 1. Cultural Importance of Chieftainry . . . . . 96

By JUSE lioHLer. 
Section 2. Authority of the King .

\section{CHAPTER V}

RELIGION AND LAW

Section 1. Religious Origin of Ancient Law . . . . . 104 By Fustel de Coulanges.

Section 2. Religions Element in Hindu Law . . . . . . 110 By Henry S. MaINe.

Section 3. Taboo as a Primitive Substitute for Law . . 120 By Josef Kohler.

\section{CHAPTER VI}

Evolution of Criminal Law . . . . . . . . . . 122

Section 1. Primitive Criminal Law . . • . . . 122

By Richard R. Cherry.

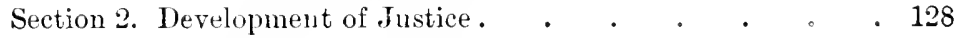

By L. T. Hornouse.

Section 3. The Origin of Punishment . • . . . . 151

By Ellsworth Faris.

\section{CHAPTER VII}

The Forms of Law

By IIENRY S. Maine.

CHAPTER VIII

Metnods of the Law's Growtil

By Henry S. Maine.

\section{PART II \\ PERSONS}

\section{CHAP'TER IX}

Kinship .

Section 1. The Tribe . . . . . . . . . 181

Section 2. The Clan . . . . . . . . 187

By J. W. Powell. 
CHAPTER $\mathrm{X}$

The Patriarchal Theory

By George E. Howard.

\section{CHAPTER XI}

Totemisu AND Exogamy . . . . . . . . . . 215

Section 1. Exogamy as a Surviral of Group Marriage . . . 215

By Josef KoHler.

Section 2. Origin of Exogamy and Totemism . . . . . 216 By Axprew Laxg.

CHAPTER XII

Wonen in Prinitive Society

By L. T. Hовногse.

CHAPTER XIII

MARRIAGE

Section 1. Forms of Marriage . . . . . . . . . 276

By Josef Íohler.

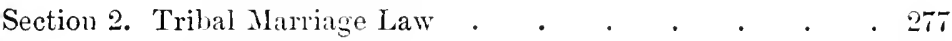

By J. W. Powell.

Section 3. Religious Basis of the Fanily . . . . . 28:3

By Frstel de Collanges.

Section 4. Marriage in Greece and Rome . . . . . 285

By Fletel de Coclinges.

\section{CHAPTER XIV}

Patria Potestas.

By Henry S. Malne.

\section{CHAPTER XV}

Women and Marriage teder Civilization.

By L. T. HobHovse.

\section{CHAPTER XVI}

Childrex axd TIE Family

By Josef KoHler. 


\section{CHAPTER XVII}

Adoption anl Artificial Relationship. . . . . . . 341

Section 1. Survey of Artificial Relationships . • • • • . 341

By Josef Koller.

Section 2. Religions Basis of Adoption .

By Fustel in Coulanges.

\section{CHAP'TER XVII}

\section{SLAVERY}

Section 1. Historical Importance of Slavery . • • • . 347 By Josef Kínler.

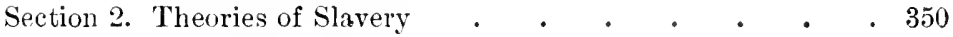
By Henry S. Maine.

\section{CIIAPTER XIX}

Capitis Deminctio 353

By Rudolph SoHM.

\section{CHAPTER XX}

Existimationis Minutio 356

By RUdolpII SOHM.

\section{PAR'T III}

THINGS

\section{CHAPTER XXI}

Tine Law of Property . . . . . . . . . . 361

Section 1. Religious Basis of Property . . . . . . . 361 By Festel de Collanges.

Section 2: Development of the Idea of Property . . . . 372 By L. T. Hobirouse.

Section 3. Early IIistory of Property and the Village Community 380 By Hexry S. Maine.

Section 4. The Village Community as a Primitive Institution 392 By George Laurexce Goune.

\section{CHAPTER XXII}

Origin of Commercial Institutions

By Levix Goliscinmot. 
Primtive Commeracial Law

By Carl Koehye.

CHAPTER XXIV

Barter and Transfer

Section 1. Barter

$$
\text { By Josef holler. }
$$

Section 2. Primitive Transfer of Goods . 499 By Flitx somló.

\section{CHAPTER XXV}

Pledge .

Section 1. Forms of Plelge Rights

By Josef Kolller.

Section 2. The Pledge Idea .

By John H. Wignore.

\section{CHAPTER XXVI}

Stretrship

BY JoseF KOHLER.

\section{CHAPTER XXVII}

Evolution of tine Law of Contraet .

Section 1. The Fides Commandment . . . . . . 401 By B. W. Leist.

Section 2. Early History of Contract By Hexry S. Mane.

Section 3. Sponsio and Primitive Contract By Pol Collinet.

\section{CHAP'TER XXVIII}

\section{Sales axd Loaxs at Roye}

By Rudolpi Sohy.

\section{CHAPTER XXIX}




\section{CHAPTER XXX}

Section 1. Survey of the Law of Succession . . . . . . 536

BY JOSEF KínLer.

Section 2. Religions IBasis of Inheritance . • . . . 542 By Fustel he Collanges.

Section 3. Early IIistory of Testamentary Succession . • . 553 By Heni: S. Maine.

\section{PART IV}

PROCEDURE

\section{CHAPTER XXXI}

Procentre . . . . . . . . . . . . 575

Section 1. Survey of the Law of Procedure . . . . . . 575 By Joser lionler.

Section 2. Ancient Magistracy . . . . • . . . 580 By Fustel de Coulanges.

Section 3. Primitive Forms of Legal Remedies . . 586 By Hexir S. Malne.

Section 4. The Ordeal and the Oath . . . . . . 609 By Gestave Glotz.

Section 5. Ancient Formalism . . . . . . . 638 By Andreas heusler.

Section 6. Ancient Semitic Procedure . . . . . . 654

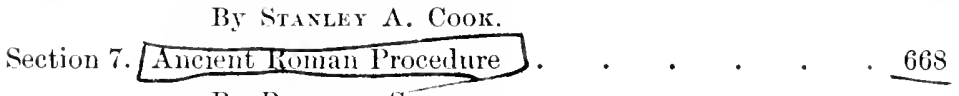
By Rointpi Sonv.

Section 8. Erolution of Procedure . . . . . . . 691 Iy Gabinel Tarie. 


\title{
PRIMITIVE AND ANCIENT LEGAL INSTITUTIONS
}

\section{INTRODUCTION}

\author{
SECTION 1. EVOLUTION OF LAW \\ By Josef fohler
}

SECTION 2. ETINOLOGICAL JLRISPREDENCE

By Almeit H. Post

SEction 3. THE ORIGIN OF LEGAL INSTITLTIONS

No. 1. THE IMITATION THEORY

By Gabriel TARde

No. 2. CRITICISA OF THE IMITATION TIIEORY

Br Pall Fiédénic Girari

SECTION 4. LNIVERSAL COMPARATIVE LAW

By Georgio Del Veccilo 



\section{EVOLUTION OF LAW}

\section{Volume II \\ PRIMITIVE AND ANCIENT LEGAL \\ INSTITUTIONS}

\section{INTRODUC'TION}

\section{Section 1 \\ EVOLUTION OF LAIV 1}

Comparative legal history is a science of most recent date. In the period of our juristic studentship, very few persons had any notion that the deepest roots of legal history and legal philosophy were here to be found. If our instructors, not quite twenty years ago, when we ourselves listened as students in the lecture halls, had spoken of the laws of primitive peoples, we would have been as little impressed, as might have been the elegant humanists of the sixteenth century if someone had told them of the language of the Hottentots or the Bushmen. . . . In the same way that the study of Germanie law has brilliantly justified its existence through the rich discoveries which, from day to day, it has laid at our feet, so also comparative legal history, by the fulness of its results, the width of its horizon, and a cultivation of the legal historical sense, will generously render compensation for the field of activity allowed to it. The traditions of Roman law, and the monuments of the Latin language go back to a time covered by night and mist; and not even the most acute vision will be sufficient to penetrate this veil, and look upon the facts and forces which lie in the

${ }^{1}$ [By Josef Kohler; from Grünhut's “Z. f. d. privat-und öffentliche Recht," Bd. XIV (1S87), p. 410 seq.; translated by Albert Kocoureh.] 
depths of the past. Everything attempted by way of conjecture proceeds only from specious hypotinesis, - especially if the investigator is unable to re-live the irleas, feelings, and point of view of past ages, in his effort to reconstruct the small fragments of ancient legal life on the basis of the ideas of the present day, just as it would be with the ethnologist who might seek to explain the remains of the weapons of the lake dwellers by comparison with the firing arms of modern times. Germanic law leads us hack farther into the primitive age than Roman law; but even the oldest sources of Germanic law, Tacitus, the Lex Salica, and the most ancient records, tell of the old institutions a story which is highly fragmentary and unsatisfactory.

Thus, we come to the point reached by the investigator who searches the monuments of the Latin or Germanic stem languages to their origin where he encounters what seems an invincible intcrogation. What has been the course of development of these perfected systems of language in reaching their position of organic symmetry? In what way is an explanation to be given of the conspicuous affinities, on one hand, and the remarkable differentiation, on the other, among languages? Comparative philology has given the answer; it has established the elements of language; it has sought to show how language from the first expression of human needs has become the trustworthy instrument of man's mental faculties, in an minterrupted evolution, representing the most refined sublimate of ideas, and the most delicate nuances of feeling; and it explains how, with departures from an original tongue, individual languages have developed according to analogies and following various laws of growth - how, in the construction of languages, the great law of organic nature, unity in diversity, has been maintained. Comparative law has the same function in the sphere of law, as the science of comparative philology in the field of language; it is its mission to explore the path of legal development from its most primitive point of beginning to the stage where it enters the domain of the science of legal history. such a science, it must be conceded, would have been in vain, if the law were an accidental creation, the sport of chance, in which case the study of peoples would, indeed, disclose laws, but not law ; it woukl exhibit, even, an interesting profusion of details, a chaos of particulars, without organization, and wanting in regularity of development. Happily, there is no danger of stumbling upon such ohjections, since in this day there may no longer be any question, that the law is not the chance product of profitable and unprofitable 
hours; but is the result of an innately reasonable impulse of humanity, a sociological process pushed forward by necessity through the coexistence of reasonable beings with material and spiritual wants, ${ }^{1}$ and which therefore, like every evolutionary process which expresses reason, has its own principles and eternal laws.

Another proposition opens the way through the countless turns of evolution in which the idea of law struggles to unfold - the essential sameness of the factors of human development among the most diverse branches of mankind. If this proposition is ralid, then it is certain that in a definite stage of legal development, the legal systems of the most diverse peoples will show sccondary differences, but in the midst of these differences must exhibit a unifying principle. ${ }^{2}$ This truth is one of the most brilliant achievements of modern ethnology. The science of ethnology has not oniy demonstrated general similarities, but also the most striking analogies in detail, - analogies of institutions not only of a kind which lie close to human nature, but also such as relate to the most infrequent, bizarre, and unnatural customs of peoples ${ }^{3}-$ analogies which cannot be explained as borrowings, but which are independent phenomena appearing among tribes where no trace of ethnic connection is to be found. This principle applied to the law immeasurably widens our historical horizon; and the thick fog which has surrounded ancient times is illuminated. In the legal systems of extant primitive peoples are found the analogies of those legal conditions under which our most ancient ancestors lived, of which all recollection has died away and every record has faded. And how could it have been otherwise in the law" Innger and love have been, from the beginning of time, primal impulses of the human race. Solicitude for the individual, as well as solicitude for the species, has burrowed under human nature, producing endlessly inexhaustible conflicts. Hunger and love have everywhere given birth to the law; and their primitive force has generated one legal institution after the other.

This new science to-day is revealed to us in immeasurable significance. In the same way that philology has undertaken from the most scanty germs of language construction to explore the compounded agglutinative forms of speech to reach the inflectional languages, and, again, to proceed from the lowest to the highest forms of language, so, also, comparative legal science has the mis-

${ }^{1}$ See my article in "Z. f. vergleichende Rechtswissenschaft," III, p. 161 seq.

${ }^{2} \mathrm{Cf}$. my article in "Krit. Vierteljahresschrift," $\mathrm{X}$. F. IV, p. $176 \mathrm{seq}$.

${ }^{3}$ Cf. my article in "Z. f. rerer. R.." V. p. 400 seq.

"Cf. my article in "Krit. Vierteljahresschrift," X. F. IV, p. 175 seq. 
sion of showing the development of the law from the carliest germination of legal conseionsness to the time when it has grown into a mighty tree, and thrown its shade over the world. ${ }^{1}$

When we contemplate this derelopment, we must shudder to think of the enormous effort which mankind must make to bring forth a legal institution. ${ }^{2}$ To achieve the institution of marriage in the modern sense, or the parental relationship, or the law of contract, and to attain a State which looks after all interests, required an enormous outlay of human energies involving not alone individuals but peoples; thousands of young lives were blighted, thousands of hearts were broken, and streams of blood flowed to enable a fruitful new idea to come into existence; just as it required the powerful expenditure of all the forces of nature to raise up our organic world out of its original imperfection.

Comparative legal investigation deals with the evolutionary side of the law; by no means, however, with that desolate and sterile kind of evolution which derives each development from an accidental and external coincidence of particular facts; but, on the contrary, with the spiritual point of view which assumes that the world-process involves an inherently reasonable course of development, an evolutionary struggle which employs mechanical factors only for the attainment of its ends. Evolution must contend against a profusion of opposing elements; it must make way against human errors, against obstinacies, rigidity, tenacity, and defiance: but it suceeeds in pushing forward, and where the straight road of progress is blocked, it finds a devious route for the accomplishment of its purposes. When obstinacy and reserve stand in the way, it decomposes them by a withering process of centuries. It sinks its roots into hundreds of fissures and crevices, and imperceptibly one phase of life is extinguished to give place to amother. The movement of erolution may appear imperfect in that it does not imitate the speed of the lightning, but the power of resistance only with which erolution contends, is imperfect, when we hear in mind the end, and only the end, of this struggle. The way to the end is justified even though it proceeds through eons of time. Philosophically eonsidered, time is only an inferior ele-

1 Ci. my essay, "Das Rerht als Culturerscheinung," p. 5.

2 [As these lines are being translated the whole world is feeling the shock of the bloorly clash of European armies, in which struggle the learned author"s country is one of the leading combatants. Nothing, it seems to 12. wan more vividly illustrate the truth of the last sentence of the text, than this drstructive conflict. Mankind has not, up to this moment, yet paid the pric. which must he rendered before there can be granted to it the institution of international poace.] 
ment in the phenomena of things. Here, as elsewhere, in nature, perfection is not measured by human standards; for man is a temporal and limited being, and is not the measure of things. ${ }^{1}$

Evolution makes use of men and nations against their will." Struck by an inexplicable notion or desire they seek a lost trifle and find a treasure of cultural progression. Misgiving and timidity lay hold of Hamlet; his hand is restrained by an unaccountable feeling; the sword remains in its scabbard; and the revenge of blood is stayed. ${ }^{3}$ The ambition of a half-barbarous Macedonian demolished the Persian empire, and a flood of Oriental culture poured out over the Occident.

We are now competent to appreciate the unending benedictions of culture. We shall speak no more of the Grolden Age of man in a state of nature from which civilization led him to a condition of misery; on the contrary, we shall hail culture as the lamp which has shown the way to the regions of light from the darkness of night. It is the highest consolation which science can grant for the future, that it is allotted to humanity to achieve a better end, and a more exalted form of existence. Therefore, let us interlock anew with the wheels of cultural and legal evolution! The more powerfully our forces are applied, the quicker will mankind be carried to its higher destiny, and the sooner will one mission after another of humanity be fulfilled! However great the sorrows and pains may be, with which mankind is afflicted, they have a reasonable meaning, and an evolutionary purpose; ${ }^{*}$ for every stage of historical progress involves suffering. ${ }^{5}$ In order that a fort may be carried, thousands must fall, and the flag of victory is planted only over the bodies of the dead. Sarastro's reign first trimphs after Pamina is plundered. Wrongs and suffering are the soil upon which the flower of the law blossoms. ${ }^{6}$

1 Everything which has heen adranced against teleology, touches only an anthropomorphic or individualist teleology which always applies a human standard, or which denies that mankind is organic in construetion. for which purpose individuals alone are considered as factors in erolution.

${ }^{2} C \dot{f}$. my article "Rechtsgeschichte und Weltentwickelung," in " $Z$. f. v. R." T, p. 328 seq.

3 The objections raised against my Hamlet interpretation rest on the most singular esthetic misunderstanding. Immortal Shakespeare, why did you not provide rour. Hamlet with its fabula docet!

"Cf. my "Aus dem Lande der" Kinst." p. 18 seq.

"George Eliot, "Mill on the Wloss" (Germ. trans. hy Kolh, II, p. 14i).

${ }^{6}$ Even the application of law hings with it unmerited sufforing. When the head of the father of a family falls under the ax, the whole family is plunged into misery. "Wo "an lhink of no retribution which does not exceed its purpose and inflict undeserved pain." - George Eliot, op. cit;; p. 94. C $f$. also, my "Shakespeare ror dem Forum der Jurisprudenz," p. 95 seq., and the "Nachwort," p. 1 seq. 
And now, what is the ultimate lestiny of mankind with its struggle and eflort? The question is one of philosophy, but yet the law may share it, since the law is one of the chief factors of human progress. The end of human development is divine unity through knowledge (science), perception (art), and metaphysical feeling (religion). The eultivation of all these highest objects is possible only under the greatest refinement of social condition, under conditions which the law alone can bring about. Legal science, in that it operates to further these conditions, levels the road upon which science, art, and religion celebrate their triumphal march. Jurisprudence, however, does not accomplish its mission by this practical activity ; like every science and art, it has also its own independent purposes. ${ }^{1}$ And like all knowledge, knowledge of the law is one of the most important objects of the human mind. We may regard it as one of the highest emanations of a god-like force which sways mankind, and leads it, even against its own will, to its destiny.

And what would be the life of the nations without science? And what of its joys, its fcars and hopes, its tenderness with its sighs and longings, its family life with its charms and cares, its commercial activities with all their changing fortunes and their hurry and bustle, - if all this were to be swallowed up in the maw of time without ultimate result? And what record would be left after thousands of ycars of our struggle for existence, of our efforts and striving, if it were not for the monuments of science and art?

Dimmi, o luna: a che vale

Al pastor la sua vita ? 2

A point needs to be emphasized against the aberrations into which the philosophy of nature and history once fell; it is not for us to master facts, or to substitute fancies for science. A phantasmagoria is not science, and alchemy is only a divergence from the proper line of effort. Inexhaustible and unfathomable are the ways of nature and history. It would be a frivolous endeavor to attempt to interpret them with our ideas - ideas which span but a small part of what has come to pass. Against the great abundance of enduring nature the narrowness of our limited, particular existence must make head. 'Therefore we must undertake, dili-

${ }^{1}$ Cf. my artirle, "Rerhtsgeschichte und Culturgeschichte," in "Grünhut's Z.,"XII, p. 590 seq.

2 Leopardi. "Canto notturo di un pastore errante dell' Asia" red. Capelline, Milan, 1S53), p. 91. [Canto Notturno, Poem xxiii, "The Poems of Lcopardi," edited by Francis Brooks, Manchester, 1909.] 
gently, an investigation of details. No particular is so unimportant, no tribe of people is so lacking in interest even though it be one of the most degraded anthropomorphous trpes, and no historical tradition of ancient times is so scantr, as not to be worthy of attention. ${ }^{1}$ What is a philosophy of history without facts? What is an interpretation of legal evolution without the rich observation of this development itself? If one speaks constantly of the barbarism of earlier legal srstems, it is not to eommend as worthy of imitation, but as an object of the movement of culture. The age of barbarism must be profoundly studied; for only historieal knowledge gives us freedom and widens our horizon, in order that we may understand the laws of evolution. Of course, no botanist would want to fill the streams with alga, but yet, he finds in them the eridence of the eternal laws governing the regetable kingdom.

After the materials are collected, the task will be to abstraet from them principles, to discover the operative, constructive impulse manifested in the positive movement of progress, ${ }^{2}$ and to discover what was the elastic force, and what the machinery which lifted humanity from one level of development to another, until culture, and even superculture, replaced the rudest forms of existence. This procedure will be no different than the procedure of science in general. It is the method of the philologist who investigates the laws of the mutation of consonants, or traces back verbal abstractions to sensible ideas. It is the method of the geologist who explains the evolutionary stages of the earth, by the stratification of the rocks, and by the discovery of petrified remains of life. Finally, it is the method, in general, of the investigator, who discloses in the flow of phenomena the eternal laws which goverin the universe.

1 "To the mind which looks out from a higher point of view, nothing is unimportant, since everything may be regarded as having an endless ehain of relations." - George Eliot, op. cit. (Kolb's trans.), II, p. 145.

2 Against the remarks of Dargun (in "Rerhtsgeleerd Magazijn," $1 \leqslant \$ 6$, p. 391 seq.) it may be emphasized that the evolution of law does not proeeed according to mathematical rule any more than the Ireclopment of eulture in general; since indivilual cireumstances are endless in therp differences, and in that now one factor, and then another, is predominant. This, at the same time, is one of the allurements presented by the manifoldness of legal history. Even tribes governed by the principle of Fatherright, frequently retain the rule of suceession through nephews: and the institution of wife-purchase may persist for centuries alongside of Dotherright. When, as among many tribes, the husband must dofend his possession of his wife against the tribe, this may he explained as a conspicuous survival of a condition where the wife belonged to the trile. What at one time was a right frequently appears with the greatest stulibornness in the form of a wrong. 


\section{SECTION 2}

\section{ETHNOLOGICAL JURISPRUDENCE ${ }^{1}$}

Ethnological jurisprudence, the most recent branch of the science of law, so richly claborated by every method of research, has still to battle for its existence. Wide circles in the world of juridical learning utterly ignore it, or assume a hostile and at best sceptical attiturle towards it. Neither the history of law nor the phitosophy of jurisprudence has accorded it scientific recognition, and eren the tenability of the principles upon which it is based has been characterised as highly questionable.

It is universaly true that every new departure in science at first meets with opposition, and that it camnot aspire to recognition until it is in a position to present results that are incontrovertible. Ouly by presenting such results can it acquire recognised standing in the roll of the sciences, and only by the elaboration of these results can it repel definitively the attacks directed against it. But this process may be expedited by giving in the clearest and most explicit terms possible a sketch of its underlying principles, and so in the present case, while ethnological jurisprudence is still in the initial stages of its development, it will not be amiss, in the interests of our study, to attempt a substantiation of its scientific pretensions. We shall, by so doing, at least throw obstacles in the way of superficial criticism from the traditional standpoint.

Ethnological jurisprudence stands in marked contrast with the tendencies that at present dominate the science of law. Its method of procedure is fundamentally inductive, and has for its starting-point the customs and jural concepts of all the nations of the earth. Its method furthermore is specifically comparativeethnological; that is to say, it is on the one hand socio-psychological and on the other hand comparative in the sense that it pro(ceds by comparison eren where the historical comnexion between the fiacts of the jural life is lacking.

It is thus opposed to -

1. Evcry philosophy of jurisprudence which is essentially deductive in its methods.

2. Every sistem of jurisprudence founded upon the law of a single nation or a single group of nations.

${ }^{1}$ [By Albert Herman Pont. Translated from the German by Thomas I. Mcrormack. Reprinted, hy permission, from "The Open ('ourt," Fol. NI, Nus. 11, 12 (November, December, 1897).] 
3. Every system of jurisprudence which is individuo-psychological in its origin.

4. All investigations of historical jurisprudence which on principle do not quit the ground of historical connexion in the treatment of the facts of jural life.

These innovations have given to ethological jurisprudence its peculiar impress, and it is this peculiarity that demands scientific vindication.

The first point of view that presents itself for the examination of the jural order is unquestionably the individuo-psychological. For the domain of jural life comprehends the action of the forces that emanate from individuals, and the law finds its most immediate expression in the jural sense of the individual. It is daily born anew in the depths of the human soul. Here it appears in the form of passion and desire, so soon as a misdeed is committed, and urges to vengeance and expiation. The written law of statutebooks and the courts, however, is but the mediate expression of the jural life.

The first point of view presenting itself is therefore the following: to regard all jural order as the product of the differences and coincidences of the jural sense of human individuals, and to endearor to explain the same from the nature of man, that is, from the nature of the individual.

This idea still rules supreme in modern jurisprudence. We meet on all sides with arguments explanatory of state and law, which are derived from the nature of the human individual. And seeing that the individuo-psychological method of investigation derives its materials directly from the living source of life, while the socio-psychological starts from the jural phenomena of the life of all nations, deriving thence its inductions as to the causes which underlie the same, certainly, if it were possible to explain jural life adequately from the nature of the human individual, the individuopsychological method would have the preference.

But this latter method does not lead far towards the understanding of jural life. The sequence of causes soon vanishes in so inacessible a sphere as the personality of the individual, and true seientific inquiry is displaced by ingenuity and sophistry.

Viewed from the individuo-psychological standpoint, the facts of jural life are partly matter of our subjective and partly matter of our objective experience.

Matter of subjective experience is merely our own individual jural sense, that is our individual consciousness as bearing upon 
right and wrong. This individual jural sense is made up of a sumtotal of psychical activities, of which we become conscious when from inward or outward excitation we are confronted with the question as to whether something is right or wrong. These psyehical activities are partly feelings and desires, and partly judgments, the former tending towards action and the latter tending towards expression by word or sign. Jural feelings are principally feelings of indignation as when an injustice is experieneed by an individual, a feeling of fear as when the individual is affected by an inclination to do wrong, a feeling of penitence as when the individual has committed a wrong. With the feeling of indignation is joined a desire for vengeance, with the feeling of penitence a desire of atonement, the former tending towards an act of vengeance and the latter towards an act of expiation. The jural judgments of individuals are not complete judgments; they are based upon an undefined sense of right and wrong. In the consciousness of the individual there exists no standard of right and wrong under which every single circumstance giving rise to the formation of a jural judgment can be subsumed. A simple instinct impels the individual to declare an action right or wrong.

It thus becomes evident that the individuo-psychological analysis of the individual jural sense, in so far as it rests upon subjective experience, can atiord only meagre results. All psychical phenomena of the jural sense are, so far as regards our subjective experience, ready-made products. The psychological development of jural emotions, desires, and judgments, is not accessible to our inner experience. The psychological processes whereby we beeome conscious of jural emotions, desires, and judgments, lie without the reach of consciousness.

Further, subjective observation of the psychical processes from which the jural sense springs, bears the same character as subjective observation of psychical processes generally. Systematic self-observation is impossible, inasmuch as the observing subject and the observed object are one and the same, and the very act of observing thus modifies the object observed. ${ }^{1}$ It is likewise impossible to evoke, arbitrarily or artificially, a jural desire or an instinctive jural judgment; they always appear instantaneously and unbidden in consciousness. As material for observation, aecordingly, there remains only the recollection of such occurrences in the mind of the individual.

1 ("omte, "Positive Philosophy," abridged by Rig; German translation by Kirchmamn, 1s\$3, I., p. $13 \mathrm{ff}$. Wundt, "Logils," 1s\$3, II., p. 482. 
Still another drawback to the employment of subjective observation for scientifie inquiry is the fact, that it is almost utterly impossible to distinguish in general between jural feelings, desires, and judgments, and moral feelings, desires, and judgments.

Scientific inquiry attains more favorable results when it adopts as the subject of investigation the expressions of the individual jural conscience in the external world of sense - that is, the phenomena of the individual jural sense as appearing in acts on the one hand and in words and signs on the other. Here self-observation discovers facts which are represented as events in the outward world of sense, and which are consequently subject to external observation. True, the observation of the outward expressions of the individual jural conscience in acts, words, and signs affords scarcely more material for the psychologieal analysis of the individual jural sense than the direct inward observation of the same. The material for observation increases, however, if the observer, not confining himself to the expressions of his own jural sense, compares with these the expressions of the jural sense of other people, or even compares the expressions of the jural sense of other people with each other.

From this method dissimilarities in the phenomena of the jural consciousness appear at once, and these are in a high degree adapted to throw light upon its nature. In the first place it is possible to distinguish differenees in the jural sense of individuals according to their ages. It is possible to follow the jural sense of children in its development. We are also able to fix degrees of jural sense in youth and manhood, perhaps too in old age. It will be possible. furthermore, to point out variations of jural sense between the male and female sexes. Then further, there are to be noted marked irregularities of jural sense resulting from derangement; which derangement may rest on biological as well as sociological canses. Mental diseases, affecting the whole consciousness of the individual, affeet the jural sense also. Besides these, there are a great number of persons whose jural sense, though not disturbed by any psychical disarrangement, is far below the normal state; namely, criminals. Such persons, endowed with a jural sense of a socio-pathological kind, furnish the material for a separate branch of peschology ; viz., criminal psychology. Marked irregularities in the individual jural sense may be further distinguished according to the social cirele in which the individual moves. Even in a single nation these irregularities are quite considerable; according to caste, culture, occupation, politics, religion, and the like. Yet 
the most considerable deviations are to be found between the jural consciences of different peoples, and they are more considerable according as the difference in civilisation is greater, or as the development of the same has been more unique.

In all these ways it would be possible to observe the expressions of the individual jural sense and by a process of individuo-psychological comparison to arrive at scientific results. It is evident, though, that it would be difficult to collect the material for observation, and that the olservations of individuals themselves to this end would be subject to innumerable sources of error.

These observations could not acquire scientific value unless made upon the most extensive plan, and with persons of different ages, different sex, different intellectual ability, different social standing, and different nationality ; and unless the material accumulated were so considerable that all the sources of error in individual observation could be eliminated. To limit the observations to a narrow field, would necessarily yield incorrect results; for it is now beyond question that the jural sense of individuals is subject to the most varied differentiations. The most distorted presentation of all, however, is produced when the inquirer confines himself mainly to his own individual jural sense, and persuades himself that this should determine the conduct of humanity. He has here merely systematised his own jural consciousness ; manifestly a doleful scientific result.

How is it possible to observe the manifestations of the individual jural sense, which appear only instinctively and occasionally, exhaustively enough to obtain really valuable scientific material for a causal analysis of the jural order? It is unquestionably hopeless.

And even were it possible to proceed thus, we should be far from exhausting in this way the data of jural life. Jural life, as a social province, is by no means made up of immediate expressions of the individual jural sense only'; there are also mediate and indirect expressions of the same in it. The positive laws of nations with their statutes and provisions, have, it is true, their first origin in the expressions of the jural sense of individuals. But after these have become positive laws they are no longer the immediate expressions of the individual jural sense, but the objective products of the jural sense of whole spheres of social development, of countless individuals with variously formed jural consciences - individuals of existing generations as well as individuals that have long passed away. 
It would be a manifestly precarious attempt to seek the explanation of these phenomena in the nature of the human individual itself. Lnlimited scope would be given to caprice and imagination.

And ret, in the face of all, this method of studying the Science of Jurisprudence is still greatly in vogue, and meets with unqualified approval from contemporary students. They endow the human individual with certain instincts, the social instinct and the instinct of self-preservation : or they will have it pursue different ends according to its constitutional bent, happiness, liberty, etc., and upon these phantasms they build their structure as becomes the kindly heart and academic culture of the philosopher. 'These artistic productions are often charming reading, often teem with clever conceits, and give us a pretty picture of how blissful all would be, were it not so different in the world. If these works did not claim to be more than light and entertaining reading, we might joyfully welcome them. But they pretend to be more; they assert that they are scientific and would actually influence the practical mechanism of the jural order. Herein is their danger. Ethnological Jurisprudence, in my opinion, must stand aloof from all attempts to define State and Law on the basis of individual psychology. And now to the discussion and proof.

* $*$ * $*$ * $\quad * \quad * \quad * \quad * \quad *$

It is not only in the province of Jurisprudence that we find attempts to explain the phenomena of social life on the basis of individual psychology. This method is common to all the other social sciences. It rests upon a broad and fundamental psychological principle, which at the present day shows signs of instability and will sooner or later be completely overthrown.

All human science takes on a difierent form, according to whether we assume that the nature of man can be determined from his ego alone, or that the soul and ego of man are not identical but that man is conscious of a portion only of his psychical activity. In the first instance, the psychology of the individual is the irreversible basis of human science; in the second, we have to look about us for broader foundations. Ethnology, and likewise ethnological jurisprudence, is founded upon the second view. It assumes that, in the individual consciousness, only a small portion of his psychical activity is manifest to the individual and that the greater part is lost to his consciousness. It regards individual psychology, therefore, as no proper basis of science. 
That which we call our consciousness is in any case but an infinitesimally smail portion of the totality of psychic life active within us. It hovers like a tenuous and shimmering cloud above an unfathomalle ocean. All manner of images rise from the depths of our soul, yet few assume such sharpness of contour as to be recognised. By far the greater portion of our spiritual life remains unknown to us. By far the greatest portion of the spiritual life of which we are conscious, is known to us only as the resultant product of unconscious psychieal processes, and not as something in process of production. We remain totally unconscious of those spiritual activities which touch most nearly the vital centre of our being, the activities which create on the one side an ego and on the other a world. At the instant a child first becomes conscious of itself, the ego and the world are already existent: their birth is concomitant with the act of consciousness. The unconscious activities of the soul have shaped them, until, appearing as readyformed products, they give rise to that radical contrariety by which man becomes conscious of himself and a world. We remain utterl! unconscious, too, of those psychical workings which give to the world its sensible character and to the ego its spiritual. Our world, in every phase in which it is accessible to us, is virtually a product of psychical activities acting unconsciously within us. Light, heat, color, sound, taste, smell, pressure, weight, even space and time, do not belong to the world as such: on the contrary they are creations of mental activities, corresponding to the psychological activities of our sensory and central organs and project without a world created within.

Rokitansky ${ }^{1}$ expresses himself upon this subject as follows:

"We see the world that surrounds us by means of light; but it is now known that light does not exist as such apart from us; on the contrary it is ribrations of ether, which we transpose into light, and recognise as such, by means of mechanisms of specific irritability located beyond the sensory organs proper. Thus we oursclves illuminate space and come to know things therein through their relation to light; we acquire knowledge not only as to their surface and outlines, but also as to their inner constitution. It is likewise the vibrations of sounding bodies of different magnitude and velocity, taken up and communieated to us by the air, that we convert into sound and tone. And so, too, the things which we perceive through impressions upon the other senses, are, apart from our conception of them, quite different, and undoubtedly consist

1 "Der selbst. Werth des Wissens," 1\$69, p. 6, et seq. 
of the molecular or molar motions of matter. It must strike every impartial person as strange that we recognise as external objects things of which the conception is really formed within us. How does this come? There is undoubtedly a subjective organic activity present here.

"This much is known: that the impelling power in obedience to which we project objects conceived, outside the subject conceiving them, must lie in the inward organisation of the mind; that the conception of things in space is a function of the organs of our cognitive faculty which even in dreams creates in our imagination an external world.

"The perceptible world about us is essentially a creation of our personality ; it is by the functioning of imner organs that objects appear as things outside of us, as things of definite quality and form, of definite size and greatness. Further, when we behold in the genesis of things and in their different stages and mutations a succession and a connexion, we say that the succession takes place in time and that the connexion between the changes is a causal one. But when we ask ourselves how we arrive at these conclusions, it turns out that we do so by virtue of subjective forms which must lie in our organisation and by means of which we are in fact enabled to apprehend successions and connexions."

Even the world that remains after we remove the mantle of sensible phenomena, the world of ether and matter vibrations, is still not the world proper; it is the world only as it appears to human cognitive activity.

The psychical operations, too, that create our ego are totally hidden from us.

And even the greater part of those psychical operations of which we are conscious, are presented to consciousness as finished products, the genesis of which took place in unconscionsness. Ratiocination alone is effected wholly in consciousness. Feelings and desires come to consciousness as results only, and many judgments are not logical judgments, but incompleted ones, lying, with the principle upon which they were formed, in the province of the unconseious.

If all this be correct, it is evident that our consciousness is in no wise fitted for the thorough comprehension of human nature; for only an insignificant portion of our spiritual life ever becomes immediately conscious. What we are able to fathom by sclfcontemplation is soon exhausted. Yet unlimited is the province of knowledge that opens before us, if to the inward observation of 
self we add outward observation by the senses; in other words, if, from the phenomena of unconscious psychic life as expressed in the outward world of sense, we draw inferences as to the unconscions activities at work within us.

To this end the whole sensible world presents itself. Our sensible world is not the real world-in-itself. It is merely a worldimage, made by man, created by human psychical activities. From this, therefore, we shall be able to gather a great part of our unconscious psychical life, and thus come infinitely nearer the essence of our being than would be possible through the introspective observation of our own psychical activities.

In this way we arrive, not at the psychology of the past, which attempted to unfold the nature of man from the ego, but at a psychology which will endeavor to disclose the same from the worldimage created by man.

* $\quad * \quad * \quad * \quad * \quad * \quad * \quad * \quad * \quad * \quad *$

Among the phenomena of our sensible world which admit of inferences as to unconscious psychical activities, the phenomena of social life assume a prominent place.

And social life, though made up of the activities of individuals, supposably in possession of free will, is also essentially instinctive, resting upon the more or less unconscious impulses of the individual. Whosoever has had to do with the more intricate problems of ethnology, will entertain no doubt whatever of this fact.

Turn where we will in the domain of social life, we shall everywhere see fixed social laws at work, everywhere meet with a tendency of derelopment, which leading through centuries and centuries, makes towards some definite end, and of whose aims the individuals comprehended in the movement have no idea. Contemplate the history of the growth of language, the development of forms of divinity, of art, of legal institutions, even of fashions and utensils; they come, grow, and go, like things of life. There is but little here that is the product of individual reflexion ; almost everything is of organic growth. The individual follows blind impulses and coercive social conditions; the individual most frequently intends the very opposite of what he produces by his work, and all that he does accomplish, unless fitting in with the course of organic development, will soon come to naught.

That the indiridual in social life acts for the most part instinctively, we may ascertain by self-observation and by the observation of other individuals. A man, in speaking to another, employs 
the words he needs quite instinctively; they come to him, as a rule, without further reflexion. He need not know anything of the grammar of the language he speaks, and ret many employ the language with the greatest ease. A man who is confronted with the question whether he is acting advantageously or not, whether he is committing an act of justice or injustice, generally decides from pure instinct, oceasionally from feeling, but seldom through clear reasoning, and then always liable to the danger of mistake. A poem, a melody, a picture, a statue, arises before the mind's eye of an artist: something comes to him. Not until something comes to him, can he elaborate it further by thought. Creations that are not unconsciously born in the artist are not works of art, although every artifice of resthetic manipulation have been emploved. Every original and powerful idea in science is born of unconsciousness like a stroke of lightning.

We need but glance at every-day life to become convinced of how instinctive in its workings the whole mechanism of human existence is. Take the habits and customs of ordinary social life. When do we ever hear of reasons for acting in this mamner or in that? We act so because things are not otherwise than they are, because we must, because others do so. We all know how impossible it is to convince a person who can adrance no reasons for his conduct, that his way of thinking is wrong. If there were a possible prospect of being able to do this in the case of a man, it would certainly fail with a woman, whose springs of life are pre-eminently more instinctive than man's. In fact, a man who does not act and live instinctively is ridiculed and despised: he is no longer capable of inspiration and enthusiasm for any cause.

The deposits, therefore, of the unconscious workings of the human mind in the customs and conceptions of nations, are a source of incalculable importance to the understanding of the human soul; and the history of social activity furnishes an infinitely more copious material to this end than could be obtained by introspection and observation of the psychical life of a single human individual. An important part of our psychical life, which for the most part does not directly appear in conscionsness, can thus be gathered from the eustoms and conceptions of the peoples of the eartl..

Our statements as to consciousness in general are likewise true of the jural sense. The jural sense by no means ex!lansts the totality of psychical processes which constitute the jural life of a man. More properly, the majority of these processes come into 
the jural consciousness as results, as feelings and desires, or as instinctive jural jurlgments; while the genesis of these psychieal formations are hidden in unconscionsness. But in the jural institutions and conceptions of nations a creat deal of jural life comes to light that remains unknown to the individual, and so it is possible to penetrate much farther by this method into the cognition of the human mind in its jural aspects than was possible by the observation of one's own jural sense or by observing the expressions of the jural sense of single individuals.

But apart from this broad psychological standpoint, the very nature of Law itself indicates that the individuo-psychological method can learl to nothing, and that only the socio-psychological method ean produce satisfactory results. It will appear on closer ohservation that the individual jural sense is not the creator of the jural order, but on the contrary, that the individual jural sense is a product of law as a sphere of social life. Only in so far as the jural sense is consciousncss per se are we concerned with a biological basis; in so far, however, as it is a jural consciousness, the foundation is sociological. The human consciousness has a physical basis in the central organs of the body, but we should search in vain in the human body for an organ that is the seat of the moral or jural sense. A human being, reared in a state of perfect isolation, wonld think because he possessed a brain and had to use it in the struggle with nature. But we should find no trace of a moral sense or a jural sense in such a person. They are both the exclusive product of life in hman society. 'They first arise through adaptation to the social relations in which men live, and not until this adaptation is perfected does human conscionsness acquire, anong innumerable other notions, conceptions of right and wrong, of rights and ohligations.

'The jural order, therefore, is not to be explained from the nature of the human individual, but from the nature of the social bodies in which it has becn erolved. And it is only from this source that the individual jural sense also becomes intelligible.

Although the jural sense acts purely from instinct within us, it is nevertheless the creation of social and not of individual factors. This will appear from the fact that it acts in opposition to individual inclination. IIow are we to find one biological basis for the two psychical forces that come into conflict when the individual becomes possessed of an inclination to commit a crime and his jural sense restrains him from it? Anul if there be no biological basis, then the psychological theory that a person can control his 
sensuous inclinations by the innate rational faculty rests upon imagination. In reality the controlling clement here is not a biological or an individuo-psychological factor, it is a sociopsychological one.

The most telling proof that the individual jural sense is not a biological but a sociological product is found in the circumstance that, apart from the changes it suffers as consciousness proper (through age, insanity, etc.), its content is determined by the character of the social community in which the individual lives or has grown up. Were this not the case the jural sense of Fronchmen, Germans, Russians, and Chinese, who had attained the same degree of intellectual culture, would be one and the same. But this is obviously not the case. Identity of jural sense means identity of social organisation.

* $*$ * $*$ * $\quad * \quad * \quad * \quad * \quad *$

The individuo-psychological standpoint, accordingly, is inadequate for the explanation of the facts of jural life and we must expect really valuable scientific results only from a socio-psychological analysis of jural phenomena.

The socio-psychological method proceeds, in its investigation of the causes of jural life, not from the human individual, but from the forms which Law assumes in society, from jural customs, jural conceptions, and jural institutions as they are met with in the life of nations themselves. All these forms arose originally from expressions of the individual jural sense, and these expressions are in their turn founded upon social instincts developed by life in human society. By frequent repetition and the elimination of concrete notions, these expressions gradually lose their individual character. They become expressions of the corporate jural sense of a concrete sphere of social development. In this way a nation acquires a set of jural customs and jural conceptions, which regulate its acts and judgments, and whose conservation is entrusted to the government of the social sphere in which they were evolved. In this so-called positive law, the organic law of a nation assumes an objective form. It is a precipitate, in a social shape, of the jural sense, just as religious rites, forms of divinity, and doctrinal faith are the precipitates of the religious sense, or human language of human thought. In the positive law of a definite cpoch lies, essentially, the normal jural sense of the totality of individuals embraced within a single sphere of social development, as founded upon the jural order transmitted from previous generations. 
These positive laws constitute the combined data of the sociopsichological investigations of jural life; and they are full of promise. In the evolution of positive laws the creative national genius has instinctively accomplished a scientific work, such as could only be obtained by thoroughly analysing the utterances of the jural sense of all the individuals that now live or ever have liver within the social sphere governed by the positive law in question.

The study of the individual jural sense is thus in reality unnecessary, and the science of jurisprudence may begin at once with the analysis of positive laws.

The question now arises as to what method of conducting the analyis of jural life, as a field of social activity, will be most productive of results.

It is obvious that in the first place the jural customs and jural notions of all the nations of the earth must be carefully collated and accurately described. For only the aggregate of all the expressions of the jural sense of mankind can afford material warranting inferences as to the nature of the human jural sense in general.

And since the mass of jural customs and jural notions necessary to this task lies scattered among very many different peoples, it follows that the natural classification of the material will be according to the nationalities in which the notions in question prevail.

Such a collection of the jural customs and notions of all mankind arranged according to nations, would afford a highly useful basis for juridical research. It would be possible to carry out, within this framework, a uniform and systematic arrangement of the material. There are numerous customs and conceptions which repeat themselves among different peoples, and these would serve as the leading divisions of the sistematised arrangement we have in mind. The following, for instance, might properly be regarded as divisions: the relations of kinship as derived from mother-right, father-right, and parental rights generally, with the stages of transition between the same, the subsequent derelopment of the bonds of consanguinity (clan-fraternity, milk-tie, foster-tie, etc.), endogamy and exogamy, wedlock in its various phases (restrained and unrestrained promiscuity, wedlock by groups, polyandrous, polygynous and monogamous wedlock, leviratical marriages), the capture of wives, the acquisition of the bride by service, the purchase of brides, betrothal-rights, obligation of abstinence before and after marriage, suitors, discualifications to wedlock, forms of mar- 
rying, divorce, second marriage, mourning-time, the status of women and children, age of arming, age of majority, child-bed of the husband, the status of the old and the sick, forbiddance of intercourse between persons near of kin, guardianship, federal and monarchic forms of organisation, community of house and farms, sistems of joint responsibility and solidarity, blood-feud, rights of refuge, ordeals, forms of oaths, et cetera. This list might be continued for pages. In this material are to be found legal conceptions and customs of the most widely different nations of the earth which partly agree and partly vary. We could arrange all ('ustoms and conceptions under these headings, and the classification so reached would be a preparatory work of great value for the causal analysis of legal customs and conceptions generally. It would then appear in how far given legal customs and conceptions varied among themselves and among different peoples.

One foundation for such a causal analysis is afforded by the historical comnexion between the legal customs and conceptions of different periods within the same social organisation. But this analysis is only possible where traditions are at hand relating to corresponding legal customs and conceptions taken from the different periods of the same people's development. As a rule this is only the case with peoples having a history. With peoples having no history these traditions are wanting, unless perchance observations relating to their law be made during different epochs by travellers from civilised nations.

The historical method, therefore, in so far as it presents the history of the development of a given legal custom or conception in a given society, is restricted to provinces comparatively limited. So far, we only know of a history of Roman and Germanic law with the beginnings of the history of Slavonic, Celtic, Indian, Mosaic, and Islamitic law. The history of all the other systems of the earth has not been treated, or at least what has been accomplished is confined to the beginnings. Here and there historical treatment would be possible. But with the majority of the peoples of the earth material for such a treatment is wanting altogether, and will, in all probability, never be accessible.

The question arises now whether a really causal analysis of legal customs and conceptions is still evcrywhere possible. The only aid at the disposal of science here is, as with every such anilyis. the method of comparison. But this is possible only when there is an external similarity between legal customs and conceptions. The use of a chronological comexion is here altogether out of the 
question. Can such a comparison yield scientific results of any value whatever, or are we here at the end of our science? That is the question, the answer to which will determine whether Ethnological Jurisprudence is a science at all, or whether it is a will-o'the-wisp the pursuit of which is to be given up as soon as possible.

The question cannot be answered a priori: it depends entirely upon our snccessfulness in arriving at definite results. If we are successful, the method is warranted; if not, the attempt goes for naught. 'The scientific possibility of a purely comparative method depends upon facts, the existence or non-existence of which can only be determined by the application of the method itself. The question is whether in the development of human law definite legal customs and conceptions exist and regularly occur even among unrelated peoples, or whether the law of every people, at least of every kindred group of peoples, is an isolated product standing in no relation whatever to the law of other peoples. If there be rules of legal conduct which recur everywhere on the globe and which pass through a stated course of development, the method by comparison is applicable: to explain a given legal custom of one nation we may avail ourselves of the corresponding legal customs of another. If such be not the case, a purely comparative method is a scientific chimera.

For instance, if a table of the legal customs of all the nations of the earth were to present such a picture as the languages of all the nations of the earth (e.g. in Franz Muiller's "Grundriss der sprachwissenschaft"), a purely comparative method such as I have employed in my works upon ethnological jurisprudence, would be out of the question. A comparison of non-cognate tongues is impossible, for these are isolated formations. It may be that certain results for the general evolution of himan thought could be obtained only from a conspectus of all the languages of the earth; but generally languages are isolated products of certain ethnic groups. With other creations of social life this is not the case. The cvolution of the religious sense affords phenomena of manifold similarities, which extend far beyond the boundaries of philological races; and so the jural life of mankind affords a succession of phenomena which are not the especial creations of certain peoples or of a certain congeries of peoples, but which recur on the contrary in wide domains, among unrelated nations, and extend over such broad fields that they may be regarded as the common and universal property of the whole race.

When such analogous legal customs and conceptions are dis- 
covered among unrelated peoples of the earth, it then becomes a question whether they owe their origin to analogous causes; for phenomena of jural life which are outwardly alike may rest upon quite dissimilar causes. Yet we may attempt to explain one by the other, and whether this is possible, we shall soon discover. When we meet with the same or a similar legal eustom among many peoples, we usually find a sphere of ideas which readily explains it. Whilst certain legal customs and conceptions occur only within extremely limited domains, and do not lend themselves at all to the comparative method, on the other hand we meet with such as recur among all possible peoples and races in infinite rariations, and the divergences are such that we are often unaroidably led to assume that these isolated customs represent different stages in the development of a jural institution which in its fundamental features is everywhere uniform. This can be shown only by illustrations, and it remains for me to explain what I mean by a definite example.

Thus under the rubric of leviratical marriages we may include a group of phenomena regarding which we possess accounts from the most diverse peoples of the earth, varying greatly in compass and credibility. Such accounts are for instance the following:

\section{North American Indians}

Among the Kolushes the brother or sister's son receives the widow of the deceased in marriage. Among the Ojibways and the Omahas the widow became the wife of her brother-in-law after the mourning period was over, and the latter had to eare for the children of his deceased brother.

\section{Astec and Toltec Nations}

In the States of Anahuac a man was only allowed to marry the widow of his deceased brother when children were still living whose education had to be cared for.

\section{South American Indians}

Among the Arawaks a second marriage is not left to the will of the widow, for the nearest relative of the deceased husband has the right to marry her, and the latter may thereby of ten become the second or third wife unless sold to a third party. If she marry any one without the consent of the lawful heir, the deadlicit fends 
may result. Among the Calchaquis in the interior of Brazil, the brother marries the widow of his brother, to beget descendants for the deceased. According to Von Martius, it is a custom rigoronsly practised among all Brazilian Indians, that upon the death of a husband the eldest brother, or in case there be none, the nearest male relative of the deceased marries the widow, and the widow's brother marries her daughter; which is the case with the Mundrucús, Lainumas, Juris, Mauhés, Passés, and Coërunas.

\section{Oceanic Peoples}

In Australia when the husband or affianced dies, his brother on his mother's side inherits his wife and children; the widow repairs to him with her children after the interval of three days. In Western Australia the brother of the deceased has a right to the widow, and, if he choose, may take her for himself. On the Flinders Islands, near Australia, if the husband die his brother marries his wife.

Among the Polynesians the brother of the deceased is regarded as the husband of the widow and the father of the deceased's children.

\section{Semitic and Cognate Peoples}

Among the Bedouins, if a roung husband leave a widow, his brother as a rule oflers to marry her ; but it is not in his power to foree her to marry him. With the Beni Amer, if the brothers of a deceased husband do not wish to marry his widow, she can, after the expiration of the mourning period, marry at her own will, and she may not be forced into marriage by the brother of her deceased husband. With the Barea and Kunama, if a man die, his widow is married without further ado by his brother of the same mother, or ultimately by the son of the deceased's man's sister. With sevcral Berber tribes of the Atlas region, the male rclative who after the death of her first spouse first throws his shawl (Haik) over the widow, becomes her husband and has to care for her children and manage her property. Among the Bogos, when a married man dies; his sons by a previous marriage, his brothers or next of kin, succeed to his wife, that is, marry her, without further consultation with her father. Among the Hebrews leviratical marriages occur in the following form: If brethren live together and one of them die and have no child, the wife of the deceased shall not marry 
without unto a stranger: her husband's brother shall go in unto her and take her to him to wife. And it shall be that the first born which she beareth shall succeed in the name of his brother which is dead, that his name shall be not put out of Israel. With the Galla, the brother must marry the widow of his deceaced brother. With the Somali, the widow may marry again only with one of her husband's nearest relatives, who has to pay her half of her first dowry; if the latter die too, his wife is married to one of the same family for a compensation of one-fourth of the first sum. If the wife die, the husband has the right to demand in marriage an unmarried sister of his dead wife for one-half of the marriage dowry.

\section{Negro and Congo Peoples}

In the interior of western equatorial Africa, the nephew marries the relics of his maternal uncle, and with the Bakalai the son marries the widows of his father, with the exception of his own mother. With the Bechuana the son succeds to all his father's wives, and if an older brother die, the younger brother comes by his wives.

\section{\%. Indo-Germanic Peoples}

With the Afghans the brother is bound to marry the widow of a deceased brother if she wish it. In the laws of Manu, leviratical marriage occurs only in case a virgin widow be left. In the latter case, the same custom prevails among the Ideyars in South India, among the Jat families in the P'unjab, and with some of the Rajput classes of Central India. It oceurred in the old German law, that the heir to whom the guardianship of the widow came with the inheritance, particularly the brother of the deceased or indeed her own stepson, took the widow to himself as though part of the inheritance.

* $\quad * \quad * \quad * \quad * \quad * \quad * \quad * \quad * \quad * \quad * \quad *$

From such a collection of ethnological facts, embracing the whole earth and including the customs of nations in no ways related, no one, unless starting from a prejudical point of riew, could entertain the supposition that it were possible for such strange phenomena, agreeing in so many particulars, to rest everywhere upon eauses different in character and place. There am he no doubt that broader foundations to these exist: they must repone upon universal forms of social organisation, -- forms which in individual instances find diversificd expresion only. 
These universal forms of organisation are not to be discovered directly from the facts themselves: to determine them a person must possess a knowledge of the general jural status of the nations in question, and this knowledge can be obtained only from accounts of the legal eustoms of the said peoples. With the aid of information thus obtained, no doubt can be entertained that all the above mentioned customs belong to a form of organisation which extends over the whole carth, and which is exhibited exclusively among peoples living in a state of nature - viz., the clan. Thence arise characteristic conceptions of law which are repeated in all the customs above mentioned. It is a universal prineiple of the clan-system that women are not independent subjects of jural relations, that they are, so to speak, pieces of property belonging to the clan. They stand under the guardianship of the clan, which disposes of them at will, but which likewise provides for their maintenanee. 'These rights and duties of guardianship are lodged by preference in the hands of a definite person, the head of the family, and after the latter's decease fall to the person who succeeds him. And so the women of the family chief pass to the new family chief by way of inheritance, and the same rights and duties that the former chief possessed, arise in the person of his successor. With the gradual disintegration of the elan-system women acquire more and more recognised legal status, while the right and duty of guardianship becomes more and more invalidated.

This is the fundamental principle upon which all the abovementioned customs rest. If the guardian of a woman die, the latter passes by inheritance to the person to whom the guardianship now falls. Aecording to the strict interpretation of tribal institutions, there lies in the idea of guardianship the right of absolute disposal on the one hand, and on the other the obligation to provide for the woman in question.

A great number of other coneeptions of clan-law might be adduced in explanation of the customs mentioned.

1. First, two sistems of relationship exist in the clan: the system of mother-right, agreeably to which relationship is determined solely through the female line, and the system of fatherright, agreeably to which relationship is determined solely through the male line. Deseent and guardianship conform to these șrstems. The third sistem that oceurs, the system of parent-right generally whereby the relationship is determined through the male as well as the female line, first appears after the dissolution of the clan-sistem. 
It appears from the instances cited, that leviratical marriages and inheritance of women occur as well under the sistem of mother-right as under that of father-right. Cnder mother-right, women are transferred among the North American Indians, Australians, Barea, Kunama, and among the tribes of equatorial Africa, according to the systems respectively prevailing among these peoples. Under father-right, women are transferred among the peoples of the Malay peninsula, the Himalaya and Caucasus districts, among the Mongolic-Tartaric, most of the Semitic, most of the Negro, Congo, and Indo-Germanic peoples, according to the systems respectively prevailing among them. Here and there the aecounts fail in establishing whether inheritance takes place according to mother-right or father-right, and since both sistems often exist side by side, these instances demand more detailed investigation. With the Brazilian tribes mentioned a complication of father and mother-right is found. The widow is married by the nearest relative according to the patriarchal system, while the daughter is married by her mother's brother on the maternal side according to the matriarchal system.

With the Dyaks, who live according to parent-right, leviratical marriages are in a state of total decadence. The widow may be freed from marriage with the nearest relative of her husband by surrendering her property to the family of such relative.

2. In strict conformity to clan-law, the nearest male-relation of the deceased husband is empowered and obligated to take the widow in marriage, while the consent of the widow is not asked. After the dissolution of the clan the heir generally continues to enjoy the right of marrying the widow, although no longer obliged to do so; on the other hand, he is still obliged to provide for her, although he may become absolved from this duty by giving her in marriage to another person - a procedure empowered by his guardian-right of disposition. The wirlow acquires the privilege of no longer being forced to marry without her consent the person that inherits her; but on the other hand she is not allowed to enter into another marriage without his approval. If a third person should marry her without the consent of the heir, he would be guilty of an infraction of the heir's guardian rights, and according to clan-law this leads to blood-feud.

Here belong the customs of the Arawaks, the Australians, the Malayans, and most of the others mentioned.

3. All male relatives are entitled to such inheritance who, according to the system of kinship prevailing, are next of kin. 
Thus the sister's son or mother's brother, according to motherright, and according to father-right the son or the brother on the father's side, inherit the wive's as well as the property and enter into marriage with the former by inheritance. 'The brothers of the deceased figure in almost all the custons mentioned. The sister's son figures as heir, for example, among the Kolushes, the Barea, and Kunamas, in equatorial Afriea; the son, among the Tunguses, the Bakalai, the Bechuana, the Kaffirs. The only exception to the inheritance of the son is his natural mother, who falls to a brother of the father.

In accordance with the notion that the right of guardianship resides in the whole elan, all members thereof are in a mediate way supposed to be entitled to the inheritance, as is the case among the Alfurs.

4. A legal custom prevailing among all clan-organisations is the purchase of the bride. The family of the female, or its clanhead, sells the future wife for a certain sum to the family of the future husband, or to the latter in person. By this sale the family of the female either renounces all claims to the wife, or certain defined rights still remain with them. When the wife is transferred by marriage to the family of her husband, she remains there even after his death. The family of her husband has to dispose of and eare for her: she stands under the guardianship of her husband's family. Without the consent of the latter she is not allowed to enter into marriage with a third person, ant in case of such a marriage her deceased husband's family receives the amount paid for her as bride.

If a kinsman of the deceased husband marry the widow, no bridal price is paid the family of the female, provided all rights have passed to the family of the husband through the original bridal purchase. Otherwise, a smaller parment is made at remarriage.

If the guardian-rights of the female's family are not totally abolished by the bridal purchase, the relations between the family of the female and the family of the husband may take various shapes.

Thus among the Benget-Igorrots the wife belongs to the family of the deceased husband, and among the Papuas of Geelvink Bay and on the Aru islands the family of the husband gets the bridal sum for the widow who enters into an alien marriage. No bridal sum is paid among the Alfures of Buru and on the Aru islands in case of leviratical marriages. The law of the Somali is also to be compared here. 
The rights of the wife's family still appear in the custom of pre-emption, which is mentioned among the Lsbegs, in the law of Timor, where the next of kin to the deceased can absolve himself from the obligation of providing for the wirlow by the parment of a certain sum to her family.

5. To the clan-guardianship already noticed, belongs the custom of the Karo-Karo according to which, if there be no near relative of the deceased to take the widow, the family chief assigns the latter a spouse from the Marga of the deceased husband. And similarly among the Circassians, the widow and her chilcren pass to another member of the clan. The provision here is quite characteristic that the clan has no obligations in this line if the widow be too old for marriage. With the Bechuana also the whole kindred determines which among the kinsmen has to marry the wirlow.

6. The provisions of the Batak-law of Angola and Sipirong are to be taken into consideration here arcording to which the widow of the elder brother always falls to the younger brother, while the marriage of the elder brother with the vidow of the younger is regarded as incest. On the other hand, with the Alfures of Buru the eldest brother of the deceased inherits the widow of the deceased, whereas a brother younger than the deceased husband may not marry the latter's widow. This last provision appears to owe its existence to entirely specific causes. With the Malagasy the brother next succeeding marries the widow. With the Khatties the widow of the elder brother falls to the younger, while the widow of the younger brother may do as she pleases. It thus appears that also in this instance the eler brother can make no claim to the widow of the younger. With the Chassaks the women pass from one brother to another in the line of succession, apparently thus: the widow of the elder brother, always to the next younger. With the Bechuana also the younger brother succeeds to the widow of the elder. And so it appears to be the rulc in general, that the next younger brother is in every case authorised and obligated to contract leviratical marriages.

7. A peculiar group is formed by the leviratical marriages of the Calchaquis in the interior of Brazil, of the Malagats, and of the Hebrews. In these instances the object of leviratical marriage is to perpetuate the fimily of the deceased - an object which is aimed at by many other features of the clan-sistem. Children begotten in leviratical marriage are considered the children of the deceased husband. The law of the Malagasy recognises all children as such; that of the Hebrews only the first son. Firth the Ossetes 
the same thing reappears as with the Malagasy: only in this instance the widow's children which are subsequently born out of wedlock, also pass for the children of the deceased husband, just as among the Kaffirs natural children of widows pass as the children of the deceased husband and consequently fall to the latter's heirs.

S. To the decadence of the clan-system belong those customs according to which the obligation to marry the widow is only a duty of propriety, and according to which the woman must consent to the marriage; in the first place, however, the provision of the law of Anahuae whereby a leviratical marriage is permissible only when the education of the deceased brother's children has to be providerl for.

9. To an entirely different group belongs the custom of Ponapi, according to which, upon the death of a wife, the widower marries her sister. This custom is also found among the North American Indians, the Knistineaux and the Selish, and in many other districts besides. It is found among the Somali together with the customs above noticed. There may be a close relation between this and the legal principle so widely diffused that the wife's family stands security to the man in bridal purchase that he shall keep his wife, and that if she die, a new one shall be substituted. Yet the matter might be considered from other points of view, and more thorough investigation is demanded for an adequate explanation of this phenomenon.

Numerous groups of facts similar to those just discussed may be discovered in the jural life of the peoples of the earth, and this being the case, it will no longer be possible to deny that the purely comparative method is allowable in the province of jurisprudence; and this holds true, whatever individual opinions may be as to the value of the facts reported and the inferences drawn from them.

That the inferences are unsafe, is at once evident. This comes from the fact that sufficient material is not ret at hand and has not yet been properly assorted. But it is just as perfectly evident that inferences have to be drawn and will have to be drawn still. The material would never be procured, if it could not be shown from such inferences that a collection of facts in the direction indicated would lead to solid icientific results. Furthermore it is only through inferences of this sort that points of view can be won from which further work may be directed with intelligence. For all material is certainly not of equal value to science, and the tendency 
to delve into irrelevant details is widely prevalent in learned circles, and especially in Germany. On the other hand, one must be on one's guard against pronouncing a discovered fact irrelevant because we do not happen to know at the time of any analogous phenomenon. It is impossible to prescribe a detailed method of procedure for the field of ethnological jurisprudence. Such a method must first result from the very material to which it is applied.

At present we can offer but a few general points for consideration:

1. Although the collection of material must take place with separate races and nations (and the most detailed observations are here of the highest value), nerertheless in the causal analysis of the jural customs of a single nation, it is highly experlient alway's to adduce the corresponding jural facts of cognate as well as of noncognate peoples: for we may thus aroid such false conchusions as easily arise from insufficient material in treating of a definite custom of a given people. This is but the extension of a view which has already asserted itself in the investigation of the history of law.

An exposition of what is stipulated in the law of a single European municipality would be much more exhaustive if expounded from other sources beside its own and if the laws of kindred municipalities were adduced in explanation. In wider fields, the recent study of Indian Law has aided considerably in perfecting the expositions of Germanic, Roman, Grecian, and Celtic customary law. If legal customs exist which are more universal and which prevail throughout extended ethnic fields, it is certain that an understanding of these is of proportionately more value if the explanation of such a custom in a single nation is under consideration. We do not wish to say by this that no attempt should be made to expound the legal custom first from the more limited sphere in which it appears. On the contrary, this endeavor should be aided as much as possible, and historical investigation in particular should be pushed as far as practieable in the separate provinces. But in any single provinee of law, historical investigation will always reach a point where original material no longer warrants conclusions of demonstrable certainty. Vagrant hypotheses necessarily arise, where the admission of facts from more extended regions might lead to safe conclusions. It is quite obvious that in considering the laws of peoples having no history, a comprehenive understanding of the laws of all other peoples of the earth pos csies 
incomparably higher value than in the case of pcoples that do possess a history ; incleed it is indispensable in the first instance if false conclusions are to be avoided. It must therefore be recommended to those who intend to kabor scientifically in the field of ethological jurisprudence, first to acquire at least a tolerable knowledge of every existing legal system before entering upon more limited fields of research : otherwise they will always be liable to partial judgments. Even for the mere collection of legal customs, this will be expedient, for an investigator with European opinions of law might very easily receive a wrong impression from a legal custom discovered among a people living in a state of nature. The causal analysis will be the more correct, in proportion as the inrestigator's knowledge of all existing systems of law is the more comprehensive.

2. The history of law deals with historical data in their chronological succession. Ethnology in so far as it treats of peoples having no history does not recognise such a connexion; it has no chronology. Ethnology takes no cognizance of decades or centuries: it has to do with periods and strata only, somewhat like geology. In any epoch you choose ethnology meets with all manner of legal customs, from the lowest and crudest to those of the highest development, existing near each other and among all nations of the earth. The materials whereon it can found its conclusions are like or analogous data, and such data among the different peoples of the earth are separated from one another not by decades but by hundreds and thousands of years. Legal customs which are practised to-day among one people, belong to the most primitive periods of another. The chronology of ethnological jurisprudence is not a computation of years from a point of time arbitrarily adopted. It is the graduated scale of development which any characteristic legal custom or conception has passed through among the different people with whom it is found.

This idea can be transferred to historic nations also and with important results. Every living historic nation still rests in its undermost strat a upon the primitive society whence it has arisen, and upon this foundation strata upon strata of culture and civilisation are piled. All these strata still lie one above the other in the positive law of a people of any period. Even in the most recent of modern codifications there is an abundance of heirlooms from primitive times, and we may trace in the current law of to-day the history of its development as easily as we can trace in the structure of the human body the history of the human race. This point, too, 
may often become of great importance in explaining any single legal custom; for it is often impossible to explain such customs from the times in which they occur, it being necessary to recur to periods long since past.

3. Hitherto, the science of jurisprudence has believed that it possessed the most valuable material for research in the laws of nations which had reached the highest plane of civilisation, and that it could dispense altogether with the study of civil life among the ruder and more uncivilised peoples. It is exactly upon this point that ethnological jurisprudence must lay the greatest emphasis, for only in the laws of uncivilised peoples are the germinal conditions of law to be discovered, and for universal history of the development of law a knowledge of the latter conditions is indispensable. As the science of physiology is based upon the physiology of the cell, so will the future science of jurisprudence be founded upon the germinal element of civil society - the primitive gens. And this primitive gens as an elementary form is to be found at present only among purely aboriginal peoples.

4. Social customs and conceptions, as we find them among the nations of the earth, are regarded by the ethnologist as organic products. The fact of their existence can no more be subjected to criticism than the fact of the existence of individual plant or animal species, than the fact of the existence of a solar șistem or of the universe at large. They are regarded as natural growths, and merely the causes that have produced them are made the subject of ethnological research. In the same manner the legal customs and conceptions of the various nations of the earth, are regardcd by ethnological jurisprudence as irreversible facts. They too are not to be subjected to asthetical or ethical criticism from the individual standpoint. They are to be investigated objectively in reference to their causes, just as we examine a plant or an animal in search of the laws of its growth and the conditions of its life.

In ethnology, therefore, and particularly in ethnological jurisprudence, the question never arises as to whether a thing be good or bad, right or wrong, true or untrue, beautiful or ugly. The sole question is whether a certain custom or conception really exists in the life of the nations; and if it exist, why? and if not, why? No importance can be attached here to the judgments of individuals regarding such a custom or conception ; and if ethnology and cthnological jurisprudence are to acquire a strictly scientific character, this purely objective standpoint is to be rigorously adhered to.

Individual estimation is an extremely inconstant factor, and 
its recognition would utterly invalirlate a strict and scientific treatment of ethnological subjects. An exhibition of indignation on the part of an ethnologist at relatively immoral practices, adds nothing to the solution of ethnological problems. It matters not whether a people live without the institution of marriage, practice cannibalism, offer human sacrifices, impale its wrong-doers or burn its witches and sorcerers; for the sentimental disapproval of such practices, in investigation, tends to disarrange that equipoise of judgment which is requisite to determining the causal relation existing between ethnological phenomena. The ethnologist is called upon to seek this causal relation with the cold indifference of the anatomist. A person who speaks of senseless customs and senseless institutions, is not fitted to engage in ethnological research.

* $\quad * \quad * \quad * \quad * \quad * \quad * \quad * \quad * \quad *$

The above are the principal points of view which at present admit of establishment for ethnological jurisprudence. Others may suggest themselves as the science is further developed.

\section{SECTION 3}

\section{THE ORIGIN OF LEGAL INSTITUTIONS}

\section{The Initation Theori ${ }^{1}$}

Of all phases of social life the law is that one in which philosophical speculation has in our day been the least exereised. It has been given full scope in comparative philology and mythology in politics, in morals, in esthetics, in political economy; but the Corles have inspired its fear. It has left the law to the jurists, the mine to the miners. Has it recoiled, I know not why, from the special studies which the development of that new vein would demand? Or is there between the juridieal and the philosophic spirit a certain incompatibility of nature?

Be that as it may, this surrender of the legal field to mere day-

${ }^{1}$ [This passage is from the Introduction and Chapter VII of "Les transformations du Droit," by (iABRIEL TARDE (Paris, 1st ed. 1893, 7 th ed., 1912; the 7 th edition is a reprint of the first, with the addition of a Prefice taking account of the criticisms of M. Girard, printed post, as \$2). M. Tarde. eminent as magistrate, psychologist, and sociologist, died in 1909; an account of his work is given in the editorial preface to the translation of his "Penal Philosophy" (Modern Criminal Science Series, 1913). Nime. Tarde has consented to the translation; from advance copy of which, hy she pard Barclay, of St. Louis, the parts presented here were selected and edited.] 
laborers (known as commentators) and to men of business has had unfortunate results. The science of Law itself has remained isolated and sterile, dominated by its own donestic routine. And the other sciences, too, have suffered, that of economics especially, which has forgot its parentage and its rights of joint inheritance and has unconsciously overpassed its natural boundaries. The socialistic reaction, arising so enthusiastically in the latter half of the $1800 \mathrm{~s}$, against the old-school economics was in part due to the latter's unwitting encroachments; for there was no worthy and powerful theory of law to impose a rival and fraternal check upon the ambitious theories of wealth put forth by economics.

\section{The Theory of a C'niform Exolution; its Fallacies}

But for some years past we have been witnessing the rise of a new influence in criminal law, - the influence of Darwinism, of evolution, of anthropology ; and this influence, rapidly increasing and spreading, has begun to gain a foothold within the civil field of law. ${ }^{1}$ Already, indeed, the learned researches of the archæologists of our legal system had prepared the grouml. Lntil they appeared, the Roman law was the only one studied historically with complete thoroughness. For the theorepical jurist, it had always been what the scriptures were to the historian of old, - a unique and sacred phenomenon, totally incomparable with anything else, and hence, for lack of standards of comparison, absolutely beyond the sphere of explanation. But when the Egyptologists and the Assyriologists of to-day revealed to us the Egyptian law, the Assyrian law; when similar researches into the relics of the Indo-European and Semitic families, of the Germans, Slavs, Persians, Celts, as well as of the Moslems, of the Hebrews, etc., furnished for us, little by little, a rast juridical museum (of which M. Dareste, ${ }^{2}$ among 11 , might be called the convervator), then the traditional orthorlox legal science began to feel a mulden expansion and rejuvenation.

Nevertheless, it would be mislearling to suppose, becantse one had noted many and striking resemblances between different languages and founded a comparative philology, that he harl

${ }^{1}$ It is worth noting that in all epochs the reconstruetion of a legal system - the grafting of new ideas on the juristic tree - has begun with the criminal law, the earliest branch to put forth new shoots, and always the one most prominent for our attention.

2 "Etudes d'histoire du Droit," by .M. Dareste, of the Institute (Lerose et Forcel 1359). 
made a theory of language. It would be a like error to persuade oneself that it is sufficient for a lawyer-philosopher to have diseovered some resemblances between certain developments in the law, more or less independent the one of the other, and thus ereated a eomparative jurisprudenee. Those resemblances are only the materials of the problem to solve; the point is first to limit them, to replace them in their natural positions, often disturbed by excessive ingenuity, and to interpret them by tracing back their causes.

These are of two kinds, organie or social. The first are found in the inherent and hereditary wants of human nature, which continue the same despite diversity of races and of times; the seeond, in wants derived and aequired by imitative contact between man and man. It is needful to join these two incomplete acts to understand the historieal transformations of the Law, as well as those of language, of religion, of institutions, of industries, of manners. But, to join them, one must by all means not confuse them, but rather distinguish them, with all the nicety possible, and give to each of them its proper part.

Not but that admirable philosophie works on the law have appeared, here and there, exceptionally. Suffice it to cite the leading effort of Sir Henry Maine, on "Ancient Law," and the remarkable sturlies which followed it. But we find that the school of evolution, although rapidly advaneing, although quick to inspire flights beyond its eradle in Darwinism, has shown itself most backward in respect of the Law. Maine is not committed to it except by a sort of collateral relationship, quite distant; and it was the historieal sehool, very French in its origin, that antieipated the advent of either Darwin or Spencer into the world. It is true that in penal law there has been dabbling with the doctrine of evolution for several years. But yet there is much more of "criminal anthropology" than of penal evolution in question therein. As to the civil law, it has remained outside the scope of the morement until a much later period. Note, nevertheless, that we already hear announced the terms "juridieal anthropology" and "juridical evolution"; but more like the names which old geographers used to give in advance to partly umexplored regions of Africa or America. In reality, without ignoring the merit of the first explorers of those unknown lands, we may be allowed to belicve that they have left quite a erop to be gleaned after them. Further is it manifest that many explorers strive to launch out in their footsteps. 
The historians and archeologists of the law had long since prepared the roads for them. But history and archelogy appear, unhappily, to be subjects the least in mind of the disciples of Herbert Spencer, who, applying here a general formula of evolution, the magic key of the universe, accept for explanation its application pure and simple.

It is true that the new evolutionists of the Law are, in general, also anthropologists, ${ }^{1}$ and we may anticipate from this junction of anthropological researches with the grand constructive sistems of Darwin and Spencer the most fortunate result. We may renture to believe that a minute comprehension, in detail, of the organs and needs of the individual, as furnished by the one, wotild complement or temper the inordinate tendency to generalization suggested by the other; that the one would allow us for the first time to introduce to the law of the future its true ideal, the pursuit of a Law truly natural conforming to the natural demands of the human organism, while the other would unfold the necessity of the vicissitudes encountered by the Law of the past in the course of its history. But truth obliges me to confess that, until now at least, this confluence of the two great schools has not been very productive in stable ideas, nor do I yet see arising, among the many small towers of Babel, hastily constructed, in the law, any. Eiffel tower to dim in its shadow the prior works of Maine and of Fustel de Coulanges. The "Ancient City" of the latter, despite even its comments on the origin of the feulal system, unhappily marred by the spirit of system and of useless polemies, stands as one of those works which indirectly has best penetrated the very" life of the Law and the secrets of its changes. ${ }^{2}$ As to the "Ancient Law" and other works of the great English law-philosopher, although wholly deroid themselves of ambitious pretensions, they would seem to have extracted from our subject all the philosophic sweet that it contains. But, nevertheless, that is an illusion;

"For instance, M. Letournerzu. author of the "Evolution juridique" (1891) anc .I. Giuseppe "lgmmmo, whose hook entited "La gemese e l'evoluzione del dirito rivile serondo lo resultanz" delle seience anthropologiche e storico-soriali" "Turin, 1\$9(9), will have consiser"able claim on our attention. We refer again. in another line of thought. to the work of Ihering on the "struggle for Law." It is high time that the famous "struggle for life" had a word to say in the law.

${ }^{2}$ Excessive and exclusive study of the witten word led that great historian, at the close of his career to hecome biased, so as an be unjust in respeet of the discoveries of others. It is curions, for instances. (1) sce him reproaching XI. de Laveloy. XI. Chlasson. ete. for their nse of the comparative method. Whinh was the very featuce giving valus is his chief work, the "Ancient City." 
and there remain yet, assuredly, many other discoveries to be made in this field so little or so poorly explored. . . .

Much clearer ostensibly than the idea of a "legal anthropology" is that of "legal evolution." Nevertheless, it also has great need of being defined. If it does nothing more than to substitute for the study of the Roman law that of the Aztec law, of the Peruvian law, of the Fuegian law, of the Australian law, of the law of the bronze age or of the stone age (rough or smooth), of all the barbarian or savage laws whatsoever, to get at the sources of law, the result would only bring a certain amount of easy learning to the aid of a large measure of imagination. And this latter will always commant approval of a special audience, if it has that "trite form of originality" which consists in being at one time slow and confirlent, deductive and ingenious - adapted to conform at the same time, by its scientific hypotheses, to the beaten track of opinion and to the taste for novelty. Here, as to some extent generally in sociology, we have greatly imposed upon the savages; since spencer, who officially inaugurated the exploitation of that mine of hase metal, there are current a small number of stories, always the same, ascribed to several tribes, American, African or Oceanie, which have made the roumls of the sociological press for a long time, nuter diverse heats. Without a shadow of proof (unless it be such as gives but a surface indication), one is asked to give credence to the idea a priori that the primitive social state, the supposed starting point of Progress, is the same among all sarages. It is, however, impossible to close our eyes to the profound dissimilarities which mark real savages, even the lowest; their worl-roots, the grammatical structure of their languages; their ceremonies and their beliefs, their germs of government tespestic or paternal, their manners in peace or in war, gentle or fierce, honest or dishonest, their musical melorlies, their efforts at art, differ, out and out. But the seholars are not embarrassed by such smail things: the savages who are elifferent, are so, they say, because they have raised themselves more or less in the scale of savagery; even their differences are instructive from the point of view of an original identity, of which they measure the degree of departure; that does not contradict it. As to sarages which have resemblances, they concede at once that those are entirely spontaneous; they do not in general take into account the great probability of association which was bound to occur, either between them or between their ancestors, in the long night of their history, or perhaps before it; nor do they think of asking if, at that 
time, much more naturally than by any supposed formula of singular and inevitable evolution, may not be explained an important part of those resemblances.

Unfortunately, this theory is strained. If, by evolution, we are expected to understand a regulated series of phases, of changes, equally inevitable and recularly repeaterl as those of insects, despite purely aceidental and supposerly insignificant variations, is it not necessary, first of all, that the initial phase should be regarded as every $w$ here the same? The misfortune, for the transformistic theory, is that having taken its birth among naturalists, not sociologists or physicians, it is accustomed to consider as the only possible type of development the single sort, of development (notable for its routine features) shown by organical beings. It persuades itself too readily that evolution means not only the production of successive phases brought about in obedience to laws of mechanics and of logic, but further reprorluction in multiple examples of predetermined phases, by analogy to the successive ages of an individual animal or vegetable. ${ }^{1}$

The idea does not occur to them that this law of the ages, thus conceived on the model of those exceptional beings, could not well be applicable, in its entirety, to the solar systems or to the transformations of society; that the growth of a language, of a religion, of a body of laws, of an art, though it may conform as well to a universal law as the growth of a seed or of a quadruped, may yet otherwise be entirely original and unique in itself. It allows itself too readily to think and to assert that, because every living being is or appears to be ${ }^{2}$ impelled unto death by an internal impulse, there must be also, for every astronomical system, although it may have reached its phase of stahle equilibrium, and equally for every language, for every religion, for every law, although it has attained to a state of relative perfection and of settled vitality, an intemal necessity of death. Now, that sooner or later it ought probably to encounter from without some destructive shock, in which woukl be swept away language, religion, legal system (the most stable until then), nothing is easier to concede;

${ }^{1}$ One is too apt to confound the connection, truly forrilule, hetween cause and effect, of the conditions with the conditioned, with the connection, muel more loose and fluctuating, of phase to phase, in any erolution whatsoever.

2 Aceording to Dr. Hoissman ("Essais sur l'Hérédite," 1s:22) livingr monocellular beings are immortal; they disintegrate themselves hut where is the corpse? Death would be only a "practical process" (invention) of life, but a fairly resent one. M. Delhonf also has very murious views thereon, and most profound (in "La matière brtutr ct la matiere vivante"). 
thus have perished the antique civilizations of Asia which long endured without any mishap from war; thus, perhaps, after all will perish creeds attacked by science; thus ancient China, perhaps, by contact with Europeans. But that violent death, the interruption of an immortality possible and normal, is a very different thing from the natural death which nothing living escapes within a time limit approximately marked. ${ }^{1}$

Before generalizing into a paramount law these last phenomena and many other apparent or real characteristics of life, it would be well to ponder them a little. The model idea of development, instead of being borrowed from natural life, could it not as well be expected from astronomy or from comparative philology or mythology? Are the laws of mechanies and the laws of logic, the one reflected in the other, dominated by those of vegetation and of animality? And is not the notion of development, as it is suggested to us by the celestial mechanism, as being essentially the result of an established and variable balance, or such even as is suggested to us by the logic of individuality or of society as being the result of some harmonious system, indefinitely durable, of thoughts and wills operating without opposition, in good accord among themselves, - is not that notion superior in definiteness, in clearness, in explicative value, to the idea of that insensate and fatal march toward death which our natural life suggests?

We shall attempt to outline or to indicate the principal features of the evolution of the Law, considered as a high and complex process of the logic of society; but at the outset, we have to show the insufficiency of social evolutionism such as it is generally interpreted. A victim to its own fixed theory, it falls fatally into two fallacies: $1^{\circ}$ It exaggerates the number and significance of the resemblances which strike the mind, at first sight, when we compare the bodics of supposed foreign laws, one with another, as well as the languages, religions, armies, nations, regarded in their political, industrial, artistic and moral aspects; $2^{\circ}$ It holds all those resemblances, true or false, as spontaneous, without accorling or attempting to accord its legitimate part to the principle of initation. It is curious to see those minds calling themselves "positivists" yield to the seduction of the marvelous, realized (according to them) by those multiplied coincidences; and preferring, to the clear explanation of those resemblances by the

1 "Some would like to know if colonies (of animals) disorganize and expire of themselves at the end of a limited period as do the single individuals which compose them. If have not bien able to collect any cvidence to cstablish it." (Espinas, "Sociétés amimales," p. 513.) 
contagion of example, their own obseure explanation of atavism or of heredity. We may be allowed to enter into some developments of this subject.

The best minds may be warped by systematic preoccupation. For proof thereof I wish none other than M. Dareste. "One thing which modern works have clearly brought to light," says he, at the opening of his book on the "History of Law," "is the affinity, not to say identity, of diverse primitive legal systems. Philology has disclosed by admirable discoveries a common origin for the greater part of the European languages, which it has found connected with the ancient tongnes, now extinct, of India and Persia. Yet more close is the relationship of various laws. Not only have they all undergone analogous transformations, but they often reappear, one and another, feature for feature, and almost word for word, across the most enormous reaches of distance and the longest intervals of time, when any direct borrowing has not been possible; so that, to explain the resemblance which could not be known to be fortuitous, it is necessary to armit either that the two peoples had one origin and hence a common tradition, or that the same causes every where have the same effects." Manifestly, M. Dareste strains much for that last construction; moreover, we notice, he states the problem quite well, and restricts himself, besides, to comparing the laws of superior races, to the discreet exclusion of savages of every race. But, even within those limits, we observe, he asserts much more than his book proves. Be that as it may, since he expresses himself in that manner, we need not be astonished to see M. Letourneau, who extends to all tribes and nations known the field of his comparisons, ascribing the same unfortmate uniformity to the course of their juridical transformations. Nevertheless with him the truth often has the better of his predisposition; he admits original divergencies in the social development, emerging from the lowest savagery, because it would cost him too much to merge republican with monarchical tribes; and that base of distinction, although at best obviously too narrow, is woll to note. In his florid style, he proceeds also to portray strikingly the juridical physiognomy peculiar to each people, entirely "sui generis"; and although he seriously misconceives therem, through a professed horror of Romanists and imperialism, the commanding originality of the Roman Law, he exalts beyond measure that of the Athenian law, in his love for democracies.

The evolutionists, in spite of all, therefore, agree in affirming 
the existence of a peeuliar and neeessary law of juridical evolution. But their discord appears when they undertake to formulate it and to define the phases which the law would surmount in passing through the course of its history. . . . The truth is las the present volume aims to demonstrate in detail] that in no one of the principal branches of Law does the theory of a uniformity of evolution find any support. And for that matter, most evolutionists are too eareful and too sagacious to close their eyes to the important dissinilarities which distinguish the historie transformations of different Laws. But they believe themselves warranted to give thercto but little weight, on the plea that if in each society erolution was leit to itself, it would adapt itself to their formula. The misfortune is that this hypothesis is untenable. What Law is there which, without influences external and aeeidentalborrowings from some foreign law or innovations created by original genius or even indigenous - would ever be spontaneously transformed?...

The word "evolution" is deceptive. It is so easy to pronounee that it naturally imparts an impression like that of flowing over sand, without obstacle or pause. But, if we enter into detail, we perceive that the fluidity, the apparent continuity, attributed thus to a series of changes, is imaginary. Take any law, and you will see that its so-ealled cvolution continues to deeompose into laborious importations, - most frequently ruddy with new ideas added in, from time to time, from one side or another, suddenly, none knows why. They have been grafted upon it, - be it by a proselytic religion (Christian, Islamie, Buddhist), by external conquest (the Roman law, absorbed more than imposed upon the ranquished, even on the Egyptians and on the Greeks; the English Law replacing the Hindu laws; the French Law islamized in Algeria, etc.), or be it by internal revolutions, which transfer the power of patricians to plebeians, or of the Senate to the Emperor, or of the Nobility to the Third Estate, ete, or by an intermittent infatuation for foreign institution and laws. The examples of this last cause of juridical renovation are numerous: it will suffice us to point out the influence exerted by the Roman Law even beyond the Roman empire, by the Greek law among the Barbarians, by the Chinese Law throughout all oriental Asia, - by the Canon Law, in another way, upon the secular law of the mildle rages and of modern times.

Now during these painful engraftings, slow to heal and not always successfully, the Law called national appears to have 
not the least tendency to "evolute"; it only seems inclined to sit still. Each of those advances is an unexpected stroke of a lash which arouses and sways it. Can any one seriously pretend that the classie Roman Law waited and aspired to receive the impulse given it by the propaganda of Christianity, and which so strongly byzantinized it in its last stage. Who, from its birth, predestined it to that regenerating impulse? And, to go back further, was it the "actiones legis" of Roman law which of themselves tended to the formulary system? The edicts of the pretors, the voted laws, the royal ediets, ete., were merely so many intermittent springs of the law, which never flowed without external stimulus. This supposed necessity of juridical evolution is like that disearded theory which insisted that all language passed through the three successive phases of monosyllabism, of agghutination, and of inflection. Modern linguists know what value to ascribe to that formula. . . .

\section{The Theory of Imitation}

No instance of similitude can be found in the Universe which has not as a cause one of the three great forms, superposed and blended, in the universal repetition: undulation (for physical phenomena), heredity (for living phenomena), imitation (for social phenomena properly so-ealled). I need not repeat here ${ }^{1}$ the mutual bearings of these three factors in universal analogy. It is elear that we should take account of the three, and not of the last alone, to furnish a complete explanation of the analogies presented by the workd of society, which springs from the living and expires into the physieal orler. 'There is then no doubt that the influence of climates and races do not furnish the key to many resemblances observed among social bodies of the same blood or the same latitude. 'The importance of these two influences in sociology has been much exaggerated, because of ignoring the dominant part of the third, which always end by using the others or impressing them with its stamp. What is continuous, what is essential, what is subject to laws susecptible of scientific formulation, in the events of society, is the characteristic common to them all, and exclusively proper to them collectively, namely, that of being imitative or initated."

"I have devoted to that subject my book on the "Lois de l'imitation" (Alean).

2 We do not even except inventions and discoveries in so far as they are sociological facts. Not only are they always in part imitative, formed 
Whether imitation is conscious or unconscious, intelligent or stupid, instruction or habit, matters not. Speaking, praying, working, fighting, doing whatsoever sort of social act, involves repeating what one has learned from some one, who had acquired it from some one else; and so one after another back to the first framers of each word-root transmitted identically from mouth to mouth, for thousands of years, - like the waves of light or sound from atom to atom, - back to the first authors of each form of rites, of each method of labor, of each mode of war, fencing-boots, taetics, strategic ruses, which pass from man to man during a period more or less prolonged.

I lo not say that Imitation is all of social reality; it is but one expression of the sympathy which antedates it and which it intensifies in expressing; and it depends upon invention, the spark from which it is only the greater light. It begins by being in some sort a vassal to Heredity, as long as the social group is confined to the family, and the effect of examples is limited to the narrow circle of the relatives. Then, when it became free of the family, when it even dominated in its turn, it yielded so much the more to another rule: it was subjected, we know, to the higher laws of Logic, as was undulation to the laws of mechanies. But it is none the less certain that it alone weaves together the tissues of society arranged by social Logic. It is the warp and woof of humanity. The artist views it from the right side, the side of its embroideries, of its variations bright and fleeting; but which the philosopher is bound to examine from the back, from the side of its repetitions, - singly to be weighed, singly numberable, singly formulable into statistical groups or into seientific laws. What was physics before the theory of undulation had made its entry therein, even though the laws of mechanies were already known? Very little. So will be sociology, as long as it does not accord due place, a large and controlling part, to the theory of Imitation.

From failing to observe the universality, the continuity, the greater importance of the fact of Imitation in history, many archeologists, many historians, even the most circumspect and lucid, are led into most erroneous inferences. ... M. Fustel de Coulanges himself, after remarking that the feudal system mani-

by a mental junction of various imitations, but again, even in so far as they are most original, they must be imitater to hecome social facts, not merely individual facts. An invention not utilized, an idea not carried out, not reflected in the soul of another, is as if it did not exist, socially viewed. 
fested itself among peoples not in the least Germanic, in Southern Gaul, the Brzantine Empire, Slavonia, Hungary, Ireland, the same as among those nations who were not in the least liomanic, concludes thus:

"It manifested itself among all races; it is neither Romanic nor German ; it belongs to human nature."

Nevertheless, before having recourse to a quasi-miraculous hypothesis of spontaneous generation of that unique system, everywhere the same, in Heaven-knows-how-many different places, is there no room to inquirc if its relative ubiquity - cxaggerated, at that - is not cxplainable by simpler methorls of ordinary up-building of society, - that is to say, of Imitation? Now, all the researches of the eminent historian that I have just cited tend precisely to show that the scattered elements of the feudal system existed almost in entirety in the institutions of the Roman Empire, and that their simultaneous synthetic derelopment has been the result of the special circumstances in which the Roman world of the West, especially Gaul, found itself after the fall of the imperial power. . . .

All, then, that is clear, definite, characteristic in resemblances of whatsoever category - whether of language, religion, politics, economies, law - which the evolutionists have pointerl out among different peoples, even far apart, has Imitation for its cause. Such, beyond doubt, are the striking analogies presented to those different points of view, by the Hindus, the Germans, the Slars, the Celts, the Latins, the Greeks, - nations which some are pleased to group, under the name of Aryan, in the same hypothetical race. Whether that hypothesis prove correct or not, . . the misfortume is that, when once this family tree of the so-ralled Aryans had been specifically described (as also that of the Semites and of other extensive race-stoeks) scholars began to letect, among peoples unrelated to each other, resemblances in religion and law, equal in exactness and in importance to those of the races regarded as co-related. For instance, the several Aryan peoples, as between themselves, show us nowhere any coincidence more complete than that which M. Seignette ${ }^{1}$ has pointed out between the customs of the Arabs before Mahomet and the institutions of the primitive liomans. "The patcrnal anthority" in all its rigor, the perpetual tutelage of the women, wills, the

'French translation of the "Code musulman" of Khalil, introduction, p. xxxvii. 
heredity of male descendants, patrons and gentiles, their tutelage testamentary guardianship, the '11exum,' the 'pignoris eapio, the noxal surrender, retaliation, composition for feuds, the relations of patron and client, - all these customs, inscribed in the lioman law of the Twelve Tables, correspond to ante-islamitic usages identically similar, in Arabia, of which some were continued, the others abolished, by the Koran." If we recall the proximity of Arabia and of India, where analogous customs prevailed, and the mutual inclination of neighboring peoples to borrow their civil institutions, much more than their religions and above all, more than their idlioms, it is easy to explain those resemblances by imitative action. What confirms this interpretation is the many other points of juridical contact between the Aryans and the semites. They are of such exactness that their spontaneous appearance is absolutely inconceivable. . . .

But, perhaps we have not sufficiently remarked upon the direct, immediate action of Imitation upon the law, when it has the latter itself as its objective. By that process, the juridical unity of diverse classes and of diverse provinees of a nation camnot fail to be wrought, in course of time. It unites classes as well as provinces by the everlasting yearning of the inferior to imitate the superior. The juridical customs of the higher classes descend, through the various grades of the nobility, to the lowest ranks of the commonalty, and help to obliterate the diversity of their own customs. Likewise, the large cities pass on their charters to the small, the small cities to the towns, and their disparity of custom disappears. The most brilliant nations illumine in the same way the more obscure. I have above already indicated the contagious descent of the law of primogeniture from the nobility to the people. . . . In a group of peoples in contact, the most civilized communicates its Law to its neighbors by a sort of juridical exosmosis. Thus, in the milllle ages, the German law penetrated into Bohemia and Poland and was introduced there at the besiming through the most enlightened strata of the population, through the cities. 'The law of Magdeburg has served as a model for the greater part of the Čech cities of the north and for nearly all the Polish cities. Italian influence, during the same epoch, made itself felt in the laws of Dalmatia. . . . 


\section{The Element of Losic in Erolution}

But not all the similitudes, even of social origin, appearing in legal systems (or, better say, juridical activities) of diverse peoples. have Imitation as their cause. Many arise from Logic.

Though man is imitative, it is because he is inventive. Though the influence of a flood of examples ceaselessly operates, like the leveling process of the watersheds, whence millions of rivulets, brooks, and rivers, each contributes to what may be called the alluvial deposits of civilization, yet this, I repeat, is because from time to time innovations, great or small - mountains or hills -have risen up. And if man is inventive, it is because he is logical. Logical or inventive - it is all one, at bottom. An invention, a discovery, is but the response to a problem; and that response consists always in connecting with each other, through the adjustment of means to end, methods of action formerly isolated and barren; by connecting with each other, through the no less fertile relation of principle to result, those ideas or perceptions which previously secmed to have nothing in common. ${ }^{1}$. . .

Now, though there are reasons to think that this work of logic, as it progresses, should end in divergent results, characteristic and artistic, there are also reasons to believe that, in many respects, its effects will inevitably be more or less similar. These similitudes will be of two sorts: some will be merely formal, others substantial.

Here is an example of the first sort. M. Dareste points out, in passing, an indisputable resemblance between the development of the Moslem law and that of the Roman law; but the main thing is to interpret this correctly. The erreat Arabic jurists worked on the rather narrow basis of the Koran, as the great Roman jurists did on the no less narrow foundation of the law of the Twelve Tables. Tlie former, like the latter, developerl the law by means of doctrinal authority, changing constantly by innovations umler the pretext of construetion. IIanifat, Malek, Chefë, and Hanbal in the 700 s and 800 s. " created the Moslem Law, as Sabinus and Labeo before them had created the lioman

1 This is not the place to derelop this thought. But the learned reacher will not fail to supply examples drawn from the history of the sejentes and industries. The disconory of Newton, for instance, consisted in viewing two ideas, until then strangers to eareh other, the fall of terrestrial bodies and the atraction of gravitation of the moon atround the carth, as two effects of the same prineiple. The invention of the loromotive ronsisterd in uniting treologirally two modes of artion, until then sepallated, the steam pistou and the notrment on whecls, ete. 
Law. Rome had had the Sabinians and the Proculians. Islam had the Hanifites, the Malekites, the Chefeites and the Hanbalites, all equally orthodox," but of vision more or less broad. "At last this great movement ended with the Arabs as it had at Rome. At a eertain moment, production ceased and sterility came." This is very true. But to see correctly the significance of this comparison it is needful to compare it with many others, in the juridical world or even beyond it. The Hebrew Law was developed entirely in the same way. The great rabbis had elaborated the law of Moses, which beeame little by little the Mishnal and the Talmud; they founded rival schools, and their work, at last, stopped, having reached a relative perfection. In the same way, in every land which beeomes civilized, we see learned grammarians elaborate, refine, expand, and establish the national language, a sort of Koran fallen from the sky, of which they are the respectful and ingenious commentators or falsifiers. . . . A language, especially on its grammatical side, is a logical whole. So, too, is a religion, when reduced to theologr. So, too, a Code. Amidst ages of invasions and disasters, the Corpus Juris reigns yet in Europe. Hore remarkable still, the Mishnah - the Corpus Juris of the Jews, elaborated by the great Hebrew jurists - persists still, in spite of the dispersion of its people.

This inherent force of resistance in every system, and this tendency of everything social to develop into a system, is a resemblance which has nothing imaginary about it; and it is universal and deep-rooted. But what does it signify? Does it mean that there is any magieal formula for an evolution through which everything must perforce pass? By no means. It signifies merely that man is a logical animal, - that his need for sistem and coörclination has periods of exeitation followed by periods of ealm. We may observe the birth and growth of his religious ideas, the logical elaboration of them, their consummation in theologies; the rise of new problems, and the new efforts to solve them. ... so too in man's desires, and the process of their harmonization, the logic of social growth proceeds in the same manner. The hmman heart is born replete with aspirations as incoherent as its thoughts; to make a world from that chaos, to transform that incoherence into mutual advantage, be it in the breast of the individual, be it consequently in the social group, - that is the problem which confronts the first law-givers, often the same as the makers of their creeds. It was solved by laws regarded as divine, - the law of Moses, of Zoroaster, of Manou, 
of Mahomet. But, after a certain time, new requirements, new domestie precepts engendered by the inventions of civilization, by contact with foreigners, as in the case of Israel and of Islam, became difficult to harmonize with the established laws. Then would the jurists on the one hand, the easuists on the other, exert themselves to disguise the inconsistencies or to absorb them into some paramount harmony. They are supposed only to exponnd the ancient law; but, in reality, they are forced to substitute in part for its commands others no less imperative, prompted by the new requirements. . . .

Sir Henry Maine has pointed out the important rôle of fictions in transforming the law gradually. The authors of these ingenions expedients produce, in the concrete, the same thing as lid the author of the law himself in creating it; Mahomet. for instance, did nothing more than re-east the ancient eustoms of the Arabs and adapt them to his epoch. Then there comes a moment when the structure of jurisprudence and of casuistry seems complete. People admire it, they call it sacred, - so long at least as the social state be not reformed. But when this reform takes place, the development by logic retains what is most attractive, always the same at bottom. Tho be sure, modern legislators, in contrast with the ancient, do not seem to take account of precedents. However, that is but in mere appearance. The power of legislatively upsetting everything which in theory belongs to our deputies and senators, is but ostensible; they are compelled to respeet, in a certain measure, the ancient laws, the juridieal habits of the people, and also to suggest for their needs, old or new, what should satisfy them conformably to those habits. In fact, their apparent omnipotence is nothing but a willing or enforced obedience to those needs, to these commands of their electors. These orders are for them what the commands of Moses were for the rabbis, or the precepts of the Koran for the Arabian jurisconsults. Oldtime jurisconsults or contemporary legislators equally exhibit such submission to superior commands, which they work out logically in subordination to hicrarehical principles, conforming the one to the other. After which, the statutes voted and promulgated are given effect by our commentators of to-ilay. professors, judges, counsclors, in the form of judicial decisions or of scientifie doctrine, - a mass of things of which their aluthors never dreamed.

After all, then, the similitude of evolution, very vague and altogether formal, between the Moslem Law and the Roman 
Law, as alleged by M. Dareste, is merely a case of resemblance, on a larger and more prolonged scale. And it consists in this, that evolution, in every category of social facts, has alwars as a starting point a certain number of natural perceptions or ideas learned, of needs inborn or acquired, won which operates a general need (both innate and more and more developed) for logical coordination; which general need itself has its vicissitudes of agitation and of appeasement, - the latter when it is satisfied for a time by an imposing and monumental work, and the former when the growth of new ideas and desires necessitates the work of remodeling or of reform....

\section{Lan as a Branch of Sociology}

Before concluding, I have to insist on the importance, sometimes much ignored, of studying the law as a branch of sociology, if we wish to grasp it in its living and complete reality. It is not, furthermore, a mere branch of that great tree which can be severed with impunity from the trunk, and which does not draw its sap from its location in relation to the others, by reason of multiple resemhlances, and of differences not less instructive, which that relationship reveals in their diverse modes of growth. Juridical "rolution most of all calls for elucidation in this way. Strictly speaking, the development of a religion, of an art, of seience (such as geometry), of an industry (such as that of metals or of textile fabrics), may be explained separately. Not so a body of Law ; for the Law, among the other social sciences, has this distinet characteristic of being, like language, not merely an integral part but an integral mirror of social life.

That is why so frequently, in the course of this study, I have remarked the similitudes between the march of the law and the march of language in the evolution of humanity. These similitudes are the more interesting in that they evidently belong in the category of those not caused by Initation. To all the analogries which I hare pointed out in the foregoing, in passing, I could add many. Let us gather some of them, at random, barely enough to give to others a taste of the reaping here, and to furnish a passing illustration of the general truths announced by us.

Law and Language, we know, are imitative and follow routine to a leading point. Nothing is evolved therefrom save by the steary and combined play of three forms of imitation: the imitation of others, under its two aspects, the copy of a contemporary 
model ("fashion"), and the copy of an old model ("custom"), and the imitation of itself ("habit"). But that which dominates and gives the tone, is, both in Language and in Law, the influence of custom. When the rush of novelties gathered by fashion, here or there, exceeds a certain degree, alway's very low, the difficulty of classifying them and placing them logically in a system of theories or of institutions already long established, produces a crisis, a disorder of the law or of the language; and it must needs be that one or the other either die thereof, or that it expel violently a greater part of those undigested foods, too hastily swallowed. Moreover, it has always been impossible to implant and to keep alive in any nation, even the most enslaved, a Language or a Law made entirely of fragments, however logically and artistically collected they may possibly be. Those excellent compositions perished almost at birth, despite the insistenee of the amalgamated legislators or grammarians that they should live. Why? Precisely because logic is the supreme thing wanting. For this need of Logic, in Language as in Law, divides asunder those who eombat it. And this combat infuses all the life, all the difficulty, all the interest into the elaboration of the law and of language throughout all time.

If there was no issue involved but to reconeile with each other the elements of a law or of a language, so as to produce a regular and coherent whole, the task would be very easy. But, coincident with the effort of the grammarians or the jurists (or rather of the entire public), thus conspiring, wittingly or unwittingly, but invariably, against such logieal internal arrangement of a grammar as refines it little by little of its exceptions and incongruities, or of a codification which little by little is improved and systematized, another and primary task is presented to put the grammar and the codes in accord with the society which they should govern, and to perfect this accord constantly. This last aceord itself is a logical arrangement, in another sense of the word, - teleolosical, to speak exactly. Now, the state of society, if we inclucle in one glance the opposing ideas and claims which there confront each other, is always, in great part, illogical and incoherent. For a body of Law, therefore, as for the structure of a Language. the problem of evolution consists in adapting it to itself as murh as possible, while also adapting it to a society which never very well. adapts itself to itself.

It consists, in other words, in making the logical out of the illogieal. It follows that the danger is ever present of sacrificing 
one of these two concurrent and contradictory aspirations. And the grammarians, like the jurists, have a pronounced predilection to insist improperly upon the former, while the public, happily, has the contrary tendency. Hence, the two different maladies by which the Law, and Language also, may be affected: namely, cither to accord with themselves, but not with the social environment, - like a revolutionary Constitution, or like Volapük, the most regular of languages; or to harmonize fully with the social world but not with themselves, - like the confused mass of the English laws, and like most of our European languages. . . .

We cannot, of course, more than touch this vast subject. We may remark, in closing, that if we attempt to embrace in but one glance the successive phases of different languages, we perceive nowhere any tendency of these various linguistic evolutions, much as they seem independent, to converge toward one single language or toward one single final state. To an analogous result the study of the various juridical evolutions has led us. All that we see clearly is the tendency to supremaey of one sole language or of a very small group of languages, and of one sole Law, or of a very small group of Laws, and of a language or of a Law common to all classes of the society. Now this is the double inevitable consequence of the long continued influence of Imitation. The farther we trace back into the past, the more we discover of distinct idioms, and of customs having the force of law; so that in the begimning we might suppose that there were as many languages and laws as villages. ${ }^{1}$ But, in proportion as the relations between men multiply, the greater part of these linguistic and juridical creations, so astonishingly multiplied, are impeded or destroyed; hecause a small number of them, and not ahways the best, are indebted to circumstances historical, ethnical, geographical, much more than to their intrinsic superiority, for the privilege of expanding over the globe. On the other hand, and simultaneousty, changes are brought about in languages by borrowing of "noble" words into common speech, of literary words into the ordinary style - acquisitions often ironical, but always imitative. And these changes correspond, in the Law, to those produced by importation (e.g. the rule of primogeniture imported into the plebeian birthright), and by the gradual extension to inferior classes of some laws originally reserved to the superior classes.

1 This is so true that, even for our own epoch. the village, according to M. Arsene Dumont, is the linguistic unit ("Rev. scientif.," 10 Sept. 1802 . 
Little by little, in that way, is established one language alike for all, and one Law alike for all.

\section{CRITICISM OF THE IMITATION THEORY I}

Unfortunately, it is necessary to confess that the views expressed by M. Tarde are not at all those which we believe to be well founded. Scarcely at any point are we able to join in his conclusions. Assuredly, M. Tarde is a man of too much intelligence, and of too keen a mind, but that much may be extracted from his last work (like those which preceded it), and but that this work woukd be very rich in sound methods of thought, and in profitable themes and reflections, and would advance a variety of fertile ideas. But this is not the book on the evolution of law which the friends of this science would have desired - an inventory of the researches already made, at once friendly and critical, setting: forth neither with an easy-going faith, nor with preconceived hostility, the results which seem to be attained, those which appear only probable, and those which are yet in cloubt, giving conjecture for conjecture without masking objections, and admitting more frankly the legitimacy of the method and what it has accomplished.

It is, in truth, on the contrary, almost entirely a book of negative controversy, directed as well against the principle of the new studies [on the evolution of law] as well as its applications. It is a denial both of the whole and its parts. Going to the entirety of the principle, M. Tarde rejects the doctrine that one evolution, identical in its chief features, normally is presented under the influence of the same causes, and apart from all imitation, in the juridical institutions of the most diverse peoples. He combats the idea according to which the different groups of mankind, in their social development, follow the same path of derelopment; which, while it does not yet leal, and may perhaps never leak, to the same social destiny, yet shows the same direction for all ; and according to which those peoples which have proceeded more rapilly in the march of evolution have necessarily passed the stages shown among races of tardier development. Touching the detail of the matter, he denies, for example, in criminal law, that our modern colles have sprung from a sistem of private vengeance. In the fieds of family law, he denies the priority of female kinship and the

1 [By Pacl Frédéric Girard. Translated by Alhert Focourek, from "Mélanges de droit Romain (I, Histoire des sources)," Recueil Sirey, Paris, 1912.] 
maternal family (which howerer is not to be confused with the somewhat inproper term "matriarchate" - according to the hypothesis of a general phase of female authority) to the patriarchal family and masculine relationship, from which, in turn, the modern family arose. In the sphere of immovable property, he rejects the development of collective proprietorship of the clan and the tribe, leading to collective ownership in the family, and then to individual ownership. He opposes also a variety of other things which appear to be clearly established from the bringing together of primitive institutions.

In this respect, talent apart, and with all deference, this little volume does not differ greatly from those which, thirty to fifty years ago, protested in the name of orthodox spiritualism against the intermixture of natural science in the domain of psychology, or the current accounts of those who to-day combat, with the same zeal, the pretension to the diseovery of sociologieal laws. M. Tarde's originality lies in this, that he does not reject these laws, and that he repudiates, as frankly as anyone, the narrow skepticism which sees in social facts only a fortuitous combination of conflicting contingencies. M. Tarde admits that juridical facts are governed by law, or rather, in chief, by one law ; and he renounees all other explanations in order to make more room for his own explanation of this law of imitation. It is to this law that he offers a holocaust of all the results which the investigations in comparative law have been obliged to derive from other foundations. We claim openly for these researches the right of existence.

We are quite ready to admit, that in the growth of law, imitation has played a very important part - a part much more important than is generally believed, if M. Tarde wishes. But it is not allowable on this aceount to deny all other development, or to draw the history of all other, or nearly all other, changes from a single inventor whose diseovery then in rapid waves has swelled over the entire globe. It is much more likely that there have been a great many inventors. They have been, we believe, eountless, and their successive and similar in ventions, greatly multiplied in number and very limited in seope, have been the produet of another ause, as it were, the meehanical operation of circumstances. It is seen, even in our own epoch, in astronomy, in physics, and in chemistry, how the same discoveries and the same inventions have been independently made, a few day's apart by different scientists; at the moment when the general state of knowledge made these inventions imminent, or when, as we may say, they were demanded 
by surrounding conditions. The same multiplicity was all the more necessary to produce juridical inventions in epochs and places widely separated, among those where it must well be conceded, notwithstanding M. Tarte, that communication was much more rare and difficult than among the learned of the civilized world of to-day. There, also, the same surrounding eircumstances must have urged into being, repeatedly, at divers times and in divers places, the same fundamental juridical inventions; afterwards developed and transformed by a variety of partially identical inventions, under the influence of similar circumstances, following a mechanical operation, corresponding exactly to that which to-rlay produces the discovery of the same planet or the same industrial improvement by different men strangers to each other. There can be no question there either of imitation, or of laws of initation. It is, we believe, even precisely and solely when imitation is not involved, when it is not a factor, and when legal development clearly proceeds without any borrowing, in its independent originality, that we may, in the proper sense, inquire into the laws of legal evolution; according to which not only certain juridical institutions, but certain forms of such a given institution, appear in each group at a definite period and not at another, after a certain phase of development and before another.

M. Tarde summarizes nearly all the laws of juridical development in that of imitation. We believe, on the contrary, that it can scarcely be doubted that there are laws other than that of imitation. The phenomena of imitation, however, camnot be ignored ; they are a part of the aggregate of juridical derelopment. One who wishes to umderstand this development cannot omit to study what produces it; how, when by the will of an alien power, or by reason of spontaneous imitation, a foreign legal institution is introduced in the law of a people, the alien element thus incorporated may, as the case may be, either perish, or be gradually eliminated, or lastly, be assimilated by an internal series of changes which develops a new channel of imitation. But the phenomena which constitute the true material of the history of comparative law, those in respect to which the phenomena of imitation have only a subordinate interest, like the detail of a picture, or a condition of disease for knowledge of a condition of health, are the facts of normal development which follow free of outsile influences. From an observation of these facts as minute and as extended as possible, we may hope to derive at once a series of partial laws, and, perhaps, in time a general formula which will embrace them 
all. Of course, we have not yet attained a general principle which may be here, as in other scientifie studies, the crown and conclusion of a mass of isolated discoveries. But it may, we think, be regarded as demonstrated, that there are a number of special laws of evolution.

$\begin{array}{lllllll}* & * & * & * & * & * & *\end{array}$

Space does not permit a discussion of the details of all the points raised by M. Tarde. We may, however, offer eertain general observations. First, it appears to us, that M. 'Tarde in many conneetions has claimed too easily to have proved the nonexistence of a determinate chain of evolution where he thinks he can show that it has not operated in this or that partieular case. Social laws do not always have the elearness of mathematical laws. Praetical application of these laws may, in being masked or paralyzed by an infinitude of cireumstances, prevent their being discerned. M. Tarde appears, also, to forget in his diseussions, that the absence - in a given group, of vestiges of a phase long since overshot by civilization is a regrettable aceident, but natural enough; and that it does not outweigh all the probative foree of other positive vestiges of the same phase found in numerous other societies. Sueh a fact does not any more hinder a general eonclusion, than it would, for example, in linguisties or geology. Finally, we may be permitted to ask, if, for the purpose of a discussion of problems which involve all the observed facts past and present of human society, the material assembled by M. Tarde is not somewhat scanty?

So, with reference to the inductions, from our point of view perfectly legitimate, drawn from knowledge of primitive societies and from existing customs of peoples less advanced than ourselves, M. Tarle speaks of "a small number of anecdotes, always the same, drawn from various American, African, or Oceanic tribes, which have made the round of the sociologieal press, and which, for a long time, will continue the operation under various labels." It is, indeed, not necessary to say, and the explanation is sufficiently dear, why always the same decisions are cited in the hand-books of the law, and the same experiments entered in the compendia of physics. In the first place, it is very commendable to invoke the most convincing examples which have already been discovered; next, it is the height of morlesty that the books which are not original should freely eopy one from another. But in resorting to such books, it is not implied that no other materials are in existence. The student would err who supposed that there are no other 
decisions than those cited in his Merlin; and the candiclate for the bachelor degree would make a mistake if he thought that no other experiments had ever been made than those enterel in his paper. But, holding strictly to the literature of comparative law, M. Tarde, without resorting to the general works on sociology, will be able to find some more anecdotes either in the excellent "Zeitschrift für vergleichende Rechtswissenschaft," published since 1878 under the direction of Franz Bernhöft, Georg Cohn, and Josef Kohler; or again in the numerous studies of all kinds and shapes of Kohler; and again, for example, in the considerable collection of concrete references assembled since some rears with great patience by a colleague of M. Tarde - Judge Post of Bremen; thus, from a geographical point of view, in the 70$)$ pages of his "Afrikanische Jurisprudenz," or, from a systematic standpoint, in his "Grundriss der ethnologischen Jurisprudenz."

And if $\mathrm{MI}$. Tarde speaks in this manner of the researches relating to the existing customs of savage peoples of the present day, wc may doubt whether his information is more complete in that. which concerns the able inquiries marle in our time into the history of the past. There, also, he takes the conclusions of elementary books of second and third hand as the sum of science; and he is astonished that he finds so little. A passage from the author has it that in the renascence of historical legal studies at first "only Roman law was investigated historically from its sources"; and then was followed by the Egyptian and Assyrian law, and then again only, it seems, by "similar researches into Indo-European and Senitic antiquities, the Germans, Slars, Persians, and Celts, as well as the Mussulmans, the Hebrews," etc. This suffices to show a somewhat superficial notion of the magnificent erudition and critical investigation first made in our age in Germanic legal history, and perhaps rather than in Roman law; which movement of research has since spread to Slavic, Hindu, Greek, and Hebrew law, and has extended still more tardily to Egyptian and Lssy rian law. The very good book of M. Dareste ("Etudes d'histoire du droit"), which is the most solid and the best of those to which he has appealed, points out a whole literature which he appears scrupulously to have avoided.

This, we believe, is the great defect of the book, and is the general explanation of the defective solutions in which it results. Being inclined by nature more to abstract reasoning than to systematic observation, M. Tarde has treated almost exclusiredy, by a process of reasoning, questions which depend entirely on obser- 
vation, and for which personal observation remains more indispensable than anywhere else; because the effort to sum up, and to classify positive facts, is still liable to disregard what has already long since been recorded in numerous collections, as is the case for the greater part of the other sciences of observation. We will give a final example of this, which seems to us to be striking.

M. Tarde speaks of the wonderful similarity observed by M. Seignette ("Codle musulman par Khâlil") between the customs of the pre-Islamitic Arabs and those of the Romans at the time of the 'Twelve Tables - absolute paternal power, perpetual tutelage of females, the will, inheritance and tutelage of the agnates, patron an! client, testamentary tutelage, nexum, pignoris capio, noxal abandonment, retaliation, composition, etc. He finds here, as always, the influence of imitation, and that "if we recall the proximity of Arabia and India where similar customs have prevailed . . there is no difficulty in explaining these resemblances by imitative action." It is easy to understand how one so adept in the loctrine of initation may heroically support the similarity between the legends of the Zulus and our children's tales, by supposing an importation of these stories by merchants and European soldicrs who on the whole were more occupied with the destruction and spoliation of the natives than with the recital to them of the Ass's Skin and Little Poucet. But this is an affirmation, and not a demonstration. The method of science proceeds otherwise. In order to ascertain if the similarity between the laws of Rome and pre-Islamitic customs is derived or not by imitation from a primitive system of law common to the Romans and the Hindus, a scientific method of inquiry will discover if the same institutions existed among the Hindus as among the Romans, on one hand, and if, on the other hand, they are found among the founders common to the two races, before their separation. Having determined for a certainty that they exist among the Romans, and not among the IIindus; or, again, that they exist among both Romans and Hindus, but that they developed among them only after the separation, it may not only be supposed, but it will be proved, that the first institutions have arisen independently under the influence of identical canses among the early Arabians and the Romans; that the second have had the same kind of origin among the Hindus and Romans; and that those facts make very questionable any explanation of imitation for those cases where the impossibility of such a theory cannot be directly shown.

There, as in many other places, the error of M. Tarde proceeds 
from this, that he wishes to treat a science of observation by other methods than those of the sciences of observation. This does not prevent an attentive reading of the book, which is still useful in that, by its very character of opposition, it gives to the students, who in future will pursue these studies, a good motive to test their own ideas. But since, as we think, he has failed to shake seriously any of the propositions of the doctrines which he combats, his theory is very far from bringing a revolution, as some enthusiasts have too hastily proclaimed. ${ }^{1}$

\section{SECTION 4}

\section{SCIENCE OF UNIVERSAL COMPARATIVE LAW 2}

1. It is recognized, now, that the study of positive law of all peoples, and in all ages, is scientifically possible and necessary. Likewise, it is admitted that an examination of primitive and embryonic stages is indispensable for full understanding of later phases of growth; and that comparison of different ideas is the best method to determine the character and tendencies of legal evolution. There is implanted in the minds of all scholars a belief in the propriety and importance of experiential investigation in all sciences, and especially in that of the law. The only objections which may be urged against this method relate to the intrinsic difficulty of the investigation and the limits assigned to it; not by virtue of a preconceived idea of dogmatic order of the materials, but on account of the means and efforts which must be emploved. A complete and universal study of juridical phenomena, in truth, is a scientific ideal which we are able and ought to seek, but which, for reasons easy to find, can never be fully attained. How many peoples there are recorded which have disappeared leaving only the scantiest traces of their history, or perhaps nothing! How many documents irreparably injured, or hidden, or indecipherable! To what extent has the law been observed simply as custom, with-

${ }^{1}$ [Mr. Tarde replied to this review in a letter to the "Revue Philosophique" (December, 1893, pp. (i2')-(i29), and republished in the prefare to later editions of his "Transformations du droit," tht hecl. 1909, pp. iviii). Professor Girard rejoined in "Revue Philosophique" (1s!4, Tol. XIX, pp. 210-212) and republished in his "Mélanges de droit Romain," Tome I, pp. 429-432.]

2 [By Grorgio del Veccho, former professor at the Tniversity of Messina, and now professor of Philosophy of Law at the University of Bologna: translated by Albert Kocourek from the French version of Mi. Rene Franetz ("Extrait de la Revue Critique de Législation et de Jurisprudeneo," Paris, 1910).] 
out other sanction, and without written form! The difficulty of knowing at this time with precision of the legal systems of peoples which did not attain an elementary elaboration of law, either legislatively or scientifically, is manifestly very great, and when we deal with ages far removed, is frequently insurmountable. Especially, knowledge of origins, and of prehistorical developments does not appear to be easy to obtain, except for him who ignores the special conditions of an investigation of this kind, and is disposed to supply, in default of docments and critical proofs, the products of imagination, or dogmatic credulities. Nevertheless, the difficulties and the compass of the matter, instead of eausing a slothful or skeptical abandonment of the subject, ought rather to induce more diligent efforts; sinee the infinite richness and variety of the phenomena of nature are a motive of zeal, and not of discouragement to the naturalist who seeks to discover its laws.

* $\quad * \quad * \quad * \quad * \quad * \quad * \quad * \quad * \quad * \quad * \quad *$

To-day, notwithstanding considerable progress due to the labors of a few indefatigable scholars, knowledge of universal juridical phenomenology is rather incomplete and imperfect. This, it may incidentally be remarked, is the cause, and partially, also, the effect of the complete absence of this subject in the programs of study. In this state of things, there being a lively and profound belicf, more or less clearly defined, of the necessity of this study, it is not astonishing that its want makes itself felt indireetly. Its absence is the cause of disorders and erils which disadrantageously affect the system of studies and the economy of thought.

That which is understood as sociology, frequently is only a collection of experienced facts which logically ought to appertain to the science of universal comparative law, and, in a larger sense, to juridical science from which these faets are excluded only by virtue of a too narrow conception which it still supports. Those institutions and those phenomena of social life, which, considered from a certain stage of evolution, or under a like, special aspect. better known, show themselves unmistakably to be of a juridical nature, are, on the contrary, rejected as berond the "official" scope of juridical science; since they appear in a more primitive form, among peoples less civilized, or even in different civilizations. For example, a rork on the parental and patrimonial récime of the Papuans or the Bogos, and perhaps even of the Aztecs or the Loreans will have little chance of consideration by the jurists who dislike to look beyond the horizon of the tradi- 
tional culture. At the same moment, they easily take refuge in that collection, often chaotic, of facts and conjectures, which constitutes what is called sociology, and which in its defective systematization bears precisely the mark of the imperfections of contemporary culture. The truth is that the only sociology having a reason for existence is one which treats the rules of method common to different sciences, from observation of human facts.

We shall show here, briefly, what these rules are in connection with the law, and how they are able to accord and harmonize, in a coherent program, as well with the science as with the philosophy of law.

2. We must, first of all, proceed from the principle that all positive law whatsoever, and however it may appear in the order of phenomena, is a natural fact; that is to say, determined by sufficient causes, and eomected with all other aspects of reality. . . . It is necessary elearly to understand the relativity of positive law, in order that a phenomenon, and even a general phenomenon, will not be confused with the law or with the criterion of valuation to which, logically, the reality is subordinate. . . .

From any such principle it follows at once that no juridical institution is to be regarded as a prototype of others. All without exception ought to be equally examined and analyzed in the historical setting which produced them. For the same reason no institution should be put aside or regarded as unworthy of scientific investigation. All undervaluation in these matters is as unjustifiable as all over-preference. Thus, as Post remarks, a feeling of revulsion because a people live without marriage, practice human sacrifices or camnibalism, or burn sorcerers and witches, is without value in the solution of ethnological problems, but rather diverts attention from the search for the causes of these phenomena. ${ }^{1}$ Whoever maintains that popular customs and beliefs are devoid of meaning shows that he is not qualified for this study. Against the judgment of Cicero ${ }^{2}$ who declared the law of all peoples, strangers to Rome, "pœene ridiculum," we may urge the more profound saying of Spinoza ${ }^{3}$ - "non ridere, non lugere, neque detestari, sed intelligere."

Another consequence of the principle stated is the necessity of not neglecting the origins and the primitive phases of institutions which we do not discover as completely formed and dereloped. If it is admitted that in the empirical order of things, everything

$$
\begin{gathered}
{ }^{1} \text { [See Section 2, supra, p. 36.] } \\
\text { 3."Tract. Polit." e. 1, See t. }
\end{gathered}
$$


results from a cause, and that nothing happens without sufficient factors to produce it, then we shall be obliged in the study of all juridical institutions to take account of their antecedents. And the further back we go into the knowledge of these antecedents, the better we shall attain a complete notion of the institution. Comparison of the different phases of its growth, of the changing aspects assumed according to circumstances, is necessary for a clear understanding of its present situation. For this purpose, the most valuable information, in fact, is furnished by its original, its rudimentary, and lowest forms of development, which to a superficial observer would appear as of no importance. For this reason it is also necessary to state that each product of evolution, however adranced, sums up all earlier forces. The law of any people in all stages retains the signs and residues of precedent phases of growth, however remote. Juridical rules and beliefs of the ages past survive in some sort in the present; they are never completely lost. But these elements mixed with others supervening later, and recast in a new form, frequently escape the observer.

A survival, unimportant though it may seem, may throw an unexpected illumination over a mode of life which has disappeared from view. A rare form preserved by unconseious tradition, a eustom profoundly rooted in spite of its discord with written law, may permit an entire reconstruction of an age which has passed away. Such a reconstruction is notably rendered possible by the frequent fact that a detail which in a certain phase of culture appears as an anomaly, may be found in vigor in a complete and harmonious system among other peoples of lesser culture.

3. The principle of method above indieated has a fundamental importance. Nevertheless, it is insufficient to constitute a science of juridical phenomena. It establishes the generie condition of an investigation of this sort in so far as it has an empirical character, but not its specific condition in that its object is juridical phenomena as such. From this arises the necessity equally fundamental of determining from a logical standpoint what is to be understood by law, and upon what elements the juridical character of a phenomenon depends. . .

This inquiry, of course, in its nature, goes beyond an empirical investigation which as sneh seeks to assemble special and concrete juridical facts, and not to discover a logical universal form.

Let it suffice to reaffirm that this formal idea is a necessary condition to experience of juridical facts. It is recognized in all 
phenomena of law but always in a special attitude, with a content variable and logically accidental. On the contrary, it comprehends and limits in equal measure all possible cases in the juridical sphere, surpassing, therefore, by far, the facts rerified in the domäin of experience. Recognition of this transcendental condition of juridical experience does not diminish the value of experience itself. Rather, it puts experience in its true light and guarantees its authority in its own field. In reality, we are able and ought to borrow from experience as an inexhanstible fountain, knowledge of the content that law has provided in space and time. From what has been just said nothing which credits the study of historical facts in which a juridical character is found, is an obstruction to going back in turn to the formal idea of which facts are only the applications and illustrations.

4. In agreement with these fundamental criteria, an objective study and comparison of juridical phenomena may be attempted. We may therefore set up an autonomous science which may be called the "science of universal comparative law." But in order thoroughly to apprehend the basis and object of this comparison, it is necessary to return to the principle which dominates its materials - the profound unity of human nature of which the law is a necessary manifestation. We find here also one of the premises of empirical investigation, the results of which however confirm and illustrate this unity, but in reality rest upon it and draw from it its scientific character.

Every man bears within himself the principle of law. Every mind possesses the elements with which to elevate itself to its proper empirical position as a personality whence it may harmonize ethically with the personality of others. It is essential not to lose sight of this eternal principle of justice which is firmly anchored in the depths of the human mind, in order that the manifold series of facts which issue from it, and which observation attempts to discover, may be thoroughly understood.

Thus, we recognize at once that the psychological aptitude to distinguish in a certain measure the just and the unjust, and to feel and to conceive juridical truth is not the possession of a few men only, but belongs to all persons. Again, law is not an isolated fact which alone is encountered among this people or in that epoch; but everywhere that men are found, there are discovered traces of an ethical syrstem, and of a law which reflects a common activity of man's spirit.

On the other hand, in the same way that the human mind devel- 
ops slowly from the most obscure forms of knowledge to clear ideas, so also the law grows from a phase almost unconscious, and, little by little, attains the stage of reflection. An obscure instinct and a vague intuition of their objects is sufficient to generate among men organizations and institutions which seem to indicate, so complex is their structure, profound and mature thought. They are not, however, less a product of mind and intelligence, although created spontaneously, and, as it were, unconsciously. . . .

The unity of the human mind, in which the law has its source, does not, in general, spring solely from the continuity and universality of law. A series of identities and resemblances which are met in the positive law of all peoples is another special proof of this. The prejudice which for a time dominated, especially under the influence of the Historical School according to which each people necessarily has a system of law peculiar to it, which is a part of that people and fits its own conditions, and which as a result would be different among other peoples, compelled a broader study of juridical phenomena to yield. This study has already demonstrated for a certainty that a large part of fundamental juridical principles and institutions is the common heritage of all humanity in all epochs. The modern specialists of comparative law insist upon this proposition ${ }^{1}$ because they well understand, without expressly saying it, that this science has its true reason for existence in the substantial unity of the human mind which is revealed in the law.

The fact that juridical institutions are subjected to a process of evolution may appear to negative this unity. On the contrary, it provides a new confirmation; since evolution itself manifests a general attribute of humanity which is realized in an analogous manner among different peoples widely separated in space and time, and having no connection with each other; where, otherwise, to explain these phenomena, it would be necessary to revert to the hypothesis of a common origin of the races which in many cases is not verified, and where, for the rest, it would be insufficient to justify the analogies observed. The same evolution governs the general expression of the ethico-juridical system and special institutions (such as property, the family, ete.). They pass through a series of determinate stages in a definite order and frequently

${ }^{1}$ Post, "Bausteine," i (1880), pp. 14, 54, "Ueb. die Aufgaben einer algem. Rechtswiss." (1891), pp. 17-19; Kohler, [Introduction, Sec. 1, of this rolume, and] "Ueber die Methode der Rechtsvergleichung" in Grünhut's Z. (1901). p. 274 seq.; Dareste "Etudes d'histoire du droit," $1^{\text {re }}$ serie (2d ed. 1908), p. xiii seq. 
with the most remarkable resemblances; even to the point of the smallest details, and among nations without any historical association.

It is necessary to make reference to another fact which equally confirms, on last analysis, the principle advanced, and, of which, ordinarily, the generality and importance is not fully recognized. We refer to the ease with which juridical institutions are adopted by peoples other than those among whom they originated. This aptitude reveals itself in the same proportion as the degree of development to which it applies. Thus, it happens that the laws and even the customs of the more developed nations are nearly always understood (directly or indirectly) beyond the limits where they originate; and are applied, frequently, with a great deal more facility and rapidity than one would suppose in places where a different law is already established. In this manner, the law of each people is able to profit from elements elaborated by others by renewing or reënforcing itself through their strength, or by drawing from them partial adaptations according to the circumstances. The importance of this fact which intervenes almost constantly in the vicissitudes of the law, and chiefly in its periods of progress, will be hard to exaggerate. It implies that in essence the force of juridical institutions, in general, exceeds the causes and the contingencies which produce them; for while being always determined by historical conditions their internal logic nevertheless gives them an independent vitality, and renders them fit for new adaptations, and a function infinitely greater than that appearing at the time of their creation. In a word, the same institutions may be considered in an aspect other than that of historical contingence; they may be regarded as expressions or products of the human mind; and, we may say, from an universal point of view, that they are superior to history.

It has been observed with justice ${ }^{1}$ that the Historical School never offered a sufficient explanation of the reception of Roman law in Germany. It is now clear that this fact could not have been understood by this school precisely because its concept of the historical and national character of law was too narrow. Again, it was because of the narrowness of the path on which this school operated, that it was all the more incapable of acquiring the universal notion of this reception, which as has been stated is encountered among all peoples and in all epochs. Thus Roman law which was received in Germany, on its part received a large number of

${ }^{1}$ Bechmann, "Feuerbach und Sarigny" (1594), p. 15. 
elements of Attic and other Mediterranean law. We may also note, by way of further examples, the reception of Hindu law in Burma, of the law of Islam in Africa, of German law among the Slavs and IJungarians, and more recently of Freneh law in many parts of Europe and in Ameriea ; ${ }^{1}$ without discussing the special borrowing's, equally very remarkable, in private and public law, as for example, the English parliamentary strstem which has spread and is spreading among other States.

It remains to bring to light a capital fact which to a certain extent sums up the points already made. In the course of the development of law the elements of general human significance prevail over particular and strictly national elements which mark the inferior phases of this development. Special rules disappear and make way for more comprehensive rules conforming to rational and universal principles. In the progressive movement in which juridieal institutions of the peoples take on a rational and universal character, they tend to coineide. In other words, there comes about a convergence of special developments which establishes a more extensive coördination and a more proiound harmony among the laws of different nations. This tendeney is only an aspect of the development of the human spirit; likewise, at the same time, it has a character of spontaneity and necessity; and it does not depend on external circumstances or influences. Nevertheless, an explanation of this tendency is faeilitated and its realization is favored in the system of facts by the aptitude already noticed with which juridical ideas are communicated among different peoples - an aptitule which itself presupposes a definite unity of human nature without which it would not be possible. The conjunctures which, in consequence of diverse contingencies, but with increasing frequeney, oceur among different groups are an excellent means of reconnizing that the essence of the human spirit is alwars identical, and thus of establishing connections which are based, at least in part, on a recognition of this unity of nature.

Thus, whether by the internal elaboration which goes on in the hosom of the law of each people, or whether by the borrowings which occur among different peoples, we arrive degree by degree to

1 Cf. Bermhöt. "Ither Zweck und Mittel der rergleich. Rechtswiss." (Z. f. V. R., 187s), p. 27; Post, "Ueber die Aufgaben einer allg. Rechtswiss." p. 22; Kohler. "Leher die Methole der Revhtsverg." p. 279 . Witl reference to the difforent linds of transmission and imitation, direct or indirect, conscious or unconscious, see Freman, "Comparative Polities," $2 d$ ed., 1stof; Emrico Ammi, "Critica di una scienza delle legislazioni romparate" (1S.5), pp. 5:3-69; Tralalt-Papule, "D' una scienza delle legislazioni comp." (ext. Circolo Giuridico, Palermo, 1582). 
a realization of universal jiridical criteria sufficient to govern all humanity. In a word, there is established and perfected an ensemble of common principles, a sorietas humani generis based on laws inherently natural to all persons. That which rationally is a demand a priori is realized in history by a sluggish process operating amidst the most diverse and complicated changes.

It is precisely the mission of the science of universal comparative law to collect and arrange the phases of this process which reveals the achievement of an end toward which human reason tends. Therefore, it ought itself to be an efficacious instrument for the progressive unification of the law. This science is distinguished from legal history in the narrow sense, and dominates the particulars of the law, just because its object has an universal character. It does not embrace the data of juridical experience as simple events which depend peculiarly on special eauses, but makes use of them so far as they represent, in a definite degree, the development of the human spirit in the form of the law. The point of view which is simply historical and chronological is thus left behind. Every juridical form has the function which belongs to it by reason of the idea which it cloaks, whatsoever mar be the epoch or the people where it is presented. Such a criterion, no doubt, presupposes historical knowledge, but is itself superior to history. It permits the grouping of the institutions ancient and modern of the peoples of all parts of the world, wheresoever they have realized the same juridical idea. Such an idea shows its human significance precisely in that it appears uniformly among remote peoples who are strangers to each other, in a form determined by their respective developments.

In directing its researches in this sense the science of universal comparative law follows and retraces the steps of evolution of that notion of law which is found unified and complete in pure reason. Two methods are possible and in the end lead to the same result: that the human mind produces the law in the sistem of phenomena, and regards it in itself sub specie eterni; and that it is the same need of justice which, satisfied partially and by degrees in the course of history, is affirmed categorically by conscience as an abolute ideal to which the rarious facts in the empirical order of things ought to adjust themselves.

5. From what has preceded it is easy to draw the conclusion. If the seience of universal comparative law is set in motion in the domain of experience, and is supported br knowledge of juridical phenomena, it is none the less subjected to a whole scries of philo- 
sophical premises and constructions without which it would fall of its own weight. While it is, and ought to be, an empirical science, ret it marks the limits of the reconcilement of the science and philosophy of law. The science of law discovers in the philosophy of law its principles and its complement; just as, in its turn, the philosophy of law may and should profit for the application and verification of its criteria, by that which science has brought to light. ... 


\author{
PART I \\ LAW AND THE STATE \\ Chapter I \\ FORMS OF SOCIAL ORGANIZATION \\ BY J. W. POWELL \\ Chapter II \\ EVOLUTION OF THE STATE \\ By Josef KoHler
}

Chapter III

OMNIPOTENCE OF THE ANCIENT STATE

By Fustel De Coulanges

Chapter IV

CHIEFTAINRY AND KINGSHIP

Section 1. Cultural Importance of Chieftaingy

By JOSEF KOHLer

Section 2. Authority of the King

By Festel De Coulanges

Chapter V

RELIGION AND L.IT

Section 1. Religious Origin of Ancient Law By Festel De Coulanges

Section 2. Religiols Element in Hinde Law BY HENRY S. MAINE

Section 3. Taboo as a Prinitive Substitete for Law

BY Josef KOHLer 


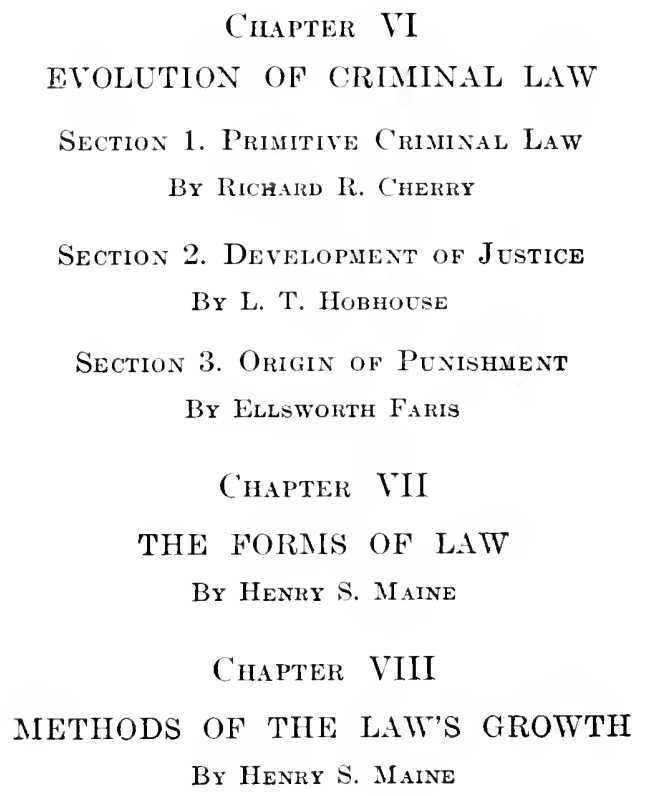




\section{Chapter I}

\section{FORMS OF SOCIAL ORGANIZATION 1}

The officers of the Bureau have now been engaged for many rears in investigating the institutions of savagery, and while these researches are far from complete and many questions are unsettled it seems desirable, for many reasons, that an outline of certain conclusions should be published.

Regimentation in sociology is the analog of organization in biology. The accomplishment of justice in institutions is the analog of function in the biotic realm. Often the terms organ and function are transferred from biology to sociology. This double use of terms is a very general device of speech, and is both legitimate and useful when properly understood; but the terms organ and function are tropes in sociology, and must be so understood lest they should lead astray. By regimentation is meant the grouping of people by institutional bonds, while the aecomplishment of justice is the social function or office which a confederation or group of people performs.

Two radically distinct methods of regimentation are found extant in the world and recorded in the history of the past; these may be known as the tribal system and the national system. By the tribal system men are organized on the basis of Einship, real or artificial. By the national system men are organized on the basis of territory. Thus kinship groups are found in tribal society, territorial groups in national society. In history, transitional forms are found, the most important of which are feutal. Thus feudal soeietre exhibits both methods, and forms a connecting link in the evolution of tribal into national government.

In savagery families are organized into clans, and clans sometimes into tribes, and tribes into confederacies. Sometimes intervening units are discovered, but the family, clan, tribe, or

${ }^{1}$ [By J. W. Powell. Reprinted, hy permission. from the 1.ith Annual Report of the American Bureau of Ethology (The Smithonian Institution). The origina! title of this study is "On Regimentation."] 
confederacy are always found. In barbarism families, gentes, tribes, and confederacies are organized into a hierarchy of units, and there are sometimes intervening units. The differenee between the elan of savagery and the grens of barbarism is important and fundamental. The clan is a group of people reckoning kinship in the female line, while the gens is a group of people reckoning kinship in the male line. Tribes reckon kinship in the male or female line together with affinity, and adopted members of the tribe are given artificial linship. When tribes unite in confederacies, artificial kinship is established as a legal fietion, and the members of one tribe know the members of another tribe and address them by kinship terms. The manner in which this kinship organization is elaborated varies greatly from tribe to tribe. Radical differences exist between the tribes of savagery and the tribes of barbarism. In barbarism patriarchies are found as concomitant with nomadic tribes, but in savagery the patriarchy does not exist, nor are sarage peoples properly nomadie, as nomadism begins with the domestication of animals and higher agriculture.

The plan of organizing states into units of different orders so as to form a hierarchy of groups is denominated regimentation, and it can be made clear by explaining primitive regimentation.

With national states, territorial organization obtains. People are divided into bodies or groups by districts. No two nations are organized in precisely the same manner; though the general plan is the same - i.e., by territorial boundaries - the specific manner in which the organization is worked into detail is ever variable. It is impossible here to set forth all these various methods. It will be sufficient to take some one nation and explain its organization as a type, and for this purpose the Government of the Lnited States is chosen.

The grand unit, or the nation, is divided into states and inchoate states, or territories. States are divided into counties, and comties are divided into townships, sometimes called towns. In addition to the hierarchy of units thus enumerated, there are cities and rillages, which are again divided into wards, and these again into polling districts, while other districts are sometimes found. The various units thus set forth are established for executive purposes. This regimentation is that which obtains for executive purposes.

There is another system of regimentation for judicative purposes. In part, but only in part, judicial districts coincide with executive districts, and there are national courts, state courts, 
county courts, and municipal eourts. Again, judicative functions are differentiated, as criminal and civil, and special courts are organized therefor, while other courts are organized, as railroad commissions, warehouse commissions, etc.

A third system of regimentation is used for legislative purposes, and in this sistem the districts correspond only in small part with those established for executive and judicative purposes.

A fourth sistem of regimentation is established for operative purposes. The General Government carries on worlis, states carry on works, counties carry on works, and cities and towns carry on works.

Still a fifth system of regimentation is found, namely, that for school purposes.

By the district system thus briefly and imperfectly elaborated the people are organized or regimented into bodies, and speeial functions are relegated to the several units. These funetions are constitutive, legislative, executive, operative, and judicative. It is by constitutive action that regimentation is accomplished; and it is by regimentation that specialization is accomplished. This specialization is carried on to such an extent in the Lnited States that much of the govermment is local self-govermment. Every school district has special functions, every township special functions, every county special functions, every state special functions, and every municipality special functions; while general functions are exercised over all by the Federal Government. 'Thus, the people of the Lnited States are constituted and regimented into a congeries of hierarchies of units all woren into one complex system as the Govermment of the United States, and so adjusted in interdependent parts as to secure a high degree of specialization.

In addition to the governmental regimentation, there is a vast congeries of societies or corporations organized for religious, industrial, educational, and other purposes, all of which constitute part of the state or nation.

The regimentation of all people is founded on natural families, for there are lussbands and wives, parents and children; but such families have lineal and collateral lines of kinship involving both parents. A larger group than that composed of parents and children is organized in the crudest society known. For this purpose all of these persons reckoning consanguineal kinship through the female line are regimented or organized in a clan. The term clan should always be used to designate this group, though it is 
sometimes improperly used to designate other groups. The husband and wife do not belong to the same elan, but the husband belongs to the clan of his mother, while the wite belongs to the elan of her mother. It is thus that the first constitutive unit of organized society is based on kinship reckoned through the female line. The next unit recognizes kinship by affinity, and a number of related clans that intermarry constitute the tribe. The term tribe should always be used in this manner. Curiously enough all of the terms which are used in defining the units of regimentation are often used promiscuously, so that clan, gens, tribe, and confederacy, with many other terms which are synonymous, have a vague meaning in popular estimation; but in science we are compelled to give a definite meaning to fundamental terms. A clan, then, is a mion of persons who reckon consanguineal kinship in the female line; a tribe is compounded of clans whose members reckon kinship by consanguinity and affinity, while a confederacy, which is more or less ephemeral, is a union of tribes reckoning kinship as a legal fiction.

In the clan the group is ruled by an elderman. But this elderman may or may not be the oldest living male in the clan; to understand this it becomes necessary to understand the method of kinship naming in vogue in savagery. In the clan the children of one woman are not only brothers and sisters to each other, but also "brothers" and "sisters" to such of their cousins as reckon kinship in the female line. Thus, if there be three sisters their children call one another by reciprocal kinship names, as "brothers" and "sisters"; but if there be three brothers their children do not call one another by common kinship names, but by the kinship names determined through their mothers; that is, they call one another cousins. Among the collateral descendants through the female line there are thus a number of persons of varying ages calling each other "brother" and "sister," though the term used always has a further significance in that it designates relative age, so that there is no single term for brother, but two, one signifying elder brother and the other younger brother; there are also two terms for sister, one signifying younger and one elder. Now, it is a law of savage society that one person must address another in the elan, in the tribe, and in the confederaey by a kinship term, and as superior age always gives authority, to address a person as elder is a symbol of yickling authority, and to address him as younger is a symbol of claiming authority. There is a curious modification of this custom which is a legal fiction. If any 
individual in the group of brothers exhibits superior ability, the clan or some other constituted authority takes him ont of his kinship rank into a higher rank. "Thus his linship name is changed; roumger brother becomes "elder brother," and elder brother becomes "younger brother" by a legal fiction; or the son may" become the legal "father" and the father the legal "son."

A promotion in kinship is always attended with much tribal ceremony. Among the Iroquoian tribes it is called "putting a spike on the horns." In some tribes it is called "adding a feather to the bonnet," in others it is "adding a stripe to the war paint." There is often a preliminary course of instruction for the ceremony, which is performed by the priest. Important promotions may be revoked, and a man who becomes mworthy in his office may have his "horns" linocked off, or his "feathers" plucked out, or his "paint" washed away. In all such cases he falls back to his natural kinship name and state.

Every clan in a tribe receives a special name, which has come to be known as its totem. Thus in a tribe there may be a buffialo clan, a beaver clan, a cloud clan, a wind clan, an eagle clan, and a parrot clan, with others. Sometimes the clan name is the common name for all persons in the clan, but more often there is a group of names signifying some real or mythologic characteristic of the animal or object taken as the totem. For example, in the buffalo clan there may be a name signifying "sitting bull," another "standing bull," still another "mad buffalo": and names taken from the mythology of the buffalo may be used. The clan name or totem is used to distinguish the members of one clan from the members of another. It is never used in the first and second persons, but always in the third person. In direct address the kinship name expressing relative age must always be used. Lncles in the rlan are addressed as "fathers," cousins in the clan as "brothers" and "sisters."

If two or more tribes unite in a confederacy, the first thing to be considered in the council by which such a confecteracy is established is the kinship terms by which one tribe shall address another. Where two unite, one may be called "father" and the other "son," while with the fomales" "mother" and "daughter" are used. One may be called "clder brother" and the other "younger brother," with "llder sister" and "vounger sister." In compounding many tribes in this manner curious complications arise. 
We thus see that a sarage tribe is regimented by kinship through devices of naming, especially for the clan, tribe, and confederacy, and these names are so constituted that relative age is always expressed, for the elder has rights and the younger duties.

As in territorial organization special functions are relegated to the several units, so in kinship regimentation special functions are relegated severally to the hierarchy of bodies thus constituted - that is, certain offices are performed by the clan, others by the tribe, and still others by the confederacy. The possession of property which is exclusively used by the individual is inherent in the individual, such as clothing, ornaments, and various utensils and implements. Individual property can not be inherited, but at death is consigned to the grave. That property which belongs to the clan, such as the house, the boat, the garden, etc., inheres in the corporate person. No article of food belongs to the individual, but is the common property of the clan, and must be divided by the authorities of the clan, often according to some rule by which some special part is given to the person who provides the food. Thus when a hunter dispatches a deer a particular portion is given to him; other portions may be given to those who assisted in its capture. All the rest is divided according to the needs of the individuals of the clan. The women gather fruits, seeds, or roots. That which is consumed at the time is divided by like methods, but that which is preserved for future use sometimes becomes the property of the clan. The elderman of the clan is responsible for the training of children, and it is no small part of his duty daily to exercise them in their games and to instruct them in their duties. Thus he who enforces clan custom is the same person who instructs in clan custom, and when councils of tribe or confederacy are held he is the representative of the clan in such councils. The chief of the confederacy is usually the chief of one of the tribes, and the chief of the tribe is usually an elderman in one of the clans. There are clan councils, tribal councils, and confederate councils, chief councilors and eldermen.

Another organization, which involves all civic relations, must be explained. There is a body of men, and sometimes women also, who are known as medicine-men, or shamans, or sometimes as priests, who control all religious ceremonies, and who are diviners. As disease is supposed to be the work of human or animal sorcery, it is their function to prevent or thwart sorcery. They have the management of all ceremonies relating to war, hunting, fishing, 
and gathering the fruits of the field and forest. It is their office to provide for abundant harvests, to regulate the climate, and generally to divine and control good and evil by means of ceremonies. The principal shamans are men, but all the people are united into shamanistic societies. Lsually there is some determined number of these societies, over each of which some particular shaman presides, but he has subordinates, each one of whom has some particular office or function to perform in the societies. Sometimes a person may belong to two or more of these societies; usually he has the privilege to join any one, and a revered or successful shaman will gather a great society, while a shaman of less skill will preside over a society more feeble. Let us call these, ecclesiastic corporations, and call the shamans priests. The only corporations in savagery are ecclesiastic. The way in which they are regimented and controlled differs from tribe to tribe, and there is a great variety of ceremonial observances. In all civic councils the ecclesiastic authorities take part and have specified functions to perform, and introduce into civic life the ceremonies which they believe will procure good fortune. Perhaps the ecclesiastic authorities may be more powerful than the civic authorities, and the hereditary line of special ecclesiastic governors may gradually overpower the civic constitution and absorb it as a secondary element in the ecclesiastic constitution, for it must be remembered that the chief priests are men; the women play a very small part in ecclesiastic affairs. Now, as the men manage ecclesiastic affairs as chief priests, so civil aftairs are managed mainly by men as eldermen, and the conflict which sometimes arises between the two forms of govermment is mainly between men and men - between able eldermen and able shamans. Sometimes both offices are combined in one person, and the great elderman may also be the great shaman.

There are five fundamental principles of justice; that is, to secure justice, five fundamental purposes must be considered: Justice is the establishment of peace. Justice is the establishment of equality. Justice is the establishment of liberty. Justice is the establishment of equity ; and justice is the establishment of truth. In all law, primitive and modern alike, these principles are recognized, and all institutions are organized for these purposes.

In the study of North American tribes it is always found that the purpose assigned and recognized for the organization of that unit is the establishment of peace. Two or more bodies have 
come to war and finally agree to live in peace and make a treaty, and the terms of the treaty are invariably of one character if they unite as a tribe. If they unite as a confederacy, it is for other purposes. 'This fundamental condition for the organization of a tribe is that the one party agrees that its women shall be the wives of the other, with a reciprocal obligation; and this is the characteristic which distinguishes tribes from confederacies. A body of people that is organized for the purpose of regulating marriage is a tribe, and a body of people organized for war is a confederacy. Thus the organization of a tribe itself is the first recognition of the principle of peace in the origin of constitutions.

The principle of equality is recognized in the method of distributing the spoils of the arrow, the fish net, and the fruit basket, which is an equal division to all the members of the clan. The prineiple of liberty is first recognized when slavery is established, and the means of obtaining freedom are provided, and that is always the case in savage society. Slaves are captured enemies, who therefore deserve to die. They are not always killed, but sometimes (even quite often) adopted into the tribe. A captive can not become a member of the tribe without some kinship position, therefore he must be adopted by some woman as her child, and adoption in savagery is often called new birth. Now, he takes the kinship name under a legal fiction - that is, he is "younger" to every living person of the tribe at that time, and all persons subsequently born are younger to him. This is not yet slavery. If the captive belongs to a tribe of hereditary enemies who have from time immemorial been designated by some opprobrious term, as camibals, liars, snakes, etc., then it may be that the captive is doomed to perpetual younger brotherhood, and can never exercise authority over any person within the tribe, though such person may be born after the new birth of the captive. This is the first form of slavery. Esually, though not invariably, the captives adopted are children. Now such children may ultimately become useful members of the tribe and by their virtues even win rank in kinship, and a captive may thus pass from slavery to freedom. The many methods adopted for conferring freedom would be a long and weary story, but they are practically the same as those conferring rank in linship. This must be briefly explained, though it has been already shown in part. The successful warrior, hunter, or food gatherer is rewarded by a special portion of the spoil as an equity. Now he who has for a term of years been successful in any of the activities of tribal life and who ex- 
hibits skill and wisdom therein is promoted by giving him an advanced kinship designation. One or more grades may be climber at one time and promotions may follow one another rapidly, so that a brilliant youth may beeome an elderman, and gray-haired men must address him as "father," and he must even eall his natural grandfather "grandson." By such methods primordial equity is established.

That which in modern civilization is the highest function of the court and best exhibits the talents of the advocate is the discovery of facts; but ready methods for discovering the truth prevail in savagery. 'This is the function of the priest, who by some form of divination diseovers the facts. Thus it is that justice is distributed in its five elements of peace, equality, liberty, equity, and truth.

Justice is not always performed in savage society, and it even goes awry in eivilized society ; hence we have remedies in savagery and civilization alike. But sometimes there is no remedy, when punishment is executed. We have already shown how exogamous groups are organized. A man can not marry within his clan, because already the clan has promised its women for the wives of another clan, yet the marriage may be accomplished and crime is done. This is incest. Often nominally the punishment is death, and sometimes the law is executed, but there are many" ways by which justice may be clone without inflicting the ultimate penalty. The crime may he condoned and a price paid, and this often done may ultimate! result in a eustom of marriage by purehase. The elans of a tribe may prosper equally, and there may be more men in one elan than there are women in another, and men may quarrel or even fight for wives, and such contest may ultimatel. be regulated by law; this results in marriage by wager of battle. If the woman is unwilling, it may also require capture, and this may be legalized under certain forms and ceremonies, and we have marriage by eapture. But young men and young women form mutual attaehments whieh are sometimes stronger than tribal law, and they may abscond and live together as man and wife. If they ean suceessfully maintain themselves in the wilderness until a child is born, the child becomes the certificate of marriage and the wedding is thus lecalized, and with this certificate the crime is atoned. This is the only marriage by choice.

Now, in all of these extratribal marriages, crime is committed, and the peeuliar methods and ceremonies of marriage by purchase. marriage by wager of battle, marriage by capture, and marriage 
by choice result in the reëstablishment of justice as it is conceived in the savage mind. We have already explained much of personal law in the explanation of the law of marriage and the law of promotion and reduction. Yet there are other subjects worthy of present consideration. Murder is punished with death. The crime is against the clan, and any member of the clan may become the avenger, though often some particular person is delegated to that office. The murderer may also be defended by his clan; in such case the death of any of the murderer's clan atones for the death of the murdered man, but the murderer may be declared in outlaw by his clan, and any man of any elan may dispatch him with impunity. In some eases murder may be atoned by substitution; that is, the murderer may be expatriated, driven from his home and clan, and thus become dead to his own people and then be adopted by the injured family to replace the murdered person. Thus the wife of the murdered man may adopt the murderer for her husband; in so doing he loses his own name and all relations of kinship and adopts the name and relations of kinship of the murdered man. A quarrelsome man may embroil clans, and this may be carried on to such an extent that the clan will declare him an outlaw. Sometimes murder is atoned by the parment of a stipulated or customary price, and usually blood barter is graded by rank. Maiming is also avenged by the clan, "an eye for an eye and a tooth for a tooth;" but it may be compounded by common agreement between the belligerent clans.

A belief in witchcraft is universal. A person suspected may finally come to be universally recognized as practicing black art. Such a wicked person is lilled as an outlaw. The wizard may not have such a reputation in his own clan, but may be accused of witcheraft by another clan; if there is a wish to preserve him, his witcheraft may be compounded.

We have already explained the equal division of property in the clan, the equitable dirision made to the successful hunter, and that personal property is inherited by the grave, while clan and tribal property belong to a perpetual person. Theft sometimes but rarely occurs; when it does, the object stolen may be restored; when it ean not be restored, the theft is compounded in some multiple proportion. The only corporations in savagery are ecclesiastic, and crimes against the medieine societies are those which result from the divulging of secrets or the teaching of rites by unauthorized persons or the exercise of such rites by persons incom- 
petent therefor. Proceedings for witcheraft are conducted by the ecclesiastic bodies.

Such, in outline, are the plan of regimentation and the funclamental prineiples of justice recognized in the most primitive tribal states found among mankind. This stage of society is known as savagery. Sarages are primitive sylvan men; they are denizens of forest and wold without the skill necessary to clear away the forests and establish higher agriculture and domesticate herds of animals. When these feats are accomplished, then men are said to have reached the stage of barbarism.

Savagery gradually develops into barbarism and barbarism itself is represented in the plan of regimentation, which involves a change in constitution, legislation, execution, administration, and adjudication. The change of regimentation is represented by the extinction of the clan and its replacement by the gens. The term gens is here used to mean the unit of government herein described as a group of persons who reckon consanguineal kinship in the male line.

We have already described the double organization of every savage tribe as civil and ecclesiastic, and noted the conflict which arises between groups as thus organized. A powerful ecclesiastic organization will sometimes absorb the civil organization, especially when the priest and elderman is the same person. Quite often the sacerdotal office is hereditary, descending from father to son, and thus grows up a method of reckoning kinship in the male line as fundamental. Now there are many circumstances in primitive life which reinforce this tendency. When the men of the clan have to go to the ammual fishing ground for the summer catch, they take with them their wives and children. Such wives and children are no longer under the power of the eldermen; they are geographically separated from them, for the men of the clan who work together are distinct from the men of the other clans where each group fishes by itself. Iunting is often managed in this manner by clans. Such annual hunting and fishing excursions weaken the authority of the mothers, brothers, and uncles, and strengthen the authority of husbands and fathers. But there are two agencies which seem to be even more potent. Agriculture is born in arid lands where irrigation is necessary, and the men of the clan unite to manage the stream which is used in irrigation and to protect the erops which lie under the canals, though the (rop)s themselves may be cultivated chiefly by the women. Here again there is a geographical segregation of the women and children 
under the immediate supervision and control of husbands and fathers. Finally, animals are domestieated and there are floeks and herds under the control of the men. The pasturage for one clan flock is in one valley and for another clan flock in another valley, for the property is thus kept apart; and this also serves to segregate the women from the men of their elan lindred and place them under the authority of husbands and fathers. By all of these methods clanship is broken down and a new fundamental method of reckoning in kinship is developed through males; this is the gens. Nuch time may be taken in making these ehanges, while the authority of the clan is gradually weakened and the authority of the gens established. Many of the tribes of North America are in the transitional stage.

When the change is made, councils as well as ecelesiastic bodies are still controlled by men, but the regimentation is radically distinct. Perhaps the most fundamental change that comes is the right of the father over his own children, especially in deciding their marriage relations, for this right is not transferred from clar. to gens, but from clan to father. With this change comes another of fundamental importance. With the acquisition of herds, farming lands, and stores of grain, wealth is accumulated, and this wealth is eontrolled by the gentile patriarchs. It is no longer elan property, but gentile property in the possession and under the control of the patriarch, who wields a power never known in savagery. The patriarch now is alway's chief and priest and the practical owner of the wealth; he thus becomes the master of the destiny of his retainers. A particular effect is noted in the council. The number of persons who compose the eouncil is gradually reduced, and these chiefs and councilors are regimented into patriarehies for war and public works, while instruction falls mainly into the hands of husbands and fathers, and the wife is no longer controlled by her clansmen, for she is no longer under their protection. Thus the husband becomes the master of the wife and children.

In the clan the head is an elderman and is an "uncle" or "great uncle" heeause kinship is reckoned through females. This is expressed in Indian tongues by the aphorism that "the woman carries the clan," while in barbarism "the man carries the gens." This is the first great revolution in tribal society accomplished by the consolidation of power in the hands of the few and the organization of the gentile family. The gens is ruled by the patriarch who represents the family in the councils of the tribe and the con- 
federaey and holds all the property in trust for the gens over which he rules by civil law with eivil sanction and ecclesiastical law with ecelesiastie sanetion.

In savage society there is no written language, hence the laws are classed and expressed in terms of kinship, but in barbarie society an additional mnemonic and classific method is developed, which must now be delineated; it arises out of ecclesiastic functions of government and ultimately becomes dominant so as to modify the kinship system. In savagery the world is divided into regions - the east, west, north, south, zenith, nadir, and center. This is continued in a more highly developed form in barbarism until it finally becomes the dominant system. Sometimes the regions are but five in number - east, west, north, south, and center; but more often the seven regions are recognized. Sometimes the number five, but more commonly the number seven, beeomes the sacred number. This division of the world into regions is naturally born in the usages of language and at last becomes as deeply woven into society as language itself, and the reality of the regions becomes sacred, as language is held to be sacred. The theory of the regions is not only woven into their speech and into their institutions, but it becomes one of the principal elements of picture writing and is represented by some form of the cross signifying the east, west, north, and south, to which are attached some other devices for representing the zenith, nadir, and center. Thus the swastika is found as a simbol among many savage tribes, and it seems to be universal among barbaric tribes.

These world symbols often govern methods of architecture. The theory of worlds is of vast extent and of profound influence. It is found to pervade tribal society not only in America, but elsewhere throughout the world. I am tempted in this place to go to the Orient for an example to show how laws and the maxims of laws are formulated in savage and barbaric society, but I must premise the statement by explaining one other method of formulating laws. The particulars of law are often represented by numbers - one number for each finger of the hand; and the reciprocal rights and duties by the five numbers represented by the five fingers of the other hand. Thus by pointing in the direction of one region with the proper finger of the right or left hand any particular law or maxim can be expressed in gesture speech.

I quote from the Sigīlowāda Sutta, a table of aphorisms published by Rhys-Davids in his book on Buddhism, which might be 
duplicated as a method of schematization in many of the tribes of North America. The scheme in which the aphorisms are arranged is by regions. It has the same design as a scheme, that the swastika has as a picture writing, and both are as natural to the human race as the recognition of the cardinal points. The regimentation in kinship society is taken by analogy from the recognized relationship of consanguinity and affinity for schematic and mnemonic purposes. The following schemes prevail among savage and barbaric people for a great variety of purposes : Schemes of four, five, six, or seven are derived from the regions, schemes of five are fixed and perpetuated by the number of fingers on the hand, schemes of ten are derived from the number of fingers on both hands, and schemes of twenty from the number of fingers and toes, while schemes of four are sometimes found derived in a fanciful way from the colors of the four regions - east, west, north, and south. The scheme which Rhys-Davids records from India is, first, a scheme of six regions; second, it is a scheme of reciprocal fives as the fingers on the hand are reciprocal. In the second division of the sixth regional group it will be noticed that the last aphorism violates the symmetry of the arrangement. In all others there are five; in this there are six. This peculiarity may be found anywhere in North America and South America. It is the thirteenth of the baker's dozen. It is the common method of showing that the tale is complete. Thus Rhys-Davids:

The Teacher was staying at the bambu grove near Rājagriha; and going ont as usual to beg, sees the householder Sigāla bowing down, with streaming hair, and wet garments, and clasped hands, to the four quarters of the heaven, and the nadir, and the zenith. On the Teacher asking the reason why, Sigāla says that he does this, "honoring, reverencing, and holding sacred the words of his father." Then the Teacher, knowing that this was done to avert evil from the six directions, points out to him that the hest way to guard the six quarters is by good deeds to men around him - to his parents as the east, his Teachers as the south, his wife and children as the west, his friends and relatives as the north, men devoted to the religions life (whether Brahmans or Buddhist mendieants) as the zenith, and his slaves and dependents as the nadir. Then in an orderly arrangement, evidently intended to assist the memory, after some general precepts and a description of true friendship, the chief duties men owe to one another are thus enumerated under the above six heads; [for example] :

\section{Parents and Children}

Parents should -

1. Restrain their children from vice.

2. Train them in virtue.

3. Have them tanght arts or sciences.

4. Provide them with suitahle wives or husbands.

5. Give them their inheritance. 
The child should say -

1. I will support them who supported me.

2. I will perform family duties incumbent on them.

3. I will guard their property.

4. I will make mrself worthy to he their heir.

5. When they are gone, I will honor their memory.

* $*$ * $*$ * $\quad * \quad * \quad * \quad * \quad *$

I have spoken of phratries as a srstem of groups, sometimes found in savagery and always in barbarism. We are now able to explain the meaning of the phratry. There may be many elans or gentes in a tribe, and two or more clans or gentes may constitute an intervening unit which we call the phratry. With the Nuskhogean there are four phratries, one for the east, one for the west, one for the north, and one for the south. With the Zuni there are six phratries, one for the east, one for the west, one for the north, one for the south, one for the zenith, and one for the nadir. Thus the phratries are organized by mythologic regions: and this method of regimentation finds expression in the structure of the council chamber, in the plaza, and in the plan of the village. Here in the phratry we have the beginning of district regimentation, which ultimately prevails in civilization.

The fabric of primitive society is a web of streams of kindred blood and a woof of marriage ties. This tapestry is wrought in wonderful patterns, for on it can be traced the outlines of primitive mythology. Some scholars have seen in the fabric only the mythic patterns enwrought and failed to discover the real institutional foundation. 


\section{Chapter II}

\section{EVOLUTION OF 'THE STATE ${ }^{1}$}

1. The State was originally a totem State, and consisted of the union of various groups bound together by the unity of their animal god, which sacred bond, however, gradually went to pieces, leaving the clan or family tie. This is based, as was the sacred bond, mainly on the unity of blood, but with the rejection of the animal god which had fused the families together in one uniform spirit. Worship of ancestors then took the place of the totem belicf, and it is the spirits of the dead that hold the family together, give stability to the clan, and in the worship of which the whole finds its consecration. All our cultural States were formerly clan-States ; and in the minity of blood, the unity of descent, the unity of their view of life, lay their strength. Such a clan-State does not require dearly defined territory. It remains the same even when the dans wander. The German tribes remained as they were, even when they wandered from the Balkans over the endless Russian plains to the Elbe, from there to the Rhine, to the Rhone, and from there to Italy; and it is just the same with the numerous Bantu tribes and Hamitic peoples who wander, constantly changing their place of abode. There is an extraordinary communal nerve in this clan connection; and it is comprehensible that all phenomena of life under these conditions are social in character; and that all thought and action unite in the idea that each individual is a member of the tribe whose famons ancestors are worshipped as divine, and that he performs his great deeds in the sight of his forefathers.

2. A tremendous change takes place when the tribal tie gives way to the territorial tie; and this appears in two new legal institutions which embrace all life and activity. The first is that persons are received into the nation who do not belong to the tribe; so

${ }^{1}$ [Reprinted, by permission, from Josef KoHLer, "Philosophy of Law", (Albrecht's trans.), Boston Book Co., 1914 ("Philosophy of Law Series," Tol. XII).] 
that the number of clans and families can constantly and that in this way persons enter who do not worship the $c$ spirits of the tribe, and whose ancestors are in no way con. with the ancestors that compose the tribal cult. This is, of co a sign of a certain decline of ancestor worship, and the clans certar must have felt this for a long time, and have persecuted the intruders with all their might; nevertheless, this event, like every other development that lies in the hidden folds of the world's history, cannot be prevented. What universal history desires may for a time be delayed by the mind of man, but cannot be permanently suppressed.

3. A second factor comes under consideration. Whereas, formerly, the tribe lived in and to itself, inchding only itself and its slaves in the sphere of its power, and leaving its neighbors alone even when they lived on the same land, the necessity now arose of exercising complete dominion over a certain territory in which the members of the State have the upper hand. Disputes with those living outside the boundaries, however, became so numerous and violent that there was no alternative but to extend the authority to them also; at least to the extent of repressing certain activities injurious to the State, establishing certain police regulations, and defending the State against the encroachment of this alien population. Chieftainry especially is often rery prominent in this comnection. Herewith the idea of the territorial state is firmly established; not only do the tribes admit others to their ranks, but even persons who are outside the circle of those belonging to the State must submit to the commands of the ruling people. This was the system that was carried out in all our culture states after the destruction of the old Germanic principle of personality. Only in the Orient does the old system still exist; but there is a privilege that the Occidentals with their high culture have obstinately wrestled from the Orient: the Occidentals refuse to submit to the law and jurisdiction of 'Turkey and Persia, and wish to live under their own laws and own authority, even on the territory of these Oriental States.

4. A further division into classes of the population is sometimes accomplished by way of conquest. It often happens that the conquerors force back the original people entirely, or so decimate them that they no longer play any part in the life of the state. But not infrequently the old population is preserved as a second layer or class, if for no other reason than because the conquerors are not able to perform all the useful labor that is necessary to the main- 
tenance of their life, and hence make use of the conquered inhabitants as a servant class. The latter may be oppressed and held in slavery or helotry, or they may be granted a freer position, partly in recognition of their develnped civilization, partly in consideration of the fact that free labor appears to be more advantageous, or that the original people are so far masters of the situation that the conquerors must live on terms of agreement with them, and cannot litterly subjugate them.

In this way, a mixed population easily arises in which the conquerors assume the rôle of masters, and form a sort of nobility in contrast to the lower inhabitants.

Sometimes, another layer or class of population is formed by the addition of some other people that is dragged from its own place of abode and settled in the country.

All these circumstances oblige the tribal State to adapt itself to the altered conditions, and to blend the added elements more or less with the life of the State.

5. In the transition from the tribal State to the territorial State, much of the unity of the people is transferred to the State territory, and the State system of rulers now embraces the land without reference to the inhabitants.

This might easily lead to the conclusion that a man's residence on State territory established the fact of his belonging to the State. This of itself would mean a tremendous transformation: there could no longer be any citizenship independent of the place of residence. But such a development could only thrive if the aspirations and endeavors of the different States were so uniform that the change of allegiance from one to another could follow without a displacement of interests. Hence, it was possible to carry out this system in a confederacy of States; so that its citizens could belong to one or another of the individual States according to their residence or place of abode. But as long as the interests of States are so various, indeed, even antagonistic, and each State develops independently to a certain extent, this system would be detrimental. Neither would it be ethically desirable; for in such disputes and struggles, it is necessary for the individual to adopt a certain definite course, and to make the collective interests of one or another of the communities his own. Hence, it is still necessary to maintain citizenship apart from the place of residence, and to give it a greater significance in the position of the individual in lecal life; also, in particular, to combine political activity with ritizenship. 
6. In spite of the territorial principle, therefore, the difference between citizens and aliens still exists; and in such a way that citizens still remain citizens, even if they settle in a foreign country : and that aliens living in the State must indeed submit to its laws, but can have no part in the government, and that their family conditions are regulated according to their hereditary rights.

Thus, a certain disagreement arises which, however, is allowed to remain as long as it is not dangerous to the State. But if it becomes undesirable, it then is necessary to drive the aliens out.

A complete solution of the disagreement has never becn achieved, and will not be here attempted. A compromise has bcen adopted by some States, however, based on the principle that in certain cases the alien becomes a citizen without further steps. Thus, the rule has been established that an individual born in the country is a citizen, or, in some States, only if also his parents were born there. And instances are not few where residence for some time suffices to give aliens the right to acquire citizenship. In this way the number of foreigners living in the country can be reduced, and the discord spoken of above can be partly avoided. 


\section{Chapter III}

\section{OMNIPOTENCE OF THE ANCIENT STATE ${ }^{1}$}

TuE city had been founded upon a religion, and constituted like a church. Hence its strength; hence, also, its omnipotence and the absolute empire which it exercised over its members. In a society established on such principles, individual liberty could not exist. The citizen was subordinate in everything, and without any reserve, to the city ; he belonged to it body and soul. The religion which had produced the state, and the state which supported the religion, sustained each other, and made but one; these two powers, associated and confounded, formed a power almost superhuman, to which the soul and the body were equally enslaved.

There was nothing independent in man; his body belonged to the state, and was devoted to its defence. At Rome military service was due till a man was fifty years old, at Athens till he was sixty, at Sparta always. His fortune was always at the disposal of the state. If the city had need of money, it could order the women to deliver up their jewels, the creditors to give up their claims, and the owners of olive trees to turn over gratuitously the oil which they had made. ${ }^{2}$

Private life did not escape this omnipotence of the state. The Athenian law, in the name of religion, forbade men to remain single. ${ }^{3}$ Sparta punished not only those who remained single, but those who married late. At Athens the state could prescribe labor, and at Sparta idleness. It exercised its tyranny even in the smallest things; at Locri the laws forbade men to drink pure wine; at Rome, Miletus, and Marseilles wine was forbidden to women. ${ }^{4}$ It was a common thing for the kind of dress to be invariably fixed by each city ; the legislation of Sparta regulated the

1 [By Fustel De Coulanges, "The Aneient City"; translated by Willard Small; 11th ed., Lothrop, Lee, and Shepard Co., Boston; reprinted by permission.]

2 A ristotle, "Econom.," II.

${ }^{3}$ Pollux, VIII. 40. Plutarch. "Lysander," 30.

"Athenous, X. 33. Elian, "T. H.," II. 37. 
headdress of women, and that of Athens forbade them to take with them on a journey more than three dresses. ${ }^{1}$ At Rhodes and Byzantium the law forbade men to shave the beard.?

The state was under no obligation to suffer any of its citizens to be deformed. It therefore commanded a father to whom such a son was born, to have him put to death. This law is found in the ancient codes of Sparta and of Rome. We do not know that it existed at Athens; we know only that Aristotle and Plato incorporated it into their ideal codes.

There is, in the history of Sparta, one trait which Plutarch and Rousseau greatly admired. Sparta had just suffered a defeat at Leuctra, and many of its citizens haci perished. On the receipt of this news, the relatives of the dead had to show themselves in public with gay countenances. The mother who learned that her son had escaped, and that she should see him again, appeared afflicted and wept. Another, who knew that she should never again see her son, appeared joyous, and went round to the temple to thank the gods. What, then, was the power of the state that could thus order the reversal of the natural sentiments, and be obeyed?

The state allowed no man to be indifferent to its interests; the philosopher or the studious man had no right to live apart. He was obliged to rote in the assembly, and be magistrate in his turn. At a time when discords were frequent, the Athenian law permitted no one to remain neutral; he must take sides with one or the other party. Against one who attempted to remain indifferent, and not side with either faction, and to appear calm, the law pronounced the punishment of exile with confiscation of property.

Education was far from being free among the Greeks. On the contrary, there was nothing over which the state hard greater control. It Sparta the father could have nothing to do with the education of his son. The law appears to have been less rigorous at Athens; still the state managed to have education in the hands of masters of its own choosing. Aristophanes, in an elorpent passage, shows the Athenian chillen on their way to school; in order, distributed according to their district, they march in serried ranks, through rain, snow, or scorching heat. These children seem al21.

1"Fragm. Hist. Greer." Didot, t. II. p. 129, 211. Pluturch, "solon,"

"Athenceus, XIII. Plutarch."cleomenes," 9.

"The Romans thought no marriage, or rearing of children, nay, no frast

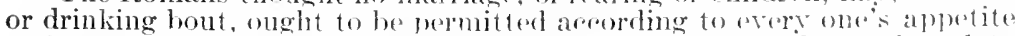
or fancy, without heing examined and inquired into." Plutarch, "('ato the Elder," 23. 
ready to understand that they are performing a public duty. ${ }^{1}$ The state wished alone to control education, and Plato gives the motive for this: " Parents ought not to be free to send or not to send their children to the masters whom the city has chosen; for the children belong less to their parents than to the eity."

The state considered the mind and body of every citizen as belonging to it; and wished, therefore, to fashion this body and mind in a manner that would enable it to draw the greatest adrantage from them. Children were taught gymnastics, because the body of a man was an arm for the city, and it was best that this arm should be as strong and as skilful as possible. They were also taught religious songs and hymns, and the sacred dances, because this knowledge was necessary to the correct performance of the sacrifices and festivals of the city. ${ }^{3}$

It was admitted that the state had a right to prevent free instruction by the side of its own. One day Athens made a law forbidding the instruction of young people without authority from the magistrates, and another, which specially forbade the teaching of philosophy. ${ }^{4}$

A man had no chance to choose his belief. He must believe and submit to the religion of the city. He could hate and despise the gods of the neighboring city. As to the divinities of a general and universal character, like Jupiter, or Cybele, or Juno, he was free to believe or not to believe in them; but it would not do to entertain doubts about Athene Polias, or Erechtheus, or Cecrops. That would have been grave impiety, which would have endangered religion and the state at the same time, and which the state would have severely punished. Socrates was put to death for this crime. Liberty of thought in regald to the state religion was absolutely unknown among the ancients. Men had to conform to all the rules of worship, figure in all the processions, and take part in the sacred repasts. Athenian legislation punished those by a fine who failed religiously to celebrate a national festival. ${ }^{5}$

The ancients, therefore, knew neither liberty in private life, liberty in education, nor religious liberty. The human person counted for very little against that holy and almost divine authority which was called country or the state. The state had not only, as

1 Aristophanes, "Clouds," 960-96.5.

"Aristophanes, "Clouds," 966-968.

2 Plato, "Laws," VII.

"Xenophon, "Memor.," I. 2. Diogenes Laertius, "Theophr." These two laws did not continue a long time; hut they do not the less prove the omnipotence that was conceded to the state in matters of instruction.

sPollux, YIII. 46. Clpien, Schol, in Demostheres; "in Meidiam." 
we have in our modern societies, a right to administer justice to the citizens; it conld strike when one was not guilty, and simply for its own interest. Aristides assurchly had committed no crime, and was not even suspected; but the city had the right to drive him from its territory, for the simple reason that he had acquired by his virtues too much influence, and might become dangerous, if he desired to be. This was called ostracism; this institution was not peculiar to Athens; it was found at Argos, at Megara, at Syracuse, and we may believe that it existed in all the Greek cities. ${ }^{1}$

Now, ostracism was not a chastisement; it was a precaution which the city took against a citizen whom it suspected of having the power to injure it at any time. At Athens a man could be put on trial and condemned for incivism - that is to say, for the want of affection towards the state. A man's life was guaranteed by nothing so soon as the interest of the state was at stake. Rome made a law by which it was permitted to kill any man who might have the intention of becoming king. ${ }^{2}$ The dangerous maxim that the safety of the state is the supreme law, was the work of antiquity. ${ }^{3}$ It was then thought that law, justice, morals, everything should give way before the interests of the country.

It is a singular error, therefore, among all human errors, to believe that in the ancient cities men enjoyed liberty. They had not even the idea of it. They did not believe that there could exist any right as against the city and its gods. We shall see, farther on, that the government changed form several times, while the nature of the state remained nearly the same, and its omnipotence was little diminished. The govermment was called by turns monarchy, aristocracy, democracy; but none of these revolutions gave man true liberty, individual liberty. To have political rights, to vote, to name magistrates, to have the privilege of being archon, - this was called liberty; but man was not the less enslaved to the state. The ancients, especially the Grecks, alway's exaggerated the importance, and above all, the rights of society ; this was largely due, doubtless, to the sacred and religious character with which society was clothed in the beginning.

1 Aristotle, "Pol.," VIII. 2, 5. Scholiast on Aristoph., "Knights," 851.

2 Plutarch, "Publicola," 12. $\quad{ }^{2}$ Cicero, "De Legib.," II I. 3. 


\section{Cilapter IV}

\section{CHIEFTAINRY AND KINGSHIP}

\section{SECTION 1 \\ CULTURAL IMPORTANCE OF CHIEFTAINRY 1}

1. There is scarcely another institution that has done so much for the growth of culture as chieftainry, the consequence of the peculiar psichic constitution of humanity, of the suggestive influence of strong natures, and of the tremendous power which the recklessness and superiority of individual genius exereises over other persons; in other words, the consequence of super-mankind and of the existence of orerpoweringly strong natures. The spirit of history was obliged to use this means in order to advance mankind, even though it were by force and compulsion ; for such strong natures are able to arouse and stir up the nations and to overcome a stagnant and halting evolution. Certain progressive movements of culture are always agrecable to them, and in order to bring these movements about, they apply powerful methods which universal history would not otherwise know. Their effect may be likened to that of a volcanic eruption, which does indeed work great destruction, but also raises up new lands, and brings them within the reach of culture.

2. The listorical beginnings of chieftainry are probably originally to be found principally in bands of youths; at any rate, to a great extent, though not exclusively. In other way's, too, a bold warrior or powerful brigind could seize the authority of a chief. 'The dangers that threatencd a community from outside, in particular, frequently gave rise to autocracy ; for it required a strong and ingenious personality who could inspire the mass and hold it to withstand attacks from without. If oince such an individual by victory has averted the external danger, he gains the confidence

1 [Reprinted, by permission, from Josef Kohler, "Philosophy of Law" (Albrecht's trans.), Boston Book Company, 1914 (Philosophy of Law Series, Vol. XII).] 
of the people, and there is no limit to his power within the nation; successes abroad have always served as a shield and cloak for the true tyrant.

3. When once the chieftain has obtained control, it will later be possible for him to surround himself with a religious nimbus. Provided the priests are not against him, it is easy for him to appear as the son of hearen, or of the sun, or as some kind of divine messenger, and to act as the exponent of the divine law. The result will be that the whole foundation of the law is displaced, and that the law will appear as an issue of his personality. Now he is in a position to sway and rule the people at will. Thenceforward, his subjects are nere tools in his hands, and the sacred relics of tradition dissolve under his power as soon as he desires it ; as soon as he seeks the advantage of the State in something else.

The further presentation of chieftainry and the development of the idea among the different nations does not lie within our province; but it is certainly our task to describe what ehieftainry did for the development of culture, and how it later became lingship.

4. Its influence on culture undoubtedly lies mainly in this, that it protected the country against outside enemies, and thus secured the peace and quietude necessary to its inward development. In addition, it furthered the idea of the State and repressed the constant dissipation of the population by kin-revenge and self-rindication ; for the chief wishes to maintain order and strives, in order to extend his power, to take the administration of justice entirelyinto his own hands. He is also inclined to develop the resources of the country; for the more it produces, the more his power and wealth are increased, as he alone controls the country's goods.

5. Chieftainry develops into kingship under the influence of two ideas : first, the idea that permits the State as well als the chief to be recognized as a personality. Even though the ehief be the unrestricted representative of the State, ret the conception is nuavoidable that he has the State in his hands only temporarily, and this again will give rise to the thought that he is only an organ of the State and that the latter, though it be temporarily embodied in him, is vet distinct from him.

The second important idea is that of duty, the thought that the advantage of the ehief is not the sole consideration, and that, as an organ of the State, he must act for its benefit. This idea can only develop fully, of course, where the conception of morality is already grown. Nevertheless, it must appear, in earlier times in the form 
of a religious commandment, wherever religious notions have become firm enough to allow clear principles and regulations to be formulated; for which, above all things, a separate priesthood is necessary which as the exponent of the good may succeed in upholding religion, even when opposed to the ruler. Wherever this religion exists, it will require logical action in certain directions, and the indulgence of certain considerations, and will, therefore, also demand of the sovereign that he shall not give way to his moods. Thus, the way is levelled for further development; and whoever feels it his duty to care for the welfare of the people, who even takes an oath to do so, as, for instance, among the Aztees, is no longer a chief but a king.

6. Kingship, like chieftainry, has a great task to perform in the development of culture, and this is accomplished in several ways.

(a) The person who acts is firmly established in his place, and can therefore influence certain cultural tendencies far more incisively and logically than can any other organ of the State. This, of course, also involves a great weakness: the personality of the sorereign becomes of extreme importance, and there are wide mental and psychic differences among personalities. One person may be fitted by nature to rule, while another lacks all talent in this direction. It has been attempted to solve this difficulty by making kingship elective; so that in this way a person could be chosen who had already proven by his deeds that he was suited to the office; but this system failed, because it led to corruption, and to constant upheavals, and to internal struggles. A modified form of elective kingship is found among some peoples, where of the members of the royal family, one is chosen to reign who appears to be particularly able; or, in some nations, a member who proves to be unfitted is deposed in favor of another member. But this system also gives rise to many disputes, quarrels, and enmities.

(b) Kingship brings with it a certain strengthening of the whole situation and frequently àlso greater protection agaiust danger from without.

(c) It may prevent not only destructive movements among the people from gaining the upper hand, but also the appearance of powerful party elements which in the form of plutocracy, class spirit, and party tyramy are a hindrance to the real progress of the State.

(d) Kingship may create an intellectual centre, and advance both arts and sciences; though such an arrangement is not without its disadvantages; for the bad features of the patronage of a 
Mreenus are often increased if such patronage exists by the grace of the king.

7. The principal remedy against the disadvantages of kingship, especially in as far as they relate to the contingency involved in getting an able personality for the head of the government, is to place other powers beside the king, such as the popular assembly or representatives of the people, and the ministry.

\section{Section 2}

\section{AUTHORITY OF THE KING ${ }^{1}$}

\section{Religious :Authority}

We should not picture to ourselves a city, at its foundation, deliberating on the form of government that it will adopt, derising and discussing its laws, and preparing its institutions. It was not thus that laws were made and that governments were established. The political institutions of the city were born with the city itself and on the same day with it. Every member of the city carried them within himself, for the germ of them was in each man's belief and religion.

Religion prescribed that the hearth should always have a supreme priest. It did not permit the sacerdotal authority to be divided. The domestic hearth had a high priest, who was the father of the family; the heart of the cury had its curio, or phratriarch; every tribe, in the same manner, had its religious chief, whom the Athenians called the king of the tribe. It was also necessary that the city religion should have its supreme priest.

This priest of the public hearth bore the name of king. Sometimes they gave him other titles. As he was especially the priest of the prytaneum, the Greeks preferred to call him the prytane; sometimes also they called him the archon. Linder these different names of king, prytane, and archon we are to see a personage who is, above all, the chief of the worship. He keeps up the fire, offers the sacrifice, pronounces the prayer, and presides at the religious repasts.

It may be worth while to offer proof that the ancient kings of Greece and Italy were priests. In Aristotle we read, "The care of the public sacrifices of the city belongs, according to religious

1 [By Fustel de Coulaxges, "The Ancient City"; translated by Willard Small; 11 th ed., Lothrop, Lee, and Shepard Co., Boston; reprinted by permission.] 
anstom, not to special priests, but to those men who derive their dignity from the hearth, and who in one place are called kings, in another prytanes, and in a third archons." I 'Thus writes Aristotle, the man who best understood the constitution of the Greek cities. This passage, so precise, shows, in the first place, that the three words limg, mytane, and archon were a long time synonymous. So true is this, that an ancient historian, Charon of Lampsacus, writing a book about the kings of Lacetemon, entitled it "Archons and Pritanes of the Lacedemonians.2 It shows also that the personage to whom was applied indifferently one of these three names - perhaps all of them at the same time - was the priest of the city, and that the worship of the public hearth was the source of his dignity and power.

This sacerdotal character of primitive royalty is clearly indieated by the ancient writers. In Eschyhus the daughters of Danaus address the king of Aroos in these terms: "Thou art the supreme prytane, and watehest over the hearth of this eountry." ${ }^{3}$ In Euripides, Orestes, the murderer of his mother, says to Menelaus, "It is just that I, the son of Agamemnon, should reign at Argos." And Menelaus replies, "Art thou, then, fit, - thou, a murderer, - to touch the vessels of lustral water for the sacrifices? Art thou fit to slay the victims?" \& The principal office of a king was, therefore, to perform religious eeremonies. An ancient king of Sieyon was deposed because, having soiled his hands by a murder, he was no longer in a condition to offer the sacrifices. ${ }^{5}$ Being no longer fit for a priest, he could no longer be king.

Homer and Virgil represent the kings as continually oceupied with sacred ceremonies. We know from Demosthenes that the ancient kings of Attica performed themselves all the sacrifices that were prescribed by the religion of the eity; and from Xenophon that the lings of Sparta were the chiefs of the Lacedamonian religion. ${ }^{6}$ The Etruscan, Lucumones were, at the same time, magistrates, military chiefs, and pontifis. ${ }^{7}$

The case was not at all different with the Roman kings. Tradition always represents them as priests. The first was Romulus, who was accpuainted with the science of augury, and who founded the city in aceordance with religions rites. The second was

1 Aristutle, "Polit.," VII. 5, 11 (VI. S). Comp. Dionysius, II. 65.

2 Suidas, X. Xápev. 3 Esch., "Supp.," 361 (357).

${ }^{4}$ Euripides, "(Orestes," 1605.

${ }^{5}$ Nic. Dames., "Frag. IIist. Gr.," t. III. p. 394.

"Demosthene's, "in Near." Nenophon. "Gov. Laced.," 13.

7 Tirgil, X. 17.5. Livy, V. 1. C'usorinus, 4. 
Numa: he fulfilled, Liry tells us, the greater part of the priestly functions; but he foresaw that his successors, often having wars to maintain, would not always be able to take care of the sacrifices, and instituted the flamens to replace the kings when the latter were absent from Rome. Thus the Roman priesthood was only an emanation from the primitive royalty.

These king-priests were inangurated with a religions ceremonial. The new ling, being conducted to the summit of the Capitoline Hill, was seated upon a stone seat, his face turned towards the south. On his left was seated an angur, his head covered with sacred fillets, and holding in his hand the augur's staff. He marked off certain lines in the heavens, pronounced a prayer, and, plaeing his hand upon the king's head, supplicated the gorls to show, by a visible sign, that this chicf was agreeable to them. Then, as soon as a flash of lightning or a flight of birds had manifested the will of the gods, the new king took possession of his charge. Liry describes this ceremony for the installation of Numa; Dionysius assures us that it took place for all the kings, and after the kings, for the consuls; he adds that it was still performed in his time. ${ }^{1}$ There was a reason for such a custom; as the king was to be supreme chief of the religion, and the safety of the city was to depend upon his prayers and sacrifices, it was important to make sure, in the first place, that this ling was accepted by the gods.

The ancients have left us no account of the manner in which the Spartan kings were elected; but we may be certain that the will of the gods was consulted in the election. We can eren see from old eustoms which survived to the end of the history of sparta, that the ceremony by which the gods were consulted was renewed every nine years; so fearful were they that the king might lose the favor of the divinity. "Every nine ycars," says Phutarch, "the Ephors chose a very clear night, but withont a moon, and sat in silence, with their eyes fixed upon the hearens. If they sam a star cross from one quarter of the heavens to the other, this indicated that their kings were guilty of some neglect of the gods. The kings were then suspended from their duties till an orade came from Delpli to relieve them from their forteiture." 2

\section{Politiral Authority}

Just as in the family the authority was inherent in the priesthood, and the father, as head of the domestic worship, was at the
${ }^{1}$ Liry, I. 18.
Dionysius, I1. 6; IV.s').
2Pluturch, "Agis," 11. 
same time judge and master, so the high priest of the eity was at the same time its political chief. The altar - to borrow an expression of Aristotle - conferred dignity and power upon him. There is nothing to surprise us in this confusion of the priesthood and the civil power. We find it at the beginning of almost all socicties, either because during the infancy of a people nothing but religion will command their obedience, or because our nature feels the need of not submitting to any other power than that of a moral idea.

We have seen how the religion of the city was mixed up with everything. Man felt himself at every moment dependent upon his gods, and consequently upon this priest, who was placed between them and himself. This priest watched over the sacred fire; it was, as Pindar say's, his daily worship that saver the eity every dar. He it was who knew the formulas and prayers which the gods could not resist; at the moment of combat, he it was who slew the rictim, and drew upon the army the protection of the gods. It was very natural that a man armed with such a power should be accepted and recognized as a leader. From the fact that religion had so great a part in the government, in the courts, and in war, it necessarily followed that the priest was at the same time magistrate, judge, and military chief. "The kings of Sparta," says Aristotle," "have three attributes: they perform the sacrifices, they command in war, and they administer justice." Dionysius of Halicarnassus expresses himself in the same manner regarding the kings of Rome.

The constitutional rules of this monarchy were very simple; it was not necessary to seek long for them; they flowed from the rules of the worship themselves. The founder, who had established the sacred fire, was naturally the first priest. Hereditary succession was the constant rule, in the beginning, for the transmission of this worship. Whether the sacred fire was that of a family or that of a city, religion prescribed that the care of supporting it should always pass from father to son. The priesthood was therefore hereditary, and the power went with it. ${ }^{3}$

A well-known fact in the history of Greece proves, in a striking manner that, in the beginning, the kingly office belonged to the man who set up the hearth of the city. We know that the population of the Ionian colonies was not composed of Athenians, but that it

${ }^{1}$ Pinder, "Nem.," XI. 5.

2 Aristotle, "Polities," III. 9.

${ }^{3}$ We speak here only of the early ages of cities. We shall see, farther on, that a time rame when hereditary surcession ceased to be the rule, and we shall explain why at Rome royalty was not hereditary. 
was a mixture of Pelasgians, Eolians, Abantes, and Cadnieans. Yet all the hearths of the cities were placed by the members of the religious family of Codrus.

It followed that these colonists, instead of having for leaders men of their own race, - the Pelasgi a Pelasgian, the Abantes an Abantian, the Eolians an Eolian, - all gave the rovalty in their twelve cities to the Codride.' Assuredly these persons had not aequired their authority by force, for they were almost the only Athenians in this numerous agglomeration. But as they had established the sacred fires, it was their office to maintain them. The rovalty was, therefore, bestowed upon them without a contest, and remained hereditary in their families. Battus had founded Cyrene in Africa ; and the Battiadre were a long time in possession of the royal dignity there. Protis founded Marseilles; and the Protiadx, from father to son, performed the priestly office there, and enjoyed great privileges.

It was not foree, then, that created chiefs and kings in those ancient cities. It would not be correet to say that the first man who was king there was a lueky soldier. Authority flowed from the worship of the sacred fire. Religion created the ling in the city, as it had made the family chief in the house. A belief, an unquestionable and imperious belief, declared that the hereditary priest of the hearth was the depositary of the holy duties and the guardian of the gods. How could one hesitate to obey such a

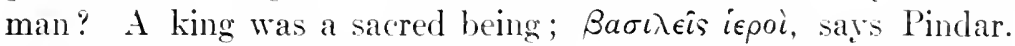
Men saw in him, not a complete god, but at least " the most powerful man to call down the anger of the gods" ; 2 the man without whose aid no prayer was heard, no saerifice aceeted.

This royalty, semi-religious, semi-political, was established in all cities, from their foundation, without efiort on the part of the kings, without resistance on the part of the subjects. We do not see at the origin of the ancient nations those fluctuations and struggles which mark the painful establishment of modern societies.

* $\quad * \quad * \quad * \quad * \quad * \quad * \quad * \quad * \quad * \quad *$

${ }^{1}$ Herodotus, I. 142-14S. Pausanias, VI. Strabo.

2 Sophocles, "Edipus Rex," 34. 


\section{Chapter V \\ RELIGION AND LAIV}

\section{SECTION 1 \\ RELIGIOUS ORIGIN OF ANCIENT LAW 1}

Awowa the Greeks and Romans, as among the Hindus, law was at first a part of religion. The ancient codes of the cities were a collection of ites, liturgical directions, and prayers, joined with legislative regulations. The laws concerning property and those concerning succession were scattered about in the midst of rules for sacrinces, for burial, and for the worship of the dead.

What remains to us of the oldest laws of Rome, which were called the Royal Laws, relates as often to the worship as to the relations of civil life. One forbade a guilty woman to approach the altars; another forbade certain dishes to be served in the sacred repasts; a third prescribed what religious ceremony a victorious general ought to perform on re-entering the city. The code of the Twelve Tables, although more recent, still contains minute regulations concerning the religious rites of sepulture. The work of Solon was at the same time a code, a constitution, and a ritual; it regulated the order of sacrifices, and the price of vietims, as well as the marriage rites and the worship of the dead.

Cicero, in his Laws, traces a plan of legislation which is not entirely imaginary. In the substance as in the form of his code, he imitates the ancient legislators. Now, these are the first laws that he writes: "Let men approach the gods with purity ; let the temples of the ancestors and the dwelling of the Lares be kept up; let the priests employ in the sacred repasts only the prescribed kinds of food ; let every one offer to the Manes the worship that is due them." Assuredly the Roman philosopher troubled himself little about the old religion of the Lares and Manes; but he was tracing a code in

1 [By Festel de Coulasges, "The Aneient City;" translated by Willurd Smoll: 11th erl., Lothrop, Lee, and Shepard Co., Boston; reprinted by permission.] 
imitation nat a unanimous rote was sufficient to make a law bindinsert ruldecision of the people required to be ratified by the ponAt Ro the augurs were required to attest that the gods were pontiff e to the proposed law. ${ }^{1}$

could $\mathrm{k}$ ay, when the tribunes of the people wished to have a law religion by the assembly of the tribes, a patrician said to them, As theright have you to make a new law, or to touch existing laws? religior no have not the auspices, you, who, in your assemblies, decision no religious acts, what have you in common with religion judges red things, among which must be reckoned the laws?" 2 marpm this we can understand the respect and attachment which werencients long had for their laws. In them ther saw no human as $k$, but one whose origin was holv- It was no vaiu word when talto said, "To obey the laws is to obey the gods." He does no sore than to express the Greek idea, when, in Crito, he exhibits Socrates giving his life because the laws demanded it of him. Before Socrates, there was written upon the rock of Thermopylæ, "Passer-by, go and tell Sparta that we lie here in obedience to its laws." The law among the ancients was always holy, and in the time of royalty it was the queen of the kings. In the time of the republic it was the queen of the people. To disobey it was sacrilege.

In principle the laws were immutable, since they were divine It is worthy of $r$ wark that they were never abrogated. Men could indeed make new ones, but old nus still vemained, hower they might conflict with the new ones. The code of Draco was not abolished by that of Solon; ${ }^{3}$ nor were the Royal Laws by those of the Twelve Tables. The stone on which the laws were engraved wasinviolable; or, a most, the least scrupulous only thought themselves permitted to turn it round. This principle was the great cause of the confision which is observable among ancient laws.

Contradictory las and those of different epochs were found together, and all claimed respect. In an oration of Isaus we find two men contesting an inheritance; each quotes a law in his favor: the two laws are absolute contraries, and are equally sacred. In the same mar ner the code of Mamm preserves the ancient law which establishes, rimogeniture and has another by the side of it which enjoins an equal division among the brothers.

The ancient law never gave any reasons. Why should it? It was not bound to give them; it existed because the gods had made

\footnotetext{
1 Dionysius, IX. 41 ; IX. 49.

${ }^{2}$ Dionysius, X. 4. Liry, I1I. 31.

"Andocides, I. 82, 83. Demosthenes, "in Everg.," 71.
} 
it. It was not discussed - it was imposed; it was a work of authority; men obered it beranse they hat faith in it.

During long generations the laws were not written; they were transmitted from father to son, with the creed and the formula of prayer. They were a sacred tradition, which was perpetuated around the family hearth, or the hearth of the city.

The day on which men began to commit them to writing, they consigned them to the sared books, to the rituals, among prayers and cercmonies, $X$ Varro cites an ancient law of the city of 'Tusculum, and adds that he read it in the sacred books of that city. Dionysus of IIalicarnasus, who had consulted the original documents, ways that before the time of the Decemvirs all the written laws at liome were to be found in the books of the priests. ${ }^{2}$ Later the laws were removed from the rituals, and were written by themselves; Int the custom of depositing them in a temple continued, and priests had the care of them.

Written or mwritten, these laws were always formulated into very bricf sentences, which may be compared in form to the verses of Leviticus, or the slocas of the book of Manu. It is quite proballo, eren, that the laws were rhythmical. ${ }^{3}$ According to Aristotle, 1 wre the laws were written, they were sung. " Traces of this ellotom have remained in language; the Romans called the

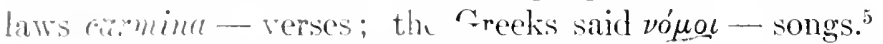

These ancient verses were invariable texts. To change a letter of them, to displare a word, to alter the rlythm, was to destroy the law itelf, ly dentroying the sarred form under which it was revealed to man. The law was like prayer, which was areeable to the divinity only on comlition that it was recited correctly, and which became impious if a single word in it was changed - In primitive law, the exterior, the letter, is everything there is no need of st king the sense or spirit of it, The value of the law is not in the me I principle that it contains, but in the words that make up the fe ula. XIts force is in the sacred words that compose it.

Among he ancient: and especially at Rome, the idea of law was inseparably comected with certain sacramental wordsy If, for example, it was a question of contract, one was expected to say, hari spondes.' and the other was expecterl to reply, Spondeo. If

1 Yrarro, "I. L.," VI. 16.

"Elian, "Y. II.," II. 39.

2 Dionysius, X. 1.

4 is ristotle, "Probl.," XIX. 28.

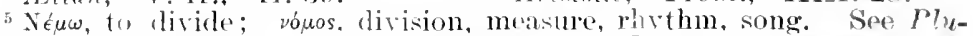

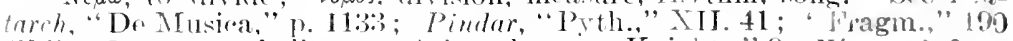

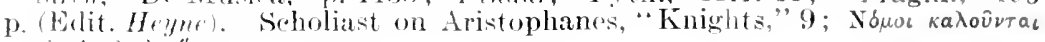
it eis thours incurot. 
these words were not pronounced, there was no contract. In vain the ereditor came to demand payment of the debt - the debtor owed nothing; for what placed a man under obligation in this aneient law was not conscience, or the sentiment of justice; it was the sacred formula When this formula was pronounced between two men, it established between them a legal obligation. Where there was no formula, the obligation did not exist.

The strange forms of ancient Roman leagl procedure would not surprise us if we but recollected that ancient law was a religion, a sacred text, and justice a collection of rites. The plaintiff pursues with the law - agit lege. By the text of the law he seizes his adrersary: but let him be on his suard; to have the law on his side, he must know its terms, and pronounce them exactly. If he speaks one word for another, the law exists no longer for him, and cannot defend him. Kains gives an account of a man whose vines had heen cut by his neighbor; the fact was settled; he pronounced the law. But the law said trees; he pronounced vines, and lost lis case.

Repeating the law was not sufficient. There was also needed an accompaniment of exterior signs, which were, so to say, the rites of this religious ceremony called a contract, or a case in law. For this reason at every sale the little piece of copper and the balance were employed. To buy an article, it was necessary to touch it with the hand - mancipatio; and if there was a dispute ahout a piece of property, there was a feigned combat - mammm consertio. Hence were derived the forms of liberation, those of emancipation, those of a legal action, and all the pantomime of lesal procerlure.

As law was a part of religion, it participated in the mysterious character of all this religion of the cities. The legal formulas, like those of religion, were kept secret. They were concealed from the stranger, and even from the plebeian. This was not because the patricians had calculated that they shomld possess a great power in the exchuse knowledge of the law, but because the law, by it: origin and nature, long appeared to be a mystery, to which one could be initiated only after having first been initiated into the mational worship and the domestic worship.

The religions origin of ancient law also explains to us one of the principal eharacteristics of this law. Religion was purely ciril, t that is to say, peculiar to each city. There could flow from it, therefore, only a civil law. X3ut it is necessary to distinguish the sense which this word had among the ancients. When they said that the law was civil, - jus cinile, vónot mo understand simply that every city had its code, as in our day every 
state has a code. They meant that their laws had no force, or power, except between the nnembers of the same cityd To live in a city did not make one subject to its laws and place him under their protection; one had to be a citizen. The law did not exist for the slave: no more did it exist for the stranger.

We shall see, further along, that the stranger domiciled in a city could be neither a proprietor there, nor an heir, nor a testator; he could not make a contract of any sort, or appear before the ordinary tribunals of the citizens. At Athens, if he happened to be the creditor of a citizen, he could not sue him in the courts for the payment of the debt, as the law recognized no contract as valid for him.

These provisions of ancient law were perfectly logical. Law was not born of the idea of justice, but of religion, and was not conceived as going beyond it $X$ In order that there should be a legal relation between two men, it yas necessary that there should already exist a religious relation, that is to say, that they should worship at the same hearth and have the same sacrifices When this religious community did not exist, it did not seem that there coukd be any legal relation $X$ Now, neither the stranger nor the slave had any part in the religion of the city $\alpha$ A foreigner and a citizen might live side by side during long years, without one's thinking of the possibility of a legal relation being established between them. Law was nothing more than one phase of religion. Where there was no common religion, there was no common law.

\section{SECTION 2}

\section{RELIGIOUS ELEMENT IN HINDU LAW 1}

The most ancient of the books containing the sacred laws of the Hindus appear to me to throw little light on the absolute origin of law. Some system of actual observance, some system of custom or usage, must lie behind them; and it is a very plausible conjecture that it was not unlike the existing very imperfectly sacerdotalised customary law of the Hindus in the Punjab. But what they do show is, if not the beginning of law, the beginning of lawyers. They enable us to see how law was first regarded, as a definite subject of thought by a special learned class; and this class consisted of lawyers who were first of all priests. There are signs of the ancient identity of the two professions in the earliest recorded

${ }^{1}$ [By Sir Henry S. Maine. Reprinted from "Early Law and Custom," by permission of IIenry Iolt and Company, New York.] 
usages of several races, Celts, Romans and Freeks. Nobodry, for example, will understand the ancient Roman lawyer, with that obstinate adherence of his to texts which has characterised his profession during so many centuries, and that method of stating his facts in inflexible formulas which has only just died out in this country, unless it is realised that the jurisconsult sprang from the pontifi or priest $A l l$ through the Middle Ages the lawyer who was avowedly a priest held his own against the lawer who professed to be a layman; and ours is the only country in which, owing to the peculiar turn of our legal history, it is difficult to see that, on the whole, the canonist exercised as much influence on the course of legal development as the legist or civilian. If the Roman Empire had merely transmitted its administrative system to Western Europe, and if it had not bequeathed to it a coherent body of codified secular law maling considerable approach to completeness, it is very doubtful whether the general law of the West would not even now reflect a particular set of religious ideas as distinct as the Hindu law reflects the sacerdotal conceptions of the Brahmans.

It is necessary first, of all, to observe how the priestly character of the Brahmanical authors of the law-books affected their view of conduct, a word which must be used at the outset in preference to 'law.' Shortly, this view is intimately affected thromghout by their belief as to the lot which awaits human beings after death. This lot will be made up of various experiences, some of which correspond to direct reward or punishment in Heaven or Hell as conceived by the Western religions. But the Hindu belief concerning the posthumous state of man and the Buddhist belief which has mainly sprung from it, differ from the most widely diffused Western beliefs in that the Transmigration of souls fills as large a space as direct reward and punishment, and in that rewards and punishments in all their forms are regarded, not as eternal but as essentially transitory. . . . When a man still contaminated by impurity dies, his spirit passes through a series of purgatories; from the last of these it escapes to clothe itself with one animal shape after another, and at last it finds embodiment in a human frame, which at first will probably be frail or sickly. But, after a second birth thromgh the study of the Scriptures, the virtuous at death pass straight into Jeaven, where their stock of virtue will keep them for long anes; but it will gradually wear out, until some remnant of it (arries them back to earth, to real)pear among the prosperous and the powerful. "Men of all castes, 
if they fulfil their assigned duties, enjor in Ileaven the highest imperishable bliss. Afterwards, when a man who has fulfilled his duties returns to this world, he obtains, by virtue of a remainder of merit, birth in a distinguished family, beauty of form, beauty of complexion, strength, aptitude for learning, wisdom, wealth, and the gift of fulfilling the laws of his caste or order. Therefore in both worlds he dwells in happiness, rolling like a wheel from one world to the other' (Apastamba, Ir. i. 2. 2 and 3). Even the gods in Heaven, who are looked upon as not much more than men of extraordinary virtue, will in time exhaust their store of merit and pass out of blessedness. 'It is by farour of the Brahmans,' says Yishnu (xix. 22), 'that the gods reside in Heaven.'

The Wheel mentioned in the above passage from Apastamba is a farourite image with these writers. They figure existence as a wheel spinning round. Religious pictures, representing the circle of life with its various compartments, with Heaven at the top and Hell at the bottom, and with human and animal existence at the sides, are common in the East; but though they are not unknown to Hindus, they are more frequently found among Buddhists, who must have borrowed the symbol of the Wheel from an older Hinduism, and who appear to attach to it a special spiritual significance.

It is very probable that these beliefs were themselves compounded of divers more ancient parts, and that direct reward or punishment, and indirect reward or punishment by transmigration, did not originally belong to the same body of doctrine. Heaven and Hell and the Transmigration of Souls are, however, all referred to in the oldest of the law treatises, though briefly and slightly. In the more recent writings (some of them, however, not so modern as Manu) these subjects occupy a great space, and have been vastly amplified by gloomy and fantastic imagination. Heaven, as is not unusual in religious systems, is but faintly sketched; but the Hells, or, as they would more properly be called, the P'urgatories (since they are essentially transient), are deseribed with the utmost minuteness of detail. They are twentytwo in number, each applying a new variety of physical or moral pain.

The sojourn of the sinful soul in each of these places of punishment is, as I have said, alwars terminable, but its length is expressed in language suited to astronomical magnitudes. If, for example, a Brahman be slain, as many as are the pellets of dust which his blocd makes on the soil - that is to say, on the burnt-up 
soil of India - so many are the periods of a thousand years the slayer must pass in Hell (Manu, xr. 208). The duration of punishment is imagined by the Buddhists with even greater extravagance; and indeed on all these subjects they seem to have outdone the doctrine of the Hindus. The frightful Buddhist pictures of torments in hell are tolerably well known. They are mostly of Chinese origin, and probably exaggerate (but do not more than exaggerate) the criminal justice administered from time immemorial in the great organised Chinese Empire and its dependent kingdoms, in which the highest importance seems always to have been attached to the deterrent effeets of punishment.

The series of Purgatories, is, however, at last worked through, and the soul or portion of life emerges to begin a course of transmigration which may bring it again to humanity. . . . It is hard not to smile at the grotesque particularity of detail with which such writers as Yishnu and Manu depict the transmigration of souls. 'Criminals in the highest decree enter the bodies of all plants successively. Mortal sinners enter the bodies of worms or insects. Minor offenders enter the bodies of birds. Criminals in the fourth degree enter the bodies of aquatic animals. Those who had committed a crime affecting loss of caste enter the bodies of amphibious animals' (Tishnu, Xur. 2). These general statements are followed by a prodigious number of others, mentioning the class of creature into which particular sinners enter. There is perhaps a natural fitness in some of them, but others look like arbitrary assertions or wild guesses. One who has appropriated a broad passage becomes a serpent living in holes. One who has stolen grain becomes a rat. One who has stolen water becomes a waterfowl. But what is to be said of the transformation of the stealer of silk into a partridge; of the thief of linen into a frog; of the cattle-stealer into an iguana? I may venture at the same time to suggest that what seems to us most difficult to understand in these beliefs once appeared simple and natural. It has been observed that savages look upon the transmutation of one creature into another as almost an easy, everyday process. Primitive men, living constantly in the presenee of wild animals, prering on them and preyed upon by them, do not seem to have been struck by the immense superiority of the man to the brute. They appear to have been impressed by the difference between living things and everything else, but to have considered the forms of animate being as separated from one another hy a very slight harrier.

But these Hindu law-books hive wrought up the ancient belief 
into a moral and theological philosophy of the greatest precision and amplitude. Their special principle is that man's acts and experiences in one form of being determine the next. Whether he will in a future existence become a plant, a reptile, a bird, a woman, a Brahman, or a semi-divine sage, depends on himself. He goes out of the world what his own deeds have made him ; and the impossibility of dissociating the past from the future is declared by these writers in language of much solemnity. If a man departs modified by voluntary sinfulness or involuntary impurity, and if he has not expelled the taint by due penance, he will become one of the lowest creatures; if he dies purer than he was born, he may reach the highest stage of humanity or become indistinguishable from divinity. The whole theory is saved from contempt by its power of satisf ying moral cravings, and by the apparently complete explanation which it offers of the unequal balance of good and evil in this world.

With these explanations, some features of those writings which are at first sight very perplexing become comparatively intelligible. Thus, they are chiefly called law-books because they contain rules of conduct stated with the utmost precision. But what happens to a man if he disobeys the rule? This is the principal question to the modern jurist. What is the punishment, or, as the technical phrase is, the Sanction? Understood in the modern sense, it is hardly noticed in the oldest of these books. It is in fact to be inflicted in another state of existence, and therefore, though it may be asserted, no directions can be given about it. Thus the place which in a modern law-book is taken by the Sanction - that is, by the various penal consequences of refusing to obey a law - is taken in these writings by Penances. You are to punish yourself here, lest a worse thing happen to you elsewhere. These penances are set forth in the most uncompromising language and in apparent good faith. ${ }^{1}$ In one place, the penitent is told to mutilate himself and to walk on in a particular direction till he drops dearl. In another he is to throw himself three times into the fire, or to go into battle and expose himself as a target to the enemy. For one great crime he is to extend himself on a red-hot iron bed, or to enter a hollow iron image, and, having lighted a fire on both sides, to burn himself to death. For the comparatively venial offence of drinking forbidden liquor a Brahman is to have boiling spirit poured down his throat. Other penances are extraordinary xxxy.

"Apastamba," I. i. 15; "Gautama," xxir ; "Vishnu," xxxiv. 
from the length and intricacy of the self-infictions which they suppose. The old books hint a doubt here and there as to the efficacy of penance: what good can it do, they say, since the eril deed itself remains; still, they add, the authoritative opinion is, that the penance should be performed. 'Man in this world,' writes Gautama (xix. 2), 'is polluted by a vile aetion, such as sacrificing for men unworthy to offer a sacrifice, eating forlsidden food, speaking what ought not to be spoken, neglecting what is prescribed, practising what is forbidden. They (i.e. some Brahman authorities) are in doubt if he shall perform a penance for such a deed or if he shall not do it. Some declare that he shall not do it, because the deed shall not perish. (But) the most excellent opinion is that he shall perform a penance.' This opinion is then supported by copious quotations from the Hindu scriptures. The remarkable thing is, that no one of these writers seems to feel, what would be our doubt, whether anyboly could be got to perform the severer penances.

How then does what we should call Law - that is, law, civil or criminal, enforced by sanctions or penalties to be inflicted in this world - first make its appearance in these books? It appears in connection with the personage whom we call the King. His authority is more or less assumed to exist in the oldest of these treatises, but, all taken together, they suggest that the alliance between the King and the Brahmans was very gradually formed. The most ancient of the books give comparatively narrow place to the royal authority, but the space allotted to the King and his functions is always increasing, until in the latest treatises (such as Manu) the whole duty of a King is one of the subjects treated of at the greatest length and with the greatest particularity. It may be observed that, with the increased importance attributed to the King, there is a change in the sacerdotal view of his relation to the law. In what appear to me to be the most ancient portions of these books, the King is only represented as the anxiliary of the spiritual director. $\mathrm{He}$ is to complete and enforce penances. 'If any' persons,' says Apastamba (II. v. 10. 13), 'transgress the order of their spiritual director, he shall take them hefore the King. 'The King shall consult his domestic priest, who should be learned in the law and in the art of governing. He shall order them to perform the proper penance, if they are Brahmans, and reduce them to reason by forcible means, except corporal punishment and servitude, but men of other castes, the King, after examining their aetions, may punish even by death.' In a later treatise (Vishmu, 
III. 2) the duties of a King are summed up in two rules: he is to protect his people; he is to keep the four castes, and the four orders of Student, Houscholder, Hermit, and Ascetic, in the practice of their several duties; or, in other words, he is to enforce the whole social and religious system as conceived by the sacerdotal lawyers. The further progress of change consists in the further exaltation of the personage who in the passage from Apastamba is called the King's domestic priest. In the end, the law-books come to contemplate an ideal tribunal composed of the King, with learned Brahmans as assessors. The later writings clothe the King with right divine. He is formed of eternal particles drawn from the substance of the gorls. "Though even a child, he must not be treated lightly, from an idea that he is a mere mortal. No; he is a powerful divinity who appears in human shape' (Manu, rit. iv. S). But he has lost in actual personal power. He can only act with the advice of his Brahman assessors. 'Just punishment camnot be inflicted by an ignorant and covetous King, who has no wise and virtuous assistants, whose understanding has not been improved and whose heart is addicted to sensuality. By a King, wholly pure, faithful to his promise, observant of the Scriptures, with good assistants and sound understanding, may punishment be justly inflieted' (Manu, vis. xxx. 31).

From this point the law set forth in these treatises becomes true civil law, enforced by penalties imposed in this world by the Court itself. The Brahmans themselves no doubt from first to last claim a considerable benefit of clergy. 'Corporal punishment,' it is written, 'must not be resorted to in the case of a Brahman; he at most can have his crime proclaimed, or be banished, or be branded.' At the same time the abstract doctrine of punishments or penal sanctions found in Manu (viI. 17 et seq.) might satisfy the English jurists who make the sanction the principal ingredient in a law, so uncompromisingly is it declared. Jeremy Bentham could hardly complain of such language as this: 'Punishment governs all mankind; punishment alone preserves them; punishment wakes when their guards are asleep; if the King punish not the guilty, the stronger would oppress the weaker, like the fish in the sea. The whole race of man is kept in order by punishment; gods and demons, singers in heaven and cruel giants, birds and serpents, are made capable by just correction of their several enjoyments' (Manu, loc. cit.). The full consequences of juridical doctrine like this do not, however, appear in such a law-book as the extant Mann, which, besicles a great deal of civil law, contairs 
a mass of sacerdotal rules, mostly, as it seems to me, in a state of dissolution and decay. A still later treatise, Narada, ${ }^{1}$ is almost wholly a simple law-book, and one of a very interesting kind. The ancient Brahmanical system has been toned down and tempered in all its parts by the good sense and equity of the school of lawyers from whom this book proceeded. The portions of it which deal with Evidence appear to me especially remarkable, not only for the legal doctrine, which (though the writer believes in Ordeals) is on the whole extremely modern, but for the elevation of moral tone displayed in its language on the subject of true and false witness, which should be set off against the unveracity attributed to the modern Hindu. "No relatives, no friends, no treasures, be they ever so great, are able to hold him back who is about to dive into the tremendous darkness of Hell. Thy ancestors are in suspense when thou art come to give evidence, and ponder in their mind, "Wilt thou deliver us from Hell or precipitate us into it?" Truth is the soul of man; everything depends upon truth. Strive to acquire a better self by speaking the truth. Thy whole lifetime, from the night in which thou wert born up to the night in which thou wilt die, has been spent in vain if thou givest false eridenee. There is no higher virtue than veracity; nor is there a greater crime than falsehood. One must speak the truth, therefore, especially when asked to bear testimony' (Narada, pp. 42,43 , Jolly). The somewhat analogous passage in Manu (mir. 112) is defaced by the often reprobated qualification, 'In ease of a promise made for the preservation of a Brahman, it is no deadly $\sin$ to take a light oatl.'

The difficulties under which the student of the so-ealled sacred Laws of the Hindus has so long laboured have been almost entirely caused by the transitional character of the book which was first introduced to European scholarship as the original souree of Hindu Law. If the sample of this branch of Hindu literature first translated into a Western language had been Narada, it would have been regarded as a law-book of a familiar trpe, and the traces of sacerdotal influence which are to be found in it would probably have been neglected. If, on the other hand, the book first made accessible had been Gautama, or Baudhâyana, or Apastamba, it would probably has been set down at onee as a manual of practical religious conduet, the Whole Duty of a Hindu; the law contained in it would probably have been considered adventitions or acci-

1 The "Institutes of Narada" have heen translated into English by Dr. Julius Jolly. London: Trübner \& Co., 1571. 
dental. But Manu, which Sir William Jones made famous in Europe, neither falls wholly under the one description nor wholly under the other. And so long as it stood by itself there was the greatest difficulty in determining its place in the general history of law. . . The whole of the literature to which it belongs sprang, it would now appear, from a double origin ; in part from some body of usage, not now easy to determine (though the recent investigation of local bodies of Indian custom has thrown some light upon it), but chiefly from the Hindu scriptural literature. The last exercised by far the most important influence. Its creators, far back in antiquity, did not start with any idea of making or stating law. Beginning with religious hymnology, devotional exercises, religious ritual, and theological speculation, some of their schools were brought to Conduct, and to stating in detail what a devout man should do, what would happen to him if he did it not, and by what acts, if he lapsed, he could restore himself to uprightness. Gradually there arose in these schools the conviction that, for the purpose of regulating Conduct by uniform rules, it was a simpler course to act upon the rulers of men than on men themselves, and thus the King was called in to help the Brahman and to be consecrated by him. 'The beginning of this alliance with the King was the beginning of true civil law.

Nothing which thus happened seems to me to be very unlike what would have happened in the legal history of Western Europe, if the Canonists had gained a complete ascendency over Common Lawyers and Civilians. The system which they would have established might be expected to give great importance to the purgation of crime by penances. This in fact occurred; the preference of the ecclesiastical system with its penances over the secular system with its cruel punishments, had much to do, as mav be seen from the legendary stories, with the popularity of St. Thomas (Becket). C Then. it would be probable that, in the case of graver sin, the ecclesiastical lawyer would invoke the aid of the secular ruler to secure the proper expiation, and this again occurrer in the form of entrusting the severer punishments to the secular arm. Finally, if the sole arlvisers and instruments of the European $\mathrm{King}$ in the administration of civil and criminal justice had heen exclesiasties, they would have been driven in the long run to construct a system of civil and criminal law with proper sanctions enforced by the Courts. But the system would have been deepar tinged in all its parts with ecclesiastical ideas, and though it woukl posibly have borrowed some or many of its rules from older 
usage, it would have been very hard to detect their sources and their precise original form.

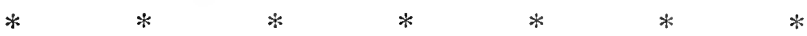

I said that this ancient literature threw less light on the beginning of law than on the begimning of lawyers. But it is of course to be understood that the men who conceived and framed it were much more than lawyers. All the world knows that they were also in some sense priests; but they were much more than priests. What we have to bring home to ourselves is the existence in ancient Indian society of a sole instrueted class, of a class which had an absolute monopoly of all learning. It included the only lawers, the only priests, the only professors, the sole authorities on taste, morality, and feeling, the sole depositaries of whaterer stood in the place of a seience. These books are one long assertion that the Brahmans hold the kers of Hell and Death, but they also show that the Brahmans aimed at commanding a great deal more than the forces of the intellect, and that all their efforts came to be directed towards bringing under their influence the mighty of the earth of another sort, the conquering soldier and the hereditary king. They were to become partners with princes in their authority, their advisers and assessors. 'A King and a Brabman deeply rersed in the Vedas, these two uphold the moral order of the world;' thus it is written in one of the oldest of the books. Doubtless, the alliance between Brahman and King was often sealed, and produced great effects; for, amid the obscurities of early Indian history, the fact does seem to emerge that, although religions doubtless at first extended themselves by conversion, they were established over wide areas and again overthrown much less by propagandism than by the civil power. On the whole, the impression left on the mind by the study of these books is, that a more awful tyranny never existed than this which proceeded from the union of physical, intellectual, and spiritual ascendeney. It the same time it would be altogether a mistake to regard the class whose ideas are reflected in the literature as a self-indulgent eccleviastical aristocracy. It is not easy, I must admit, to describe adequately the intensity of the professional pride which shoms itself in all parts of their writings. Everyborly is to minister to them; everybody is to give way to them; the respectful salutiltions with which they are to be addressed are set forth with the utmost minuteness. They are to be free of the criminal law which they themselves prescribe. 'A Brahman,' writes Gautama, 
'must not be subjected to corporal punishment, he must not be imprisoned, he must not be fined, he must not be exiled, he must not be reviled or exeluded (from society).' Their arrogance perhaps reaches the highest point in a passage of the law-book of Vishnu, where it is written that 'the Gods are invisible deities; the Brahmans are visible deities. 'The Brahmans sustain the world. It is by favour of the Brahmans that the Gods reside in Heaven.' Yet the life which they chalk out for themselves is certainly not a luxurious and scarcely a happy life. It is a life passed from first to lavt under the shadow of terrible possibilities. The Brahman in youth is to beg for his teacher; in maturity, as a married householder, he is hedged round with countless duties, of which the involuntary breach may consign him in another world to millions of years of degradation or pain; in old age, he is to become an ascetic or a hermit. It is possibly to this combination of selfassertion with self-denial and self-abasement that the wonderfully stubborn vitality of the main Brahmanical ideas may be attributed. As I have shown, the sacerdotal legal syrstem, as a system, owes probably much of its present authority to its adoption by the Anglo-Indian Courts of Justice as the common law of India ; but some of the points of belief which underlie it, as they do the whole Brahmanical literature, make the most durable part of the mental stock of every Hindu.

\section{SECTION 3}

\section{TABOO AS A PRIMITIVE SUBSTITUTE FOR LAW 1}

The law issues commands and prohibitions, the essence of which is not that the rights of the individual shall be preserved, but that the original interests of culture in general shall be promoted. Cnder this head belong the many regulations in respect to sanitation, to the promotion of norality in general, to the preservation of a certain state of the earth's surface (the supervision of rivers, conservation of forests, etc.). Here, too, belong the manifold statutes that refer to education, social and economic conditions, etc. This is the field of cultural adrancement through police and penal regulations.

In connection with this stands the law of taboo.

Taboo in general means forbidden, and refers to everything

I [Reprinted, by permission, from Josef KoHLER, "Philosophy of Law" (Allrecht's trans.), Boston Book Company, 1914 (Philosophy of Law Series, Tol. XII).] 
that, for reasons based on mystical and religious grounds, is forbidden to the individual, the whole or a part of the people. Thus the conception grows out of primitive mysticism, but it has a strongly formative effect, for a great deal of what is necessary to human progress is accomplished by means of such prohibitions. We need only recall the great number of sanitary measures that could not have arisen except in this way. Of course, originally, the taboo was enveloped in a mass of so-called superstitions, that is, in a mass of ideas which, in one direction or another, gave expression to a principle of faith, only to die out later because they were merely of temporary significance, and disalppeared in the light of more advanced knowledge.

In this way the custom of taboo could, to a great extent, take the place of our police regulations; for as soon as priesthood and chieftainry become more powerful, not only thos things are tabooed that have hitherto been sacred fut the priests and chiefs have the right of putting others under tabog. If they do not exercise this right arbitrarily, but on rational grounds, the taboo becomes a beneficial means of removing the absurdities and indecencies of the people, and investing life with a certain dignity and sublimity. 


\title{
Chapter Ti
}

\section{EVOLUTION OF CRIMINAL LAW}

\author{
SECTION 1 \\ PRIMITIVE CRIMINAL LAW 1
}

The earliest view which we obtain of political society shows us in each case the same system prevailing for the redress of wrongs and punishment of offences, namely, a system of private revenge and personal redress of injuries. Each person avenged, in whatever manner he thought right, a wrong done him by another, and the customs of the tribe sanctioned his doing so with impunity. The idea of retaliation is one deeply rooted in man's nature. A savage or a child naturally revenges an injury by inflicting a similar one on the aggressor. Retribution in kind is viewed, even in rivilised societies, with satisfaction. An eye for an eye, a tooth for a tooth; whoso sheddeth man's blood, by man shall his blood be shed - such is the rule in all early societies. As Mr. Morye, in speaking of the Roman Law, well says: "A system of selfredress, in the form of private vengeance, preceded everywere the establishment of a regular judicature; the injured person, with his kinsmen or dependents, made a foray against the wrongdoer, and swept away his cattle, and with them perhaps his wife and children, or he threatened him with supernatural penalties by 'fasting' upon him, as in the East even at the present day'; or, finally, he reduced his adversary to servitude, or took his life." 2 There are only slight traces of this system of self-redress in the Roman Law of the time of Gaius and Justinian. Still there are sufficient to prove, conclusively, that the early history of Law was the same in Rome as elsewhere. When we apply ourselves to

${ }^{1}$ [By Richard R. Cherry, Barrister-at-Law ; Reid Professor of Constitutional and Criminal Law in the University of Dublin. Reprinted from "Lectures, Growtl of Criminal Law in Ancient Communities," Macmillan \& Co., London, 1890.1

${ }^{2}$ Justinian, "Insts.," ed. Moyle, rol. i, p. 614. 
other sistems of law which, from various causes, did not develop in the same manner as the Roman Law did-such, for instance, as the Brehon Laws of Ireland, and the legal systems of Semitic nations - we find the system of private retaliation in full vigour, even in the most highly developed stage to which the law erer attained. There can be no doubt, also, that the primitive history of English Criminal Law was in this respect exactly the same. "The fact," says Mr. Justice Stephen, "that private vengeance of the person wronged by a crime was the principal source to which men trusted for the administration of criminal justice in early times, is one of the most characteristie circumstances comnecter with English Criminal Law, and has had much to do with the development of what may, perhaps, be regarded as its principal distinctive peculiarity, namely, the degree to which a eriminal trial resembles a private litigation" " Hist. of Criminal Law," i. 245). The development of both the English and Roman syrstems has, in a great measure, obliterated the traces of this system of primitive retaliation; and it is difficult to trace in them the various steps of the progress to a mature system of law. It is here that we invoke the aid of the other systems of law which I have mentioned. The Brehon Laws, arrested in their growth, at an early stage of legal development, by the unfortunate history of Ireland, throw a flood of hight upon the early history of Penal Law, and supply us with the missing link of legal history. They exhibit to us, flourishing in full rigour, institutions and methods of procedure, of which only very slight traces remain in the Roman Law, and the very remembrance of which has been almost entirely lost in our own more perfect system of Criminal Law.

The primitive method for the redress of wrongs was, as I have said, simple retaliation upon the person of the wrongdoer. At this stage of human progress, Law, in any sense in which we use the term, cannot be said to have existed. It would be absurd to call sarage retaliation Law ; still this system of retaliation is the germ from which Penal Law has gradually developed itself ; and we can, by comparing the laws of different nations at different periods of their development, actually trace the stages by which the practice of retaliation became transformed into a regular srstem of Criminal Law. The first stage in this progress was the growth of a custom for the injured person to aceept some pecuniary satisfaction in lien of his right of vengeance. The wrongdoer might thus buy off the revenge which he dreaded, if he chose to do so. This was, at first, a purely voluntary matter on both sides. 
There was no compulsion whatsoever. It lay entirely in the discretion of the injured person whether he would accept pecuniary satisfaction or wreak his vengeance on the wrongdoer. And the latter, if he were strong enough, could safely defy his enemy, and refuse to give any satisfaction. It was altogether a matter of private bargaining; the injured man, according to his power, and according to the fierceness of his anger, exacting whatever sum he could from the wrongdoer. Gradually, however, a regular scale of payment was established - at first, for slight injuries, and then, afterwards, for more serious offences. Custom has enormous force among uncivilized nations. Men, naturally, and without any constraint, were satisfied to accept the same compensation as others in similar positions had been content with. Still there was no compulsion - no constraint whatsoever - and no intervention of any julicial authority.

It must not be forgotten that the right of personal revenge was also in many cases a dity. A man was bound by all the force of religion and custom to avenge the death of his kinsman. This duty was by universal practice imposed upon the nearest male relative - the avenger of blood, as he is called in the Scripture accounts. Among most nations, murder, like any other offence, conld be compounded for between the wrongdoer and the nearest relative of the slain. We never hear of the death fine in historical times in Greece, but in Homer it is referred to more than once. Thus, in the 9th Book of the Iliad, Ajas, in reproaching Achilles for not accepting the offer of reparation made to him by Agamemnon, reminds him that even a brother's death may be appeased by a pecuniary fine, and that the murderer, having paid the fine may remain at home among his own people free. One of the scenes said to have been depicted on the shield of Achilles is a dispute about a death fine. Among the ancient Germans the custom prevailed universally. Tacitus tells us that atonement was made for homicide by a certain number of cattle, and that by that means the whole family was appeased. By the Lex Salica the fine was paid in money, and varied according to the rank, sex, and age of the murdered person. ${ }^{1}$ The early English laws were bascd on the same principle: the fine for homicide is constantly referred to in the laws of Edgar and Athelstan. In Sweden the death fine was also recognized by the name kinbote, as a compensation for homicide. In the Roman Law there is no trace of it,

${ }^{1}$ See "Lex Salica," edited hy Hessels and Kern. Titles 14, 24, 35, 41-45. 
so far as I am aware; but the provision of the Twelve Tables regarding homicide has not been preserved to us; and it is only from an incidental reference, many centuries later, that we learn that death was the penalty imposed for the crime. It is possible that, as in the case of lesser injuries, primitive Roman Law allowed a murderer to compound for his offence by a money payment; but it is more probable, I think, that the law regarded the life of a Roman citizen as too sacred to be atoned for by moner payment. Among Semitic nations the death fine was very general, and it continued to prevail in the Turkish Empire down to our own day ; but the acceptance of a death penalty was distinctly forbidden to the Jews by the Mosaic legislation. The life of a man was considered too sacred to be atoned for by money. ${ }^{1}$ Religious influence had much to do everywhere, as we shall see, with the development of Criminal Law.

The death fine was, of course, a most important matter in cases where it was permitted to he paid and received, and it is in reference to it that a dispute would naturally arise: firstly, because its amount would necessarily be larger than that for lesser injuries; and, secondly, because the acceptance of too small a fine would naturally be looked upon as an evasion of his duty by the avenger of blood. The latter might accept a fine, but he could not, without disgrace, accept any small compensation for the death of his kinsman.

The first germ of any judicial proceeding is to be found in the settlement of the amount of these fines by the tribal assembly, which was held periodically anong most primitive nations. Each party would naturally appeal to it, and probably in early times its principal work was the settlement of such disputes. At first the settlement was only suggested, neither party being bound by the decision; and it was not, apparently, for a very long period that any attempt was made to enforce decrees as to the amomnt of the fines. Where both parties were willing to refer the matter to the assembly, the decision of the latter was of course binding, and gradually it came to be usial and eustomary to do so.

We have, in English Law, very little trace of such a system as that which I have endearoured to describe, but the Brehon Iaw: give us an exact picture of this state of society" and there "an be little doubt that it preceded, everwwhere, the establishment of a regular judicial sprstem.

In fixing the amount of the fine to be paid, the Tribal Assembly

$$
\text { isee Numbers, xxxv. } 31 \text {. }
$$


would naturally pay attention to the likelihood of the injured person being satisfied with its decision. Thus the feelings of the aggrieved party, rather than the moral guilt of the offender, or even the amount of damage inflicted, was the primary matter which regulated the amount of the fine. At a later period, when law was fully dereloped, and the decisions of courts of justice regularly enforced, traces of this system remained in the rules regarding the penalty for different offences. The curious rule by which, according to Roman Law, a theft detected in the act was punished by a fine of twice the amount of that inflicted for a theft not so detected, is mudoubtedly to be traced to this source. "The reason," says Mr. Poste, "why furtum manifestum was subjected to a heavier penalty than furtum nec manifestum, was not because the barbarous legislator supposed that detection in the acc was an aggravation of the offence, but because he wished, by the amplitude of the legal remedy offered, to induce the aggrieved party not to take the law into his own hands and inflict summary vengeance on the offender." 1

The Roman Law only exhibits, incidentally, as it were, traces of the existence of such customs; but the Brehon Laws exhibit the system in full operation. The "Book of Aicill" mentions with great detail the various circumstances which are to be taken into account in fixing the amount of fines; and instances are recorded where injured persons refused, for various reasons, to accept the amomint fixed.

How then did this purely voluntary system become transformed into a regularly enforced parment of the fines was a matter of şradual development. The Brehon Law traets, for instance, contain no provision whatsoever for the enforcement of the fines, so that we are much puzzled to know what obligation there was on any one to pay. We may conjecture that when first tribal assemblies or kings began to decide disputes authoritatively, they gave (if the wrongdoer were present) such assistance as was necessary to the complainant in exacting the punishment imposed. If the wrongdoer did not attend, there was, so far as we can learn, no means of compelling him to do so; but the principle of retaliation was again invoked here. He who refused to pay the fine was deprived of its benefits. If any man refused to pay the fine imposed upon him by law for any offence, he was declared henceforth incapable of recovering fines for offences against himself. In other words, he was outlawed. There can be little doubt that

$$
{ }^{1} \text { Poste's "Gaius," p. } 160 .
$$


outlawry was the first punishment imposed by sockt rye more archaic a body of law is the more minute are its pror. regarding outlawry. Such is the conclusion at which sir $L_{1}$. Maine arrives:- "The earliest penalty for disobedience to the court was probably outlawry. The man who would not abide by" its sentence went out of the law. If he were killed, his kinsmen were forbidden, or were deterred by all the force of primitive opinion, from taking that vengeance which otherwise would have been their duty and their right." 1 The introduction of the system of outlawry is extremely important in that it marks the real origin of Criminal Law. In ancient law there is no such thing as a crime. The word "crimen" . . . is of comparatively modern origin in Roman Law, and necessarily implies a judicial proceeding of some kind.

Criminal Law, as distinct from Penal Law, involyes some element of public condemnation - such was a sentence of outlawry. The right of vengeance, or the penalty paid and accepted in lieu of it, is a matter more of private than of public law. The term "pœena" does not, like "crimen," involve anything of a public nature. "There can be little cloubt that the term 'pona' originally meant not so much penalty as composition for injury; the earliest 'pœnæ' were sums in consideration of which the injured person consented to forego his customary right of self-redress, and the penal sums recovered by the plaintiff in a Roman action on delict attest the nature of the practice, though in them the 'penalty' is usually fixed by the State, and not by the parties." a

The prototype of a modern criminal trial appears in the solemn proclamation at the tribe meeting, after full inquiry, of the sentence of outlawry. In Iceland the sentence was pronounced at the Althing by the Law man. In the Saga of Gisli the outlaw, we have an account of the mamner in which sentence of outlawry was passed in that country. Gisli in a quarrel had slain his opponent. He flies, and is pursued by Bork the stout, brother of the slain man. "The next thing that happens is that Gisli sends word to his brothers-in-law, Helgi, and sigurd, and Vestgen, to go to the Thing (i.e. local assembly held periodically) and offer an atonement for him that he might not be outlawed. So they set off for the Thing, the sons of Bjartmar, and could bring nothing to pass about the atonement; and men go so far as to say that the be-

${ }^{1}$ See his chapter on "The King in his relation to carly civil justice." in "Early Law and (ustom," pp. 170-17.t.

2 Moyle. "Insts. of Justinian," vol, i, n. 616.

${ }^{3}$ "The Story of Gisli the Outlaw," Ed. Wy Sir G. Dusent. 
haved very ill, so that they almost burst out into tears ere the suit was ower. They were then very young; and Bork the Stout was so very wroth they could do nothing with him." In England it was, under the old law, necessary that a man should be solemnly called at four county courts ${ }^{1}$ before the sentence of outlawry could be pronounced against him. In theory outlawry still exists in our law, though it has long since become obsolete in practice.

Such is a slight sketch of the manner in which Criminal or Penal Law appears to have originated in all legal systems. When we pass this initial stage we find that Laws dereloped themselves differently in different countries, according to differing circumstances of government, occupation, and temperament of the people. Difierent acts became crimes under different sy'stems, but the general principle which underlay all was the principle of revenge. Those acts have everyhere come to be regarded as crimes which in early times tended to provoke vengeance or retaliation. The judicial authority, either the king or tribal assembly, at first regulated the manner in which this vengeance was to be enforced, and the terms upon which it might be commuted. Individuals were constrained to obey by sentences of outlawry. Gradually, then, partly in order to suppress disorder, and partly in consequence of the disappearance, for various reasons, of the system of pecuniary fines, a regular șrstem of Criminal Law came into existence; the same acts being punished as offences as were formerly liable to fine or personal revenge. We thus see how completely different the early development of Criminal Law, as a matter of fact, was, from what, according to the principles of analytical jurisprudence, we might naturally suppose it to have been.

\section{SEction 2}

\section{DENELOPNIENT OF JUSTICE ${ }^{2}$}

1. To the civilized man it seems the merest truism to say that the business of Government is to make and execute laws, to see that crime is suppressed, and that its subjects are maintained in possession of their just rights. Not only so, but the broad lines upon which justice is administered are to him so familiar and

1 The County Courts were, in all probability, a survival, among the Anglo-Saxons, of the periodical tribal assembly of the Teutonic nations.

"[By L. T. Новноеке. Reprinted from "Morals in Erolution," by permission of Itemry Holt and Company. New York. Abbreviated and omitted book-titles with the detail of editions are supplied by the author's reference list on p. xiii seq., Vol. I of the original work.] 
seem so clearly marked out by reason and common sense that if he were to think of their origin at all he woukd naturally imagine that here, if anywhere, we had to do with simple and elementury moral ideas, implanted in men by nature, and needing no troining nor experience to perfect them. Thus, what could be more obvious to begin with than the distinction of ciril and criminal justice? A may trespass upon the rights of $B$, but he may do so without fraud, violence, or any criminal intent. In such cases the loss suffered by $\mathrm{B}$ must be made good, but no further punishment should fall upon $A$. That is, there is ground for a civil action. Or, on the other hand, in injuring $B$, A may have committed an ofience against the social order. In that case he must be punished as a criminal, and is not to escape merely by making good the loss inflicted on B. He has offended society, and society insists on punishing him. But, further, if $A$ is a wrong-doer, it must be proved that he is a responsible agent. Ile must have done wrong with intention, and, if so, he alone ought to suffer. Socially, no doubt, his fall must affect his innocent wife and children, but this is a regrettable result, not a consequence which the law goes about to inflict. Lastly, whether in a civil or criminal case, the function of the law is to set up an impartial authority, before whom the question is arsued. Both sides are heard. Evidence is cited, and witnesses called, whose testimony the court is free to sift and weigh. Formalities and rules have to be observed, but apart, perhaps, from some which are archaic, they are devised mainly as safeguards against wrongful decisions, and the real business of the inquiry is to get at truth as to the material facts. In the end, the decision being given, the court can freely use the executive power of Government to enforce it.

Elementary as all this sounds, it is, historically speaking, the result of a long evolution. The distinction between civil and criminal law, the principle of strictly individual responsibility, the distinction between the intentional and the unintentional, the conception of the court as an impartial authority to try the merits of the case, the exchusive reliance on evidence and testimony, the preference of material to formal rectitude, the execution of the court's decision by a public force - all are matters very im-? perfectly understood by primitive peoples, and their definite? establishment is the result of a sow historical process. Perbips no other department of comparative ethies gives so vivid an idea of the difficulty which humanity has found in establishing the simple elements of a just social order. 
2. The growth of law and justice is pretty closely connected in its several stages with the forms of social organization. In quite the lowest races there is, as we have seen, scarcely anything that is strictly to be called the administration of justice. I'rivate wrongs are revenged by private individuals, and any one whom they can get to help them. The neighbours interfere in the least possible degree, and how far a man's family, or the wider group to which he belongs, will stand by him, is a question which is decided in each particular case as its own merits, or the inclinations of those concerned, direct. ${ }^{1}$ But even at a very low stage this uncertain and fitful action begins to take a more definite shape. We find something that corresponds roughly to our own administration of justice, and from the outset we find it in two broadly distinct cases. There are occasions upon which a

1 See the account of the Veddahs and Fuegians (original work, ch. ii). With these may be joined the Andamanese, who live in small communities numbering from twenty to fifty individuals, and have no distinct institutions for the maintenance of order or the settlement of disputes. Each group, indeed, has a chief, but his powers are extremely limited, extending to lit tle heyond the right of calling the people together and exercising over then what influence he ean. There is no form of covenant, no oath, no form of trial, no ordeal. Justice is left altogether to the aggrieved party, who shoots an arrow at his enemy or throws a burning faggot at him, the neighbours playing their part in the matter by running away until the fuarrol is over, which at any rate prevents the spread of the misehief. The law of vengeance is not developed. A relative may avenge the death of a murdered man, but it is not necessary that anything should happen. The neighbours are afraid of the murderer, and he finds it desirable to alssent himself for a while. Not uncommonly a man will show his resentment, not by punishing the wrong-doer, but by destroying all the property that he can lay hands upon, including his own. The chief's property alone will be respected. In other words, the Andaman Islander, like the Malay, is apt to run amok, and such men are not resisted hecause they are held to be possesserl. Conjugal fidelity among this monogamous people is enforced by the hushand, but in punishing the guilty party he runs the risk of retaliation. There appears, however, says Mr. Man, to he an understanding that the greater the provocation offered the less is the risk incurred by the injured person or his friends, in avenging the wrong - a sentiment which very aptly characterizes the degree in which justice is recognized as a public matter at this stage of social development. There is no definite redress, but an injured man may hope to earry the support of the neighbours with him in rough proportion to the strength of his case. Injuries lone hy a member of another tribe lead to more regular feuds and are avenger if possible by a night attack upon the neighbouring camp, which, if surcessful, results in the slanghter of the males and the destruction or appropriation of the property of the vanquished. The women of the enemy, it may be notert, are not deliberately killerl; at any rate their death is not, as among some more advanced peoples, a matt er for boasting: and the child captive would be treated kindly with a view to its arloption by the captors' tribe. Cannibalism, the frequent eon romitant of savage warfare, is held in horror, but is attributed liy the southern Andamanese to the inhalitants of the northern island. (E. H. Man, "Journal of the Anthropological Institute," vol. xii. 108 siq.) 
whole community will turn upon an offender and expel him, or put him to death. Sometimes, indeed, this is merely a hind of lynch law directed against a man who makes himself unbearable or commits some crime which touches a general feeling of resentment into life. But berond this there are at almost, if not quite, the lowest stages certain aetions which are resented as inrolving the community as a whole in misfortune and danger. These include, besides actual treason, conduct which brings upon the people the wrath of God, or of certain spirits, or which riolates some mighty and mysterious taboo. ${ }^{1}$ 'The actions most frequently regarded in this light are certain breaches of the marriage laws and witcheraft. The breaches of the marriage law which come in question here are confined to those transgressions of the prohibitions of intermarriage, upon which primitive races lay such extraordinary stress. A mere violation of the marriage tie is generally in savage society a private matter, avenged by the husband alone, or by those whose duty it is to help him; but a breach of the rules of exogamy, a marriage within the totem, for example, or a marriage outsile the permissible class, is regarded as an offence endangering the community herself, and only to be wiped out by the extinction of the offender. A Central Australian tribe, for instance, which has no regular means of enforcing any law, will make up a war party to spear the man and woman who have married in defiance of these customs." Similarly common action will often be taken to protect the community from witcheraft, obviously a terrible offence in a society which firmly believes in it. Among the North American Indians a public sentence was often pronounced and carried out by the chiefs in cases of sorcery, and sometimes also in cases of cowardice or breaches of the marriage customs. ${ }^{3}$ The punishment of witcheraft is as widespreald as the fear of it, and, prompted as it is by the sense of a danger to the whole community, is often peculiarly ferocious, and directed to the destruction of every one connected with the offender. ${ }^{\text {t }}$

${ }^{1}$ Cf. Steinmetz, "Ethnologische Studien zur ersten Entwickelung der Strafe," ii. pp. $328-341$.

2 Sometimes the old men of the tribe will invite a neighbouring group to execute the eriminal. Cutting and burning are sometimes substitutes for death. (Spencer and Gillen, "Native Tribes of Central Australia," p. 495.$)$

${ }^{3}$ Kohler, "Zeitschrift für vergleichende Rechtswissenschaft," 1s97, pp. 412-416. For the punishment of sorcery, see Waitz, iii. p. 12s.

4 "The punishments affecting sorcerers can srarcely he called punishments. They are acts of annihilation." - Post, ii. p. 395, where numerous instances are given from all parts of the world. In some cases, the whole family of the offender perishes with him. 
The object of the community in exterminating the criminal is not so much to punish the wicked man as to protect itself from a danger, or purge itself from a curse. Achan takes the accursed thing, the thing which had been devoted to Jahreh. The taboo on the thing deroted is at once communicated to Achan himself as though it were a poison or an infection, or, to take another metaphor, a charge of electricity. It passes from the spoil appropriated to the appropriator, and no resource remains but to derote Achan with all his family and belongings, everything, in fact, which the accursed thing had infected. The Roman criminal, if his offence bore a religious character, was "sacer" - separated from men, made over to the offended deities. ${ }^{1}$ His goods were set apart (consecratio bonorum), for they were involved in his impurity. He was banished, so that none might come into contact with his accursed person. He was cut off from fire and water, not primarily because fire and water were necessary to his life, so that he was sentenced to death by being deprived of them, but rather for fear that his accursed touch should pollute the sacred elements and convey the pollution to others. That the eriminal suffered in consequence was a satisfactory collateral effect, but the main thing was to secure the fire and water from pollution.?

Thus far, then, public punishments, where they are any more than an explosion of indignant feeling, may be regarded as public action taken for the sake of public safety. The community is threatened with palpable treason, or with occult magic influence, or by the wrath of the gods. ${ }^{3}$ It protects itself by destroying the traitor, or sacrificing, or, at any rate, getting rid of, the witch. It is a kind of public hygiene rather than a dispensation of justice which is in question.

1 Thus the undutiful son is "sacred" to the parental deities. "Si parentem puer verbcrit, ast olle plorassit, puer divis parentum sacer esto." (Bruns, "Fontes Juris Romani Antiqui," p. 14.) 'Treason to a client, or ploughing up a neighbour's landmark, would also render a man "sarel." ('f. the curses in Dent. xxvii. At bottom the idea of some North American Indians is similar, among whom the murderer is taboo, herause hamted by the ghost of the victim. (Kohler, "Z. f. vgl. Rechtswst.," 1 s $\$ 7$, p. 40s.)

"Jhering, "Geist des Römischen Rechts," i. pp. 275-277, etc.

3 Among the German tribes the worst offenders were sacrificed to the gods, unles the latter showed signs of grare, in which case the offender hecame a slave of the gods, or was sold into slavery, or became an exile. 'The great offences were: - breach of the peace of the temple, the army, or the meeting, of a special festival, or finally of the house; grave-robbing, treason, raising an army in rebellion, arson, black magic; anti-social crimes of peruliar depravity, such as breach of a sworn peace, unnatural desile, and acts of powardice, such as desertion from the army; concealed murder and theft, in opposition to open murder and robber. (Schrödcr, "Lehrbuch der Deutschen Revelitsgeschichte," pp. 74 and 76.) 
3. With the redress of wrongs, the maintenance of private rights, and the punishment of the bulk of ordinary offences, it is different. For these purposes primitive soeiety has no adequate organization. Administration of justice in this sense is in the main a prirate matter. It is for the sufferer to obtinin restress or to revenge himself, and in the lowest stages of all, the rengeance is, as we have seen, casual, arbitrary and mostematizerl. But as the family and the clan acquire definite and coherent structure a systematic method of redress grows up. The leading characteristies of this method are two - (1) that redress is olbtained by retaliation, and (2) that owing to the solidarity of the family the sufferer will find support in obtaining the redress that he seeks. The individual man, woman or child no longer stands by himself or herself, but can count with considerable certainty on the protection of his relatives, who are bound to arenge a wrong done to him, or to stand by him in exacting rengeance by every tie of honour and religion. In other words, this is the stage of the blood feud. "He that sheddeth man's blood, by man shall his bloorl be shed," is the earliest law given in the Old Testament, and on this point the Old Testament may be said to be a faithful reflection of the historical facts.

Though the blood feud is an expression of vengeance, this vengeance is by no means wholly without regulations and rules of its own. There is a rough justice recognizable in its working, though it is not the justice of an impartial third person survering the facts as a whole. There is no question of a just judge rendering each man his due, but rather of a united kin simpathizing with the resentment of an injured relation when expressing itself in certain traditional forms. Justice as we understand it - the rendering to each man his (hue as judged by an impartial authority - is not distinctly conceived as a social duty in primitive ethics and that is what, morally speaking, differentiates the primitive ethical consciousness from the ethical consciousness at a higher stage of development. Yet primitive ethics works upon rules in which a certain measure of justice is embodied. Thus in the first place custom preseribes certain rules of retaliation which are reeognized as right and proper and have the approval of the neighbours and clansmen. The simplest and earliest of these rules is the famous Lex Tuliomis, "An eye for an eye, and a touth for a tooth," familiar to 11: from the chapter of Exodus, but far earlier than Exodus in its first formulation. We find it, like many other primitive rules of law, in the reentere-discovered corte of King 
Iammurabi, ${ }^{1}$ which is earlier than the Book of the Covenant perhaps by 1300 years, and we find it at the present day among people sociologically at an carlier stage of development than the Babylonians of the third millennium before Christ. We find it applicable to bodily injuries, ${ }^{2}$ to breaches of the marriage law ${ }^{3}$ and perhaps we may say in the rules of the twofold restitution for theft and in the symbolic form of mutilating the offending member even to the case of offences against property. ${ }^{4}$ In some cases the idea of exact retaliation is carried out with the utmost literalness a grotesque literalness sometimes, as when a man who has killed another by falling on him from a tree is himself put to death by exactly the same method - a relation of the deceased solemnly mounting the tree and, much one would say at his own risk, descending upon the offencler. ${ }^{5}$ More often, of course, vengeance is simpler. Stripes, mutilation or death are inflicted without any attempt to imitate the original offence, though there may very well be a grading of the vengeance in proportion to the original wrong. The homicide is slain, the adulterer speared, beaten, or mutilated, the thief slain, enslaved or forced to make restitution, the defaulting debtor enslaved or flogged. ${ }^{6}$

4. But at a fairly early stage in the growth of social order a fresh principle is introduced tending to mitigate the blood feud and so maintain peace and harmony. For the special vice of the system of retaliation is that it provides no machinery for bringing the quarrel to an end. If one of the Bear totem is killed by a

${ }^{1}$ Hammurabi, $\$ 195$. If a man has struck his father, his hands one shall ent off.

196: If a man has caused the loss of a gentleman's eye, his eye one shall cause to be lost. limb.

197. If he has shattered a gentleman's limb, one shall shatter his

200. If a man has made the tooth of a man that is his equal to fall out, one shall make his tooth fall out, etc.

2 See instances in Post, ii. pp. $240,241$.

The allulterer has to yield his own wife to the injured husband (loc. cit., ef. Hititz, iv. 361).

4 The thief loses eye or hand. Similarly the adulterer or ravisher may he castrated - and with this we may perhaps compare the punishment of the mulhaste wife by prostitution. The perjurer loses his tongue or the "schwurfinger." (Pिost,l.c.)

5 In the Leges Henrici, Pollock and Maitland, vol. ii. pp. 470, 471. MIutilation is punished by retaliation among the Barea and Kunama, the Whydah, Bogos, and Congo people. (Post, ii. 241.)

"E.g. among the Cherokees the defaulting dehtor was tied to a tree and flogged. (II aitz, iii. p. 131.) In other tribes disputes as to money matters wre regulated hy arbitrators chosen by the conflicting parties. Those who were prevented by illness or any real obstacle from paying their debts, were not comperlect to do so, but those who could pay and did not fell into general contempt. 
Hawk, the Hawk must be killed by one of the Bears, but it by no means follows that this will end the matter, for the Hawks may now stand by their murdered clansmen and take the life of a second Bear in revenge, and so the game goes on, and we have a true course of vendetta. Accordingly peaceable souls with a view to the welfare of both families, perhaps with the broader view of happiness and harmony within the community, intervene with a suggestion of peace. Let the injured Bears take compensation in another form, let them take cattle or other things to make good the loss of the pair of hands which served them. In a word, let the payment of damages be a salve to vindictive feclings. In that way the incident may come to an end and peace will reign. When such a practice becomes a customary institution we enter upon the stage of composition for offences, a stage peculiarly characteristic of the settling down of barbarous tribes into a peaceable and relatively civilized state, and especially of the growth of the power of a chief whose influence is often exerted to enforce the expedient of composition upon a reluctant and revengeful family. As the institution takes shape a regular tariff is introduced, so much for an injury, so much for the loss of an eye, so much for a life. Often a distinction between classes of crime appears. For some it is the rule that composition should be accepted. Others are recognized as too grave to be washed out except by blood. Thus among the German tribes murder and rape excited blood. revenge, while other injuries were punishable by fine, and the fine is significantly called "faida," as being the feud commuted for money. ${ }^{1}$ The distinction lasted into the Middle Ages, even in a period when the fine or a part of it went to the king. Our Leges Menrici still distinguish emendable offences, in which sacrilege and wilful homicide without treachery are included, from unemendable offences such as housebreaking, arson, open theft, aggravated homicide, treason against one's lord and breach of the church's or the king's peace. ${ }^{2}$ These are crimes which in the

1 Waitz, "Deutsche Verfassungsgeschichte," i. p. 437, who, howeror, denies that the fine was a merely buying off of revenge.

${ }^{2}$ Post, "Afrikanische .Jurispruclenz," ii. 30, gives a list of ten Afriean peoples in which eomposition is allowed for all offences. In three of her's it is allowed for all cases exrept the gravest, such as murder: among the Kimbundas, for all except soreery ancl treason; among the Batrolone for all except rebellion, and among the Kaffirs for all except treason, sorocry. and sometimes murler. In mediaral England there was much lowal variation in the fines. At Lesves the fine for hloodsher was $7 / 4$, for adultery $8 / 4$, the man paying the King, the woman the Arohbishop. In Shropshire the fine for bloodshed was 40/-. In Worestershire rape was not emendable. (Pollocli and Malland, ii. p. 457.) 
Anglo-Saxon term had no bôt - no bôt or money payment atoned for them - they were bot-less, boot-less. Even when the bôt was payahle it stood at first at the discretion of the injured family to accept or reject it, and we find the Germanic codes in the early Middle Ages setting themselves to insist on its acceptance as a means of kecping the peace. If the fine is not fortheoming of course the feud holds.

But when injuries are being assessed, not only must there be a distinction between the injuries themselves, but also between the prrous injured. There must be a distinction of rank, age, sex; a frec-born man is worth more than a slave, a grown-up person than a child, generally speaking a man than a woman, a chief or person of rank than a free man. And so we have the system of "wergilds" familiar to us in the early stages of our own history," and again recognizable in the code of Hammurabi. ${ }^{3}$ In one form or another the system of composition prevails or has prevailed almost to this day over a great part of the barbaric world, among the North Anerican Indians, ${ }^{4}$ in the Malay Archipelago, ${ }^{5}$ in New Guinea, among the Indian hill tribes, among the Calmucks and Kirghis of the steppes of Asia, among the rude tribes of the Cau-

${ }_{1}$ Charlemagne s capitulary of 802 forbids the kin to increase the evil by refusing peare to the manslayer who eraves it. (Jenks, "Law and Polities," p. 102.) In England, down to the ninth and tenth centuries, the agreressor might thect to bear the blood feud, but by an ordinance of Alfred, the injured party might have the help of the ealdorman to enforce payment. (Pollock and Maitland, i. 47.)

2 Anong the ciemanic peoples, in the carty mediaral period, the wergild of a noble was generally touble that of a free man. A post in the King's service trebled the wergild of the official's hereditary rank. The Liti (IIörig(s) had as a rule half the wer of free men, whilst slaves arcording to strict principle had none, but only a valuation. In fact, howerer, some barbarian codes assigned them half the wer of a litus. (Áchröler, pp. $345,346$.

${ }^{3}$ Iammurabi illustrates two subsidiary points. (1) An offence against a man of higher rank may be unemendable (i.e. punished by retaliation), while the sime offence against a man of lower rank is commutable. (2) The rank of the aggressor may influence the punishment as well as that of the sufferer. Injuries to eye or limb of a "gentleman" are punished by retaliation (sections 196,197 ), but in section 198 , "If he has caused a poor man to lise his eye or shat tered a poor man's limb, he shall pay one mina of silver." Further, hy section 199, the slave has no wer - for the same injury the agrressor "shall pay half his price." Similarly for the loss of a tooth (sertions 200, 2011)....

${ }^{4}$ Kohler, "Zeitsehrift für vercl. Rechtswissenschaft," 1897, pp. 406, 407 ; Alrord, in "Srhooleraft," $\vee$. 6is ; Morgun, "Leagne of the Iroquois," 331,332 . Failing a present of a helt of white wampum the family of the eleceased appointed an avenger.)

5 Itrits, v. p. i. 143. The wergild varies from 200 to 1000 gulden according to thr rank of the doad man. In case of poison, the poisoner becomes the slare of the family. A paramour may be enslaved by the hushand if taken in the act, hut if the matter is brought before a court, money compensation must be accepted. 
casus, the Bedouins of the Arabian desert, the Somali of Fast Africa, the negroes of the West Coast, the Congo folk of the interior, the Iaffirs and Basutos of the South.

5. Primitive vengeance, then, may be exacted by retaliation or compounded by money payments. In either method a rough justice is embodied, but it is justice enforced by the strong hand. Even graver differences separating barbaric vengeance from civilized justice have now to be mentioned. These differences are inherent in the nature of the social organization upon which the blood feud rests. For the blood feud is retribution exercised by a family upon a family; it rests upon the support which each individual can count upon from his own immediate relations, possibly from his whole clan; it rests, in a word, upon the solidarity of the kindred. But the effect of this solidarity upon the working of retributive justice is by no means wholly favourable. In the first place it has the effect that the lives of members of other clans are held indifferent. A perfect ilhustration is afforded by the Ungani Nagas, a tribe of the North-East frontier of India who live in villages composed of two or more "khels," as their clans are called, which, though living side by side and intermarrying," are for purposes of defence independent communities. A hostile tribe may descend upon the village and massacre all the members of one "khel" while the other "khels" sleep peacefully in their beds and do not raise hand or foot to protect their neighbours. This is cold-blooded, but it is not without a certain reason. The exterminated "khel" has incurred a feul from which the others are free. If they rise in its defence they not only incur the danger of the present fight, but they also involve themselves in the permanent feud. ${ }^{3}$ Next, in so far as justice rests on the blood feur, and the blood feud is of the nature of a private war hetween distinct families or clans, it follows that public justice will not deal with offences committed within the family. These do not excite the blood feud. In some cases no fixed punishment appears to be assigned for them, but this may happen not only because they do not belong to the province of public custom, but also, perhips, because they are too rare for any definite custom to have arisen for dealing with them. Like parricide among the Romans, they repre-

${ }^{1}$ Post, ii. pp. $256,257$.

2 The khel is exogamons.

${ }^{3}$ Godden, "J. A. I.." xxvi. p. 167. Similarly in rontemporary Afriea, so far as blood revenge holds, the slaying of any one out-ide the clan is no more regarded as wrong than the killine of an enemy in hattle among us. (Post, "Afrikanische Jurisprudenz," i. 160.) 
sent the absolute ultimate of human wickedness. Further, generally speaking, there is no need for any recognizable general rule, because offences within the family are dealt with by the arbitrary justice of the paterfamilias or of the kin collectively, who, even if other means of enforcing authority failed, have always the ready remedy of outlawry, which puts the offender at the mercy of the firstcomer.' Outlawry from the clan is the most effective of all weapons, because in primitive society the exclusion of a man from his kinsfolk means that he is delivered over to the firstcomer absolutely without protection. An illustration may be drawn from the early history of Mahommed's teaching, when the Korâis, who found that Mahommed's gospel was very inimical to their gains, wanted above all things to put him out of the way and made the most strenuous efforts to induce Mahommed's uncle, who was head of the clan, to disown him. Had the uncle consented, Mahommed would have been left without protection and might have been dispatched by any one without fear of consequences, but till the death of the uncle the clan stood by him; and the leading men of Mecca, powerful as they were, were not bold enough to take upon themselves a blood feud with Mahommed's family. ${ }^{2}$ The fear of the blood feud is the great restraint upon disorder in primitive society, and conversely he whose death will excite no blood feud has no legal protection.

So far the negative side of clan justice. The positive side has peculiarities not less startling to the modern mind, for since it is a member of one body who has done a wrong to a member of another body, the whole body to which the offending member belongs is held responsible by the whole body to which the injured member belongs; and it is not merely the original criminal who may be punished, but logically any member of his family may serve as a substitute. Responsibility is collective, and therefore also vicarious. Sometimes the whole family of the offender is destroyed with

${ }^{1}$ Among African peoples there is, generally speaking, no blood feud for homicide within the clan. But among the South-Western Arabs the parricide is put to death, and for fratricide the father may put the offender to death or demand the blood price. (Post, "A. J.," i. 63.) Among the Bogos the slayer of brother or father would be killed on the spot if taken. But if he escapes, his fate will depend on the question whether his victim has or has not left children. If so they will talie up the feud. If not he can make his peace without payment, anc then inherit his brother's property and widow. ( $I b$., ii. 60.) In the Malay region the murder of a relative is dishonouring, but has no money penalty. (Waitz, v. i. 149.) For illustrations of the variety of customs under this head, see Steinmetz, ii. $153-176$.

"Palmer, "Introduction to the Koran," pp. 24, 25. 
him. ${ }^{1}$ Sometimes any relation of the offender may suffer for him vicariously. John, who has done the deed, being out of reach, primitive vengeance is quite satisfied with the life of Thomas, his son, or brother, or cousin. Just as in the blindness of warfare the treacherous act of an enemy is generalized and perhaps arenged in the next battle by a retaliation which does not stay to ask whether it is falling on the innocent or the guilty, so in the primitive blood feud. The wrong done is the act of the family or clan to which the aggressor belongs, and may be avenged on any member of that family or clan. ${ }^{2}$ Sometimes the retaliation is made more specifie by a fresh application of the Lex Talionis, and to the rule "eye for eye," there is the pendant "son for son, laughter for daughter, slave for slave, ox for ox." You have slain my son? Then the true and just retribution is that I should slay yours. ${ }^{3}$ It is my daughter who is slain? Then it is with your daughter that you must pay for her. Sometimes rengeance is specially

${ }^{1}$ E.g. among the Kaffirs, at Loango, and among the Barolong, the relatives are held responsible for parment by the accusers, and on the Gold Coast the relatives of the sorcerer are slain or enslaver along with him. (Post, "A. J.," i. 46.) Among the North American Indians the family and the whole tribe were held responsible for a murder committed by one of them. (Waitz, iii. 132.) In Anglo-Saxon law it was possible for a family to be enslaved for a theft ly the father. (Pollock and Maitland, i. 56.)

2 For instances, see Post, "Grundriss," i. 230 ff. Professor Tylor instances the Bedouins, Australians, South Sea Islanders, and Kaffirs, as peoples among whom the blood feud involved the whole clan. " Contemp. Review," 1873, p. 59.) In some cases the wergild involved the slaving of several persons for one. Thus by Anglo-Saxon law, six ceorls must die for one thegn. (I'ollock and Maitland, ii. 450.) Edmund set himself to suppress feuds, forhidding attacks on the kindred unless they harbour the homicide. Mahometin law, while admitting retaliation, restricts it to the offender. (Post, loc. cit.) But the kin are liable for money composition. (Dareste, p. 64.) In many African tribes a ereditor will seize and sell as a slave any relation of the debtor's whom he can find, or even any member of the same town. It is not surprising to learn that this method of distraint is a fruitful source of war. (Post, "A. .J.," ii. 140.) A still wilder development of virarious revenge is found in the Gazelle Peninsula among the Papuas, where the hushand whose wife has heen stolen, goes into the bush and kills the first man he meets. This man': kindred do the same thing, and the process is repeated till the strolie lights upon the original offender, whose goods have to pay all the clamage. (Kohler, "Z. f. vgl. Rechtsw.," 1900, p. 381.) Cf. a similar practice in S. Guinea. (Post, "A. J.," ii. 22.)

3 The most astonishing rase is in the treatment of the builder in the code of Hammurabi, 229 : - "If a builder has built a house for a man and has not made strong his work, and the house he built has fallen, and he has caused the death of the owner of the house, that builder shall be put to death.

230 . If he has raused the son of the owner of the house to die, one shall put to death the son of that builder.

231. If he has caused the slave of the owner of the house to die. het shall give slave for slave to the "wmer of the house." Though harbaric, these sections might have a use if suitably posted in modern suburbs. 
directed against the chief as representing the clan. Sometimes it may be visited on any male, or even on any adult member of the clan, children alone being excluded. Sometimes this last shred of humanity is torn away. 'The principle is pushed to its furthest and most revolting development among the head-hunting tribes common in South-East Asia, in which magical ideas combine with those of revenge, and the skull of the enemy has a potency of its own which makes its possession desirable in itself. The head of a child or woman of the hostile body is no less coveted an object than that of the fighting warrior, and is probably easier to obtain. When the principle of composition arises collective responsibility is reduced, by a less barbarous logic, to a common pecuniary liability. The clan are collectively responsible for the blood money due from a member, and by the same logic they are the collective recipients of blood money due to any member. ${ }^{1}$ And as with blood moner so with other debts. ${ }^{2}$ There is a collective liability - a conception which in this softened form has its uses in the social order, and is in fact enforced and applied to the commune - though in right it belongs rather to the clan by many Oriental Govermments. ${ }^{3}$

6. Further, with the theory of collective responsibility goes almost necessarily the failure to distinguish between accident and design. In primitive society the real gravamen of a charge against an aggressor is that he has done an injury. How he did the injury, whether of set purpose or by accident, is a matter of less moment. My son, or brother, or cousin, or clansman, is killed; that is enough for me: I must have some satisfaction out of the man who did it, and, what is more, my family must have some satisfaction out of his family. Furthermore, the whole distinction between design and accident is by no means so clear to primitive man as it is to us, for though it needs little reflec-

${ }^{1}$ E.g. among the Bogos and Bedouins (Post, i. 253), and compare Post, "A. J.," i. 4.5 and ii. 3.5. For collective rlaims on the blood money, $c f$, Tacitus, "Cermania" (ap). C. llatz, "Deutsche Verfassungsgeschichte," i. 32), "recipitque satisfactionem universa domus."

2E.g. at (rreat Bassam. (Post, "A. J.," i. 45.) Among the Yoruba, Tshi, and Ewe speaking peoples, rollective responsibility which formerly applied gencrally is now restricted to debts. (Ellis, "Yoruba-speaking Peoples," 229.) ("f. Writz, ir. 306. - In Yucatan the whole family is responsible for delit.

3 And elsewhere; e.g. at Sierra Leone and in several other parts of Africa, responsibility for del,t extends to the Commune. (Post, "A. J.," i. 75.) In the IIalay ronstitution the family is responsible for its members, the sulu (clan) for its families, the village for its sukus, the district for its villages. (Waitz, v. i. 141.) 
tion and a very molerate amount of self-knowledge to distinguish between what one has done one's self by accident or by design, and a very moderate degree of reasoning power to apply the distinetion to other men - still, the nascent reflection of the savage is strangled at birth by the prevailing theory of witcheraft and possession. If a tree falls upon a man's hearl the savage holds that a spirit guided it. If a man, cutting a branch from a tree, dropped his axe on to another's head, it may not have been the man's own soul which guiderl the axe, but it was another soul which possessed him temporarily ; he was possessed by some spirit, and as possessed he should be put out of the was. ${ }^{1}$ The treatment of the subject in the Hebrew codes illustrates the dificulty which is experieneed even at a higher stage in strictly distinguishing between the two spheres of design and accident. Each code assigns a city of refuge for the excusable homicirle, but none makes it perfectly clear whether it is unintentional or unpremeditated man-slaring that is in view. The Book of the Covenant simply says, "If a man lie not in wait, but God deliver him (the vietim) into his hand, then I will appoint thee a place whither he shall flee. And if a man come presumptuonsly upon his neighbour to slay him with guile, thou shalt take him from mine altar that he may die." 2 In Deuteronomy there is an attempt to define accident. The eity of refuge is appointed for "whoso killeth his neighbour unarares and hated him not in times past." The first qualifieation would be true of unintentional, the second of unpremeditated homicide. Then follows a somewhat elaborate illustration of a case of pure accident. ${ }^{3}$ " As when a man goeth into the forest with his neighbour to hew wood, and his hand fetcheth a stroke with the axe to cut down the tree, and the head slippeth from the helve, and lighteth upon his neighbour, that he die. he shall flee unto one of these cities and live:" and then it is once more stated that the slayer ought not to die, "inasmuch as he hated him not in time past," which would be true of any want of premeditation. Furthermore, even in this relatively enlightened code the unintentional slayer is not fully protected. It is elearly" anticipated that the "arenger of blool" will pursue him "while his heart is hot, and overtake him because the way is long, "and smite him mortally, and there is no hint that the avenger will be punisherl.

1 Post, "A. J.," ii. 29. In West Equatoria the man who injures another" in cutting down a tree is held the agent of an indwelling magical power, and must submit to the ordeal of Mbundu drinting. (Ib.)

${ }^{2}$ Exodus xxi. 13, 14.

${ }^{3}$ Deut. xix. 4-6. 
Nor was the alternative, exile to the city of refuge, a merely nominal penalty. Finally, in the Priestly Code there is an elaborate attempt to distinguish different cases. 'The cities of refuge are appointed for every one that "killeth any person unwittingly," or, as the margin renders it, "through error." (An attempt is made to render the meaning clearer by specifying the implements userl, of iron, wood or stone.) On the other hand, he who has killed another, "lying in wait" or "in enmity," is to be put to death by the avenger of blood "when he meeteth him." In intermediate cases the congregation shall judge. "But if he thrust him suddenly without enmity, or hurled upon him anything without lying in wait, or with any stone, whereby a man may die, seeing him not, and cast it upon him, so that he died, and he was not his enemy, neither sought his harm: then the congregation shall judge between the smiter and the avenger of blood according to these judgments." 1 Even here, then, the three cases of accident ("seeing him not"), assault without intent to kill ("thrust him suddenly") and unpremeditated homicide ("without lying in wait") seem to be in a measure confused. And even in this code the avenger may slay the man-slayer anywhere outside the borders of the city of refuge until the death of the high priest.

Not infrequently in early law we find the distinction that unintentional homicide is atonable by paving the wergild, while deliberate murder gives rise to the blood feud. Thus in the code of Hammurabi ${ }^{2}$ the homicide might swear that the blow was unintentional and escape with a fine. So, again, though Germanic law begins by holding a man equally imputable for all that he has done, it is an ancient mitigation that for unintentional homicide the wer is due, and the blood feud should not be waged. ${ }^{3}$ The disentanglement of innocent from culpable homicide was a very gradual achievement in medixval Europe though aided by the Civil and Canon Law, and the forfeiture of goods - the direct

1 Numbers xxxy. 15, 20, 21, 22-24.

2 Hammurabi, 206-20s.

${ }^{3}$ Pollock and Matland, ii. 470 and 471 . In many cases, however, the innocent homicide can only escape by a recommendation to mercy. In the Anglo-sixon law the distinction is not so much between intentional and unintentional as between open and secret slaying. (Ib., i. 52.) This recalls the difficulties in Deut. and Numbers. Generally speaking, according to Post, "A. J.," ii. 28, the responsibility of the agent is not presumed as a ground of his punishment in Africa. But in some cases, as in Aquapin and Ashanti, the penalty for an accidental offence is redured, and later (in contradistinction to earlier), Kaffir law imposes, as a rule, no penalty on accidental homicide. 
survival of the wergild - remained in theory in English law down to 1828.1

It is a natural, though, to our minds, a bizarre consequence that in early justice animals and even inanimate objects may be regarded as appropriate subjects of punishment. The slaying of offending animals is provided for in the Book of Exortus. Many cruel punishments were inflicted upon animals in the corle of the Zendavesta, ${ }^{2}$ and the same thing occurred in medieval Europe, where, perhaps under the influence of the Mosaic legislation, it even survived in isolated cases to the sixteenth or serenteenth century. ${ }^{3}$ The punishment of animals and inanimate objects was no mere wreaking of blind fury on innocent creatures. Probably to the primitive mind the ox that gored a man, the sword that slew, and the murderer that wielded it were much more on one level than they can be to us. The animal or tool, if not conscious themselves, might be endued with a magic power or possessed with an evil spirit. It was well to get rid of them before they did more harm. If not destroyed they might be purified. Thus in the English law of Deodand, which was not abolisher till the middle of the last century, there is a survival of the view that anything that has killed a man must undergo a kind of religious purification ; a cart, for instance, which ran over a man, or a tree which fell on him was confiscated and sold for charity - at bottom merely a somewhat humanized version of the ancient Athenian process whereby the axe that had slain a man was brought to trial, and, if found guilty, solemnly thrown over the boundary. It need hardly be added that where responsibility is extended to animals and inanimate objects, it is apt to be inadequately defined in the case of idiots, lunatics, and minors. ${ }^{*}$

The principle of collective responsibility does not necessarily disappear with the rise of public justice under central authority. It lingers on, partly through sheer conservatism, but also in many cases for political reasons, to a late date. Thus it is particularly

${ }^{1}$ Blackstone, iv. p. 18S. In practice "as far hack as our records rearh," the defendant could obtain a pardon anfl writ of restitution. The clear demarcation of individual responsibility is far from being unirersal in civilized law. In the Mahometan world a man's family is collectively. responsible even for tamage done by him involumtarily. (Post. "Girmdriss," ii. 216, cf. Dareste, p. 64.) In China involuntary offences are punished, though on a reduerd scale. In the Japanese code of 1871 areidental injury to parents is heavily punished. (Post, ii. p. 21s.)

${ }^{2}$ Entirely, no doubt, under the influence of magiral idleas.

${ }^{3}$ For other instances, see Post, ii. 231.

" See Post, ii. 219, and, for the variation of custom under this head, Westermarck, "Moral Ideas," pp. 265-277. 
common to find that in political offences the family of the offender suffers with him. The principle of collective responsibility has alwars been maintained in the Far East, in China, ${ }^{1}$ in the Korea, and, under the influence of Chinese civilization, in Japan, while it is noteworthy that for political offences the parents and children might be punished under French law right down to the time of the Revolution. Parallels could be found in the laws of the ancient East, of ancient Persia, ${ }^{2}$ and of many states of mediaval Europe. It is, in fact, only the decay of the joint family system and the rise of the free individual as the basis of the modern State which definitely does away with this principle, so fundamentally irreconcilable with the strictly ethical notion of justice. An interesting transitional phase is to be found in the Old Testament, where the visiting of the sins of the fathers upon the children is very definitely laid down as a piece of Divine justice in the earlier legislation (I mean in the second Commandment), whereas in the time of Ezeliel it was strongly maintained to be an injustice that when the fathers had eaten sour grapes the children's teeth should be set on edge. It was, in fact, part of the ethical revolution introduced by the liter prophets to establish morally for the Jewish code the principle of individual responsibility. ${ }^{3}$

1 Post, ii. p. 226. With this is associated punishment for unintentional offences. (Ib., 217.) In Chirese law, arecidental parricide is still capital, though the older law appears to have been mitigated. A man who accidentally killed his mother in attempting to defend her, was senteneed to the lingering death, commuted by special decree to decapitation, subject to the Empress's pleasure. See, for various instances, Alabaster, p. $159 \mathrm{ff}$. A wife litling her husband unintentionally is sentenced to decapitation. (Ib., 192.) A misdeed which however indirectly caused the death of a senior relation is also punished, if the relative be a parent, by death. (Ib., 320 seq.) A senior relative is punishable for a junior's offence, even if he knows nothing of it. E.g. a father was sentenced to one hundred blows because (unknown to him) his son had abducted a girl. (Alabaster, p. 152.) A junior relation is still more heavily punishable for the offence of a senior. If a man murders four members of one family he suffers the lingering process, and his male children, irrespective of age, die with him in equal number to those murdered. In the case of Wang Chih-pin a child of ten was condemned to death for murders by his father. In another instance, the children were condemmed to be castrated, the father having killed three persons. ( $I b ., 164$.$) The motive is partly to$ punish the murderer's spirit by cutting off his male descendants, on whose offerings he depends in the new life. (Ib.,58.)

2 Post, ii. 227 .

${ }^{3}$ Ezek. xviii. 2; Jer. xxxi. 29. The result is embodied in Deut. xxiv. 16. "The fathers shall not be put to death for the children, neither shall the children lie put to death for the fathers: every man shall be put to death for his own sin." "The same transition is found in the law of the Visigoths. "Let not father" for son, nor" son for father, nor brother for brother fear any areusation, but he alone shall be indieted as culpable who shall have committed the fault." (Siutherland, "Origin and Growth of the Moral Instinet," ii. 1tis.) By salic law a man might eut himself off from his family, but then, of course, he also lost its protection. (Ib., 167.) 
7. With the evolution of social order, and in particular with the growth of central authority, the redress of wrongs begins to take the form of an independent and impartial administration of justice. Let us trace this growth in outline from its begimings.

The blood feud proper is revenge guided and limiterl by custom. It is not justice. It is waged by two conflicting parties, and there is no impartial third party to judge between them. But eren in barbaric society the blood feud does not rage wholly without check. The public opinion of the group is always a force to be reckoned with. Every man's rights and obligations are fixerl by custom. The very vengeance taken on those who infringe them is a custom, and directed in all its details by tradition. The headman or the elders of the clan or village are prepared to histen to complaints, to decide whether a wrong has been done, and, if so, what the reparation ought to be. The injured party may appeal to them if he pleases, and it may be that the aggressor will abide by their decision. If so, the affair is arranged perhaps by composition, perhaps by a stated penalty. Otherwise the parties will fight it out or it will come to a feud. In short, there is an effort on the part of the leading men to keep the peace and adjust the quarrel. Sometimes they will intervene of themselves if a feud becomes serious and threatens the general peace. ${ }^{1}$

The "court," if so it may be called, appears at this stage rather as peacemaker than judge. ${ }^{2}$ The disputants may ignore it, preferring to trust to their own strength and that of their friends. Yet it is from the first the avenger's interest to have pulblic opinion with him. He relies on the comtenance and practical help of his kindred and fellow-tribesmen. At least he must avert their opposition. If the facts are peculiarly flagrant the reighbours will be with him and he will have the less difficulty in executing vengeance. ${ }^{3}$ Perhaps eren the kindred of the wrong-doer will refuse to stand by him. Thus it becomes the interest of the avenger to make his case plain to the neighbours and they in

1 Thus among the Esquimanx, acoording to Reclus, muder was avenged? by the nearest relative. but if fresh retaliation ensued, soreral villagus intervened and the chief men pronounred sentence, otherwise public interrention was rery rare. ("Primitive Folk," p. s.).)

2 Thus among the Fondhs we read that socinty interemes to presont revenge by composition, "which has in view exclusivoly the private satisfaction of individuals, not the vindication of any civil or moral rules of right." Hence, notwithstanding this intervention, retaliation is generally. the sole remedy for wrongs of whatever order. (Macpherson, "Memorials of Service in India," p. SI.)

${ }^{3}$ There may he no trial and no set form of justice. lut merely, as amoner the Central Australians, a merting eombened by the dder men to earry out the act of vengeance. (See sipeneer and Gillen, ii. 5is6-56s.) 
turn wish to hear what the aceused party has to say. A palaver is held. The avenger comes with his kinsmen and friends. They state their case and annomce their intention of seeking revenge. 'The accused is also present, backed by his kin, and repels the demands made on him. It may be that the matter is settled between the groups concerned. It may be that the neighbours or the chief give sentence, but even so it does not follow that they enforce it. They may give the appellant their moral support, ${ }^{1}$ and leave it to him to obtain satisfaction as best he can. But of course their decision helps him to get the opinion of the tribe on his side, and their moral force will be translatable into physical force. It will mean so many more backers for him, and so many less for his opponents. This support may be disdained by the strong, but it will be valued by the weak, and will be upheld by those who desire intermal peace. Thus even under the clan and tribal organization of society some form of public intervention may arise alougside of private redress. Feuds are averted by the adjustment of disputes, or, if a wrong has been done, by getting the complainant to accept composition, and the aggressor to undergo some penalty which will be a mitigated form of revenge, or by bringing the two parties to fight it out under the regular forms of a duel.

Such methods of mitigating the blood feud are stimulated by the growth of the kingly power - that is to say, of an organized force outside the contendiug families or clans, which can summon them before its bar, decide their cause, and require them to keep the peace. The king, whose duty and interest it is to maintain public order, treats crime - or certain kinds of crime - no longer ats an oflence against the individual whom it primarily affects, but as a menace to public tranquillity, a breach of his "peace." 2

1 Thus among the North Ameriean Indians, the Ojibways and the Wyandots and other tribes have a council before which the avenger gets a judgment in his favour. He then demands compensation, and that failing, takes revenge. (Fohler, “Z. f. v. R.," 1897, p. 407.) So again in the Malay region eases come hofore the chief of the suku, or, if grave, hefore a gathering of chiefs, but the execution of the murderer falls to the nephew of the deceased. (IVaitz, v. i. 143.)

${ }^{2}$ Common in Germanic law. See, for England, Pollock and Waitland, ii. 451. The Kaffirs distinguish (1) offenees against the king, which consist in infringements upon his property or the number of his subjects. In these they include treason, soreery, murder, cruelty, rape, and abortion. (2) Offences against private people, which include adultery, immorality, theft, injury to a garden, etc. A similar distinction is found among the Kimbunda. (Post, "A. J.," ii. 54.) This is in effect a rudimentary distinction between civil and criminal justice, and shows at least one avenue of transition to the eonception of public crime. The notion of injury to an individual is applied to the king, but owing to the king's special relation to the community, the notion in being applied to him is 
This, if he is strong enough, he will punish directly ; if not sufficiently strong, he will deprive the offender of his protection, put him outside the king's peace, and compel him by fine to buy back what he has lost. Thus we find crime punishable by wite as well as by bôt - a fine to the ling side by side with compensation to the kinsfolk.

But from moral assistance the transition to physical assistance is not very difficult in idea, however slow and cumbrous it may have been in practice. 'There is more than one method of transition. Sometimes we find the public authority, the elders or the whole body of the neighbours, or later the regular magistrate exerting themselves to arrest the ofiender and handing him over to the arenger of blood for execution, or judging between the avenger of blood and the man-slayer, whose act was " mwitting." Thus in Deuteronomy, if the deliberate murderer flies to a city of refuge, "then the elders of his city" shall send and fetch him thence and deliver him into the hand of the avenger of blood that he may die." 1 But without taking an active part in the pursuit and capture of the offender the court had an effective weapon in the power of outlawry. Since in accordance with early ideas all personal rights depend upon membership of a society united for mutnal protection, it follows that the man excluded from the group is in the position of a stranger and an enemy; he is a wolf"s head, a wild animal whom the firsteomer may put to death at sight, with whom nobody may associate, to whom nobody may give food or lodging. Outlawry an therefore be applied either as a punishment or as a process - as a method of bringing the accused into court. What more reasonable than that if he will not submit to law he shall lose the protection of the law? With this weapon, potent in proportion as the social order is developed, the court of early law consolidistes its authority, and from being a casual institution of colmutary resort for those who wish the srmpathy of their neiglubours in avenging their wrongs, beeomes an established authority with compulsory powers before which either party can be simmoned to appear at the instance of his opponent.

unavoidably extended and modified. In fact, potentially it covers all antisocial action.

${ }_{1}$ Deut. xix. 12. So still in the priestly code, Numbers xxxy. 12-2,5. The Law of the Germanic peoples in the Frankish period, appears in a transitional stage. The Eastern Goths, Burgundians, Bararians, and Anglo-Saxons left execution to the complainant. The law of the Western Gotls excluded private exerution; the Salic law gave the complainant. the ohoice. (sichröler, p. 371.) 
s. But we are still a long way from a modern Court of Justice. The primary function of a court thus established is not so much to discover the merits of the case and make an equitable award, as to keep the peace and prevent the extension of wild and irregular blood feuds. What the court has to deal with is the fact that a feud exists. A cones before it with a complaint against $B$ of having killed his kinsman, or stolen his cattle, or carried off his daughter. Here is a feud which, in the absence of a court, A will prosecute with his own right-arm, and that of his kinsmen if he can get them to help him. B, again, will resist with the help of his kinsmen, and so there will be a vendetta. The court, whose primary object is to secure a settlement, does not go into nice questions as to the precise merits and demerits of $A$ and $B$, but it can prescribe certain tests whereby the appellant or the defendant may establish his case. It sets the litigant "a task that he must attempt. If he performs it, he has won his cause." 1 'The performance of this task is not, to our minds, proof of the justice of his cause. It is rather the compliance with a legal and orderly method of establishing a case, but at the stage we are considering it was probably regarded as satisfying justice, at least, as far as justice claimed to be satisfied.

What task, then, would the court award? It might be that the litigant should maintain his cause with his body. The parties would then have to fight it out in person or by their champions. Here we have the methor of the blood feud, but regularized, limited, and transformed into the judicial duel. Again, the court might put one or both parties to the oath. But this is not the oath of the modern Law Court - that is to say, it is not a solemn asseveration of the truth of certain evidence of fact, but an assertion of the general justice of the claim alleged, or of its injustice, as the case may be. And as the feud will not he waged by the individual claimant alone, but with the aid of all his kindred, so the court will expect the kindred to come and take the oath along with him. Hence the institution of oath-helpers, the compurgators, who are in point of fact the fellow-clansmen, all bound to the duty at this stage of swearing their friend out of the difficulty, just as before they were bound to leelp him ont of it by arms. The compurgators are simply the clansmen fighting with spiritual weapons instead of carnal ones. Success in the cause will depend not on the opinion formed by the court as to the veracity of one side or the perjury of the other, but on the ability of the parties to get the full number of

${ }^{1}$ Pollock and Maitland, ii. 602. 
compurgators required, on formal correctness in taking the oath, and if both parties fulfil all conditions and no further means are arailable for deciding between them, on certain rules as to the burden of proof. ${ }^{1}$

The provision of such further means of deciding between the parties is logically the next step. So far, the judicial process has appeared merely as a regularization of the blood feud, but both the oath and the judicial combat point the way to a ligher ideal. The court itself is not in a position to try the merits of the case unless it be some very simple matter of the criminal caught redhanded, but it may refer the decision to the Lnseen Powers, to the Gods, or to the magical qualities inherent in certain things. Thus the judicial duel, instead of being a mere carnal fight regularized and limited by certain rules, may be conceived rather as an appeal to the judgment of God, and the victory as His sentence which the court hesitates to pronounce on the basis of its merely human wisdom. Similarly the oath - though less than evidence as we conceive evidence - is also more, for it is an appeal to powers in which primitive man implicitly believes, to take vengeance on him who swears, if his cause be not just. Hence the form of the oath is everything, for the Cnknown powers are great sticklers for form. The oath-taker calls down their punishment on himself and his family by a set formula which they will rigidly ober. If in the formula he can leave himself any loophole of escape the oath is roid: it is no true summoning of the vengeful powers, and the court will disregard it, but if it is complete and sound in point of form, then there is no escape. One of two things must happen : either the oath was true or the curse will fall, and thus perjury brings its own punishment. ${ }^{2}$

Hence it is that for any given charge the law may call upon a man to purge himself by oath, or perhaps to purge himself along

1 Which oath prevailed in case of a conflict, would be decirled accorrling to the custom ruling the case. One party would be "nearer to the oath" than the other. For instance, where the eriminal is caught in the act, the oath of the prosecutor with his oath-helpers is conclusive proof and the offender has no opportunity of self-defence. (Schrödter. p. 363; cf. Pollock and Maitland, ii. 579.) In the Frankish period the complainant might also, if the eireumstances allowed, demand the ordeal: in other cases, with a few exceptions, the burclen of proof was on the opposite side. (Schröder, op. cit., pp. 363-366.) Where the oath is not decisive, the parties go to the duel or to the ordeal.

2 Thus the subsequent misfortune is taken as proof of perjury. and sometimes with a certain inconsisteney the serular arm is then called in to increase the penalty. Thus among the Kondhs of Orissa, and also among the Congo people, if the curse falls, the oath-taker is banished along with his family. (P'ost, ii. 493.) 
with a specified number of oath-helpers who will suffer with him if the oath is false, and the oath-helpers required may be increased according to the seriousness of the crime. If the oath fails the prescribed punishment follows. If it is duly taken, then either the accused was innocent, or he has inflicted the punishment entailed by the broken oath on himself and his oath-helpers.

But the consequences of a false oath were not immediately apparent. If the court wished to have the judgment of the Unseen Powers before it, some more summary process was necessary. This was found in the Ordeal, a test to which both parties could be submitted if necessary, and of which the results were immediate and manifest. Probably no institution is more universal at a certain stage of civilization than that of testing the truth or falsity of a case by a certain magico-religious process - the eating of a piece of bread, the handling of burning iron or boiling oil, jumping into water, walking through fire, exposure to wild beasts, and so forth. The details vary, though even in details resemblances crop up at the most remote periods and in the most remote places, but the general principle is still more clearly constant through the ages and the climes. Truth cannot at this stage be tested by human eridence. At most the criminal canght red-handed may be summarily dispatched upon the cridence of eye-witnesses given there and then, but the complicated civil or criminal processes of the civilized world imply an intellectual as well as a moral development which makes them impossible at an early stage. It is the gods who judge; the man who can handle hot iron is proved by hearen to be imnocent; the woman whom the holy river rejects is a witch; he whom the bread chokes is a perjurer. Nor are these tests wholly devoid of rational basis; it is not so difficult to understand that the guilty man would be more liable to choke than the innocent, not because bread is holy, but because his nerves are shaken. It is quite intelligible that in a credulous age the false oath would bring its curse in the form of a will paralyzed by terror, just as we know that amongst many savages witchcraft really kills through the sufferer's intense fear of it. Lastly, if the criminal may be ready to take his chances of the curse in preference to the certainties of the scaffold, he may find it difficult to get compurgators to stand by him, and in the face of their plain knowledge involve themselves in the same risk.

* $* * \quad * \quad * \quad * \quad * \quad *$ 


\section{Section 3}

\section{THE ORIGIN OF PUNISHMENT ${ }^{1}$}

The following discussion of the origin of punishment is undertaken with a view of obtaining some light on a difficult subject by means of the genetic method of approach. Our institutions are so complex and our tendency to idealize the existent is so inveterate that we are driven from one theory of punishment to another in the effort to justify what may, perhaps, have no real justification.

It is believed that a clear statement of the origin of punishment will throw some light on the nature of the punishing attitude. . . .

Punishment is nowhere regarded as a specific instinct. It is not a part of the "original nature of man." Its manifestations grow out of the instinct of pugnacity and its accompaniment, the emotion of anger. But even these instinctive reactions are not themselves simple and direct, but are, in their turn, dependent on the thwarting of other instincts and impulses. Fighting and anger are social in their nature, requiring for their arousal, the presence of another animal of the same or related species which enters into some sort of competition or opposition and attempts to check the carrying out of any one of the stronger impulses. ${ }^{2}$ Hunger, thirst, the desire for the possession of any object, or the sex instinet, can, most obviously, be the oceasion of the arousal of the fighting reaction if a sufficiently serious check is encountered.

But the fighting reaction is not punishment. There is a popular use of the word in which one prize-fighter is said to receive "punishment" from the other, and the "natural punishments" are referred to by Herbert spencer, but for such uses of the term there is only a metaphorical justification. Neither combat nor calamity is sufficiently social in character to deserve the designation of punishment.

The common statement is that punishment is derived from this feeling of anger and reaction of fighting in a direct fashion. MacDougall, ${ }^{3}$ for example, follows Laing in deriving the whole punitive situation from the "primal law" which is thought of as arising out of a situation within a small tribe of kinsmen in which

\footnotetext{
1 [By ElLsworth FARIs, Reprinted by permission, from the "International Journal of Ethirs," Vol. XXV, No. 1 (October, 191t).

a MacDougnll: "Soctal Psrchology, p. 59.

" "Soeial Psychology", p. 282.
} 
the patriarch, who wished to have control of the females of the group, drove off the younger males of the tribe as they grew up and forced those who remained to submit to his direction and control. The result of disregarding these directions waş, in every case, punishment by the patriarch, who might go to any length until submission was reached. In short, punishment is held to follow directly upon the opposition, by any one, to the operations of the sex instinct.

The same general notion appears in Pollock and Maitland, ${ }^{1}$ in which the original situation is described as one in which each member of the group was his own avenger, and the position defended, that pumishment follows directly upon the opposition of any member of the group to the serious purposes and plans of another. Naturally, the place for the origin of the institution of punishment will, accordingly, be found in the tribe. An eye for an eye and a tooth for a tooth is held to be the natural and normal way in which a member of the group answers the action of another in opposing his acts.

The analogy which suggested this theory is, as will be readily seen, the phenomena of struggle for leadership that occurs occasionally among gregarious animals. Rival candidates for the leadership of a herd of elephants have been observed to fight desperately, and the defeated one wanders off to lead a life of comparative solitude as a "rogue." But it is not difficult to see that such an effort to banish one member of the group is a very different sort of undertaking from the normal punitive situation. In fact, there is very little resemblance between a duel to the death and any normal procedure of punishment. In punishment there is an endeavor to be fair and just to which the old account does not do justice. There is, even in extreme punishments, a mental measurement of the offence with the penalty and some rough equation results. But in the "primal law" situation, there is only the deadly struggle betwcen infuriated and excited rivals.

There is abundant reason for questioning whether any one inside the primitive group was ever punished, at least by those within his own tribe. In an instinctive way the members of the group are bound together and in the most homogeneous groups they do not punish each other. Present-day people of some 1 "History of the English Law.". 
uncivilized tribes do not punish their children. The writer, during a residence of severil years among the Bantus of the upper Congo river, in which time the people were under constant observation, failed to observe a single case of the punishment of a child. This is not a deliberate or reflective process, but rather an instinctive and uncritical one. The child in a small community that is homogeneous and in a situation where outside influences do not penetrate, will find himself fitting in to the social situation where he grows up and is without the stimulus to commit acts of an anti-social character.

And when, by any chance, such an aet is committed, it is highly improbable that it will arouse any resentment whaterer; in the event that it does, there is no remedy, and the tribe simply does nothing save where the ofience is so serious as to break all botnds. The situation is analogous to that in which one breaks or damages his own property by accident; it is regrettable, but there is no remedy save an imprecation. It is impossible for some people to thrust a knife into their own flesh for, in some way, the weapon refuses to enter. The primitive tribe is a unit in just as real a sense. Every member is to be credited with the good deeds of the whole and to be blamed to the faults of any one. Expulsion from the tribe in extreme cases might take place.

The Congo State government in the old days was never at a loss in the effort to apprehend criminals, for while the direct pursuit of a native in the forest would be like trying to orertake an antelope, such a chase is quite umnecessary. The tribe is a unit to such an extent that it is only necessary to send to the rillage for the chief, whose dignity will not permit him to flee in any ordinary emergency, and to cause the arrest and detention of this chief, if necessary, after which the man who is wanted always comes in voluntarily and surrenders. The only alternative to doing so would be to leave the country entirely; for existence would be unbearable with the hear of the tribe in bondage on account of the offending member's failure to give himself up.

The point in this connection is that phrsical force is not the means of securing this supreme degree of sociality which will lead a man to give himself up to a fate that is desperate in the extreme. The earlier theories on this point are probably erroneous. The typical group control did not depend on force. The fact that the military leader of a war-like people was often, perhaps usually, a man of great strength, has led to the totally unwarranted inference that the rule was to the one who was physically the strongest. 
The savage is rery ready to admire physical strength, but the leadership of one who is physically strong will not depend on this fact entirely or chiefly. He who rules must do so on account of some measure of wistom in ruling and on account of the support he has from the loyalty of the rest of the wroup. Achilles is the greatest warrior among the besiegers, but the leadership lies not with him who sulks in his tent or who is indifferent to the death of his own people in unequal strife. Those who have assigned the dominant part in early group control to force, physically understood, have failed to understand that the sneer and scorn of those within our own group are infinitely more powerful forces.

An incident personally observed on the Ipper Congo river illustrates quite adequately the part played by public opinion in group control. A gigantic young warrior, under the influence of foreign and alien ideas, which were beginning to appear in the community following the European occupation, violated some minor point in the native system of taboos and was quite unrepentant when attention was called to it. The matter came to the attention of the oldest woman of the tribe who set out at once in indignation to find him. He hurried off to his hut, but she followed him to the very door, uttering all the while a stream of indignant protest to which the man vainly attempted to respond, but without opportunity of interrupting the unbroken course of her invective. He went into his hut and she crouched at the door; he retreated into the inner room, but she only raised her voice. The encl of the unequal contest was reached when he came to the door, hesitaterl a moment, and then ran off into the forest, leaving the field to the victor. But the victor was a woman nearly a hundred years old, gray-haired, toothless, shrunken and lean, so frail that a blow from the fist of the warrior would have crushed her skull. She was the incarnation of public opinion and there was more power in her voice than in his muscle. Nor would it be just to say that it was his fear of the consequences which restrained him from resorting to force to rid himself of the troublesome adversary. The fact is that the force of the expressed common will is so strong that it does not oecur to the individual to contest it. Obedience is unreflective and almost instinctive. For just as the parental instinct urges the mother to care for her chilel, so the child's instinct impels him to respond to the mother. And there is no need to explain why the child obers the mother, the phenomenon requiring explanation being the failure on the part of the child to respond, when this does occur. 
It seems clear to the writer that the explanation of the tension and friction in modern groups, including family groups, is most easily found in the complexity of the groups in which modern children grow up. An analogy to the primitive simplicity of conduct is to be found in the absence of errors in the speech of primitive children. If a language is pure and has no foreign idioms and if the children are not in the company of those who speak other languages or dialects, then it is probable that they will make no errors in grammar. MY own observations confirm this conclusion. During my residence among the Congo tribes no child was ever heard by me to make a mistake in grammar. The influences are all homogeneous, the stimuli are all consistent, and there is no occasion for an crroneous reaction in the matter of the rocal gesture called language. The language is almost perfect in its regularity. The real phenomenon that demands explanation is that a mistake should be made at all, for the normal method of response will be to adopt the conventional words if these are received from a consistent source.

It is confidently believed that a careful report of the facts and conditions among present-day savages would establish the nonexistence of the punishment of children among many of them. ${ }^{1}$ V. Stefansson says: "We count it as one of the chief triumphs of the four-year expedition of the American Museum of Natural History to the Eskimo that we discosered why it is that children are not punished; for such immaterial things is the money of scientific institutions expended!" 2 He then gives the two previous explanations that have been assigned, namely, that the children are so good that they do not need it, and secondly, that the Eskimos are so fond of their children that they cannot hear to punish them. Both of these explanations are rejected in firvor of the theory that the belief of the natives that every child is the reincarnation of the spirit of an lonored ancestor is the real explanation of the forbearance of the parents under circumstances which the white man often found very trying. Whether this explanation points out the real cause of the phenomenon or whether it was a theoretical formulation which grew up to aceomt for the practice and to justify it, is not important for this aliscussion. The main thing to observe is that there is no punishment of children among these people. With the coming of the white man, the group will be more and more subject to ontside influences and

1 [See "The Point Barrow Eshimo," Vol. I, p., 24ts.]

2 I. Stefatsson, "My Life with the Eskimo." p. 39.). 
there will be increasing opportunities for tension; but during the ages when they were living their own life, there was no thought of punishing the children.

Stefansson also deals at length with the subject of the immense power of publie opinion in the Eskimo society. Resort to force is so rare as to be almost negligible. They are a unit, rule is not by force, though there is always a leader. The authority of the leader depends, however, not on his strength, but on the extent of his influence with the larger group. ${ }^{1}$

Absence of punishment is also the characteristic of the Japanese system of governing ehildren. President Sato of Sapporo College in a conversation with the writer, says that the Japanese do not punish their children even yet, although the foreign influences are very pronounced at the present time in Japan. But for a long time, the sistem was homogeneous and unified and the momentum of it endures till the present. It is true that President Sato considers that the Japanese are too indulgent with their children and that they should exercise more careful control over them, but the fact of the absence of a system of physical punishments for ehildren is highly significant.

The solidarity of the truly primitive group in this respect can, therefore, hardly be overstated. There is no remedy for an infraction of eustom by a member of a group. No physical force is used or ean be used. The whole of the remedy is rocal disapproval, reproach, and scorn. But for reasons that will later appear in this discussion, it is contended that scorn and ridicule are the most powerful weapons that are available in the service of conformity. ${ }^{2}$

This much is, therefore, clear from the discussion so far. Punishment could not have arisen within the early group owing to the absolutely social character of their early organization and the absence of physical force from their methods of dealing with each other. It is recognized that offences might oceur and did sometimes occur which would be so serious as to dissolve the bonds entirely, but as will be seen, such a situation was met by a mode of reaction that is not properly ealled punishment.

How, then, did punishment arise? If it did not begin inside the group in some sort of formal infliction of penalty or violence

${ }^{1}$ Op. eit., p. 305 .

2 The Roman Assembly of the Tribes could not inflict death, only a fine, for the life of a Roman was sacred inside the walls. (Maine, "Anrient Law": 375.) But the military court could inflict the death penalty. 
of force, did it originate in the reactions against the enemies of the tribe? This question will now be considered.

\section{II}

The really primitive group, we have seen, was probably bound together by ties of an instinctive nature which made it impossible to proceed in any way against one of the number for an offence that should work injury to the offender. The opposing theory finds the origin of punishment in the wars with the enemies of the tribes. Westermarck thinks that the instinct of resentment, in most cases "srmpathethic resentment," but alway's some strong emotional state of mind, is the key to the understanding of the punishing reactions. Hobhouse finds a cognitive basis for the origin of punishment in the concepts that are formed when the evil effect of the offence is observed. ${ }^{1}$ Steinmetz traces it to the expansion of personality that follows the retaliation against an affront.

But it seems quite unnecessary to go beyond the simple, inherited reaction of all gregarious animals of the carnivorous type, all females with young, and even insects of the social kind, as bees and wasps. There is a natural, inherited reaction, of defence against the attack of a stranger or an enemy. The sarage fights anyone from the outside who has attacked his child or his brother or his father or any of his kindred or clan, and does so just as a hive of bees or a nest of hornets responds to a disturbance of a hostile nature. The reaction is not lue to reflection, does not arise out of concepts of justice or right or property, and is not due to any antecedent feeling. The beginning of the whole process is this reaction of a protective eharacter absolutely essential to the preservation of the group, which takes into account only the dangerous character of the enemy and the need of securing his annihilation.

The fixed character of the primitive group is one of its most striking characteristics. In seneral, it is almost true that the only way to become a member of the group is to arrange to be born into it. There is, to be sure, a natural tendency toward the enlargement of the social group, but for the primitive man, (xen the nature peoples of the present day, it is of ten true that the whole world is divided into just two dasses, namely: kin who cammot

${ }^{1}$ [See the next preceding Section of this Chapter for the riews of Hobhouse.] 
become enemies, and enemies who can never become lin. The former are never liable to punishment for reasons shown, and the latter are equally exempt from mumishment because they are the olject of attack in war.

The attack on an encmy or a stranger who oflends is often made when the dictates of prudence or self-interest would make another course of action desirable, but the tribe is without any other alternative. Just as a rattlesnake exhausts his venom in futile strikes and is captured with impunity, so many a native tribe would have been able to maintain itself and get ahead, if it had been able to take a cool and rational attitude toward attacks, but this is not possible. The attack is made because there is nothing else to do.

Just what punishment is will presently appear, but it is evident that an attack which ceases only with amnihilation of the enemy, which is without any relation to the nature or gravity of the offence committed, and which is directed towards those who are thought of in the most abstract way as enemies, is not ret the sort of reaction that we eall punishment. It may be called a war, a fend, a vendetta, or a foray, but the disregard of consequences, the lack of measure or restraint, the wholly impersonal relation that is assumed, marks the phenomenon off from true punishment.

The literature of feuds and the vicarious infliction of suffering on the innocent members of the group is very complete, but the following personally observed circumstance will bring out the facts that it is desired to emphasize in this connection. A native woman of the Lpper Congo secured the remission of the parment of dowry and returned in a perfectly regular and legal manner to her father, but passed with unseemly haste to the home of the co-respondent. The deserted husband, in a fit of jealousy, came from his tistant village with a party, and proceeded in the darkness to fire the hut in which the couple was sleeping, but, as it was afterwards explained, included some near-by huts because the huts of the enemy were not very well built. The next morning saw a counter foray into the villages of the house-burners, but this attack was directerl against a remote portion of the enemy's rillage in order that they might be taken by surprise as the news of the affair had not spread. Accorlingly, an approach was made and a volley fired at close range, killing a man and a woman who did not know that there was any trouble between the two communities. After this, slaughter went on merrily for several months.

Now it is significant for this discussion to note that the group has no censure for those who are the occasion for trouble of this 
kind. The woman whose action causer the death of several of her tribe is not reproached, even hy those who are the heaviest losers in the fighting. The actions of the quarrelsome members of the tribe, in so far as they affect outsilers, are accepted unquestionably and the whole tribe joins in the natural, normal, and often joyously exciting reaction called out by the instinct of pugnacity. Nor is there any blame for the enemy. He is conceived as doing his part. He is not supposed to take into account the interest of a group other than his own; he is thought of in the most abstract fashion as a target and source of danger, game and hunter in one, and with nothing even resembling a fellow-feeling.

There was a little Congo lad who owned a chicken which one day appeared with only one leg because the boy felt olbliged to practice economy by eating one lew and letting the rest of the fowl wait! This killing on the installment plan is hardly to be thought of as cruelty, but is due to the fact that the fowl is riewed from the point of view of food alone. The lad would as soon have thought of showing merey to a potato or a mango, as to a chicken; for mercy and consideration belong to the members of your own family and are unthinkable in any other situation. The camuibal tribes, which are not the lowest but represent the highest development among the peoples of the Congo valley, often stick the living victim full of bamboo skewers to preempt portions of the meat before the slaughter!

A social attitule toward a member of another group is, therefore, unthinkable. A snake, a leopard, a slaughtered sheep, or a crushed worm is not more abstractly treated. It is felt that an attitude of this sort cannot by any stretch of meaning be taken to include punishment.

The conclusion is, therefore, that there is no punishment of any one in a thoroughly primitive society. The whole universe is divided into two classes for the theoretically primitive savage, and these are the members of his own gromp whom he does not ever think of striking or punishing in any way, and the rest of the world who are to be watched carefully at all times but who are to be destroyed if they are foumd in an attitule of attack.

A thoroughly analogous situation is foumd in the attiture of civilized nations in their international relationships. The citizens of a foreign country, so long as they remain on their own territory, are not subject to punishment by any other nation whose citizens may have suffered injury. If an expedition is marle aleross the border and damage is done the goods and persons of another 
nation, there is no punishment by the nation that receives the injury. Any attempt at redress by a foreign nation inside our territory is war. There are only two courses open to an offended people in such a case. They ean send an attacking force across the border to arenge the wrong, but this is not punishment, it is war. "The only other course open to the injured government is to appeal in a friendly way for the govermment of the offenders to take cognizance of the offence and do justice. But clearly here the injured nation is not punishing anyone. They may appeal to another to punish, but this appeal is a friendly and social act. Punishment must, therefore, be administered by the group to which the offender belongs. But we have seen that when the group is homogeneous, it is impossible for the category of punishment to have any place. There are groups organized within civilized society which are so thoroughly social that there is no thought of punishment within the circle, as for example, a college faculty or a social elub.

\section{III}

For a situation which would make the attitude of formal punishment possible, we must have a soeiety that has grown so complex that there are varying degrees of relationship and of fellowfeeling. This is, to be sure, the natural result of a prosperous community for, as populations multiply and migrations are rendered necessary by part of the company in order to find more room, it is inevitable that some distant tribes should also be distant kin and the reaction of enmity would tend to become modified. Indignation would be present, but it would be tempered by other feelings, in ease an offence should be committed. The presence of slavery as an institution is also one of the early manifestations of complexity. Exogamous marriages also imply alliances with otherwise hostile tribes and these alliances are often of the most serious and binding nature. Also there are numerous temporary alliances for barter and for protection.

In such a complex situation it would be a rare ease in which an offender would not have some friends within the very group that is concerned. Should two slaves, for example, have a serious quarrel, there might be nothing in the way of a battle to the death if they were of different tribes. But the owner of the two would naturally wish to save his property. In case of a federation of villages, the leaders would naturally be in favor of an amicable settlement of feuds between constituent members of the larger 
organization. There will be those in such a complex group who would wish to see the offender destroyed, that is, they would take the part of an enemy. There would also be those who would wish to have him escape entirely and who would, therefore, defend his cause. And there is necessary in any real punitive situation an impartial umpire who has interests on both siles.

Here, then, is the solution to the problem of the origin of punishment. So long as there are just two groups in the social world of the savage, no punishment could take place, but when there are three or more groups in his world, the attitude of formal punishment becomes a natural one. There is the group to which the offender belongs, the group which he has attacked, and a third which is relatively neutral and has interests in both.

Our institutions of punitive justice exhibit this phenomenon quite accurately. The criminal is the expression of a group and is normally quite loyal to the group ideals and the code of his clan. This group is represented before the bar by comsel, appointed, if necessary, by the state itself, and the counsel for the defence is interested in making such a showing in the trial of the cause that the rights of the defendant will be fully protected.

There is also the group which the prisoner has attacked, represented by the prosecuting attorney whose sole task it is to paint the offence in the blackest colors, or, in other words, to represent his enemies and to destroy him, if possible. The fact that he is said in our legal procedure to represent the "people" should not blind us to the fact that there is also a third group necessary in the situation, represented by the judge and the jury. These stand for the great body of those who are not directly concerned and who are, in reality, attempting to arrange the conflicting claims. The jury is supposed to have no interest in the case and preferably. to have no knowledge of the matter, to be, therefore, wholly disinterested and of another social group entirely.

According to this diseussion, punishment is a practice that has arisen out of group activity and owes none of its origin to private vengeance or the rule of force within the group. Pumishment is the expression of the chashing of groups; with a "buffer-group" to lessen the shock. It is a phenomenon of social psychology and can only be approached intelligently from the social point of view. 


\section{Chapter VII}

\section{THE FORMS OF LAW ${ }^{1}$}

The most celebrated system of jurisprudence known to the world begins, as it ends, with a Code. From the commencement to the close of its history, the expositors of Roman Law consistently employed language which implied that the body of their system rested on the 'Twelve Decemviral Tables, and therefore on a basis of written law. Except in one particular, no institutions anterior to the Twelve Tables were recognised at Rome. The theoretical descent of Roman jurisprudence from a code, the theoretical ascription of English law to immemorial unwritten tradition, were the chief reasons why the development of their system differed from the development of ours. Neither theory corresponded exactly with the facts, but each produced consequences of the utmost importance.

I need hardly say that the publication of the Twelve Tables is not the earliest point at which we can take up the history of law. The ancient Roman code belongs to a class of which almost every civilised nation in the world can show a sample, and which, so far as the Roman and Hellenic worlds were concerned, were largely diffused over them at epochs not widely distant from one another. They appeared under exceedingly similar circumstances, and were produced, to our knowledge, by very similar causes, Unquestionably, many jural phenomena lie behind these codes and preceded them in point of time. Not a few documentary records exist which profess to give us information concerning the early phenomena of law; but, until philology has effected a complete analysis of the Sanskrit literature, our best sources of knowledge are undoubtedly the Greek Homeric poems, considered of course not as a history of actual occurrences, but as a description, not wholly idealised, of a state of society known to the writer. However the fancy of the poet may have exaggerated certain

${ }^{1}$ [By Sir Henry S. Maine. Reprinted from "Ancient Law," by permission of Henry Holt and Company, New York.] 
features of the heroic age, the prowess of warriors and the potency of gods, there is no reason to believe that it has tampered with moral or metaphysical conceptions which were not yet the subjects of conscious observation; and in this respect the Homeric literature is far more trustworthy than those relatively later documents which pretend to give an account of times similarly early, but which were compiled under philosophical or theological influences.

If by any means we can determine the early forms of jural conceptions, they will be invaluable to us. These rudimentary ideas are to the jurist what the primary crusts of the carth are to the geologist. They contain, potentially, all the forms in which law has subsequently exhibited itself. The haste or the prejudice which has generally refused them all but the most superficial examination, must bear the blame of the unsatisfactory condition in which we find the science of jurisprudence. The inquiries of the jurist are in truth prosecuted much as inquiry in physics and physiology was prosecuted before observation had taken the place of assumption. Theories, plausible and comprehensive, but absolutely unverified, such as the Law of Nature or the Social Compact, enjoy a universal preference over sober research into the primitive history of society and law; and they obscure the truth not only by diverting attention from the only quarter in which it can be found, but by that most real and most important influence which, when once entertained and believed in, they are enabled to exercise on the later stages of jurisprudence.

The earliest notions connected with the conception, now so fully dereloped, of a law or rule of life, are those contained in the Homeric words "Themis" and "Themistes." "Themis," it is well known, appears in the later Greek pantheon as the Gordess of Justice, but this is a modern and much developed idea, and it is in a very different sense that Themis is described in the Iliad as the assessor of Zeus. It is now clearly seen by all trustworthy observers of the primitive condition of mankind that, in the infancy of the race, men could only account for sustained or periodically recurring action by supposing a personal agent. Thus, the wind blowing was a person and of course a divine person; the sun rising, culminating, and setting was a person and a divine person ; the earth yielding her increase was a person and divine. As, then, in the phrsical world, so in the moral. When a king decided a dispute by a sentence. the judgment was assumed to be 
the result of direct inspiration. The divine agent, suggesting judicial awards to kings or to gods, the greatest of kings, was Themis. The peculiarity of the conception is brought out by the use of the plural. Themistes, Themises, the plural of Themis, are the awards themselves, divinely dictated to the judge. Kings are spoken of as if they had a store of "Themistes" ready to hand for use; but it must be distinctly understood that they are not laws, but judgments, or, to take the exact Teutonic equivalent, "Jooms." " "\%eus, or the human king on earth," say's Mr. Grote, in his "History of Greece," "is not a law-maker, but a judge." He is provided with Themistes, but, consistently with the belief in their emanation from above, they cannot be supposed to be connected by any thread of principle; they are separate, isolated judgments.

Even in the Ilomeric poems we can see that these ideas are transicnt. Parities of circumstance were probably commoner in the simple mechanism of ancient society than they are now, and in the succession of similar cases awards are likely to follow and resemble each other. Here we have the germ or rudiment of a custom, a conception posterior to that of Themistes or judgments. However strongly we, with our modern associations, may be inclined to lay down à priori that the notion of a Custom must precede that of a judicial sentence, and that a judgment must affirm a custom or punish its breach, it seems quite certain that the historical order of the ideas is that in which I have placed them. The Homeric word for a custom in the embryo is sometimes "Themis" in the singular - more often "Dike," the meaning of which visibly fluctuates between a "judgment" and a "custom" or "usage." Nómos, a Law, so great and famous a term in the political vocabulary of the later Greek society, does not occur in Homer.

This notion of a divine agency, suggesting the Themistes, and itself impersonated in Themis, must be kept apart from other primitive beliefs with which a superficial inquirer might confound it. The conception of the Deity dictating an entire code or body of law, as in the case of the IIndoo laws of Manu, seems to belong to a range of ideas more recent and more advanced. "Themis" and "Themistes" are much less remotely linked with that persuasion which (lung so long and so tenaciousls to the human mind, of a divine influence underlying and supporting every relation of life, every social institution. In carly law, and amid the rudiments of political thought, symptoms of this belief meet us on all sides. A supernatural presidency is supposed to consecrate and 
keep together all the cardinal institutions of those times, the State, the Race, and the Family. Men, grouped together in the different relations which those institutions imply, are bound to celebrate periodically common rites and to offer common sacrifices; and every now and then the same duty is even more simnificantly recognised in the purifications and expiations which they perform, and which appear intended to deprecate punishment for involuntary or neglectful disrespeet. Everrbody acquainted with ordinary classical literature will remember the sacra gentilicia which exercised so important an influence on the early Roman law of adoption and of wills. And to this hour the Hindoo Customary Law, in which some of the most curious features of primitive society are stereotyped, makes almost all the rights of persons and all the rules of succession hinge on the due solemnisation of fixed ceremonies at the dead man's funeral, that is, at every point where a breach occurs in the continuity of the family.

Before we quit this stage of jurisprudence, a caution may be usefully given to the English student. Bentham, in his "Fragment on Government," and Austin, in his "Province of Jurisprudence Determined," resolve every law into a command of the lawgiver, an obligation imposed thereby on the eitizen, and a sanction threatened in the erent of disobedience; and it is further predicated of the command, which is the first element in a law, that it must prescribe, not a single act, but a series or number of acts of the same class or kind. The results of this separation of ingredients tally exactly with the facts of mature jurisprudence; and, by a little straining of language, they may be made to correspond in form with all law, of all kinds, at all epochs. It is not, however, asserted that the notion of law entertained by the generality is even now quite in conformity with this dissection; and it is curious that, the farther we penetrate into the primitive history of thought, the farther we find ourselves from a conception of law which at all resembles a compound of the elements which Bentham determined. It is certain that, in the infancy of mankind, no sort of legislature, nor even a distinet author of law, is contemplated or conceived of. Law has scarcely reached the footing of custom; it is rather a liabit. It is, to use a French phrase, "in the air." The only authoritative statement of right and wrong is a judicial sentence after the facts, not one presupposing a law which has been violated, but one which is breathed for the first time by a higher power into the judge's mind at the moment of adjudication. It is of course extremely diffieult for us to realise 
a view so far removed from us in point both of time and of association, but it will become more credible when we dwell more at length on the constitution of ancient societr, in which every man, living during the greater part of his life under the patriarchal despotism, was practically controlled in all his actions by a regimen not of law but of caprice. I may add that an Englishman should be better able than a foreigner to appreciate the historical fact that the "Themistes" preceded any conception of law, because, amid the many inconsistent theories which prevail concerning the character of English jurisprudence, the most popular, or at all events the one which most affects practice, is certainly a theory which assumes that adjudged cases and precedents exist antecedently to rules, principles, and distinctions. The "Themistes" have too, it should be remarked, the characteristic which, in the view of Bentham and Austin, distinguishes single or mere commands from laws. A true law enjoins on all the citizens indifferently a number of acts similar in class or kind; and this is exactly the feature of a law which has most deeply impressed itself on the popular mind, causing the term "law" to be applied to mere uniformities, successions, and similitudes. A command prescribes only a single act, and it is to commands, therefore, that "Themistes" are more akin than to laws. 'They are simply adjudications on insulated states of fact, and do not necessarily follow each other in any orderly secpuence.

The literature of the heroic age discloses to us law in the germ under the "Themistes" and a little more developed in the conception of "Dike." The next stage which we reach in the history of jurisprudence is strongly marked and surrounded by the utmost interest. Mr. Grote, in the second part and ninth chapter of his History, has fully described the mode in which society gradually clothed itself with a different character from that delineated by Homer. Heroic kingship depended partly on divinely given prerogative, and partly on the possession of supereminent strength, courage, and wistom. Gradually, as the impression of the monarch's sacredness became weakened, and feeble members occurred in the series of hereditary kings, the royal power decayed, and at last gave way to the dominion of aristocracies. If language so precise can be used of the revolution, we might say that the office of the king was usurped by that council of chiefs which Homer repeatedly alludes to and depicts. At all events from an epoch of kingly rule we come evcrywhere in Europe to an era of oligarchies; and even where 
the name of the monarchieal functions does not absolutely disappear, the authority of the ling is reduced to a mere shadow. He becomes a mere hereditary general, as in Lacediemon, a mere functionary, as the King Archon at Athens, or a mere formal hierophant, like the Rex Sacrificulus at Rome. In Greece, Italy, and Asia Minor, the dominant orders seem to have universally consisted of a number of families united by an assumed relationship in blood, and, though they all appear at first to have laid claim to a quasi-sacred character, their strength does not seem to have resided in their pretended sanctity. Inless they were prematurely overthrown by the popular party, they all ultimately approached very closely to what we should now understand by a political aristocracy. The changes which society underwent in the communities of the further Asia occurred of course at periods long anterior in point of time to these revolutions of the Italian and Hellenic worlds; but their relative place in civilisation appears to have been the same, and they seem to have becn exceedingly similar in general charaeter. There is some evidence that the races which were subsequently' united under the Persian monarchy, and those which peopled the peninsula of India, had all their heroic age and their era of aristoeracies; but a military and a religious oligarchy appear to have grown up separately, nor was the authority of the king generally superseded. Contrary, too, to the course of events in the West, the religious element in the East tended to get the better of the military and political. Military and eivil aristocracies disappear, annihilated or crushed into insignifieance between the kings and the sacerdotal order; and the ultimate result at which we arrive is, a monareh enjoying great power, but circumscribed by the privileges of a easte of priests. With these differences, however, that in the East aristocracies became religious, in the West civil or political, the proposition that a historical era of aristocracies succeeded a historieal era of heroie kings may be considered as true, if not of all mankind, at all events of all branches of the Indo-European family of nations.

The important point for the jurist is that these aristoeracies were universally the depositaries and administrators of law. They seem to have suceeded to the prerogatives of the king, with the important difference, however, that they do not appear to have pretended to direct inspiration for each sentence. The eonnection of ideas which caused the judgments of the patriarchal chieftain to be attributed to superhuman dictation still shows itself here and there in the claim of a divine origin for the entire body of 
rules, or for certain parts of it, but the progress of thought no longer permits the solution of particular disputes to be explained by supposing an extra-human interposition. What the juristical oligarehy now claims is to menopolise the knouledge of the laws, to have the exchusire pessession of the principles by which quarrels are decided. We have in fact arrived at the epoch of Customary Law. Customs or Observances now exist as a substantive aggregate, and are assumed to be precisely known to the aristocratic order or caste. Our authorities leave us no doubt that the trust lodged with the oligarchy was sometimes abused, but it certainly ought not to be regarded as a mere usurpation or engine of tyranny. Before the invention of writing, and luring the infancy of the art, an aristocrate invested with judieial privileges formed the only expedient by which accurate preservation of the customs of the race $c^{r}$ tribe could be at all approximated to. Their genuineness Was, so far as possible, insured by conficling them to the recollection of a limited portion of the community.

The epoch of Customary Law, and of its custody by a privileged order, is a very remarkable onc. The condition of jurisprudence which it implies has left traces which may still be detected in legal and popular phraseology. The law, thus known exclusively to a privileged minority, whether a caste, an aristocracy, a priestly tribe, or a sacerdotal college, is true unwritten law. Except this, there is no such thing as unwritten law in the worle. English case-law is sometimes spoken of as unwritten, and there are some English theorists who assure us that if a corle of English jurisprudence were prepared we should be turning unwritten law into written - a conversion, as they insist, if not of doubtful policy, at all events of the greatest serionsness. Now, it is quite true that there was once a period at which the English common law might reasonably have been termed unwritten. The elder English jurlges did really pretend to knowledge of rules, principles, and distinctions which were not entirely revealed to the bar and to the lay-public. Whether all the law which they claimed to monopolise was really unwritten, is exceedingly questionable; but at all events, on the assumption that there was once a large mass of (ivil and criminal rules known exclusively to the judges, it presently ceased to be unwritten law. As soon as the Courts at Westminster Iall began to base their judgments on cases recorded, whether in the year-hooks or elsewhere, the law which they administered became written law. At the present moment a rule of English law has first to be disentangled from the recorded 
facts of adjudged printed precedents, then thrown into a form of words varying with the taste, precision, and knowledge of the particular judge, and then applied to the circumstances of the case for adjudication. But at no stage of this process has it any characteristic which distinguishes it from written law. It is written case-law, and only different from corle-law because it is written in a different way.

From the period of Customary Law we come to another sharply defined epoch in the history of jurisprudence. We arrive at the era of Codes, those ancient codes of which the Twelve Tables of Rome were the most famous specimen. In Greece, in Italy, on the Hellenised sea-board of Western Asia, these codes all made their appearance at periods much the same everywere, not, I mean, at periods identical in point of time, but similar in point of the relative progress of each community. Everrwhere, in the countries I have named, laws engraven on tablets and published to the people take the place of usages deposited with the recollection of a privileged oligarchy. It must not for a moment be supposed that the refined considerations now urged in favour of what is called codification had any part or place in the change I have described. The ancient codes were doubtless originally suggested by the discovery and diffusion of the art of writing. It is true that the aristocracies seem to have abused their monopoly of legal knowledge; and at all events their exchusive possession of the law was a formidable impediment to the success of those popular movements which began to be universal in the western world. But, though democratic sentiment may have added to their popularity, the codes were certainly in the main a direct result of the invention of writing. Inscribed tablets were seen to be a better depository of law, and a better security for its accurate preservation, than the memory of a number of persons however strengthened by habitual exercise.

The Roman code belong; to the dass of codes I have been describing. 'Their value did not consist in any approach to simmetrical classification, or to terseness and clearncss of expression, but in their publicity, and in the knowledge which they furnished to everybody, as to what he was to do, and what not to do. It is, indeed, true that the 'Twelve 'lahles of liome do exhibit some traces of systematic arrangement, hut this is probably explained by the tradition that the framers of that hody of law callerl in the assistance of Greeks who enjoyed the later Greck experience in the art of law-making. The fragments of the Attic code of Solon 
show, however, that it had but little order, and probably the laws of Draco had even less. Quite enough too remains of these collections, both in the East and in the West, to show that they mingled up religious, civil, and merely moral ordinances, without any regard to differences in their essential character; and this is consistent with all we know of early thought from other sources, the severance of law from morality, and of religion from law, belonging very distinctly to the later stages of mental progress.

But, whatever to a modern eye are the singularities of these codes, their importance to ancient societies was unspeakable. The question - and it was one which affected the whole future of each community - was not so much whether there should be a code at all, for the majority of ancient societies seem to have obtained them sooner or later, and, but for the great interruption in the history of jurisprudence created by feudalism, it is likely that all modern law would be distinctly traceable to one or more of these fountain-heads. But the point on which turned the history of the race was, at what period, at what stage of their social progress, they should have their laws put into writing. In the Western world the plebeian or popular element in each State successfully assailed the oligarchical monopoly, and a code was nearly universally obtained early in the history of the Commonwealth. But, in the East, as I have before mentioned, the ruling aristocracies tended to become religious rather than military or political, and gained, therefore, rather than lost in power; while in some instances the physical conformation of Asiatic countries had the effect of making individual communities larger and more numerous than in the West; and it is a known social law that the larger the space over which a particular set of institutions is diffused, the greater is its tenacity and vitality. From whatever cause, the codes obtained by Eastern societies were obtained, relatively, much later than by Western, and wore a very different character. The religions oligarchies of Asia, either for their own guidance, or for the relief of their memory, or for the instruction of their disciples, seem in all cases to have ultimately embodied their legal learning in a cole; but the opportunity of increasing and consolidating their influence was probably too tempting to be resisted. Their complete monopoly of legal knowledge appears to have enabled them to put off" on the world collections, not so much of the rules actually observed as of the rules which the priestly order considered proper to be observed. The Hindoo Code, called the Laws of Manu, which is certainly a Brahmin compilation, un- 
doubtedly enshrines many genuine observances of the Hindoo race, but the opinion of the best contemporary orientalists is, that it does not, as a whole, represent a set of rules ever actually administered in Hindostan. It is, in great part, an ideal picture of that which, in the view of the Brahmins, ought to be the law. It is consistent with human nature and with the special motives of their authors, that codes like that of Manu should pretend to the highest anticuity and claim to have emanated in their complete form from the Deity. Manu, according to Iindoo mythology, is an emanation from the supreme God: but the compilation which bears his name, though its exact date is not easily discovered, is, in point of the relative progress of Hindoo jurisprudence, a recent production.

Among the chief advantages which the Twelve Tables and similar codes conferred on the societies which obtained them, was the protection which they afforded against the frauds of the privileged oligarchy and also against the spontaneous depravation and debasement of the national institutions. The Roman Code was merely an enunciation in words of the existing customs of the Roman people. Relatively to the progress of the Romans in civilisation, it was a remarkably early code, and it was published at a time when Roman society had barely emerged from that intellectual condition in which civil obligation and religious duty are inevitably confounded. Now a barbarous society practising a body of customs, is exposed to some especial dangers which may be absolutely fatal to its progress in eivilisation. The usages which a particular community is found to have adopted in its infancy and in its primitive seats are generally those which are on the whole best suited to promote its physical and moral well-being; and, if they are retained in their integrity until new social wants have taught new practices, the upward march of society is almost certain. But unhappily there is a law of derelopment which ever threatens to operate upon unwritten usage. 'The customs are of course obered by multitudes who are incapable of understanding the true ground of their expediency, and who are therefore left inevitably to invent superstitious reasons for their permanence. A process then commences which may be shortly described by saying that usage which is reasonable generates usage which is unreasonable. Analogy, the most valuable of instruments in the maturity of jurisprudence, is the most dangerous of snares in its infancy. Prohibitions and ordinances, originally confined, for good reasons, to a single description of acts, are made to apply to all acts of the same class, because a man menaced with the anger of the gods for 
doing one thing, feels a natural terror in doing any other thing which is remotely like it. After one kind of food has been interdicted for sanitary reasons, the prohibition is extended to all food resembling it, though the resemblance occasionally depends on analogies the most finciful. So again, a wise provision for insuring general cleanliness dictates in time long routines of ceremonial ablution; and that division into classes which at a particular crisis of social history is necessary for the maintenance of the national existence degenerates into the most disastrous and blighting of all human institutions - Caste. The fate of the Hindoo law is, in fact, the measure of the value of the Roman Code. Ethnology shows us that the Romans and the Hindoos sprang from the same original stock, and there is indeed a striking resemblance between what appear to have been their original customs. Even now, Hindoo jurisprudence has a substratum of forethought and sound iudgment, but irrational imitation has engrafted in it an immense apparatus of cruel absurdities. From these corruptions the Romans were protected by their code. It was compiled while usage was still wholesome, and a hundred years afterwards it might have been too late. The Hindoo law has been to a great extent embodied in writing, but, ancient as in one sense are the compendia which still exist in Sanshrit, they contain ample evidence that they were drawn up after the mischief had been done. We are not of course entitled to say that if the Twelve Tables had not been published the Romans would have been condemned to a civilisation as feeble and perverted as that of the Hindoos, but thus much at least is certain, that with their code they were exempt from the very chance of so unhappy a destiny. 


\section{Cinapter ViII}

\section{METHODS OF THE LAW'S GROITH ${ }^{1}$}

When primitive law has once been embodied in a Code, there is an end to what may be called its spontaneous development. Henceforward the changes effected in it, if effected at all, are effected deliberately and from without. It is impossible to suppose that the customs of any race or tribe remained unaltered during the whole of the long - in some instances the immense interval between their declaration by a patriarchal monarch and their publication in writing. It would be unsafe too to affirm that no part of the alteration was effected deliberately. But from the little we know of the progress of law during this period, we are justified in assuming that set purpose had the very smallest share in producing change. Such imnorations on the earliest usages as disclose themselves appear to have been dictated by feclings and modes of thought which, under our present mental conditions, we are unable to comprehend. A new era begins, however, with the Codes. Wherever, after this epoch, we trace the course of legal modification, we are able to attribute it to the conscious desire of improvement, or at all events of compassing objects other than those which were aimed at in the primitive times.

It may seem at first sight that no general propositions worth trusting can be elicited from the history of legal systems subsequent to the codes. The ficld is too vast. We cannot be sure that we have included a sufficient number of phenomena in our observations, or that we accurately understand those which we have observed. But the undertaking will be seen to be more feasible, if we consider that after the epoch of eodes the distinction between stationary and progressive soeicties begins to make itself felt. It is only with the progressive socicties that we are concerned, and nothing is more remarkable than their extreme fewness. In spite of overwhelming evidence, it is most difficult for a citizen of

${ }^{1}$ [By Sir Hexry S. Malne. Reprinted from "Ancient Law," hy permission of Henry Holt and Company, New York.] 
Western Europe to bring thoroughly home to himself the truth that the civilisation which surrounds him is a rare exception in the history of the world. The tone of thought common among us, all our hopes, fears, and speculations, would be materially affected, if we had vividly before us the relation of the progressive races to the totality of human life. It is indisputable that much the greatest part of mankind has never shown a particle of desire that its civil institutions should be improved since the moment when external completeness was first given to them by their embodiment in some permanent record. One set of usages has occasionally been violently overthrown and superseded by another; here and there a primitive code, pretending to a supernatural origin, has been greatly extended, and distorted into the most surprising forms, by the perversity of sacerdotal commentators; but, except in a small section of the world, there has been nothing like the gradual amelioration of a legal system. There has been material civilisation, but, instead of the civilisation expanding the law, the law has limited the civilisation. The study of races in their primitive condition aflords us some clue to the point at which the development of certain societies has stopped. We can see that Brahminical India has not passed beyond a stage which occurs in the history of all the families of mankind, the stage at which a rule of law is not yet discriminated from a rule of religion. The members of such a society consider that the transgression of a religious ordinance should be pumished by civil penalties, and that the violation of a civil duty exposes the delinquent to divine correction. In China this point luas been passed, but progress seems to have been there arrested, because the civil laws are co-extensive with all the ideas of which the race is capable. The difference between the stationary and progressive societies is, however, one of the great secrets which inquiry has yet to penetrate. Among partial explanations of it I venture to place the considerations urged at the end of the last chapter. It may further be remarked that no one is likely to succeed in the investigation who does not clearly realise that the stationary condition of the human race is the rule, the progressive the exception. And another indispensable condition of success is an accurate knowledge of Roman law in all its prineipal stages. The Roman jurisprudence has the longest known history of any set of human institutions. The character of all the changes which it underwent is tolerably well ascertained. From its commencement to its close, it was progressively modified for the better, or for what the authors of the modification conceived 
to be the better, and the course of improvement was continued through periods at which all the rest of human thought and action materially slackened its pace, and repeatedly threatened to settle down into stagnation.

I confine myself in what follows to the progressive societies. With respect to them it may be laid down that social necessities and social opinion are alway's more or less in advance of Law. We may come indefinitely near to the closing of the gap between them, but it has a perpetual tendency to reopen. Law is stable; the societies we are speaking of are progressive. The greater or less happiness of a people depends on the degree of promptitude with which the gulf is narrowed.

A general proposition of some value may be advanced with respect to the agencies by which Law is brought into harmony with society. These instrumentalities seem to me to be three in number, Legal Fictions, Equity, and Legislation. Their historical order is that in which I have placed them. Sometimes two of them will be seen operating together, and there are legal systems which have escaped the influence of one or other of them. But I know of no instance in which the order of their appearance has been changed or inverted. The early history of one of them, Equity, is universally obseure, and hence it may be thought by some that certain isolated statutes, reformatory of the ciril law, are older than any equitable jurisdiction. My own belief is that remedial Equity is everyhere older than remedial Legislation; but, should this be not strictly true, it would only be necessary to limit the proposition respecting their order of sequence to the periods at which ther exercised a sustained and substantial influence in transforming the original law.

I employ the word "fiction" in a sense considerably wider than that in which English lawyers are accustomed to use it, and with a meaning much more extensive than that which belonged to the Roman "fictiones." Fictio, in old Roman law, is properly a term of pleading, and signifies a false arerment on the part of the plaintiff which the defendant was not allowed to traverse; surch, for example, as an arerment that the plaintiff was a Iioman citizen, when in truth he was a foreigner. The object of these "fictiones" was, of course, to give jurisdiction, and they therefore strongly resembled the allegations in the writs of the English Queen's Bench and Exchequer, by which those courts contrived to usurp the jurisdiction of the Common l'leas: - the allegation that the defendant was in custody of the king's marshal, or that the plain- 
tiff was the ling's debtor, and could not pay his debt by reason of the defendant's default. But now I employ the expression "Legal Fiction" to signify any assmuption which conceals, or affects to conceal, the fact that a rule of law has undergone alteration, its letter remaining unchanged, its operation being modified. The words, therefore, include the instances of fictions which I have cited from the English and Roman law, but they embrace much more, for I should speak both of the English Case-law and of the Roman Responsa Prudentium as resting on fictions. Both these examples will be examined presently. The fact is in both cases that the law has been wholly changed ; the fiction is that it remains what it always was. It is not difficult to understand why fictions in all their forms are particularly congenial to the infancy of society. They satisfy the desire for improvement, which is not quite ranting, at the same time that they do not offend the superstitious disrelish for change which is always present. At a particular stage of social progress they are invaluable expedients. for overcoming the rigidity of law, and, indeed, without one of them, the Fiction of Adoption whieh permits the family tie to be artificially created, it is difficult to understand how society would ever have escaped from its swaddling-clothes, and taken its first steps towards civilisation. We must, therefore, not suffer ourselves to be affected by the ridicule which Bentham pours on legal fictions wherever he meets them. To revile them as merely fraudulent is to betray ignorance of their peculiar office in the historical development of law. But at the same time it would be equally foolish to agree with those theorists who, discerning that fictions have had their uses, argue that they ought to be stereotyped in our system. There are several Fictions still exercising powerful influence on English jurisprudence which could not be discarder without a severe shock to the ideas, and considerable change in the language, of English practitioners; but there can be no doubt of the general truth that it is unworthy of us to effect an admittedly beneficial object hy so rude a device as a legal fiction. I cannot admit any anomaly to be innocent, which makes the law either more difficult to understand or harler to arrange in harmonious order. Now, among other disadrantages, legal fictions are the greatest of obstacles to symmetrical classification. The rule of law remains sticking in the srstem, but it is a mere shell. It has been long ago undermined, and a new rule hides itself under its cover. Hence there is at once a diffienlty in knowing whether the rule which is actually operative should be classed in its true 
or in its apparent place, and minds of different casts will differ as to the branch of the alternative which ought to be selected. If the English law is ever to assume an orderly distribution, it will be necessary to prune away the legal fictions which, in spite of some recent legislative improvements, are still abundant in it.

The next instrumentality by which the adaptation of law to social wants is carried on I call Equity, meaning by that word any body of rules existing by the side of the original civil law, founded on distinct principles and claiming incidentally to superserle the civil law in virtue of a superior sanctity inherent in those principles. The Equity whether of the Roman Prætors or of the English Chancellors, differs from the Fictions which in each case preceded it, in that the interference with law is open and avowed. On the other hand, it differs from Legislation, the agent of legal improvement which comes after it, in that its claim to authority is grounded not on the prerogative of any external person or body, not even on that of the magistrate who enmonciates it, but on the special nature of its principles, to which it is alleged that all law ought to conform. The very conception of a set of principles, invested with a higher sacredness than those of the original law and demanding application independently of the consent of any external body, belongs to a much more arlvanced stage of thought than that to which legal fictions originally suggested themselves.

Legislation, the enactments of a legislature which, whether it take the forms of an autocratic prince or of a parliamentary assembly, is the assumed organ of the entire society, is the last of the ameliorating instrumentalities. It differs from Legal Fictions just as Equity differs from them, and it is also distinguished from Equity, as deriving its authority from an external body or person. Its obligatory force is independent of its principles. The legislature, whatever be the actual restraints imposed on it by public opinion, is in theory empowered to impose what obligations it pleases on the members of the community. There is nothing to prevent its legislating in the wantonness of caprice. Legi.lation may be dictated by equity, if that last word be wied to indicate some standard of right and wrong to which its enactments happen to be adjusted; but then these enactments are indehted for their binding force to the authority of the legislature and not to that of the principles on which the legislature acted; and thus they differ from rules of Equity, in the terhnical sense of the word, which pretend to a paramount sacredness.

* $*$ * $*$ * $\quad * \quad * \quad * \quad * \quad *$ 



\section{PART II}

\section{PERSONS}

\section{Chapter IX}

KINSHIP

Sectiox 1. The Tribe

Sectiox 2. The Clan

By J. II. Powell

Chapter X

THE PATRIARCHAL THEORY

By George E. Howard

Chapter XI

TOTEMISA AND EXOGAMY

Section 1. Exogamy as a Survival of Grotp Marriage

By Josef Kohler

Section 2. Origin of Exogany

By ANdrew Lang

Chapter XiI

WOMEN IN PRIMITIVE SOCIETY

BY L. T. HoBHotse

\section{Chapter XIII}

\section{MARRIAGE}

Section 1. Foris of Marriage

BY JuseF KOHLER

Section 2. Tribal Marriage Law By J. II. Powell

Sectiox 3. Religious Basis of the Family By Festel de Cotlanges

Section 4. Marriage in (ireece and Rome By Fustel de Collanges 
Chapter xiv

PATRIA POTESTAS

By Henry s. Maine

Chapter XV

WOMEN AND MARRIAGE UNDER CIVILIZATION

By L. T. Hobhouse

\author{
Chapter XVi \\ CHILDREN AND THE FAMILY \\ By JOSEF KoHLer
}

Chapter XVil

ADOPTION AND ARTIFICIAL RELATIONSHIP

Section 1. Sertey of Artificial Relationships

By Josef Kohler

Section 2. Religious Basis of Adoption

By Fustel de Coulanges

Chapter XVili

SLAVERY

Section 1. Historical Importance of Slavery

BY JOSEF КОHLER

Section 2. Theories of Slavery

By Henry S. maine

Chapter Xis

CAPITIS DEMINUTIO

By Rudolph Som

Chapter XX

EXISTIMLTIONIS MINUTIO

Br Rudolpi SoHM 


\section{Chapter IX}

\section{KINSHIP 1}

\section{Section 1}

\section{THE TRIBE}

So far as is now known, tribal society is everywhere based on kinship. In the simplest form of whieh there is any knowledge, the tribe consists of a group of men calling one another brother, who are husbands to a group of women calling one another sister. The children of these communal parents call all the men fathers, and all the women mothers, and one another brother and sister. In time these children become husbands and wives in common, like their parents. Thus the kinship sistem reeognizes husbands and wives, fathers and mothers, sons and daughters, brothers and sisters, and grandparents and grandehildren. The only kinship by affinity is that of husband and wife. The only collateral kinships are those of brother and brother, sister and sister, and brother and sister. The lineal kinships are father and son, father and daughter, mother and son, mother and daughter, with grandparents and grandchildren also recognized. There is no recognized father-in-law, mother-in-law, brother-in-law, nor sisterin-law; there is no uncle, no aunt, no cousin, no nephew, no niece recognized.

It will thus be seen that all of the collateral kinships of uncle and aunt and nephew and niece are ineluded in the lincal kinship of parent and child, and cousins of whatever degree are reckoned as brothers and sisters. Let any person be designated as Ego. Then all the men of the antecelent generation are his fathers, and all the women his mothers; all the males of his own generation are his brothers, and all the females his sisters; and all the males of the following generation are his sons, and all the females his daughters.

${ }^{1}$ [By J. W. Powell. Reprinted, by permission, from the 3 d Annual Report of the American Bureau of Ethnology (The Smithsonian Institution).] 
Selecting the Ego from any generation and reckoning from him the antecerlent and subsequent generations, the following consanguineal kinship groups will be found: Ego will be one of a group of brothers; there will be a group of sisters, a group of fathers, a group of mothers, a group of grandfathers, and a group of grandmothers; there may also be a group of sons and a group of daughters, a group of grandsons and a group of granddaughters.

In the use of the terms " brother," " sister," "father," " son," "mother," "daughter," "grandfather," "grandson," " grandmother," and "grandelaughter" in this manner, it must be clearly" understood that in every case the term applies to every one of the members of a group, only a part of whom bear the relation which that term implies among civilized peoples, who classify by degrees of consanguinity.

Thus, the father-group embraces the father and all his own brothers; but as the father ealls all his male cousins brothers, it also inclurles the father's male cousins. The father-group therefore includes the father and all of those persons whom the father calls by the name of "brother."

Ego ealls all the sons of his father and mother brothers; he calls also all his father's brothers' sons, and his father's sisters' sons, and his mother's brothers' sons, and his mother's sisters' sons, brothers. And if there be male cousins of the second, third, fourth, fiftl, or any other degree, he ealls them all alike brothers. The brother-group, therefore, may be very large. In like manner the mother-group, the sister-group, the son-group, and the daughter-group may be correspondingly large. The grantfather-group and the grandmother-group include all collateral kindret of that generation; and in like manner the grandson-group and the granddaughter-group include all the collateral kindred of their generation. Inder this system all kinships may be thrown into a very few groups, and each one of these groups is tesignated by the kinship term properly belonging to the person in the group nearest of kin to Ego.

The essential principle of this method of reckoning kinship is that collateral kinship is not recognized. All of the kindred are incluted in the lineal groups; and in every generation a group of brothers is eonstituted, including all of the males of that generation, anda group of sisters is constituted, including all of the females of that generation.

That such a kinship boly has ever existed is a matter of inference; its discovery as an ohjective fact has not been made. How- 
ever, it is predicated upon very strong inferential evidence. In the forms of society actually found among the lower tribes of mankind, institutions are discovered that are believer to be survivals from such a form of tribal organization. And the philologie evidence is perhaps still stronger; in fact, the hypothesis was originally based solely upon linguistic data, as languages have been found in which terms for husband, wife, father, mother, son, daughter, elder brother, younger brother, elder sister, and younger sister occur, together with those expressive of the kinships that arise through the recognition of grandparents and grandchildren, while terms for collateral kinships are not found.

All tribes that have yet been carefully studied present a more elaborate form of social organization than that above described. This more highly developed structure is usually exhibited, among other things, in a more elaborate system of classifying kinships. Additional groups are constituted, so that eertain collateral kinships are differentiated.

In the brothers and sisters of parents four natural kinships are possible, namely, (a) paternal uncle, called by the Romans patruns; (b) maternal uncle, called by the Romans avunculus; (e) paternal aunt, called by the Romans amita; and $(d)$ maternal aunt, called by the Romans matertera. The recognition of these four groups would lead to the recognition of the correlative cousins, in four classes, male and female in each class; and if terms were used distinguishing sex, eight classes of cousins would arise through the four classes of uncles and aunts. In this direction the first step in the differentiation of additional kinships is made. Let us eall paternal uncles patruates, maternal uncles arunculates, paternal aunts amitates, and maternal aunts materterates.

Let us suppose that the relation of husband and wife is not the same as the relation of brother and sister; that is, that men do not marry their own sisters, but a brother-group marries a sistergroup in common. In this case fathers' sisters will no longer be mothers, but will constitute a group of amitates. In like manner, mothers' brothers will no longer be fathers, but will constitute a group of avmeulates. The institution of a group of amitates will necessitate the establishment of the correlative cousin-groups. 'Thus, with the reduction of the father-group there will be a corresponding reduction of the brother and sister groups; and with the reduction of the mother-group there will be an additional corresponding reduction of the brother and sister groups; that is. the paternal aunts and maternal uncles will carry with them their 
corcelative nephews and nieces, and such nephews and nieces will be subtracted from the brothers and sisters. In this stage of kinship development there is still communal marriage. It may not ahways be actual, as gradually restrictions are thrown around it; but if not actual, it is always potential. The form of kinship now reached is not an inference from philology and the survival of customs, but is an observed fact among some of the tribes of the earth.

The recognition of patruates (paternal uncles) must next be considered. Such a recognition results in the establishment of two additional cousin-groups, as the sons and daughters of patruates are taken out from the "brothers" and "sisters" of Ego. At this stage brothers and sisters are still own (natal) and collateral, but the collateral brothers and sisters include only the children of mothers' sisters, and this because a group of materterates is not established.

We have now reached that kinship system which is perhaps the most widely distributed anong existing tribes of mankind. It will be well, then, to clescribe it once more, that it may be clearly understood :

The brother-group consists of the sons of a woman, together with the sons of all of her sisters, own and collateral; and the sister-group is of like extension. The son-group is coextensive with the brother-group to which the son belongs; the daughtergroup is coextensive with the sister-group to which the daughter belongs; the father-group is coextensive with the brothergroup to which the father belongs; and the mother-group has a like extension. The patruate-group is coextensive with the brother-group of the paternal uncle; the amitate-group is coextensive with the sister-group to which the paternal aunt belongs; the avunculate-group is coextensive with the brother-group to which the maternal uncle belongs; but there is no materterategroup (maternal aunt).

The essential characteristic of this system of kinship is that the brother-group consists of own brothers,' together with the collateral brothers that come through maternal aunts; and that the sister-croup consists of own sisters, together with the collateral sisters that come through maternal aunts; and it matters not whether maternal uncles and paternal uncles are distinguished from each other. They may or may not be thrown into one group. The cousins which arise from the discrimination of paternal and maternal uncles and paternal aunts may be thrown into two, four, 
or six groups; but the general system does not seem to be affected thereby. Where this system of kinship prevails, the brother and sister groups are on the mother's side, the children belonging to their mothers and not to their fathers, and descent is said to be in the female line.

There is another system of tribal organization which widely prevails. In this the mother's sisters are recognized as maternal aunts, and a materterate-group is constituterl of the mother's sisters, own and eollateral, and the cousins arising therefrom are taken out from the brother and sister groups. But in this ease the father's brothers, own and collateral, are still consilered as fathers; there is no patruate group. The brother-group is thus composed of the sons of the father with the sons of all his brothers, own and collateral. It is therefore a large group, and the sister-group corresponds therewith. When the brother and sister groups arise through paternal uncles, children belong to their fathers, and descent is said to be in the malc line.

From the above statements it will be seen that one of the fundamental principles used in elassifying kinships in tribal soeiety is that which arises from the discrimination of generations. The simple communal form first deseribed is classed in groups of kindred on characteristics of generations and sex, and in the various systems which develop from it the eharacteristic of distinet generations still remains, although collateral descents are to some extent differentiated from lineal deseent.

It would seem that generation-groups extending eollaterally many degrees would speedily become confused, as a series of generations might be much shorter in one line than in another. If three sisters have each three daughters, the eldest danghter of the eldest sister may be many years okler than the youngest daughter of the youngest sister, and in several generations the discrepaney of ages might become very great. We do not know in all eases how this eonfusion is avoided, but in some tribes a method of adjustment has been diseovered which is very simple.

It must always be remembered that relative age is expressed in the kinship terms of this stage of culture. Thus there are two terms for brother, one signifying elker brother, the other younger brother. There are also two terms for sister-chler sister and rounger sister. In the Shoshonian cases to which reference is here made, if a male child is horn who is a "group" " brother of Ego's father, but rounger than Ego, Ego does not eall him father, but younger brother. In one ease discovered, 
Ego calls the "group" father born after himself, son. Among the same tribes, in the case of uncles, the uncle born after the nephew is called nephew.

A case like the following has been discovered: There are two brothers born of the same mother; the elder brother calls a particular person son, because that particular person was born after limself; but the younger calls him father, because he was born prior to himself. 'This method of adjusting generations has been discovered in but few cases, viz., among the Shoshonian tribes, and perhaps among the Wintuns. In this stage language frequently lends its aid to adjustment. This is the case when the kinship name is a reciprocal term with a termination signifying elder or younger. Thus, in a Shoshonian tribe ain is such a reciprocal term used by uncle and nephew; the termination sen is diminutive. The nephew calls his uncle ain, the uncle calls the nephew ainsen or aitsen, little uncle; and in this case, if the uncle was born after the nephew, the nephew would be called ain and the uncle aitsen. A reciprocal relationship term, i.e., one designating a relationship and used by both parties, is common.

In some of the cases arljustments are known to have been made by convention, and individuals have been taken from one generation and placed in another, by agreement of the elder women of the clan.

Lnadjusted kinships are frequently discovered, so that the kinships claimed secm strange to civilized persons accustomed only to the kinships recognized in the higher states of culture. Thiss it has frequently been found that an adult has claimed a child for his grandmother and a babe for his father. The subject is one of interest, and deserves careful study.

The method of classifying and naming by kinship terms the six groups of cousins, their children and their children's children, has been neglected, in order that the general subject might not be buried in details, and from the further consideration that the principles of tribal organization, can be set forth without the aid of such additional facts.

In the above statements the fundamental principles of tribal kinship have been explained, and they may be restated as follows:

I. - A body of kindred constituting a distinct body-politic is divided into groups, the males into groups of brothers and the females into groups of sisters, on distinctions of generations, regardless of degrees of consanguinity ; and the kinship terms used express relative age. In civilized society kinships are classified on 
distinctions of sex, distinctions of generations, and distinctions arising from degrees of consanguinity.

II. - When descent is in the female line, the brother-group consists of natal brothers, together with all the materterate male cousins of whatever degree. Thus mother's sisters' sons and mother's mother's sisters' daughters' sons, \&c., are ineluded in a group with natal brothers. In like manner the sister-group is composed of natal sisters, together with all materterate female cousins of whatever degree.

III. - When descent is in the male line, the brother-group is composed of natal brothers, together with all patruate male cousins of whatever degree, and the sister-group is composed of natal sisters, together with all patruate female cousins of whatever degree.

IV. - The son of a member of a brother-group calls each one of the group, father; the father of a member of a brother-group calls each one of the group, son. Thus a father-group is coextensive with the brother-group to which the father belongs. A brother-group may also constitute a father-group, and grandfather-group, a son-group and a grandson-group. It may also be a patruate-group and an avunculate-group. It may also be a patruate cousin-group and an aruneulate cousin-group; and in general, every member of a brother-group has the same consanguineal relation to persons outside of the group as that of every other member.

The principles enunciated above may be stated in another way, namely : A kinship body is divided into brother-groups and sistergroups, and group is related to group lineally and collaterally; and every group bears a distinet relationship to every other group.

It will thus be seen that the brother-group and the sistergroup constitute the fundamental units of tribal society.

A tribe may be defined as follows: A tribe is a congeries of brother-groups and sister-groups, and every group recognizes a distinct correlative consanguineal kinship with every other group; and series of groups are related to series of groups by the tirs of affinity, i.e., marriage; to explain whieh necessitates the consideration of the clan.

\section{SECTION 2}

THE CLAN

In tribal society the tribe, or body-politic, is divided into groups of brothers and groups of sisters. One form of the brother- 
group includes not only the sons of one woman, but also the sons of her sisters; and not only the sons of her natal sisters, but also the sons of her collateral sisters; i.e., the brother-group includes the natal brothers, together with all of the male cousins of the first, sccond, or $n^{\text {th }}$ collateral line, reckoning always through females. Sister-groups are constituted in like manner.

Another form exists in which to the natal brothers are added all male cousins to the $n^{\text {th }}$ degree that come through paternal uncles, reckoning always through males. Sister-groups are constituter in like manner.

With some tribes the brother and sister groups arise from male descent; but a much larger number of tribes have these groups constituted through female descent. The two sistems of kinship are at the base of two distinct systems of clan organization.

When the brother and sister groups arise through female descent, a larger group is constituted, reckoning kinship through females only. The constitution of this larger borly, a group of groups, must be clearly understood. Every brother-group has its correlative sister-group. Take, then, a brother-group and a sister-group that are thus correlated and call them the Ego group. The mothers of the Ego group constitute another sistergroup within themselves, and the brother-group to which they are correlated are the avunculates of the Ego group. Call this brother and sister group the first ascendant of the Ego group. The mothers of the first ascendant group constitute another sistergroup within themselves, and the brother-group to which they are correlated are the avunculates of the first ascendant group. Thus a second ascendant brother and sister group is constituted. In the same manner third, fourth, and $n^{\text {th }}$ ascendant brother and sister groups may be constituted.

Returning now to the Ego group. The sisters of the Ego group have sons and daughters who are brothers and sisters to one another, and they constitute a first desccndant brother and sister group. The sisters of the first descendant group have children who are brother and sister to onc another and constitute a second descendant group. In the same manner the third, fourth, and $n^{\text {th }}$ descendant group may be constituted. 'The Ego group, together with the ascendant groups and descendant groups, constitute a lineal series of brother and sister groups, reckoning always through females. Such a borly is here caller a group of enates, and kinship thus reckoned is called enatie kinship. On the other hand, if the brother and sister gromps come through paternal uncles, and the 
lineal series is reckoned exclusively through males, it is called a body of agnates, and the kinship is called agnatic kinship.

Whenever enatic or agnatic kinship is recognized, the tribe becomes much more highly composite than in the case of the communal family. There are always several co-ordinate groups of people united into a larger group, the tribe. For the present let us use the term "tribe" for the name to distinguish the group of the highest order, and the term "clan" to distinguish each of the co-ordinate groups of the second order into which the tribe is divided.

The first characteristic of the clan is thus reached. A clan is one of the co-ordinate groups into which a tribal state is divided.

The tribe itself is a body of intermarrying cognates; so that, in the tribe, kinship by consanguinity and affinity is recognized. Within the clan, kinship by affinity is not recognized; that is, the husband and wife do not belong to the same clan, and kinship by consanguinity is limited to kinship traced through females, or to kinship traced through males, as the case may be ; and in both, but a part of the cognates are included. In one case the clan is enatic, and in the other it is agnatic. In the one case descent is through females, in the other through males. An enatic clan consists of a brother-group and a sister-group in each of the generations represented in the clan, and the kinship is reckoned only through females. An agnatic clan consist of a brother-group and a sistergroup in each of the generations represented in the clan, and the kinship is reckoned only through males.

A sccond characteristic of a clan may therefore be given: A clan is a body of either enatic or agnatic kindred.

When the clan is enatic it usually has a common worship of a tutelar god. This must be distinguished from the tribal worship, which is more miscellancous, and based upon polytheism. The tutelar god, or totem, is often an animal ; or sometimes it may be a river, a mountain, the sun, or some other object; in which case the members of the elan call themselves the children of the animal, the river, the mountain, or the sum, as the case may be. When the clan is agnatic, the tutelar god is usually some ancestor who has distinguished himsels for valor or wisdom.

A third characteristic of a clan is thus reached: A elan is a body of kindred having a tutelar god, totemic or ancestral, who is considered to be the father of the clan.

When the clan is totemic it usually takes the name of its tutclar god as its name, and the picture-writing, or simbol of the tutelar 
god, is used as a badge to distinguish the clan. That the members of a clan have descender from a common parent, seems at present to be usually a legal fiction. In tribal soeiety age is greatly revered, and "elder-rule" largely prevails; so the gods are spoken of as " fathers," or more usually " grandfathers," or even " ancient fathers," and sometimes simply as "aneients," that is, "the venerable." But the tutelar gool is espeeially the guide and protector of the elan, and is therefore ealled "father," and it seems that in many cases a myth is developed, explaining this fatherhood as being real. When the tutelar god is a real aneestor (and such seems to be the case when the clan is agnatic) the clan takes the name of the ancestor.

1 fourth characteristic of a elan is therefore reaehed: A clan is a body of kindred having a common name, the name of its tutelar deity.

The clan, whether enatic or agnatic, is composed of brothers and sisters in each generation; and in the custom-law of this stage of culture brothers and sisters cannot intermarry. In like manner, when the clan is enatie, by the same custom-law a mother camnot marry her son, natal or fictitious; and when the clan is agnatic a father eannot marry his daughter, natal or fictitious. 'Thus it is that marriage within the enatie or agnatie group is ineest, and is usually punished with death. The rules for marriage outside of the elan are various, and the subject need not here be entered upon. It is suffieient to note that the group is exogamous. It will be seen that the term "exogamy" is here used in a sense altogether different from that given it by MeLennan and the writers of his school.

The fifth characteristic of a clan, therefore, is reached: A clan is a group of exogamous kindred.

As a elan is a brother-group and sister-group in eaeh generation, though these ties are in small part real, and in large part artifieial, ret they are eonsidered to be the elosest, and to eombine the group into the firmest union. The body, therefore, eonstitutes a feudgroup to secure one another's rights and to avenge one another's wrongs. The elan is held responsible by the tribe for the conduct of its members. All controversies arising within the clan are settled by the elan; controversies arising between members of difïcrent clans are settled by the tribe. For personal injury, especially for maiming and murdering, every elan holds every other clan responsible. Out of this arises the blood-feud, and out of blood-feud arises outlawry ; for when a elan finds that one of its 
members has become so outrageous in his conduct that the other members no longer wish to hold themselves responsible therefor, the clan formally declares that the culprit no longer constitutes one of the community. The offender is expelled from the clan and becomes an outlaw, and any one may kill him.

A sixth characteristic of a clan has been reached: A clan is a feud-group of kindred.

In tribal society great wealth is not accumulated. The indirect personal relations which arise through property are of minor importance as compared with direct personal relations, which are regulated by kinship and relative age. The institution of personal property is very slightly developed, and such property, especially in the lower forms of tribal society, is destroyed at the death of the individual. It is a widely-sprear law in savage society that personal property is inherited by the grave. The tenure to the greater part of property is communal, and inheres in the clan.

A seventh characteristic of a clan has therefore been reached: The clan is the chief property-holding group.

It has already been mentioned that clder-right, in some form or other, is universally recognized in tribal society. In general, coteris paribus, the elder has authority over the younger, and in all tribal languages a special derice is found to facilitate this custom, viz., individuals must always address each other by kinship terms in which relative age is expressed; thus, there is no general term for " brother," but a special term for " elder brother," and another for "younger brother." This elder-rule applies to the clan, as the eldest man of the clan is its chief, and such a chief, whose rulership is by right of superior age, will here be called the presbyarch.

An eighth characteristic of a clan has therefore been reached: A clan is a presbyarchy.

Let these characteristics be combined into a definition: A clan is one of the co-ordinate groups into which a tribe of cognatic people is divided, and is based upon enation or agnation, has a totemic or ancestral tutelar god, a common name for its members, is exogamous, is a feud-group, a proprietary group, and is ruled by a presbyarch.

There are many other charaeteristies of a clan that are found, now here, now there. For example, sometimes a clan will not eat the animal or some portion of the animal whose name it bears: it will thus have what is usually ealled a "taboo." Somotimes the several clans of a tribe will elaim as their own, particular hunting 
or fishing grounds. Sometimes a clan will have a body of personal names to be given to its members, whieh the clan elaims as its own. Often a clan has a particular place assigned to it as the site for its residence or residences in the village group, and will occupy the same relative place in the village wherever the tribe may have a permanent or temporary residence. Thus there are many rights and duties which inhere in a elan and which may be said to eharacterize it. But the eight characteristies ineluded in the above definition are those most eommonly found. In the definition of the clan thus given, the tribe has been assumed to be of very simple strueture - as composed of a number of co-ordinate clans. But this simple structure is not universal - in fact, a more complex structure is more common. Whenever a tribe has a more complex strueture, the charaeteristies above enumerated may not all inhere in every one of a number of co-ordinate groups, but may be distributed among groups of different orders. It oceasionally happens, also, that some of these charaeteristies are not found in any group. Some of these cases must next be considered.

Let one of the most frequent cases be taken first. Suppose that a tribe, becoming very large, divides in such a manner that segments from every one of the clans separate from the parent tribe and organize a new tribe with the same clans. Thus the elans found in the parent tribe are represented in the new tribe. Suppose that this fissiparous generation of tribes continues until there are five, ten, or twenty tribes, every one having the same clans as every other. Inder such circumstances the same clan extends through many tribes, and any one tribe has in its body-politic no more than a segment of any elan; but every tribe is composed of like segments. Now, such a uniform division of tribes is rarely found. The division is usually more irregular, from the fact that the departing body whieh is organized into a new tribe usually takes with it segments of only a part of the clans; and as these divisions oceur from time to time, no two tribes are likely to have representatives of exactly the same clans, and it may sometimes happen that two tribes may be found in the same body of cognate tribes that will have entirely diverse clans. The segmentation of elans in this mamner eomplicates the definition of a clan. It is no longer one of the co-ordinate groups of a tribe. These coordinate groups are but segments of clans, and each such segment is likely to become a distinet feud-group and a distinet proprietary group. Sometimes in such a case all the segments will yet recognize one presbyareh, but oftener a distinet presbyareh for each 
segment is dereloped. Enatic or agnatic distinctions, the common tutelar god, the common name and the characteristic of exogamy. are more likely to remain permanent.

This fissiparous generation of tribes leads to a emplication in the definition of the term " tribe," as such eognate tribes are likely. to unite into confederacies, with a council and a chief presiding over the larger body thus constituted; and in the various changes which may be wrought upon the different groups of sereral orders in a confederacy by many redistributions of characteristics, it sometimes becomes difficult to say just what orker of groups shall be called tribes. Conferleracies also form alliances, and though they are apt to leare the conferleracies or tribes of which they are composed independent and autonomous, exeept for offensive or defensive purposes against more foreign peoples, they loubtless sometimes continue and become more thoroughly cementerl by the development of kinship ties and governmental organizations.

Sometimes elans divide into sub-clans, while yet remaining in the same tribe. The nature of this division in enatic clans is not clearly understood. It may be that it does not oeeur normally but that the apparent instances are due to the recoalescing of tribes. Be this as it may, it occurs with agnatic clans. Agnatic clans may be ruled by a presbyarch, and may be divided into segments, each one of which is ruled by a patriareh, the patriarchies being subordinate groups within a presbyarchal agnatic elan. Inder these circumstances, however, the authority of the presbyarch is likely to wane, and the patriarchies are likely to be more enduring. and so the clan is divided into sub-clans. Thus it happens that the presbrarehy is not always a characteristic of a clan.

Again, the members of enatie claus do not always have a common name. This has been found true of most of the Shoshonian tribes of North America, of the Wintuns, and of other peoples in the western portion of the Lniterl states. Whether a common name was never used, or whether such common names have been lost in the flux of time is uncertain. A common name, therefore, is not an invariable eharacteristic of a clan.

The most enduring characteristies of a clan, therefore, are these: enatic or agnatic kinship, exogamy, and feul-protection. But even these may be distributed among different groups; so that the ideal definition of a clan above given will apply in all its parts to but few clans; ret in most of its parts it will apply to nearly all clans. But there are cases when these characteristics are so distributed through the various groups of a body-politic that it will 
he well nigh impossible to decide which should be ealled the clan. Inder such circumstances it perhaps will be best to apply the term "clan" to the group based upon enation or agnation, as the case may be, and perhaps it will always be found that such a group is exogamous.

In Australia there seems to be another complication. Fison and Howitt describe a very peculiar condition of affairs which seems to extend through many of the tribes of that great island. Among them, marriage within a prescribed group still remains. Enatic kinship, a tutelar god, and a common name still attach to the clan, but clans are divided into many segments constituting the different tribes. It seems also that a limited marriage, or the right to temporary sexual association, is still communal. It seems further that two or more systems or tribes are in somewhat the same stage of institutional culture. These different systems of tribes appear not to be cognate, or, if cognate, they are very remotely so. But having been long associated, and having common institutions in the respects abovenamed, the clans in the different non-cognate tribes have become assimilated, so that a clan with a totemic name in one group of tribes has come to be considered as the equivalent of another clan having another totemic name in another group not cognate to the first; that is, the clan of one group is supposed to be equivalent to the dan of another group, and temporary marriage rights extend across the lines which demarcate non-cognate groups.

Some of the Australian clans present another interesting variation. It must be understood that a clan is composed of a lineal series of brother-groups, one for each generation, together with a lineal series of sister-groups, one for each generation. In the case under consideration the series of brother-groups is distinguished from the series of sister-groups by a different name. Thus the clan is divided, the males from the females, and the enatic kindred are separated into two groups, the daughters falling into the group of their mothers, and the sons falling into the group of their mothers' brothers.

Still other tribes in Australia have a clan system in which the brother-group of one generation is distinguished from the brothergroup of the next generation by a different name, but the brothergroup of the third generation takes the name of the brother-group of the first generation. The same change of names occurs in the series of sister-groups. The grandmother belongs to a group having the same name as the granddaughter. 
The typical tribe which has been described, is a body of kindred divided into brother and sister groups, every group having sonie kinship with every other group. Marriage is without the clan but within the tribe, therefore a man cannot marry into his own sister-group, but must marry into some cousin-group. To the consanguineal tie an affinital tie is added. A male cousin becomes the husband, and a female cousin becomes the wife. In many cases the brother-group of the husband becomes a husband-group, and the sister-group of the wife becomes a wife-group. The brothergroup of the husband is related to all the other groups of the tribe, and the sister-group of the wife is also related to all the other groups of the tribe. It is interesting to study the effect which marriage (real or potential) has in changing the consanguineal kinships into affinital kinships. Among the tribes of North America there is much diversity in this respect, but the subject is too much burdened with details to be considered here. 


\section{CHAP'TER X \\ THE PATRIARCHAL THEORY ${ }^{1}$}

\section{Statement of the Theory}

STEDENTs of comparative institutions have generally regarded the family as the unit or germ from which the higher forms of social organism have been evolved. A German scholar declares that among all the races of antiquity "the constitution of the family. was the basis and prototype of the constitution of the state."? The same theory is clearly set forth and the process of political expansion carefully described by Plato and also by Aristotle, ${ }^{3}$ who base it upon their own obserration both among "Hellenes and barharians," and each illustrates it by reference to the Cyclops of Homer. It is not wholly improbable, as will presently appear, that the family in some form must be accepted as the initial society, possibly among all the races of mankind. At a very early ethnicai period the family, so far as it implies great authority, perhaps

1 [By George E. Howard. Reprinted by permission, from "A History of Matrimonial Institutions," Vol. 1, p. 9 se'q., The University of Chicago Press, 1904.]

2 Marquardt, "Das Privatleben der Römer," I, 1. The theory is also held by Bluntschli. "Theory of the State," $182-89 ;$ Schrader, "Sprachvergleir.hung und Urgeschichte," 391-95; Leist. "Alt-arisches Jus Gentium," 113; Müller, "Handbuch der klass. Alterthumswissensehaft," IV, 1s-20; Gilbert, "Handbuch der griech. Staatsalterthümer," II. 302 ; Maine, "Village Communities," 15 ff.; "Ancient Law," 1 is ff.; "Early Law and Custom," chap. iii ; Fustel de Coulanges, "Ancient City," 111 ff.; Grote, "History of Greece," I, 561; Thümser, "Die griech. Staatsalterthümer," $28 \mathrm{ff}$.

3 Pluto, "Laws," Book III, 6SO, 6S1; Jowett, "Dialogues," IV; 209 ; Arrstotle, "Polities," Book I, 2 ff.; Jowett, I, 2 ff. These are followed by r'ieero. "De Officiis," I, 17.

4 ..They (the Cyclops) have neither assemblies for consultation nor themistes, hut everyone exerrises jurisdiction over his wives and his rhildren, and they pay no regard to one another." - "Odyssey," Book IX, $106 \mathrm{ff}$. as rendered by Waine, "Ancient Law," 120. Cf. "Odyssey, Bool VI, 5 ff.; Bryant's Trans., I, 141, 215, 216. On the themistes, as inspired commands of the hero-king, handed fown to him from Zeus by Themis, see Maine, chap. i; and on the import of the passage in Homer rompare ibid., 120, with Fremen, "Comparative Politics," 379 n. 20, and Botsford, "Athenian Constitution," 3, 4. 
even the despotic power of the house-father over his wife and children, may often have been "patriarchal." To admit this, however, is very different from accepting as the primordial cell of social development the strictly defined patriarchal family of sir Henry Maine's "Ancient Law." In this book, which made its appearance in 1861, we are told that the "effect of the evidence derived from comparative jurisprudence is to establish that view of the primeval condition of the human race which is known as the Patriarchal Theory:" 1 The primitive family as thus conceived is substantially the Roman family, not in all respects as it actually" appears in the historical period, but as it is thought that it must have been before the process of transformation and decay began. It is a much more extended group than the modern family, embracing under the headship of the eldest valid male parent all agnatic descendants and all persons united to it by adoption, as well as slaves, clients, and other dependents." The power of the house-father is most despotic, though exercised during his entire lifetime over the unmarried daughters and over even the married sons and their wives and children. Thus originally, it is said, the Roman pater familias has power of life and death, vita necisque, over his children. He may sell them into slavery, and sons, even those who hold the highest offices of state, can originally own no property. $^{3}$ The patriarch is king and priest of the household. As a sort of "corporation sole," he is likewise its representative and administrator; for the property is regarded as a part of the fimily, and on the death of the house-father the family devolves upon the universal successor. ${ }^{*}$ A characteristic feature of the patriarchal family is agnation, or the system of tracing kinship through males

1 “Ancient Law," 118.

2 Clients, serrants, and rven those admitted to the hearth as guests, by observance of the proper rites, were regarded as member's of the family group and sharers in the sacra. Herm. "Arran Household," $7: 3,107 \mathrm{ft}$; Fustel de Coulanges, "Ancient City," 150 ; Maine, op. cit., 1.j6 fì., 18ij fif. (sacra).

${ }^{3}$ For the Roman patrin potestas see Poste. "Craius," (i1 fi.: Lecist, "Graeco-italische Rerhtsgeschichte." 57-102: Sohm." Institutes," 120 fif., 356 ff., 355-95; Burnhöt, "Römische Fönigszeit," 175 fit.: Purhtr. "Institutionen," II, 3St fï.: Morry. "Outlines of Roman Latw." 23. 24; Scheurl, "Institutionen," 271, 272; Kuntze, "Excurse," 570 fi. : Mainc,

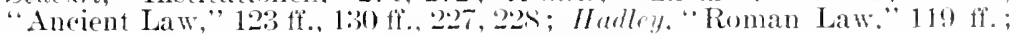
Clark, "Early Roman Law." 25; Murkerl, "Hist. Int. to the Prisate Law of Rome," 27 ff., 11S, 222; Lamgr, "Römisehes Alterthümer," I, 112 ff.; Grupen, "Cxore romana," 19 fit., 37 ff.; Barler. "Lat fomme

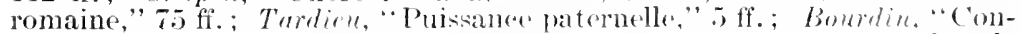
dition de la mère," of fi. On the powere of the father to exposs female infants during the early "mpire, sere C'upes. "Age of the Antonines." $19 \mathrm{f}$. 4 . Waine, "Incient Law," 12.2, and chap. vi. 
only." Agnatic relationship "is in truth the connection hetween members of the family, conceived as it was in the most ancient times.". Its foundation is "not the marriage of father and mother. but the authority of the father. . . In truth, in the primitive view, relationship is exactly limited by patria potestas. Where the potestas begins, kinship begins; and therefore adoptive relatives are among the kindred. Where the potestas ends, kinship ends; so that a son emancipated by his father loses all rights of agnation. And here we have the reason why the descendants of females are outside the limits of archaic kinship." Indeed "it is obvious that the organization of primitive societies would have been confounded, if men had called themselves relatives of their mother's relatives." 3 The basis of the patriarchal family is the patria potestas, but in its "normal shape" it has not been and could not be "generally a durable institution." 4 Yet its former universality may be inferred from certain derivative institutions, such as the perpetual tutelage of women, the guardianship of minors, the relation of master and slave, and especially from agnation which is found "almost everywere" and is "as it were a mould" retaining the imprint of the paternal powers after they have ceased to exist. Applying this test chiefly, Maine finds evidence of the existence of the potestas among the Hebrews as well as all the peoples of the Aryan stock; and he believes that it would be hard to say "of what races of men it is not allowable to lay down that the society in which they are united was originally organized on the patriarchal model." 6

The patriarchal family as thus constituted is the "type of an archaic society in all the modifications which it was capable of assuming." From it as in concentric circles have been successively evolyed all the higher forms of political organization. Everywhere, as at Rome, "the aggregation of families forms the gens or house. The aggregation of houses makes the tribe. The aggregation of tribes constitutes the commonwealth." 7 The state

1 On the Roman agnation see Poste, "Gaius," $113 \mathrm{ff} . ;$ Leist, "Graecoitalisehe Rechtsgeschichte," $64 \mathrm{ff}$.; Solhm, "Institutes," 124, $355 \mathrm{ff}$.; Puchto, "Institutionen," II, 17 ff.; Moyle, "Institutiones," I, 155, 156; Horry, op. cit., 6, 34; Kuntze, "Exeurse," 435-37 ("Agnationsverband"); Lange, "Römische Alterthümer," I, 211 ff.; Muirhead, "Hist. Int. to the Private Law of Rome," $43 \mathrm{ff} ., 122 \mathrm{ff}$. ; Hadlcy, "Roman Law," $130 \mathrm{ff}$.; Mainc, op. eit., s6, $141 \mathrm{ff}$.

2 Maine, op. cit., 142.

${ }^{5}$ Ibill., $141 \mathrm{ff} ., 145 \mathrm{ff}$.

${ }^{3}$ Ibid., 144.

${ }^{6}$ Ibid., $118 \mathrm{ff}$. passim.

7 Ibid., 123, 124, 128. See the table of comparative groups in Schrader, "Sprachrergleichung und Urgeschichte," 394. For the Ionic groups cf. Schömann, "Antiquities," 317,364; "Athenian Constitution,"3-10; Wachsmuth, "Hist. Ant.," I, 342 f.; Müller, "Handbuch," IV, 17-22 ; 
is therefore the result of the expansion of its primordial cell ; ${ }^{1}$ and the genealogical organization of society precedes and overlaps the territorial. All these groups, lower and higher, regard themselves as united by the bond of kinship. But, as a matter of fact, the kinship is often assumed; and the heterogeneity of blood is explained as the result of the fiction of adoption by which relationship is artificially extended and strangers are admitted to the sarra. Without this fiction, says Maine, "I do not see how any one of the primitive groups, whatever were their nature, could have ahsorhed another, or on what terms any two of them could have combined, except those of absolute superiority on one side and absolute subjection on the other." Society could hardly have escaped from its "swaddling clothes." 2 Furthermore, a strong motive for the artificial extension of the family is derived from the worship of ancestors. The earnest desire of the ancients for male issue to perpetuate the family rites has tended to foster adoption, and it probably accounts for the levirate and other similar expedients to provide an heir. ${ }^{3}$

\section{Criticism of the Theory by Spencer and McLennan}

The patriarchal family of the "Ancient Law," whose leading features have now been presented, reappears with slight modification

Grote, "Hist. of Greece," III. 52, 53. In general, cf. Frstel de Coulanges, "Aneient City," 141 ff.; Hearu, "Arvan Household," 63 fif., 112 ff.. passim; Leist, "Graeco-italische Rechtsgeschichte," and "Alt-arisches Jus Gentium."

1 For Freeman's well-known theory of political expansion see "Comparative Politics," chap. iii.

2 Maine, "Ancient Law," $125 \mathrm{ff} ., 26$. On the new mode of adoption in India see Mayne, "Hindu Law and Usage," $\$ 8 \mathrm{ff}$.; Lymll, "Asiatic Studies," chap. vii; "Fortnightly Review,"Jan., 1s77; Jolly. "Hindu Law of Partition," 144-66. On the formation of non-genealogical clans see Hearn, "Aryan Household," $296 \mathrm{ff}$. Cf. Post's discussion of "Künstliche Verwandtschaft" in "Studien zur Entwirklungsgeschichte des Familienrechts," 25-42; Kohler, "ZVR.," V, 41.j-40.

${ }^{3}$ Maine, "Early Law and Custom," chaps. iii, iv, viii. For ancestorworship see especially Fustel de Coulanges, "Anrient City," 9-.)2; Herm, "Arvan Household," 15 ff., 45. 46, 59, 60; Tylor. "Primitive Culture," II ("Animism"); Mayne, "Hindu Law and Usage," 5., 4:38; Lyall, "Asiatic Studies," chap. ii ; Duruy. "ITist. of Rome," I, 206; Zimmer, "Altindisches Leben," 413; Botsford, "Athenian Constitution," 24, 2., passim, who holds against Schroder, "Sprar-hrergleichung" (2d ed.). 613-15, that ancestor-worship arose hefore the separation of the Aryan races. Fustel de Coulanges, "Ancient City," 49-i)1, and Hearn regard the religious tie as of more importance than the hlood-bond in the formation of the gentile groups. "Aryan Household," 66; and Le ist. " Craeroitalische Rechtsgeschichte," $7 \mathrm{ff} ., 11 \mathrm{ff}$., also makes the formation of the first recognized groups of relationship depend on the sacra. r'f. Kohler. in "ZVR.," TI, 409-17, for animism; and for additional references, al subsequent note. 
in the later writings of Sir Henry Maine. ${ }^{1}$ It has been widely accepted. Yet it was inevitable that a theory which on its face appears to neglect many of the most remarkable facts everywhere observable in the social life of primitive men ${ }^{2}$ should arouse most serious doubt. Nor will it do, with Stareke, ${ }^{3}$ to exeuse the author on the ground that his conclusions are intended to be true only for the domain of the law-books, of comparative jurisprudence; for obvioush his language will not bear that construction.

Herbert Spencer was the first writer to subject Maine's hypothesis to a luminous eriticism. ${ }^{4}$ First he points out that Maine has not been entirely guiltless of "the lofty contempt" entertained by civilized peoples for their barbarous neighbors, which he himself censures as a serious error. For he "has practically disregarded the great mass of the uncivilized" peoples, and "ignored the rast array of facts they present at variance with his theory." Nor, in favor of a primitive patriarchal state, is it safe to assume that "the implicit obedience of rude men to their parents is doubtless a primary fact." For, "though among lower races, sons, while young, may be subordinate, from lack of ability to resist; yet that they remain subordinate when they become men eannot be assumed as a uniform, and therefore as a primary, fact." This objection is sustained by reference to many savage and barbarous tribes among which parents exereise little or no control over the children. Again, it is by no means established that "the history of political ideas begins, in fact, with the assumption that kinship in blood is the sole possible ground of community in political functions." On the contrary, "political co-operation arises from the conflicts of social groups with one another;" ${ }^{5}$ and though it may be facilitated by a feeling of common descent, examples of political com-

1 "Early Hist. of Institutions," $64 \mathrm{ff} ., 115 \mathrm{ff.,} 217 \mathrm{ff} ., 306-41$; "Village Communities," 15, 16, prssim; "Early Law and Custom," chaps. iii, iv, and especially chaps. vii, viii, where adverse criticism is considered. Cf. McLennom, "Patriarchal Theory," 1-23, for" a collation of the more important passages of Maine's writings.

${ }_{2}$ "The rudiments of the social state, so far as they are known to us at all, are known through testimony of three sorts - accounts by contemporary observers of eivilization less advanced than their own, the records which particular races have preserved conceming their primitive history, and ancient law." (If these three sources of information, Maine regards ancient law as the best. He fails entirely to appreciate the true importance of the first source, from which, obviousty, are derived most of the data of recent ethniral, and anthropological, and sociological investigation, including murh that Maine himself has presented. C $\mathrm{f}$. the criticisms by speneer, "Principles of Sociology," I, 713, 714; Lubbock, "Origin of Civilization," $6 \mathrm{ff} . ;$ McLeman, "Patriarchal Theory," 29, 30.

3 "Primitive Family," 94, 95.

4 "Prineiples of Sociology," I, 713-37. $\quad{ }^{5}$ Ibid., 716, 717, 540-53. 
bination may be produced in which relationship is not consiclered. Furthermore, it is hard to conceive how so advanced a conception of government as is implied by the patria postestas could exist in the "infancy of society"; " nor has it yet heen proved that in the primitive state the individual is entirely lost in the family group, which holds all property in common. Instances of "personal monopoly" of property among low races are not wanting. Finally the astumption that in the primordial state women remained in perpetual tutelage is without foundation. ${ }^{1}$. . .

But the patriarchal theory has been vigorously attacked in its very strongholds, the laws of the Hebrews and the primitive customs of the Indo-Germanic peoples. The well-known polemic of the late J. F. McLemnan is of special interest in this comnection.? Among none of the Aryan races, the Romans only excepted, does he find the patria potestas or the strict rule of agnation; while among them all, he believes, abundant evidence of original promiscuity and of the maternal system of kinship is disclosed. Eren the Hebrew Scriptures, where Maine perceives "the chief lineaments" of the patriarchal society, ${ }^{3}$ so far from revealing the patria potestas and agnation, bear witness to "beena" 4 marriage

$1 \mathrm{Mr}$. Spencer also points out that Maine does not take into account "stages in human progress earlier than the pastoral or agricultural." Op. cit.. I, $724 \mathrm{ff}$.

" "The Patriarchal Theory," edited and completed by Donald McLennan (London, 1855).

3 “Ancient Law," 11S-20, 123.

${ }^{4}$ The marriage of Jarob with Lahan's daughters is the case in point. In "beena" marriage - the name given to the institution in Cerlon - "the young husband leaves the family of his hirth and passes into the family of his wife, and to that he belongs as long as the marriage subsists. The children born to him belong, not to him, hut to the family of their mother. Living with, he works for, the family of his wife; and he commonly gains his footing in it by service. His marriage involves usually a change of village; nearly always (where the tribal system is in forco) a change of tribe - so that, as used to happen in New Zealand, he may he hound even to take part in war against those of his father's house; hut alwars a change of family. The man leaves father and mother as completely as, with the patriarchal family prevailing, a bride would do; and he leaves them to live with his wife and her family. That this arcords with the passage in Genesis will not be disputerl." "Patriarchal Theory," 42, 43. Nerertheless, in this case MeLennan is certainly mistaken. We have here to do with that form of wife-purchase called "marriage by service:" see Lichtschein, "Die Ehe," 10, 11 ; the argument of II "ilee, "Narriage and Kinship," 239-44; and Fristrichs, "Familienstufen und Eheformen," "ZVR.," X, 207, 208. "Berena" marriage existed, howerer, amone other Semitic peoples and possibly also among the Hebrews: smith. "Kim-hip and Marriage," $108,175-75,146$. It is found also in Afrim and in many other places: Wake, op. cit., 149, 299-301; WcLennen, op. cit., 49; Hestermarck, "Human Marriage," 109, 3s!-90: Tylor, "On a Mothod of Investigating Institutions," 2 if ff.; Starclie, op. cit., Ts; Helludl., "Dio menseh. Familie," 25.5, 266. 
and the recognition of kinship in the female ${ }^{1}$ line. Sir Henry Maine in this connection refers incidentally to Sir Robert Filmer in whose "Patriarchia " the existence of the patria potestas among the ancient Hebrews is alleged. But, as McLennan justly observes, "to those who have stuclied the controversy between Locke and Fihmer" it may seem wonderful that the truth of Filmer's main position could be thus lightly assumed by anyone, and especially by any lawyer, who had read Locke's masterly reply to the pleadings of his opponent." 3 The principal conclusions of McLennan are sustained in a striking way, for a sister-branch of the Semitic race, by the researches of Wilken and Robertson Smith into the marriage customs of early Arabia. ${ }^{4}$ The ancient Hebrews did not have agnation; ret they "traced descent from the father for the purposes of what we may call rank, or a feeling of caste," and this was the source of paternal power. ${ }^{5}$ The house-father exercised a high degree of authority over his wives and children, but he can scarcely be regarded as a patriarch in the strict sense of the term. ${ }^{6}$

1 On the Hebrew family see "Patriarchal Theory," 35-50, 132, 133, $243-47,273,274$ note, 289, 306, 307, 315, passim.

"Filmer's "Patriarchia, or the Natural Power of Kings," appeared in 16s0; Locke's "Two Treatises on Government," in 1690. "Both works are reprinted in the ninth number of Morley's "Universal Library."

"See "Patriarchal Theory," $36 \mathrm{ff} ., 243 \mathrm{ff} ., 273$ note, where a summary of Locke's argument, with additional evidence against the existence of agnation and potria potestas and in faror of an original maternal system anong the Hebrews, will be found.

"Robertson smith, "Kinship and Marriage"; Wilken, "Das Matriarchat bei den alten Arahern," a work suggested by Smith's "Animal Worship and Animal Tribes," "Journal of Philology," 'IX, 75-100. These writers have found among these Semitic tribes the system of kinship through the mother in artual use, with traces of polyandry, exogamy, and the totem gers; and Wilken helieves that he finds evidences of early promiscuity. S'se especially Kohler, "Ueber das vorislamitische Recht der Araber," "ZVR.," VIIİ, 238-61; and Friedrichs, "Das Ehereeht des Islam," ibid., VII, 240-84, especially $255 \mathrm{ff} .$, who shows that the Moliammedan house-father exercises great authority over his wife, vet she has her own property and receives a dower. At present, relationship in Arabia is generally counted in the male line; and therefore, Itestermarck, "Human Marriage," 102, note t, regards the conclusion of Smith that originally the system of female kinship exclusively prevailed as "a mere hypothesis."

5 ir ake, "Marriage and Kinship," 24.

${ }^{6}$ According to Ewald the anrient Hebrew father might "sell his child to relieve his own distress, or offer it to a creditor as a pledge." - "The Antiquities of Israel" (London, 1876), 190; Westermarek, op. eit., 228; and the Levitiral law prescribes death as the penalty for striking a parent (Leviticus 20: 9); Exodus 21:15, 17); but the penalty could only be administered through appeal to the whole community, Itestermarek, op. cit., 228. Cf. Wichatlis, "Commentaries on the Laws of Moses," I, 444, who slows that the mother, as well as the father, might sometimes choose wives for the sons; while MeLennan and Locke prove that the position of the mother in Israel was higher than is consistent with Roman patriarchalism. 


\section{The Theory in the Light of Recent Research}

Let us now see somewhat more in detail what light is thrown by reeent investigation on the controversy between Maine and McLennan. Westermarck has taken great pains to enumerate the uncivilized peoples, chiefly non-Arran, among whom descent and usually inheritance follow the paternal side $;^{1}$ and he finds that the number is "scarcely less" than the number of those among whom the female line is exclusively recognized. But in many of these cases it seems probable that the parental rather than the agnatic sistem prevails, though the male line may take precedence. In some instances rank or authority descends from father to son, while in other respects the female line predominates. Doubtless more frequently than is usually imagined a mixed system rather than a strictly paternal or a strictly maternal sistem would be found to exist. $^{2}$ As the result of his inquiry, Westermarck rejects the hypothesis that kinship through the mother is a primitive and universal stage, though he does not substitute the agnatic theory in its place. Starcke, on the other hand, after an extended examination of the customs of rude races, especially in America and Australia, suggest that the paternal as a general rule probably preceded the maternal system which arose only with the development of the gentile organization. ${ }^{3}$ But Starcke's eridence can scarcely be accepted as convincing.

Similar difficulties are presented by the question of the prevalence of the so-calied patriarchal power among non-Aryan races. Many apparent examples of despotic authority ean be enumerated; but it is often hard to determine whether, as in the cases of the Arabs and Hebrews, we have to do merely with a high degree of

1 "HIuman Marriage," 97-104, notes. Cf. Friedrichs, "Ueber den Ursprung des Matriarchats," "ZVR.," VIII, 371-73; Kohler, ibid., VI, 403 (Korea); VII, 373 (Papuas).

2 Compare Wale, "Mrarriage and Kinship," $267 \mathrm{ff} ., 362 \mathrm{ff} ., 382,396 \mathrm{ff}$; especially Friedrichs, "Familienstuf('n und Eheformen," "ZVR.," X, 20412; and Dargun, "Mutterrecht und Taterrecht," 3. 2S, $11 \mathrm{~s}$, who believed the so-called "mixed systems" are merely a consistent union of two entirely different principles - the principle of relationship with the principle of power or protection.

${ }^{3}$ Starcke, op cit., 26, 27 (Australia), 30 (America), $59 \mathrm{ff} ., 101 \mathrm{ff}$. Com-

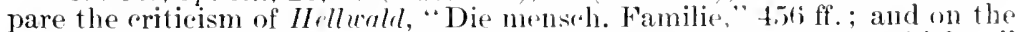
development of the patriarchal family, see Lippert. "Kulturgeselhichte," II, $505-54$.

4 Festermarck, op. rit., 224-35, gives an enmmeration. Noteworthy examples of patriarchal power are afforded hy the ancient Peruvians and Mexicans, and by the modern Chinese and Japanese. (In the Nahua and Maya natives see Bancroft. "Xative Races," II, 247-53, 66i3-6is Cf. Kohler, "Das Rerht der Aztelen," "ZVR.," X1, 54, 5.); also ibril. VI, 374 (Chinese), 333, 334; VII, 373 (Papuas). 
power on the part of the house-father or with a genuine patria potestas of the Roman type. Naturally, as Westermarck suggests, the father's authority anong savages "dlepends exclusively, or chiefly, upon his superior strength ;" 1 while anything like a patriarchal "system" can only arise later under the influence of ancestor-worship and more developed social and industrial conditions. Where anthority depends solely or mainly upon brute force, it is evident that a very protracted patriarchal despotism over the sons is hard to conceive. Noreover, much error has doubtless arisen through falsely assuming that paternal authority and mother-right are incompatible; whereas they may well coexist, as will presently appear.

For the Indo-Germanic or Aryan peoples the investigations of Zimmer, Schrader, Delbrück, Kohler, and especially the researches of Leist, enable us to speak with a higher degree of confidence, though only for the period covered by positive linguistic and legal evidence. Bachofen, McLemman, and after them many other writers, ${ }^{2}$. . . have maintained that among all branches of the Aryan stock conclusive proofs exist of a former matriarchate, or, at any rate, of exclusive succession in the female line. But this view is decidedly rejected, if not entirely overthrown, by the philologists, and depends for its support on the presence in later institutions of alleged survivals. The judgment of Delbrïck must probably be accepted as decisive for the present state of linguistic, if not of all seientific, inquiry. He declares that "no sure traces of a former maternal family among the IndoGermanic peoples have been produced." 3 Similar conclusions are reached by Schrader, Max Müller, and Leist." Also, among the

${ }^{1}$ Wrestermarck, op. cit., 225.

2 Bachofen, "Das Mutterrecht;" McLennan, "Studies," I, $121 \mathrm{ff}$.

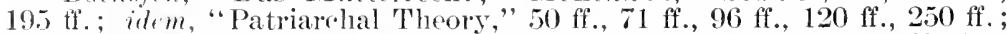
Darguin, "Mutterpecht und Raubehe," 8, 13, passim; Giraud-Teulon, "Les origines du mariage," $130 \mathrm{ff.,} 286 \mathrm{ff} ., 329$ ff. ; idem, "La mère chez rertaines peuples de l'antiquité", Lippert. "Geschichte der Familie," $4 \mathrm{ff} . ;$ Lubbock, "Origin of Cirilization," 153, 154. Kohler. "Indisehes Ehe- und Familiemrecht," "ZVR.," III, 3933 ff., holds that the primitive Aryans must neressarily have recognized relationship through the mother. For the literature of this subjert see the next chapter.

3 Delluruck, "Das Muttrirecht hei den Indogermanen," "Preussiche Jahrbücher," XCVI, 14-27, a clear summary of the results of recent research. (f. his "Die Indogermanischen Verwandtschaftsnamen" (Leipzig, 1sig). According to Ifellwald, "Die mensch. Familie," 453-80, especially 459,460 , patriarchalism was fully established at the earliest dawn of Indic history; but there are nevertheless traces of earlier motherright.

4 Schrader, "Sprachvergleichung und Urgeschichte" (2d ed.), 536 ff.; Jeron's Translation, 369 fl.; Leist, "Alt-arisches Jus Gentium," 51-58. Max Muller leclares that "whether in unkiown times the Aryas ever 
institutional writers, Wake declares that "primitively among the peoples belonging to the wide-spread Aryan or Indo-European stock, while relationship was acknowledged through both parents, descent was traced preferably in the male line ;" ${ }^{1}$ and Bernhöft, constrained through the evidence presented by Schrader and Delbrück, believes that it is now placed "beyond question that the primitive Aryans did not live according to mother-right," but were united in family groups resembling the south Slaronian house communities. ${ }^{2}$ On the other hand, Dargun, the foremost defender of the theory of mother-right, thinks that Bernhöft has "capitulated" too easily. ${ }^{3}$ In his last monograph, entitled "Nutterrecht und Vaterreeht," he maintains essentially the conclusion of his "Mutterrecht und Raubehe," that before their separation the Aryan people had developed the system of kinship "through the mother as the only or chief basis of blood-relationship " and had "subordinated their entire family law to this principle." \& But the later treatise contains a very important modification, or perhaps, more justly speaking, extension, of the author's theory. Setting aside as still an open question the general prevalence of promiscuity or sexual communism at the very dawn of distinctively human life, Dargun conceives that, before any system of kinship, maternal or agnatic, became recognized as a principle of customary family law, there must have existed a family, or rather parentgroup (Elterngruppe), in which the father was protector and master of the mother and her children. This parent-group is the "hypothetical primordial cell of the family," brought together by sexual requirements and the need of sustenance and protection. It is "structureless, devoid of any firm bond, since it rests neither upon the principle of relationship nor that of legalized power." Its resemblance to the patriarchal family, though mislearling, "is not without signifieance." For it "forms the necessary stage of an

passed through that metrocratic stage in which the children and all family property belong to the mother, and fathers have no recognized position whatever in the family, we can neither" assert nor deny." - "Biographies of Worels," xvii.

"Wake, "Marriage and Kinship," $359 \mathrm{ff}$., esperially 382 , where a thorough and detailed critirism of MrLemnan's theory is given.

"Bernhöft, "Die Principien des eur. Familienterhts," "ZVR.," IX. 41S. 419, $437 \mathrm{ff}$. See also his "Römische Königszeit," $202 \mathrm{ff}$; and his artirles in "ZVR.," VIII, 11; IV, 227 ff, ; and compare Dargun, "NInt terresht und Vaterreeht," 91-94, 108. "Starcke, op. cit., 101-18, also gives a searching examination of the theory of MeLennan and the eartier views of Dargun, rejecting their concdusions.

" "Mutterrecht mol Vaterrer.ht," 10s.

"Dargun, "Mutterrecht und Raubehe," 13. Cf. the "Mutterrecht und Vaterrecht," 95, 117 ff., passim. 
crolution which in analogous manner is also passed through by property. Inductively it is still demonstrable that individualism and atomism, not communism, as is usually assumed, are the starting point of evolution." I As a general rule, according to Dargun, the structureless parent-group is superseded by the maternal family, whose basis is mother-right, or the exclusive legal recognition of blood-rclationship in the female line. Only in rare cases does the patriarchal agnatic family follow immediately upon the primitive group, without prior development of motherright ; ${ }^{2}$ and hence, under exceptional conditions hindering the rise of the maternal system, do we find a form of the family in which, from a very early period, the house-father is the source of authority, practical or legalized.

Aside from his theory of evolution, in his principal thesis, which he fairly sustains by powerful argument, Dargun has rendered to science a distinct service. It is, he insists, highly necessary carefully to distinguish between pouer and relationship. "Mother right" does not involve "maternal power" or the matriarchate, though sometimes actually united with it; nor does the headship of the house-father as provider, protector, and master imply agnation, the so-called "father-right." 'There is no contrast between power and relationship. "Nother-right in the sense of exclusive maternal kinship is compatible with a patriarchate just as exclusive." They may, and often do, coexist. It follows that the presence of the maternal system of kinship does not imply the existence of maternal power; just as it does not imply the nonexistence of paternal authority. The distinction between power and kinship is justly declared to be an "indispensable key" for the solution of the greatest difficulties arising in this branch of sociological seience, the disregard of which has often vitiated or confused the argument even of the foremost investigators. ${ }^{3}$ With the aid of his key Dargun examines the linguistic evidence, which he finds favorable to the existence of mother-right among all the Aryan peoples after the separation, though united with a real supremacy of the house-father ; ${ }^{4}$ and he protests vigorously against the tendency, even on the part of Leist, to confound old Indic with old

1 Dargun, "Mutterrecht und Vaterrecht," 41, 42, 4 ff., 28, 29-42, 118, passim.

${ }^{2}$ Ibid., 41.

3 Ibid., $3 \mathrm{ff} ., 28,36,86 \mathrm{ff} ., 155$, passim. As remarked in the text, the whole work is concerned with the thesis in question. The distinction is also made in the "Nutterrecht und Raubehe," 18.

"See "Mutterrecht und Vaterrecht," $86-116$, for his criticism of the linguistic argument. 
Aryan law; for the "Indians of the Vedas are in many respeets more advanced than the Germans a thousand or the Slars two thousand years later." 1 Valuable as the criticism of Dargun undoubtedly is, notably his distinetion between power and relationship, it can scarcely be admitted that he has done more than reopen the question of the existence at any time of mother-right among the Aryans. His results are negative. He has not shifter? the burden of proof ; while his argument tends to confirm the view of the philologists that from the primitive stage the Aryan father was head of the household. ${ }^{2}$

But the patriarchal theory, strictly considered, fares little better than the maternal at the hands of recent investigators. Leist, who has been able with wonderful completeness to reconstruct the juridical life of the early household, though largely on the basis of old Indie sources, declares positively that " the Aryan people has not within itself a single element of patriarchalism." ${ }^{3}$ This statement, as Bernhöft observes, ${ }^{4}$ is perhaps too sweeping, even when tested by the results of Leist's own researches; but the patriarchal family of Sir Henry Maine does not appear. The evolution of juridical conceptions among the old Aryans, according to Leist, presents two general phases. First is the rita stage, or period of fixed, divinely appointed order, of natural law, corresponding to the Greek cosmos or plussis and the Latin ratum or ratio naturalis. In this "natural history" or pantheistic stage there is at first little idea of law as something to be separately con-

1 Ibid., 91, 92. Cf. a similar protest against conclusions as to the primitive Aryans derived from Greet and Roman sources, ibid., 116; and "Mutterrecht und Raubehe," 14.

2 "Mutterrecht und Vaterrecht," 69 , denies that women have ever attained political headship; but $(113,114)$ derlares, though the researches of the philologists make it probahle that the Aryans lived under the rule of house-fathers, that neither this fact nor any other circumstance tells against the view that mother-right coexisted from antiquity; while, in a still more remote period, this may have implied matriarchal power in the family; but of such a matriarchate no proofs are presented.

${ }^{3}$ Leist, "Graeco-italische Rerchtsgeschichte," 64 . This work is continued in the "Alt-arisches Jus Gentium," the two books really constituting a single treatise. Compare the more conservative view of "Jolly. "Ueber die rechtliche Stellung der Frau," 4 ff., 20-22, and "Hindu Law of Partition," $76 \mathrm{ff}$., who, however, denies the existence of an authority on the part of the Hindu husband equal to that of the Roman patcr.

"Bernhöf, "Zur Geschichte des eur. Familienrechts," "ZVR.," VIII, 12,15 , who also regards the view of Dargun, "NIut terrecht und Raubehe," 8, 13, as extreme. Cf. his "Principien des eur. Familienrechts," "ZVR.," IX, 416, n. 39. Kohler favors the patriarchal system and agnation for the Indic peoples, in "ZXR.," VII, 201, 210, 216;"X. S.. Hearn." Aryan Household," chaps. iii-ri, passim. talies plartirally the same riew as Maine regarding the patriarchal theory, rejecting entirely for the Aryans the matriarchal hypothesis. 
templated. Ender rita is eomprehended the unchangeable order observable in the material world as well as in the physical and social life of man; but the universe and the creative energy, the All and Varmua, are identified or blended in thought. ${ }^{1}$ Only slowly are these concepts differentiated and the immutable order of nature becomes looked upon as dhama, or a holy ordinance established by Varuna, who now appears as a protecting and creative spirit.

Dhama thus forms a means of transition to the second juridical phase, that of dharma, or divine law, corresponding to the Greek themis and the Latin fas. ${ }^{2}$ In the dharma period, law is regarded as inspired by the gods, whose earthly agent, the priest or heroking, is intrusted with its application; and in it the rules governing civil and public conduct, according to modern conceptions, are not distinguished from those relating to manners, morality, or religion. When history dawns, our early Aryan ancestors had already entered the dharma phase of evolution; and even now the Hindus have scarcely gained the third phase, prevailing in the civilized West, in which the element of "civil law" is separate from all other ingredients. ${ }^{3}$

Of the family relations of our primitive ancestors in the rita period we know little, except through inference or analogy. The so-called "natural forms" of marriage by purchase and capture were doubtless practicel, but probably not exclusively ; and these customs were handed down to the second period, though they were modified to bring them into harmony with the higher ethical and

I The rita-conception is well expressed by Dr. Botsford: "This mankind learned from the revolution of sun and stars, from the suecession of the seasons, from the unchanging movements of nature. The conception thus gained was transferred to human modes of activity. The sexes in marriage were subject to the naturalis ratio, as well as the continuance of the race through suecessive generations. The relation of parents to children with their reciprocal obligations and privileges - the protection and support which the father, as the stronger, offered, the hind care of the mother for her infants, the reverence and affection with which the children requited their services, the love of youth and maiden, leading to marriage - all these rested, in the rita period, on the one foundation of natural law." - "Athenian Constitution," 29, 30.

2 The disenssion of the two general phases of rita and dharma, with their transitional stages, constitutes one of the most valuable parts of Leist's contribution to comparative jurisprudence: "Alt-arisches Jus Gentium," 3, $111 \mathrm{ff} ., 132,133,174$ ff., 606; "Graeco-italisehe Rechtsgeschichte," 175-2s5. Cf. Bot.ford. op. cit., 21, 25, $26 \mathrm{ff}$., for an excellent account; on the Roman stages see Muirhead, "Private Law of Rome," 14-23; and for the Greek themis and the themistes of the hero-kings consult Maine. "Ancient Law," chap. i.

${ }^{3}$ For a tlefinition of tharma see Bernhoft. "Ueher die Grundlagen der Rechtsentwicklung bei den indlogermanischeu Tölkern," “ZVR.," II. 266 fi., $261 \mathrm{ff}$. 
social ideas which had then gained predominance. ${ }^{1}$ Whether or not the absolute power of the father and the strict rule of agnation prevailed it would be as difficult to affirm as to deny.2 In the dharma period the ancient rita conception of marriage as an ordinance of nature, whose real purpose is to provide posterity, is still retained; but it gains a social character. ${ }^{3}$ The central principle of the Aryan household is the Hestia-Vesta cult, or the worship of the sacred hearth. To gain the protection of the ancestral gods the hearth-fire must be kept always burning; and the care of the family sacra is the special function of the house-father, who is lord and priest of the family. But the house-mother holds a worthy position in the domestic worship. From the first kindling of the hearth-fire at the nuptials, she appears as co-priestess and helper of her husband in the sacred rites. The whole life-partnership of the wedded pair is shaped and dominated by lofty religious motives. The Aryan housewife is not the chattel of her husband; she is a free woman and shares in his highest sacred functions. The primary purpose of the union is the birth of a legitimate son to perpetuate the paternal line and to foster the ancestral cult. ${ }^{4}$ So paramount is this motive that, in ease no son is born in wedlock, resort may be had to adoption, or to analogous expedients for the fictitious extension of fatherhood. For among the Aryans, as Maine suggests, the fiction of adoption is of the highest legal importance; and, indeed, very widely among the races of man-

${ }^{1}$ Leist, "Alt-arisches Jus Gentium," 122 ff., 125-33.

2 Botsford, "Athenian Constitution," $10 \mathrm{ff} ., 21 \mathrm{ff} ., 25 \mathrm{ff} .$, divides the rita period into two stages: that of the "primitive Aryan Iousehold," and that of the "early Aryan household," and thinks that the latter stage is represented by the house-communities of the southern Slavs; but this may be doubted. Dr. Botsford favors the existence of agnation and the absolute power of the father in the rita period; and believes that the liberal tendencies, presently to be pointed ont, are a development of the dharma period, beginning before the separation (24-26). On agnation and the power of the early Aryan house-fathers see Schrader. "Sprachvergleichung und Urgeschichte," $3 \$ 6$ ff.; Zimmer, "Altindisches Leben." 319 ff'., $326 \mathrm{ff}$.; Delbrück, "Die indogermanischen Verwand tschaftsuamen," 352, 586-88, 543, 544; Jolly, "Ueber die rechtliche Stellung," etc., 4 fi., 20-22 ; "Hindu Law of Partition," $76 \mathrm{ff}$.

${ }^{3}$ Leist, op. cit., 80.

4 On ancestor-worship. in connection with the literature already cited, p. 13, note 4, see Leist, "Graeco-italisehe Rechtsgeschichte," 7 fl., $121 \mathrm{fl}$.; "Alt-arisches Jus Gentium," D!-11s; Zimmir. "Altindisches Lehen," 318; Schneider. "Die Naturvölker," I, 202 ff., II, 64 f., 75, 76. 10s. 126 t.. 25.5 ff., 369; Kohler. "Indisches Fhe- und Familienrecht," "ZVR.," 1 II. 408 ff.; "Studien üher künstliche Verwandtschaft," ibid., V, 423-25; also for the Papuas, ibid., VII, 37:3. For the influenee of aneestor-worship among the Slavs see Koralewsky. "MIod. Customs and Anc. Laws of Russia," $33 \mathrm{ff}$; among the Ameriran aborigines, Pcet. "Ethnographio Religions and Ancestor-Worship," "Am. Antiquarian," $\mathrm{XV}, 230-45$, and "Personal Divinities and Culture Heroes," ibid., 345-72. 
kind it has served a uscful purpose in social progress. ${ }^{1}$ Here also the Aryan wife appears as co-priestess with her husband. Each is regarded as having a share in the begetting of the child, and they unite in giving the som in adoption to another household. ${ }^{2}$ Accordingly the wife is not the nuere chattel of her husband, who owns the children by virtue of his proprietorship in the mother. ${ }^{3}$ The house-father appears in the sacred books as lord of the wife, who owes him reverence and obedience; yet she is not reduced to patriarchal slavery. With the husband she exercises joint control over the sons; and these are released entirely from parental authority when they marry and establish new households. ${ }^{4}$ The male line takes legal precelence; but the maternal kindred are clearly recoguized in a way wholly inconsistent with strict agnation. According to the primitive Indic conception the wife is regarded as incapable of property. Neither the widow nor the daughters could inherit, the estate passing to the sons as in theory

1 McLennon, "Patriarchal Theory," 10-14, 275 ff., 282, 284, 294 criticises Maine's theory of adoption. Kohler's investigations show that adoption, artificial brotherhood, milk-kinship, and like institutions have widely prevailed and rendered important service. Adoption, he holds, may arise in different motives; sometimes being due to sexual conmunism, when it is a means of assigning the children to particular fathers; but very generally arising in the desire for descendants to perpetuate the family-worship: "Studien über die künstliche Verwandtschaft," "ZVR.," $\mathrm{V}, 415-40$; see also for much important matter his various other writings in "ZVR.," III, 40S-24, 393 ff. (India); VI, 190 (Chins), 345 (Indian Archipelago), 377-79 (China). 403 (Korea); VII, $218 \mathrm{ff}$. (Punjab); VIII, 100 (Rajputs), 109-12 (Dekkan), 243, 244 (Arabia). See also Post, "Familienrecht," 25-4", for an interesting account; also Maine. "Hindu Law and Isage," (60 ff., 77, 99-207; Leist. "Alt-arisches Jus Gentium," $103 \mathrm{ff} ., 115,606 ;$; Tornaww. "Das Erbrecht nach den Verordmungen des Islams." "ZVR.," V, 151 ; Friddrichs, "Familienstufen und Eheformen," ibirl., X, 237-45; Starcle, "Primitive Family," 146, 233 ; Huc, "Chinese Empire," II, 226.

${ }_{2}^{2}$ Lrist, op. cit., 103, 115, $50 \pm \mathrm{ff}$. On the position of the house-mother cf. II carn, "Arran Household," \&(j-91.

${ }^{3}$ Leist, op. cit., 122, $12 \%, 126 \mathrm{ff}$, successfully combats the theory of Kohler ("Indisches Eho- mul Familienrecht," "ZVVR.," III, 394), who declares that it is a cardinal principle of Indo-Germanic legal evolution that "Wie Vatersehaft l suht anf dem Rechte des Mannes am Weibe, kaft dessen dem IIansrater das Kind des Weibes zukomme, ebenso wie dem Eigenthïmer des Feldes die Frumt." The same view is expressed by Kohler in "Krit. Vjschr," N. F., IV, 17, 18; and in "Vorislamitisehes Rerht," "ZVR.," VIII, 242. Cf. Unger, "Die Ehe," 11, 77; Lippert, "Cieschichte ler Familie," $95 \mathrm{ff} ., 99,15 \mathrm{~s}$.

4 Althongh the married son possessed a hearth and was a free member of the grns." his house dicl not herome fully independent in religious and property matters till the death of the father and the final division of the property." - Bot.ford, "Athenian Constitution," 27, and the sources there rited. Cf. Zimmer, "Altindisches Lehen," 326 ff.; Leist, "Altarisehes .Jus (rentium," 124.

5 McLemnan, "Patriarchal Theory," chaps. xvi, xvii; Leist, op. cit., $124,504 \mathrm{ff}$. 
a means of providing for the saera of the deceased house-father. Still the bride possessed her personal belongings - her couch, clothing, and ornaments; and from this germ gradually arose, beginning even in remote antiquity, her existing rights of property and inheritance. In short, the old Aryan household reveals but the elements of agnation and the potestas as they appear in the Roman law. ${ }^{2}$

This conclusion is confirmed by the customs of the Aryan peoples after the separation. Among the Hellenes at the first dawn of history the family appears as a member of the gens, which is held together usually by the ties of blood-relationship. The housefather is lord or monarch of the family. But his authority is tempered in various ways. Originally, as among the primitive Aryans, he may have exercised the power of life and death over his children; but in no case could he "put a child to death witiont the consent of the collective ancestors," or near lindred. ${ }^{3}$ By the Aryans the jus vitae necisque was never looked upon as an arbitrary right of destruction, but merely as a means of domestic discipline." The Greek father might sell his minor sons and unmarried daughters; but "it appears that, even here, merely the labor of the routh,

${ }^{1}$ Leist, op. cit.. 496-508; Kohler. "Indisches Ehe- und Familienrecht," "ZVR.," III, $424 \mathrm{ff}$.

"Leist, "Graeco-italische Rechtsgeschichte," 95, 96. Lack of spare prevents any attempt at a detailed discussion of the old Aryan or Indie family and matrimonial law; a general reference must suffice: Lrist, "Alt-arisches Jus Gentium," 59 ff., 496 ff.; "Graeco-italische Rechtsgeschichte," $7 \mathrm{ff} ., 57 \mathrm{ff}$, pessim; Schrader, "Sprachrergleichung und Urgeschichte," 379-95; Zimmer," Altindisches Leben, "30.-36 ; Jolly." Rerhtliche Stellung," 1 ff.; idem, "Hindu Law of Partition," 70 ff.; Kohler, "Indisches Ehe- und Familienrecht," "ZVR.," III, 342-442 ; and his varions articles, ibid., VI, 344-46 (Indian Archipelago and Caroline Islands); VII, 201-39 (Punjab) ; VIII, s9-147, 262-73 (Indian customary law); IX, 323-36 (Bengal); X, 66-134 (Bombay); XI, 163-74 (Indian Northwest Provinces); Botsford, "Athenian Constitution," 2-67 (cxcollent); Wake, "Marriage and Kinship," $159 \mathrm{ff} ., 355 \mathrm{ft}$. index: Bernhört. "Altindisches Familienorganisation," "ZVR.," IX, 1-45; MeLeman, "Patriarchal Theory," $50 \mathrm{fl} ., 96 \mathrm{ff}$., especially the chapters on "sonship anong the Hindoos," 266-339, combating the view of Maine, "Early Law and Custom," 7S-121, 232 ff.; "Early ITist. of Inst.," $116-1 \mathrm{~s}, 3 \mathrm{i} 0 \mathrm{fl}$ : and Mayne, "Hindu Law and Usage," $50 \mathrm{ft} ., 60 \mathrm{ff} .$, passim; Starelu. "Primitive Family," 100 ff.; Letourneru, "L'évolution du mariage," index ; Ilearn, "Arran Household"; Unger, "Die Ehe," 21-27; Buder." La femme dans l'Inde antique." $39 \mathrm{ft}$.: Jacolliot, "La femme dans l'Inde," $7 \mathrm{ff}$.

${ }^{3}$ Botsford, "Athenian Constitution," 50 ; Leivt. "Ciraero-italische Reehtsgeschichte," $59 \mathrm{ff}$. If estermarek, "Human Marriage," 230, justly observes that the power of the father among the Cireeks. (iermans, and Celts, "to expose his rhildren when they were very young and to soll his marriageable daughters, does not imply the possession of a sorererignty like that which the Roman house-father excreisel over his desondants at all ages."

${ }^{4}$ Leist, op eit., 60, and $59 \mathrm{fr} .$, for his diseussion of the Aryan (nustom of exposing new-born "hildren. 
and not the person itself was disposed of by sale," and the eustom was controlled by the usage of the gens." The wife, as among the Hindus, holds a dignified position in the household. She is her husband's partner in the domestic economy and the saered rites. Equally with him she is " the cause of the son's existence," and in consequenee exercises over him conjointly with the father the powers of sale and life and cleath. ${ }^{2}$ Thus Hellenic custom preserves the essential element of the Aryan paternal authority, which signifies a protecting, not an arbitrary or ruthlessly destructive, power. Among the historie Greeks the agnatic principle finds expression especially in the right of guardianship, which is transmitted in the paternal line. Such is the judgment of Leist, whose masterly account of the devclopment of the Aryan agnatic conception proves that here as elsewhere the Roman and the Greek stood upon common ground. ${ }^{3}$ The point of divergence is the lifelong eontinuance of the Roman potestas; whereas in Hellas the son was emancipated at maturity. ${ }^{4}$

Examination of the eustoms of the Celts, ${ }^{5}$ the Slavonians, ${ }^{6}$ and ancient Germans leads to a like result. Accordingly we are foreed to admit the aceuraey of Gaius's conclusion. Writing in the

${ }^{1}$ Botsforl, op. cit., 51; Fustel de Coulanges, "Ancient City," 118, 120, notes ; Plutarch, "Solon," 13.

2 Botsforl, op. cit., 52; Leist, op. cit., 57, 58, 64, $11 \mathrm{ff}$.

${ }^{3}$ Le ist. $57-102$.

${ }^{4}$ In the post-Homeric age agnation did not exist; see Botsford, op. cit., 73. In general on the Greek family see Hruza, "Ehebegründung nach attischem Rechte," \& ff.; McLennan, "Studies," I, 121-23, especially the essay on "Kinship in Ancient Greece," ibid., 195-246 (favoring the maternal system); Botsford, op. cit., chaps. i, ii, iii, supporting the patriarehal theory; but Dr. Botsford's patriarchal family is not that of Sir Henry Maine; Lasaulx, "Zur Gesch. u. Philos. der Ehe bei den Griechen," 3 ff.; Dargun, "Mutterrecht und Raubehe," 2, 3, 14; Giraud-Teulon, "Les origines," ete., 2\$6-301; Wake, "Marriage and Kinship," $24 \mathrm{ff}$., $355 \mathrm{ff} ., 366 \mathrm{fi}$., who eriticises Mr.Lennan's view in detail for the Aryan peoples; Kocalewsky, "Tableau," 35, 36; Bernhöft, "Das Gezetz von Gortvn," "ZVR.," VI, 281-301, 430-40; and his "Ehe- und Erbrecht der gricehischen Heroenzeit," ibid., XI, 326-64, both articles being of great value: Kohler, "Die Ionsage und Vaterrecht," ibid., V, 407-14, who proves the existence of "judicial" fatherhood ; Hestermarck. "Human Marriage," 232. 233; C'nger, "Die Ehe," 52-65; Bader, "La femme greeque," I, $41 \mathrm{ff}$.; II, $1 \mathrm{ff}$. See also IIearn, "Aryan ITousehold," and Fustel de Coulanges, "Ancient City," for much valuable matter.

5 Mclennan, "Patriarchal Theory," 120-31 ; "Studies," I, $68 \mathrm{ff.,} 118$; Giraun-Trulon, "Les origines," etc., 329-32; Koralewsky, "Tableau," 31. 32; Waine, "Early Hist. of Inst.," $216 \mathrm{ff.,} \mathrm{passim.}$

${ }^{6}$ The South Slavonian house community is an early institution; see Krauss, "Sitte und Brauch der Südslaven," $2 \mathrm{ff} ., 64-128$; Botsford, op. cit., 12-21; Giraud-Teulon, op. cit., 340, 341 ; McLennan, op. cit., 71-119; Maine, "Ancient Law," 11s; "Early Law and Custom," 232-82. But it is not primitive. Kovalusky, "IIod. Customs and Ane. Laws of Russia," rhaps. i, ii, finds many survivals, as he believes, of an earlier maternal system of kinship and suecession. 
time of the Antonines, he declares his belief that the patria potestas is peculiarly a Roman institution. Only among the Asiatic Galatæ had he observed a similar authority exercised by the father over his children." Instead of existing " almost every where," of ten preserving as in a mold the imprint of the paternal power which it has outlived and upon which it is thought always to depend, among Aryan peoples agnation is found together with the potestas only in one instance, that of the Roman law; and even in this case it was virtually the first to expire. ${ }^{2}$ For, as is well known to the student of Roman jurisprudence, strict agnation, as determining right of succession, disappeared under the influence of the edict and imperial statutes long before the last vestige of the real patria potestas was swept away by the legislation of Justinian. ${ }^{3}$

Furthermore, in addition to the historical difficulty, there is another strong reason for doubting the dependence of agnation upon patria potestas: the inconsistency of the latter in its effects upon kinship. If the descendants of married women are excluded from relationship, solely on the ground that they belong to another potestas, why, for the same reason, should not the children of men, say of brothers sui juris, ${ }^{4}$ be likewise mutually excluded? Plainly some more satisfactory explanation of this remarkable discrimination between the sexes must exist. Such an explanation McLennan finds in exogamy, or the custom which forbids marriage between persons of the same group of acknowledged kindred. ${ }^{5}$ It seems probable that in early times the patrician family was coextensive with the gens. Agnatio and gentilitas were equivalent expressions. ${ }^{6}$ During the historical period, at any rate, gentilitas is traced through the male line; and it is not impossible that originally intermarriage was forbidden between those bearing the

${ }^{1}$ Gaius, I, 55, Poste, 61.

2 Such is the view of McLennan, "Patriarchal Theory," 136-10, $181 \mathrm{fi}$., $205 \mathrm{ff} ., 214,260-62$, where Maine's theory of agnation is criticised.

3 "The last vestiges of the two disappeared from the law together. But, in fact, agnation went first. The paternal powers were susceptible of abridgment and restriction in various wars short of extinction. The wife might become free from them; the children also; and ret they might remain for the slaves. And it was thus gradually that they perished. But agnation is perfect, or it ceases to be agnation. And the moment the ties of blood through women received civil effects agnation was no more." - "Patriarchal Theory," 182. On the decay of agnation and patria potestas see sohm, "Institutes," 357, 358, 3\$9-93, 435-47; Puchta, "Institutionen," II, 18. 384ff., $431 \mathrm{ff.,} 457 \mathrm{ff} . ;$ M Mirhead. "Introduction to the Private Law of Rome," 422 fi.. 343-49; Maine, "Ancient Law," chap. v ; Morey. "Roman Law," 78, 129, 150, 240-43, 24 s.

4 MeLennan. "Patriarchal Theory," 190.0 "Ibid., 194. 19.).

'Ibid., 204-14. Cf. Muirhead, "Introduction to the Private Law of Rome," 43. 
same gentile name.' In that case, agnation appears as the natural result of the gentile rule of exogamy, retained, after the weakening of the gens, for the regulation of succession within the family. Exogamy, however, does not necessarily imply the patria potestas, but is found more frequently perhaps with the maternal than with the paternal system of kinship.2 In fact, for the Romans and kindred Italic tribes, considerable evidence has been collected by various writers pointing, as they believe, to an early transition from the maternal to the cognatic or the agnatic system. ${ }^{3}$ While this conclusion may be rejected, it must nevertheless be admitter that criticism of the patriarchal theory has been very successful in its general results. It appears to have established beyond question the complex and highly artificial character of the Roman family. So far from being the type of early social organization, it is seen to be relatively modern and ill fitted to the condition of primitive men.

${ }^{1}$ Plutarch, "Roman Questions," VI, tells us that "in early times the prohibition of marriage extended as far as the tie of blood; and, if this be received, it involves - since the gentiles considered themselves to be of the same blood - that there could not be marriage between persons of the same gens." - McLennan, op. cit., $206,207$.

${ }^{2}$ Leist, "Graeco-italisehe Rechtsgeschichte," 59, 96, also denies (against Marquarlt, "Privatleben," I, 22, 29) that the distinctive feature of the Roman family is dependent on the patriarchal authority, sinee the elements of agnation and paternal power are Aryan. Bervihoft. "Germanische und moderne Rechtsideen im rezipirten rom. Recht," "ZVR.," IV, 234 , holds that Roman agnation does not depend upon blood-relationship, but upon power; and this was an Aryan charaeteristic; idem, “Röm. Königszeit," 69 ff., 94, 201. MreLennan's hypothesis is plausible, though not strongly" supported by proof. Cf. Starcke, "Primitive Family," 101: Hake, "Marriage and Kinship," 384, 385.

${ }^{3}$ Such are' the isolated facts comprised in the early annals which seem to imply acknowledged kinship in the female line, even precedence of the latter; the fact that the status of slaves, illegitimate children, and the children of concubines was determined by the condition of the mother; the efferts of marriage hy usus; the supposed evidences of former wiferapture and wifo-purchase, marking the transition to the agnatic system; the instances of wife-lending, as by the elder Cato; and especially the plebeian element; for cognation, not agnation, prevailed among the plebeians, and possibly among them kinship was at first eounted only through the mother; see Dargun. "Mutterrecht und Raubehe," 9-13, 14. "MIutterrecht und Vaterrecht," 115; Bernhöft " Zur Geschichte des europäischen Familienreehts," "ZVR.," VIII, 197-201; "Germanische und moderne Rechtsideen im rezipirten röm. Recht," ibir., IV, 227 ff.; "Staat und Reeht der röm. Königszeit," 192, 202-7; Giraud-Teulon, "Les origines rlu mariage," 408-26; Sohm, "Institutes,"360, 361, notes ; Karlowa, "Die Formen iker röm. Ehe," $1 \mathrm{ff.}$; McLennam, "Patriarchal Theory," $194 \mathrm{ff}$., $205 \mathrm{ff} ., 259 \mathrm{ff}$.

"Die Ehe des römischen Civilrechts (justum matrimonium) war eine formgebundene, durch und dureh künstliche Institution." - Dargun, "Matterrecht und Raubehe," 10. Cf. Beruhöft, "Staat und Recht der röm. Königszeit," $196 \mathrm{ff}$. 


\section{Chapter XI \\ TOTEMISM AND EXOGAMY}

\section{Section 1}

\section{EXOGAMY AS A SURVIVAL OF GROUP MARRIAGE 1}

1. As a survival of the system of group-marriage, the principle remained, that marriage should not take place in the same group, but in another. This was accomplished as follows:

2. A member of the group A was obliged to marry a member of the group B; this is called exogamy ; and a distinction is made between positive and negative exogamy. In the former, a certain group is designated, from whieh the man must ehoose his wife; in the latter he may not marry in his own group, but he may marry a woman out of any other. When the group system and totemism decayed, the principle was retained that no one should marry one of his immediate kin, and a eertain remoteness of relationship hat to exist before a marriage was permitted. This system has transplanted itself more or less into eivilized ages; in such a manner, however, that the group of persons between whom marriage was forbidden has shrunk more and more; so that the circle of those who might marry each other has grown ever willer. But, to a certain extent, the system of exogamy has remained, especially in this, that marriage between brothers and sisters, between parents and children, and between certain degrees of relationship in law, is forbidden. This is not entirely without reasonable fommation. One reason is of hygienic nature: it is assumed that there is reason to fear that marriage between immediate relatives leads to legeneration or to sterility ; certainly pluysical and mental family defeets should not be accentuated by such marriages, but should be effaced by marriage with members of other families. A second reason is that different families should form some connection with one an-

1 [Reprinted, by permission, from Josef Kohlier, "Philosophy" of Law," (Albrecht's trans.), Boston Book Company, 1914 (Plilosophy of Law Series, Vol. XII).] 
other, so that the structure of the State may be firm and close, and not shaken by friction between the various clans or families that compose it; and there is no firmer tie than that formed by marriages between different families. A third reason is ethical in charaeter. 'The development of sexual passions within the immediate family eirele must be prevented, and this can be best accomplished by making sexual relationships in the family itself detested, so that sexual life between members of the same family may be inconceivable. In this way, culture has artificially created a horror naturalis - a phenomenon of frequent appearance; culture creates a second nature, of whieh, however, the philosophy of law in earlier times had not an inkling.

\section{SECTION 2}

\section{ORIGIN OF EXOGAMY AND TOTEMISM ${ }^{1}$}

Exogamy is manifestly the greatest and most far-reaching of taboos. By this taboo every one is affected. Something is forbidden, - a taboo is always prohibitive of something, and, if we want to understand why anything is forbidden, we ask "to whose interest is it to prohibit this or that; cui prodest?" Usually the persons who reap advantage by a taboo are the seniors of the community, the makers of customary law. Were any seniors ever interested in prohibiting all sexual unions (except their own) within any given circle? I think there were such seniors!

As to the origin of Exogamy, I eonceive, (following Mr. Atkinson in his "Primal Law"), that man efwelt originally, as in Darwin's opinion, in small family groups, the Sires in each case expelling the young males when they were arriving at puberty. The Sires are the interested seniors for whom we are looking! "The younger males, being thus expelled and wandering about, would, when at last suecessful in fincling a partner, prevent too elose interbreeding within the limits of the same family," says Darwin. ${ }^{2}$ The sire among horses, stags, (and gorillas, according to Darwin), thus expels the young males through no idea of "ineest" in unions of brother and sister, mother and son, through noaversion to unions of persons elosely akin by blood, but from animal jealousy. Darwin supposed that man dirl not cease to be fiercely jealous as he

${ }^{1}$ (By (the late) Andrew Lang. Reprinted, by permission of Mrs. Andrew Lang' and the Folk-Lore Society, from "Folk-Lore" (London), Vol. XXIV, No. 2 (July 1st, 1913). This is a detached chapter from an unpublished manuseript.]

2 Darwin, "The Descent of Man" (2d ed.), vol. ii., p. 395. 
became human. The expulsion of young males was a practical enforcement of exogamy, of marriage out of the brutal herd, out of the sarage camp.

As progress alvanced, I conceive that the sire was moved, (by the tears, perhaps, of some female mate, in Mr. Atkinson's theory, and by a softening of his own heart, now becoming human), to let the son of his old age, his Benjamin, remain in the camp, so long as he did not interfere with any of the females, but found a mate outside the group. The custom of brother and sister avoidance, among tribes known to Mr. Atkinson in New Caledonia and other isles, seemed to him a result of this law. Mr. J. M. Robertson calls this idea "a violent assumption of a dramatic reconciliation effected by a mother between father and son on the basis of exogamy for the latter: we are unable to see how the happy solution was repeated all through the species." 1

Does not Mr. Robertson believe in the blessed words Natural Selection and Survical of the Fittest? He appears to admit that "early" man, like the gorilla and wild bull" (and many other animals) of "to-day, forcibly expelled or slew his male young when they aroused his jealousy." If early man did so, man not so earlỵ. left off doing so, certainly ; and for that he must have had some reason, and some early men must have begun the practice of permitting the young males to remain in the camp or fire-circle, but not to choose a mate within it. They were of milder mood; the mothers, too, were growing more maternal; had it not been so, we should all be more brutal than we are at this moment. Then came in Natural Selection. Groups which contained several fine young males would be " the fittest," would overcome in all encounters groups with only one male, perhaps a tottering old male; and the fittest groups would survive. The reform would be imitated by other groups till " the happy solution was repeated all through the species."

Mr. Atkinson merely gave dramatically, in his remarks on the mother, son, and sire, an example of the way in which advancing humanity might modify the old brutal custom.

MY theory is practically that of Mr. Atkinson. The expulsion of the young sons by the sire was his unspoken enforcement of exogamy. The irlea is Darwin's, it is not that of an amateur naturalist: hypnotised by no belief in the promiscuity of the earliest men. With them, solitary and fierce, my theory of exogamy begins. 
Mr. IIowitt, if I understand his meaning, thought that exogamy arose in a society which, save for exogany, was as advanced as that of an Australian tribe of to-day. After quoting two tribal legends of the rise of exogamy, (legends of an opposite sort are ignored), from the dividing of the tribe into phratries, "with intent to regulate the relations of the sexes," Mr. Howitt says, "I can see very clearly how such a social change might be brought about. . . . Such a man," (a voyant, a medicine-man), "if of great repute in his tribe, might readily bring about a social change, by announcing to his fellow medicine-men a command received from some supernatural being such as Kutchi of the Dieri, Bunjil of the Wurunjerri, or Daramulun of the Coast Murring. If they received it favourably, the next step might be to announce it to the assembled headmen at one of the ceremonial gatherings as a supernatural command, and this would be accepted as true without question by the tribes-people." 1

But this theory postulates the modern organised tribe, with a supreme All-Father, a probouleutic council of medicine-men, a Boule of headmen, with ceremonial gatherings, and tribal consent.

To such a tribe, hitherto promiscuous, the headmen announce that, by a supernatural command, they must so arrange themselves that no man may marry his mother, nor any woman of her tribal status, nor his sister, nor any woman of her tribal status, nor any woman in his own division of the tribe. The tribe accept a proposal so contrary to their previous promiscuity. But why Daramulun issued this edict, if he did, or why the medicine-man conceived such a curious idea, no theorist who believes in this legislative action ean make even a guess. A theory which postulates that, when exogamy arose, tribes were organized on the present model; a theory which postulates a decree totally bereft of any plausible motive, and conducing to no perceptible advantage to any mass or class of men, seems to me futile. It merely re-states the facts, - there is at present an exogamous division which prevents marriages of some consanguine and of many more nonconsanguine people, - but why there is such a division Daramulun only knows! My theory answers the question, cui bono? "Who has an interest in enforeing an exogamous decree?" Mỹ guess, adopted from the greatest of naturalists, Mr. Darwin, is obliged to contradict the theory of Mr. Howitt at every point. I suppose the "primal law" of the half-brutal sire to have persisted in local groups longer, owing to the armission of sons with their alien mates, I "The Native Tribes of South-East Australia," pp. $89,90$. 
than the harem of the old sire. There was as yet no organiserl tribe: the groups preserved the ancestral jealous hostility. This can neither be proved nor disproved, but the hostility is the kerstone of my arch.

As to primal hostility of groups, it is a curious fact that, in the Banksian island of Mota, the two veve, (or intermarrying phratries), "in the old days . . . hated one another, and even now there is a feeling of hostility between the two. . . There are a number of customs of avoidance which receive their most natural explanation as evidence of this old feeling between the two divisions." " Given hostility, to obtain wives from each other, men, on my theory, had recourse to robbery.

I would add, that if brothers and sisters were allowed to make love to each other, (and the boys to their mother, which seems hardly conceivable), the family circle must, on occasion, have been broken up by murders and revenges, red revenge between sire and son, brother and brother. No small society could have lived if such amours were permitted. Nan had thus good human reasons for slaying such amorists; otherwise capital punishment is all but unknown to savage law.

I next suppose the local groups to have come to distinguish each other by names derived usually from animals, more rarely from plants, for totem kins are so distinguished. For my reasons and mỵ answers to objections I must refer to my books, "Social Origins," and "The Secret of the Totem" (pp. 114-34). Of this later book I reprint what seems necessary: a few passages need alteration.

The establishment of totemic beliefs and practices cannot have been sudken. Men cannot have, all in a moment, conceived that each group possessed a protective and sacred animal or other object, perhaps of one blood with themselves in explanatory myths. There must have been dim beginnings of the belief (so surprising to us) that each human group had some intimate connection with this, that, or the other natural species, plants, or animals. We must first seek for a cause of this belief in the connection of human groups with animals, the idea of which conneetion must necessarily be prior to the various customs and rules fombled on the idca. Mr. Baldwin Spencer remarks, "What gave rise in the first instance to the association of particular men with particular animals and plants it does not seem possible to say.", 2 Mr. Howitt askis, " Iow

"W. H. R. Rivers, "The Father's Sister in oceania," "Folli-Lono," vol. xxi., p. 55. The Ilaida intermarrying sets, aceording to Mr. Swanton, hate each other bitterly.

2"The Native 'Tribes of Central Australia," p. 127. 
was it that men assumed the names of objects, which in fact must hate been the commencement of totemism?" I The answer may be very simple. It ought to be an answer which takes for granted no superstition as already active; magic, for instance, need not have yet been developed.

Manifestly, if each group woke to the consciousness that it bore the name of a plant or animal, and did not know how it came to bear that name, no more was needed to establish, in the savage mind, the belief in an essential and valuable connection between the human group Emu, and the Emu species of birds, and so on. As Mr. Howitt says, totemism begins in the bearing by human groups of the name of objects.

It is difficult to understand how a fact so obvious as this, that the totemic name, if the name existed, and if its origin were unknown, would eome to be taken by the groups as implying a mystie comneetion between all who bore it, men or beasts, - can have escaped the notice of any one who is acquainted with the nature of savage thinking, and with its survivals into civilised ritual and magie. Mr. Frazer has devoted forty-two pages of his "Golden Bough " 2 to the record of examples of this belief about names, in various forms. He quotes Sir John Rhys to the effect that probably " the whole Aryan family, believed at one time not only that his name was a part of the man, but that it was that part of him which is termed the soul, the breath of life, or whatever you may choose to define it as being." So says Sir J. Rhys in an essay on Welsh Fairies. ${ }^{3}$ This opinion rests on philological analysis of the Aryan words for " name," and is certainly not understated. ${ }^{4}$ But if the name is the soul of its bearer, if his soul be his essence, if he and his totem are of one essence and name, then the name and the soul, and the soul and the totem of a man are all one! There we have the rapport between man and totemic animal for which we are seeking. ${ }^{5}$

1 "The Native Tribes of South-East Australia," p. 153.

2 2d. ed., vol. i., pp. 404-46.

3 "Nineteenth Century," vol. xxx. (1891), p. 567.

"See examples in "Cupid and Psyche," in my "Custom and Myth," and Mr. Clodd's "Tom Tit Tot," pp. 91-3.

${ }^{5}$ In Mr. Frazer's theory the origin of this idea of rapport is the North and Central Australian helief that the essence of each human being is the spirit of a primal being of animal or vegetable form, and so totemie, which enters a woman and is reincarnated. To me it seems that this belief is a theory constructed by men who were already totemists, and already animistic, and who asked themselves, "Why have we totems? Whenre have we souls?" If I am wrong, why do but two human sources of the many totem names exist? 
Whether "name" in any language indicates "soul" or not, the savage belief in the intimate and wonler-working connection of names and things is a well-ascertained fact. Now, as things equal to the same thing are equal to each other, animals and sets of men having the same name are, in savage opinion, mystically connected with each other. That is now the universal totemic belief, though it need not have existed when names were first applied to distinguish things, and men, and sets of men. Examples of the belief will presently be given.

Thus, given a set of local groups ${ }^{1}$ known by the names of Eagle, Hawk, Crow, Wolf, Raven, or what not, the idea that these groups were intimately connected with the name-giving animals in each case was, in the long run, sure to occur to the savage thinker. On that assumed mrstical connection, implied in the common name, and suggested by the common name, is laid the foundation of all early totemic practice. For the magical properties of the connection between the name and its bearer, the reader has only to refer to Mr. Frazer's assortment of examples, already cited. We here give all that are needed for our purpose.

In Australia, each individual Arunta has a secret name, aritna churinga, "never uttered except on the most solemn occasions," "never to be spoken in the hearing of women, or of men, or of another group." To speak the secret name in these circumstances would be as impious "as the most flagrant case of sacrilege amongst white men." 2

The facts prove, I repeat, that to the early mind names, and the things known by names, are in a mystic and transcendental connection of rapport. Other Australian examples of the secrecy. of a man's name, and of the power of magically injuring him by knowledge of his name, are given by Mr. Howitt, Brough Smyth, Lumholtz, Bulmer, Dawson, and others. It would appear that this superstition as to names is later than the first giving of animal names to totem groups, and that totem names were not given to groups by the groups themselves, (at least, were not given after

${ }^{1}$ I am sure to be told that I derlared local totem groups to be the result of reckoning in the male line, and not primitive, and that, here, I make the primitive animal-named group local. Mr reply is that in this passage I am not speaking of totem groups, but of local groups braring animal numes. a very different thing. A group may have borne an animal name long before it evolved totemir beliefs about the animal, and recogniserl it as a totem. No group that was not loral could get a name to itself at this early stage of the proceerlings. The "local habitation" precedes the "name."

2 Spencer and Gillen, "The Native Tribes of Central Australia," p. 139. 
the superstition about names (ame in), for to blazon their own group names abroad would be to give any enemy the power of injuring the group by his knowledge of its name. Groups, had they possessed the name-belief, wonld have carefully concealed their group names, if they could. There are a few American cases in which kins talk of their totems by periphrases, but every one knows their real names.

He who knew a group's name might make a magical use of his knowlerge to injure the group. But the group names or kin names being already known to all concerned (having probably been given from without), when the full totemic belief arose it was far too late for groups to conceal the totem names, as an individual can and does keep his own private essential name secret. The totem animal of every group was known to all groups within a given radius. "It is a serious offence," writes Mr. Howitt, "for a man to kill [the totem] of another person," ${ }^{1}$ that is, with injurious intentions towards the person.

An individual, says Mr. Howitt, " has of course his own proper individual name, which, however, is often in abeyance because of the disinclination to use it, or even to make it generally known lest it might come into the knowledge and possession of some enemy, who thus having it might thereby 'sing' its owner - in other words, use it as an 'incantation.'," 2

Thus, in Australia, the belief that names imply a mystic rapport between themselves and the persons who bear them is proved to be familiar, and it is acted upon by each individual who conceals his secret name.

This being so, when the members of human groups found themselves, as groups, all in possession of animal group names, and had forgotten how they got the names, (all known groups having long been named), it was quite inevitable that men, always speculative, should ask themselves, - "What is the nature of this connection between us and the animals whose names we bcar? It must be a connection of the closest and most important kind." This conclusion, I repeat, was inevitahle, given the savage way of thinking about names. Will any anthropologist deny this assertion?

Probably the mere idea of a mystic connection between themselves and their name-giving animals set the groups upon certain superstitious acts and abstentions in regard to these animals. p. 53.

1 "The Journal of the Anthropological Institute," vol. xviii. (1888),

Ibid., p. 51; "The Native Tribes of South-East Australia," p. 581. 
But being men, and as such speculative, and expressing the results of their speculations in myths, they would not rest till they had evolved myths as to the precise nature of the connection between themselves and their name-giving animals, the connection indicated by their names. 'There are scores of such myths.

Now, men who had arrived at this point could not be so inconceivably unobservant as to be unaware of the blood-connection between mother and children indieated in theobvious facts of birth. A group may not have uncierstood the facts of reproduction and procreation (as the Arunta are said not to have understood them), but the facts of blood-connection, and of the relation of the blood to the life, could escape no human beings. ${ }^{1}$ As savages undeniably do not usually draw the line between beasts and other things on one side, and men on the other, as we do, it was natural for some of them to suppose that the animal bearing the human group name, and therefore solidaire with the group, was united with it, as the members of the human group themselves were visibly united, namely, by the blood-bond. 'The animal is thus explained as men's ancestor, or brother, or primal ancestral form. (Or the man's soul is an emanation from a supposed primal being of animal form.) This belief would promote kindness to and regard for the animal.

Cnessential to my system is the question, how the groups got animal names, so long as they did get them and did not remember how they got them, and so long as the names, according to their way of thinking, indicated an essential and mystic rapport between each group and its name-giving animal. No more than these things - a group animal-name of unknown origin; and belief in a transcendental comnection between all bearers, human and bestial, of the same; - was nceded to give rise to all the totemic creeds.

Now, we can prove that the origin of the totem names of savage groups is unknown to the savages, because they have invented many various myths to account for the origin of the names. If they knew, they would not have inventerl such myths. Thus that, by their way of thinking, the name denotes a transeendental comnection, which may be exploited, between themselves and their name-giving animals we have proved.

In "Social Origins" I ventured to guess as to how the group names first arose, namely, in sobriquets given by group to group." I showed that in Frante, England, the Orkneys, and I may now

1 Cf. "The Colden Bough" (2d ed.), vol. i., pp. 360-2.

2 The passage will be found in "Social Origins," 1)p. 166-75. 
ald Guernsey, and I believe Crete, villagers are known by animal names or sobriquets, as in France-Cows, Lizards, Pigeons, Frogs, Dops; in Orkney - Starlings, Oysters, Crabs, Seals, Auks, Cod, and so forth. I also gave the names of ancient Hebrew villages, recorded in the " Book of Judges," such as Lions, Jackals, Inrnets, Stags, Gazelles, Wild Asses, Foxes, Hyænas, Cows, Lizards, scorpions, and so forth. I also proved that in the Orkneys, and in the Siomx tribe of lied Indians, rapidly ceasing to be totemic, the group sobriquets were often "Eaters of" this or that animal, or (where totemism survived among the Sioux) "not Eaters of" this or that. " I thus established the prevalenee in human nature, among peasants and barbarians, of giving animal group sobriquets. "In Cornwall," writes an informant (Miss Alleyne), "it seems as if the inhabitants do not care to talk about these things for some reason or another," and "the names are believed to be very ancient." When once attention is drawn to this curious subject, probably more examples will be discovered.

I thus demonstrated and I know no earlier statement of the fact) the existence in the classes least modified by education of the tendency to give such animal group sobriquets. The same principle even now makes personal names derived from animals most common among individuals in savage countries, the animal name usually standing, not alone, but qualified, as Wolf the Unwashed, in the Saga; Sitting Bull, and so on. As we cannot find a race just becoming totemic, we cannot, of course, prove that their group animal-names were given thus from without, but the process is clsewhere undeniably a vera causa, and does operate as we show, while it certainly operates in conferring names on clans just emerging from totemism.

As to this suggestion about the sources of the animal names borne by the groups, Dr. Durkheim remarks that it is "conjectural." 2 Emphatically it is, like the Doctor's own theories, nor can any theory on this matter be other than guess-work. But we do not escape from the difficulty by merely saying that the groups "adopted" animal names for themselves; for that also is a mere conjecture. Perhaps they did, but why? Is it not clear that, given a number of adjacent groups, each one group has far more need of names for its neighbours than of a name for itself? "We" are "we," "The Men" ; all the rest of mankind are "wild blacks," "barbarians," "outsiders." But there are a score of sets of out- 
siders, and "we," "The Men," need names for each and every one of them. "We" are "The Men," but the nineteen other groups are also "The Men," - in their own opinion. To us they are something else ("they" are not "we"), and we are something else to them; we are not they; we all need differentiation, and we and they, by giving names to outsiders, differentiate each other. The names arose from a primitive necessity felt in everyday life. Through taunts bandied between groups, and through women stolen by group from group, the names would' become generally known.

That such sobriquets, given from without, may come to be accepted, and even gloried in, has been doubted, but we see the fact demonstrated in such modern cases as "the sect called Christians" (so called from without), and in Les Gueux, Huguenots, Whigs, Tories, Cavaliers, Cameronians ("that nick-nome," cries Patrick Walker (1720), "why do they not all call them 'Cargillites'? if they will give them a nickname?")." I later prove that two ancient and famous Highland clans have, from time immemorial, borne clan names which are derisive nicknames. Sereral examples of party or local nicknames, given, accepted, and rejoiced in, have been sent to me from North Carolina.

Another example, much to the point, may be offered. The "nations," that is, aggregates of friendly tribes, in Australia, let us say the Kamilaroi, are usually known by names derived from their word for "No," such as Kamil (Kamilaroi), I'ira (Wirajuri), IVonghi (Wonghi tribe), Kabi (Kabi tribe). Can any one suppose that these names were given from within? Clearly they were given from without and accepted from within. One of the Wonghi or of the Wirajuri or Kamilaroi tribe is "proud of the title." Messrs. Spencer and Gillen write, "It is possible that the names of the tribes were originally applied to them by outsiders and were subsequently adopted by the members of the tribes themselves, but the eridence is scanty and inconclusive." " There can hardly be any evidence but what we know of human nature. Do the French call themselves.(Oui Oui? No! But the natives of New Caledonia call them Oui Oui. ${ }^{3}$

Moreover, to return to totem names, savage groups would have no reason for resenting, as derisive, animal names given from without. Considering the universal savage belief in the mystic wisdom

1 "Six Saints of the Corenant" (1901), rol. i., p. 241.

2 "The Northern Tribes of ("entral Australia," p. 11 (note).

3 J. J. Atkinson. The natives call us "White Ifen." We do not call ourselves "Goddams," but Jeanne d'Are did. 
and wakan, [or mana], or power, of animals, there was no lind of objection among savages to being known by animal group names. The names came to be regarded as rather honour-giving than derisive. This has not been understood by my eritics. They have said that among European villages, and among the Sioux of to-day, group nicknames are recognized, but not gloried in or even accepted meekly. My answer is obvious. Our people have not the sarage ideas about animals: while the Sioux clans do aceept their sobriquets.

Mr. Howitt, in his turn, does not approve of my idea, thus stated by him, that "the plant and animal names would be impressed upon each group from without, and some of them would stick, would be stereotyped, and each group would eome to answer to its niekname." He replies, _ "To me, judging of the possible feelings of the pristine ancestors of the Australians by their descendants of the present time, it seems most improbable that any such nicknames would have been adopted and have given rise to totemism, nor do I know of a single instanee in which such names have been adopted." 1

Mr. Howitt, of course, could not possibly find kinships now adopting animal and other such names given from without, because all kinships where totemism exists have got such names already, and with the names a sacred body of customs. But does he suppose that the many local tribes ealling themselves by their word for "No" (as Kabri, Kamil, Wonghi, and so on), originally gave these names to themselves, saying, "We are the people who, when we mean 'No,' say 'Wonghi'"? That seems to me hardly credible! Nuch more probably tribes who used a Kamil or Kabi for "No" gave the name of Wonghi to a tribe who used IVonghi in place of their Kamil or Kabi. In that case the tribes, as tribes, have adopted names given from without.

Again, I consider that the feelings of that noble savage, the Red Indian, are at least as sensitive to insult as those of Mr. Howitt's blacks. Now it so happens that the Blackfoot Indians of North America, who apparently have passed out of totemism, have "gentes, a gens being a body of consanguineal kinsmen in the male line," writes Mr. G. B. Grimnell. ${ }^{2}$ These elans, now no longer totemie, needed names, and some of their [new] names, at least, are most insulting nicknames. Thus we have Naked Dogs, Skunks, They Don't Laugh, Buffalo Dung, All Crazy Dogs, Fat Roasters,

1 "The Native Tribes of South-East Australia," p. 154.

2 "Blackfoot Lodge Tales," p. 208. 
and - Liars! No men ever gave such names to their own conmunity. In a diagram of the arrangement of these clans in camp, made about 1850, we find the gentes of the Pi-kun'-I under such pretty titles as we have given. ${ }^{1}$ (Other instances are given at the close of the chapter.)

If we want to discover clans of fiery Celts adopting and glorying in names which are certainly, in origin, derisive nicknames, we find Clan Diarmaid, whose name, Campbell, means "Mry Mouth," and Clan Cameron, whose name means "Crooked Nose." "2

Moreover, South African tribes believe that tribal sacred animals, siboko, as Baboon and Alligator, may, and did, arise out of nicknames; for their myths assert that nicknames are the origin of such tribal and now honourable names. I cannot prove, of course, that the process of adopting a name given from without occurred among primitive men, but I have demonstrated that, among all sort and conditions of men in our experience, the process is a vera causa.

Dismissing my theory, Mr. Howitt, in place of it, "could more easily imagine that these early savages might, through dreams, have dereloped the idea of relationship with animals, or even with plants." 3

That animal nicknames, given from without, can be and are accepted in Australia Mr. Howitt seems to think possible in his own book, in the very page in which he says that the fact "seems to him most improbable." He writes, "The hypothesis suggested by Professor Haddon is that groups of people, at a very early period, by reason of their local enviromment, would have special rarieties of food. This receives support from the fact that analogous names obtain now in certain tribes, $\ell . g$. the Yuin." If this be the case, my theory is so far accepted; groups may and do receive names from their articles of food. How the steps respecting the animals or other objects, denoted by the names of the human group:, would be taken, I have shown. But I cannot find that Mr. Howitt gives any examples of such group-sobriquets among the Yuin and other tribes. Some Yuin personal names are Thunder, Stonetomahawk, and so forth; the "family" names are place-names.t The elderly Kurnai receive personal nicknames from the animals which they are skilled in catching, as Bunjil-tambun, "Good man perch." " I repeat that nobody could find "groups" accepting

${ }^{1}$ Op. cit., pp. 208, 225.

2 Macbain, "An Etymological Dictionary of the Gaelic Language," p. 357 .
${ }^{3}$ Op. cit., p. 154.
${ }^{4}$ Op. cit., p. 739.
s Ibid., p. 738. 
new animal nicknames now, as the totem "groups" are, of course, already named Cat or Dingo or Iguana and so forth.

Meanwhile Mr. Haddon's suggestion, made in the same year (1902) as my own, is really a form of my own, differing in so far as he derives the group sobriquets entirely from artieles of food in the area of the group; and supposes the group-folk to have lived mainly on the object, and bartered what was superfluous with other groups in exchange for [supplies of the objects on which the latter mainly lived]. His chief example was drawn from a myth of two totem kins in a tribe to the effect that their totem names, a small fish and a very small opossum, had once been their staple as food. But the known five other totem kins in the tribe, according to their myth, were deseended from their totems, and one myth is as worthless as another. ${ }^{1}$

Against Mr. Haddon's theory Mr. Baldwin Spencer urged obvious eriticisms. Every group eats everything that is edible in its area. $^{2}$

Moreover, I add, nobody eats Morning Star or Rainbow; the Red Ochre lin of the Dieri live very far from the red-ochre pits, and Mr. Haddon ean hardly think that any kin lives mainty on carpet smakes, or black bees, or sandal wood, or bats, or wolves and ravens - dura ilia!

Mr. Haddon's theory, however, agrees with my own in the essential point that group assumed names were given from without.

I may best deal here with Mr. Frazer's other objections of 1910 to Mr. Haddon's theory, as in essence Mr. Haddon's idea and mine aremuch akin. Obriously unacquainted with my views, Mr. Frazer confines his eriticism to those of Mr. Haddon, and is clearly unaware that in "The Secret of the Totem" (1905) I replied to his objeetions as formulated by other writers. Concerning Mr. Haddon's view Mr. Frazer writes, ${ }^{3}$ — "The view that the names of the totem clans were originally nicknames applied to them by their neighbours, which the persons so nicknamed adopted as honourable distinctions, appears to be very unlikely. Strong evidence would be needed to convince us that any group of men had complacently accepted a nickname bestowed on them, perhaps in derision, by their often hostile neighbours. . . ." I had answered all this and supplied the strongest possible evidence, in "The Secret of the Totem " (pp. 129-34), giving modern examples, examples of High-

1 See Mr. Huddon's views in "Report of the British Association," Belfast 19(1).

" "Totemism and Exugamy," vol. iv., pp. 50-1 and Notes.

${ }^{3}$ Ibid., vol. iv., p. 51. 
land clans (who are touchy on points of honour), examples from the Blackfoot Indians, and (pp. 25-6) the instance of Bakuena tribes who account for their tribal sacred animals (sibolio) as the result of accepted nicknames.

* $\quad * \quad * \quad * \quad * \quad * \quad * \quad * \quad * \quad * \quad * \quad *$

Mr. Frazer continues his criticism : this strong evidence

"would be needed to convince us that any group of men had complacently accepted a nickname bestowed on them, perhaps in clerision, by thein often hostile neighbours, nay, that they had not only adopted the nickname as their distinctive title and badge of honour, but had actually developed a religion, or something like a religion, out of it, contracting such a passionate love and admiration for the animals or plants after which they were nicknamed that they henceforth refused, at the risk of dying of hunger, to kill and eat them.", 1

This is somewhat exaggerated. Mr. Frazer has declarer that totemism is not a religion. ${ }^{2}$ Again, I know no evidence to prove that any totemist would rather die of hunger than eat his totem: several Australian tribes eat their totems freely. For the extraordinary influence of the name as implying the closest rapport between all who bear it, I merely refer to Mr. Frazer's "Golden Bough," vol. i., pp. 404-46. On my theory, as totemists certainly do not know how they got their totem names, they would seldom suspect, like the Bahurutsi, that they were nicknames, perhaps derisive. I have proved on unimpeachable evidence, Mr. Price's, that the Northern Bakuena think that a process occurred which only "strong evidence" would make Mr. Frazer believe in. However, I am able to prove that savages can accept, and have accepted, "clan" nicknames from without.

Take this "strong evidence": Mr. Frazer writes of the Wendal or Wrandot, the Hurons' name for themselves. "According to L. H. Morgan the original form of the name Wyandot is wane-dot, 'calf of the leg,' a name given to these Indians by the Iroquois and adopted by themselves." 3 Again, the Black Feet Indians have, or had, exogamous clans with male descent. The names of these clans are no longer totemic. Among them now are Liars, Biters, Patched Moccasins, "They Don't Laugh," Worms, Buffalo Dung, Crazy Dogs. ${ }^{4}$

I cite these as obvious and derisive sobriquets, but the clans have now no other names. Other dan names occur anong the

${ }^{1}$ Ibid., vol. iv., p. 51 .

${ }^{2}$ Ibid., vol. iv., p. 5.

3 Ibid.. vol. iii., p. 30, n. 1 .

"Grinnell, "Blackfoot Lodge Tales," pp. 20S-10, cited in "Totemism and Exogamy," vol. iii., p. S4, n. 3; "The Sorret of the Totem," p. 132. 
Dacotas, who, as Mr. Frazer points out, appear, in the seventeenth century, to have had badges, as that of the Eagle, Panther, Tiger, Buffalo, ete., from which each band "is denominated." 1 Nou their clans are styled "Not encumbered with much baggage," "Bad Xation," "Breakers (of the law)," the law broken being that of exogamy!" No community ever called itself "Incestuous," or "Bad Nation"; these clan names are sobriquets.

Once more, the Crows have exogamous clans; out of twelve, four are totemic in name, Antelope, Raven, Prairie Dog, Skunk. I presume that these totem names were, in origin, sobriquets, just as some of the other clan names of the Crows, Bad Leggings, Treacherous Lodges, Bad Honours, are undeniably hostile yet accepted sobriquets. ${ }^{3}$

In Europe the sobriquets, animal or vegetable, of the villages are now resented, and one village is angry, in Cornwall, when another village hangs up its Mouse, or whatever its animal may be, dead, by way of a taunt. Mr. Frazer's readers cannot be aware (nor is he, I daresay) that in 1905 I defended my theory that savages can and do accept even injurious clan sobriquets from without by actual examples, and that I have shown how, the animal name once accepted, " a religion, or something like a religion" of it, was "actually developed." Mr. Frazer writes

"No single instance of such an adoption of nicknames from neighhours was known to Dr. Howitt, the most experienced of Australian anthropologists, in the whole of Australia." 4

I have quoted, above, my reply, given in "The Secret of the Totem," to Mr. Howitt.

Here may close my chapter of answers to objections against the possibility of complacent acceptance of sobriquets. It occurs in savage as it does in cirilised societies: many of the facts are recorded by Mr. Frazer himself, others he has overlooked; and certainly my array of the facts in 1905 has escaped his vigilant industry in study, otherwise he would not have ignored what is essential.

My theory of the origin of the phratry system, as given in 1905, has now to be modified in consequence of the general acceptance of certain evidence.

${ }^{1} J$. Corver, "Travels through the Interior Parts of North America," (3d enl., 17s1), p. 256.

2 "Totemism and Exogamy," vol. iii., pp. $86-7$, n. 4.

${ }^{3}$ Itrid., vol. iii., pp. 153-4.

${ }^{4}$ Ibid., vol. ir.. p. 52, 11. 2; Howitt,"The Native Tribes of South-East Australia," p. 154. 
I next suppose that a local exogamous group of, say, Ducks, and another neighbouring group named Dogs, weary of fighting for wives against the kin of their own wives and own children, made peace with commbium. Here we have the evidence of the Lrabunna, Karamundi, and Itchumundi arrangement by which people of one totem must marry only people of one other totem, as Dingo, among the Lrabunna, marries only into Water Hen. ${ }^{1}$

The Itchumundi nation contains four tribes. A man of the Mukwara (Eagle Hawk) totem and phratry "married a Kilpara" (Crow phratry) of the Bone-fish totem; a Mukwara of the Kangaroo totem married a Kilpara of the Emu totem, a Mukwara of the Dog totem married a Kilpara of the Padi-melon totem, and so on. "The tribes of the Karamundi nation have a similar rule [like that of the Itchumundi nation] by which a member of either class" [phratry] "may marry only in one totem of the other class." 2 Messrs. Spencer and Gillen and Mr. Howitt assign the same rule to the Urabumna nation. All these tribes are in the most primitive state of social organization, with female descent and no subclasses; the Lrabunna have, the others have not, pirraum. Mr. Frazer, Mr. Spencer, and Mr. Howitt make no attempt to explain their unique rule of one totem to one totem marriage. It must make the two intermarrying totem kins in a high degree consanguineous, and can scarcely have been adopted to prevent marriages of near kin, if cousins were reckoned near kin.

These marriages are mainly marriages of first cousins, which Urabunna law permits, if the bride be a daughter of the man's mother's younger brother, or of his father's younger sister. When one small community may select wives only from one other small community, - Water Hen group from Dingo group with restrictions on that, - if the people may not marry some of their first cousins, whom may they marry?

The Dieri, on the other hand, may marry any person of the right tribal status, (all first cousins are excluded), in any of the many totems in the phratry which is not their own; whereas among the Lrabumna, Karamundi, and Itchumundi the members of each totem kin may only marry into one totem kin in the opposite phratry.

I would suggest that, among the Lrabumna and the other "nations," first Dingo and Water Hen, say", made a covenant to marry"

1 "Totemism and Exogamy," vol. i., pp. 176-, 357-S, quoting Howit and Spencer and Gillen.

2 Howitt, op. cit., pp. 194, 159. 
peacefully with each other alone, (some two kins must have begun the practice), and that then other pairs imitated the example; and, finally, all pairs coalesced into one federated phratry or the other. What they gained by this was peace.

The arrangement, I conjecture, would be worked out thus: first we have $x$ animal-named exogamous local groups raiding each other for wives. Two such groups, Water Hen and Dingo, tire of this, and make a marriage treaty for peaceful betrothals: other groups, however, may still raid them, and they may raid other groups, as they probably would, in revenge for raids on themselves, and beeause, in two small communities, marriageable women were not very plentiful. But other groups follow their example, two by two. This, however, does not prevent any adventurous braves in any of the groups from raiding every group which is not the one linked by marriage treaty with his own. This dangerous license would cease when half of the groups federated, and the other half also federated into what are now the phratries, each phratry as a whole making a covenant of peace with the other. But, by an amazing conservatism, the pairs of totem-kins still only marry into each other among the Urabunna, Itchumundi, and Karamundi. How otherwise than by my conjecture can we account for this strange limit to choice in marriage?

The rule of one totem-kin wedding into only one other totemkin in the opposite phratry must be earlier than marriage into any kin of the opposite phratry. When men, as among the Dieri, or any other tribe with female descent and two phratries, had once been permitted to seek wives in all of the totem-kins of the phratry not their own, they never could submit to a restriction limiting them, for no conceivable reason, to brides from a single totem-kin. The only reason for restrictions being, by the ordinary theory, closeness of consanguinity, there could be no objection to Water Hen, in phratry $A$, wedding into any totem-kin of phratry B. Mr. Howitt, however, writes that "the Lrabumna restriction" (or "marriage to one or more totems") "is certainly later in origin than the Dieri rule." 1

This seems impossible. Men who had once enjoyed the wide freedom and ample latitude of choice of the Dieri would never limit themselves to brides from a single totem-kin, and do that for no conceivable reason, except that which I have suggested. Dingo, who may only marry Water Ilen, is not consanguineous with any of the other totem-kins into which he may not marry :

${ }^{1}$ Howitt, op. cit., p. 189. 
he is not barred from union with them for that cause. Reason, if there were a dislike of consanguine marriages, would urge a larger latitude of choice than a single kinship offers, for, when two small kinships marry exchsively with each other, they both become extremely consanguine. Therefore the Lrabuma are foreed to allow first cousins to marry, as far as the age-grades rules permit ; they have no choice if they are to marry at all. On the other hand, the Dieri, anong whom members of any totem-kin of $B$ phratry may marry into any totem-kins of A phratry, are able to indulge their consciences by forbidding all marriages between what we call "first cousins." Mr. Howitt himself sees that this rule, "the Dieri rule is evidently a development of that of the Irabunna, and is therefore the later one." 1 Mr. Frazer agrees."

The Dieri rule about consins is the later of the two, ${ }^{3}$ and it is rendered possible by the Dieri emancipation from the Crabuma and Karamundi rule that each totem may marry only into one other totem.

It follows that the Lrabumna, Karamundi, and Itchumundi rule, - one totem marries into one totem only, - is not later, as Mr. Howitt writes, but earlier than the Dieri rule, - any totem in phratry A may marry into any totem in phratry B. Emancipation from the Crabunna, Itehumundi, and Karamundi law, one totem to one totem only, - enabled the Dieri to bar the marriages of all first cousins. Consequently the one totem to one totem rule is the earliest of all; and how can we explain it except by the alliance, with conmubium, of two groups with totemic names? The example thus set was followed by pair after pair of linked totem-kins, and for this reason there is necessarily a dual union and division of intermarrying kins throughout the Australian system. This is an automatic result of one totem to one totem marriage, followed by ferlerations of the intermarrying pairs of totem-kins.

Why only two groups, in the first place, made alliance with connubium, I have not to explain. It is enough that they certainly did it, (in several nations they still arlhere to commbium between two totems only), unless any other reason for the one totem to one totem law can be discovered. Dislike to consanguineons marriages could not produce this drastic rule, I repeat, for each totemkin must have recognised no consanguinity with any other.

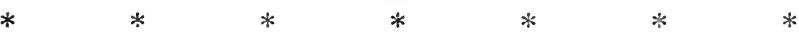

${ }^{1}$ Howitt, op. cit., p. 189.

2 "Totemism and Exogamy," vol. i., p. $346 .{ }^{3}$ Ibid., vol. i., p. 346. 
Mr. Frazer makes no reference to myself, or to M. van Gennep, on this matter, but (vol. i., pp. '2\$-5), argues against the theory of amalgamation, withont noticing our replies to certain objections that had already been urged on us by others. "Why," he asks, "were these federal communities so regularly either two in number or multiples of two?" M. van Gemep had briefly said that our theory of convergence (amalgamation) "seule explique entre autres le fait du dualisme des éléments de chaque groupe [p.xxxiv].' He added that the Australians generally "n'ont de noms de nombres que jusqu'à deux," and, for an element of symbolism in this, refers to Mr. McGee, "Primitive Numbers," in " The Nineteenth Annual lieport of the Bureau of American Ethnology," vol. ii., pp. 821-51. These are not my own ideas, but those of M. van Gennep.

I would say that, if amalgamation began in the Urabunna "one totem to one totem" marriage, while such pairs finally federated into each phratry, Mr. Frazer's question is answered. I regard the later bisections of two classes into four, and of four into eight, as deliberate and intelligent imitations of the original model, the sets of pairs, the "two class strstem." The natives, like Mr. Frazer, would think that it had been the result of bisection, not of amalgamation, and would imitate what they supposed to have been the wise inethod of their ancestors.

Mr. Frazer's argument ought to be given in his own words (vol. i., p. 285) :-

"While we may without much difficulty conceive that communities," (in this case totem-kins) "which in their independent state had been exogamous, should remain exogamous after they had united to form a ronfederacy; it is far more difficult to understand why in uniting they should have adopterl the complicated rule of descent which characterises the four-class and eight-class organisations of the Australian tribes."

Nobody has ever suggested (as far as I know) that "in uniting" the totem-kins instantly "adopted" the four or eight class system. The tribes of one totem to one totem marriage: the Dieri, without that rule: the To-tathi, Barkinji, and many other tribes, have not the four class or eight class system, but all agree that tribes began with the two class or phratry model. Many tribes adhere to it; others have gone on to the four ; others (all with male descent) to the eight class system. Their motive and method, I think, are obvious. They do not know how the phratry, or two class system, arose, but they see that it excludes from marriage some close consanguines, mother and son, brother and sister. They suppose that the system was made for this very purpose, and when they wanted to exclude other consanguines, whom the sys- 
tem did not exelude, they did so in the honoured ancestral model, by repeated bisections, making first two, then four "subclasses" in each phratry.

Mr. Frazer goes on:- "We can imagine that each community" in the eonfederacy should continue as before to take its wires from another community," ("conmunity" apparently now means phratry), "but why should the two intermarrying communities now cede their child to a third?" The third ("community" clearly means "subclass"). Mr. Frazer knows, and has very well explained, why the children are "ceded to a third community," that is, enter the subclass in the brother or mother's [sister's?] phratry, which is not that of father or mother (vol. i., p. 163). It "is to prevent the marriage of parents with children." The child is not driven into an alien "community" ; it is still in the totemkin and phratry of its father and mother, but the rule "maks sicear" there can be no union of child with father or mother without violating an express law.

The same obrious reply answers this objeetion: "On the theory" of amalgamation what motive can be assigned for the rigid exelusion of all children from the communities of both parents?" There was no such exelusion, no subelasses existed, when the amalgamation was made; there was none till, long afterwards, a subclass arrangement was derised to stereotype and express publiely the already existing bye-law against the union of father and daughter, mother and son. The poor ehildren, "rigidly excluded from the communities of both parents," are still in the parental or maternal "communities" of the totem-kin and the phratry and in the family fire-cirele. They have lost nothing. That exclusion is perfectly intelligible on the hypothesis that it was devised to prevent the marriage of parents with children, but it is diffieult to see how it can be explained on any other: who is dreaming of explanining it on any other? People entered into the phratriac exogamy by the amalgamation which I and $M$. van Gennep suggest, and then, for conseientious reasons, "kept compounding it as they went on," as Brron sar's about people who "began with simple adultery.."

* $*$ * $*$ * $\quad * \quad * \quad *$ *

On my theory the primal prohibition was not based conscionsly on consanguinity, but on locality and ornership. The semibrutal Sire sars, - "No amours except my own in my camp." When the groups got names, - Emu, Lizard, Grub, Iguana, Kangaroo, - the prohibition was "no amours within the name." 
When two groups first coalesced into commbium, the first rule was "no marriage with peace save into one other totem group." The final rule was "marriage into any totem-kin not in your own phratry." As the rise of the phratries instantly and automatically produced classificatory relationships or "classes," people were confined in marriage to one set of such relations in the opposite phratry", the Nupa or Noa set. Men, reflecting on the system, saw that it barred the marriage of persons of close consanguinity, and thought that other persons, also consanguine but not so closely consanguine, should be excluded; hence the four and eight class șrstems.

In the same way the Catholic Church excluded first cousins, and relations in "gossipred," - godfathers and godmothers, godsons and goddaughters, - from intermarriage, and introduced other restrictions hitherto unknown. In Scotland, among the noblesse, it became very difficult for any marriage to occur without a dispensation, and many pairs were divorced because of some scarcely traceable relationship. The Australian blacks, in precisely the same way, conceived new scruples, and passed more stringent regulations, till human nature revolted, and the exogamous system was abandoned among the Kurnai and the Narran-ga. They had run the whole round of the labyrinth and come out into daylight. 


\section{Chapter XiI}

\section{WOMEN IN PRIMITIVE SOCIETY ${ }^{1}$}

* $\quad * \quad * \quad * \quad * \quad * \quad * \quad * \quad * \quad *$

1. It will help us to begin by distinguishing the principal questions to be asked about the marriage customs of any society. Thus we may classify marriage:

(1) According to the number of parties to the union (monogamy, polygamy, ete.).

(2) According to the restrictions on marriage (exogamy and endogamy).

(3) According to its stability (law of divorce).

(4) $\mathrm{By}$ the methods of obtaining a husband or wife (e.g. capture, purchase, contract).

(5) $\mathrm{B} y$ the relations between husband and wife (in the family).

The two last questions are closely related, and both have an important bearing on the general position of women. Inder each head we shall see what are the prineipal forms of marriage customs that exist, and which are the prevalent types in the savage and barbaric world. We shall then briefly trace the history of marriage and of the position of women among civilized peoples. ${ }^{2}$

2. I. We have to ask first in any community, who, or rather how many, are the possible parties to a marriage. Is it $(a)$ a union of one man with one woman, or $(b)$ of one man with two or more women, or $(c)$ of two or more men with one woman, or $(d)$ of a group of men with a group of women, or $(e)$ is it wholly irregular, the negation of union, promiscuity". All these are types of marriage which exist or have existed, or at least lave been alleged to exist. Further they split up into sub-types. Polygrny, for example, the union of one man witl two or more women, is found in the

${ }^{1}$ [By L. T. HobHorse. Reprinted from "MIorals in Evolution," by permission of Henry Holt and Company, New York. Abbreviated and omitted book-titles with the detail of editions are supplied by the author's reference list on p. xiii seq. Vol. I of the original work.]

${ }^{2}$ [Chapter $\mathrm{XV}^{2}$ of this rolume.] 
two fairly distinguishable types of polygamy proper, in which several women are alilie wives, and concubinage, in which there is one chief and fully legitimate wife, and one or more in a subordinate and perhaps servile position.' 'Theonetype, moreover, shades off into the other by gradations according as the chief wife's position is more or less fully defined, ${ }^{2}$ and as that of the secondary wives is more or less servile. Polyandry, again, though far less common than polygamy, has many varieties. The several husbands may, and in the commonest case do, form a definite group. Generally, as in the well-known case of 'Thibetan marriage, they are all brothers. ${ }^{3}$ But this is not always so. Polyandry may merely take the form of permitting a woman to have many husbands without specifying any particular relationship between them except such as may follow indirectly from the other marriage regulations of the community. This is the case among the Nairs of the Malabar coast. The same people illustrate a still further variety, the combination of polyandry and polygamy. For as the Nair woman may have many husbands, so the Nair husband may have many wives." Again, in the relations between the hus-

${ }^{1}$ In China there is only one chief wife. The others are secondary, but legitimate wives. The old Babylonian law recognizes one wife (allowing a second in ease of her being invalided), with concubines who were to recognize the wife as mistress. The ease of Leah and Raehel illustrates a family in which there were two legitimate wives as well as coneubines. Nussulman law allows four legitimate wives and an indefinite number of coneubines. The old Japanese law recognizes polygamy with a headwife. (Post, i. 62; Kohler, "Z. f. V. R.," vi. p. 369.) For instances among uncivilized peoples, see Howard, i. pp. 143-4, and Westermarck, p. 412, etc., and "Cambridge Anthropologieal Expedition to the Torres Straits," p. 230.

${ }^{2}$ In some cases a second wife may only be taken if the first is childless, t.g. among peoples of the Punjab, and the Dekkan, the Santals in Bengal some Bombay tribes. (Post, l.c.) Post also refers to Bulgarian and Montenegrin customs.

Among the Malays, under the Semando form of marriage, the taking of a second wife is a gromnd of divoree, and at Mokomoko the husband must pay her a fine, 40 gulden. (ITaitz, v. 145, 146.) Among the Khonds the wife's eonsent is required. (Reclus, "Primitive Folk," p. 281.) P'ost gives similar instances among the Khyengs, the Tamils of Ceylon, and Punjab peoples (Post, i. 63, from Kohler, “Z. f. V. R.," vi. p. 192), and Howard (i. p. 144) quotes a case among the North Ameriean Indians. Among the Tonaregs the taking of a seeond wife is a ground of divorce. (Letournecu, "La Femme," p. 308.)

3 Among the Todas the wife helongs to the elder brother, but the younger brothers also have rights over her as they grow up, and an extra lover is permitted as well. (Reclus, p. 196.) Polrandry is, however, disappearing exeept among the indigent. Aecording to Wrstermarck (p. 453) there are only three cases in Asia in which polvandry is not limited to brothers - viz. the Nairs, Khasias, and eertain Cossacks, but Letourneau " La Femme," p. 216) denies that it is strictly limited to brothers in Thibet.

"Compare Casar's aceount of the ancient Britons: "Uxores habent 
bands there are differences quite parallel to those which distinguish polygamy from concubinage. All the husbands . . . may have equal rights, or there may be one chief husband and others inferior and secondary to him. Of such a character is the secondary husband who assumes both the rights and the duties of the proper husband in his absence among the Aleuts. ${ }^{1}$ Some peoples have the punishment - to our eyes the very paradoxical punishment - for adultery that the paramour on detection is compelled to becoline a secondary husband and contribute to the maintenance of the family. ${ }^{2}$

3. Of group marriage, again, more than one variety is abstractly possible. Though as here the evidence becontes scantier it is not so easy to say which types, if any, have been actually represented in history. Indeed, it camot be regarded as certain that any such institution as the actual marriage of two groups, as distinct from a combination of polygamy and polyandry with certain marriage taboos, has ever existed. As the whole subject is involved in controversy, it will be well to summarize what is

deni duodenique inter se communes, et maxime fratres cum fratribus parentesque cum liberis; sed, si qui sunt ex his nati, eorum habentur liberi, a quibus prinum virgines quaeque deduetae sunt." ("I3. G.," v. 14.) That is, there was a chief hushand and the rest were secondary. Among the polyandrous tribes of primitive Arabia the wife, aceording to Strabo, passed the night with the elder brother, but the others had access to her. (Starcke, p. 137.) For the Nairs, see Reclus, 162.

${ }^{1}$ Reclus, pp. 66-67. Among the Thlinktets and Koloshes a vounger brother is preferred for this purpose. Secondary husbands occur among the Papuas. (Kohler, "Z. f. V. R.," 1900, p. 334.)

2 Among the Konyagas, if the paramour is a member of the hushand's family the latter may compel him to obey his orkers and those of the wife, with whom henceforth the association is legitimate. (Reclus, p. 67.) Altogether Westermarck enumerates some thirty-six instances of tribes practising polyandry (p. 450). To these must be added the people of Langerote and Portaventura in the Canary Islands in the sixteenth century (Letourneau, p. 303), and in antiquity the Arabs and British (Westermarck, p. 454). The ease of the primitive Aryans in India is doubtful. The two Aswins in the Rig Veda win one damsel as the prize of a chariot race, and she acknowledges their "hushandship." In the llahabharata Draupadi is won by the eldest of five Pandava princes and becomes the wife of them all, but her father doscribes this as "an unlawful act, eontrary to usage and the Vedas." The princes plead as precedent the rase of a "most excellent moral woman," who dwelt with seren saints, and of Varski, who cohabited with ten brothers "whose souls had heen purified with penance." Mayne ("Hindu Law and Usage," p. 64) points ont that these were bad precedents, being eases of saints who were above ordinary laws. He adds that in the Ramavana polvandry is mentioned with abhorrence, and sums up in favour of the riew that sexual looseness rather than recognized polyandry is indicated. (Hayne, p. $6.5,4 t h$ ed.)

In Sparta a seeondary hushand was sometimes tolerated for the sake of increasing the family. ... (Tenophon, "Rep. Lac.," i. 9, quoted in Grote, Part II., chap. vi. p. 520.) 
actually found in a leading ease. Among the Central Australian tribes two types of marriage custom have been distinguished by Messrs. Spencer and Gillen. The first which specially concerns us is that practised among the Crabumna. The tribe is divided into two classes, and these classes are exogamous - that is to say, a man must not marry within his class, but must choose his wife from the other. Secondly, there are distinct totems within the tribe, and these are similarly exogamous. Thirdly, each of the two classes is divided into four groups, and in choosing a wife a man is restricted to one of these groups. How the group division is arrived at need not concern us for the present. The point is merely that there exists for any given group of men a definite group of women with whom they may marry, and who are called their Nupas. So far, then, our result is that there are in the tribe a group of men and of women who are Nupa to each other - that is, potential husbands and wives. To come now to the actual marriage, a man will have one or more of his Nupas assigned to him as his wives. He will also have others to whom he is Piriamgaru - that is, he has access to them under certain conditions. Similarly a woman may be Piriannaru to several men, and lastly a man may lend his wife to any of her Nupas, and on the occasion of a visit, for example, is expected as a matter of courtesy and good feeling to do so. Thus the husband has only, so to say, a preferential right in his wife, and the wife in the husband. The husband will have a secondary right to other women as his Piriaungaru, while his wives are in turn Piriaungaru to other men. ${ }^{1}$

1 In the Dieri tribe there is hoth individual and group marriage. In the latter case the headman allots certain men and women (subject to the clan or totem restriction) to one another as Pirauru, but their rights, as the different hushands and wives are often members of different local groups, are exereised mainly when the groups meet. When they separate the right of the Noa or principal hushand predominates. (A. W. Howitt, "The Organization of Australian Tribes," Transactions of Royal Society of Victoria, rol. i., pt. ii., pp. 124-7.)

The custom of the Arunta and other Central Australian tribes is still further removed from a true group marriage, as here there are no Piriaungaru. A woman is restricted to one man unless he lends her. What suggests group marriage, apart from the nomenclature of relationships, is (1) that the name for wife is the group name Unawa, the term (corresponding to Nupa) applied to all women of the class with whom the man may lawfully marry; (2) that wives are freely lent within the group and enjoyed promiscuously at festivals. How much stress is to be laid on this is not easy to determine. It is certain that the class restrietions on marriage are held much more vital by most savages (whatever their marriage rustoms) than the marriage tie itself. Among the Australians Messrs. Spencer and Gill'n remark that jealousy is little developed, alultery is at most an infringement of rights of property (so also among 
Now as it stands this scheme of marriage may be classified as a form of polyandry combined with polygamy, such as we have already met with among the Nairs, only complicated by the taboos which limit the intercourse of the sexes to the two groups which are Nupa to each other. It is possible to explain the srstem as the relic of earlier customs where the two Nupa groups were actually married to each other, so that intercourse between them would be promiscuous. 'This, however, is an inference as to the

North American Indians, see Waitz, iii. p. 131), wife lending is habitual, and dirorce is easy. Under these circumstances the very use of the term marriage can only be justified by the difficulty of finding any other. it is not marriage as we understand the relation, and the tie. whaterer we call it, is exceedingly loose. On the other hand, the taboos which mark out special classes for each other are among the most sacred laws of the tribe. Generally spealing, these restrictions are of a negative character - a man must not marry within his totem, or his clan, but sometimes, owing to the multiplication of restrictions, particularly in the form of classificatory relationships (of which the Australian class divisions are really a case), the result is to confine the intending spouse to a specific group. This group will then consist of his Nupa or Unawa, and so it is easy for him to change his wife within the group and impossible for him to take one outside it; and as this applies to all the men and all the womrn we may say that the two groups are more strictly bound together than any individuals within it, and this we may, if we please, term group marriage. But the expression is undesirable unless deliberately intended to suggest the theory of an earlier form in which men and women were actually united by groups.

The real importance of these isolated and partial illustrations of group marriage lies in their association with the classificatory system of counting kinship. In name, an Australian has not one father, but a group of fathers, i.e. all the potential husbands of his mother; not one brother, but a group of brothers, i.e. all the sons of his potential fathers, and so on. This system of naming is widely spread in parts of the world where there is little or no trace of group marriage. Those who uphold group marriage argue (1) that this method of reckoning kinship is the only possible method where group marriage exists, (2) that no other satisfactory explanation of its origin and meaning has ever bren put forward, (3) that we can understand its existence where individual marriage now prevails if we suppose group marriage to have existed previously. If this is granted it is tempting to argue further to a general theory of the origin of marriage, according to which its history would begin (1) with the temporary mating of a man and woman. This would he restricted (2) hy a taboo on all women recognized as of the same hlood or of the same totem - the conception of unity being in any rase macical - as the man. This would rield group marriage with such imporfect individual appropriation as we find among the Urabumna, and then would deretop (3) into a more permanent appropriation of certain women to a man or men. Bunt these considerations lead into a rexion of hypothesis which lies outside the blan of the present work, the ohjeret of which is to analyze and comparr institutions which we find, not to postulate institutions which we do not find.

Cases in which a man marries his wife's sisters or possibly eertain other relatives along with her are partial developments of polygamy rather than group marriages, and the institution of the Omaha, quoted by Koller ("Z. f. V. R.," 1897, p. 320) as a "ase of group marriage, whor" a man marries the aunt and sister or nices of his wife, while on his death the widows pass to his brothers, is a combination of this form of polygany with the levirate. 
probability of which others must determine. What we actually find is not this marriage of two groups, but exceedingly loose relations, polygamous and polyandrous, within the groups combined with strict taboo outside them.

There the marital relation becomes very loose we approach promiscuity, or the sheer negation of marriage, as between all who are not separated from each other by any taboo. If such taboos also fail, we get complete promiseuity. Does this exist? Dr. Westermarck ${ }^{1}$ enumerates some thirty-one cases in which it has been alleged. But in the majority of these it is also denied by other authorities, and in several the allegation is known to be false. There remain a number of eases in which the marital relation is so loose that the husband sinks into the position of a lover, temporarily visiting the woman's house and readily dismissed at will. Sheer promisenity is probably to be regarded rather as the extreme of looseness in the sexual relation than as a positive institution supported by soeial sanctions. ${ }^{2}$

4. The looser types of marriage are almost, if not entirely, confined to savage and barbarous races. It is here if anywhere that we find promiscuity and group marriage. It is here, certainly, that we find the marital relationship so loose as to approach promiscuity and group marriage. It is here also that we find polyandry - a custom practised by no people with any pretension to civilization except the Thibetans and the ancient Spartans. lolyramy, on the other hand, while also very common among uncivilized peoples, may be said to dominate the middle civilizations, and monogamy the higher. But here we must guard against too sweeping statements. Monogamy, and a strict monogamy too, is found in several quite savage peoples, including among them

1 Hestermarch, pp. 52-55.

2 The statement of Herodotus about the Massagetae (Bk. i. chap. 216) and of Cosmas of Prague (eleventh century A.D.) about the ancient Bohemians are reducible to this. Cosmas writes, "Connubia erant communia. $\mathrm{Nam}$ more pecudum singulas ad noctes novos probant hymenaeos, et surgente aurora . . ferrea amoris rumpunt vineula." "Kovalewsky, "Modern Customs and Ancient Laws of Russia," p. 10.) Post gives as instances of peoples among whom "marriage relations are almost unreeognizable," tribes of California and the coast of Venezuela, aborigines of Brazil and some Peruvian tribes, six instances in Oceania, three in India, and four in Africa. ("Ethn. Jurisprudenz," i. 52.) He adds further instances, malsing seren in all for Africa. ("Afrik. Jurisp.," p. 301.) Among the Irintuns of California, according to Powers, a man generally pars nothing for his wife, but merely "takes up with her." If (not hoing a headman) he takes a second wife, the two wives fight till one is driven out, while the hushand looks on and abides in the lodge of the conqueror or follows the vanquished as he chooses. ("Tribes of California," p. 23s.) Can this relation be called marriage? 
some of the very lowest. The Veddahs and Andamanese have been mentioned. Elsewhere it occurs sporadically, it is impossible to see for what specific reason, among races which are generally polygamous. Thus polygamy and easy divorce are both general ${ }^{1}$ throughout Oceania, but among the Dorians of New Guinea there is neither polygamy nor concubinage. Among the Indian hill tribes there are several instances. Some of the Naga tribes are monogamous, some polygamous. The Karens have only one wife; the Santals take a second only if necessary to obtain an heir; but in all these cases divorce is allowed. The Kukis are polygamous, but the people called the Old Kukis keep to one wife. Monogamy occurs among some of the ruder Malayan tribes. Of the Central Asian peoples the Kara Tangut nomads are mentioned by Ratzel as monogamous. Monogamy is rare among the North American Indians, ${ }^{2}$ but it occurs in a few tribes of South America. ${ }^{3}$ Polvgamy is the general rule among the Negro and Bantu races, but instances of monogamy are found among peoples of Northern Africa as the Touaregs and the Beni Mzab.

We shall understand the occurrence of such exceptions better if we bear in mind what precisely is meant both by monogamy and by polygamy when these institutions are attributed to a rude tribe. Whether monogamous or polygamous, sarage tribes ustally tolerate divorce on very easy terms, especially for the husband. But the division between a form of monogamy which easily admits a change of wives and sheer polygamy is no very deep one. On the other side, it is to be observed that though polygamy in one form or another is ordinarily permitted in uncivilized races, it must not be supposed to be the rule among many peoples. Generally speating, the numbers of the sexes are approximately equal. There are exceptions to this in certain races which partly account for the abnormal development of polyamy among them, but where the relative numbers are normal it follows as a matter of arithmetic that either monogamy must he the prevalent practice, or a great number of men must go without wives. In point of fact, porerty, as well as law or custom, fights on behalf of monogamy. It is in

${ }^{1}$ Kohler states, howerer, that among Papuan tribes polygamy is sometimes permitted only with the consent of the first wife. (Kohler, “Z. f. V. Rwt.," 1900, p. 349.)

2 Instances are the Yuroks of California, and the Karoks - among whom bigamy is not tolerated exen in a chief, and, what is still rarer. a man may own as many women for slaves as he can purchase. but cohabitation with more than one lrings obloquy (Powers, p. 2.2) - and the Klamaths (ib., p. 405). For other cases see If estermarch, p. 435.

${ }^{3}$ Schmidt, “Z. f. T. R.," 1898, p. 304, enumerates five instances. 
most cases only the eomparatively rich and powerful who have a large harem, and this is one reason among others why polygamy is less developed in the lowest races, and the possession of many wives comes about when wealth and population are alike growing. When we speak of polygamy being the normal custom of uneivilized races, therefore, we mean the permission of polygamy, and it is this permission that exists almost everywhere throughout the savage and barbaric world and among the lower civilizations. Te should, then, distinguish between an ethical monogamy, based on the belief that it is wrong to have more than one wife, and an habitual monogamy, based on the practical difficulty of obtaining and maintaining more than one wife. Where, owing to general poverty and the equality of conditions - which would bar the making of exeeptions in farour of rich men or chiefs - the practice of monogamy has become universal, and as such is of long standing, it would harden into a custom (sustained by whatever sanctions are recognized) without implying any very great advance in the ethical conception of marriage. And this may account for some of the cases mentioned, and in particular for the point often noted, that it is the ruder tribe which is monogamous, while the growth of wealth in neighbouring peoples enables richer individuals to indulge in a harem. ${ }^{1}$ We shall not, then, be far wrong in conchuding that polygamy, limited, often very narrowly, by poverty and the relative numbers of the sexes, is the prevalent type of marriage in uncivilized society. ${ }^{2}$ Of the development in the civilized world we shall speak more in detail later on. ${ }^{3}$ Polyandry, on the other hand, is by comparison an exceptional practice, the

1 Travellers and ethnologists sometimes describe people as monogamous who in fart are so only by prevailing habit. The Iroquois, for instance, always figure among monogamous peoples, and no doubt that form of marriage prevailed with them and became the strict rule. Thus Morgan ("League of the Iroquois," p. 324) states that polygamy was forbidden and never became a prartice, but from Coldan's account given in Schoolcraft's work, i. 221, it appears that it existed, though rarely practised, in lis time. Repeaterlly we hear that the mass of the people are monogamous, but that the chicfs or the wealthier tribesmen have several wives or concubines. This was the case with the ancient Germans. Polvany was rare in practice, but was legal.

${ }^{2}$ Dr. irestermarch (p. 43.5) entmerates in all hetween forty and fifty cases of savage and harbarian tribes which are monogamous. Many of these are single tribes, which are exceptions to the general rule among their kindrey and compatriots. It seems to be only among the Hill Tribes of India and the Malay region, which are pich in rarieties of marriage eustoms, that any number of monogamous tribes are found. Post ("Eth. Juris.," i. 5s, 59), after pointing out that innumerable peoples live in practical monogamy, adds, "Eine wirliliche Zwangsmonogamie ist eine rerhältnissmässig seltene Ersoheinung."

${ }^{3}$ [In Chapter XV of this volume.] 
principal causes of which are most probably poverty and a deficiency in the number of women. On the eridence before us it is hardly to be deseribed as an institution belonging to one of the great types of social organization.

\section{II. Impediments to Marriage.}

A quite distinct classification of marriage sytems could be made on the basis of the prohibitions which almost everywhere restrict, in greater or less degree, the choice of a husband or wife. These prohibitions exhibit a rich variety of differences, and their meaning and origin are extremely obscure. We have already noted that they fall into two great divisions. On the one hand, there are restrictions forbidding marriage within a certain wroup - laws of exogamy; on the other, and quite possibly among the same people, there are rules forbidding it outside a certain wroup - laws of endogamy. Both kinds of restriction appear in a great variety of forms. Thus endogamy may take the form of prohibition to marry outside the clan, as in old dars among the grpsies. ${ }^{2}$ or the caste as in India, or even the family. In the ancient world foreigners could rarely intermarry unless their respective states had the jus commbii, and there were generally barriers on the intermarriage of slave or serf with free men or women, and a social, if not a legal, bar on the marriage of noble and commoner. In the modern world legal barriers have for the most part disippeared, and, socially speaking, equality in education alone is exacted." Far more various and difficult to understand are the rules of exogamy. Marriage may be forbidden within the totem, as among many North American Indians and some Australian tribes; within the clan, as among the Tagas $^{3}$ and Somali, ${ }^{+}$etc.; within the village, as among the Battas ${ }^{5}$; or the tribe, as in Rotuma. $^{6}$ It may also be prohibited within the kindred, and here again great differences appear. All the kindred, so far as relit-

1 Post, "Grundriss," i. 33. See ib. for several instances in which it is the duty of relations to marry. I am not clear that it is distinctly forbidden to marry another thain a relation.

2 There are exceptions, such as the prohibition of marriage with negroes in twenty-two of the United States, with Indians in four states. with Mongolians four states. ("Parly. Papers, Miscell.," No. 2, 1s94, p. 155.) Otherwise the intermarryng of roval families is the principal exception. In the German cote the marriage of a high noble with a commoner involves certain disabilities. (Westermarek, 373.)

${ }^{3}$ Godden, "J. A. I.," xxvi. 173.

${ }^{4}$ Post, "A. J.," i. 38:3.

5 Haitz, v. i. 186.

${ }^{6}$ Cardiner, "J. A. I.," xxvii. 478. There appear to be sporadie cases of prohibition within the same caste, or the same religious division. See Post, "Grundriss," i. 41. 
tionship is traceable, may be prohihited, as among the Andamanese and the Yoruba. ${ }^{1}$ Or the prohibition may be applied to all the kin on that side to which the greater importance is attached, as in the Brahmanic and Chinese prohibitions." Where relationships are of the "classificatory" type, e.g. where the mother and all her sisters are addressed by the same name, while the daughters of all that group of women again have one form of address in common, the prohibition of marriage may extend to all members of the group, and society will divide itself into classes within which a man may marry, and classes within which the women are strictly taboo to him. This class division of society runs through the Australian peoples. ${ }^{3}$ Again, kinship may be reckoned by degrees, as among ourselves, and exogamy may be enjoined for certain degrees only, while beyond them marriage is permitted. In point of fact, under one rule or another, prohibition of marriage within the first and second degrees (parent and child, or brother and sister) is almost universal, if we take account only of the basis of relationship recognized by any given people. Thus, if the totem is exogamous, and passes by mother-right, all kindred through the mother will be excluded from marriage, but brother and sister by the same father will be no relations, and may intermarry. Indeed, if the principle is carried to its logical conclusion, the same will be true of father and daughter. On the other hand, the totemic prohibition may be eked out by a custom forbidding or discouraging the marriage of near relations as such. Thus, in New Britain we are told that though legally a man may marry liis brother's daughter, since she is not of his totem, yet in point of fact such unions excite great repugnance. ${ }^{\ddagger}$ Apart from cases in which kinship is only reckoned on one side, so that intermarriage is allowed within the half-blool, the permission of incest within the nearest degree appears very rare. Indeed, with this reservation we may say that the nearer the relationship (counting that of the son to his mother as closer than that of daughter to father),

1 Man, "J. A. I.," xii. 126. Ellis, "Yoruba-speaking Peoples," p. 176. The Andamanese recognize adoption and affinity as bars, but, through want of records, fail to trace kinship beyond the third generation. ( $\mathrm{Man}$, "J. A. I.," xii. 127.)

2 If the clan is based on father-right, it will he seen that the prohibition to marry an annate is, at least in theory, equivalent to prohibition of marriage within the clan. Identity of name, again, is taken as equiralent to common membership of a putative clan.

${ }^{3}$ Among is peoples examined by Tylor, who count relationship on the elassificatory system, 33 are at present exogamous. ("J. A. I.," xviii. 264.)

"Danks, "J. A. I.," xviii. 283. 
the rarer is the failure to prohibit. ${ }^{1}$ Such failure probably occurs most often in consequence of a strongly endogamous tendency, in the form of a desire to maintain purity of blood. Hence we find cases of in-and-in breeding among roval families, e.g. in ancient Persia and Egypt, and among high castes as the Llitaos of Micronesia." But the prohibitions may be carried far berond the first and second degrees. The Roman Church still forbids marriage to third cousins, and the attempt was made to carry it much further. Again, relationship may or may not be constituted by marriage. In many cases a son inherits his father's wives, with the exception of his own mother, along with the rest of the family property. We find the Jewish legislators, and, later, Mohammed, setting themselves against this practice. On the other side, rules of affinity may be construed as sererely as those of blood relationship. On this method an immense extension of the forbidden degrees was effected by the mediæval church, ${ }^{3}$ which was still further widened by the creation of a spiritual affinity between god-parents of the same child. The effect of this complex mass of prohibitions was such that hardly any marriage was clearly valid, while dispensations were and still are attainable allowing unions even between uncle and niece. Protestantism swept away this mass of prohibitions, and for the most part allowed marriage of first cousins, and confined the restrictions of affinity to the direct line. ${ }^{4}$

Of these very various rules it seems possible to say three things generally. The first is that they tend to bar marriage between people who are bound together by some other important relation. Thus the totem or the clan, which is exogamous, is also as a rule

1 The marriage of father and daughter, as well as that of brother and sister, is said to be allowed among the Aleuts. (Reclus, 65.) According to Post, "A. J.," i. 382, there is no case in which incest with a mother is allowed in Africa, but among the Wanyoro, sister and even daughter marriage occur. Incest between parents and children is also found in some South American tribes. (Starche, "The Primitive Family," 224. Cf. Schmidt, "Z. f. V. R.," 1S9S, p. 304.) Among some of the Veddahs the younger sister is the regular wife. (Sarasin, "Ergehnisse naturwissenschaftlicher Forsehungen auf Ceylon," iii. 465, quoting Bailey.)

${ }^{2}$ Sister marriage wals common in ancient Egrpt. (W. Hax Müller, "Liebespoesie der alten Egypten," pp. 7-S, and Waitz, v. ii. 111.) For other instances see Westermirck, 290 .

${ }^{3}$ See Huth, "Marriage of Near Kin," 117. II uth (op. cit., 120) instances the repuctiation of Ingeburga of Denmark by Philip Augustus, on the ground that she belonged to a family which had previously intermarried with the family of Plilip's first wife. It is fair to say that in this instance the Pope procured Ingeburga's restoration.

${ }^{4}$ The English prohibition of marriage with the wife's sister is the most conspicuous cxception. 
bound in a kind of brotherhood to mutual assistance. Secondly, the particular relation which is the commonest bar is that based on blood kinship. Thirdly, the violation of the rules of exoramy, whatever they are, is generally regarded with peculiar horror. It is often an object of public vengeance when no other crimes, except perhaps that of witcheraft, have been raised to that dignity, and in the civilized world the intensity of feeling which it excites in no way diminishes.

6. Notwithstanding the great variation in the forms which it takes, the exogamic impulse seems to perform certain functions which are fairly constant. 'Thus (1) it checks in-and-in breeding, both intermarriage with near kin, and often in the lower races marriage within the narrow limits of the clan or village, which in their isolation would otherwise become entirely filled with people related to one another by a network of cousinship. What precisely are the physical disadrantages of in-and-in breeding or the advantages of crossing are, however, harder to say than is popularly supposed, and it is probable that this biological side of the matter is the least important of the functions served by exogamy. ${ }^{1}$ But (2), as indicated above (Chap. II.), ${ }^{2}$ it has the important sociological function of binding distinct groups together. (3) A third function of more importance in the civilized world is of a distinctly ethical character. For us the prohibition of incest is the only form of exogamy which persists, and incest is a crime which affects us with a horror, of the kind we call instinctive, and which is certainly not weaker in civilized than in barbarous humanity. What is the meaning of this horror? It is too real and deeply rooted to be explained as a survival. It is not based on tradition and convention, for it is not felt in relation to many crimes which the laws forbid. 'Thus, among peoples who accept the law of the Roman Church the marriage of cousins is forbidden, but frequently occurs. In our own country men may approve or condemn marriage with a deceased wife's sister, but any one who should put it on a par with incest with a hlood-sister would be a very abnormally constituted person. Is the horror, then, of incest instinctive? The usual objections to this view are based on a misunderstanding of instinct. It is said that the horror is not universal, and that the objects to which it is directed differ widely in different

1 See the evidence, especially that of Mr. G. II. Darwin, collected in Huth's "Marriage of Near Kin," chap. viii.

2 [Of the original work.] 
peoples. But many instincts in the animal kingdom fail in universality and are modifiable in their application. And, as we have seen, what is instinctive or hereditary in human nature becomes more and more a feature of eharacter, a tendency or disposition to feel or act which obtains its actual direction from experience, and espeeially from education and social tradition. Hence, to say that the horror of incest is instinctive is merely to say that there is in it something rooted in the character which the average man inherits, but it still remains to determine what that something is and to understand how it ean be developed in such a variety of ways. Analysis of the feeling itself seems to justify the view of Lotze that it is the mind's protest against the blending of two distinet attitudes towards the same person. Sexmal love and parental love have an element in common, or we should not use the term love of them both, but in other respects they are as incompatible as oil and vinegar. Even love and hate have something in common, an intense magnetized interest in the personality of another. But love and hate cannot fuse. The one is the enemr of the other, and so is it also with the two fundamentally opposed forms of attachment. That this is so is a truth about human relationships based on human nature, and in that sense the outcome of an instinet. But like other truths of the same kind it is not to be explained by calling it an instinct, but by analyzing its nature and explaining its function. That function has been, in earlier stages, to draw families together into society, and at all stages to keep distinct, and therefore in healthy development, the deepest affections of mankind. The earlier function being now superfluous, laws of exogamy tend to confine themselves to restraint on the marriage of that near kindred between whom strong relations and affections - incompatible with sex feeling arise. This account enables us to understand in a general way the fluctuations in the rules of exogamy and their gradual reduction in the civilized world to the familiar prohibitions. In the first place, the feeling against the marriage of kindred will only extend to the kindred recognized. Hence, where mother-right holds we shall find inarlequate provisions against marriage with the paternal kin. The relation of the child to its mother is the first strongly realized, and remains the most sacred of all human relations, and cases where the breach of that relation is tolerated are the rarest of all. We may take this relation as the starting point of the prohibitions, and then bear in mind that it is all in accordance with the ways of primitive thought to extend them 
to everything indirectly or remotely associated with the tabooed relation - e.g. to the mother's ehildren, her relatives, all of her totem or her name. 'The father may come into the account independently through the recognition of paternity or through contact with the mother, and starting from the paternal relation the taboo may be extended in the same way. The eccentricities of exogamy, then, are explained as arising (1) from an unduly extended taboo, (2) from an insufficiently felt recognition of natural relations. These are the ordinary faults of excess and defect which characterize rude morality, and are on the whole removed as civilization advances.

Thus, in earlier customs we find rules of endogamy restricting marriage by clan or easte exclusiveness, and of exogamy restricting it by rules bearing an indirect or irregular relation to the natural feeling which we are led to conceive as their starting point. In more civilized ethies we find the first set of restrictions nearly annihilated, and the latter reduced to a simple expression of the permanent feelings from which we supposed them to emanate. In both directions the more civilized ethies tends to discard rules which hamper the free exercise of choice in accordance with normal human feeling.

\section{III. The Stability of the Marriage Relation.}

Not less important than the number of parties to the union is the permanence of the marriage tie, and on this basis it would be easy to make a classification cutting right across all others. In many of the lower races, as we have already seen, the dissolution of marriage is so easy and frequent that it becomes a question whether the term marriage is at all applicable. In other cases the marriage bond is as strictly regarded as in the Roman Church. Here, again, we cannot find a continuous and unbroken development in any single direction, but once more we can with tolerable accuracy lay down that certain tendencies predominate at given stages of culture. This will be clear if once again we begin by distinguishing the different possibilities, and then briefly indicate the stage of culture at which each is or has been most frequently realized.

Divorce may (1) be perfectly free to either party ; (2) it may be free to both by mutual consent; (3) it may be absolutely at the will of the hushand or (4) of the wife. Next, (5) it may be free to one party or both on obtaining the consent of the family, the elan, or a court; (6) it may be open to either party on certain condi- 
tions. These conditions are infinitely various, but we ought to distinguish as cases differing in principle $(a)$ those in which the only condition is of the nature of a fine, usually taking the form of forfeiture of dowry or the restoration of the bride price, and (b) those in which the essential condition is some fault or defect in the other party to the marriage. Further, $(c)$ it may be open on the same conditions to man and wife, or $(d)$ on different conditions. Very often, in fact, it is free to the husband and allowed under conditions to the wife. (7) It may be wholly forbidden, marriage being indissoluble. In this latter case a separation a mensa et thoro is usually allowed, but sometimes this too is forbidden.

Marriage is indissoluble among the Andamans, some Papuans of New Guinea, at Watubela, at Lampong in Sumatra, among the Igorrotes and Italones of the Philippines, the Veddahs of Ceylon, ${ }^{2}$ and in the Romish Church.

Ordinarily, however, both in the civilized and uncivilized world marriage may be dissolved either at pleasure or under certain conditions. Among uncivilized peoples divorce is not infrequently free to either party. The man dismisses his wife without ceremony, or the discontented or injured woman leaves her husband's house without more ado and runs back to her own relations, ${ }^{2}$ or they part by mutual agreement. ${ }^{3}$ In the higher stages of barbarism and in primitive civilization the consolidation of the family under the growing power of the husband tends to make divorce rarer and more difficult. Sometimes it drops almost entirely out of use. Thus it was a Roman boast that though divorce was not legally impossible before the case of Sp. Carvilius Ruga in B.c. 2:31, no instance had been known since the foundation of the city. Sometimes, with less justice, the power of divorce is left to the husband and withheld from the wife. It may even remain entirely at the husband's pleasure to send back the chattel which he has bought. Thus the Hebrew who found anything unseemly in his wife merely gave her a writing of divorcement and had done with her. In other cases there was at least a pecuniary deterrent. The divorcing husband forfeited the dowry, or, if the fault was his, could not regain the bride price. He had to leave his wife all

I I take the foregoing from $D r$. Westermarclis list, p. .i1. He quotes Wilken's opinion that the same held good of the Niasians and Batalis.

${ }^{2}$ Sometimes it is a condition that she returns the prife paid for leer, e.g. in Soulimana and frequently in Africa. (Howard, i. 2.26.)

3 This Post considers to he the rule under the clan organization of society. (Post, "Grundriss," ii. 117.) 
the gifts he had made to her, or, finally, if she had no such property of her own, he had to pay a definite sum. Again, if there were children, provision might be made for their maintenance, or the right of divorce itself might in this case be withdrawn. ${ }^{1}$ Similarly, where the wife has the right of divorce, she may incur pecuniary forfeits, losing her dowry, or having to repay the bride price and return the presents made at or during marriage.

Such pecuniary penalties render marriage relatively stable; but a further step is taken when it is dissoluble only under assigned conditions. These again show extraordinary variations. The husband is generally able to divorce the wife for unfaithfuhess, very often for sterility, and sometimes ${ }^{2}$ because she bears no sons; often, ton, for disobedience, bodily defects, or what are considered moral failings. The wife, again, often has the right of leaving the lusband in case of neglect, desertion, impotence, or cruelty more rarely in case of unfaithfulness. As a rule, the divorced husband may marry again, but it is not always that the divorced wife has this right, especially under the system of marriage by purchase. Sometimes she is wholly prohibited from marrying; sometimes she must refrain till she has the leave of her former lord and master.

The customs of savage and uncivilized peoples as to divorce vary in such wild profusion that it is very difficult to make any general statement with regard to them. It may, however, be said that, with the few exceptions mentioned, divorce is allowed; that it is generally free to the husband on easy terms, and very often also to the wife, or to the two parties by mutual agreement, ${ }^{3}$ but is sometimes restricted to special cases, and that the derelopment of the patriarchate, and particularly of marriage by purchase, ${ }^{4}$ tended to increase the privileges of the husband as compared with those of the wife in this relation. ${ }^{5}$ In the Oriental civilizations,

${ }^{1}$ E.g. areording to Post, "A. J.," i. 434, among the Moorish tribes of the Sahara and the llottentots.

2 E.g. in Burmah. (Post, "Grundriss," ii. 114.)

${ }^{3}$ In comparing the position of husband and wife, it must be borne in mind that divore almost nniversally sets the hushand free to marry again, while the wife, in a large number of cases, especially under marriage by purchase, is more or less narrowly restricted in this respect, so that for her, divorce rather corresponds to what we call separation. (Howard, "A History of Matrimonial Institutions," i. 244, 245.)

${ }^{4}$ Howard, i. 231, notes the influence of wife-purchase in this direction.

${ }^{5}$ Diverce among Savages. - Divorce is apparently either quite free or open on very easy terms to either party among many North American Indians Columbians, Howard, i. 238; Iroquois, Schoolcraft-Drake, i. p. 221; Upper Californians and Innuit, Kohler, “Z. f. V. R.," 1897, p. 368). Among the Furols divorce is very easily accomplished at the will of the hushand. (P'owers, p. 56.) In this last case the husband 
with one or two exceptions, the inequality has been pushed still further, as we shall presently see in detail. In the West the

regains the bride price. It is free to both parties among the Eskimo of Point Barrow and of Behring Straits and Pawners. (Howard, i. pp. 227, 228.) Among other trihes it is at the pleasure of the husband; [so stated of the North American Indian generally (Schoolcraft, i. 171); of the Oregons (ib., v. 65.); of the Hupa (Powers, p. 8., ) here the displeased husband gets back the bride price; of the Dakota (Howarl, i. 232) ; and the Abipones (ib.). In the last case, howerer, it may leat to a feudl. Among other peoples the man must lose the bride price if he divorces without good cause. (Thlinkeets, Kohler, l. c.) In some the wife can leave at pleasure. The Navajo women are said by Colonel Eaton (Schoolcraft, iv. 217) to leave their husbands on the slightest pretext. Among the Digger Indians the wife leaves the lusband at pleasure. (Ib.,223.) Among the Cegiha the wife's relations take her away if ill-treated (IIoward, 228), and the Sioux and Dakota women leave their husbands for unfaithfulness or other causes. Among the Upper Californians the deserted husband demands the return of the bride price. In the later form of marriage among the Creeks the bond holds for a year only.

Among the tribes of tropical South America the power of the husband is more developed, and he ean lend, give, prostitute, sell, or exchange his wife at pleasure. (Schmidt, l. c., 189S, p. 297.) In Brazil, according to Anchicta (quoted in Howard, p. 228), the wife may leave at pleasure. So among the Moxos (ib., 239). The Bonak, (ivanan, and Gilatamalan women have similar freedom (authorities rited hy Howard, p. 239).

In Oceania divorce is generally easy, though thore are one or two cases in which it appears to be unknown. In Polynesia divorce by mutual consent is lawful. (Howard, p. 230.) A Tongan husbant divorces his wife by simply telling her to go. (Ib., p. 231.) In Mieronesia divorce is at the man's pleasure, and the same is true of the Papuan peoples, among whom the woman, if she flies, must return the brifle price, while the husband, if in earnest about it, can generally reclaim her from her relatives by the terrors of witeheraft. (Kohler, "'z. f. V. R.," 1900, p. 347.) In the Torres Straits divorce appears to have been rare. Infidelity and sterility were the chief causes, but incompatibility of temper appears to have been recognized as sufficient. ("Cambridge Expedition," p. 246.) Among the Australians the husband can dismiss his wife at pleasure. If she runs away she belongs to any one who may re-capt ure her. (Letourneau, pp. 13 and 18.) In Western Victoria couples may separate by mutual consent, but the husl and wishing to divores his wife must obtain the consent of the chief men of his own and his wife's tribe. She may also complain of his unfaithfulness and get him sent away for two or three moons. (Dawson, "Australian Aborigines," quoted by Howard. pp. 229, 230.)

In Africa divoree at the will of the hushand is gencral (Post, "A. J.," i. 433). The corresponding right of the wife is rarer, but not infrequent. Some 16 cases are enumerated hy Post ("Afrik. Jurisp.," p. 43(i), but some of them are doubtful, or depend on special conditions. Amone the Fantis, Foulahs, and Kaffirs (Post, “A. J.," p. 43S), and in Kordofan and Baka (Post, "A. J.," p. 439) the negleet or ill-treatment of the wife are good grounds of divorce. Among the Bogos her third tlight is talien as final. (Post, "A. J.," p. 4:37.) In many tribes the wil" can be divoreed for sterility (Post, "A. J.," p. 4399) and among the Kimbundas the husband can be divorced for impotences. (Post, "A. J.," p. 441.) In many cases compensation must be given by the party which dissolves the marriage, c.g. among the Foulahs and the Katfirs for groundless repudiation. In Bornu the wife retains hre dowry. (I'ost, "1. J.," pp. 442-3.) Among the Banrars she recives a small sum and retains all the presents she has received. (Post, "A. J.," p. 442.) Anong the Basutos, unless guilty of an offence, she is entitled to support. (Post, "A. .J.," p. 412.) In Egypt she can also elaim a certain provision, and in Abyssinia she can 
changes of law and opinion as to divorce have been numerous and sweeping, as will appear fully when we deal with marriage among

daim her dowry as well. (Post, "A. J.," p. 442.) Among the Bogos she takes the lousehold utensils with her, among the Barea and Kunama she las half the joint property, and in Noroceo a sum awarded by the judge. (Post, "A. J.," pp. 442, 4.3.) If the woman leaves the man her family must return the bride price, and perhaps more. But the question of compensation is very naturally affected by the cireumstances of the divoree. If the divoreing party has good grounds he or she pays less, or perhaps pays nothing. Thus among the Kaffirs, Fonlahs, Fantis, and in Kordofan the wife does not restore the brid" price if she has good grounds for learing her hushand. (Y'ost, “A. J.," p. 445.) Among the Beni Amer, if it is the man who divorces, the woman's property is divided, the husband taking his weapons, and the wife the house and contents. If the woman divorees the man for ill-treatment or infidelity, she gets only one-third of the common stoek; if impotence is the cause she gets half. (Post, "A. J.," p. 44ti.)

Among the Yoruba (where father-right holds) the husband can divorce the wife and reclaim the lide price if she is unfaithful; otherwise he loses the price. If he neglects the wife, she summons a palaver of her relatives, and if he persists, she may leave him. If he is of inferior rank he is liable to be flogged by her relations. (Ellis, "Yoruba Peoples," p. 187.) Under mother-right, where the woman is not bought out of her lanily, the children often follow the mother in case of divorce. But this is not always the case, and sometimes the eircumstanees of the divorce determine the children's future. (Post, "A. J.," p. 447.)

No obstarle is offered to the re-marriage of the man, but under marriage hy purchase the husband generally retains some control over the divoreed wife. Among the Hottentots and Ashantis she cannot remarry; among the Banguns, not in the same village; among the Kaffirs, only if she had good grounds for leaving her husband; among the Marea and the Habul, not till her husband declares her free. But in many cases (Post, "A. J.," p. 450, enumerates 8) apparently after a certain interval she is free to re-marry.

On the whole. throughout Africa, marriage by purchase prevails, and the position of the wifo is accordingly less favourable.

Among the Indian IIill tribes the variations are great. The Nair wife may not only dismiss any of her twelve husbands at pleasure, but may even let him be sold into slavery for dobt. (Reclus, "Primitive Folk," p. 158.) Often diroree is free to either party. Instances are the Todas, Bodo and Dhimals (but here an adulteress must refund the bride price), and the Karens. Among the Barlagas the wife may leave if she pleases, but the husband retains the ehildren. He is also free to divorce her. (Reclus, op. cit., p. 195.) Among the Nagas there is a fine aecording to the rause of the divoree. (Godden, “J. A. J.," xxvi. p. 177.) Among the Santals divorce is rare, but is permitted to eitler party on obtaining the consent of the husland's clan. Among the Khonds the wife may leave the husband on repaving the bride price. (In some tribes this privilege is restricted to the childless.) On the other hand, she ean be diroreed only for adultry or prolonged misconduct, and her consent is required if the husband wishes to tako a concubine (Rcclus, p. 280); and, a rare note in the savage world, infidelity on the part of the man is held dishonourahle.

Among the peoples of Central Asia divoree appears to be open to the man at pleasure and to the woman for persistent ill-treatment. (Ratzel, vol. iii. p. 342; Letourneau, "La Femme," p. 210.)

Among the Malays, divorce is greatly influenced by the form of marriage. In the Ambil Anal marriage the wife may divoree the husband. In the Djudjur marriage all the adrantage is on his side, but she ean generally escape from him if ill-treated. In the Semando form of marriage (sef If aitz, r. p, 145) the taking of a serend wife or eoneubine is a ground of divoree, and in one plare (Moliomoko) this is the only form 
civilized peoples. For the present, we content ourselves with noting the prevalence of a loose and easily dissolved marriage tie in the lower stages of eulture, which gives way to a binding form of marriage with decided privileges for the hushand at the next grade. We shall find this to be in line with a more general morement.

8. IV. To understand this movement, we deal first with Tethods of Marriage. The principal methods by which a wife is obtained in the uncivilized world come under four heads:-
a. Capture.
b. Purchase.
c. Service.
d. Consent.

A few words may be said here of the general character of these four methods, while their bearing upon the marriage relation will be further discussed in the following section.

a. Marriage by capture is a somewhat ambiguous term. The practice of taking women eaptives in war or in petty raids is widely diffused over the savage world. In the gemine and unadulterated form of carrying off a bride from a strange tribe against her will and that of her relations, it occurs, according to Professor Tylor, in some forty cases.' From this genuine capture Professor Tylor distinguishes connubial and formal capture. Connubial capture is not a mere form, but is a recognized method of obtaining a bridge between families living at peace with one another, and is not regarded as a sufficient ground of quarrel. Of this Professor Tylor finds forty-six cases. Finally, he enumerates forty-four cases in which the form of capture is retained without the reality as part of the wedding ceremony. One illustration will suffice:- "Among the Bedonins of rinai the bridegroom seizes the woman whom he has legally purchased, drags her into his father's tent, lifts her, violently strugghing, upon his. camel, holds her fast while he bears her away, and finally pulls her

recognized. (Waitz, v. 145, etc.) Among the Battaks of Last Sumatra there is no one-sided divoree, exeept for attempt to murder, and mutual agreement is required. (Howard, p. 229.)

1 As an ineident of savage warfare it is probably more frequent. A long list of instances of the prartice is given in IIomard, vol. i. p. 15s. From Cape Horn to Hudson's Bay women are regarded as legitimate hooty. The practice of rapture prevails throughout Melamesia. has existed throughout Tasmania, New Zealanel, Samoa, New Guinea, among the Fiji Islanders, the Indian Arehipelago, and to a limited extent in Iustralia: it is found oecasionally in Afriea, and in various aneient nations. 
forcibly into his house, though her powerful resistance may be the occasion of serious wounds." " In other cases the resistance is less determined, and the form of capture is reduced to a mere s! mbolical act. The wide prevalence of these forms led McLennan and others to the belief that capture was originally universal; but this opinion is now abandoned. Capture, as we shall see further, is incompatible in principle with the widely-diffused primitive system of mother-right, and its existence as a form may be explained in many instances by the necessity of a symbolic act to express appropriation. The symbol, in fact, is not necessarily a survival of something more real, but may be rather a legal expression of the character of the act performed.

b. Purchase. A far commoner method of obtaining a wife is that of purchase. Where this method is fully developed the unmarried girl is not her own mistress. She is one of the family; more, she is the property of the family or of the family's representative - the governing male, her father, brother, guardian, whoever he may be. She is an asset of a certain value to the family, the amount depending partly on her attractiveness, partly on her labour, partly on the scarcity of the article. This article can be sold for so much, and the purchaser naturally becomes wholly possessed of what he buys.

We shall see, accordingly, that this form of marriage is intimately associated with the extension of marital power, but the extent of this power and the subjection alike of the unmarried woman and the wife vary very greatly in different cases. The nature of the purchase also varies. Very frequently there is a return gift from the bride's parents, and in some cases the return gifts equal, or even surpass, the price originally paid. ${ }^{2}$ It is generally assumed that this exchange is a modification of purchase, and that it is through the increase of the return gift that the opposite practice of the dowry arises. It is also possible that the exchange of presents arises independently in connection with marriage by free consent of the parties as a method of cementing the union of the two families. Howerer, when gifts of serious

1 Howard, i. 165, 166.

${ }^{2}$ E.g. in Columbia (Howarl, wol. i. 192). In the Torres Straits, apparently the gifts are ultimately balanced by return presents, yet the transaction seems to retain a commercial character. The chief Maino told Dr. Haddon that he paid for his wife a camphor-wood chest with 7 bolts of calico, one dozen shirts, one dozen singlets, one dozen trousers, one dozen handkerchiofs, two dozen tomahaws, one dozen hooks, two fishlines, one long fish spear, one pound of tobaceo, two pearl shells, and "by golly, he too dear!" ("Cambridge Expedition," p. 231.) 
value are exchanged, we must admit that the whole proceeding bears the character of a commercial transaction in which the girl, so to say, is an item on one side of the account. ${ }^{1}$

c. Service. Where the husband is not able to pay for the wife he sometimes receives her on credit, and in default of the possibility of parment may work out his debt in the form of service. This practice is familiar to us from the case of Jacob, and is found to this day in many parts of the world. ${ }^{2}$ In this case the husband enters the wife's family for the period of his service, which being concluded he returns to his own people and sets up a house on his own account. But while residing with his wife's relations the husband is rather a tolerated risitor than the lord and master of his own family. Indeed, he is but partially tolerated, for this residence in the wife's home is frequently associated with the taboo separating the husband from the wife's relations. Ther are bound to mutual avoidance because, as being generally members of separate totems or clans, they are in theory enemies. On the other hand, when the service is completed and Jacob has led Leah and Rachel to his own home, his authority is rindicated and he has whatever rights the custom of the tribe allows. The sustaining cause of this form of marriage appears to be principally economic. The man serves because he has not the property to buy a wife, and so we find marriage by service existing side by side with marriage by purchase.

d. Consent. In all grades of culture the human factor has its say in the arrangement of marriage, and probably in the lowest grades of all the agreement of the parties is often sufficient to determine a union. Even where capture or purchase is developed, this factor cannot be wholly elminated. A pair who are determined on having each other will settle all questions of right, in the savage as in the civilized world, by elopement. The actual influence of the woman's wishes is, of course, often a question of fact rather than of right. If confining ourselves to the latter

${ }^{1}$ Very often the girl purchased is balanced by another girl upon the other side of the account; in other words, $A$, wishing to mary B's daughter, gives B's son his own sister in exchange. (For instances. see Hourard. i. 18.5; Westermarch, 390.) We might, indeed, maks a stparate type of this practice and eall it marriage by ("xchange.

${ }^{2}$ In Africa, among the (uoja, Fantis, Banrai, Ederahs, and in Futatoro, also among the Zulus and Basnto. It is found in $\mathrm{X}$. Amerisa among the Alents and other Indian tribes; in S. America among the Brazilians; and in the backward tribes of Asia among the Nagas of Asinam, the Koolis, and among other hill tribes, also among the Tunguses, the Ainu, the Kamchadeles, and the aborigines of China; among the Draks and some of the Philippinos, and here and there in Oesania. (W'stermarch, "Human Marriage," 390; and Post. "A. J.," i. 37s.) 
point, we put together the numerous cases of child betrothal, the instances in which women are acquired by purchase or exchange, or by hostile capture, and finally, cases in which, though the consent of the woman is asked, that of her guardian is also necessary, we shall arrive at the conclusion that the explicit recognition of a woman's free power to dispose of herself is upon the whole the exception in the uncivilized world. In practice her liberty is greatest where the family organization is lowest, and the authority of the father least developed.

1 Hestermarck (p. 215) makes a faily long list of cases in which the bride's consent is of greater or less importance. But from the nature of the ease it is diffieult to classify the eustoms of different peoples on this head. 1t does not need arguing that a woman may find means of making her own views felt whaterer the customs of the tribe. Of the Fuegians, who are referred to by Dr. Westermarek, Messrs. Hyades and Deniker say distinetly that the parents give the girl in marriage without asking her consent. We can accept this statement and still believe that if she is resolute enough to leave her hushand and persist in her aversion she will get her parents to give her to some one whom she likes. (Westcrmarek, l. e.) Among the Hottentots and Kaffirs distinet compulsion is exercised aceording to Post, "Afrik. Jurisp.," i. p. 363. But, no doubt, the woman's choice also has influence among these peoples. Often the most opposite customs oceur in the same tribe, e.g. eapture, purchase and choice by the woman among the Digger Indians (Sehooleraft, iv. p. 223), and this is merely what the facts of human nature would lead us to anticipate. Elopement and a peculiar form of child betrothal co-exist among the Central Australians, and by way of exception they also have marriage by capture. (Spcneer and Gillen, p. 104.) In the Marquesas Islands Letourneau remarks that the parents' objections are often overcome by the pair decamping together. ("La Femme," p. 106.) This is a remedy known to the civilized world as well, but it proves nothing as to law or custom. Matters are more strictly defined among the Oregon Indians, where marriage is hy purchase, or lf, as will happen, a runaway match occurs, the woman is looked down on as a prostitute. (Schoolcraft, v. p. 6.5.5.)

In many cases child betrothal co-exists with the right of choice by the grown up woman. Thus, among the Yoruba, according to Captain A. B. Ellis ("The Yoruba-speaking Peoples," pp. 183-185), there is child betrothal, but a woman cannot be forced into marriage though she may be prevented from it. Among the Ainu, Batehelor (p. 141) notes ehild betrothal as an occasional practice now extinct, marriage going now in the main by the eonsent of the parties.

P'ost ("Afrik. Jurisp.," i. pp. 364 and 371), who notes eight cases in Africa where the bride's consent is required, remarks that practieally the consent of the guardians is also nceessary, hut information is scanty. The Yoruha, quoted above, would he a case in point.

The means of securing consent are often sufficiently savage. E.g. aceording to Post (l. e., p. 3633) the reluctant Hot tentot maiden must pass a night with the lover and boome his wife if he succeeds in ravishing her. Among the Mandingos the girl has the option of remaining unmarried, and if ever given to another, her first lover may make her his slave.

A variant to the ordinary case of the disposal of a girl by her parents occurs when a man acquires a right to a woman by his position. This appears under the Levirate and also in cases like that of the Oregon Indlians, where marrving an oldest daught er entitles a man to all her sisters, even if one of them be already the wife of another. (Schoolcraft, v. p. 654.) 


\section{V. The Relation of Insband and Wife.}

To understand the ethical import of this bewildering variety of customs we must look to the eoneeption of the family and of the relations of its members to one another. The specific explanation of the rise of particular forms at particular times and places may be unattainable, but by taking the enception of the family as our starting point we shall, I think, be able to understand how it is that abnormal forms like polyandry and partial promiscuity are possible in primitive society, why they disappear at a later stage, why polygamy existing in the lowest eulture is extended and reaches an abnormal development in the middle civilization, and why in the West it has given place to monogany. Here, if anywhere, again we may hope to gain some insight into the causes affecting the permanence of marriage, and to trace out the derious and tangled laws by which this varies in different stages of culture, to understand finally the eonditions under which the methods of marriage just enumerated arise in early society, and how the first three forms gradually yield to marriage by consent. In tracing this evolution we have to deal not with any single eause or with any single and continuous development, but with a blending of ethical conceptions, themselves various, confused and cren conflicting, with religions prineiples, and economic and social forces.

The result which emerges from all this confusion may, however, as I think, be briefly stated, and it will conduce to clearness if it is set out beforehand. Broadly, the family may be said to have gone through three stages of development. In its first form the natural family, by which I mean husband, wife and ehildren, is not yet complete; husband and wife are not as yet united in the sense in which they become legally and morally one flesh in the higher forms of marriage. This form of marriage, of course, corresponds to the maternal clan system. In the sceond form of marriage the natural family is eomplete, and the husband is the head ; but it is eompleted at the cost of the greater subjection of the wife, who, in passing into the husband's family, merges her personality in his, often almost like a slave. In the third form of marriage the union of the family is maintained by the closest moral bond, but the full legal and moral personality of the wife, as well as of the husband, is preserved. This third form of marriage must be regarded as a type or as an ideal rather than as an actuality. 'To

1 I do not add the religious conception of marriage (as a sacrament) as a fourth type, because the religions (or magieal) conception is present at 
achieve it is a problem which civilization has yet to solve, since the solution involves a certain reconciliation of contradictories; and if we wish to recognize any types of marriage as belonging to this class we must exercise a little liberality and admit all such as make a bona fide effort towards the solution. These efforts belong, in the main, to the story of cirilized marriage. We have first to consider the two lower forms, which together dominate the uncivilized world. In the early stages of historical investigation into the beginnings of eivilization it was thought that society arose out of the patriarchal family, and that in Abraham, Isaac and Jacob, or again in the Roman paterfamilias, as we reconstruet lim from the laws of the Twolve Tables and what we know of earlier Roman law, we have a type of primitive human government. The researches of Bachofen, McLennan, Morgan, and others opened up an entirely new field of speculation. It was shown that the lower we go in the scale of civilization the more prevalent we find a type of organization which is in many ways the opposite of patriarchal, putting the mother for many purposes into the father's position. Amongst civilized nations which have passed out of this stage we find indubitable traces of their having gone through it at an earlier period. These observations led to the setting up a matriarchal, as opposed to the patriarchal, theory, and to the belief that in the dim red dawn of man there was a golden age of woman, which later on passed into the iron age of male despotism. The facts were sound, but the inference drawn from them was precarious, for it was not sufficiently recognized that there was a distinction between matriarchy, the rule of the mother, and what I have spoken of already as mother-right, rule going through the mother and dependent on the mother. What is really common among the lower savages, and may even have been universal at a certain stage, is not matriarchy, but mother-right, and along with mother-right, and where it most flourishes, it is perfectly possible for the position of women to be as low as the greatest misogynist could desire. The actual number of cases in which the woman has a controlling or even an equal position are very few. I will mention one or two of them later on. As a general rule, where the father is not head of the household that place is taken by the wife's brother, and the maternally organized clan consists of units com-

each stage as a hasis or framework for law or eustom rather than as an independent form of the marriage relation. At the same time these religious coneeptions, narticularly under Clristianity, have deeply affeeted the artual contents of the law, and in relation to the perinanence of the union may he said to have eonstituted a special type. 
posed each of a woman, her brothers, and her children. The woman is not necessarily any better off because she is ruled by a brother in place of a husband.

Let us set the two types of family in contrast. Under motherright the wife, under father-right the husband, is the pirot on which the family relationships turn. Under mother-right the wife remains a member of her own family. Under father-right she passes out of her family altogether, she is even separater from the family cult and family gods, her husband's people are her people and his gods her gods. Inder mother-right the children take the mother's name and belong to her kindred. In cases of dirorce they follow the mother. It is the mother's family who protects them. Her brother is their natural guardian, and exercises all the rights and duties which may belong to that position. The maternal kinsfolk stand together in the blood feud, they and not the husband protect or avenge the wife and her children. They may even protect her and them from the husband himself. In extreme cases the children are not held to be related to their father or to their father's family at all, whence in some peoples, halfbrother and half-sister may intermarry as in the well-known case of Abraham and Sarah. ${ }^{1}$ Under father-right, on the contrary, it is relationship through the male which counts. The father is the natural guardian and protector of the children and in ease of divorce retains them. It is to him and his kin that wife and children look for protection. In extreme cases it is only such relationship that is regarded. The wife and her children cease to have claims on her family, while relationship to the male ancestors and descendants is traced to the remotest degrees. These consequences of the strict principle of father-right, however, are seldom pushed to the full length. Relationship through the mother is generally a bar to marriage, though the degrees are not carried so far as upon the masculine side $;{ }^{2}$ nor is the wife of ten so

1 Similarly among the Spartans children of the same mother might marry, but not those of the same father. The Samovedes had a similar rule. (Post, ii. p. 60.) But these logical consequences are hy no means always pressed. The actual farts of kinship have their weight. Thus, to take a single instance, in Now Britain a man may legally marry his brother's daughter, but in practice is restrained by the general feeling of repugnance to such unions. (Danks, "J. A. I.," xviii. p. 2.3.)

2 Thus a Hindu must not marry within the seventh degree on the father's or the fifth on the mother"s side. (Wayne. "Hindu Law." p. 87 , 4th ed.) Manu makes a reeper distinetion: "a damsel who is neither Sapinda on the mother's side nor belongs to the same family on the father's side is recommended to twice-born men." (Wann, iii. j.) Sipindas are relations whose common ancestor, if a male is not more than six, if a female not more than four degrees, removed from either of them. Mauu 
cut off from her relations as the strict consequences of the paternal theory might lead us to expect. Her family as a rule retains a right of protecting her if she is ill-treated; she will fly to them for succour, and their right to guard her is recognized. ${ }^{1}$ Lastly, under mother-right the property passes through the woman, if not to the woman. Luder father-right it goes from father to son.

10. How father-right arose in history we do not know, we cannot even say with certainty that the alternative form of motherright in all cases preceded it. We do know, however, that motherright extends over a great part of the savage world of to-day, in some cases in a pure and typical form, in other cases blended with foreign institutions belonging in logic to the opposite principle. Pure or mixed, it prevails over a great part of the Indian population of North and South America, among the Oceanic peoples, and among many Negro peoples. It is so common as almost to deserve the name of the dominant form of family life among many of the lowest races of the world. This is not all. Among almost all races are to be found traces of the same institution, so that, if not certain, it is still probable, that mother-right was once universal, and represents the primitive form of the family. On the other hand, father-right is the prevailing system in all Indo-Germanic peoples, among the Semites and Mongolians. It appears in some cases among the Red Indians, and more often among the South American tribes. In Oceania it is rare ; throughout Africa it is intermingled with the opposite system.

If we do not know how or when it arose, we can with some certainty specify certain conditions under which it arises. The first of these is the recognition of paternity, the second is the rise of certain forms of marriage involving the appropriation of a woman by her husbant. ${ }^{2}$ As to the first point, paradoxical and almost incredible as it may appear to us, there are cases in which primitive men find a difficulty in understanding that a man is

thus insists on complete exogamy to the male line, while forbidding the female kin only to certain degrees.

In Roman law the praetors early began to recognize the full right of blood (eognatio) as against the strict agnatio of the patriarchate. (Maine, "Ancient Law," p. 151.)

1 (f. Tinogradoff, "Crowth of the Manor," pp. 11, 12 (the Celts); 136 (the Germans).

Both of these I take to be essential to the full development of the paternal system, but either by itself may engender some of the consequences of father-right. E.g. in some Central Australian tribes the son follows the father's totem, though paternity is not understood. It suffices that the husband is master of the mother. (Spencer and Gillen, ii. 145, 175.) 
responsible for the birth of a child, and attribute it to the action of a spirit or an inanimate object. ${ }^{1}$ It is clear that the recognition or non-recognition of fatherhood must make all the difference to the position of the husband in the family, and in fact we find the transition to father-right frequently associated with the curious custom of the couvade, which, however it is to be understood, is elearly a recognition of the relation of the father to the new-born son. The essence of the couvade is that the father has to take certain precautions at the time of birth. Whatever the precise meaning of these precautions - whether they are to protect the father, a portion of whose soul is passing into the child, or the child in whom the soul is finding a new lodgment - they represent a recognition of paternity, and apparently recognition in a crude and early form in which it is conceived as a passage of the father's soul into the child's bodr: Hence it is very natural that the eustom should flourish at the stage at which father-right begins to assert itself, and this is what we find. Among the Melanesians, for example, there are islands where mother-right prevails, but the husband has begun to assert himself, taking the wife to his father's house or to his own, if he has one ready, where he remains undoubted master. Here there is a mild courade, the father refraining from exertion, and from eertain foods. But in the SouthEastern Solomon group, where father-right is more developed, the couvade is also more conspicuous. ${ }^{2}$ So again in quite another part of the world, among the South Americans, we find it just at the turning point where mother-right passes into father-right. Where the position of the father has long been recognized and is thoroughly established, the eustom disappears. Its flourishing time is at the period when the one system is beginning to give way to the other. ${ }^{3}$

If the first condition of the paternal sistem is the recognition of the man's relation to his ehildren, the second condition is that he should appropriate the wife as his own. This he clearly does not do as long as she remains in her own family, retaining her property as a member of that family and having her children

1 This is the theory of the Central Australians. (Spencer and Gillen, i. 265 and ii. 330.) Some Melanesians hold that paternity is due to a cocoa-nut, bread-fruit, or something similar. Codrington, "J. A. I.." xviii. 310. .)

${ }_{2}^{2}$ Codrington, "J. A. I.," xviii. 309-11. Cf. Kohler, "Z. f. I. R.," 1900, p. 35.5, on the convade in Papman custom.

${ }^{3}$ Schmidt, "Z. f. V. R.," 1 S9S, 297 . "Sie (i.e. the enstoms connerted with the couvarle) werden sich also am ausgeprägtesten geräde während jene Uebergangszeit zeigen wo das eine Prineip (i.e. Fater-redit) das Andere abzulösen beginnt." 
in turn reckoned as members of it. But there are two processes known to primitive man by which a man can make a woman his own property and transfer her to his own family, viz. the methods of marriage described as capture or purchase. Professor Tylor justly points out that the practice of capture must tend to break up the whole sistem of mother-right. When the woman is carried off from her own clan to her husband's house the physical facts conflict with any custom or law regarding her and her children as still belonging to her family rather than to his. Hence out of forty cases of genuine or "hostile" capture Prof. Tylor finds that six only oceur in the maternal stage. Of "connubial" capture he places twenty-one instances in the stage of transition from the maternal to the paternal sistem, and twenty-five in the paternal system proper. There are no instances under pure mother-right. Finaly he enumerates forty-four cases in which the form of capture is retained without the reality as part of the wedding ceremony. Of these he finds no instances under mother-right, but twenty-one in the transitional stage and twenty-three under the paternal system. ${ }^{1}$

Now though, as we have seen, there is no reason to think that capture was ever universal or that it was the original form of marriage, it is beyond doubt one very primitive way of compassing that type of marriage which involves ownership of the woman, and it is quite intelligible that in a tribe where mother-right prerailed those men who by their own bow and spear could obtain women from a neighbouring elan should treat those women as their own property, and so establish a working model of the patriarchate. It is also reatily credible that the new type should be more popular than the old - at any rate among the men - and that they should seck to extend it to cases in which the wife belonged to their own clan, and so establish miversal father-right. But to lay down that this was the actual process by which father-right came to prevail woukd be to go far beyond onr evirlence. There is no proof that all patriarchal socicties have gone through the stage of marriage by eapture, and its frequent appearance as a form is not conclusive. The explanation may be that some form was necessary to assert definite ownership, and that the natural form of asserting definite ownership was the form of capture.

The alternative and in reality commoner method of appropriating a wife is that of purchase, and the fact of purchase is closely associated with the whole position of women in cases where the

$$
{ }^{1} \text { Tylor, “J. A. I.," xriii. } 259 .
$$


patriarchate is strongly developed. We are moving here in a region permeated with ideas of slavery, the ownership of one human being by another, permeated also by the idea of a family as a unit to which each nember belongs as a limb. The bride purchased from her own family passes out of it and into that of her husband. ${ }^{1}$ There the consequences are pressed to their furthest extent her family lose the power of protecting her, and, since in barbaric soeiety there is no law except the protection of one's family, the wife is at the merey of her husband as to life and limb. He may dispose of her at pleasure, he may sell her, give her avay, or lend her; and she has no right of redress against him.. ${ }^{2}$ At best she may escape from him if her family return her price and buy her back. Also, there is nothing in this order of ideas to prevent the husband buying as many women as he wishes. This extreme form must not be taken as the normal case. Natural feeling after all has its way everywhere in the world, affection and the sense of kinship survive the technical exclusion from the family, and so we more often find that by a kind of compromise the wife's relations retain certain powers of proteeting her. Her murder would in many cases excite the blood feud, and if she runs away from her husband, and can satisfy her relations that she had good eause in his ill-treatment, they will in many instances stand by her and give her protection. ${ }^{3}$ Still, her position, even in such cases, is

${ }^{1}$ It must not he assumed that marriage hy purchase always implies father-right. Under mother-right a man may pay a bride price for the usufruct of a woman (e.g. among the Papuas, Kohler, “Z. f. T. R.," 1900 , pp. 347, 348). But it is easy to sce that out and out purchase goes naturally with, and may be said logically to necessitate a thorough-going paternal system.

${ }^{2}$ Post (i. p. 171) instances former rustoms among Parthians and Armenians, the Gypsies, Tschertessen, Maravis of South Africal, and ancient Germans, and quotes Casar on the Gauls: "Tiri in uxomes siruti in liberos vitae necisque hahent potestatem." Among South American Indians the father can lend, sell, or exchange the wife. (Schmidt. l. c.. p. 298.) The right of the hushand to kill the wife talien in adultery is general - Post, i. p. 172, says "gänzlir.h universell."

${ }^{3}$ See above, No. 9. Anong the Somali and in the Gaboon the husband who kills his wife must pav a fine to her family. (Post. "Afrik. Jurisp.," p. 62.) This, I suppose, is a composition for hlood rengraner. So too among the Kaffirs. (Ib., p. 101.) Among the Ainu. Butrhetor ("The Ainu of Japan," p. 138) notrs a change. Formerly the liead of a family had absolute powers to divoree, disinherit or punish. Now hitl? can be done without consulting noighbours. Among the Australians, the elan will protect the wife from txassive cruclty. Letournetu. "la Femme," p. 13; Post, l. c., p. 17,3.) Among the Xiandingos the wifo is protected hy the judge. (Post, "Afrik. Jurisp.," p. f(1)2.) Among the Yoruha by her family. (Ellis, op. cil., 1st.) Among the Malays in tles "djudjur" marriage the wife passes hy purchase into the hushand's family. yet the wife's parents ran interfere to protert her in case of remel tratment. (Waitz, v. p. 144.) Aceording to Dr. Westermarch ("Position of Women 
rather that of a protected dependent than of a free woman. Slavery is still slavery though the position of the slave may be mitigated by law, and such mitigation is in reality no rare occurrence even for the actual slave at the level of civilization which we are considering. ${ }^{1}$

The appropriation of the wife consolidates the "natural" family, but at the cost of a more or less complete subordination of the wife. Hence the position of the woman seems, if anything, to change for the worse as society takes its first step in advance. This deterioration, however, is perhaps less severe than appears at first sight.

\section{The Position of IToman in Early Society.}

Favourable as the position of woman under mother-right appears on the surface, the truth is that it is no bar whatever to complete legal subjection. Among the Caribs, where descent goes through the female only, the women were nevertheless in an inferior position. The husband alone had the right of divorce and he could exercise it at will, the only effect of mother-right being that in case of divorce the wife would retain the children. Among the North American Indians generally, notwithstanding the tendency to mother-right, the position of women is on the whole admitted to be low. ${ }^{2}$ In Melanesia, where there is strict motherright, the mother is in no way head of the family. The family house is the father's, the garden is his, the rule and government are his. ${ }^{3}$ In Oceania generally, where mother-right is common,

in Early Civilization," "Sociological Papers," p. 155), "there are peoples among whom the husband's authority is almost nil, although he has had to pay for his wife." But no instances are given, and I imagine them to he rare. An interesting trace of the feeling that it is the duty of a wife's relations to avenge her, is found in the "Alcestis," vv. 731-3, where Admetus' father threatens him with the vengeance of Alcestis' brother, though Alcestis has ehosen voluntarily to die on Admetus' behalf. Naturally, however, the right of protection by her relations is more effective when the wife is still regarded as a member of their family. (Post, i. p. 173.)

1 For instances see Post, i. 171-177.

2 See Waitz, iii. 101, 382; Callin, "N. A. Indians," i. 23 and 226. Ratzel puts it that the position of the women is not in all cases one of oppression (ii. 128).

${ }^{3}$ Collington, "J. A. I.," xviii. 309. Dr. JVestermarck, who on the whole takes a favourable view of the position of women among savages, deelines to attribute any influence in this direction to mother-right. ("Sociological Papers," p. 157; "Moral Ideas," 65.5-7.) Herein he is opposed to Steinmetz, and to Ratzel. (See e.g. Ratzel, "The History of Mankind," ii. 334.) The argument that (e.g. among the Australians) the position of women is not sensibly affected by the srstem of descent, is not very forcible, since the importance of the family is so small as com- 
the two sexes are in large measure separated in their lives through the complex mass of taboos which prohibit their intercourse. ${ }^{1}$ The head of the maternal family may have the same despotic power as the patriarch - thus among the Barea and Kunama he has the power of life and death; among the Bangala, the Kimbunda, and on the Loango coast the right of selling any member of the family; and in general under the maternal as under the paternal system the head is a male. ${ }^{2}$

Apart from the general tendency to overlook the masculine headship of the maternal family, and so confuse mother-right and matriarchy, mistaken views have arisen from the identification of marriage by service with the subordination of the husband to the wife. The man who cannot buy a wife becomes a servant to her family, but not to her. Jacob did not serve Rachel, but Laban, and when the term of service was completed both Leah and Rachel remark that they have now passed out of their father's family. They identify themselves with Jacob, and Rachel steals Laban's household gods on his behalf. At the same time marriage by service does fairly illustrate some of the conditions which modify the relation of husband and wife, and may even affect the question whether mother- or father-right is to prevail. The man serves because he has not the property wherewith to buy him a wife, and so we not infrequently find that the two kinds of marriage subsist side by side. Thus among some Californian tribes purchase is the rule, but if a man can only pay half the bride price he enters the wife's house in a servile position. ${ }^{3}$ Similarly among the Micronesians of Mariana the husband must serve if he has not wealth enough to support the wife. The best instance may be drawn from the Malay Archipelago, where the two opposed types of marriage are found fully developed with special names. In one, Ambil anal, the husband is purchased by the wife's family; he enters it as a rule in a dependent position, the children all belong to the mother's family, and the wife has the right of divorce. In the other form, Djulliur, the husband or the husband's family has to purchase the wife; she becomes his property, the children are his, and he has the right of divorce. Her parents only retain a certain right of intervention in case of cruel

pared with that of the local group and its divisions, that the mode of reckoning descent naturally counts for lit te.

${ }^{1}$ In some instances, however, the position of women is, or has been. favourable in Oceania, f.g. in Micronesia, and in New Zealand. (Ratzel, i. 273-274, and Waitz, iii. 101.)

2 Post. "Grundriss," i. 134-6). Post notes that there are exceptions.

${ }^{3}$ Kohler, "Z. f. V. R.," 1597, p. 383. 
treatment. ${ }^{1}$ In such cases at least it is clear that the relations of husband and wife are determined not by any prevalent custom or opinion prescribing what such relations ought to be, but by the actual success or failure of the man in finding means whereby to appropriate a woman to himself." Thus the differences between the maternal and paternal sistems do not turn on divergencies of. principle as to the rights of women, nor does the superior position of the wife's family necessarily imply any similar superiority in the wife herself. No doubt under mother-right the woman derives some advantages from her position, such as the retention of her children in case of divorce, but the cases in which it has given her real equality or superiority prove on examination to be very rare. Among the Nairs, who are sometimes quoted in this connection, and who, as has been mentioned, combine polygamy and polyandry, the woman chooses her husband and brings him to her home. Possessions pass from mother to daughter. The woman may divorce her husband, or rather any of her husbands, at pleasure. Among some of the tribes, e.g. the Pani Kotche, the husband goes to live with his mother-in-law, who is head of the house, and may incur no expense without her authority or else he is personally responsible. It sometimes happens that for this reason he is sold as a slave. ${ }^{3}$ Often a brother and sister set up house together, the tie between them being held closer than that between husband and wife, and if in such a case the wife goes to live with a husband she will be subject to the sister. It follows also that the child

"Waitz, v. i. $144 \mathrm{ff}$. Cf. Marsten, "History of Sumatra," p. 220, etc., cited in spencer's "Descriptive Soeiology."

2 We may note in this connection that among civilized peoples which have completely developed the patriarchal system, and perhaps even passed heyond its extreme phases, there is a tendeney to the subjugation of the husband, in cases where women are allowed control of their own property, if the wife is the wealthy one. I am not speaking from the point of view of the humorist or the novelist, but of the lawrer. Thus, few peoples have pushed the right of the father to a more extreme point than the Japanese in the Far East, or the ancient Romans in the West. Iot ainong the Romans, when women acquired by the Lex Julia complete control over their dowry, the result was that the husband frequently passed into practical suljugation to a rich wife. In Japan it is astonishing to find the recrudescence of the primitive custom of the husband coming to live with the wife, and taking her name in the case where the fldest daughter inherits an estate, or where the bride's father supplies the house. From instances like these, drawn from eases where the patriarchate had its most extreme development, we can understand the full strength of the economic factor in determining marital relations, and we may draw the inference that where in the uncivilized world we find the hushand passing into the wife's family, even in an inferior position, it does not follow that any favourable inference is to be drawn as to the prevalence of an cthical conception of women's rights.

¿see Reclus, "Primitive Folk," pp. 156-8. 
is attached to the uncle rather than the father. In such an organization the family, as we understand it, is of course completely broken up, and there is no doubt that the position of the woman makes her in a way the centre of the whole organization. There is equally no doubt that in this case she acquires from this position a considerable authority. But we are also told that, although she inherits the property, her brother or maternal mole administers it, and, again, it is administered rather on behalf of the whole group of kinsfolk - that is to say, as collective property - than as belonging to any individual owner, so that after all we are not very far removed from the normal state of things under motherright, where the woman is subject to her brothers instead of to her husband.

Somewhat similar cases may be cited from among the North American Indians. Here the women had occasionally a certain measure of political importance; for example, they might be represented by a spokesman, either male or female, at the men's couneil, and they sometimes originated warlike expeditions with the object of replaeing, by a raid and the capture of a prisoner, the loss of a warrior of the clan. To them, also, as we shall see later on, was referred in many eases the fate of the prisoners taken. They decided whether prisoners should be tortured or adopted, and, moreover, took a special part, with a peeuliar zest, in the execution of the tortures when a decision was taken in that direction.

Among the Iroquois, where we have some of the most detailed accounts, we are told that the women oceupied a dominant position in the Long House where the joint family lived. "Isually" the female portion ruled the house, and were doubtless elannish enough about it. Stores were in common, and woe to the luckless husband or lover who was too shiftless to do his share of the providing. No matter how many children or whatever goods he might have in the house, he might at any time be ordered to take up his blanket and budge. . . The house would be too hot for him, and unless saved by the intercession of some aunt or grandmother, he must retreat to his own clan, or, as was often done, go and start a matrimonial alliance in some other." " The women, says Morgan, were the great power in the clans. They could "knock off the horns" of a chicf, and of certain chief's they hat

${ }^{1}$ From a letter by the Rer. A. Wright, a missionary among tho Senecas, written in 1873, and given in Vorgur's "Houses and Houselife of the Ameriean thorgines," p. (i.). 11 is worth noting that Mr. Wright anpers to be decribing a past state rather than that which he actually saw. 
the nomination. Set even among the Iroquois we do not find that the position of women was altogether good. On the contrary, they did all the drudgery of house and field. They were soeially separate from the man, and the conquered Delaware were named women as a term of reproach, and compelled to forego arms as a mark of contempt. ${ }^{1}$ Of the North Ameriean Indians generally, Waitz ${ }^{2}$ makes a remark which goes to the root of the matter, that though property passed by the women they seem to have had little or none of their own. There remain a few seattered eases in whieh the wife - not merely the wife's family - is said to enjoy superiority or even authority. Among the Koochs of Bengal it is stated by Dalton that the husband goes to live in the wife's clan, and that his property passes to her daughters only, and not only this, but he has to obey his wife, and what is, perhaps, more extreme, her mother as well. ${ }^{3}$ Aecording to Herrera, men in Nicaragua in his day beeome slaves to their wives, ${ }^{4}$ and among the tribes of Escuimaux at Nootka Sound and at Cross Sound, women are somewhat vaguely said to have a superior position to men. ${ }^{5}$ Other cases ${ }^{6}$ in which a higher position is attributed to the wife either depend on her superior soeial or economic position, or on the failure of the husband to pay her price. ${ }^{7}$ They do not indieate that the position of the woman is as such equal or superior to that of the man. ${ }^{8}$

A handful of exceptions such as these, however interesting as disproving sweeping generalizations, do not alter the fact that

1 schoolcraft - Drake, i. 277, 385. Morgan, "League of the Iroquois," 323.

${ }^{2}$ Waits, iii. 129. $\quad 3$ Letourneau, "La Femme," p. 384. $\quad{ }^{4}$ Ib., 175.

5 Waitz, iii. 327-333.

${ }_{6}$ 'The well-known statement of Diodorus as to the supremacy of Egyptian wives will be dealt with below [chap. xv].

${ }^{7}$ In one or two other rare cases the law of divorce favours the wife. For instance, among the Khonds of Orissa she may leave her husband on repaying her price, but may only be divoreed for adultery or misconduct. (D)r. Westermarck states that constancy is not required from the wife, and that the hushand may be punished for adultery. "Sociol. Papers," p. 152.) The husband may not strike the wife taken in adultery - a very exceptional rule. (Reclus, p. 281.) These liberties appear to be connected with a scarcity of wives, and with the relies of polyandry. (Reclus, ib.)

"In addition to the ahove list, Post, "A. J.," 400, considers that the position of the wife among the Sarae is equal to that of the husband, and even superior among the Beni Amer and the Galla. But among the last-named he adds that if the husband has once brought home the trophies of a departed enemy, he becomes absolute master. According to Hahn (quoted by Westermarck, op. cit., p. 154), the Khoikhoi (Hottentot) wife is mistress within the house, but according to Kohler, "Z. f. V. Rn," 1902, pt. iii. 341, 355 (speaking of the Hottentots generally), though the wife has a fairly independent position, the husband has the right to chastise her in moderation. 
in the great majority of uncivilized peoples the position of women is in greater or less degree inferior to that of man in point of personal rights. ${ }^{1}$ Apart from a sufficiently frequent inferiority in her right to property or to the mere protection of life and limb, apart from the fact that the drudgery of life so often fills on her while the men hunt or fight, ${ }^{2}$ the prevalence of the capture, purchase and exchange of wives testifies strongly in this direction. The common facility of divorce, even where the conditions are equal to the two parties, tells against the woman, who is the more interested of the two in the permanance of the tie. And very often the condi-

${ }^{1} \mathrm{Dr}$. Westermarck, who objects to the term "subjection" as a general description of the position of women in the lower races, writes: "Among many of them the married woman, although in the power of the husband, is known to enjoy a remarliable degree of inclependence, to he treated hy him with great consideration, and to exercise no small influence upon him. In sereral cases she is even stated to be his equal, and in a few his superior." ("Soc. Papers," p. 151.) Admitting this to he the case, we shall clearly be right in persisting that in the great majority of cases women's legal position is inferior. It may be added that considerate treatment is a totally different thing from equality of rights. In his new work on "The Origin and Development of the Moral Ideas," Dr. Westermarek gives a long list of cases in which the wife's position is more or less favoured. But in comparatively few of them is equality of rights asserted, and in still fewer superiority. Even where equal rights are mentioned, the statements with two or three exceptions lack precision. Dr. Westermarck himself says: "All these statements certainly do not imply that the husband has no recognized power over his wife, but they prove that his power is by no means unlimited. It is true that many of our authorities speak rather of liberties that the woman takes herself than of privileges granted her by custom; but, as we have seen before, customary rights are always more or less influenced by liabitual practice." (P. 646 , the italies are mine.) The distinction here admitted cuts deeper than Dr. Westermarck seems to admit. In a relationship so personal and subtle as that between men and women, de facto influence and power may develop to the highest pitch, without in the least affecting the recognized rights or status of the sex. A favourite of the harem may sway an empire and yet remain a slave. The frecuent statement of travellers that the wife rules the household, or that the husband does nothing without consulting her, might have been made of this eountry in the days when the legal position of the wife was most abject. The power to influence and recognized ethical equality are not only different, but have no necessary tendency to pass into one another.

2 The extent to which women fill the place of slaves in the rudest societies has perhaps been exaggerated by some writers. Ir. Westermarch ("Sociol. Papers," p. 150) points out that for the men to fight while the women toil, is a natural division of labour in a world where fighting is a frequent necessity. But this, though it explains, hardly alters the fact that an oceupation recognized as inferior falls to the women. (Cf. Westermarck, "Moral Ileas," pp. 633-637.) There are many variations, and it would be easy to multiply quotations on either side, but on the whole it seems elear that the more toilsome and least esteemed work tends to fall on the women. Soe the general statements in Ratzd, as to Oceania, vol. i. p. 273; the Malay Legion, ib. p. 441; North Ameriea, ii. p. 129 ; the Aretic races, p. 225; the Negroes, p. 334; Kaffirs, pp. 1322, 433; and the Mongols, iii. p. 341. The position in the two first-named regions is the most favourable, particularly among the more dereloped peoples. 
tions are not equal, but favourable to the man. The general permission of polygamy points in the same direction. Lastly, the woman's person is not, strictly speaking, her own property, but that of her husband or guardian, and it is in this sense in the great preponderance of cases that chastity and respect for women are understood in the savage and barbaric world. This peculiarity makes itself felt in many directions. In the first place wife lending is an extremely common custom among sarages. The husband who would kill or mutilate the wife whom he discovered in clandestine intercourse with a lover will also lend her as a matter of courtesy to a guest. ${ }^{1}$ In the one case she infringes his right of property, in the other case it is as his property that she is acting. ${ }^{2}$ She is not in our modern phrase a person with the full rights of self-respect and respect from others attaching to personality. Secondly, where the obligations of marriage are binding the rules for the ummarried are often very lax. Further, the principal exception to this laxity is constituted by the system of child betrothal, whereby the unwedded girl is already the husband's property. ${ }^{3}$ Generally speaking, the requirement of chastity depends on the developed power of the guardian." Thirdly,

1 Numerous instances are given by Starcke (p. 122) and Westermarck (pp. 73, 74). The custom is pretty general among the North American Indians. (Waitz, iii. p. 111. Ile excepts only the Sioux and the Chippeway.) (f. Schoolcraft, r. p. 684. Post, "Afrik. Jurisp.," i. pp. 471, 472, gives numerous instances in Africa. Waitz, v. ii. p. 105, attributes the practice to the Micronesians generally.

2 In the Torres Straits any irregular intercourse was called "stealing a woman," and there seems to have been no word for formication or adultery apart from theft (puru). ("Cambridge Expedition," 275.)

3 Where the young girls are guarded, precautions are sometimes pushed to disagreeable lengths, as in New Britam, where, between eight and ten, they are put into cages and kept there till they are married.

4 Post, i. pp. 21-23. The first step towards insistence on the chastity of ummarried and mbetrothed girls, is taken when the husband expects virginity at the time of marriage. Unchastity may then become a breach of the proprietary rights of the guardian. Hence it is often punishable, especially if it results in pregnaney. Thus among the Takue, the Marea and the "Beni Amer, the seducer who malies an unmarried girl pregnant excites the hlood feud, and among the Bogos the full blood price is demanded in such a case. (Post, "Afrik. Jurisp.," i. pp. 61 and 70.) Among the Wanyanwesi the lover must marry the pregnant girl under a penalty of a fine (Post, "A. J.," i. p. tiss), and in Unyoro she is taken to his house, and, hy a characteristic piere of primitive reasoning, he must pay for her if she dies, while if she lives she returns to her father unless the lover pays the hride price. (For other instances in Africa, see Post, ib., p. 459, ii. P. 70, and ef. Letourneau. "La Femme," p. 48.)

Westermarch (pp. 61-(j4) enumerates over thirty cases among uncivilized races where unchastity out of wedlock is condemned - but to some of these there are qualifications, e.g. among the Gypsies and Kalmucks unchastity is tolerated and it is only the hirth of a child that is a disgrace.

In some instances, the umchastity of an ummarried woman is regarded as bringing a curse or some misfortime on the family or the tribe. Thus 
the claim to fidelity is usually one-sided. While any offence on the wife's part exposes her to punishment, and while an outraged husband may lawfully arenge himself on the man who has trespassed on his property, the unfaithfulness of the husband to the wife is but seldom regarded as an offence. Finally, it is of ten

the Aleuts fear that the whale would punish them if their wives were unfaithful in their absence, or if their sisters were unchaste before marriage. (Reclus, p. 52.) Similarly in Loango. the unchastity of a girl is held to bring a curse on the country (Westermarck, p. 61), and a similar idea seems to underlie the punishment of a pregnant maiden on the Gold Coast. where she is chased by the women to the sea, covered with dirt and ducked, after which she receives rharms from the fetishman. (Post, "A. J.," i. p. 460.) Apparently this is not so much by way of punishment as to avert evil.

With a few exceptions such as these, we may say that among uncivilized races unchastity is regarded universally as an infringement of rights of property, and that generally only the rights of the hushand present or future are considered, but that in some cases the value of a woman is depreciated by the loss of sirginity, and this is accordingly regarded as the infringement of the rights of her guardian. The man is of course punished, often with death, for the infringement of these rights. We may find the germ of a different conception in the belief that the unchastity of a man under certain ronditions will eause misfortume. Thus the Aleuts above quoted believe that the whale will punish them, not only if their wives are unfaithful, but if they are unfaithful, while on a fishing expedition, to their wives. It is a widely-diffused belief among the North American Indians that unchastity on the war patl would bring defeat, and hence captive women are generally spared. For the rare cases in which a husband incurs penalties to his wife for unfaithfulness see next note.

1 Authorities give one instance to the contrary among African peoples, viz. in Great Bassam. Here the husband pays a fine to the wife if mfaithful to her while she is with the prince. (Post, "Afrik. Jurisp.," ii. p. 72.)

Among the Hottentots the hushand as well as the wife may be flogged for adultery, and except for ill-treatment there is no divores without the consent of the council. But these observations refer to Christianized tribes. (Kohler, "Das Recht der Hottentotten," "Z. f. V. R.," 1902, pp. 344 and 3.54.)

Among the Mariana the husband could kill an adulteress, but if he on his side were unfaithful, he would be set upon and would be glad to cscape with a whole shin. (Wratz, r. ii. p. 106.)

The Sioux and Santal (Dakota) women are said to beat their husbands for unfaithfulness. (Howarl, i. p. 239.)

Aecording to Dr. Westermarek, among the Shans of Burmah the wife may divorce the hushand for drinking or other miscondurt, retaining the common property. (Westermarch, "Soriol. Papers." p. 1.j4.) But Col. Woodthorpc ("J. A. I." xxri. p. 21) states that the Shans of the Cpper Mekong follow the law of Manu as to divoree, i.f. the wife has no powers of diroree at all. In W. Viretoria, as mentioned above (IImerol. i. P. 229). a wife may get a slight punishment inflieted on an moaithful hushand. and in some Queensland tribes the women take advantage of the initiation ceremonies to punish men who have ill-treated them. (Whestemercli. "Sociol. Papers," p. 148.) The case of the Khonds has beren mentioned above.

As mentioned above. Powers states that among the Karoks of California cohabitation even with a female slave is considered risorareful. Two or three more similar instances are found among the North Aneriean Indians.

We could prolong the above list if we were to add cases in which bring- 
open to fathers to devote their daughters to prostitution. This is not infrequently a religious duty, and in many cases there are recurring religious festivals of which promiscuous intercourse is a feature. ${ }^{1}$

12. All the world over, certain forces, ethical, political, economic, and perhaps religious, act from either side upon the relations of men and women. On the whole, apart from a sufficiently strong development of the ethical factors, those which fight for the man, as physically the stronger, have the upper hand. But when there are always forces tending the other way, favourable circumstances will oceur here and there to give them peculiar strength. For example the circumstances attending marriage by service, especially when we compare it with marriage by purchase or capture, have shown us how much the relations of husband and wife are determined by what in the modern world we should call the economic factor. 'The savage woman s price - if by price we mean the difficulty of appropriating her - may be high or low. Where it is always possible to organize a raid and carry her off it is decidedly low, and she becomes the captor's property. Where this is not countenancel, it is possible to buy her from her guardian, and then presumably her price, like that of other things, is a matter of supply and demand. The actual number of girls born and the practice as to infanticide must affect their value, and we can understand that better treatment of a wife becomes necessary to the husband who wishes to retain her. ${ }^{2}$ In other cases the economic value of the woman may be high - for example, where agriculture is becoming important and is still regarded as women's work. In yet other cases women are the repositories of magical lore, and men fear them. ${ }^{3}$ These and doubtless other disturbing causes considerably modify the status, nominal or real, of women in the uncivilized world, but the fluctuations which they cause are fluctuations about a centre of gravity which is sufficiently low.

ing a second wife or a concubine into the house is a ground of divoree. Broadly spealing, however, in the savage world, under mother-right or father-right, the husband is master of the wife's person.

1 For instance in Africa, sce P'ost, "Afrik. Juris.," p. 465. In several Australian tribes the women are common at the corroboree, except to their fathers, brothers or sons by blood. (Speneer and Gillen, p. 97.)

${ }^{2}$ Hence probahly the favourable position often enjoyed by women in polyandrous communities. To us polyandry seems necessarily degrading to a woman. To the women of the polyandrous tribe it means that they are sought after, and therefore prized.

${ }^{3}$ This important suggestion is due to Dr. Westermarck ("Soc. Papers," p. 159). who is also inclined to lay stress on the economic factor. (On this point $c f$. Ratzel, ii. 130.) 
To sum up our account of marriage in the uncivilized world. We have found two distinct forms of the family, the one based on mother-right, the other on father-right. Lnder mother-right the woman is undoubtedly the legal centre of the family. From this she sometimes derives certain advantages, such as the power to leave or dismiss a bad husband, or the right to retain her children. But, as a rule, when looked into, her position is found to be inferior. She is held in little respect, and is seldom the owner of the property which passes in her name. The cases in which she enjoys a real equality with men prove on examination to be exceedingly rare. The characteristic of the lower savage life is rather that the family is as ret incompletely organized. Hence the facility of divorce, which is often so great that marriage can scarcely be said to exist, hence also the sporadic appearance of polvandry and partial promiscuity. The advent of father-right implies on the whole a firmer organization. The vife now passes out of the hands of her own kindred, and is appropriated by her lusband, whether as the result of capture, purchase, or service. Her legal position often becomes semi-servile or worse, and though socially, as among the ancient Germans and the early Romans, she is often held in high respect, her incorporation in her husband"s family is often pushed to such an extreme that her subordination does not end with his death. In some instances she follows him to the grave. In others, where she belongs to the family rather than to the individual, she becomes the property of his brother, or of the male head of the clan.

Under both forms of marriage the permission of polyamy is the rule, and divorce is easy for the husband. Lnder the second form it is generally less easy for the wife. Under both, moreover, it is not easy for the wife but the woman that is under tutelige. The civilized conception of the sanctity of woman exists only in germ; her destinies, her freedom and often her life are in many cases at the disposal of her legal guardians. . . . 


\section{Chapter XiII}

\section{MARRIAGE}

\section{Section 1 \\ FORMS OF MARRIAGE 1}

THE institution the purpose of which is to serve propagation and all the psychic impulses and ideals that surround it, is marriage. Its development and the form it took among the different nations is one of the most fascinating studies of scientific research; but we cannot follow it here. Nor can we deal at length with its original form, group-marriage, in which reproduction took place in groups, the members of which were married to a group of husbands and wives, both men and women being common husbands and wives. This has been elsewhere authenticated, and we need only add, that when people seek to refute the fact by pointing out the sexual relations that exist among the anthropoid apes, etc., that live in small companies, we may reply that it is a characteristic of mankind to strive and work together in larger numbers, and in earlier times the form of marriage that corresponded to this mode of life was not monogamy but group-marriage.

Group-marriage may lead to polyandry, a form that is still found among a large number of peoples, a common custom being for several brothers to have but one wife. This has certain psychic advantages, but also the weighty disadvantage that it decreases the population - especially when it is combined with the slaughter of the female children, the only means of explaining the consistent carrying out of such a system.

Much more frequent, in later periods, is polygyny (or polygamy) which follows naturally in the wake of capture and purchase marriage; for, whatever a man takes possession of, or acquires in this way, he regarrls as his own. The great expense

${ }^{1}$ [Reprinted, by permission, from Josef KoHLer, "Philosophy of Law" (Allirecht's trans.), Boston Book Company, 1914 (Philosophy of Law Series, Vol. XII).] 
of such a custom, however, often interferes with its practice; and it must, therefore, be regarded, even among the peoples that permit it, as an exception, not as the rule.

The civilized peoples of to-klay are sharply divided into nations of Christian and nations of Mohammedan culture. While Mohammedan culture has retained polygamy, all Christian peoples have adopted monogamy, and regard this institution as such an essential principle of their cultural order that they have declared bigamy to be a grave, major crime. The cultural idea that underlies this, is that a mutual psychic intermingling of lives is made possible only by the self-restraint of two individuals, and that a plurality of wives must lead of itself to the basest passions, to an egoistic self-assertion that poisons marriage, and to constant petty jealousies, suspicions, and prejudices, unless the wires are in complete subjection, and consequently are mentally inferior and without self-assertion - a condition that is equally detrinental to all development. . . .

$\begin{array}{llllllll}* & * & * & * & * & * & * & \end{array}$

\section{Section 2 \\ TRIBAL MARRIAGE LAW 1}

A tribe cannot be developed through the expansion of a clan. The clan is not the antecedent of the tribe, nor is the tribe the antecedent of the clan. A clan is an integral part of a tribe, and there is no tribe without the clans of which it is composed, and no clan without the tribe of which it is a part. The communal family seems to be the antecedent of the tribe; but a single communal family could not develop into a tribe. A tribe seems to have primitively been a federation of communal families. Whatever its primitive origin, the special organization of any particular tribe must have been accomplished by combining borlies-politic that were previously distinct, and the basis of federation must have been one of intermarriage. In the simplest form two such distinct bodies could unite by making an agreement that the women of each should become the wives of the other. If three bodies-politic combine, the women of $\mathrm{A}$ might become the wives of the men of $B$, the women of $B$ wives of the men of $C$, and the women of $\mathrm{C}$ wives of the men of $\mathrm{A}$. In the thirty-fourth chapter of Genesis we read:

${ }^{1}$ [By J. W. Powell. Reprinted, by permission, from the 3d Annual Re port of the American Bureau of Ethology (The Smithsonian Institution).] 
"And Ifamor the father of Shechem went out unto Jacob to commune with him.

$\begin{array}{lllllll}* & * & * & * & * & * & *\end{array}$

"And Hamor communed with them, saving, The soul of my son Shechem longeth for your daughter: I pray you give her him to wife.

"And make ye marriages with us, and give your daughters unto us, and take our daughters unto you.

"And ye shall dwell with us: and the land shall be before you; dwell and trade ye therein, and get you possessions therein."

'The essence of tribal organization is this: The institution of a tribe is an institution for the regulation of marriage; and hence marriage is primitively by prescription. But the selection of wives by legal appointment ultimately develops into selection by personal choice, and tribal organization is greatly modified thereby.

\section{Excursus - Law}

A definition of the term "law," that will hold good under all circumstances, must be divested of the many theories of its origin, the source of its authority, and its ethical characteristics, which are expressed or implied in customary lefinitions, and laws must be considered as objective facts. The following definition will perhaps do under all cireumstances: A law is a rule of conduct which organized society endeavors to enforce.

In civilization, law is theoretically founded on justice; but in savagery, principles of justice have little consideration. There are two fundamental principles at the basis of primitive law : viz. first, controversy should be prevented; second, controversy should be terminated. A third is derivative from them; namely, infraction of law should be punished. These principles enter into primitive law in many curious ways.

It was customary among the tribes of North America for individuals to mark their arrows, in order that the stricken game might fall to the man by whose arrow it had been despatched.

A war-party of Sioux surprised a squad of sleeping soldiers, who were all killed at the first volley from the Indians. Their arms, blankets, and other property were untouched, because, the attacking party being large, it could not be decided by whose bullets the soldiers were killed.

It has been widely believed that the practice of placing the 
property of deceased persons in their graves when they are buried has its origin in religion, and testifies to the universal belief that the dead live again, and will need such articles in their new life. But many tribes of North America who have not yet been long in contact with white men arow that, there being no owner for the property, its disposition might lead to controversy, and hence it is destroyed. Many examples of this fact have been collected. Ownership to the greater part of property in savagery is communal, some classes of property being owned by the clan, others by the tribe; and for such there is no proper inheritance, as the clan and tribe do not die; but purely personal property is inherited by the grave. It seems probable that such is the origin of the custom of burying various articles with the dead. Subsequently it has religious sanctions thrown about it, as have many social customs.

There is a law, among the tribes of North Ameriea, that superior age gives authority. This law is widely spread, and perhaps universal, and exercises a profound influence in tribal society, as the oceasions for its applieations are multifarious. No man knows his own age; but every man, woman, and child in the tribe knows his relative age to every other person in the tribe who are older and who are younger than himself - for, in addressing any other person in the tribe, he must necessarily use a term which implies that the person addressed is older or younger. 'The law that authority inheres in the elder is a simple and ingenious method of preventing controversy.

The above is the explanation of another custom observed among savage tribes; namely, that it is illegal to address a person by his proper name. Kinship terms are used in direct address, proper names in speaking of a thirl person. It is hardly necessary to state that by this device controversy is prevented.

An interesting form of outlawry exists among some tribes. When a man has frequently involved his clan in controversy with other clans by reason of quarrels or other outrageous conduct, his own may decide no longer to defend him, and will formally announce in tribal couneil that such person is no longer under their protection. If the person thereafter by his conduet maltreats any member of the tribe, the injured party may do as he will witl the offender, and not be held accomtable by the kindred of the outlaw.

Three especial methods of terminating controversy are wilcly spread among the tribes of Nortl America.

When controversy arises in relation to ownership, the property 
is usually destroyed by the clan or tribal authorities. Thus, if two men dispute in bartering their horses, a third steps in and kills both animals. It seems probable that the destruction of property the ownership of which is in dispute is common to all tribes.

A second method of ending controversy is by the arbitrament of personal conflict. For example: if two persons disagree and come to blows (unless the conflict end in the maiming or killing of one of the parties), it is considered a final settlement, and they cannot thereafter appeal to their clans for justice. By conflict a controversy is barred. 'This law seems to be universal.

The third method of terminating controversy is by the establishment of some day of festival - sometimes once a month, but usually once a year - beyond which erimes do not pass. The day of jubilee is a day of forgiveness. The working of this principle might be illustrated in many ways.

Law begins in savagery through the endeavor to secure peace, and develops in the highest civilization into the endeavor to establish justice.

Society is organized for the regulation of conduct, and conduct is regulated by law in the several stages of human progress in relation to those particulars about which serious disagreement arises. In the carly history of mankind it appears, from all that we may now know of the matter, that the most serious and frequent disagreements arose out of the relations of the sexes. Men disagreed about women, and women about men. Early law, therefore, deals to a large extent with the relations of the sexes. The savage legislator sought to avoid controversy by regulating marital relations; and this he did by denying to the individual the right of choice, and providing that certain groups of men should take their wives from certain groups of women, and, further, that the selection of the woman should not be given to the man, nor the selection of the man to the woman, but that certain officers or elder persons should make the marriage contract. This method of seleetion is here ealled legal appointment.

Now, selection by legal appointment exists among all North American tribes, and elscwhere among savages in Australia and other portions of the globe; it exists in diverse forms, which may not here be recounted for want of space. But the essential principle is this: in order that controversy may be avoided, marriage selection is by legal appointment, and not by personal choice. 
But the second fundamental principle of primitive law greatly modifies selection by legal appointment, and gives rise to three forms of marriage, which will be denominated as follows: first, marriage by elopement; second, marriage by capture; third, marriage by duel.

It very often happens in the history of tribes that certain of the kinship groups diminish in number, while others increase. A group of men may greatly increase in number, while the group of women from whom they are obliged to accept their wivesdiminishes. At the same time another group of women may be large in proportion to the group of men to whom they are destined. Inder these circumstances, certain men have a right to many wives, while others have a right to but few. It is very natural that young men and young women should sometimes rebel against the law, and elope with each other. Now, a fundamental principle of early law is that controversy must end ; and such termination is secured by a curious provision found among many, perhaps all, tribes. A day is established, sometimes once a moon, but usually once a year, at which certain elasses of offenses are forgiven. If, then, a runaway couple can eseape to the forest, and live by themselves till the day of forgiveness, they may return to the tribe and live in peace. Marriage by this form exists in many of the tribes of North America.

Again, the group of men whose marriage rights are curtailed by diminution of the stock into which they may marry, sometimes united to capture a wife for one of their number from some other group. It must be distinctly understood that this eapture is not from an alien tribe, but always from a group within the same tribe. The attempt at eapture is resisted, and a conflict ensues. If the capture is successful, the marriage is thereafter considered legal ; if unsuccessful, a second resort to capture in the particular case is not permitted, for controversy must end. When women are taken in war from alien tribes they must be arlopted into some clan within the capturing tribe, in order that they may become wives of the men of the tribe. When this is done, the captured women become by legal appointment the wives of men in the group having marital rights in the clan which has adopted them.

The third form is marriage by duel. When a young woman comes to marriageable age, it may happen that by legal appointment she is assigned to a man who already has a wife, while there may be some other young man in the tribe who is without a wife, because there is none for him in the group within which 
he may marry. It is then the right of the latter to challenge to combat the man who is entitled to more than one, and, if successful, he wins the woman; and by savage law controversy must then end.

All three of these forms are observed among the tribes of North America; and they are methods by which selection by legal appointment is developed into selection by personal choice. Sometimes these latter forms largely prevail ; and they come to be regulated more and more, until at last they become mere forms, and personal choice prevails.

When personal choice thus prevails, the old regulation that a man may not marry within his own group still exists; and selection within that group is incest, which is always punished with great severity. The group of persons within which marriage is incest is always a highly artificial group; hence, in early society, incest laws do not recognize phrsiologic conditions, but only social conditions.

The above outline will make clear the following statement, that endogamy and exogamy, as originally defined by McLennan, do not exist. Every savage man is exogamous with relation to the elass or clan to which he may belong, and he is to a certain extent endogamous in relation to the tribe to which he belongs, that is, he marries within that tribe; but in all cases, if his marriage is the result of legal appointment, he is greatly restricted in his marriage rights, and the selection must be made within some limited group. Exogamy and endogamy, as thus defined, are integral parts of the same law, and the tribes of mankind cannot be classed in two great groups, one practicing endogamy, and the other exogamy.

The law of exogamy is universal. Among all peoples there is a group, larger or smaller, and natural or artificial, within which marriage is prohibited. Exogamy is a derivative institution; its antecedent is marriage by legal appointment within a prescribed group. Marriage by prescription falls, but marriage within the enatic or agnatic group is still considered incest. Until, therefore, the right of marriage extends to all clans but that of the individual himself, exogamy is not fully established.

This may be restated: The primitive institution is marriage by prescription; this develops into marriage by personal choice. But there remains as a survival from the primitive institution a prohibition which may be called exogamy, the violation of which is a crime called incest. 
Tribal societry is of great antiquity ; and in the vicissitudes of tribal life kinship society has undergone many changes, though these changes are restricted to narrow limits. Yet, within these limits the changes are very many, and the subject is thereby greatly complicated, and cannot be understood without long and careful research. Passing travelers can no more set forth the institutions of tribal society than they can give a proper description of the flora of a country, the fauna of a region, or the geologic structure of a continent.

\section{Section 3}

\section{RELIGIOUS BASIS OF THE FAMILI ${ }^{1}$}

If we transport ourselves in thought to those ancient generations of men, we find in each house an altar, and aromnd this altar the family assembled. The family meets every morning to address its first prayers to the sacred fire, and in the evening to invoke it for a last time. In the course of the day the members are once more assembled near the fire for the meal, of which they partake piously after praver and libation. In all these religious acts, hymns, which their fathers have handed down, are sung in common by the family.

Outside the house, near at hand, in a neighboring field, there is a tomb - the second home of this family. There several generations of ancestors repose together; death has not separated them. They remain grouped in this second existence, and continue to form an indissoluble family. ${ }^{2}$

${ }^{1}$ [By Fustel de Codranges, "The Ancient City"; translated by Willard Small; 11th ed., Lothrop, Lee, and Shepard Co., Boston; reprinted by permission.]

${ }_{2}$ The use of family tombs by the ancients is incontestable; it disappeared only when the beliefs relative to the worship of the dead became

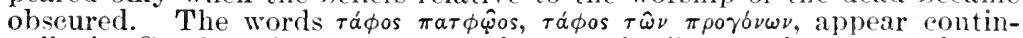
ually in Greek writers, as "tumulus patrius" or avitus. "sepulcrum gentis," are found in Roman writers. See Drmosthenes. "in Eubul.." 2s; "in Macart.," 79. Lycurgus, "in Leocr.," 25. Cicero, "De Offic.,", I. 17. "De Legib.," II. 22 - "Mortuum extra gentem inferri fas negant" Ovid, "Trist.," IV. 3, 45. Velleius, 1I. 119. Surtonius, "Nero," 50; "Tiberius," 1. "Digest," XI. 5; XVIII. 1, 6. There is an old aneedote that shows how necessary it was thought to be that erery one should be buried in the tomb of his family. It is relater that the Lacedirmonians, when about to join battle with the Messenians, attached to their right arms their name, and those of their fathers, in orter that. in ase of death, each body might he recognized on the field of hattle. and transported to the paternal tomb. Justin, III. 5. See Eschylus. "Sept.."

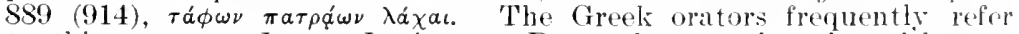
to this custom: Isteus, Lysias, or Demosthents, when he wishes to prove that such a man belongs to a certain family. and has the right to inherit its property, rarely fails to say that this man's father is buried in the tomb of this family. 
Between the living part and the dead part of the family there is only this distance of a few steps which separates the house from the tomb. On certain days, which are determined for each one by his donestic religion, the living assemble near their ancestors; they offer them the funeral meal, pour out milk and wine to them, lay out cakes and fruits, or burn the flesh of a victim to them. In exchange for these offerings they ask protection; they call these aneestors their gods, and ask them to render the fields fertile, the house prosperous, and their hearts virtuous.

Generation alone was not the foundation of the ancient family. What proves this is, that the sister did not bear the same relation to the family as the brother; that the emancipated son and the married daughter ceased completely to form a part of the family ; and, in fine, several other important provisions of the Greek and Roman laws, that we shall have occasion to examine farther along.

Nor is the family prineiple natural affection. For Greek and Roman law makes no account of this sentiment. The sentiment may exist in the heart, but it is not in the law. The father may have affection for his daughter, but he cannot will her his property. The laws of succession - that is to say, those laws which most faithfully reflect the ideas that men had of the family - are in open contradiction both with the order of birth and with natural affection. ${ }^{1}$

The historians of Roman laws, having very justly remarked that neither birth nor affection was the foundation of the Roman family, have concluded that this foundation must be found in the power of the father or husband. They make a sort of primordial institution of this power; but they do not explain how this power was estahlished, unless it was by the superiority of strength of the husband over the wife, and of the father over the children. Now, we deceive ourselves sadly when we thus place force as the origin of law. We shall see farther on that the authority of the father or husband, far from having been a first cause, was itself an effect; it was derived from religion, and was established by religion. Snperior strength, therefore, was not the principle that established the family.

The members of the ancient family were united by something more powerful than birth, affection, or physical strength; this was the religion of the sacred fire, and of dead ancestors. This caused the family to form a single body, both in this life and in the next.

${ }^{1}$ It must be understood that we here speak of the most ancient law. We shall soon see that, at a later date, these early laws were modified. 
The ancient family was a religious rather than a natural association; and we shall see presently that the wife was counted in the family only after the sacred ceremony of marriage had initiated her into the worship; that the son was no longer counted in it when he had renounced the worship, or had been emancipated; that, on the other hand, an adopted son was counted a real son, because, though he had not the ties of blood, he had something better a community of worship; that the heir who refused to adopt the worship of this family had no right to the suceession; and, finally, that relationship and the right of inheritance were governed not by birth, but by the rights of participation in the worship, such as religion had established them. Religion, it is true, did not create the family; but certainly it gave the family its rules; and hence it comes that the constitution of the ancient family was so different from what it would have been if it had owed its foundation to natural affection.

The aneient Greek language has a very significant word to designate a family. It is $\dot{\epsilon} \pi i \sigma \tau \iota \nu \nu$, a word which signifies, literally, that which is near a hearth. A family was a group of persons whom religion permitted to invoke the same sacred fire, and to offer the funeral repast to the same ancestors.

\section{Section 4}

\section{MARRIAGE IN GREECE AND ROME '}

The first institution that the domestic religion established, probably, was marriage.

We must remark that this worship of the sacred fire and of ancestors, which was transmitted from male to male, did not belong, after all, exelusively to man; woman had a part in it. As a daughter, she took part in the religions acts of her father; as a wife, in those of her husband.

From this alone we see the essential character of the conjugal union among the ancients. Two families live side by side; but they have different gods. In one, a young daughter takes a part, from her infancy, in the religion of her father; she invokes his sacred fire; every day she offers it libations. She surrounds it with flowers and garlands on festal days. She asks it protection, and returns thanks for its farors. This paternal fire is her god.

${ }^{1}$ [By Fustel de Coulaxges, "The Anrient City": translated by Willard Small: 11th ed., Lothrop, Lee, and Shepard Co., Boston; reprinted by permission.] 
Let a young man of the neighboring family ask her in marriage, and something more is at stake than to pass from one house to the other. She must abandon the paternal fire, and henceforth invoke that of the husband. She must abandon her religion, practise other rites, and pronounce other prayers. She must give up the god of her infancy, and put herself under the protection of a god whom she knows not. Let her not hope to remain faithful to the one while honoring the other ; for in this religion it is an immutable principle that the same person cannot invoke two saered fires or two series of ancestors. "From the hour of marriage," sars one of the ancients, "the wife has no longer anything in common with the domestic religion of her fathers; she sacrifices at the hearth of her husband." 1

Marriage is, therefore, a grave step for the young girl, and not less grave for the husband; for this religion requires that one shall have been born near the saered fire, in order to have the right to sacrifice to it. And yet he is now about to bring a stranger to this hearth; with her he will perform the mysterious ceremonies of his worship; he will reveal the rites and formulas which are the patrimony of his family. There is nothing more precious than this heritage; these gods, these rites, these hymns which he has received from his fathers, are what protect him in this life, and promise him riches, happiness, and virtue. And yet, instead of keeping to himself his tutelary power, as the savage keeps his idol or his amulet, he is going to admit a woman to share it with him.

Thus, when we penetrate the thoughts of these ancient men, we see of how great importance to them was the conjugal union, and how necessary to it was the intervention of religion. IVas it not quite necessary that the young girl should be initiated into the religion that she was henceforth to follow by some sacred ceremony? Was not a sort of ordination or adoption necessary for her to become a priestess of this saered fire, to which she was not attached by birth?

Marriage was this sacred eeremony, which was to produce these important effects. 'The Greek and Roman writers habitually' designate marriage by a word indicative of a religious act. ${ }^{2}$ Pollux, who lived in the time of the Antonines, but who was well instructed in the aneient usages of his language, says, that in ancient times, instead of designating marriage by its particular name, yá $\mu$ os, they designated it simply by the word $\tau \epsilon$ é 
mony, ${ }^{1}$ as if marriage had been, in those ancient times, the cercmony sacred above all others.

Now, the religion that created marriage was not that of Jupiter, of Juno, or of the other gods of Olympus. The ceremony did not take place in a temple; it was performed in a house, and the domestic god presided. When the religion of the gods of the sky became preponderant, men could not help invoking them also in the prayers of marriage, it is true; it even became habitual to go to the temple before the marriage, and offer sacrifices to these gods. These sacrifices were called the preludes of marriage; ${ }^{2}$ but the principal and essential part of the ceremony alwars took place before the domestic hearth.

Among the Greeks the marriage ceremony consisted, so to speak, of three acts. The first took place before the hearth of the father,

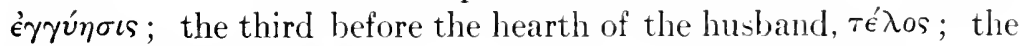
second was the passage from the one to the other, $\pi \circ \mu \pi \eta^{3}{ }^{3}$

1. In the paternal dwelling, in the presence of the future bridegroom, the father, surrounded ordinarily by his family, offers a sacrifice. The sacrifice concluded, he declares - pronouncing a sacramental formula - that he gives his daughter to the young man. This declaration is absolutely indispensable to the marriage; for the young girl would not be able to go at once to worship at the hearth of her husband, if her father had not already separated her from the paternal hearth. To enable her to adopt her new religion, she must be freed from every bond that attaches her to her first religion.

2. The young girl is carried to the house of the husband. Sometimes the husband himself conducts her. In certain cities the duty of bringing her belongs to one of those men who, among the Greeks, were elothed with a sacerdotal character, and who were called heralds. The bride was usually placed upon a car; her face was covered with a veil, and on her head was a crown. The crown, as we shall often have oceasion to see, was nsed in all the ceremonies of this worship. She was dressed in white. White was the color of the vestments in all the religious acts. She was preceded by a torch - the nuptial torch. For the whole distance

1 Pollux, III. 3, 38.

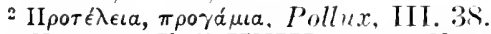

3 Homer. "Il.," XVIII. 391. Ifrsiod, "Scutum," v. 27.5. Hemototus, VI. 129, 130. Plutarch. "Thesens," 10 ; "Lreurg.," passim, "Solon,", 20; "Aristides," 20; "Crr. Quest.," 27. Demostheres. "in Stephanum." II. Isaws, III. 39. Euripide, "Helena," 722-725; "Phen.," 34.5. Harpocration, v. Taurvia. Pollix, III, e. 3. The same usage among the Macedonians. Quintus C'urtius, I'III. 16. 
they sang around her religious hymns, whose refrain was $\dot{\omega} i \mu \dot{\eta} \nu$, $\hat{\omega}$ úévaı. This hymm they called the hymeneal, and the importance of this sacred chant was so great that they gave its name to the whole ceremony.

The bricle dares not go of her own accord into her new dwelling. Her husband must take her, and simulate a seizure by force. She must cry out, and the women that accompany her must pretend to defend her. Why this rite? Is it a symbol of the modesty of the bride? This is hardly probable: the moment for shame has not yet come; for what is now to take place is a religious ceremony. Was it not to mark more strongly that the wife, who was now to sacrifice to this fire, had herself no right there, that she did not approach it of her own free will, and that the master of the place and of the god introduced her by an act of his power? However this may be, after a feigned struggle, the husband raises her in his arms, and earries her through the doorway, taking great care, however, that her feet do not touch the sill.

What precedes is only a preparation, a prelude to the ceremony. The sacred act now commences in the house.

3. They approach the hearth; the wife is brought into the presence of the domestic divinity. She is sprinkled with the lustral water. She touches the sacred fire. Prayers are repeated. Finally, the husband and wife share between themselves a cake or a loaf.

This sort of light meal, which commences and ends with a libation and a prayer, this sharing of nourishment in presence of the fire, puts the husband and wife in religious communion with each other, and in communion with the domestic gods.

The Roman marriage closely resembled that of Greece, and, like it, comprised three acts - traditio, deductio in domum, confarreatio. ${ }^{1}$

1. The young girl quits the paternal hearth. As she is not attached to this hearth by her own right, but through the father of the family, the authority of the father only can detach her from it. The tradition is, therefore, an indispensable ceremony.

2. The roung girl is conducted to the house of the husband.

1 Trarro, "L. L.," 61. Dionysius of Halicarnassus, II. 25, 26. Ovid, "Fast." II. 5.58. Plutarch, "Rom. Quest.," I. 29; "Romul.," 15. Plin., "N. H.," XYIII. 3. Tacit. "Ann.," IV. 16; XI. 27. Juvenal, "Sat." X. 329-336. Gaius. "Inst.," I. 112. Ulpian. IX. "Digest," XXIII. 2. 1. Festus. "v. Rapi." Macrobius, "Sat.,"I. 15. Servius, "ad En.," IV. 168. The same custom among the Etruscans, Varro, "De Re Rust.." II. 4. The same custom among the ancient Hindus. "Laws of Manu," III. 27-30, 172; V. 152: VIII. 227; IX. 194. "Mitakehara," Orianne's trans., pp. 166, 167, 236. 
As in Greece, she is reiled. She wears a crown, and a nuptial torch precedes the cortege. Those about her sing an ancient religious hrmm. The words of this hrmn changed doubtless with time, accommodating themselves to the rariations of belief, or to those of the language; but the sacramental refrain continued from age to age without change. It was the word Talassie, a word whose sense the Romans of Horace's time no more understood than the Greeks understood the word imévate, and which was, probably, the sacred and inviolable remains of an ancient formula.

The cortège stops before the house of the husband. 'There the bride is presented with fire and water. The fire is the emblem of the domestic divinity; the water is the lustral water, that serves the family for all religious acts. To introduce the bride into the house, violence must be pretended, as in Greece. The husband must take her in his arms, and carry her over the sill, without allowing her feet to touch it.

3. The bride is then led before the hearth, where the Penates, and all the domestie gods, and the images of ancestors, are grouped around the sacred fire. As in Greece, the husband and wife offer a sacrifice, pouring out a libation, pronouncing prayers, and eating a cake of wheaten flour (panis farreus). ${ }^{1}$

This cake, eaten during the recitation of prayers, in the presence and under the very eyes of the domestic divinities, makes the union of the husband and wife sacred. Henceforth they are associated in the same worship. The wife has the same gorls, the same rites, the same pravers, the same festivals as her husband. Hence this old definition of marriage, which the jurists have preserved to us: Nuption sunt divini juris et humani communicatio; and this other: Lxor socia humano rei atque divinio." This is because the wife participates in the worship of the husband; this wife whom, according to the expression of Plato, the gods themselves have introduced into the house.

The wife, thus married, also worships the dead; but it is not to her own ancestors that she carries the funeral repast. She no longer has this right. Narriage has completely detached her from the family, and has interrupted all the religious relations that she had with it. Her offerings she carries to the ancestors of her hus-

1 Te shall speak presently of other forms of marriage in use among the Romans, in which religion had no part. Let it suffice to say here, that the sacred marriage appears to us to be the oldest : for it roresponds to the most ancient beliefs, and disappeared only as those helicfs died out .

2 "Digest," XXIII. title 2. "Corle," IX. 32. 4. Dionysins of Hali-

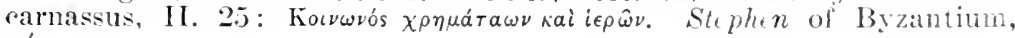
$\pi a ́ t \rho a$. 
band; she is of their family; they have become her ancestors. Marriage has been for her a second birth; she is henceforth the daughter of her husband; filix loco, say the jurists. One could not belong to two families, or to two domestic religions; the wife belongs entirely to her husband's family, and to his religion. We shall see the consequences of this rule in the right of succession.

The institution of sacred marriage must be as old in the IndoEuropean race as the domestic religion ; for the one could not exist without the other. This religion taught man that the conjugal union was something more than a relation of the sexes, and a fleeting affection, and united man and wife by the powerful bond of the same worship and the same belief. The marriage ceremony, too, was so solemn, and produced effects so grave, that it is not surprising that these men did not think it permitted or possible to have more than one wife in each house. Such a religion could not admit of polygamy.

We can understand, too, that such a marriage was indissoluble, and that divorce was almost impossible. The Roman law did indeed permit the dissolution of the marriage by coemptio, or by usus. But the dissolution of the religious marriage was very difficult. For that, a new sacred ceremony was necessary, as religion alone could separate what religion had united. The effect of the confarreatio could be destroyed only by the diffarreatio. 'The husband and wife who wished to separate appeared for the last time before the common hearth; a priest and witnesses were present. As on the day of marriage, a cake of wheaten flour was presented to the husband and wife. ${ }^{1}$ But, instead of sharing it between them, they rejected it. Then, instead of prayers, they pronounced formulas of a strange, severe, spiteful, frightful character, ${ }^{2}$ a sort of malediction, by which the wife renounced the worship and gods of the husband. From that moment the religious bond was broken. The community of worship having ceased, every other common interest ceased to exist, and the marriage was dissolved.

${ }^{1}$ Festus, v. "Diffarreatio." Pollux, III. c. 3: a $\pi \circ \pi$ н $\pi \dot{\eta}$. We read, in an inseription, Sacerdos confarreationum et diffarreationum. Orelli, No. 2648 .

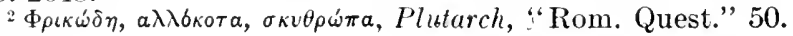




\section{Chapter XIV}

\section{PATRIA POTESTAS ${ }^{1}$}

* $* * \quad * \quad * \quad * \quad * \quad * \quad * \quad *$

Or a few systems of law the family organisation of the earliest society has left a plain and broad mark in the life-long authority of the Father or other ancestor over the person and property of his descendants, an authority which we may conveniently call by its later Roman name of Patria Potestas. No feature of the rudimentary associations of mankind is deposed to by a greater amount of evidence than this, and yet none seems to have disappeared so generally and so rapidly from the usages of advancing communities. Gaius, writing under the Antonines, describes the institution as distinetively Roman. It is true that, had he glanced across the Rhine or the Danube to those tribes of barbarians which were exciting the curiosity of some among his contemporaries, he would have seen examples of patriarchal power in its crudest form; and in the far East a branch of the same ethnical stock from which the Pomans sprang was repeating their Patria Potestas in some of its most technical incidents. But among the races understood to be comprised within the Roman Empire, Gaius could find none which exhibited an institution resembling the Roman "Power of the Father," exeept only the Asiatic Galatæ. 'There are reasons, indeed, as it seems to me, why the direct authority of the ancestor should, in the greater number of progressive societies, very shortly. assume humbler proportions than belonged to it in their earliest state. The implicit obedience of rude men to their parent is doubtless a primary fact, which it would be absurd to explain away altogether by attributing to them any calculation of its advantages; but, at the same time, if it is natural in the sons to obey the father, it is equally natural that they should look to him for superior strength or superior wisdom. Hence, when societies are placed under circumstances which eause an especial value to be attached

1 [By Sir Hexry S. Mare. Reprinted from "Ancient Law," by permission of Henry Holt and Company, New York.] 
to bodily and mental vigour, there is an influence at work which tends to confine the P'atria I'otestas to the cases where its possessor is actually skilful and strong. When we obtain our first glimpse of organised Hellenic society, it seems as if supereminent wisdom would keep alive the father's power in persons whose bodily strength had decayed; but the relations of Ulysses and Laertes in the "Odrssey" appear to show that, where extraordinary valour and sagacity were united in the son, the father in the decrepitude of age was deposed from the headship of the family. In the mature Greek jurisprudence, the rule advances a few steps on the practice hinted at in the Homeric literature; and though very many traces of stringent family obligation remain, the direct authority of the parent is limited, as in European codes, to the nonage or minority of the children, or, in other words, to the period during which their mental and physical inferiority may always be presumed. The Roman law, however, with its remarkable tendency to innorate on ancient usage only just so far as the exigency of the commonwealth may require, preserves both the primeval institution and the natural limitation to which I conceive it to have been subject. In every relation of life in which the collective community might have occasion to avail itself of his wisdom and strength, for all purposes of counsel or of war, the Filius Familias, or Son under Power, was as free as his father. It was a maxim of Roman jurisprudence that the Patria Potestas did not extend to the Jus Publicum. Father and son voted together in the city, and fought side by side in the field; indeed, the son, as general, might happen to command the father, or, as magistrate, decide on his contracts and punish his delinquencies. But in all the relations reated by Private Law, the son lived under a domestic despotism which, considering the sererity it retained to the last, and the number of centuries through which it endured, constitutes one of the strangest problems in legal history.

The Patria Potestas of the Romans, which is necessarily our type of the primeval paternal authority, is equally difficult to unclerstand as an institution of civilised life, whether we consider its incidence on the person or its effects on property. It is to be regretted that a chasm which exists in its history cannot be more completely filled. So far as regards the person, the parent, when our information commences, has over his children the jus vitce necisque, the power of life and death, and a fortiori of uncontrolled corporal chastisement; he can modify their personal condition at pleasure; he can give a wife to his son; he can give his daughter 
in marriage; he can divorce his children of either sex; he can transfer them to another family by adoption; and he can sell them. Late in the Imperial period we find restiges of all these powers, but they are reduced within very narrow linits. The unqualified right of domestic chastisement has become a right of bringing domestic offences under the cognisance of the civil magistrate; the privilege of dictating marriage has declined into a conditional veto; the liberty of selling has been rirtually abolished, and adoption itself, destined to lose almost all its ancient importance in the reformed system of Justinian, can no longer be effected without the assent of the child transferred to the adoptive parentage. In short, we are brought very close to the verge of the ideas which have at length prevailed in the modern world. But between these widely distant epochs there is an interval of obscurity, and we can only guess at the causes which permitted the Patria Potestas to last as long as it did hy rendering it more tolerable than it appears. The active discharge of the most important among the duties which the son owed to the state must have tempered the authority of his parent, if they did not amul it. We can readily persuade ourselves that the paternal despotism could not be brought into play, without great scandal, against a man of full age occupying a high civil office. During the earlier history, however, such cases of practical emancipation would be rare compared with those which must have been created by the constant wars of the Roman republic. 'The military tribune and the private soldier, who were in the field three-quarters of a year during the earlier contests, at a later period the proconsul in charge of a province, and the legionaries who occupied it, cannot have had practical reason to regard themselves as the slaves of a despotic master; and all these avenues of escape tended constantly to multiply themselves. Victories led to conquests, conquests to occupations; the mode of occupation by colonies was exchanged for the system of occupying provinces by standing armies. Fach step in advance was a call for the expatriation of more Roman citizens, and a fresh draft on the blood of the failing Latin race. We may infer, I think, that a strong sentiment in farour of the relaxation of the Patria Potestas had become fixed by the time that the pacification of the world commenced on the establishment of the Empire. The first serious blows at the ancient institution are attributed to the earlier Casars, and some isolated interferences of Trajan and Hadrian seem to have prepared the ground for a series of express enactments which, though we cannot always determine 
their dates, we know to have limited the father's powers on the one hand, and on the other to have multiplied facilities for their voluntary surrender. The older mode of getting rid of the Potestas, by effecting a triple sale of the son's person, is evidence, I may remark, of a very early feeling against the unnecessary prolongation of the powers. The rule which declared that the son should be free after having been three times sold by his father seems to have heen originally meant to entail penal consequences on a practice which revolted even the imperfect morality of the primitive Roman. But even hefore the publication of the Twelve Tables, it had been turned, by the ingenuity of the jurisconsults, into an expedient for destroying the parental authority wherever the father desired that it should cease.

Many of the causes which helped to mitigate the stringency of the father's power over the persons of his children are doubtless among those which do not lie upon the face of history. We cannot tell how far public opinion may have paralysed an authority whieh the law conferred; or how far natural affeetion may have rendered it endurable. But though the powers over the person may have been latterly nominal, the whole tenour of the extant Roman jurisprudence suggests that the father's rights over the son's property were always exercised without scruple to the full extent to which they were sanctioned by law. There is nothing to astonish us in the latitude of these rights when they first show themselves. The ancient law of Rome forbade the Children under Power to hold property apart from their parent, or (we should rather say) never contemplated the possibility of their claiming a separate ownership. The father was entitled to take the whole of the son's acquisitions, and to enjoy the benefit of his contraets, without being entangled in any compensating liability. So much as this we should expect from the constitution of the earliest Roman society; for we can hardly form a notion of the primitive family group unless we suppose that its members brought their earnings of all kinds into the common stock, while they were unable to bind it by improvident individual engagements.

The true enigma of the Patria Potestas does not reside here, but in the slowness with which these proprietary privileges of the parent were curtailed, and in the circumstance that, before they were serionsly diminished, the whole civilised world was brought within their sphere. No innoration of any kind was attempted till the first years of the Empire, when the acquisitions of soldiers on service were withdrawn from the operation of the Patria Potes- 
tas, doubtless as part of the reward of the armies which had overthrown the free commonwealth. Three centuries afterwards the same immunity was extended to the earnings of persons who were in the civil employment of the state. Both changes were obviously limited in their application, and they were so contrived in technical form as to interfere as little as possible with the principle of Patria Potestas. A certain qualified and dependent ownership had always been recognised by the Roman law in the perquisites and savings which slaves and sons under power were not compelled to include in the household accounts, and the special name of this permissive property, Peculium, was applied to the acquisitions newly relieved from Patria Potestas, which were called in the case of soldiers Castrense Peculium, and Quasi-eastrense Peculium in the case of civil servants. Other modifications of the parentat privileges followed, which showed a less studious outward respect for the ancient principle. Shortly after the introduction of the Quasi-castrense Peculium, Constantine the Great took away the father's absolute control over property which his children had inherited from their mother, and reduced it to a usufruct, or lifeinterest. A few more changes of slight importance followed in the Western Empire, but the furthest point reached was in the East, under Justinian, who enacted that unless the acquisitions of the child were derived from the parent's own property, the parent's right over them should not extend beyond enjoying their produce for the period of his life. Even this, the utmost relaxation of the Roman Patria Potestas, left it far ampler and severer than any analogous institution of the modern world. The earliest modern writers on jurisprudence remarked that it was only the fiercer and ruder of the conquerors of the Empire, and notably the nations of Sclavonic origin, which exhibited a Patria Potestas at all resembling that which was described in the Pandects and the Code. All the Germanic immigrants seem to have recognised a corporate union of the family under the mund, or authority of a patriarchal chief; but his powers are obvionsly only the relies of a decayed Patria Potestas, and fell far short of those enjoyed by the Roman father. The Franks are particularly mentioned as not having the Roman Institution, and accordingly the old French lawyers, even when most busily engaged in filling the interstices of barbarous eustoms with rules of Roman law, were obliged to protect themselves against the intrusion of the Potestas by the express maxim, Puyssance de père en France n' "lien. The tenacity of the Romans in maintaining this relic of their most ancient 
condition is in itself remarkable, but it is less remarkable than the diffusion of the Potestas over the whole of a civilisation from which it harl once disappeared. While the Castrense Peculium constituted as yet the sole exception to the father's power over property, and while his power orer his children's persons was still extensive, the Roman citizenship, and with it the Patria Potestas, were spreading into every corner of the Empire. Every African or Spaniard, every Gaul, Briton, or Jew, who received this honour by gift, purchase, or inheritance, placed himself under the Roman Law of Persons, and, though our authorities intimate that children born before the acquisition of citizenship could not be brought under Power against their will, children born after it and all ulterior descendants were on the ordinary footing of a Roman filius familias. It does not fall within the province of this treatise to examine the mechanism of the later Roman socicty, but I may be permitted to remark that there is little foundation for the opinion which represents the constitution of Antoninus Caracalla conferring Roman citizenship on the whole of his subjects as a measure of small importance. However we may interpret it, it must have enormously enlarged the sphere of the Patria Potestas, and it seems to me that the tightening of family relations which it effected is an agency which ought to be kept in view more than it has been, in accounting for the great moral revolution which was transforming the world.

Before this branch of our subject is dismissed, it should be observed that the Paterfanilias was answerable for the delicts (or torts) of his Sons under Power. He was similarly liable for the torts of his slaves; but in both cases he originally possessed the singular privilege of tendering the delinquent's person in full satisfaction of the damage. The responsibility thus incurred on behalf of sons, coupled with the mutual incapacity of Parent and Child under Power to sue one another, has seemed to some jurists to be best explained by the assumption of a "unity of person" between the Paterfamilias and the Filiusfamilias. . . I can only say at present that these responsibilities of the Paterfamilias, and other legal phenomena which will be diseussed hereafter, appear to me to point at certain duties of the primitive Patriarchal chieftain which balanced his rights. I conceive that, if he disposed absolutely of the persons and fortunes of his clansmen, this representative ownership was coextensive with a liability to provide for all members of the brotherhood out of the common fund. The difficulty is to throw ourselves out of our habitual associations 
sufficiently for conceiving the nature of his obligation. It was not a legal duty, for law had not ret penetrated into the precinct of the Family. To call it moral is perhaps to anticipate the ideas belonging to a later stage of mental development; but the expression "moral obligation" is significant enough for our purpose, if we understand by it a duty semi-consciously followed and enforced rather by instinct and habit than by definite sanctions.

The Patria Potestas, in its normal shape, has not been, and, as it seems to me, could not have been, a generally durable institution. The proof of its former universality is therefore incomplete so long as we consider it by itself; but the demonstration may be carried much further by examining other departments of ancient law which depend on it ultimately, but not by a thread of connection visible in all its parts or to all eres. Let us turn for example to Kinship, or in other words, to the scale on which the proximity of relatives to each other is calculated in archaic jurisprudence. Here again it will be convenient to employ the Roman terms, Agnatic and Cognatic relationship. Cognatic relationship is simply the conception of kinship familiar to morlem ideas : it is the relationship arising through common descent from the same pair of married persons, whether the descent be traced through males or females. Agnatic relationship is something very different: it excludes a number of persons whom we in our day should certainly consider of kin to ourselves, and it includes many more whom we should never reckon among our kindred. It is in truth the connection existing between the members of the Family, conceived as it was in the most ancient times. The limits of this connection are far from conterminous with those of modern relationship.

Cognates then are all those persons who can trace their blood to a single ancestor and ancestress; or if we take the strict technical meaning of the word in Roman law, they are all who trace their blood to the legitimate marriage of a common pair. "Cognation" is therefore a relative term, and the degree of connection in blood which it indicates depends on the particular marriage which is selected as the commencement of the calculation. If we begin with the marriage of father and mother, Cognation will only express the relationship of brothers and sisters; if we take that of the grandfather and grandmother, then uncles, aunts, and their descendants will also be included in the notion of Cognation, and following the same process a larger number of Cognates may be continually obtained by choosing the starting point higher and 
higher up in the line of ascent. All this is easily understood by a modern ; but who are the Agnates? In the first place, they are all the Cognates who trace their connection exclusively through males. A table of Cognates is, of course, formed by taking each lineal ancestor in turn and including all his descendants of both sexes in the tabular view; if then, in tracing the various branches of such a genealogical table or tree, we stop whenever we come to the name of a female and pursue that particular branch or ramification no further, all who remain after the descendants of women have been excluded are Agnates, and their comnection together is Agnatic Relationship. I dwell a little on the process which is practically followed in separating them from the Cognates, because it explains a memorable legal maxim, "Mulier est finis familix" - a woman is the terminus of the family. A female name closes. the branch or twig of the genealogy in which it occurs. None of the descendants of a female are included in the primitive notion of family relationship.

If the sustem of archaic law at which we are looking be one which admits Adoption, we must add to the Agnates thus obtained all persons, male or female, who have been brought into the family by the artificial extension of its boundaries. But the descendants of such persons will only be Agnates, if they satisfy the conditions which have just been described.

What then is the reason of this arbitrary inclusion and exclusion? Why should a conception of Kinship so elastic as to include strangers brought into the family by adoption, be nevertheless so narrow as to shut out the descendants of a female member? To solve these questions we must recur to the Patria Potestas. The foundation of Agnation is not the marriage of Father and Mother, but the authority of the Father. All persons are Agnatically connected together who are under the same Paternal Power, or who have been under it, or who might have been under it if their lineal ancestor had lived long enough to exercise his empire. In truth, in the primitive view, Relationship is exactly limited by Patria Potestas. Where the Potestas begins, Kinship begins; and therefore adoptive relatives are among the kindred. Where the Potestas ends, Kinship ends; so that a son emancipated by his father loses all rights of Agnation. And here we have the reason why the descendants of females are outside the limits of archaic kinship. If a woman died ummarried, she could have no legitimate descendants. If she married, her children fell under the Patria Potestas, not of her Father, but of her Husband, and thus were lost to her own 
family. It is obvious that the organisation of primitive societies would have been confounded, if men had called themselves relatives of their mother's relatives. The inference would have been that a person might be subject to two distinct Patrice Potestates; but distinct Patrie Potestates implied distinct jurisdictions, so that anybody amenable to two of them at the same time would have lived under two different dispensations. As long as the Family was an imperium in imperio, a community within the commonwealth governed by its own institutions of which the parent was the source, the limitation of relationship to the Agnates was a necessary security against a conflict of laws in the domestic forum.

The Paternal Powers proper are extinguished by the death of the Parent, but Agnation is as it were a mould which retains their imprint after they have ceased to exist. Hence comes the interest of Agnation for the inquirer into the history of jurisprudence. The powers themselves are discernible in comparatively few monuments of ancient law, but Agnatic Relationship, which implies their former existence, is discoverable almost everywhere. There are few indigenous bodies of law belonging to communities of the Indo-European stock, which do not exhibit peculiarities in the most ancient part of their structure which are clearly referable to Agnation. In Hindoo law, for example, which is saturated with the primitive notions of family dependency, kinship is entirely Agnatic, and I am informed that in Hindoo genealogies the names of women are generally omitted altogether. The same view of relationship pervades so much of the laws of the races who overran the Roman Empire as appears to have really formed part of their primitive usage, and we may suspect that it would have perpetuated itself even more than it has in modern European jurisprudence, if it had not been for the vast influence of the later Roman law on modern thought. The Pretors early lail holl on Cognation as the natural form of kinship, and spared no pains in purifying their system from the older conception. Their ideas have descended to us, but still traces of Agnation are to be seen in many of the modern rules of suceession after death. The exclusion of females and their children from governmental functions, commonly attributed to the usage of the Salian Franks, has certainly an agnatic origin, being descended from the ancient German rule of succession to allodial property. In Agnation too is to be sought the explanation of that extraordinary rule of English Law, only recently repealed, which prohibited brothers of the half-blood from 
succeeding to one another's lands In the Customs of Normandy, the rule applies to uterine brothers only, that is, to brothers by the same mother but not by the same father; and, limited in this way, it is a strict deduction from the system of Agnation, under which uterine brothers are no relations at all to one another. When it was transplanted to England, the English judges, who harl no clue to its prineiple, interpreted it as a general prohibition against the succession of the half-blood, and extended it to consanguineous brothers, that is, to sons of the same father by different wives. In all the literature which enshrines the pretended philosophy of law, there is nothing more curious than the pages of elaborate sophistry in which Blackstone attempts to explain and justify the exclusion of the half-blood.

$*$

*

$*$

$*$

$*$

*

* 


\section{Chapter XV}

\section{WOMEN AND MARRIAGE UNDER CIVILIZATION ${ }^{1}$}

1. It is with the Patriarchal type of Family organization, it would seem, that most of the civilized races have started their career in history. The stage of Mother-right is clearly left behind when their history begins. Traces of it remain, like the right of the Mother's Brother in the German Law, but they are mere traces which would be unintelligible if we had not a mass of customs among other peoples by which to interpret them. Whether we look at the ancient laws and customs of India, Persia, Greece or Rome, of the early Celtic and German tribes or the ancient Slavs, or turn to the Semitic and Mongolian civilizations and trace back the Family through Islam to the Arabia of Mohammed's time, through the Old Testament to the days of the Patriarchs, through Babylonian civilization to the Code of Hammurabi, through Chinese literature to the ancient classical books, we find that where civilization is beginning the Family is in some form or other already organized under the rule of the Father. ${ }^{2}$ The type of marriage law, of family structure, and for the most part the attitude to woman appropriate to the Patriarchal stage underlie the social history of civilization and are deeply imbedded in its structure. The strongly knit family life, the close persomal relations of father, mother and child have formed the nucleus of the stronger and greater social growths. Over a large part of the civilized world the extension of these relations by the family (ult and the worship of ancestors, has proved to be a social bond of marvellous strength and endurance. Yet this unity may be purchased dearly by the loss of independence on the part of the individual members of the family, and we have seen how far this is often carried in the barbaric world. We have now to see how civilization starting in

${ }^{1}$ [By L. T. Hobhouse. Reprinted from "MIorals in Erolution." by permission of Henry Holt and Company. New York. Ahbreviated and omitted book-titles with the detail of editions are supplied tyy the author's reference list on p. xiii, seq., Vol. I of the original work.]

2 The Egyptian family is perhaps an exception. 
the great majority of eases with this type of family has dealt with the social and ethical problems involved.

In the early eivilization of Asia, the position of women, and particularly of married women, was not worse, but on the whole better than one would expect on the analogy of later times and of contemporary, civilizations. In ancient Babylon in the time of Hammurabi, i.e. probably between B.c. 2250 and 1950, marriage was arranged with the parents without reference to the wishes of the bride ${ }^{1}$ by a form of purchase. It was, however, a modified form approaching more nearly to the exchange of gifts which we find in many primitive races. A sum was given, it appears from the code, to the wife's father as well as to the bride herself, but this payment ${ }^{2}$ was not universal, and on the other side of the account the father made over to his daughter on her marriage a dowry which remained her own property in the sense that it was returned to her in the case of divorce or on the death of her husband, that it passed to her children, and failing them to her father. ${ }^{3}$ Thus the method of marriage appears as a quasicommereial transaction, and the decision thereon belongs to the parents of the parties. ${ }^{4}$ Similar commercial considerations dominate the law of divorce, the leading points of which may be given in the words of Hammurabi's code.

"137. If a man has set his face to put away his concubine who has borne him ehildren or his wife who has granted him children, to that woman he shall return her her marriage portion and shall give her the usufruct of field, garden, and goods, and she shall bring up her children. From the time that her children are grown up, from whatever is given to her ehildren they shall give her a share like that of one son, and she shall marry the husband of her choice.

"138. If a man has put away his bride who has not borne him children, he shall give her money as much as her bride price, and shall pay her the marriage portion which she brought from her father's house, and shall put her away.

"139. If there was no bride price, he shall give her one mina of silver for a divoree.

"140. If he is a poor man, he shall give her one-third of a mina of silver."

1 Meissner, "Beiträge zum althabylonisehen Privatrecht," 13.

2 'The case of marriage without a bride price is contemplated in Hammurabi, section 139 (Kohler, 118), that is to say, if bride price is the right translation, and if it is not rather the sum which, in the regular contract forms, the husband agrees to give the wife in case of divorce.

3 The dowry might exceed the bride price (section 164). On the other hand, it remained in a sense in the wife's family, as, if children failed, her father regained it on re-paying the bride price (section 163).

${ }^{4}$ See sections $163-6,159-161$.

${ }^{5}$ I quote $M r$. Johns' translation, but following Kohler, have twice substituted bride price for "dowry." It is clearly intended that the unoffending wife shall have not only her dowry, which is really her own property or that of her family (section 162), but either the bride price, which 
On the other hand, the woman who "has set her face to go out and has acted the fool, has wasted her house, has belittled her husband," may either be clivorced without compensation, or retained in the house as slave of a new wife. The wife may also clain a divorce (or separation) ${ }^{1}$ " if she has been economical and has no vice, and her husband has gone out and greatly belittled her," but she acts at some risk, for if on investigation it turns out that she had been uneconomical or a goer about, " that woman one shall throw her into the waters." ${ }_{2}$ Thus the wife has certain pecuniary guarantees against arbitrary divorce, while if ill-treated she may leave her husband, but her position as his subject is marked by the manner in which infidelity is treated. The law provides that both parties should be put to death unless the king pardons his servant or the "owner" his wife. ${ }^{3}$ The lordship of the husband is seen also in his power to dispose of his wife as well as her children for debt. ${ }^{4}$

Polygamy appears, not in the rich luxuriance of later Asiatic civilization, but in a restricted form. A man might marry a second wife if a "sickness has scized" his first wife, but the first is not to be put away. ${ }^{5}$ Apparently this is the only case in which two fully equal wives are contemplated by the corle, but it was also possible for a man to take a secondary wife or concubine, who was to be subordinate to the chief wife. This was a common practice when the wife was childless, but was apparently legal even when she had children. ${ }^{6}$

represents, so to say, the worth of her own person, or, what I eannot help suspecting to be the meaning, the amount which at the time of the marriage the husband contraeted to give her in the event of a divoree. In the contracts of the period, the sum is sperified. In one ease it is a mina, in another ten shekels. The wife also states explicitly that if she repudiates her husband she shall be drowned, strangled or sold, as the case may be.

1 Nothing is said of her being allowed to marry again. She is to go to her father's house. Observe above that when a divorced woman has ehildren it seems to be implied that she will at any rate demain unmarried till they are grown up.

2 The translations differ here. I follow Mr. Johns. Hammurabi, seetions $141,142,143$.

3 Hammurabi, section 129. On the other hand, she is allowed to purge herself by oath, from an unproved aceusation; if it is made hy her husband, "she shall swear by Got and return to her house"; if it is marle by some one else, she shall plunge into the holy river. (131, 132.)

${ }^{4}$ The period of debt slavery was, however, limited to three years. II ammurabi, 117.

${ }^{5}$ Hammurabi, 148.

${ }^{6}$ The provisions of the code are not perfeetly clear. The relevant sections run as follows: - 144. "If a man has espoused a woman, and that woman has given a maid to her busband and has brought up children, that man has set his face to take a concubine. one shall not comntenanef that man, he shall not take a concubine. 145. If a man has espoused a 
To sum up, the early Babylonian marriage law contemplates marriage by purehase or exchange of gifts with a restricted polygamy and considerable authority and privileges for the husband, moderated hy eertain provisions for the protection and maintenance of the wife. But in relation to other persons the wife is a much more free agent than in many civilized countries at the present, or at any rate in recent times. She could already conduct business and in certain eases dispose of property, and, at any rate in later Babylonian times, she appears as possessed of full legal personality, carrying on processes of law and appearing as a qualified witness. ${ }^{1}$ In this later period moreover - that of the last

woman and she has not granted him ehildren and he has set his face to take a concubine, that man shall take a concubine, he shall cause her to enter into his house. That concubine he shall not put on an equality with his wife." (I have followed Mr. Johns' translation, but substituted "woman" for "votary" in aceordance with the views of other translators.) It is not (elear from this, as it stands, whether a man could compel his wife to give him a concubine, in case the wife had children, but elsewhere the case of a man having children by both wife and concnbine is clearly contemplater, and in the contracts there are cases of a man marrving two wives, of whom one is to be subject to the other. Thus Arad Samas takes Iltani, the sister of Taramka, as his wife. He promises to care for her well-being, and to carry her chair to the temple of Marchk; he is already married to Taramka, but Taramka is placed by the contract in an inferior position to Iltam. "All children," the contract reads, "as many as there are, and as many as shall be born, are Iltani's." If Taramka says to Iltani, "You are not my sister," something terrible happens, as to the nature of which a hiatus in the inseription leaves us in ignorance. If either wife says to Arad Samas, "You are not my husband," she is to be branded and sold for money; if they both do it (presumably if they conspire to do so), they are to be thrown into the river. If Arad Samas repudiates either of them, he is to pay a mina of silver. (Meissner, ib., p. 71.) In this contract, essentially the same law as that of Hammurabi is seen in active operation, and it is elear that a certain form of polygamy or concubinage is contemplated, although there are ehildren in existence by the first wife. Apparently the object of the code is to maintain the supremacy of the chicf wife, while imposing on her, if childless, the dnty of granting children to her husband. The conculine should be provided by her. If she failed to give him one, the man might take one, hut must still treat his wife as mistress of the home. Thr'e is no prohibition of concubinage nerely on the ground that the legitimate wife has children of her own. Further it is only the regular conculinage with a fixed status, determined by contract, which is thus limited. There is nothing said to limit intercourse with a female slave, whose children might be adopted at will by the father, and thus share in the inheritance with the legitimate children. (II ammurabi, 170, 171.) On the whole we gather (1) that, in case of sickness, there might be two regular wives; (2) there might be in case of childlessness, and perhaps in other eases also, a regular conculine, subordinate to the wife; (3) a slave roncubine unprotected by contract, whose children might or might not be recognized and inherit.

${ }^{1}$ Kohler and Peiser, "Aus dem Babylonischen Rechtsleben," iii. p. 8, etc. The marriage law had also improved in the wife's favour. Contracts of marriage by purchase are very rare, thongh one exists of the thirteenth year of Nebrichadnezzar, in which the wife is bought for a slave for $1 \frac{1}{2}$ gold minas. (Ib., vol. i. p. S.) 
centuries of the independent Babylonian civilization - it appears from the contracts that a woman could protect herself against the advent of a second wife by pecuniary penalties in the marriage contraet. $^{1}$ On the other hand, her marriage still appears to be at the disposal of her male relations, her brothers, for instance, when the father was dead. Indeed, even the son required the father's consent to his marriage. To this extent the patriarehal power had endured. ${ }^{2}$

2. In ancient Egypt a good deal of obscurity surrounds the position of women. We have to re-eonstruct it partly from marriage contracts which perhaps do not show us all the conditions of the bargain, partly from incirlents in stories, partly from passages in the moralists, partly from the descriptions of Greek travellers. We have no precise and certain information as to the structure of the family, on which everything turns; and we are dealing with a period of four thousand years or more, in the course of which there is time even in the slow-moving East for many things to change. In fact, our fullest information relates to the very latest period of independent Egyptian history, and to the time of the subjection to Persians, Greeks, and Romans. This information is derived from numerous marriage contracts, a few of which are as early as the time of King Bocchoris (circa B.C. 730), while the greater number are of Persian and Ptolemaic times. In this period there was no sale by the parents, ${ }^{3}$ but the bride gift went to the bride herself, and the husband in the contraet further stipulated how mueh he will give for her support, and promises that the children shall be his heirs. The woman's own property remains generally. at her disposal, and she retains the right in the contracts of leaving her husband and keeping her property together with the bride gift. She also can secure herself against divorce by a fictitious dowry

1 The husband promises if he takes another wife to give her a mina and send her home. This seems to have been a common protection against polygamy. The wife still engages to be put to death, if unfaithful. (Kohler and Peiser, i. 7, s. C'f. Fictor Harx, "Die Stellung der Frauen in Babslonien: Beiträge zur Assyriologie," bd. 4. hft. i. p. is. seq.)

${ }^{2}$ Kohler and Peiser, i. p. 9, and ii. p. 7 . The right of the father is limited in Hammurahi. Ho might only disinherit a som for a serious erime, and then only for a scrond offence, and with the approval of a judge. $(168,169$.$) In other words, the property was the family"s, and the father$ had only limited rights over it.

${ }^{3}$ Nor do they appear in the contraet. Yet probahly their authority was or had heen at least in theory ahsolute, eren orer the son. (Reritlout, "Préeis du rlroit Egrptien," p. 1102.) in the story of the enchanted princess, the daughter only gets her own way by threatening suicide. (H. Max .M̈̈ller, p. 3.) 
which the husband is to pay back ${ }^{1}$ to her in case he sends her away.

Such contracts appear to be wholly in favour of the woman, and in the light of them we can understand the statement of Diodorus that among the Egyptians the wife ruled the husband, though he clearly exaggerates when he says that in the marriage contract there was a specific agreement that the husband should in all things obey the wife. 'This, however, gives us one side of the shick only. The very fact that the wife protected herself from divorce or from the marriage of a second wife by special clauses in the marriage contract goes to prove that she was not so protected by the general law, and in point of fact there is evidence in the monments and in the popular stories both for polygany and for looser unions admitting arbitrary divorce. Thus in the story of the Squinting Woman we read that " she was twenty years in the house of her husband. When he found another woman he said to her, 'I divorce you, you squint.' "' 3 Presumably the poor lady had not taken the precaution to protect herself by a marriage contract, or perhaps she had not the means to do so, for naturally conjugal rights resting upon considerations of property coukd only be enforced among the propertied classes, and probably only there in cases where the wife's dower was a substantial consideration. And if, as good authorities ${ }^{4}$ hold, this pecuniary security against the possibility that the husband "should be averse to her and seck another wife" formed the chief difference between the wife and the mistress, we can easily understand how it was that much looser relations remained the rule both in the highest classes and among the mass of the people. The pririleged position which the wife occupies in the contracts would seem, then, to arise largely from considerations of property and inheritance, though

1 H. Mar Müller, "Liebespoesie der alten Aegypter," p. 4 ff.

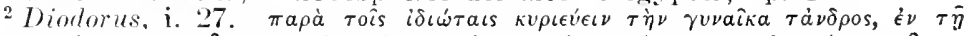

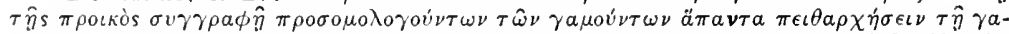

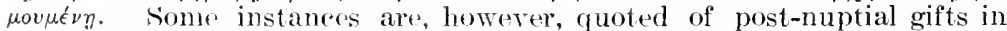
which the hushand makes over all his possessions to his wife, on condition that she is responsible for his maintenance throughout life and for his tomb. (Rerillout, 1092.) ('f. also the contract of Panofré, in which, seemingly, full power is given to the wife and none to the husband. (Ib., 1005 .) M. Revillout regards this as a compensation for seduction.

${ }_{3}$ W. Max Müller, l. c., p. 5.

${ }^{4}$ How rompletely the terns of the contract were determined by the position of the parties and the conditions of the hargain is shown by the fact that from the very same period we got contracts in which the wife hands herself over as a slave, with all her belongings down to the elothes on her hack. The man merely promises not to take a concubine. (Rewillout. p. 996.) In some rontrarts, again, the wife pledges herself, if she leares the hushand, to restore all his gifts tenfold. (Ib., 1002.) 
based also on the freedom of the Egyptian woman to carry on commerce and industry and to make contracts for her own benefit. With this freedom, which is very possibly associated with a general breakdown of an older joint family system about the epoch of Bocchoris, she - or her father on her behalf - is enabled to bargain either for the fidelity of her husband or for freedom for herself to leave him - in some cases even for both together ${ }^{1}$ - her property being secured to her and the children of the marriage. Apart from such a bargain, if this view is accurate, her position would be a very different one. ${ }^{2}$

I See Revillout, "Précis du droit Égyptien," p. 1029, and cf. Müller, p. 4 .

${ }_{2}^{2}$ In the interpretation of the contracts everything really turns on the dowry. If this is real the whole position is readily intelligible. The husband receives (as the contracts recite) so much from the wife. But he holds it in trust for her, to pay her a fixed income from it while she is his wife, or, if she leares him, to refund it. She keeps the property in case of divorce because it was originally hers, and has throughout been held for her. Moreover, the property is settled on the children of the marriage, and it appears to be in their interest as much as the wite's that the contract is made. So far the only important right of the wife is that of free separation. If, however, as seems to be held by Revillout, p. 1079 , and $M$ üller, the domry was often fictitious, the bargain was certainly favourable to the woman in a remarliable degree. In that case we must suppose that as a condition of marriage, she exacted the settlement of a man's whole propert $y$ on herself and children, retaining full liberty of learing him at will, and taking the property with her. Is this credible? Such a settlement oceurs in the Setne story. Ta-bubue makes her wonld-be seducer first execute a deed in her farour: she then calls in his children to witness it, and finally makes him kill them. This, howerer, belongs to the region of fairy tale. It seems far more prohable that in the normal ease, the free position of the wife was (as later in Rome) simply purchased by the dowry. In the Theban contracts there is no dowry, and nothing is said of divorce by the woman. On the other hand, the man makes a nuptial gift and agrees to increase it five, ten or twenty fold if he talies another wife. The property is settled on the ehildren in the name of the eldest son. (Revillout, pp. 1034, 1039, ff.) Revillout recognizes (p. 1096) that the interests of the children were the prime object of the settlement, and if so the contract merely enforces by agreement what would have oceurred automatically under a joint family system with maternal hinship. The daughter inhoriting property from her parent marries. The husband becomes its administrator, but not its owner. It passe's automatieally to their ehildren with the ellest as administrator. If the wife dismissed the husband (as under this system she often may) she would of course retain the family property. Now if this system was breaking down in the age of Bocchoris in favour of individual ownership, it would be necessary to secure the passage of the property to the woman's rhildren by a compact. This was done by making it over to the nominal ownership (and perhaps real administration) of the husband, who agreed that it should return to the wife in case of throrce, and in any case pass to their ehildren. Thus the old system of inheritance would be maintained hy the new method of eontract. It is, of eourse, possible that where the woman had the man in her power, like the witch-wife in the story of setne", sho would use this form for getting hold of all his worldly goods. 'The The hatn form of eontract is less archaic. Ilere there is a Norgen-gabe to the bride, but only an earnest of it is artually paid over. The remaincler is to be given if the husband is unfaitheful, and so acts as a guarantee for her. 
Polyamy appears to have been allowed from the first, though as in almost all polygamous countries it was for the most part confined to the rich. 'The ling has a large harem in which there is one chief wife, the "great spouse," who accompanies the king in his public acts and particularly in his religious worship, who is ahways a princess of the royal blood, and probably a sister of the king, who has her own household and her own servants, and might on the king's death obtain practical royal authority as regent. ${ }^{1}$ Lnder her there are secondary wives taking rank according to their birth, and being probably more or less secluded, and beneath them again are a troop of concubines and foreign slaves. The court of Pharaoh was imitated by the feudal chief of every nome, who also had his harem, "where the legitimate wife - often a princess of solar rank - played the rôle of Queen surrounded by concubines, dancers, and slaves." 2 Thus a frank development of polygamy, though apparently in that form in which the position of the chief wife is clearly distinguished, was practised by the highest classes of Egrpt, and it is seldom, if ever, that polygamy on a large scale goes much further. It would seem, however, that the position of women gradually improved throughout Egyptian history, and that in practice polrgamy died out. In the Middle Kingdom it appears frequent among the middle classes, but by B.c. 1100 it had become rare, and later on it died away except among the higher officials. ${ }^{3}$ While it was still clearly legal in the New Kingdom and in the Classical Period the contracts enable us to understand how through the opposition of the women it would gradually disappear. But meanwhile the whole attitude to women must have improved. In the early dynasties the king boasts of having carried off the wives of other men, and these outrages are alleged in proof of his truly royal nature. ${ }^{4}$ Now though in theory Pharaoh may have remained the absolute master of all his subjects and their wives, yet rape and adultery did not continue to be a matter for boasting. For the ordinary man, at any rate, they were recognized as sins from which he had to clear himself in the next world. ${ }^{5}$

I Maspero, “Dawn of Civilization," 270, $271 \mathrm{ff} . \quad 2$ op. cit., 298.

${ }^{3}$ Thus as late as B.c. 40 a high priest, recounting the advantages which he had enjoyed in this life, says: "I had beautiful concubines." ( $W$. Max Muller, p. 5, note 11.) p. $7 \hat{0}$

Maspero, "Recueil de Travaux," vol. iv.; "Pyramide du roi Ounas,"

5 Thus, in the Negative Confession in the "Book of the Dead" of the 1Sth Drnasty, violations of the marriage law figure as mortal sins. The Negative Confession (Flinders Pctrie, "Religion and Conseience in 
On the relations of husband and wife the moralists of the Middle and New Kingdom throw some light. They very properly enjoin kind treatment of the wife upon the husband. To this effect run the precepts of Ptah Hotep: "If thou art successful and hast furnished thy house and lovest the wife of thy bosom, then fill her stomach, and clothe her back. The medicine for her borly is oil. Make glad her heart cluring the time that thou hast. She is a field profitable to its owner." 1 These are most proper sentiments, blended, as they are, with that simple worldy wisdom and gentle appeal to self-interest which characterize the utterances of the excellent Ptah Hotep, first of all the race of platitulinarians; but excellent as the sentiment is, it does not imply the subjection of the husband to the wife, but rather the contrary. ${ }^{2}$ The maxims of Ani, some six dynasties later, are a little more detailed: "Do not treat rudely a woman in her house when you know her perfectly; do not say to her, "Where is that? bring it to us,' when she has set it perfectly in its place which your eye sces, and when you are silent you know her qualities. It is a joy that your hand should be with her. 'The man who is firm of heart is quickly master in his house." 3 All this is in the approved Oriental sty.le, and so

Ancient Egypt," pp. 134, 135) consists of a long series of offences which the dead man repudiates. The 19th reads: "I have not committed adultery with another man's wife." The next is by some translated: "I have not been impure," which would look like a general repurliation of unchastity rare in early ethies. But lläller (p. 17) renders it: "I have not stimulated sensuality," i.e. by drugs. In the earlier lists of repudiations (there are two in the "Book of the Dead") is one translated by .Mr. Budge ("Book of the Drad," ii. p. 361): "I have not committed fornication," but other renderings seem to limit the offence to cases wher" it was eommitted in a sacred plare. (Griffith, p. 5321.) As 10 women Müller (p. 7) thinks that pre-nuptial chastity was little regarded, and this would certainly fall in with the abnormal permission of brother and sister marriage. He adds that in the marriage contract no stress was laid on virginity, and that, at least in Roman times, there was no prejudien against bastards. The unspeakable corruption of the Egyptian Pantheon to which he refers would reflect the manners of the earliest period.

1 Flinders Petrie, p. 132. F. L. Griffeth, "The World's Literature," p. 5335 .

2 There is a little more point in a further maxim of Ptah Hotep, "If thon makest a woman ashamed, wanton of heart, whom hre fellow-townspeople know to be under two laws (explained hy Mr. Griffith as meaning in an ambiguous position), he lind to her a season: send her not away, let her have food to eat. The wantomness of her heart appreriateth guidance." (Griffeth, "World's Literature," p. 5337.) Appar'ently this is a recommendation, couched, it must be admitted, in mild terms, to a man who has seduced a woman to treat her with consideration. There is clearly no question of any obligation.

${ }^{3}$ The Boulak Papyrus, in Amélinear " La Morale Egyptienne," p. 1SS. Brugsch translates the first words: "Do not strilie rour wife." With the above compare the Ptolemaic prerept. "May it not happen to thee to maltreat thy wife whose stemgth is less than thine, hut may she find in thee a protector." (Flinders Petric, p. 133.) We have also the 
also in Ani's recommendation to the wife: "What does one speak of day by lay" Let the professions speak of their duties, the wife of her husband, and every man about his business." 1

In what sense, then, was the wife called "mistress of the house"? Possibly this was merely the title of the legitimate wife as opposed to the concubines. Possibly the true explanation is that adranced by Maspero, ${ }^{2}$ that, as in some contemporary tribes of Northern Africa, the practice of polygamy took the form that each wife had her own house in which she was mistess, and "where she performed all a woman's duties, feeding the fire, grinding the corn, occupying herself in eooking and wearing, making cloth and perfumes, mursing and teaching her children. When her husband visited her, he was a guest whom she received on an equal footing. It appears that at the outset these various wives were placed under the authority of an older woman, whom they looked on as their mother, and who defended their rights and interests against their master, but this custom gradually disappeared, and in historic times we read of it as existing only in the families of the gods." 3

With this system probably survivals of primitive mother-right were conjoined. Deseent was reckoned through the mother down to late times, and guardianship was exercised by the mother's brother. ${ }^{4}$ That being so, it is intelligible that the family property should pass through the female and be retained by her in case of divorce. Honour to the mother is strongly insisted on.

"Thou shalt never forget thy mother, and what she has done for thee, that she bore thee, and nurtured thee in all ways. Wert thou to forget

lament of a widower who is persecuted by his wife's ghost, and who points out that he never left her when he ohtained promotion, but shared everything with her, and never acted the master. (Rcvillout, p. 984.) This implies that he might have done so. On the other hand, it points to another possible source of respect for women, the fear of the ghost or of their magic power. This last was strongly felt. (Maspero, "Dawn of Civilization," p. 271.)

1 "Maxims of Ani," \$ 30. Amélincau, "La Morale Egyptienne," 113. It should he added that the husband could apparently put the unfaithful wife to death. In the story of the "Two Brothers" it is narrated without comment, and rather as a matter of comrse, that the husband slew his wife and rast her to the dogs. (Griffith, "World's Literature," 5257.) According to Diolorus, in cases of adultery, the paramour was punished with 1000 hows, the wife by having her nose ent off.

2 Maspero, "Dawn of Civilization," p. $51 \mathrm{ff}$.

3 The same practice is found among Columbian tribes where the hushand goes to live in the wife's tribe. She takes charge of the house and the proxisions, and there may be several wires, each with her separate fire. (starcke, "The Primitive Family," p. 34.) The contracts of the rlassical period appear to contemplate the separate life of the parties, pursuing their several arocations, and the husband agreeing to allow so much for his wife's maintenance.

"W. IIax Mriller, "Lielrespoesie," p. 6. 
hor then she might blame thee, lifting up her arms unto God, and II would hearken unto her complaint. For she earried thee long bemeath her heart as a heary burden, and after thy months were accomplished she bore thee. Three long vears she carried thee upon her shoulder and gare thee her breast to thy mouth. She murtured thes nor knew oftence for thy uneleanness. And when thou didst enter sehool and wast instrueted in the writings, daily she stood by the master with hread and beer from the house." 1

Thus it is very possible that the preservation of relics of motherright was among the forces tending to the better condition of women in Egrpt. 'These were augmented towards the close of the independent history of Egypt by the rise of free contract and the important part taken by women in industrial and commercial life. In these relations and in social intercourse generally it is allowed on all hands that their position was remarkably free. Little restraint was placed on their intercourse with men, they appear on the monuments eating and drinking frecty - sometimes too freely - in masculine company, and they surprised the Greek travellers by going out without restraint to work at their trade or manual labour while the men often worked at home." Of this position women in the commercial and propertied classes availed themselves to improve their condition as wives. But apart from marriage contracts which were perhaps restricted to a limited class for a limited period, the position of the Egyptian woman was probably, save for the remainders of mother-right, much what it has been elsewhere in the East - subject to her guardian's choice

I From the Boulak Papyrus, translated by Griffith, op. cit., p. 5340, from the German of Prof essor Erman.

${ }^{2}$ W. Max Müller, loc. cit., points out that this freedom would not apply to the bondwomen of the peasantry, who were under the arbitrary power of royal or priestly officials, antl wove for them shut up in a workhouse. Here, however, we touch the general question of slavery rather than the special position of women. It is more to the point, that to have refrained from pressing a widow remained a matter for hoasting. and that education in reading and writing was not often extended to girls. It is perhaps going a little too far to say with this writer that no ancient or foreign people, exeept those of New Zealand, have given women so high a legal position. The attitude to women in Egyptian literature is not particularly respeetful. Often she is represented as the temptress, for instance in the Boulak Papyrus.

"Keep thyself from the strange woman who is not known in her city. Look not upon her when she cometh and know her not. She is like a whirlpool in deep waters, the whirling yortex of whirls is not known. The woman whose husbant is afar writeth unto thee daily. When none is there to see she standeth up and spreadeth her snare. "Sin unto death is it to hearken thereto." (Griffith's tr. following Erman, "World's literature," p. 5340.)

The general tendeney of the passage, whirh reealls the woll-known chapter in Proverhs, is plain enough, but whether the warning is principally directed against the larlot or the adulteress is not wholly clear. 
of a husband, ${ }^{1}$ liable to be slain for unfaithfulness, subject to divorce at pleasure, and to have other wives or concubines associated with her. Out of this condition the women of Egypt at the close of its independent civilization were raising themselves by the marriage contract, and one class had so far succeeded as to achieve a position equal to that of the Roman matron at a iater day.

3. Both in Egypt and Babylonia the position of women was in some respects better than our traditional conception of the Oriental woman would lead us to expect. In other cases that conception accords only too closely with the facts. Each civilization has had its orn peculiarities, but they have been variations upon one type. In India tradition starts with the heroic age of the Vedas, in which the paternal power is already fully developed. The father is master and indeed owner of the family; wife, sons, daughters and slaves have no property of their own, but are rather his property. On his death, his place is taken by the eldest son, into whose tutelage the widow passes. The daughter might be sold to an intending husband, ${ }^{2}$ and it is not probable that her consent was a material condition. ${ }^{3}$ The widow passed to her husband's brother until a son was born: she did not in this age follow her husband to the grave, though the funeral ceremony strongly suggests the previous existence of such a custom. ${ }^{4}$ Finally the Vedas contain distinct traces of polygamy, though it was doubtless an exception. ${ }^{5}$ Thus Indian family life begins with a typical Patriarchate. To this system a religious turn was given

${ }^{1}$ In the 12 th dynasty women were definitely part of the family property, a man's widow being counted among the possessions inherited by the son. (Revillout, "Précis du Droit Égyptien," p. 990.) Here there was apparently a decided change by the time of Bocchoris, a change which naturally accompanies the break-up of the joint family.

2 The purchase of brides is mentioned in the Epic Poems. Thus Bhishma purchased the daughter of the Prince of Madras for Pandu, with gold and precions stones. (Duncker, "History of Antiquity," vol. iv. pp. 255-266.) Capture was probably an alternative to purchase, l.c.

${ }^{3}$ Muir, "Sanserit Texts," v. 459, quotes a passage from the Vedas, which suggests that some freedom of choice was exercised by women under farouralle conditions. "Happy is the female that is handsome. She herself loves (or chooses) her friend among the people." In the Mahabharata the King's daughters appear to choose their husbands, but this is a prerogative of Royalty.

${ }^{4}$ When the widow has led her husband to the place of burial, she is exhorted to "elevate herself to the world of life," for her marriage is at an end. (Duncker, op. cit., iv. 511.)

${ }^{5}$ In one hymn the poet prays that Pūshan will protect him and provide him with a supply of damsels. (Muir, v. 457, 461.) 
by the Brahman law. In some respects the Brahmans endeavour to purify the marriage relationship and to provide for the protection of the wife. This appears especially in the attempt to prohibit marriage by purchase. This form of marriage is recognized, but figures along with marriage by capture as one of the four blamable kinds, and "no father who knows the law must take eren the smallest gratuity for his daughter." He that does so is " a seller of his offspring." 1 Purchase is reduced to the form of a fee given to the Brahman for the fulfilment of the sacred law, and this fee is not to be appropriated by the relatives themselves. Set notwithstanding Manu's discouragement of the practice, marriage by purchase persisted in a modified form, the final compromise being that the present given by the suitor was assigned to the benefit of the bride and became her dowry, passing back to her own family on her death. The barbaric form of marriage by capture or abduction, which is morally condemned by Manu but legally sanctioned for the Kshatriya caste, became obsolete, being forbidden in Narada's code, and the two forms of marriage which persist in

1 Manu's eight forms of marriage and his comments on them are full of instruction for the transition from harbaric to eivilized marriage laws. The gift of a daughter, after decking her, to a man learned in the Veda and of good conduct. . . is ealled the Brânma rite. The gift of a daughter who has been decked with ornaments to a priest.. . they call the Daiva rite. When (the father) gives away his daughter according to the rule after receiving from the bridegroom, for (the fulfilment of the sacred law, a cow and a bull or two pairs, that is named the Arsha rite. The gift of a daughter (by her father) after he has addressed (the couple) with the text, "May both of you perform together your duties," . . . is called... the Prấgâpatya rite. When (the bridegroom) receives a maiden after having given as much wealth as he can afford, to the linsmen and to the bride herself, according to his own will, that is called the Âsura rite. The voluntary union of a maiden and her lover one must know (to be) the Gândharva rite, which springs from desire, and has sexual intercourse for its purpose. The forcible abduction of a maiden from her home, while she cries out and weeps, after (her kinsmen) have been slain or wounded and (their houses) broken open, is called the Râkshasa rite. When (a man) by stealth seduces a girl who is sleeping. intoxicated, or disordered in intellect, that is the eight h, the ruost hase and sinful rite of the Pisâkas. (Ianu, iii. 27-34.) Of these, the first four are allowed to Brahmans. They are all in effert religious marriages, the gift in the third or Ârsha form being of a ceremonial chararter, as it is to be "for the fulfilment of the sacred law," not a price for the daughter. A variant appears in the code of Apastamba (I1., vi. 12, 13, Mayne. P. S2). wherein a gift of value was made to the hrieles parents, but returned hy them. The four blamable rites are purclase, capture, voluntary union, and treacherous seduction. Of these. the two first. as we have seen, are allowed to the warrior caste. The fifth and eighth, the law book of Bauldhayana allows to Vaisyas and Surlras, since they "are not particular about their wives." (Baud., I., ii. 13, 14.) These are in the main rolies of barbarism, yet a higher conception appears when Balztlhayana remarks that "some recommend the Gândlarra rite (i.e. voluntary union) for all castes, because it is based on mutual affection." (Ih.) "But this germ of a true marriage by mutual consent was not allowed to fruetify. 
India to this day are the Brabma, the gift of a daughter decked and honoured with jewels to a man learned in the Veda whom the father himself invites, and the Asura, or purchase in the modified form described. ${ }^{1}$

Only in one case, moreover, does Manu recognize the free-will of the maiden in the matter of her own marriage. If her father fails to provide her with a husband within three years of her attaining maturity she may marry whom she will. ${ }^{2}$ In all other cases her guardian disposes of her hand. The woman who is thus passed from the absolute control of her father into the absolute control of her husband must honour, obey and merge herself in him. "Though destitute of virtue, or seeking pleasure (elsewhere), or devoid of good qualities, (yet) a husband must be constantly worshipped as a god by a faithful wife." 3 "She must always be cheerful, clever in (the management of her) household affairs, careful in cleaning her utensils, and economical in expenditure." 4 On his side the husband is commanded to show her respect. "Women must be honoured and adorned by their fathers, brothers, husbands, and brothers-in-law, who desire (their own) welfare." 5 He is to be faithful to her, "being constantly satisfied with her alone." Her son is even to respect her more than his father. "The teacher is ten times more venerable than a subteacher, the father a hundred times more than the teacher, but the mother a thousand times more than the father." ${ }^{6}$ And so Vasishtha sars, "A father who has committed a crime causing loss of caste must be cut off. But a mother does not become an outcast for her son." 7 But though respected if virtuous, she is to be chastised if the husband thinks her otherwise. The chastisement, however, is strictly limited. "A wife, a son, a slave, a pupil, and a younger brother of the full blood, who have committed faults, may be beaten with a rope or split bamboo, but on the back part of the body (only), never on a noble part; he who strikes them otherwise will incur the same guilt as a thief." 8 Here, as elsewhere, fluctuations of opinion show through Manu's text. In one place we read, "Day and night women must be kept in dependence by the males of their families," ${ }^{9}$ yet a few sections on the appeal is to women themselves: "Women confined in the house under trustworthy and obedient servants are not (well) guarded; but those who of their own accord keep guard over themselves

1 J. D. Mayne, "Hindu Law and Usage," pp. 79-85.
2 Manu, ix. $90 \mathrm{ff}$.
${ }^{3}$ Ibid., v. 154
${ }^{4}$ I bid., v. 150 .
5 Ibid., iii. 55 .
${ }^{6}$ Ibid., ii. 145 .
7 Vrasishtha, xiii. $47,45$.
s Manu, viii. $299,300$.
${ }^{9}$ Ibid., ix. 2. 
are well guarded." ' But this higher note is seldom struck. The Brahmans are far too much impressed with the evil disposition of women, ${ }^{2}$ and the husband is recommended to keep his wife well employed about the house keeping things clean and preparing his food, as an expedient for guarding her.

On the strict theory of Manu a wife could have no property. In this respect she is placed on one footing with a son and a slave. ${ }^{3}$ The wife could not leave her husband under any circumstances, but he might take other wives and might "supersede" rather than divorce her if she "drink spirituous liquor, is of bad conduct, rebellious, diseased, mischievous or wasteful." Further: "A barren wife may be superseded in the eighth year, she whose children all die in the tenth, she who bears only daughters in the elerenth, but she who is quarrelsome without delay." "But a sick wife who is kind to her husband and virtuous in her conduct, may be superseded only with her own consent and must never be disgraced." 4 There are indeed traces in the text of Manu, on the one hand, of a custom allowing deserted wives as well as widows to marry again, and, on the other, of an idealistic attempt to establish indissoluble monogamous marriage. But these remain as traces only. What the Brahmans actually succeeded in doing was to prevent the re-marriage of women even after the death of their husbands, while men obtained the right to take as many wives as they pleased, though they might not dismiss any existing wives save for one of the faults enumerated.5 Such having been

\section{Manu, ix. 12.}

2 When creating them, Manu allotted to women (a love of their) bed, (of their) seat and (of) ornament, impure desires, wrath, dishonesty, malice, and bad conduct. (Manu, ix. 17, and see the whole passage, 13-18.)

3 This, however, is not carried out consistently. (Manu, ix. 194.)

${ }^{4}$ Manu, ix. 80-82.

5 Manu, always liberal in inconsistencies, is more than usually so on this point. The cause, as shown by J. D. Mavne, is clearly mutilation of the text in the interest of conflicting views. Thus in ix. $46,4 \bar{\gamma}$, we read: "Neither by sale nor by repudiation is a wife released from her husband. ... Once is the partition (of the inheritance) made. (once is) a maiden given in marriage, ete." From this it is clear that the repudiated wif. could not re-marry. Further it seems that the at tempt was being made to impose monogamy and conjugal fidelity on the husband as well. "Let mutual fidelity continue unto death, this may be considererl as the summary of the highest law for husband and wife." (ix. 101.) Comnert this with v. 168. "Having thus, at the funeral, given the sarered fires to his wife who dies before him, he may marry again, and again kindle the (fires)." This seems to imply monogamy with mutual fidelity as the ideal, but in other parts a plurality of wives is freely (ontemplaited, and in ix. 77-82, the dismissal of a wife is permitted on sereral conditions as shown in the text. Further Hayme, "Hindu Law and Usage," p. 93. shows conclusively that a passage has been onitted before ix. 76 , justify- 
the position of the wife during the husband's lifetime, after his death she must remain faithful to him, "she must not even mention the name of another man after her husband has died." 1 She is now under the tutelage of her son, for a woman is never a free agent. "By a girl, by a young woman, or even by an aged one, nothing must be done independently, even in her own house. In childhood a female must be subject to her father, in youth to her husband, when her lord is dead to her sons; a woman must never be independent." 2

The chastity of women was to be preserved by their seclusion, and their unfaithfulness punished by their husbands. We have seen that in the barbaric world the infringement of chastity is regarded mainly as an offence against the woman's owner. The influence of this conception is still apparent in the Brahmanical coles, which, in assigning punishments for seduction and adultery, observe a marked distinction between the cases where the woman is properly guarded and those in which she is free from proper surveillance. ${ }^{3}$ The same conception had another conse-

ing a wife in marrying again after desertion for a period of years. Thus we trace (1) a period when widlows and deserted wives may marry again, (2) an at tempt to establish monogamy. But the net result of this sacramental conception of marriage, impinging on actual law and usage, was, in the Brahmanic eodes, the greatest liberty for the man, and the most complete bonlage for the wife.

1 Manu, v. 157. On the other hand, not only is suttee not mentioned by Manu, but the original text appear's, as we have seen, to contemplate re-marriage. (See especially ix. 175, 176.) Among the Jats of the Punjal, re-marriage is allowed to the deserted wife and to the widow; in Western India, it is allowed to the lower eastes if the husband is impotent, if the parties are continually quarrelling, or if, by mutual consent, the husband breaks the wife's neek ornament, or if he deserts her for twelve years. (J. D. Mayne, op. cit., 94, 95.) Polygamy, on the other hand, as to which the earlier text of Manu seems to have wavered, remains to this day an undoubted right. On the whole, we may say that nowhere has the subjection of women been more eomplete than in India, and Mohammedan influence, far from improving matters, has only furthered the practice of seclusion.

2 Mamu, v. 147,148 .

${ }^{3}$ For a scale of penalties modifiable according as the woman is guarded or not, sfe Manu, viii. $374 \mathrm{ff}$.

On the subjeet of legal punishments and religious penances for different forms of immorality, Manu is quite bewildering in his divergencies of statement, and the case is made worse if the other Brahmanist law books are consulted. Two instances may suffice to illustrate the difficulty of extracting a consistent view. In viii. 371, the king is to eause the adulteress to be devoured hy dogs. But in xi. 177, "an exceedingly corrupt wife" is mercly to be confined to one apartment and to perform the penance prescribed for males in the ease of adultery. Probably the explanation is that the first passage whieh speaks of a wife "proud of the greatness of her relatives" lays fown the penalty for high caste women who love men of lower caste. This is explicitly stated in the corresponding passage of Gautama's code (xxiii. 14, 15). But there is nothing in Manu hirself to clear up the point. Again, in xi. 59, intercourse with 
quence, paradoxical enough in our exes. As the husband was the proprietor of the wife, he was also the owner of her children, whether ther were his children after the flesh or not. And as children were a desirable acquisition for the purposes both of this world and the next, it was not unusual for a childless husband to compel his wife to bear him a child by another man. In the Mahabharata we read that wives who refuse such a duty are guilty of $\sin$. It was through a similar order of ideas that if the husband died childless his brother ${ }^{1}$ was appointed to raise up seed to him. This, of course, was for religious purposes only. The son of the appointed lover, on the other hand, was the son for this world as well as the next. But with the progress of civilization the Niyoga, as this custom was called, gradually fell into discredit and made way for a purer conception of the relations of husband and wife. It deserves mentioning here as one of the most remarkable paradoxes in the field of Comparative Ethics that the same teaching which insists so strongly on the guarding of women as though the preservation of their persons for the benefit of their owners were the sole object of their existence, should also say of adultery that "men who have no marital property in women, but sow their seed in the soil of others, benefit the owner of the woman." 2 But the paradox resolves itself into this, that proprietary right rather than personal self-respect and love is deemed the basis of conjugal obligation. Property is more than personality, and it is precisely

unmarried maidens is somewhat strangely classed with the deadliest of all sins - violation of the Guru's (teacher's) bed - but in $\$ 62$ it is classed among minor offences causing loss of caste.

I shall not attempt to thread my way through the maze, but will note a few salient points :

(1) Considering the low position of women, the punishments of immorality, where no caste complication is involved, seem moderate. It would seem as though but little responsibility were attached to the woman. Thus the maiden who makes advances to a man of high caste is not to be fined; only if he is of lower caste is she to be confined to her house (riii. 365).

(2) A low caste seducer suffered corporal punishment. One of equal caste had to pay the nuptial fee if demanded by the woman's father.

(3) Adultery and fornication appear as religious offences (xi. 59 seq.).

(4) The husband's right to kill an unfaithful wife is substantially recognized - the penance required being only to give a leathern bag, a bow, a goat, or a sheep, according to her caste. (.Manu. xi. 139.)

1 The Lerirate is usually connected with the prineiple that the widow belongs to her hushand's family, and probably this was its listorical origin in India. But in Manu it rests on religious considerations and is reduced to the dimensions necessary for religious purposes. The brother must only cohabit with the widow so far as is neeessary for the purpose of raising up seed to his brother (Mamu, ix. 60), and the whole practico is forbidden in the passage $64-68$, which contradiets the clauses permitting the Niyoga.

2 Manu, ix. 51. 
this that is characteristic of Oriental as on the whole of primitive marriage.

4. 'Turning from India to China, we do not find much change in the position of the woman. The arrangement of marriage is in the hands of the parents, and the son is as much at their disposal as the daughter. ${ }^{1}$

"Young people," says the Editor of the She-King," "and especially young ladies, have nothing to do with the business of getting married. Their parents will see to it. They have to merely wait for their orders. If they do not do so, but rush to marriage on the impulse of their own desires and preferences, they transgress the rules of heaven and violate the law of their lot." The marriage is, in fact, arranged by go-betweens who form a kind of profession, and as it is now, so was it perhaps three thousand years ago in the days of the She-King. ${ }^{3}$

The full ceremony of marriage is, as a rule, gone through with only one woman; bigamy or the raising of a concubine to the rank of wife is punished by ninety blows ${ }^{4}$ (unless in certain ex(eptional cases), but there are secondary wives or concubines who owe obedience to the first wife, and it is a point much insisted on in the rlassical books that the head wife should show no jealousy of her inferiors. ${ }^{5}$

1 Chinese travellers note relies of marriage by eapture in the ceremonial and point out that the ideograph for slave is compounded of "woman" and "hand," implying that the woman is the type of that which, in the phrase of the Koran, "your right hand possesses." Further, to marry a wife is written "to take a woman," while to marry a man has a different symbol. (Donglas, "Society in China," 2(02.) In this connection note that the imperial editors, writing on the "She-King," Part I., Bk. i. Ode 2, speak of a strict taboo on the relation of husband and wife in antiquity. "Anciently the rules to be observed between husband and wife required the greatest eireumspection. They did not speak directly to eaeh other, hut employed internuncios, thus showing how strictly reserved should be intercourse between men and women, and preventing all disrespectful familiarity." (Legge, "The Sho-King," Part I., Bk. i. Ode 2, p. 7, note.)

${ }^{2}$ Bk. iv. Ode 7 , Stanza 3, note.

3 "How do we proceed in taking a wife?

Announcement must first he made to our parents.

Since such anmonueement was made,

Why do you still indulge her desires?. . .

How do we proceed in taking a wife?

Without a go-between it cannot be done."

"She-King," Bk. viii. Ode 6, Sts. 3, 4.

${ }^{4}$ Fornication is punished with eighty blows, and the pander is liable to seventy. (Alabaster, "Notes and Commentaries on Chinese Criminal Law," p. "367.)

"Writing of the "She-King," Dr. Legge says: "The institution of the harem is very prominent, and there the wifo appears lovely on her entering into it, reigning in it with entire derotion to her hushand's happiness, 
The Chinese husband is master in his own household, the patria potestas is strongly developed, and the State interferes inside the family only in extreme cases. ${ }^{1}$ The husband may kill his wife if taken in adulter ; ${ }^{2}$ he may strike her without wounding her, ${ }^{3}$ whereas she receives a hundred blows for striking him $;^{4}$ while if, for abuse of his parents, he so punishes her as to cause her death, he receives a hundred blows. He may sell his wife, ${ }^{5}$ and sometimes does so in times of famine, he may divorce her for barrenness, lasciviousness, disregard of lis parents, talkativeness, thievish propensities, envious and suspicious temper, and inveterate infirmity. She, on the other hand, has no power of divoreing him, ${ }^{6}$ but at best may arrange to part by mutual consent. ${ }^{7}$

The power of the husband does not end with the dissolution of marriage; if he makes formal complaint of the commission of bigamy by his wife, she is strangled. After the husband's death the widow still owes him a duty. There is no definite institution of suttee, but contemporary authorities tell us that the suicide of widows is frequent, and in the south often public, and turning

free from all jealousy of the inferior inmates, in the most friendly spirit promoting their comfort and setting them an example of frugality and industry. It is apparently to these inferior inmates that the concluding verse of an Ode expressing the affectionate devotion of a wife, alludes:

"When your arrows and line have found them,

I will dress them fitly for you. . .

When I know those whose acquaintance you wish,

I will give them of the ornaments of wy girdle.

When I know those with whom you are cordial,

I will send to them of the ornaments of my girdle.

When I know those whom you love,

I will repay their friendship from the ornaments of my girdle."

"She-King," Part 1., Bk. vii. Ode 8.

${ }^{1}$ Douglas, 78. A father who kills his son without cause is sulject to a light penalty. If he kills him for striking or abusing his parents, he goes free. (Alabaster, 156.) The father may require the courts to order the transportation of an unruly son (ib., 1\%4), and a child may be sold for good cause. (Ib., 157.)

2 But it must be done on the spot. Otherwise he is liahle to a mitigated penalty. (Alabaster, 187, 188.)

${ }^{3}$ But he must exercise judgment in correcting her. "If he linocks leer brains out when told by his mother-in-law to give her a whipping, he will be responsible for the nurder." (Ib., 189.)

${ }^{4}$ Douglas, 81 . If the hushand kills her for striking him or his parents, extenuating eireumstances are allowed. For killing the wife without cause, the penalty is strangulation suliject to revision. (Alabaster, 1sti.) For lilling the hushand it is derapitation, a severer pumishment beratse it affects the after-life. (Ib., 192.)

${ }_{5}^{5}$ By practice, not, unless in exreptional eircumstanees, by strict law. If she commits suieide in consequence, he is lialle to three year's transportation. (Alabaster, 1s9.)

${ }^{6}$ Unless it is for impotenee. (Ib., 182.) ${ }^{7}$ Douglas, 71. 
back to the classical books, we find the widow professing life-long chastity and derotion to the memory of the departed.' Hence it is intelligible that women frequently prefer a numery or suicide to marriage. And yet the love of home and yearning for absent wife and child is, we are told, no infrequent theme of Chinese poetry. Such is the power of human feeling to survive all laws and institutions.

The position of Chinese women has not undergone any fundamental change within the historical period. Perhaps in some respects it has deteriorated. ${ }^{2}$ In particular the binding of feet

1 "It floats about, that boat of eypress wood,

There in the middle of the Ho,

With his two tufts of hair falling over his forehead,

He was my mate,

And I swear that till death I will have no other.

O mother, O Heaven,

Why will you not understand me?

It floats about, that hoat of eypress wood,

There by the side of the Ho,

With his two tufts of hair falling over his forehead,

He was my only one,

And I swear that till death I will not do the evil thing.

O mother, O Heaven,

Why will you not understand me?",

"She-King," Part I., Bk, iv. Ode 1.

$C f$. Douglas, 216, etc. The sacrifice of wives at the death of the emperor was abolished by Kanghlsi 1661-1721. (Douglas, 227.) Human sacrifice at funerals (chiefly of women) appears intermittently from the first recorded case (that of $\mathrm{Wu}$, ruler of Tsin, B.c. 677, when sixty-six people were sacrificed) to the present time. It was opposed by the Confucians. In the eighteenth century suttee was on the increase, and to check it the honours conferred on the suttee women revoked, A.D. 1729. (De Groot, "Religious Srstems of China," ii. 721-807.) De Groot considers it incredible that the case of $\mathrm{Wu}$ should really have been the first. Possibly he was the first of his house to be so "honoured."

2 The "She-King" describes the difference of attitude to the infant son and daughter in terms which are exactly reproduced to-day:

"Sons shall be born to lim;

They will be put to sleep on couches;

They will he clothed in robes;

They will have scentres to play with;

Their cly will be loud.

They will be (hereafter) resplendent with red knee covers,

The (future) king, the princes of the land.

Daughters shall be horn to bim;

They will be put to sleep on the ground;

They will be clothed with wrappers;

They will have tiles to play with.

It will he theirs neither to do wrong nor to do good.

Only about the spirits and the foor will they have to think,

And to cause no sorrow to their parents."

"She-King," Part II., Bk. iv. Ode 5, Sts. 8, 9.

In point of fact the lot of the infant daughter was often much worse. The extent of infanticide in China has undoubtedly been exaggerated. 
has grown up within the last thousand years, a mushroom growth in the antiquity of China. ${ }^{1}$ The great teachers, though personally. married to one wife, and having no concubines, did nothing for the amelioration of the position of women. Mencius, indeed, proposed to divorce his wife because he found her in a squatting position on the floor of her room, and was only restrained by his mother's advice from doing so. This same mother expressed the whole duty of Chinese women when she refused to be consulted as to where they should live. She said, "It does not belong to a woman to determine anything of herself, but she is subject to the rule of the three obediences; when young she has to obey her parents, when married her husband, and when a widow her son."

It only remains to add that where men keep women in so much subjection they generally impute to them a double dose of original sin, and the She-King, chiming in with the literature of the Hebrews and Hindoos, says, "Disorder does not come down from heaven, it is produced by the woman. Those from whom come no lessons, no instruction, are women and eunuchs." ?

5. The Hebrew marriage law begins when we first come across it in the fully-developed patriarchal stage. The analogy of primitive Arabian tribes suggests an earlier state of mother-right, but of this there are in the Old Testament only the merest traces. ${ }^{3}$ A man acquires a wife by purchase or by service, from her father or her nearest male relative. ${ }^{4}$ In either case she passes completely out of her father's family, and belongs to him who has paid for her. "Is there yet any portion or inheritance for us in our father's house?" say Leah and Rachel. "Are we not counted of him strangers? for he hath sold us and hath also quite devoured the price paid for us." 5

This very next summary of the theory of marriage by service has already been referred to. But the marriage affairs of Jacob

The killing even of illegitimate children after, though not at birth, is an offence, though but lightly punisherl. (Alabaster, 170.) The praletice, however, is frequent in many districts, and it is the daughter who is ordinarily the sufferer.

1 Yet there is an objection to the hambeo as a penalty for women, and if subjected to it, they are not stripperl as they were in England to the heginning of the nineteenth contury. (Alabester, op. cit., 107.)

2 "She-King," Part III., Bk. iii. Ode 10, st. 3.

${ }^{3}$ It is clear that Sara was roally Ahrahams half-sister, and his marriage to his father's daughter would he in acoordance with minitive custom inder mother-right.

${ }^{4}$ Laban apparently gives away Reheeca, his sister, and both he and leer mother receive precious things for her. At the same time Rebeca's own wishes clearly are considered.

${ }^{5}$ Gen. xxxi. 14. 
illustrate some further points which we can understand well from the Babylonian code. Part of the agreement between him and Laban is that he shall not "afflict" Laban's daughters, and that he shall not "take wives beside my daughters." 1 This is quite in the spirit of a Babylonish marriage contract. But there is a further point of similarity. Though Jacob took no more wives, each of his two wives gave him a handmaid precisely as is contenplated in the Cole of Inammurabi, and the handmaid's children were in each case reckoned to the wife. In Hammurabi's language, "the wife had granted him the children."

Polyamy is contemplated in the Law, the only limitation being that in the Priestly Code two sisters are not to be married at the same time. Concubinage is also contemplated, and so is the sale of a daughter for that purpose. The daughter that is sold is especially protected in the Book of the Covenant. She is not to be set free in the sabbatical year, but if she "please not her master who hath espoused her to himself, then shall he let her be redeemed; to sell her unto a strange people he shall have no power." If a girl were espoused to his son she should be dealt with "after the manner of daughters," or if married to her master she was protected in case he took another wife. "Her food, her raiment and her duty in marriage shall he not diminish." In the humane code of Deuteronomy protection is even extended to the captive bondwoman. She is to be allowed a full month for mourning before being married, and once married, "if thou have no delight in her then thou shalt let her go whither she will, but thou shalt not sell her at all for money, thou shalt not deal with her as a chattel because thou hast humbled her."

While there is no prohibition of polygamy in the Law - Deuteronomy merely states that the children of the better-loved wife are not to be preferred to the first-born - in practice, as among the Egrptians, the custom seems to have died out little by little, ${ }^{2}$ and in the Proverbs monogamy seems to be assumed throughout. The right of divoree rested entirely' with the man, and the grounds of it in Deuteronomy are very vaguely expressed. "If she find no favour in his eres because he hath found some unseemly thing in her, he shall write her a bill of divorcement." But none of the codes are at pains to define the grounds of divorce elearly. They assume it as a right of the husband, and their careless expressions

1 Gen. xxxi. 50.

2 Apparently it was not formally forbidden till the tenth century, A.D. (Bryce, "Studies," ii. p. 384.) 
have given grounds for much difference of interpretation which has affected Christian as well as Jewish Law.

There is no mention in the Law of divorce by the wife, but among the later Jews she could claim a dirorce if her husband were a leper or afflicted by a polypus or engaged in a repulsive trade.

The position of the woman in the family gives her guardian certain definite rights and duties as to the disposal of her person. Thus Judah, as the head of the family, proposes to burn Tamar, his daughter-in-law, for unchastity, but acknowledges in time that he was bound to give her as a widow of his son Onan to his other son Shelah. The husband's brother, in fact, had the duty of marrying the widow, and, failing the brother, the obligation fell on the kindred. Boaz, as Ruth's kinsman, first offers her to a nearer relative, and on his refusal weds her himself. The daughter does not inherit landed property if there are sons, but failing sons, she becomes the heir, and in that case she must marry within the tribe, a recognition of the eminent ownership of the tribe over the whole land.

Such being the position of women, it is not to be expected that the attitude expressed to them in literature should be one of great respect or admiration. At best their virtues as housewives were admitted, but in the famous description of the virtuous housewife in the Proverbs there is not a word of a union of mind

1 Of the Jewish Legalists the school of Shammai (first century, B.c.), pressing the word "nakedness" which is the most literal rendering of the term translated "unseemly," understood it of unchastity; the sehool of Hillel, pressing (in Rabbinical fashion) the word "thing," and the clause, "if she find no favour in his eyes" (though this, as a matter of fact, is qualified by the following words, "because he hath found some unseemly thing in her"), supposed the most trivial causes to be included, declaring, for instanee, that a wife might be divoreed, even if she burnt her husband's food, or if he saw a woman who pleased him better. It may be doubted, however, how far the latter opinion was literally acted upon." The grounds mentioned in the Mishnah as justifying divorce are, violation of the law of Moses, or of the Jewish customs, the former boing said to consist in a woman's causing her husband to eat food on which tithe has not been paid; in causing him to offend against the law of Lev. xviii. 19 ; in not setting apart the first of the dougl, Num. Xv. 20 ff., and in failing to perform any row which she has made; and the latter in appearing in publi. with dishevelled hair, spinning (and exposing her arms) in the streets, and conversing indiseriminately with men, to which others added, speaking disrespectfully of her liushand's parents in his presence, or brawling in his house. The Karaite Jew's linited the grounds of divore more exelusively to offenees against medesty or good taste, a change of religion, serious bodily deferts, and repulsive complaints. That the llebrew word denotes something short of actual unehastity, may be inferred from the fact that for this a different penalty is enacted, viz. death, also the same expression is used, not of what is immoral, hut only of what is unbecoming. It is most natural to understand it of immodest or indecent behariour. (Summarized from Driver, "Deuteronomy," p. 270, note.)

${ }^{2}$ Driver, p. 271. 
or soul, and there is little indeed to differentiate the wife from the cheerful, active, intelligent, and let us add, charitable housekeeper. We read that "she spreadeth out her hands to the poor," and again, "she openeth her mouth with wisdom and the law of kindness is on her tongue," but there is no word of the romance of love or of the higher side of the conjugal relation. ${ }^{1}$

On the other side of the account woman is regarded as the source of evil. "Give me any wickedness save the wickedness of a woman" is the burden of Ecclesiasticus. A bad woman is the temptress and the destroyer throughout the Wisdom literature, and it was through woman that sin came into the world, and for this reason, that she was to be subject to her husband. ${ }^{2}$

6. We have seen that among the primitive Arabs mother-right and polyandrous unions prevailed, but in Mohammed's time the women were mere chattels, forming a part of the estate of their husband or father and descending to the son. They were held in low account, and female infants were frequently put to death. "Women are the whips of Satan" is an amiable saring of the masculine trab of this period, having said which it is not surprising that he should add: "A man can bear anything but the mention of his wives." Mohammed set himself to ameliorate the position of women. "Ye men," he said, "ye have rights over your wives, and your wives have rights over you." But he was not able to carry his reforms very far according to our ideas. He limited the number of legitimate wives to four, but allowed an unlimited number of slave concubines; he insisted that the woman's consent to her marriage should be obtained, but the consent of her guardian also remained essential. Whether the temporary marriage in practice in Mohammed's time is still allowed is debated between the sects. ${ }^{3}$

But free divorce Mohanmed was compelled to tolerate: "The thing which is lawful but is disliked by God is divorce." There are, indeed, certain cases in which divoree is compulsory, ${ }^{4}$ but even apart from them the husband may divorce his wife without assigning any cause. The wife, however, is protected by the dower, or more strictly, the bride price, of which a portion is deferred, and which may be claimed by the wife if she is divorced

${ }^{1}$ It is probably another writer in the Book of Proverbs who says that "a virtuous woman is a erown to her hushand," (Pros. xii. 4.)

$2 \mathrm{Mr}$. Montefiore points out that the appreciation of a gool woman is higher in the "Wistom of the Son of Sirach" than in the Proverbs, in correspondence with the general advance in her position. ("Hibbert Lectures," 1892. p. 491.)
"II ughes, "Dictionary of Istam," p. 314.
${ }^{4}$ Ibid., pp. 87, SS. 
without cause. ${ }^{1}$ Her position is therefore somewhat similar to that which the provident Babylonian or Egyptian woman secured for herself by the marriage contract. On her side, the wife is bound to live with her husband, but if she can prove illtreatment, can obtain a separation from the Kadi. Bad concluct or gross neglect is a good defence to a suit brought by the husband for the restitution of conjugal rights.' 'The husband has, however, the right of chastisement, and the admonition of the prophet, "Not one of you must whip his wife like whipping a slave." does not, to European ears, appear to err on the side of chivalry."

Yet Mohammed made the kind and equitable treatment of wives a moral if not a legal duty: "The best of you is he who behaves best to his wives." The lord of many women must be impartial. "When a man has two wives and does not treat them equally he will come on the day of resurrection with half of his body fallen off." But if there is to be kindness, it is to be such as is due to the weaker vessel: "Admonish your wives with kindness, because women were created from the crooked bone of the side." 4

The position of the wife under the Sumni law is thus summed up by Mr. Hughes:-

"Her consent to marriage is necessary. She cannot legally object to be one of four wives. Nor can she object to an unlimited number of handmaids. She is entitled to a marriage settlement or dower, which must be paid to her in case of divorce or separation. She may, however, remit either whole or part of the dower. She may refuse to join her husband until the dower is paid. She may be at any time, with or without cause, divoreed by her husband. She may seek or claim dirorce (khnl') from her husband with her husband's consent. She may he rhastised by her husband. She cannot give evidence in a court of law against her husband. According to the Sunnis, her evidence in favour of her husband is not admissible, but the Shi'ahs maintain the opposite view. Her husband can demand her seclusion from publie. If she beromes a widow she must observe hidād or mourning for the space of four months and ten days. In the event of her husband's deat h she is entitled to a portion of her husband's estate in addition to her claim of dower, the claim of dower taking precedence of all other elaims on the estate." 5

1 Hughes, 91.

2 Ibid., 673.

3 The traditions record that the prophet forbade the Moslems to beat their wives. Brute force being thus ruled out, natural superiority asserts itself, and the faithful come to complain that the women have got the upper hand. The prophet consequently revoles the order, ant then the women eomplain in their turn. Nohammod is then reduced to moral suasion: "Those men who heat their wives do not hehave well. Ile is not of my way, who traches a woman to go astray and cntices a slaves from his master." (IIughes, 671.)

${ }^{4} \mathrm{~A}$ wife taken in arlultery might be stoned, but four witnesses with a fivefold repetition of the oath were required to prove the offence. ("Koran," Part I., Chap. iv. 15.) Nor" is the death-penalty recommended, but rather seclusion in the house. (Loc. cit. and Hughes, p. 11.)

Fornication is strietly forbidden to men.

${ }^{5}$ Hughes, p. 671 . 
Nor has a woman full legal privileges outside marriage. Her evidence is not accepted in cases involving retaliation. IIer fine is one-half that of a man, and the value of her testimony onehalf that of a male witness. Yet she may hold public positions, she may act as a judge except where retaliation is involved, and in some Mohammedan states princesses have ruled. She can hold property, retains the usufruct of her property during marriage, and takes the property with her in case of divorce. She has also a claim to inherit along with her male relations, confirmed by the express words of the prophet. ${ }^{1}$ She is not to be slain in war, and for apostasy she is not put to death, but imprisoned until she recants. The general attitude of the Mohammedan world towards her is too well known to need illustration, but two traditional sayings of Mohammed may be quoted as illuminating the intellectual chaos to which a well-meaning man is reduced when he contemplates that helpmate over whom he so complacently assumes superiority and dominion. The first is this, "I have not left any calamity more detrimental to mankind than women," and the second is the complementary expression of the master in his other mood, "The world and all things in it are valuable, but more valuable than all is a virtuous woman."

With this final contradiction mirrored in the double motive for secluding women, $(a)$ as a compliment, implying that they are elevated above the ordinary affairs of life; $(b)$ as a precaution, implying that they are not to be trusted with liberty - with this contradiction in theory and in practice, rooted as it is in a radically false view of womanhood, we may leave the Oriental world and its efforts to deal with the relations of the sexes.

7. But the first nation of the West to which we turn was in this respect largely orientalized. 'The Greeks founded Western civilization, but their rapid advance in general culture was by no means accompanied by a corresponding improvement in the position of women. On the contrary, it is in the earliest period and among some of the most backward states that the woman has most freedom.

The Homeric woman moves freely among men. Nausicaa welcomes Odysseus and brings him to her father's house. She bids him kneel to her mother if he would gain a welcome and succour from her father. ${ }^{2}$ The relation of husband and wife is

1 “Koran," i. p. 72 ; cf. Dareste, pp. 61-63.

2 At the same time Arete's position seems to have been somewhat exceptional, for Alcinous honoured her as no other woman in the world is 
close and tender; Andromache relates how her father's house has been destroyed with all that were in it, "but now, Hector, thou art my father and gracious mother, thou art my brother, nay, thou art my valiant husband." 1

We never hear of more than one legitimate wife. On the other hand, the carrying oft of women as bond-slaves was habitual. Briseis was a recognized portion of the spoil, and such capture implies concubinage along with legitimate marriage. ${ }^{2}$ If the bridegroom could' not take the bride in a raid, he bought her for a goodly number of cattle, and orer his concubines, at any rate, he exercised powers of life and death. Odysseus compels the faithless handmaidens to carry forth the bodies of the suitors and bids Telemachus put them to the sword; but Telemachus thinks this too good a death, and strings them up to a ship s cable in the hall, where they hang struggling like thrushes in a net. ${ }^{3}$

The patria potestas persisted in a mild form in the historical period. ${ }^{4}$ The father was the religious and legal head of the family; he performed the family sacra, and represented wife, children and slaves in the courts. ${ }^{5}$ Nor were limitations on personal liberty and responsibility peculiar to the wife, for here again woman was subject to the three obediences to father, husband, or son, and failing them, to her nearest blood relation.

The sons in most cases divided the inheritance, the daughters having only a right to maintenance and dowry. But what property women had remained theirs during marriage, and, in some states they even had the right of management. ${ }^{6}$ In early times the father might sell his daughters, or brothers their sisters, when under their guardianship. This right was abolished by Solon except in the case of unchastity ${ }^{7}$ but a father retained the

honoured of all that now-a-rlays keep house under the hand of their lords. ("Od.," vii., Butcher and Lang Tr., p. 10.5.)

1 "Iliad," vi. $429,430$.

${ }^{2}$ Yet the wife might resent this. Laertes bought Eurveleia in lier vouth for twenty oxen and homoured lier equally with his wife, "hut he never lay with her, for he shunned the wrath of his lady." ("Od.," i., Tr. Butcher and Lang, p. 15.)

3 "Od.," xxii. 468.

${ }^{4}$ The right of exposing a child was limited in Sparta ly the meting of the tribesmen. (Plutarch, "Lyourgus," 16 , citol hy Leist.) Leist, p. 50. thinks the a $\gamma$ ¿ at an early date, and the rexoention of the child cotild be rompelled by legal process. (Leist, ih.) The ardult son was emancipaterl.

5 The Athenian woman could follow no suit of a value experding a medimnos, except through a guardian. The wife had very limited pow trs of alienation without the husband's consent.

"Busoll, "Handbuch der Klassisehen Altertumswissenschaft," 19, 20.

"Plut. "Solon," 13, 23, cited hy Busoll, l. c. 
right of controlling his daughter and even of disposing of her by will, ${ }^{1}$ or of giving his son, while a minor, in adoption to another family." There could be no legitimate marriage without an assignment of the bride by her guardian. ${ }^{3}$ The wife passed into the husband's family, and was separated from her own hin and their sacra. At Athens she might be divorced on payment of the bride price, while on her side she could ouly obtain a divorce by the sanction of the archon. ${ }^{4}$ At Sparta, where, in some respects, e.g. in regard to property, she had a higher position, ${ }^{5}$ it seems that looser relations prevailed. Brothers might share a wife in common, and wife-lending was recognized, whereas at Athens the punishment of adultery was enforced. ${ }^{6}$ Monogamy prevailed in the main, ${ }^{7}$ but concubinage was legally recognized, provided that the handmaiclen did not reside in the same house with the legal wife. The concubine's children might be legitimated by adoption, and might then enter the phratry, whereby they acquired all the privileges of citizenship. ${ }^{8}$

But the woman, though under ward, was certainly not regarded as a chattel. Probably Aristotle expressed the ordinary Greek view accurately enough when he said that a man should rule his slares as a despot, his children as a king, and his wife as a magistrate in a free state. Yet it was a Greek thinker who first frankly argued the case for the free admission of women to all the duties

1 Letourneau, "La Femme," 416.

2 Busolt, p. 19. Accorting to Leist, p. 62, he had practical, but not legal control orer the son's marriage.

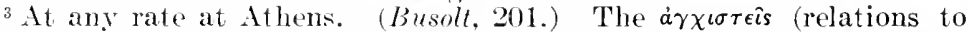
the fourtli degree on both sides) had to see that the orphan heiress was married, and her nearest male relation (after her brothers) had the right of marrying her, and correspondingly the duty of so doing or of finding a husband for her. (Busoll, 20; Leist, 40, 47.)

"Letournenu, "La Femme," 423 . At Sparta divorce for sterility seems to have been expected at any rate of a king. (Iterodt., v. 40.)

5 Accorting to Aristolle two-fifths of the land of Sparta had come into the hants of women by inheritance ant bequest in his time, and the spartiate women, having successfully resisted the attempt of Lycurgus to impose on them the same discipline as the men accepted, enjoyed a state of liberty which in Aristutle's riew amounted to licence, and was disastrous to sparta. ("Polities," ii. $1269 \mathrm{~B}, 1270 \mathrm{~A}$.)

"By the Solonian legislation the hushand who concealed his wife's adultery was punished with arıula. Yet the punishment of the adulterer was left in the hushand's hanels. If raught flagrante delicto he was absolutely at the husband's merry. In any rase he conkl be imprisoned at the husband's pleasure, and was released on payment of a fine. (Letournean, 1. 42.) The wife was not killed, hut divoreed. (Leist, p. 300.) For an instance of wife-lending at Athens, Letourneau cites the case of Kimon. (Letournetale, p. 41).)

7 Anaxandrites, king of Sparta, der.lined to divorce his barren wife, but comsenterl to take a second. This was regarded as quite un-Spartan. (Herodt., v. 40.)

- Busolt. op. cit., p. 201. 
and rights of man. Plato's position differs from that of his modern successors in that he insists rather on women's duties than on their rights, more on what the state loses by their restriction to the family cirele than on the loss to their own personality. Further, though he had the experience of Sparta to go upon, his own teaching was too much associated with polemics against the family and with a fanciful ideal of communism to be taken quite seriomsly. On the other hand, Aristotle summed up the whole philosophy of the ancient world, of the East, and perhaps the prevailing sentiment in modern Europe, when, discussing those who are fit to bear rule and order the affairs of men, he says that a slave does not possess that power of deliberation which is the basis alike of self-government and of the govermment of others. A child possesses it but imperfectly. A woman possesses it, but in her it is without authority. After all, the Greeks did little to derelop it. There appear to have been no regular schools for girls at Athens, ${ }^{1}$ and it was only the courtesan of the higher class who was a fit helpmeet mentally for Pericles or capable of sustaining a conversation with Socrates. Ienophon's ideal wife is a good houselieeper, like her of the Proverbs.

8. The modern European marriage law has three roots - Roman Law, Primitive Teutonic custom, and the Christian doctrine of marriage; but it has been largely re-modelled in the modern period under rationalizing influences. It cannot be studied statically, but has a long, varied and interesting history, of which an attempt will be made here to give the briefest possible outline. This history starts with the early Roman family, organized as it was under the highly-developed potestas of the father. All the children are the father's, and in law he can dispose of them at pleasure. ${ }^{2}$ He can chastise them, sell them into slavery, and even put them to death (jus vita necistue). ${ }^{3}$ Before exercising this supreme power he has, it is true, to consult the council of relations, but he is not bound by their judgment. In short, the paternal power is nowhere more strongly developed, nor does the position of wife and children anywhere approach in law more nearly to that of slaves, owned by the paterfamilias, and except as a matter of grace, incapable of owning anything themselves.

${ }^{1}$ Here the Spartans were more liberal, as they admitted women to the gymnasia. (Busolt, ii. 15S.)

2 Exposure, however, if the law attributed by Diomysius (ii. 15, Brmes, p. 7) to Romulus is correct, was limited to fomale infants and required the consent of the neighbours. No child was to be killed under three years.

${ }^{3}$ Bruns (p. 7), quoting Dion. ii. 23. 
Into the family thus constituted a wife passed on her marriage. The marriage might be acemplished by either of two forms, and it might also be made valid apparently without any form at all. The first form was confurreatio, in which the essential feature was the eating by both bride and bridegroom of a cake - an act of the kind which we call symbolic, but which to primitive man is rather magical, actually efficacious in establishing a unity of the man and woman. 'The second form was called coemptio, and was of the nature of a formal sale, almost certainly, in the light of what we know of other peoples, preserving the memory of a real purchase of the wife by the husband, which as anything but a form had already fallen into disuse when history begins. Both these forms transferred the wife from the power (potestas) or hand (manus) of her father into that of her husband, to whom she became as a danghter. For all purposes, sacred and profane, she passed from the one family to the other. ${ }^{1}$ But just as inanimate property, which normally passed from hand to hand by a special ceremony of transfer, might also acquire a new owner by long unchallenged possession and use, so was it also with human property. The woman who without either of the two ceremonies mentioned was given by her father to a man and lived with him as his wife for a whole vear without interruption beeame in law his wife by use (usus) and passed as completely in mannm mariti as if she had eaten with him the sacred cake.

All these three modes of marriage were in existence at the time of the drawing up of the Twelve Tables, and whichever of them she chose, the woman passed into the family and into the power of her husband. Yet her position differed in two essential respects from that of the Oriental wife. She was her husband's only wife. At no period of Roman history are there any traces of polygany or concubinage. ${ }^{2}$ And not only was she the sole wife, but the tie which bound her to her husband was diffieult to break and rarcly broken. It is true that each form of union could be undone by a certain prescribed ceremony-confarreatio by diffarreatio, coemptio by remancipatio. But these were resorted to rarely, and it would appear only for grave offences, the council of relations being first called in to give judgment. ${ }^{3}$ It does not

$1 \mathrm{Cf}$. on the religious marriage Dion. (Bruns, p. 6).

2 The eoncubinate of which we hear in Roman law is a form of union, bereft of some of the ciril rights of marriage, not the relation of a married man to a serondary wife or slave-girl.

3 Bryce, "Studies in .Jurisprudence," vol. ii. p. 403. The offences for which, according to Dionysius, ii. 25 (Bruns, p. 7), she was brought to 
appear that the wife had any means of repudiating the husband, or of emancipating herself from his manus. In practice marriage was so nearly indissoluble that the divorce of his wife by spurius Carvilius Ruga in B.c. 231 was declared to be the first instance ${ }^{1}$ known since the foundation of the city. On the other hand, it must be remembered that the unfaithful wife might be put to death without trial, and that the husband who had other good causes of complaint would be supported by the family council in executing or in repudiating her. ${ }^{2}$

9. Such was the primitive Roman marriage with the manus. But even in the days of the Twelve Tables a wholly different union had made its appearance. If the enjorment of property was broken for awhile before the vear was out, no title to it arose out of the usufruct. This idea was applied to marriage by usus, and already in the time of the Twelve Tables we find that if the cohabitation was broken for three nights in every year, the wife did not become the property of the husband. When or how it became a custom to convert this breach of cohabitation into a system, and so establish a form of marriage in which the wife did not pass into the manus of the husband, we do not know. What is certain is that this new form of free marriage rapidly ousted its older rivals. The bride now remained in her father's power, she was still a member of her own family, and by consequence had no position in that of her husband. Subject to the nominal control of her father or her guardian, she thus acquired complete control of her own property, and became, in fact, her own mistress. She was not in theory a free woman unless emancipated. She was only free from her husband. But it need hardly be pointed out that the practical control of relations with whom as a married

trial before a council of relatives were, howerer, punishahle with death. They were adultery and wine-drinking. The grounds for divoree stated by Plutarch are poisoning the children, the use of false keys, and adultery. Divorce for any other reason was punished with confiscation of propert $y$. The wife could not leave her husband in any case. (Bruns, p. 6. if. Girard, p. 154.) Divorce by the hushand was recognized in the Twelve Tables. The hushand takes the wife's keys away and turns her out of the house. "Illam suam suas res sibi hahere jussit, ex XII tabulis, claves ademit, exegit." (Cic. "Plit." ii. 28. Bruns, p. 22.)

${ }^{1}$ Ruga's wife was divorced for sterility, and Mr. Brye takes the sweening statement of the authorities to mean that it was the first instance of a divorce in which no erime was alleged (ii. 103).

2 At the same time, if Plutarch ("Rom." 22 ) is to he trusted. it was a religious offence to sell her as a slave. (Bruns, 7.) In this point she enjoyed a material advantage over the children. 
Woman she no longer lived was not likely to be a very serious matter, and in point of fact, where it was felt to be irksome, it was from time to time limited by law. 'Thus the father had naturally as a part of his potestas the right to break the marriage at will. But this logical application of the paternal power was abolished under the Antonines, or restricted to cases where there was grave cause for its exercise. ${ }^{1}$

On the other hand, the tutela was a reality for ummarried women, and the Roman law never seems to have fully acknowledged that the consent of the adult woman, and her consent alone, was the one necessary condition to her marriage. Originally, indeed, the consent of the parties does not seem to have been required at all. This would be all in accordance with primitive ideas. But here again the law was modified as time went on, and the consent of the woman, as well as the man, became a normal, and, in some cases, a legally necessary condition. ${ }^{2}$ Further, with the general emancipation of women the necessity for a guardian appears to have gradually died away. ${ }^{3}$ Hence the Roman matron of the Empire was more fully her own mistress than the married woman of any earlier civilization, with the possible exception of a certain period of Egyptian history, and it must be added, than the wife of any later civilization down to our own generation. Practically independent of her father, she was legally independent of her husband. She could bring an action against others and with some

${ }^{1}$ The separation of a wife from her hushand by her father was forbicden hy Antoninus Pius, but was permitted "magna et justa causa interveniente" hy his successor. (Nir F. Jeune, "Encl. Brit.," art."Divorce," p. 471 ; (rirard, 1. 155.) The son also aequired the right to emancipation in case of ill-ireatment. (Girard, 183.)

2 The consent of the parties was of course required if they were sui juris. On the other hand, by the strict logie of the law, if either was in tutela, and this would be the normal case with a girl (and even with a grown-up woman), the affair would have been one for the guardians alone. Thus Ulpian, r. 2, says, "Consentiant si sui juris sunt, aut etiam parentes cortum si in potestate sunt." (Cited by Girard, p. 147, note.) The "Lex Julia," A.U.C. 736, gave an appeal from the guardians, if they refused consent, to a court. Further, the best jurists, including Ulpian limself, hell the consent of the parties to be necessary as well as that of their guardians. "Nuptiae consistere non possunt nisi consentiant ommes; irl cst qui coeunt, quorumque in potestate sunt." (Digest, xxiii. ii. 2.) With this, however, we must rearl - "Sed quae patris voluntati non repugnat consentire intelligitur. Tune autem solum dissentiendi a patre licentia filiae concerlitur si indignum moribus vel turpem sponsmm ei pate' cligat." (J J ust. Digest, xxiii. i. 12. Cited in Viollet, "Droit Civil Français," p. 404.)

${ }^{3}$ Originally all women were in tutelage. "Veteres voluerunt feminas, etiamsi perfectae aetatis sint - - in tutela esse - exceptis virginibus vestalibus, quas ... liberas esse voluerunt; itaque etiana lege XII Tahularum caut um est." (Gaius, i. 144, 14.5, in Bruns, 21.) On the extinetion of the tutclu, see Girard, pp. 196 and 213. 
limitations against him. ${ }^{1}$ She could hold property and dispose of it freely. ${ }^{2}$ On the other hand, being separated from his family, she does not suceed to his property if he dies intestate, nor do her children succeed to her, nor she to them. So much followed from the strict theory of marriage without the mamus, though here, as elsewhere, natural feeling had its way, and practical rules were introduced by the Prætorian legislation to prevent consequences which would seem harsh to the temper of the time.

These changes naturally affected the stability of marriage. Is have seen that under the old law divorce was rare and difficult, but the revolution effected in marriage by the disappearance of the manus was nowhere more conspicuous than in its effect upon the permanence of the marriage tie. By the newer form of marriage neither did the wife pass into the husband's family nor the husband into the wife's family. They remained distinct persons, distinct individualities, and as they freely entered into the marriage relation, so could they freely leave it. Divorce, in short. as in so many primitive tribes, stood freely at the choice of either party. In the best time of the Republic divorce without adequate cause incurred penalties, a pecuniary fine, or, still more serious, the nota censoria. But with the growth of the new form of marriage opinion rapidly changed, and, as Mr. Bryce points out, we find at the close of the Republic not only Pomper, but "such austere moralists as Cato the Younger and the philosophic Cicero" putting away their wives. The reader of Cicero's letters who is unacquainted with the Roman law of divorce will perhaps remember the shock of surprise with which, after becoming well acquainted with Terentia from many allusions he suddenly finds Cicero calmly referring to his divorce and re-marriage. At this period divorce had, in fact, become as commonplace an incident of life as marriage itself.

How far the freedom of women had the demoralizing results which have been generally attributer to it by those whose business it has been to paint the Roman Empire in the darkest colours,

${ }^{1}$ In case of adultery the hushand rould originally kill the wife. The" "Lex Julia" compelled him to prosecute, the punishment being relcgatio. The same law punished fornication with women of rank. (Girard, "Manuel elémentaire (tu Droit Romain," 160, 176.)

2 Girard, p. 159. The dos or dowry brought by the wife from ber own family's resources to the main tenance of the joint life passed originally to the husband; but while he continued to administer it, his right over it became more and more restricted in farour of the wife, so that the jurists (e.g. Ulpian) speak of it as being her property, and this is rerognized he Justinian, who gives her a right to reclaim it on the dissolution of the marriage from whatever cause. (Girard, pp. 92-926.) 
is a matter on which the best authorities do not speak with confidence. It must be remembered that our accounts of Roman social life are drawn in part from satirists like Juvenal, or satirical historians like Tacitus, and that we should be as far astray in taking their description as an impartial account of the society in which they lived as we should be if we accepted the picture of our own social life as it could be painted for us by some preacher of reform, or some contemporary censor of morals. The satirist has a great function in the world, but it is not that of supplying the historian of manners with material ready for use without analysis. Other sources are the writings of Christian fathers, who from a different point of view were even more prone to denounce the wickedness of the world as they found it.

The very fact that the Romans took so serious a view of feminine profligacy militates against the belief that the corruption had gone quite so deep as is generally supposed. Lucius Piso declared that modesty had ranished since the censorship of Messalla and Cassius in B.C. 15t. ${ }^{1}$ Yet we have the testimony of Velleius that in the proscriptions of the Second Triumvirate, while the sons were never faithful and freed-men only sometimes so, the wives could be trusted always. The freedom of divorce was abused, as it is in the present day in America. According to Seneca there were women who reckoned the years not by the consuls, but by their husbands, but this again is obviously satire. On the other hand, there are instances of three, four, or five wives, and, again, of three to five husbands. A marriage of forty-one years is recorded as unusually long, and in this case the wife had urged divorce and re-marriage upon her husband after the death of their daughter, for the sake of getting children. This, however, is remote in sentiment from anything like profligacy, and connects itself rather with the primitive idea of the necessity of children. The literature of the time has stories of faithful wives as well as of profligate women to record - stories of wives accompanying their husbands in suicide, dying with them in proscriptions, or going with them into exile. Every one knows of Arria, who thrust the dagger first into her own bosom, and then offered it to her husband, with the words, "Paete, non dolet." But we do not all know that she became a kind of heroine of the time, and upon a

${ }^{1}$ Friedläuder, "Sittengeschichte Roms," i. 475. Friedländer's whole discussion, pp. 475-507, is instructive, if somewhat indecisive. The judgment of Professor Dill, whose work has appeared since the above was written, is more clearly favourable. ("Roman Society," pp. 77, 79, 145, etce) 
gravestone in Anagnia is addressed along with Landamia by a woman who asks her to receive her soul. ${ }^{1}$

The evidence of the tombstones, which in all ages bear a singular family resemblance, shows that the domestic ideal held sway under the free mamners of imperial Rome, as under the masculine despotism of the East or the sentimentality of the West. A panegyric on Murdia in the second half of the first century says all gravestones of women must be alike, "because their virtues admit of no heterogeneity, and it is enough that all have shown themselves worthy of the same good report." "All the greater renown has my dearest mother won, who has equalled and in no way fallen behind other women in modesty, rectitude, chastity, obedience, household work, carefulness and lovalty." Another inscription says, "She was of pleasant address and noble gait, took care of her house and span." In another, the husband has sworn not to take another wife. Another, "I await my husband"; another, "Never have I experienced a pain from thee, except through thy death."

Upon the whole the Roman Matron would have seemed to have retained the position of her husband's companion, counsellor and friend, which she had held in those more austere times when marriage brought her legally under his dominion.

1 Friedländer, i. 514. 


\section{Chapter XVI}

\section{CHILDREN AND THE FAMILY ${ }^{1}$}

1. The family is bound up with the institution of marriage: the relation of children to their parents is one of the most important problems of humanity; in the first place, because the children require long continued training and education; and then, because the preservation of the family tie, even after the children's education is completed, is of the highest importance.

2. The continuance of family feeling after the children are grown is of the greatest value to humanity; indeed, it stands above all other bonds. On the one side, there is the natural blood-tie, on the other, the close association that has been established during the years of education; both together produce a natural understanding, a harmony of conduct, which should not be lost, but should be cultivated in later life as a lasting common tie and as a pledge of self-saerificing effort for humanity.

3 . 'The nature of family feeling will differ, according to whether it is the relation to the mother, or to the father, that is determinative. We, from our point of view, combine both relations, and can scarcely conceive of the time when such a combination was considered impossible; and yet this was the case. As the mother and father belonged to different families, the combination of matriarchy and patriarchy was necessary to bring the child within the membership of both families. But that was impossible in times when each family lived to itself, and each family circle formed a separate social and political unit which maintained its interests one-sidedly, and expressed them, as far as the other families were concerned, in every way, even in disputes and war. The struggles of those ages are for the most, family wars, family fighting against family. Inder such conditions it was, if not inconceivable, at least not feasible for one person to belong to more

${ }^{1}$ [Reprinted, hy permission, from Josef KoHLer, "Philosophy of Law" (Albrecht's trans.), Boston Book Company, 1914 (Philosophy of Law Series, Tol. XII).] 
than one family, and hence be committed to both sides in case of war. An individual who belonged to more than one family was in a position similar to the sujet mixte of today who belongs to two countries; a state of things which does inleed exist, which is everywhere regarded as deplorable, and to be aroided if possible.

4. The oldest tie was that of the child to the mother and to the maternal family, ${ }^{1}$ which is easily comprehensible; for the child is borne by the mother, is often nourished by her for years, and in its early youth is entirely in her care. It the same time, the women are the keepers of the home; whereas the men walider about, and are often absent, especially in times of war. Erder such conditions, matriarchy is the only rational arrangement, and it was therefore formerly quite general. Not until later, especially under the influence of wife-purchase and rape, but also for other reasons which will be discussed elsewhere, did matriarchy give way to patriarchy and the child belong to the father and the father's family. This was the plane reached by the cultural legal systems of the ancients, in Indian, Greek, Roman, and Germanic law, and the law of the Eastern Asiatics; and this was the condition that prevailed during the time that the greatest formations of culture among the nations were accomplished.

5. Patriarchy has great advantages over matriarchy. Under the latter system, the child belongs to the mother, but it also belongs to the mother's relatives; that is, to those who have the same mother as the child's mother; hence, especially, to her brothers, so that the relation between maternal uncle and nephew is the closest that exists between two men. This relation is a natural one only if the mother lives with her brothers, so that brother, sister and sister's child form one household. But such a state of affairs cannot be maintained; as soon as the peoples become nomadic and consequently scatter, it becomes unendurable for the husband to stand apart. Then, of course, if the reproduction of children is to continue, the husband must live with his wife and child; the uncle on the other hand lives perhaps in a quite distant district, follows other aims, and has no intinate relations with them. Ender such conditions, the closer the marriage and immediate family relation becomes, the more the child, as soon as it needs the guidance of a man's hand, will attach itself to the father, and the more contrary to nature it must appear if

${ }^{1}$ Only the complete misumlerstanding of ethnology and comparative legal science can lead to a contrary assertion; refutation is superfluous. 
the man to whom the child turns is not its father. If the father belongs to family $\mathrm{A}$, the child to family $\mathrm{B}$, the seeds of discord already exist in the heart of the household: in case of war between the two families father and son stand on opposite sides. Such conflicts in a cirele in which the greatest loyalty and undivided confidence should rule, poison the whole relationship from the beginning.

Another solution would only be possible, if the wife were the head of the house, and she and her political side determined the whole relation. This system has, indeed, existed; it is called gy'narehy, but it has always been rare, and was soon recognized as contrary to nature. Women have other tasks than that of ruling, and other qualities than the persevering consistency that the life of a ruler demands. Hence, it will be the rule for the husband to be the head of the house, and the unnatural condition that arises if the children are removed from his circle of government will always be felt as a tremendous hindrance to the development of family life. Therefore, only those nations in which the father's right was paramount have been capable of fulfilling the higher duties of national life; they alone have had the inherent strength powerfully to resist storms from within and without.

6. The bringing up or training of ehildren took place in the family from the beginning. During the period that group-marriage was general, it took the form of exchanging children to a greater or less extent, so that one or another member of the group was made responsible for one or more children. When monogamy beeame customary, the child remained with its parents, and such an intimate relation between them and the children was thus developed that the strongest tie was formed. The unity of blood corresponded to the mity of all vital relations.

7. It is therefore comprehensible that history long preserved this tie, and even surrounded it with the glamor of poetry. Even today, the relation between children and parents is one of the most intimate and sacred; it is the source not only of ethical dignity, but also of deep moral strength.

8. This institution, however, is not adequate, because the lofty ideals that underlie the whole often fail, and the seeds of anticulture, even the sources of vice and social anarchy, are sometimes found in the heart of the family itself. When this is the case it is high time to take the children away from their parents, and to put their training into the hands of the State.

9. A number of nations, even in earlier times, departed from 
the custom of family training, and introluced another lind which may be divided into two separate strstems:

(a) The system of foster-paternity (Pfleguaterschaft): an altered system of family training, under which another than the real family of the children was made responsible for them. This is justifiable in cases where there is serious immorality in the fimily, or when exigencies of another nature prevent the family from bringing up the children. But, also, in other circumstances, this system may be advisable; for instance, if the children of nobles, etc., are to be brought up by ordinary citizens, so that they may learn to be simple and thorough.

(b) Under another system, the children, especially the boys, were brought up by the State and the temple, so that from their earliest youth their patriotism and civie responsibility might be developed, and that by strict diseipline and simple living they might be taught to serve their country and society.

10. The modern custom of giving children into the care of the State, or placing them in other families, therefore, easily finds a precedent in history; and in this connection, too, the principle applies, that no one sistem can be regarded as universally beneficial. On the contrary, sometimes one method, sometimes another will best fulfil the cultural conditions of a nation.

11. As long as matriarchy rules there will be no difference between legitimate and illegitimate children. And even under the laws of patriarchy the principle was originally upheld that a woman's child belonged to her husband irrespective of by whom it was begotten. Not until later was a distinction made; and the child of whom the woman's husband was not the father was disowned. But, if a child was born before marriage (out of wedlock), among many peoples it was killed (often the birth was prevented by abortion), or the child belonged to the mother's family until the mother married, when it was taken into the new family. Of any special disregard of these children born before marriage there is originally no trace whatever, and a position equal to that of legitimate children was not refused them. until, in times of patriarchy, the irlea gained gromnd that not ever! child that happened to come into the marriage was to be considered legitimate, but only those begotten by the husband. The consequence was, that the child born before marriage, like the child that was the result of adultery, remained outside the husband's family, and belonged to the mother; the rights on the maternal side, at that period, however, were not very profitable, 
as the mother did not inherit much and was restricted to the barest necessaries.

12. In later times, the legitimate child occupied another position, when, instead of patriarchy, the combined right of the father and mother was established (the cognate syrstem). The right of the mother then became more important, and this considerably improved the position of the illegitimate child; only the relation to the father and the paternal family was set aside: otherwise the child attained the complete right of the mother, and this at a time when matriarchy was again a ruling power. 


\title{
Chapter XVII
}

\section{ADOPTION AND ARTIFICIAL RELATIONSHIP}

\author{
SECTION 1 \\ SURVEY OF ARTIFICIAL RELATIONSHIPS 1
}

(a) General Remarks.

1. Among nearly all nations, beside the actual blood relationship, an artificial relationship has been recognized involving legal relations equivalent to the ties of blood. A more detailed presentation of the subject belongs to the history of law: it is one of the most interesting pages in the evolution of humanity.

2. We need only emphasize the following points here:

(a) The artificial relationship has often given the family new vitality and courage, and even saved whole tribes from decline.

(b) As in all important legal institutions, religion plased a large part in establishing the artificial relationship.

(c) Of the many different kinds of artificial relationship, foster paternity has alrcady been mentioned. Many kinds have died out, or have attained importance only in a single case in history (e.g., milk relationship in Islam). Two forms have attained universal historical importance, adoption and blood-fraternity (Blutsbrüderschaft), of which, however, the latter has disappeared from modern civilization.

(b) Adoption.

1. Adoption is an institution of high morality ; for the love between parent and child is of the highest ethical and educative value, a source of pure feelings, the starting point of devoted effort, an incentive to high moral endeavor, and thus in itself produces and furthers culture. It is just in the soil of such feelings that the most important ideas germinate, spring up, and bear the richest fruit. Moreover, the foster child that thus receives a better edu-

' [Reprinted, by permission, from Josef KoHLer, "Philosophy of Law" (Albrecht's trans.), Boston Book Company, 1914 (Philosophy of Law Series, Vol. XII).] 
cation and training, usually is more efficient than if it were left in disadvantageous circumstances where it might come to an evil end.

2. It is true that adoption would be possible without the law; it is possible for anyone to take a foster child without any legal relation and devote himself to it; but the legal activity of such a relation has a far-reaching and very considerable psychic influence. What, otherwise, only occurs occasionally and uncertainly, thus becomes a regular institution; the child that thus acquires rights, has a much better position than if it were dependent on whim. Particularly, it is spared the unhappy fate, after the death of its benefactor, of being turned out and deprived of maintenance, property, and inheritance.

3. Adoption may be so carried out that the child is taken away from its own fanily, and becomes a member of the family that adopts it. This is desirable as long as there is strong family cohesion; for a double family membership in such cases is disadvantageous, and places the child in a situation in which it cannot thrive.

It is different where family cohesion is loose so that a number of educational advantages are required outside of the family, in society and in the State, from the fact that family relationship involves its members only in certain directions.

When this is the case, the retention of certain rights in the child's own family is not only possible, but desirable: there is no reason for depriving anyone of more than is necessary to accomplish certain ends. Hence modern law has led to the introduction of a system of incomplete adoption, under which the adopted child retains as many rights as possible in its own family, and receives in addition its adoptive rights.

4. A further question concerns whether the child enters into a relation only with the father that adopts it, or also with the father's family. Modern legal systems have denied the latter, in consideration of the fact that the child retains rights in its own family. It would, however, be perfectly conceivable, and not without value, if, by a joint family resolution or something of the sort, the adopted child should also be granted rights as regards the other members of the family. The adopted child would thus be received into the whole family connection; as was the case, for instance, in the "Actleidung" of the old Norse law.

5 . With the growth of the system of incomplete adoption, another principle has also been developed: that the effects of adop- 
tion are one-sided, inasimuch as the child is incred subject to parental authority in the family that adopts him; but, in other respects, he alone acquires rights, while the father by adoption and his family have no further claim on the child. Here, too, it might be asked, whether it would not be desirable to extend this arrangement; for without doubt the connection becomes closer when claims exist on both sides. It is true that this would also have its disadrantages, sinee adoption might thus become a matter for speculation, so that motives of avarice might find a footing, and corrupt this benefieial institution. This danger, however, might be averted by careful examination into each case, and possible prohibition on the part of the authorities.

(c) Blood-Fraternity.

1. As an artificial relationship, blood-fraternity has played an important part in the life of nations. The original idea was that the "blood-brothers" were eloser to each other than real brothers, and the institution has been a source of the finest self-sacrifice, of ennoblement, of mutual devotion, of the purest unselfishness. ${ }^{1}$

2. Unfortunately, the legal institution has died out; it was much used, and also much abused; it became the spring that set kin-revenge in motion, a means of furthering rebellious acts, and the connecting element in wild and destructive societies.

Nevertheless, its disappearance is greatly to be regretted, for such an incentive to unselfishness, such an aid in all the conditions of life, must always be recognized as promoting culture; just as any ideal in itself strengthens the cultural power of a people, in so far as it is not too closely mixed with destructive elements.

3. Here, too, we must repeat, that such a psychic relation can exist without legal protection or legal form. But what was said

1 [Captain Guy Burrows ("The Land of the Pigmies," Crowell \& Co., N. Y., 1898 (?)) gives the following account of the ceremony of blood-brotherhood:"In the open air, and in the presence of all the assembled chiefs and people. I was seated opposite my prospective brother. A small incision was made in each of our forearms, from which a lit tle blood oozed. The proper performance would have been for each of us to lich the blood of the other, but on this occasion we decided to dispense with that part of the rite, merely rubbing the cuts one against the other, and thus commingling our blood. When this was done the representative of my 'brother' hegan to beat two pieces of metal together keeping up a monotonous tink, tink, tink. He reciter a sort of commination service: "If you ever make war on me, if you ever steal from me, if you ever wound me, ete. etc., may you die!' This is a good opportunity for him in ease he may want to get anything from you, so his incantation often contains such threats as, "If you do not give me plenty of guns, may you die!' After this, a similar performance was gone through by my representative. whose business it was to nullify my new brother's subtle demands. Finally the compact was sealed by an exchange of small presents."] 
of adoption also applies in this case. It is of far-reaching importance, when the law takes hold of, and shapes such institutions; they thereby become normal, and lose their exceptional character, and their significance is greatly enhanced, if what one man expects from another is also required by law. The rigid legal manner of creating and dissolving the relation gives it support and strength, and especially a series of important legal consequences may thus follow, as, for instance, if a blood-brother is privileged to refuse his testimony, or if the shielding of a blood-brother is as umpunishable as that of a real relation, or if the duty of mutual support, and perhaps also a right of inheritance exist. In all such cases, the law may be appealed to, and the uncertainty and vagueness of relations that exist merely in fact are removed by legal regulation.

4. Will this institution perhaps be revived? Unless there is somcthing in life that supports them, such customs cannot be created; the ardor and enthusiasm that lead to such an ideal camot be artificially produced; they must proceed from within the nation.

\section{SECTION 2}

\section{RELIGIOUS BASIS OF ADOPTION ${ }^{1}$}

The duty of perpetuating the domestic worship was the foundation of the law of adoption among the ancients. The same religion which obliged a man to marry, which pronounced a divorce in case of sterility, which, in case of impotence or of premature death, substituted a relative in place of the husband, still offered to a family one final resource to escape the so much dreaded misfortune of extinction; this resource was the right of adoption. "He to whom nature has denied a son can adopt one, so that the funeral ceremonies may not cease." Thus speaks the old legislator of the Hindus." We have a curious plea of an Athenian orator in a case where the legitimacy of a son's adoption was contested. The defendant shows us first the motive for which one adopted a son. "Menecles," he says, "did not wish to die without children; he was desirous of leaving behind him some one to bury him, and in after time to perform the ceremonies of the funeral worship." He then goes on to show what will happen if the tribunal annuls his adoption; what will happen, not only to himself, but to the

${ }^{1}$ [By Fustel de Coulanges, "The Ancient City"; translated by Willard Small; 11 th ed., Lothrop, Lee, and Shepard Co., Boston; reprinted by permission.]

2 "Laws of Manu," IX. 10. 
one who has adopted him. Menecles is dead, and still it is the interest of Menecles that is at stake. "If you annul my adoption, you will leave Menecles, who is dead, without a son ; and consequently no one will perform the sacrifices in his honor, no one will offer him the funeral repast, and thus he will be without worship." 1

To adopt a son, was then, to watch over the perpetuity of the domestic religion, the safety of the sacred fire, the continuation of the funeral offerings, and the repose of the manes of the ancestors. There being no reason for adoption, except the necessity of preventing the extinction of a worship, it was permitted only to one who had no son. The law of the Hindus is formal on this point. ${ }^{2}$ That of the Athenians is not less so; all the orations of Demosthenes against Leochares are proof of this. ${ }^{3} \quad$ No particular passage proves that this was the case in the old Roman law, and we know that in the time of Gaius a man might have at the same time sons by nature and sons by adoption. It appears, however, that this point was not admitted as legal in Cicero's time; for in one of his orations the orator expresses himself thus: "What is the law concerning adoption? Why, that he may adopt children who is no longer able to have children himself, and who failed of having them when he was of an age to expect it. To adopt is to seek, by regular and sacerdotal law, that which by the ordinary process of nature he is no longer able to obtain." \& Cicero attacks the adoption of Clodius, taking the ground that the man who has adopted him already has a son, and he declares that this adoption is contrary to sacerdotal law.

When a son was adopted, it was necessary, first of all, that he should be initiated into a form of worship, "introduced into a domestic religion, brought into the presence of new Penates." 5 Adoption, therefore, was accompanied by a ceremony very like that which took place at the birth of a son. In this way the new comer was admitted to the hearth, and associated in the new religion. Gods, sacred objects, rites, pravers, all became common between him and his adopted father. They said of him, In sacra transiit - He has passed to the worship of the new family. ${ }^{6}$

${ }^{1}$ Isrus, II. 10-46.

2"Laws of Manu," X. 168, 174. " "Dattaca-Sandrica," Orianne's trans., p. 260 .

${ }^{3}$ See also $I s c u s$, II. 11-14.

"Cicero, "Pro Domo," 13, 14. Aulus Gellius. V. 19.

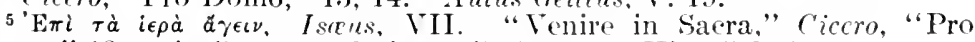
Domo," 13; "in Penates adsciscere," Tacitus, "Hist.," I. 15.

6 Valerius Maximus, VII. 7. 
By this very ceremony he renounced the worship of the old one. ${ }^{1}$ We have seen, indeed, that according to this ancient belief, the same man could not sacrifice at two hearths, or honor two series of ancestors. Admitted to a new house, the old became foreign to him. He no longer had anything in common with the hearth near which he was born, and could no longer offer the funeral repast to his own ancestors. The ties of birth were broken; the new tie of a common worship took the ascendency. The man became so completely a stranger to his own family, that, if he happened to die, his natural father had no right to take charge of the funeral, or to conduct the procession. The adopted son could not return again to the old family; or, at most, the law permitted this only when, having a son, he left that son to take his place in the adoptive family. They considered that, the perpetuity of this family being thus assured, he might leave it; but, in this case, he severed all the ties that bound him to his own son."

Emancipation corresponded, as a correlative, to adoption. In order that a son might enter a new family, it was necessary that he should be able to leave the old; that is to say, that he should be emancipated from its religion. ${ }^{3}$ 'The principal effect of emancipation was the renunciation of the worship of the family in which one was born. The Romans designated this act by the very significant name of sacrorum detestatio. ${ }^{4}$

1 "Amissis sacris paternis," Cicero, ibid.

${ }^{2}$ Iscus, VI. 44; X. 11. Demosthenes, "against Leochares." Antiphon., "Frag.," 15. Comp. "Laws of Manu," IX. 142.

3 "Consuetudo apud antiquos fuit ut qui in familiam transiret prius se abdicaret ab ea in qua natus fuerat.", Servius, "ad An.," II. 156.

${ }^{4}$ Aulus Gellius, XV. 27. 


\section{Chapter XVIII}

\section{SLAVERY}

\section{Section 1}

\section{HISTORICAL IMPORTANCE OF SLAVERY 1}

1. Slavery is not, as might be supposed, evidence that culture is lacking, but exhibits considerable economic progress; for in periods in which economic life is but slightly developed, no need of slaves is felt. The household is limited in accordance with the needs of the family and the addition of servants would mean only the increase of family cares and would make it necessary to divide the meager proceeds of industry among a greater number of consumers than formerly. It is not until there is a more developed and growing agricultural or industrial life that the need is felt of slaves as workers in agricultural or industrial pursuits. But when once this point is reached, the need of slavery is so strong that the people would risk everything in order to add to their working force in this way. Wars are carried on for the sake of taking slaves, raids are made, or people belonging to some particular class are oppressed, tormented, and driven by various economic abuses into becoming slaves and rendering a slave's obedience and service.

2. However, slavery has still another, a religious significance: the human sacrifice is generally a sacrifice of slaves. Slaves have been kept for the special purpose of being slaughtered as a sacrifice to gods or spirits, walled up when a house was being built, or offered to the gods of the harrest before a new field was planted.

3. Before the rise of technical, especially of industrial arts, slavery was the only means of obtaining a division of labor on a large seale in a uniform undertaking, for works of that kind require distinct subordination, monotonous and steady exertion,

\footnotetext{
${ }^{1}$ [Reprinted, by permission, from Josef Kohler, "Philosophy of Law" (Albrecht's trans.), Boston Book Company, 1914 (Philosophy of Law Series, Vol. XII).]
} 
tasks which the workman dislikes, and absolute discipline and order, such as were impossible anong free persons in those times. Even the oarsman in the rowing bank could searcely be a free person; for everywhere that enterprises requiring mass labor were set on foot, slaves could not be dispensed with, since machines were wholly lacking.

4. Hence, no one who looks at the matter entirely from the standpoint of our day, or of human rights, will be able to appreciate slavery in its historical development. Human rights are not advantageous to every development: technical arts must advance, humanity must make progress in industrial life and for centuries this goes on with the sacrifice of human life. The sacrifice to culture is the highest sacrifice that the individual can make, but it is also one that he must make.

5. Slavery may develop into semi-slavery or bondage:

(a) One kind of bondage is pledge service (Pfandlingschaft) in which the debtor works off his debt; as he is only temporarily a slave, his lot is lightened. He is bound to service but is not without rights.

(b) Also in other case, however, expcrience has taught that a slave will do more if his interest is aroused and he is given a "peculium" which he may use, or own, or partly own. Thus it is in agriculture where the slave is allowed to possess a small tract of land; thus, too, it is in trade and commerce: he has then to pay his lord a certain annual fee.

(c) Certain circumstances lighten the slave's condition:

(a) The possibility of buying his freedom develops. As soon as the slave appears as so much capital, the interest on which is represented by his annual service, the thought immediately follows that he can substitute, for himself to his master, capital in money : the sum with which he purchases his freedom.

(bb) The female slave is often the concubine of her master; she and her offspring therefore attain a better position. The sexual relation here, as everywhere, is connected with strong psychic influence : the lord does not want his concubine to become another's slave after his death. Therefore she becomes free when he dies, and her children are, if not entirely free, at least half-free.

(cc) The slave is allowed to have his wife and family. Thus family life develops: the family is not to be separated, its circle shall not be interfered with.

(dd) The house slaves become a part of the household, and the intimacy and confidence that thus grows up between them and 
the family make them indispensable; often the family is at the mercy of their loyalty and discretion.

(ee) Slaves even play a political part. They conduct the most important and responsible affairs and thus attain a firm and unshakable position.

(ff) Note should be taken, also, of the Bondo-Recht, that is the competency of the slave to change his master if he wishes.

6. With the coming of semi-slavery the following changes occur : the slaves become free in principle, and the services that they are required to perform take on another aspect. Such scrvices are then no longer borne in the consciousness of bondage, but are regarded as imposed tasks which cncumber the slave class and against which class feeling gradually comes to rebel. The place of the agricultural slaves is filled by free peasants, that of the artisan slaves by technical workmen - with the cessation of their special duties and liabilities they join the middle class. Work now becomes ennobled.

7. To this appreciation of work the ancients attained only in exceptional cases ; this is shown especially in Aristotle's "Politics," who, by the way, had a deep historical comprehension of the whole question of slavery.

He fully recognized that in the industrial life of the ancients slavery was a necessity; and his famous assertion, that if the weaver's shuttle worked of itself, no more slaves would be necessary, is the best explanation of the whole institution. Yet, we must reply to this ancient thinker that physical labor, especially if it is carried out with care, attention, and skill, and if the workman has a psychic interest in the result, so that he works with body and mind, by no means lacks nobility and dignity. Consequently, from our point of view, it is wrong to say that persons who perform physical labor must be without rights, so that they may be regarded only as the organs and tools of their master. Moreover, Aristotle ton arlmits that a distinction must be made between slavedom (Slilaventum) as a natural institution, and actual slavery, and that it by no means follows that all those persons who were slaves according to the law were also destined by nature to be slaves. 


\section{SECTION 2}

\section{THEORFES OF SLAVERY 1}

The Law of Persons contains but one other chapter which can be usefully cited for our present purpose. The legal rules by which systems of mature jurisprudence regulate the connection of Master and Slave, present no very distinct traces of the original condition common to ancient societies. But there are reasons for this exception. There seems to be something in the institution of slavery which has at all times either shocked or perplexed mankind, however little habituated to reflection, and however slightly adranced in the cultivation of its moral instincts. The compunction which ancient communities almost unconsciously experienced appears to have always resulted in the adoption of some imaginary principle upon which a defence, or at least a rationale, of slavery could be plausibly founded. Very early in their history the Greeks explained the institution as grounded on the intellectual inferiority of certain races, and their consequent natural aptitude for the servile condition. The Romans, in a spirit equally characteristic, derived it from a supposed agreement between the victor and the vanquished, in which the first stipulated for the perpetual services of his foe, and the other gained in consideration the life which he had legitimately forfeited. Such theories were not only unsound but plainly unequal to the case for which they affected to account. Still they exercised powerful influence in many ways. They satisfied the conscience of the Master. They perpetuated and probably increased the debascment of the Slave. And they naturally tended to put out of sight the relation in which serviturle had originally stood to the rest of the domestic system. This relation, though not clearly exhibited, is casually indicated in many parts of primitive law, and more particularly in the typical syrstem - that of ancient Rome.

Much industry and some learning have been bestowed in the Enited States of America on the question whether the Slave was in the early stages of society a recognised member of the Family. There is a sense in which an affirmative answer must certainly be given. It is clear, from the testimony both of ancient law and of many primeval histories, that the Slave might under certain conditions be made the Heir, or Cniversal Successor, of the Master,

1 [By Sir Henry S. Maine. Reprinted from "Ancient Law," by permission of Ifenry Holt and Company, New York.] 
and this significant faculty, as I shall explain in the Chapter on Succession, implies that the Government and representation of the Family might, in a particular state of circumstances, devolve on the bondman. It seems, however, to be assumed in the Amorican arguments on the subject that, if we allow slavery to have been a primitive Family institution, the acknowledgment is pregnant with an admission of the moral defensibility of Negro-servitude at the present moment. What then is meant by saying that the slave was originally included in the Family? Not that his situation may not have been the fruit of the coarsest motives which can aetuate man. The simple wish to use the bodily powers of another person as a means of ministering to one's own ease or pleasure is doubtless the foundation of Slavery, and as old as human nature. When we speak of the Slave as anciently included in the Family, we intend to assert nothing as to the motives of those who brought him into it or kept him there; we merely imply that the tie which bound him to his master was regarded as one of the same general character with that which united every other member of the group to its chieftain. This consequence is, in fact, carried in the general assertion already made, that the primitive ideas of mankind were unequal to comprehending any basis of the comnection inter se of individuals, apart from the relations of family. The Family consisted primarily of those who belonged to it by consanguinity, and next of those who had been engrafted on it by adoption; but there was still a third class of persons who were only joined to it by common subjection to its head, and these were the Slaves. The born and the adopted subjects of the chief were raised above the Slave by the certainty that in the ordinary course of events they would be relieved from bondage and entitled to exercise powers of their own; but that the inferiority of the Slave was not such as to place him outside the pale of the Family, or such as to degrade him to the footing of inanimate property, is clearly proved, I think, by the many traces which remain of his ancient eapaeity for inheritance in the last resort. It would, of course, be unsafe in the highest degree to hazard conjectures how far the lot of the Slave was mitigated, in the beginnings of society, by having a definite place reserved to him in the empire of the Father. It is, perhaps, more probable that the son was practically assimilated to the Slave, than that the slave shared any of the tenderness which in later times was shown to the son. But it may be asserted with some confidence of adranced and matured codes that, wherever servitude is sanctioned, the slave has mi- 
formly greater advantages under systems which preserve some memento of his earlier condition than under those which have adopted some other theory of his civil degradation. The point of view from which jurisprudence regards the Slave is always of great importance to him. The Roman law was arrested in its growing tendency to look upon him more and more as an article of property by the theory of the Law of Nature; and hence it is that, wherever servitude is sanctioned by institutions which have been deeply affected by Roman jurisprudence, the servile condition is never intolerably wretched. There is a great deal of evidence that in those American States which have taken the highly Romanised code of Louisiana as the basis of their jurisprudence, the lot and prospects of the Negro-population were better in many material respects, until the letter of the fundamental law was overlaid by recent statutory enactments passed under the influence of panic, than under institutions founded on the English Common Law, which, as recently interpreted, has no true place for the Slave, and can only therefore regard him as a chattel. 


\section{Cihapter XIX}

\section{CAPITIS DEMINUTIO ${ }^{1}$}

Capitis deminutio is the destruction of the 'caput' or legal personality. Capitis deminutio, so to speak, wipes out the former individual and puts a new one in his place, and between the old and the new individual there is, legally speaking, nothing in common. A juristic personality may be thus destroyed in one of three ways:

(1) by loss of the status libertatis. This is the capitis deminuitio maxima ;

(2) by loss of the status civitatis. This is the capitis deminutio media (magna) ;

(3) by severance from the agnatic family. This entails capitis deminutio minima.

Capitis deminutio maxima means the loss of a man's entire juristic personality. Capitis deminutio media and minima merely. mean the loss of the particular juristic personality which a man has hitherto possessed.

To undergo capitis deminutio maxima is to forfeit one's liberty: A Roman civis may, like others, become a slave, e.g. if he is condemned for a crime, or taken a prisoner of war. If, however, a Roman citizen returns from captivity, he becomes, at the moment of his return, a Roman citizen again and recovers all those rights which he had forfeited by his capitis deminutio in just the same manner as though he had never lost them. He becomes once more the paterfamilias of his children, the owner of his property, the creditor of his debtors, and so on. In a word, he becomes the subject of all the legal relations which his captivity had extinguished for him, to the same extent as though he had never been a prisoner of war at all. This is the nature of the so-called 'jus postliminii.' Let us suppose, however, that the Roman civis in question does not return, but dies in captivity. At the time of his death he is clearly not a ciris Romanus, but a slave. Is then the

${ }^{1}$ [By Rydolph Som. Reprinted by permission from "The Institutes of Roman Law" (Ledlie's trans.), Oxford [niversity Press, 1S92.] 
will which he executed at home, before he was taken prisoner, void or not? And, to go a step further, since a slave camnot have any heirs, ann he (the prisoner) have heirs or not? All these difficulties were solved by the so-called 'fictio legis Corneliae,' by which a Roman civis, dying in captivity, is assumed by a fiction to have died a Roman (itizen ; consequently (argued the jurists), he shall be deemed to have died at the very moment of being taken prisoner.

Capitis deminutio media (or magna) is loss of citizenship unaccompanied by loss of liberty; it occurs e.g. when a Roman citizen emigrates to a Latin colony. But in Justinian's time, since every member of the Roman empire who was free was, at the same time, a Roman citizen, media capitis deminutio is only possible in the case of banishment, i.e. expulsion from membership of the empire.

Severance from one's agnatie family also operates as a capitis deminutio (viz. minima), a destruction of one's personality. For it is in the family that the essence and force of a legal personality lie. To change one's family, therefore, is to change one's personality ; it means the destruction of the old personality and the birth of a new one.

The word 'family,' however, in the legal signification of the term, means, according to the civil law of Rome, something very different from what we are accustomed to associate with the term. By family we mean the aggregate of all persons who are connected by ties of blood-relationship, the aggregate of all members of one and the same stock. But a Roman family, within the meaning of the jus civile, means the aggregate of all those who belong to one and the same household, who are subject to one and the same 'domestic power' (patria potestas), or, at any rate, would be thus subject, if the common ancestor were still living. This is what is meant by the term 'agnatio.' And the civil law recognizes no other kind of relationship but agnatio ; it knows nothing of cognatio or blood-relationship. Thus the family of the Roman civil law means the agnatic family. A peculiar characteristic of this agnatic family is that it can be changed. Blood-relationship camnot be destroyed, and a cognatic family, or family in the modern sense, does not admit of change. But a person can separate himself from an agnatic family, because he can separate himself from the household, i.e. from the community of those who stand under the same patria potestas. And this is what happens to a daughter who contracts a marriage and thereby enters the marital (i.e. domestic) power (manus) of her husband ('in manum conventio'), or of the 
person under whose patria potestas her husband stands. Having passed from one patria potestas to another, she has thereby changed her family (her agnatic family, namely); she has changed her entire circle of relations (agnatic relations, namely); in a word, she has undergone a complete change of personality. The same thing happens to a filiusfamilias, when his father sells him into bondage (mancipium), or gives him in adoption (datio in adoptionem); and again to a person sui juris, when he suffers himself to be adopted by another (arrogatio); or lastly, to a filiusfamilias, when his father emancipates him from the paternal power (emancipatio). And it is to be noted that in spite of the fact that the emancipatus actually improves his outward position by becoming a paterfamilias instead of a filiusfamilias, he nevertheless nudergoes capitis deminutio, because the rupture of his agnatic ties involves the destruction of his previous legal personality and the creation of a new one.

Capitis deminutio minima, then, means the severance from one's agnatic relationship, and it occurs in five cases, riz. in the case of 'mancipio dare, ' of 'in manum conventio,' of 'datio in adoptionem,' of 'arrogatio,' and of 'emancipatio.'

There were two further incidents of capitis deminutio minima which flowed as consequences from the destructive effect which capitis deminutio minima had in common with the other forms of capitis deminutio. Firstly, it was a rule of civil law that capitis deminutio minima extinguished the contractual debts of the capite minutus. The praetor, however, subsequently restored to the creditors their rights of action by means of in integrum restitutio. Secondly, it extinguished all personal servitudes to which the capite minutus had been entitled, i.e. all such jura in re aliena as had belonged to him for life. This latter rule was only abolished by Justinian. According to the law as laid down in the Corpus juris personal servitudes are only extinguished by capitis deminutio maxima and media. 


\section{Chapter XI}

\section{EXISTIMATIONIS MINUTIO ${ }^{1}$}

The term 'honour' refers, in the first instance, only to social relations. To be 'honoured' is to be allowed one's full worth in society. Society treats those as entitled to honour who act in adherence to its views. The award or denial of honour, in other words, of social worth, is the sanction by means of which society cnforces on individuals not merely the commands of law and morality, but more specifically the decrees of mere usage which may conceivably run counter to law and morality. The particular lind of conduct which society requires from the individual assumes different forms in reference to the different sections into which society is divided, and it is in this sense that we speak of the honour of a particular class, of military honour, professional honour, and so on.

The effect which social relations and social views produce upon the law, finds expression in the legal rules concerning 'existimatio' or 'civic honour.' The law yields, to some extent, to the judgment pronounced by society and, in certain circumstances, imposes legal disahilities on persons whom society has declared to fall short of the standard it requires. Civic honour (in the legal sense) means full qualification in the cye of the law. Loss of honour (in the legal sense) means partial disqualification in the eye of the law.

The civic honour of a civis Romanus may be destroyed (consumtio existimationis), viz. by capitis deminutio maxima or media ; or it may be merely impaired (minutio existimationis). And it is in this last and narrower sense that the expression 'loss of civic honour' is technically applied. Minutio existimationis may be refined as the impairment of a man's civic honour which, without producing capitis deminutio (in other words, without destroying his previous personality), merely operates to diminish his personal qualifications in the eyre of the law.

${ }^{1}$ [By Rudolph SoHm. Reprinted hy permission from "The Institutes of Romitis Law" (Ledlie's trans.), Oxford University Press, 1892.] 
In the Roman civil law, existimationis minutio only occurs: in the cases determined by popular enactments ${ }^{1} ;(2)$ in consequence of a reprimand from the censor. But here again the jus honorarium outstripped the civil law. Towards the close of the republic the censor ceased to excercise his old functions and the vacancy thus created was supplied by the praetor. For the praetorian edict was concenned with persons whose ciric dignity was impaired in so far as their disabilities in regard to judicial proceedings came into question. Thus the praetor in his edict enumerated those to whom, as persons of tarnished reputation, he would refuse the full jus postulandi, i.e. to whom he would deny the right to make motions in court (postulare) otherwise than on behalf of themselves or certain close relations. In another part of the edict he specified those to whom, as persons of tarnished reputation, he declined to grant the right of being represented by an agent in an action before him. But in thus denying to certain parties full legal capacity in judicial proceedings (including, inter alia, the unrestricted jus postulandi) the praetor did not directly pronounce them 'infames.' He had neither occasion nor power formally to curtail the civic honour which a person enjoyed. But, says Gajus, 'those whom the praetor places under such disabilities we call infamous.' It was, then, in those lists contained in the praetorian edict that the views which society took of the cases of existimationis minutio found legal expression and were, so to speak, codified; imperfectly, it is true, but nevertheless in such a way as to be decisive of the future attitude of the law towards civic honour. And it was from these sections of the praetorian edict that Justinian's compilers took their catalogue of cases of existimationis minutio.

There were, more particularly, two groups of cases which were contrasted with one another, the cases of 'infamia immediata' and of 'infamia mediata.' Infamy was said to be 'immediate, if it attached to a person at once, ipso jure, on the commission of some act which deserved to be visited with social disgrace. Thus it attached to persons engaged in a disreputable trale, to soldiers ignominiously discharged from military service, to persons in the relation of a double marriage or double betrothal. On the other hand, infamy was said to be 'mediate, if it did not attach directly', but only after a court of law had passed judgment on the delinquent on the ground of some act which descrved to be visited with social

1 Thus e.g. the Twelve Tahles (viii. 22) dectared : qui so sierit testarier libripensve fuerit, ni testimonium fatiatur, improbus in testabilisque esto. 
disgrace. Such was the effect above all things of every criminal sentence touching life, limb or liberty. A similar result however followed condemnation in certain civil cases, more especially if judgment were given against a person in a civil action on account of a dishonourable breach of duty ( $\bullet . g$. as guardian, partner, depositary, agent). Those civil actions in which condemnation entails infamy are called 'actiones famosae.'

No codification of the law of honour can, in the nature of things, be complete. It was necessary, therefore, to allow the Roman judges a discretionary power to take account of such cases of infamy as had not been specified in any statute or the praetorian edict. Looked at from this point of view, there were two kinds of existimationis minutio, 'infamia' and 'turpitudo.' In the case of 'infamy' the conditions under which it should attach were fixed by the law, viz. by statutes and the praetorian edict. In the case of so-called 'turpitude,' the conditions under which it should attach were fixed, not by the law, but by the free discretion of the judge acting, in each individual case, on the verdict of public opinion, in other words, on the verdict of society.

Both these forms of minutio existimationis (viz. infamia and turpitudo) produce this result that the judge, acting on his own discretion, may take them into account, wherever the character of the person affected is concerned. He may hesitate, for example, before admitting such a person as a witness or allowing him to act as a guardian. Or again, if an infamis or turpis is instituted in a will, the judge may admit the brothers and sisters of the deceased to the querela inofficiosi testamenti. The following effects, moreover, are peculiar to infamy: it extinguishes the jus suffragii and the jus honorum; it restricts the jus connubii (by disqualifying the infamis from marrying any free-born person); and it also restricts the right to make motions in court on behalf of others. But these special disqualifications incident to infamy have ceased to exist in Justinian's time. As far as a man's personality, as such, is concerned, the only effect, under Justinian's law, both of 'infamy' and 'turpitude' is that the persons affected are liable to be subjected to certain disabilities by the judge in the exercise of his judicial discretion. 


\section{PART III}

\section{THINGS}

\section{Chapter XXi}

\section{THE LAW OF PROPERTY}

Sectiox 1. Religious Basis of Property

Br Fustel de Coulayges

Secrion 2. Develophext of the Idea of Property By L. T. HobHotse

Sectiox 3. Early History of Property and the Village Comaunty By Henry s. Miane

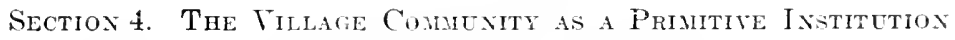
By Georcie Liunence Gomae

\section{('HAPTER XXII}

\section{ORIGIN OF COMIAERCIAL INSTITLTIONS}

By L. Goldschanidt

\section{('HApter XXIII}

PRIMITITE COMIERCIAL LAW

bi carl homene

Cinpter XXIV

BARTER AND TRANSFER

Sectinx 1. Barter

BY WNEF KOHLER

Sectiox 2. Primiture Traxifer of Goods

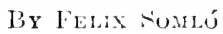




\section{Chapter XXV}

PLEDGE

Section 1. Forms of Pledge Rights By Joser hiohler

Section 2. The Pledie Idea

BY JOHN H. WIGMORE

Chapter XXVI

SURETISHIP

By Josef KoHler

Chapter MNIII

EVOLUTION OF THE LAW OF CONTRACT

Section 1. The Fides Commanduent

By B. W. LEIST

Section 2. Early Law of Contract

By Henry S. Maine

Section 3. Sponsio and Primitive Contract

By Pol Collinet

Chapter xXVili

SALES AND LOANS AT ROME

By RUdolph SoHM

Chapter XXIX

INTEREST

Br JoseF KOHLer

Chapter XXX

SUCCESSION

Section 1. Survey of the Law of Succession

By Josef KoHLer

Section 2. Religious Basis of Inheritance By Fustel de Coulanges

Section 3. Early History of Testamentary Succession By Henry S. maine 


\section{Chapter XXi \\ THE LAW OF PROPERTY}

\section{Section 1 \\ RELIGIOUS BASIS OF PROPERTY ${ }^{1}$}

HERE is an institution of the ancients of which we must not form an idea from anything that we see around us. The ancients founded the right of property on principles different from those of the present generation; as a result, the laws by which they guaranteed it are sensibly different from ours.

We know that there are races who have never succecded in establishing among themselves the right of private property, while others have reached this stage only after long and painful experience. It is not, indeed, an easy problem, in the origin of societr, to decide whether the individual may appropriate the soil, and establish such a bond between his being and a portion of the earth, that he can say, 'This land is mine, this is the same as a part of me. The Tartars have an idea of the right of property in a case of flocks or herds, but they cannot understand it when it is a question of land. Among the ancient Germans the earth belonged to no one; every year the tribe assigned to each one of its members a lot to cultivate, and the lot was changed the following year. The German was proprietor of the harvest, but not of the land. The case is still the same among a part of the Semitic race, and among some of the Slavic nations.

On the other hand, the nations of Greece and Italy from the earliest antiquity, always held to the idea of private property. We do not find an age when the soil was common among them : ${ }^{2}$ nor do we find anything that resembles the annual allotment of land

${ }^{1}$ [By Fustel de Coclaxges, "The Ancient City" ; translated hy Irillard Small; 11th erl., Lothrop, Lee, and Shepard ('o., Boston: reprinted by permission.]

${ }^{2}$ Some historians have expressed the opinion that at Rome property was at first public, and dirl not beceme private till Numa's reign. This error comes from a false interprotation of three passages of Plutarch ("Numa," 16), Cicero ("Repuhlic," II. 14), and Dimmsius of IIalinarnassus (II. 74). These three anthers sar, it is true, that Numa distributed 
which was in rogue among the Germans. And here we note a remarkable fact. While the races that do not accord to the individual a property in the soil, allow him at least a right to the fruits of his labor, - that is to say, to his harvest, - precisely the contrary custom prevailed among the Grecks. In many cities the citizens were required to store their erops in common, or at least the greater part, and to consume them in common. The individual, therefore, was not the master of the corn which he had gathered; but, at the same time, by a singular contradiction, he had an absolute property in the soil. To him the land was more than the harvest. It appears that among the Greeks the conception of private property was developed exactly contrary to what appears to be the natural order. It was not applied to the harvest first, and to the soil afterwards, but followed the inverse order.

There are three things which, from the most ancient times, we find founded and solidly established in these Greek and Italian societies: the domestic religion; the family; and the right of property - three things which had in the beginning a manifest relation, and which appear to have been inseparable. The idea of private property existed in the religion itself. Every family had its hearth and its ancestors. These gods could be adored only by this family, and protected it alone. They were its property.

Now, between these gods and the soil, men of the early ages saw a mysterious relation. Let us first take the hearth. This altar is the srmbol of a sedentary life; its name indicates this. ${ }^{1}$ It must be placed upon the ground; once established, it cannot be moved. The god of the family wishes to have a fixed abode; materially, it is difficult to transport the stone on which he shines; religiously, this is more difficult still, and is permitted to a man only when hard necessity presses him, when an enemy is pursuing him, or when the soil cannot support him. When they establish the hearth, it is with the thought and hope that it will always remain in the same spot. The god is installed there not for a day, not for the life of one man merely, but for as long a time as this family shall endure, and there remains any one to support its fire by sacrifices. Thus the sacred fire takes possession of the soil, and makes it its own. It is the god's property.

lands to the citizens, but they indicate very clearly that these lands were "onquests of his predecessor, "agri quos bello Romulus ceperat." As to the Roman soil itself - "ager Romanus" - it was private property from the origin of the city.

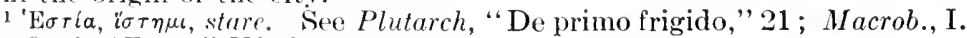
23; Ovil, "Fast.," VI. 299. 
And the family, which through duty and religion remains grouped around its altar, is as much fixed to the soil as the altar itself. The idea of domicile follows naturally. The family is attached to the altar, the altar is attached to the soil; an intimate relation, thercfore, is established between the soil and the family. There must be his permanent home, which he will not dream of quitting, unless an unforeseen necessity constrains him to it. Like the hearth, it will always occupy this spot. This spot belongs to it, is its property, the property not simply of a man, but of a family, whose different members must, one after another, be born and die here.

Let us follow the idea of the ancients. 'Two sacred fires represent two distinct divinities, who are never united or confounded; this is so true, that even inter-marriage between two families does not establish an alliance between their gods. The sacred fire must be isolated - that is to say, completely separated from all that is not of itself; the stranger must not approach it at the moment when the ceremonies of the worship are performed, or even be in sight of it. It is for this reason that these gods are called the concealed gods, $\mu \chi^{\prime} \iota\llcorner$, or the interior gods, Penates. In order that this religious rule may be well observed, there must be an enclosure around this hearth at a certain distance. It did not matter whether this enclosure was a hedge, a wall of wood, or one of stone. Whatever it was, it marked the limit which separated the domain of one sacred fire from that of another. This enclosure was deemed sacred. ${ }^{1}$ It was an impious act to pass it. The god watched over it, and kept it under his care. They, therefore, applied to this god

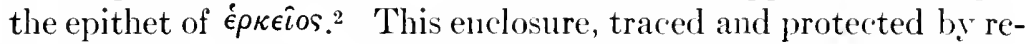
ligion, was the most certain emblem, the most undoubted mark of the right of property.

Let us return to the primitive ages of the Aryan race. The sacred enclosure, which the Greeks call épкos, and the Latins heretum, was the somewhat spacious enclosure in which the family had its house, its flocks, and the small field that it cultivated. In the midst rose the protecting fire-god. Let us descend to the succeed-

1 "Е

${ }^{2}$ At an epoch when this ancient worship was almost effaced by the younger religion of Zeus, and when they associated him with the fire-got, the new god assumed the title of $\dot{\epsilon} \rho \kappa \in \hat{o}$ os. It is not less true that in the beginning, the real protector of the enclosure was the domestir gorl. Dionysius of Halicarnassus asserts this (I. 68), when he sars that the

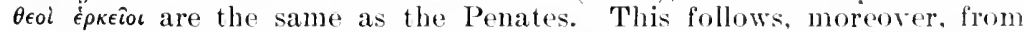
a comparison of a passage of Pausanias (IV. 17) with a passage of Euripides ("Troad.,"17), and one of Tirgil ("En.." [I. 514): the threc passages relate to the same fact, and show that Zev่s $\dot{\epsilon} \rho \kappa \in \hat{c}$ s was no other than the domestic fire. 
ing ages. The tribes have reached Greece and Italy, and have built cities. 'The dwellings are brought nearer together: they are not, howerer, contiguous. The sacred enclosure still exists, but is of smaller proportions; oftenest it is reduced to a low wall, a ditch, a furrow, or to a mere open space, a few feet wide. But in no case could two houses be joined to each other; a party wall was supposed to be an impossible thing. The same wall could not be common to two houses; for then the sacred enclosure of the gods would have disappeared. At Rome the law fixed two feet and a half as the width of the free space, which was always to separate two houses, and this space was consecrated to "the god of the enclosure." 1

A result of these old religious rules was, that a community of property was never established among the ancients. A phalanstery was never known among them. Even Pythagoras did not succeed in establishing institutions which the most intimate religion of men resisted. Neither do we find, at any epoch in the life of the ancients, anything that resembled that multitude of villages so general in France during the twelfth century. Every family, having its gods and its worship, was required to have its particular place on the soil, its isolated domicile, its property.

According to the Greeks, the sacred fire taught men to build houses ; ${ }^{2}$ and, indeed, men who were fixed by their religion to one spot, which they believed it their duty not to quit, would soon begin to think of raising in that place some solid structure. The tent covers the Arab, the wagon the Tartar; but a family that has a domestic hearth has need of a permanent dwelling. 'The stone house soon succeeds the mud cabin or the wooden hut. 'The family did not build for the life of a single man, but for generations that were to succeed each other in the same dwelling.

The house was always placed in the sacred enclosure. Among the Greeks, the square which composed the enclosure was divided into two parts; the first part was the court; the house occupied the second. The hearth, placed near the middle of the whole enclosure, was thus at the bottom of the court, and near the cntrance of the house. At Rome the disposition was different, but the principle was the same. The hearth remained in the middle of the enclosure, but the buildings rose round it on four sides, so as to enclose it within a little court.

II. 469 .

1 Festus, v. "Ambitus." V'arro, "L. L.," T. 22. Servius, "ad En.,"

Diodorus, V. $6 \mathrm{~s}$. 
We can easily understand the idea that inspired this system of construction. The walls are raised around the hearth to isolatc and defend it, and we may say, as the Greeks said, that religion taught men to build houses. In this house the family is master and proprietor; its domestic divinity assures it this right. The house is consecrated by the perpetual presence of gods; it is a temple which preserves them.

"What is there more holy," says Cicero, "what is there more carefully fenced round with every description of religious respect. than the house of each individual citizen? Here is his altar, here is his hearth, here are his household gods; here all his sacred rights, all his religious ceremonies, are preserved." ' To enter this house with any malevolent intention was a sacrilege. The domicile was inviolable. According to a Roman tradition, the domestic god repulsed the robber, and kept off the enemr.2

Let us pass to another object of worship - the tomb; and we shall see that the same ideas were attached to this. The tomb held a very important place in the religion of the ancients; for, on one hand, worship was due to the ancestors, and on the other, the principal ceremony of this worship - the funeral repast - was to be performed on the very spot where the ancestors rested. ${ }^{3}$ The family, therefore, had a common tomb, where its members, one after another, must come to sleep. For this tomb the rule was the same as for the hearth. It was no more permitted to unite two families in the same tomb than it was to establish two domestic hearths in the same house. 'To bury one out of the family tomb, or to place a stranger in this tomb, was equally impious. ${ }^{4}$ The domestic religion, both in life and in death, separated every family from all others, and strictly rejected all appearance of community. Just as the houses could not be contiguous, so the tombs could not touch each other; each one of them, like the house, had a sort of isolating enclosure.

How manifest is the character of private property in all this! The dead are gods, who belong to a particular family, which alone has a right to invoke them. These gods have taken possession of

${ }^{1}$ Cicero, "Pro Domo," 41.

2 Orid. "Fast.," V. 141 .

${ }^{3}$ Such, at least, was the ancient rule. since they believed that the funeral repast served as food for the dead. Eurip.. "Troad." 3. S1.

"Cicero, "De Legib.," II. 22; II. 26. Crains," Instit." II. i." "Digest," XLVII. tit. 12. We must note that the slave and the rlient. as we shall see farther on. were a part of the family, and were huried in the common tomb. The rnle which preseribed that every man should he. luried in the tomb of his family, admitted of an exception in the rase where the city itself granted a public funeral. 
the soil; they live under this little mound, and no one, except one of the fanily, can think of meddling with them. Furthermore, no one has the right to dispossess them of the soil which they occupy ; a tomb among the ancients could never be destroyed or displaced; ${ }^{1}$ this was forbidden by the severest laws. Here, therefore, was a portion of the soil which, in the name of religion, became an object of perpetual property for each family. The family appropriated to itself this soil by placing its dead here; it was established here for all time. The living scion of this family could rightly say, This land is mine. It was so completely his, that it was inseparable from him, and he had not the right to dispose of it. The soil where the dead rested was inalienable and imprescriptible. The Roman law required that, if a family sold the field where the tomb was situated, it should still retain the ownership of this tomb, and should always preserve the right to cross the field, in order to perform the ceremonies of its worship. ${ }^{2}$

The ancient usage was to inter the dead, not in cemeteries or by the road-side, but in the field belonging to the family. This custom of ancient times is attested by a law of Solon, and by several passages in Plutarch. We learn from an oration of Demosthenes, that even in his time, each family buried its dead in its own field, and that when a domain was bought in Attica, the burial-place of the old proprietors was found there. ${ }^{3}$ As for Italy, this same custom is proved to have existed by the laws of the Twelve Tables, by passages from two jurisconsults, and by this sentence of Siculus Flaceus: "Anciently there were two ways of placing the tomb; some placed it on one side of the field, others towards the middle." 4

From this custom we can see that the idea of property was easily extended from the small mound to the field that surrounded this mound. In the works of the elder Cato there is a formula according to which the Italian laborer prayed the manes to watch over his field, to take good care against the thief, and to bless him with a good harvest. Thus these souls of the dead extended tutelary action, and with it their right of property, even to the boundaries

${ }^{1}$ Lycurgus, "against Leocrates," 25. At Rome, before a burial-place could be changed, the permission of the pontiffs was required. Pliny, "Letters," X. 73.

"Cicero, "De Legib.," II. 24. "Digest," XVIII. tit. 1. 6.

3 "Laws of Solon," cited by Gaius in "Digest," X. tit. 1. 13. Demosthcnes, "against Callicles." Plutarch, "Aristides," 1.

"Siculus Flaccus, edlit. Goez, p. 4. See "Fragm. terminalia," edit. Goez, p. 147. Pomponius, in "Digest," XlLVII. tit. 12. 5. Paul, in "Digest," VIII. 1. 14. 
of the domain. Through them the family was sole master in this field. The tomb had established an indissoluble union of the ramily with the land - that of ownership.

In the greater number of primitive societies the right of property was established by religion. In the Bible, the Lord said to Abraham, "I am the Lord, that brought thee out of Lr of the Chaldees, to give thee this land, to inherit it ;" and to Moses, "Go up hence, ... into the land which I sware unto Abraham, to Isaac, and to Jacob, saring, Unto thee will I give it."

Thus God, the primitive proprietor, by right of creation, delegates to man his ownership over a part of the soil. ${ }^{1}$ 'There was something analogous among the ancient Greco-Italian peoples. It was not the religion of Jupiter that founded this right, it is true; perhaps because this religion did not ret exist. The gods who conferred upon every family its right to a portion of the soil, were the domestic gods, the sacred fire, and the manes. The first religion that exercised its empire on their minds was also the one that established the right of property among them.

It is clearly evident that private property was an institution that the domestic religion had need of. This religion required that both dwellings and burying-places should be separate from each other; living in common was, therefore, impossible. The same religion required that the hearth should be fixed to the soil, that the tomb should neither be destroyed nor displaced. Suppress the right of property, and the sacred fire would be without a fixed piace, the families would become confounded, and the dead would be abandoned and without worship. By the stationary hearth and the permanent burial-place, the family took possession of the soil; the earth was in some sort imbued and penetrated by the religion of the hearth and of ancestors. Thus the men of the early ages were sared the trouble of resolving too difficult a problem. Without discussion, without labor, without a shadow of hesitation, they arrived, at a single step, and merely by virtue of their belief, at the conception of the right of property ; this right from which all civilization springs, since by it man improves the soil, and becomes improved himself.

Religion, and not laws, first guaranteed the right of property. Every domain was under the eyes of household divinities, who

1 Same traditions among the Etruscans: "Quum Jupiter terram Etr"uriae sibi vindicavit, constituit jussitque metiri campos signarique agros." "Auctores Rei Agrarix," in the fragment entitled "Idem Vegoix Arrunti," edit. Goez. 
watched over it." Every ficld had to be surrounded, as we have seen for the house, by an enclosure, which separated it completely from the domains of other families. This enclosure was not a wall of stone; it was a band of soil, a few feet wide, which remained uncultivated, and which the plough could never touch. This space was sacred; the Roman law declared it indefeasible; ${ }^{2}$ it belonged to the religion. On certain appointed days of each month and year, the father of the family went round his field, following this line; he drove rictims before him, sang hymns, and offered sacrifices. ${ }^{3} \quad B y$ this ceremony he believed he had awakened the benevolence of his gods towards his field and his house; above all, he had marked his right of property by proceeding round his field with his domestic worship. The path which the victims and prayers had followed was the inviolable limit of the domain.

On this line, at certain points, the men placed large stones or trunks of trees, which they called Termini. He can form a good idea as to what these bounds were, and what ideas were connected with them, by the manner in which the piety of men established them. "This," say's Siculus Flaccus, "was the manner in which our ancestors proceeded: They commenced by digging a small hole, and placing the Terminus upright near it; next they crowned the 'Terminus with garlands of grasses and flowers; then theyoffered a sacrifice. The rictim being immolated, they made the blood flow into the hole; they threw in live coals (kindled, probably, at the sacred fire of the hearth), grain, cakes, fruits, a little wine, and some honey. When all this was consumed in the hole, they thrust down the stone or piece of wood upon the ashes while they were still warm." 4 It is easy to see that the object of the ceremony was to make of this Terminus a sort of sacred representation of the domestic worship. To continue this character for it, they renewed the sacred act every year, by pouring out libations and reciting prayers. The Terminus, once placed in the earth, became in some sort the domestic religion implanted in the soil, to indicate that this soil was forever the property of the family. Later, poetry lenting its aid, the Terminus was considered as a distinct god.

The employment of 'Termini, or sacred bounds for fields, appears

1 "Lares agri custodes," Tibullus, I. 1, 23. "Religio Larum posita in fundi villaeque conspertu." ("icero, "De Legib.," II. 11.

2 ricero, "De Legih.," I. 21.

3 Cato, "De Re Rust.," 141. "script. Rei Agrar.," edit. Goez, p. 308. Dionysius of Halimarnassus, II. 74. Orid, "Fast.," II. 639. Strabo, P. 3.

4 Siculus Fluceus, edit. Gocz, n, 5. 
to have been universal among the Indo-European race. It existed among the Hindus at a very early date, and the sacred ceremonies of the boundaries had among them a great analogy with those which Siculus Flaccus has described for Italy. ${ }^{1}$ Before the foumdation of Rome, we find the Terminus among the Sabines; ${ }^{2}$ we also find it among the Etruseans. The Hellenes, too, had sacred

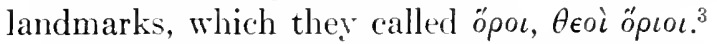

The Terminus once established according to the required rites, there was no power on earth that could displace it. It was to remain in the same place through all ages. This religious principle was expressed at Rome by a legend: Jupiter, having wished to prepare himself a site on the Capitoline hill for a temple, could not displace the god Terminus. This old tradition shows how sacred property had become; for the immorable Terminus signified nothing less than inviolable property.

In fact, the Terminus guarded the limit of the field, and watched over it. A neighbor dared not approach too near it: "For then," says Ovid, "the god, who felt himself struck by the ploughshare, or mattock, cried, 'Stop : this is my field ; there is yours.' " 4 To eneroach upon the field of a family it was necessary to overturn or displace a boundary mark, and this boundary mark was a god. The sacrilege was horrible, and the chastisement severe. According to the old Roman law, the man and the oxen who touched a Terminus were devoted ${ }^{5}$ - that is to say, both man and oxen were immolated in expiation. The Etruscan law, speaking in the name of religion, sarrs, "He who shall have touched or displaced a bound shall be condemned by the gods; his house shall disappear; his race shall be extinguished; his land shall no longer produee fruits; hail, rust, and the fires of the dog-star shall destroy his harvests; the limbs of the guilty one shall become covered with ulcers, and shall waste away." 6 We do not possess the text of the Athenian law on this subject; there remain of it only three words, which signify, "Do not pass the boundaries." But Plato appears to complete the thought of the legislator when he says, "Our first law ought to be this: Let no person touch the bounds which separate his field from that of his neighbor, for this ought to remain immovable. ... Let no one attempt to disturb the small stone

1 "Laws of Manu," VIII. 245. Vrihaspati, cited by Sicé, "Hindu Legislation," p. 159.

" V'arro, "L. L.," V. Tt.

3 Pollux, IX. 9." Hesychius, öpos. Plnto. "Laws." p. St2."

"Orid, "Fast.," II. 67.

6 "Script. Rei Agrar.," ed. Goez, p. 2.s.' 
which separates friendship from enmity, and which the land-owners have bound themselves by an oath to leave in its place." 1

From all these beliefs, from all these usages, from all these laws, it clearly follows that the domestic religion taught man to appropriate the soil, and assured him his right to it.

There is no difficulty in understanding that the right of property, having been thus conceived and established, was much more complete and absolute in its effects than it can be in our modern societies, where it is founded upon other principles. Property was so inherent in the domestic religion that a family could not renounce one without renouncing the other. The house and the field were - so to speak - incorporated in it, and it could neither lose them nor dispose of them. Plato, in his treatise on the Laws, did not pretend to advance a new idea when he forbade the proprietor to sell his field; he did no more than to recall an old law. Everything leads us to believe that in the ancient ages property was inalienable. It is well known that at Sparta the citizen was formally forbidden to sell his lot of land. ${ }^{2}$ There was the same interdiction in the laws of Locri and of Lencadia. ${ }^{3}$ Pheidon of Corinth, a legislator of the ninth century B.C., prescribed that the number of families and of estates should remain unchangeable. ${ }^{4}$ Now, this prescription could be observed only when it was forbidden to sell an estate, or even to divide it.

The law of Solon, later by seven or eight generations than that of Pheidon of Corinth, no longer forbade a man to sell his land, but punished the vendor by a severe fine, and the loss of the rights of citizenship." Finally, Aristotle mentions, in a general manner, that in many cities the ancient laws forbade the sale of land. ${ }^{6}$

Such laws ought not to surprise us. Found property on the right of labor, and man may dispose of it. Found it on religion, and he can no longer do this; a tie stronger than the will of man binds the land to him. Besides, this field where the tomb is situated, where the divine ancestors live, where the family is forever to perform its worship, is not simply the property of a man, but of a family. It is not the individual actually living who has established his right over this soil, it is the domestic god. The individual has it in trust only; it belongs to those who are tead, and to those who are yet to be born. It is a part of the body of this

\footnotetext{
${ }^{1}$ Plato, "Laws," VIII. p. \$42.

2 Plutarch, "Lycourg.," Agis." Aristotle, "Polit.," II. 6, 10 (II. 7).

${ }^{3}$ Ibid., II. 4. 4े (II. 5).

5.Eschines, "against Timarchus." Diogenes Laertius, I. 50.

6 Aristotle, "Polit.," V'II. 2.
} 
family, and cannot be separated from it. To detach one from the other is to alter a worship, and to offend a religion. Among the Hindus, propertı, also founded upon religion, was also inalienable. ${ }^{1}$

We know nothing of Roman law previous to the laws of the Twelve Tables. It is certain that at that time the sale of property was permitted; but there are reasons for thinking that, in the earlier days of Rome, and in Italy before the existence of liome, land was inalienable, as in Greece. Though there remains no evidence of this old law, there remain to us at least the modifications which were made in it by degrees. The law of the Twelve Tables, though attaching to the tomb the character of inalienabilitr, has freed the soil from it. Afterwards it was permitted to divicle property, if there were several brothers, but on condition that a new religious ceremony should be performed, and that the new partition should be made by a priest ; ${ }^{2}$ religion only could divide what had before been proclaimed indivisible. Finally, it was permitted to sell the domain; but for that formalities of a religious character were also necessary. This sale could take place only in the presence of a priest, whom they called libripens, and with the sacred formality which they called mancipation. Something analogous is seen in Greece; the sale of a house or of land was always accompanied with a sacrifice to the gods. ${ }^{3}$ Every transfer of property needed to be authorized by religion. If a man could not, or could only with difficulty, dispose of land, for a still stronger reason he could not be deprived of it against his will.

The appropriation of land for public utility was unknown among the ancients. Confiscation was resorted to only in case of condemnation to exile ${ }^{4}$ - that is to say, when a man, deprived of his right to citizenship, could no longer exercise any right over the soil of the city. Nor was the taking of property for lebt known in the ancient laws of cities." The laws of the Twelve Tables assuredly do not spare the debtor; still they do not permit his property to be sold for the benefit of the creditor. The body of the debtor is held for the debt, not his land, for the land is inseparable from the family. It is easier to subject a man to servitude than to

1 "Mitakrhara," Orionne's trans., p. 50. This rule disappeared by degrees after Brahminism berame dominant.

2 This priest was called agrimensor. See "Scriptores Rei Agrarie."

3 Stobceus, 42.

4 'This rule disappeared in the demoratio age of the citics.

5 A law of the Elieans forbade the mortgaging of land. Aristotle, "Polit.," VII. 2. Nortgages were unknown in ancient Roman law. What is said of mortgages in the Athenian law before solon is hased on a doubtful passage of Plutarch. 
take his property from him. The debtor is placed in the hands of the crelitor; his land follows him, in some sort, into slavery. The master who uses the physical strength of a man for his own profit, enjoys at the same time the fruits of his land, but does not become the proprietor of it. So inviolable above all else is the right of properti. ${ }^{1}$

\section{Section 2}

\section{DEVELOPMENT OF THE IDEA OF PROPERTY ${ }^{2}$}

1. Among primitive peoples there is little scope for the institution of private property. Land, as we shall see more fully later on, is held in common, and apart from land and its produce, such peoples possess little which can be appropriated, except their small personal belongings. These, it would seem, belong to the individual from the first. Indeed, tools and weapons are so completely identified with their owner, that they are very frequently buried with him, and that on one of two grounds - either that he may use them in his future life, or because as belonging to a dead man they are regarded as dangerous and are therefore best done away with. Now the recognition of individual property in personal belongings and of communal property in land and its produce may both be explained as resting on one and the same principle - the principle of occupation and use. It is the indiridual who actually carries and handles the spear or fishing-net, the family or the tribe which actually occupies and hunts over the land. Thus we may provisionally accept the view that property in its early stages is based on occupation and use, and cannot be dissevered from them. But with the destruction of the dead man's

${ }^{1}$ In the article of the law of the Twelve Tables which relates to insolrent dehtors, we read, "Si volet suo vivito"; then the debtor, having berome almost a slove, still retains something for himself; his land, if he has any, is not taken from him. The arrangements known in Roman law under the names of fiduciary mancipation, and of pignus, were, before the introduction of the Servian artion, the means employed to insure to the creditor the parment of the debt; these prove indirectly that the seizure of property for debt was not practised. Later, when they suppressed corporal sirvitude, it was necessary that there should be some claim on the property of a debtor. The change was not without difficulty; hut the distinction which was made between property and possession offered a resource. The creditor obtained of the praetor the right to sell, not the property, dominium, hut the goods of the debtor, bona. Then only, by a disguised seizure, the delytor lost the enjosment of his property.

2 [By L. T. Hobнouse. Reprinted from "Morals in Evolution," by permision of Ilemry lHolt and Company, New York. Abbreviated and omitted hook-titles wit he detail of editions are supplied by the author's reference list on p. xiii seq., Vol. I of the original work.] 
belongings we touch on another conception, which we must allow for at very low, perhaps at the lowest, stages. Among many rude peoples the statement that property depends upon user must be qualified by the exception that it may also be secured by taboo. This is probably the explanation of the extreme scrupulousness shown by some savages in regard to the belongings of others. Thus, among the Kunama, Dr. Tylor remarks that a hedge may be mended by a cotton thread. ${ }^{1}$ That would certainly not do in the civilized world. But then the civilized man does not fear that death will follow from a breach of the fence as a magic result. In Oceania, ${ }^{2}$ where taboo reaches its extreme derelopment, it is freely used for protection of property, real and personal. In ancient Babrlon boundary stones were secured by an imprecation, ${ }^{3}$ that is to say, a curse was laid upon them which would fall on those who should remove them. The heap of stones which Jacob and Laban set up were to be witnesses between them, and it is possible that here too the power to punish the transgressor was conceived as lying within the stone itself; while at a later stage, in accordance with the regular development of religion, the curse was laid upon him who moves the stone by Jehorah. When we read of the Western Esquimaux, whose honesty is highly praised by travellers, that other people's goods left about with a stone placed over them are quite secure, we can hardly aroirl wondering whether this is due to simple honesty of character or to the magic qualities of the stone.

Thus the legal conception of user may be reinforced by the magical idea of taboo as a basis of property. But - whether owing to the irregular development of the latter conception or not - we have next to observe that the regard actually paid to rights of property is a very fluctuating quantity in the les civilized world, and the moral attitude to the whole matter ditters serionsly from that of more dereloped races. We camot, indect, speak in general terms. Some savage peoples get a very good character from travellers for honesty, while others are severely contemned. This condemnation, again, sometimes refers merely to their hahit of stealing from other tribes or from strangers, and this, as we have seen, hardly counts. Strangers have no rights, whether of life or property, except in so far as protected by the law of hospitality. Thus among the Red Indians the guest was safe while under the

1 Tylor, "Contemp. Review," April 1873, p. 704.

${ }^{2}$ Ratzel, "History of Mankind," vol. i, p. 2\$5.

3 . Vaspero, p. 762. 
roof of his host, but might be freely robbed in the prairie. ${ }^{1}$ The real question, therefore, is how far the rights of property are recognized within the tribe. As to this we find very divergent statements, and sometimes much difference between nearly allied peoples. Thus among the Nagas, ${ }^{2}$ in some tribes theft is punishable by fines, beating, and even death, but in two of the tribes it is not eonsidered discraceful at all. In some peoples successful theft is held as by no means dishonourable. The case of Autolycus has been referred to ....... Among some of the Esquimaux theft when discovered is merely held a clever trick; ${ }^{3}$ among the Balantes in Africa it is held honourable, while among the Kaffirs the children of chiefs may steal within their own tribe. ${ }^{4}$ Even in some civilized or semi-civilized communities, as at one time in ancient Egrpt, we find a recognized organization of theft under constituted authorities who duly restore the property to the owner on payment of a portion of its value. ${ }^{5}$ Further, the distinction so frequent in early law between the manifest and the non-manifest thief - that is to say, between the thief taken in the act and the thief who has got clear away - probably points to a time when the suecessful thief was rather admired for his skill than condemned for dishonesty, and possibly acquired, or might at any rate confer, a title to the goods. ${ }^{6}$ This same distinction illustrates a further point. The tendency of early law is, as will be understood from the discussion in Chapter VI., to treat theft like other delinquencies, from the point of view of vengeance rather than of justice. The owner, surprising the thief in the act of carrying oft his goods, will naturally attack, and will very likely kill him. If so, who, on primitive principles, can blame him? But if he does not come up with the thief, but finds out the robbery in cold blood, then he ought to control his vindictive feelings, and be thankful if custom allows him to get restitu-

1 Waitz, vol. iii. pp. 129, 130.

2 Gorllen, “J. A. I.," 26, op. cit., p. 174.

${ }^{3}$ Writz, vol. iii. p. 309.

${ }^{4}$ Pust, "Afrik. Juris.," vol. ii. p. 83. Similarly there was a class of privileged thieves in Ashanti.

5 In Ahrsinia thieres are organized under a chief who pays tribute. (Post, loc. cit.) Waitz, (rol. ii. p. 218), mentions that in some parts of Africa the thief keeps half of what he steals. For the organization of thieves in Egrpt, see Diodorus, i. 80, 1.

6 See Pollock and Maitland, vol. ii. p. 497. Instances of the "receiver" being rested with ownership of movables orcur in contemporary Africa. (Post. "Afrik. Juris.," rol. ii. p. 162.) On the Congo, according to Waitz (loc. cit.), secret theft is held slavish, but open robbery lordly, and he states that the Kaffirs generally condemn theft, but admire it when cleverly exeruted. (op. cit., 401.) 
tion, with perhaps something more, for his pains. In early English law, the thief caught red-handed could be hanged without opportunity of self-defence before an impromptu court. But an action for robbery, even in the twelfth century, involved only a double restitution." In the "Book of the Covenant," "if the thief be found breaking in and be smitten that he die, there shall be no blood-guiltiness for him. If the sum be risen upon him, there shall be blood-guiltiness for him." The owner should not let the sun rise upon his wrath. The thief must merely make restitution. If the stolen animal is alive he shall pay double, if he has killed or sold it "he shall pay five oxen for an ox, and fonr sheep for a sheep." 2 The Moors, on the other hand, at the present day do not punish theft by night, but only by day, and then only when the thief is caught in the act. ${ }^{3}$ It is clear that in such distinctions as these the law takes account, not of the right and the wrong of the case, as we should conceive it, but merely of the degree of resentment natural to the man who is wronged and of the manner in which he may be expected to appease it. Clearly, wherever the thief is allowed to keep a part of the stolen property, or has simply to make restitution, stealing can hardly be considered a wicked act in our sense of the term, and even where restitution is double or manifold, we must regard it as rather intended to satisfy the injured party than as a punishment of the wrongdoer. ${ }^{4}$

On the other hand, there are also many cases, eren in the uncivilized world, where theft is severely punished, not only by fines, which are a form of manifold restitution, but also by beating, enslavement, mutilation, humiliating exposure, and even death. ${ }^{5}$ Indeed, as soon as public punishments arise, it is generally punished with great sererity. Thus in England an action for robbery, which only involved double restitution in the time of Glanvil, who died in 1190, was punished by death and mutilation in the time of Bracton, who died in $1268,{ }^{6}$ and a little while later death was the invariable penalty, even in the end for the theft of a shilling; while smaller thefts - petty larceny - were punished by whipping, pillory, or by the loss of an ear, and on repetition by death.

The conclusion to which facts such as these point, and which,

'Pollock and Maitland, vol. ii. pp. 494 and 579.

${ }^{2}$ Exodus xxii. 1-4. 3 P'ost, "Afrik. Juris.," vol. ii. p. 85.

${ }^{4}$ Restitution is a very common penalty in Africa. (Post, "Afrik. Juris.," vol. ii. p. 83.)

5 Instances of all these in Africa. (Post, l.c.)

${ }^{6}$ Pollock and Maitland, ii. p. 494. 
remembering how scanty the evidence is, we may tentatively adopt, is that the conception of property, even in relation to jersonal belongings, is somewhat irregularly developed in the uncivilized world. Where the rights of owners are very strictly regarded the cause is in many instances the fear of magic, though in some cases (as among the Iroquois and the Dakotas) ${ }^{1}$ it may have a more decisively moral character. But in a very large number of cases, if not in the majority, we have reason for supposing that the right of property is not held morally sacred as with us, theft not being punished as theft, while in some cases stolen goods are not even recoverable. On the other hand, with the rise of a scttled society, while private property in land is developing, and property in movables is increasing through the growth of the arts, the punishment of the thief is taken out of the category of vengreanee; he is dealt with as a moral offender, and that with the extreme of severity. ${ }^{2}$ This is after all only to state in special relation to property the conclusions which we reached in Chapter II. with regard to rights in general. My right to my property, like my other rights, is in the earlier stages only mine in the sense that I shall be expected to avenge its infringement by certain recognized methods. That I have a moral claim to it, which it is wicked to infringe, and not only wicked but an offence punishable by society, is a higher conception which is only perfected by degrees.

2. . In primitive society, as has been mentioned, private property is limited to the insignificant personal possessions, the arms and tools, etc., of the salvage - while the land, the great and permanent source of sustenance, is generally common to the family or to the clan, and in the rudest forms there is not only common ownership, but - so far as the land can be said to be occupied -

$1 \mathrm{Cf}$. Schoolcraft-Dralie, vol. i. p. 222. "Theft is very scandalous among them since they have no locks but those of their minds to preserve their goods." (From Coltan's account.) Among the Dakotas pilfering hy women and children was common, but the men despised it as too low a practice for them. (Ib., vol. i. p. 206.)

${ }^{2}$ In Rome the Law of the Twelve Tahles - like most laws of that stage - distinguished the thief caught in the act - the fur manifestus - from the thicf not caught in the act - the fur nee manifestus. The latter must make doulle restitution, the former is punished corporally - in the case of rohber'y by night or with the strong hand, by death: in whor cases hy heating and slavery. In the later legislation the injured party had choice of a new form of criminal action whereby corporal punishment might be inflicted, or of the aetio furti which carried infamia and double or quadruple restitution. (Girard, pp. 392-394.) In the Code of Hammurabi, loth death ant restitution are recognized. (Sections 6 and following.) Manu prescribes fines, corporal punishment and mutilations for thefts of various kincls (viii. $31 !$ ff.). 
common occupation. A group of Australians wander over a certain area with assignable boundaries, which of course they maintain against others. ${ }^{1}$ The Red Indians hunt a certain district, which is special to each tribe, but common to all within it. ${ }^{2}$ Even the produce of the hunting is often common, or is distributed by fixed customary rules. All the tribes who hunt in the plains, except the half-bred Crees, are said to make common stock of the booty. ${ }^{3}$ When agriculture begins the land is generally portioned out, at least temporarily, to the totems or the family groups within the tribe. But within the family group the produce is still common, and the land itself is still the common property of the tribe as a whole. ${ }^{4}$

We have here two linds of communism, a wider and a narrower, and these persist with various modifications through much higher grades of culture. We see the transition to the division of the tribal property among the households in such an instance as that of the Iroquois, where families may possess and retain common lands by occupying them, though the land remains strictly the property of the tribe. When a division is made, the allotments

1 Spencer and Gillen, i. p. 8.

2 Kohler, "Zeitschrift für vgl. Rwst.," 1897, p. 402.

3 Morgan, "House and Housedife of the American Aborigines," p. 69. He adds that the tribes of the Columbia River make common stoek of the fishing. Among the Western Esquimaux any one may take the game from the snares, while all large game is common. (Reclis, p. 111.) Among the South American Indians the common hunt yields common booty, but there may also be private hunting. 'The captor has the right to a prisoner's head, while the neighbours have the rest of him, but if the captive is enslaved he belongs to the community. (Schmidt, "Z. f. V. R.," 1898, p. 311.) The non-agricultural tribes of Africa know no division of land. (Post, "Afrik. Juris.," vol. ii. p. 16iz.)

${ }^{4}$ Among the Crees each village had a common field divided into patches for each family, the harrest was conducted in rommon, and a certain portion was set aside for the common store out of which the needy were supported. Among the Iroquois, the land was the property of the tribe. The harvest was carried out hy the joint family in common, and the products distributed by the women among the different departments: though the village did not make a common stock, the obligations of hospitality would prevent anybody from going short. (Morgan, "Houselife," pp. 61-66.) Common eultiration and division of the harrest is also found on the Sierra Leone Coast. (Post. "Afrik. Juris.," ii. p. 172.) Sometimes the communism is of a rough and general chararef rather than a matter of distinct right. Among some of the Papuans, for instance, every one is expected to give when asked. "The poople is God," it is irreligious to refuse anything. We see here the borderland between regular communism and the indiscriminate profusion and liberality which are sueh common eharacteristies of primitive life. (Kohler, "Z. f. V. R.," 1900 , p. 368.)

"Vorgan, "League of the Iroquois," p. 326. Similarly among the Yoruba, the land belongs to the tribe, hut it is rested in the r.linf. who allots it to the householders according to their requirements, and it hecomes hereditary and inalienable. (Ellis, "Yoruba," p. 18..) 
may only last for a short period - perhaps a year or two ; ${ }^{1}$ often, again, they depend on cultivation, ${ }^{2}$ and if deserted the land reverts to the community. But such divisions may also become customary and periodical, so that there is a redistribution at the end of a fixed period. Or, lastly, the redistribution may be given up, ${ }^{3}$ and the lots become family property, but the eminent rights of the community are still recognized - for instance, in customs regulating the methods of cultivation or forbidding alienation without its consent. These rights will also be found surviving in the common pasture, and with still greater persistence in the common woodland.

But while the communism of the village gradually wastes away, there is also a communism on a smaller scale which forms the economic basis of the joint family. The joint family consists of a whole group of relations connected by father-right or motherright, as the case may be; the property of this group is generally administered by the head, but is owned and its produce shared by all in common. It is in strictness indivisible and inalienable. It can neither be sold, given away nor bequeathed. But within this communistic scheme we find private property arising in a variety of forms in very different degrees. Thus, individual members may acquire a peculium on certain conditions. For example, the daughter, who is allowed to retain the savings of her industry and take them away with her on marriage as her dowry. Again, the joint family may break up into separate families; alienation may be allowed under varying restrictions ; ${ }^{5}$ or, finally,

1 This is common among the North American Indians. (Kohler, “Z. f. V. R.," 1897 , p. 402.)

${ }^{2}$ E.g. in many African tribes land is only appropriated while in use. On the other hand, land of ten becomes hereditary among the Foulah of Futajallon, among the Mandingos and the Somali, but uncultivated land falls back to the community. (Post, "A. J.," ii. 169, 170.)

In the Code of Hammurabi, it would seem that leaving the land unoccupied for three years destroys the title to it as against another person who has occupied and cultivated it. (Clause 30.)

3 Thus in India, thougl the lots have become inalienalle, the tradition of redistribution remains. (Mayne, p. 112.) On the other hand, in the Russian Nir, the system of periodical redistribution is, according to Kovalewsky, an innovation. ("Modern Customs and Ancient Laws of Russia," p. 93, ete.)

${ }^{4}$ This appears to be the only form of private property in the Russian joint family down to the present day. (Kovalewsky, "Modern Customs," p. 59.)

${ }_{5} \mathrm{~A}$ strong case is the Hebrew Law of Jubilee by which all land reverted to its original owners at the end of fifty years; this in effect provided that family property should not he permanently alienable. The proprietary rights of the tribe are also maint ained in the priestly code by the rule prolibiting daughters who, failing sons, have inherited property, to marry out of the tribe. (Numbers xxxvi.) NIore commonly a right of repurchase 
the house-father may aequire so much predominance ${ }^{1}$ that the common rights are merged in him.

Without attempting to generalize as to the procesess by which the village or family communism breaks up, we may leare the few points thus noted to suggest the various methods of transition that are possible and the number of gradations whereby the system of private ownership may be approached. But we must note, further, that with the rise of the monarchical or aristocratic kingdom the communal system is apt to be qualified or superseded by some form of feudal tenure. Tassalage and overlordship replace the patriarchate or the joint family. Again, the break up of the feudal organization in the more advanced societies makes room for private ownership. But even here in relation to land there are limitations. Law or custom limits the freedom of bequest and determines the rules of inheritance, so that the apparent owner is more often than not a life tenant only. With these qualifications, however, we may consider private property in land as the general rule in the more adraneed eivilizations. In relation to other forms of property the emancipation of the individual is probably more rapid and certainly more complete. The importance of "stock" or "capital" becomes greater as the arts of life improve, and here, as the joint family breaks up, the individual becomes absolute owner. The evolving conception of property as an absolute personal right has full swing, and in proportion as industry and commeree advance becomes more and more a cardinal point in the common life of society.

It would appear, then, that a double process of development lies behind the modern institution of private property. On the one hand, there is the gradual emergence of the right of ownership as a right. On the other, there is the gradual extension of ownership by individuals as against ownership by families, elans, villages,

remains where alienation has been allowed. The French right of retrait lignager was not finally abolished till 1790. (Yiollet, p. 56i3.)

I In early Rome the family property was eonjoint, but the system was much modified by the power of the Roman paterfamilias and also by the right of the heirs to demand partition at the death of the father. There was also probably a wider primitive community of land as betwen possibly the whole people or more probably the gens. (Girard, p. 249.)

For the varying positions of the father in the Indian houselond, see J. D. Mayne, "Hindu Law and Usage." p. 2222 and following. Magne makes the distinction between the patriarchal and the joint fanily turn on the question whether on the death of the eldest ascendant the family do or do not remain together (p. 223). He points out that under tlie patriarchate all acquired property fell to the father. In this stage the head of the household arequires private property indeed. but at the e $\mathrm{x}-$ pense of all the rest. 
or tribes - an extension standing in close relation to the general break up of the primitive group and the emergence of the free responsible individual as an ethical and legal personality. It appears to be only in relatively high civilizations that private property, getting within its scope the land and - with still more completeness - the other leading means of production, becomes the dominant factor in the economic organization of society.

\section{SECTION 3}

\section{EARLY HISTORY OF PROPERTY AND THE VILLAGE COM- MUNITY 1}

The Village Community is known to be of immense antiquity. In whatever direction research has been pushed into Indian history, general or local, it has alway's found the Community in existence at the farthest point of its progress. A great number of intelligent and observant writers, most of whom had no theory of any sort to support concerning its nature and origin, agree in considering it the least destructible institution of a society which never willingly surrenders any one of its usages to innovation. Concuests and revolutions seem to have swept over it without disturbing or displacing it, and the most beneficent systems of government in India have always been those which have recognised it as the basis of administration.

The mature Roman law, and modern jurisprudence following in its wake, look upon co-ownership as an exceptional and momentary condition of the rights of property. This view is clearly indicated in the maxim which obtains universally in Western Europe, Nemo in communione potest invitus detineri ("No one can be kept in coproprietorship against his will"). But in India this order of ideas is reversed, and it may besaid that separate proprietorship is always on its way to become proprietorship in common. . . . As soon as a son is born, he accuires a vested interest in his father's substance, and on attaining years of discretion he is even, in certain contingencies, permitted by the letter of the law to call for a partition of the family estate. As a fact, however, a division rarely takes place even at the death of the father, and the property constantly remains undivided for several generations, though every member of every generation has a legal right to an undivided share in it. The domain thus held in common is sometimes ad-

1 [By Henty S. Manne. Reprinted from "Ancient Law," by permission of Henry Holt and Company, New York.] 
ministered by an elected manager, but more generally, and in some provinces always, it is managed by the eldest agnate, by the eldest representative of the eldest line of the stock. Such an assemblage of joint propriators, a body of kindred holding domain in common, is the simplest form of an Indian Village Community, but the Community is more than a brotherhood of relatives and more than an assoeiation of partners. It is an organised society, and hesides providing for the management of the common fund, it seldom fails to provide, by a complete staff of functionaries, for internal government, for police, for the administration of justice, and for the apportionment of taxes and public duties.

The process which I have deseribed as that under which a Village Community is formed, may be regarded as typical. Yet it is not to be supposed that every Village Community in India drew together in so simple a manner. Although, in the North of India, the archives, as I am informed, ahmost invariably show that the Community was founded by a single assemblage of blood-relations, they also supply information that men of alien extraction have always, from time to time, been engrafted on it, and a mere purchaser of a share may generally, under certain conditions, be admitted to the brotherhood. In the South of the Peninsula there are often Communities which appear to have sprung not from one but from two or more families: and there are some whose composition is known to be entirely artificial; indeed, the occasional aggregation of men of different eastes in the same society is fatal to the hypothesis of a common descent. Yet in all these brotherhoods either the tradition is preserved, or the assumption made, of an original common parentage. Mountstuart Elphinstone, who writes more particularly of the Southern Village Communities, observes of them (" History of India," p. 71, 1905 e(nn.) : "The popular notion is that the Village landholders are all descended from one or more individuals who settled the Village; and that the only exceptions are formed hy persons who have derived their rights by purchase or otherwise from members of the original stock. The supposition is confirmed by the fact that, to this day, there are only single families of landholders in small rillages and not many in large ones; but each has branehed out into so many members that it is not uncommon for the whole agricultural labour to be done by the landholders, without the aid either of tenants or of labourers. The rights of the landholders are theirs collectively, and, though they almost always have a more or less perfect partition of them, they never have an entire separation. A 
landholder, for instance, can sell or mortgage his rights; but he must first have the consent of the Village, and the purchaser steps exactly into his place and takes up all his obligations. If a family becomes extinct, its share returns to the common stock."

. . No institution of the primitive world is likely to have been preserved to our day, unless it has acquired an elasticity foreign to its original nature through some vivifying legal fiction. The Village Community then is not necessarily an assemblage of blood-relations, but it is cither such an assemblage or a body of co-proprietors formed on the model of an association of kinsmen. The trpe with which it should be compared is evidently not the Roman Family, but the Roman Gens or House. The Gens was also a group on the model of the family; it was the family extended by a variety of fictions of which the exact nature was lost in antiquity. In historical times, its leading characteristics were the very two which Elphinstone remarks in the Village Community. There was always the assumption of a common origin, an assumption sometimes notorionsly at variance with fact: and, to repeat the historian's words, "if a family became extinct, its share returned to the common stock." In old Roman law, unclaimed inheritances escheated to the Gentiles. It is further suspected by all who have examined their history that the Communities, like the Gentes, have been very generally adulterated by the admission of strangers, but the exact mode of absorption cannot now be ascertained. At present, they are recruited, as Elphinstone tells us, by the admission of purchasers, with the consent of the brotherhood. The acquisition of the adopted member is, however, of the nature of a universal succession; together with the share he has bought, he succeeds to the liabilities which the vendor had incurred towards the aggregate group. He is an Emptor Familiae, and inherits the legal clothing of the person whose place he begins to fill. The consent of the whole brotherhood required for his admission may remind us of the consent which the Comitia Curiata, the Parliament of that larger brotherhood of self-styled kinsmen, the ancient Roman commonwealth, so strenuously insisted on as essential to the legaljsation of an Adoption or the confirmation of a will.

The tokens of an extreme antiquity are discoverable in almost every single feature of the Indian Village Communities. We have so many independent reasons for suspecting that the infancy of law is distinguished by the prevalence of co-ownership, by the intermixture of personal with proprietary rights, and by the confusion of public with private duties, that we should be justified in 
deducing many important conchusions from our observation of these proprietary brotherhoods, even if no similarly compounded societies could be detected in any other part of the world. It happens, however, that much earnest curiosity has been very recently attracted to a similar set of phenomena in those parts of Europe which have been most shightly affected by the feudal transformation of property, and which in many important particulars have as close an affinity with the Eastern as with the Western world. The researches of M. de Haxthausen, M. Tengohorski, and others, have shown us that the Russian villages are not fortuitous assemblages of men, nor are they mions founded on contract ; they are naturally organised communities like those of India. It is true that these villages are always in theory the patrimony of some noble proprietor, and the peasants have within historical times been converted into the predial, and to a great extent into the personal, serfs of the seignior. But the pressure of this superior ownership has never crushed the ancient organisation of the village, and it is probable that the enactment of the Czar of Russia, who is supposed to have introduced serflom, was really intended to prevent the peasants from abandoning that co-operation without which the old social order could not long be maintained. In the assumption of an agnatic comection between the villagers, in the blending of personal rights with privileges of ownership, and in a variety of spontaneous provisions for internal administration, the Russian village appears to be a nearly exact repetition of the Indian Community ; but there is one important difference which we note with the greatest interest. The co-owners of an Indian village, though their property is blended, have their rights distinc't, and this separation of rights is complete and continues indefinitety. The severance of rights is also theoretically complete in a Russian village, but there it is only temporary. After the expiration of a given, but not in all cases of the same, period, separate ownerships are extinguished, the land of the village is thrown into a mass, and then it is redistributed among the families composing the community, according to their number. This repartition having been effected, the rights of families and of individuals are again allowed to branch ont into various lines, which they continue to follow till another period of division comes romnd. An even more curious variation from this type of ownership occurs in some of those countries which long formed a debatable land between the Turkish Empire and the possessions of the IIouse of Anstria. In Servia, in Croatia, and the Austrian Silavonia, the villages are also brother- 
hoods of persons who are at once co-owners and kinsmen; but there the internal arrangements of the community differ from those adverted to in the last two examples. The substance of the common property is in this case neither divided in practice nor considered in theory as divisible, but the entire land is cultivated by the combined labour of all the villagers, and the produce is annually distributed among the households, sometimes according to their supposed wants, sometimes according to rules which give to particular persons a fixed share of the usufruct. All these practices are traced by the jurists of the East of Europe to a principle which is asserted to be found in the earliest Sclavonian laws, the principle that the property of families camot be divided for a perpetuity.

The great interest of these phenomena in an inquiry like the present arises from the light they throw on the development of distinct proprietary rights inside the groups by which property seems to have been originally held. We have the strongest reason for thinking that property once belonged not to individuals nor even to isolated families, but to larger societies composed on the patriarchal model; but the mode of transition from ancient to modern ownerships, obscure at best, would have been infinitely obscurer if several distinguishable forms of Village Communities had not been discovered and examined. It is worth while to attend to the varieties of internal arrangement within the patriarchal groups which are, or were till recently, observable among races of Indo-European blood. The chiefs of the ruder Highland clans !sed, it is said, to dole out food to the heads of the households under their jurisdiction at the very shortest intervals, and sometimes day by day. A periodical distribution is also made to the Sclavonian villagers of the Austrian and Turkish provinces by the elders of their body, but then it is a distribution once for all of the total produce of the year. In the Russian villages, however, the substance of the property ceases to be looked upon as indivisible, and separate proprietary (laims are allowed freely to grow up, but then the progress of separation is peremptorily arrested after it has continued a certain time. In India, not only is there no indivisibility of the common fund, but separate proprietorship in parts of it may be indefinitely prolonged and may branch out into any number of derivative ownerships, the de facto partition of the stock being, however, checked by inveterate usage, and by the rule against the admission of strangers without the consent of the brotherhood. It is not of courseintended to insist that these different forms of the Village Community represent distinct stages in a 
process of transmutation which has been every were accomplished in the same manner. But, though the evidence does not warrant our going so far as this, it renders less presumptuous the conjecture that private property, in the shape in which we know it, was chiefly formed by the gradual disentanglement of the separate rights of individuals from the blended rights of a community. Our studies in the Law of Persons seemed to show us the Family expanding into the Agnatic group of linsmen; then the Agnatic group dissolving into separate households; lastly, the household supplanted by the individual; and it is now suggested that each step in the change corresponds to an analogous alteration in the nature of Ownership. If there be any truth in the suggestion, it is to be observed that it materially affects the problem which theorists on the origin of Property have generally proposerl to themselves. The question - perhaps an insoluble one - which they have mostly agitated is, what were the motives which first induced men to respect each other's possessions? It may still be put, without much hope of finding an answer to it, in the form of an inquiry into the reasons which led one composite group to keep aloof from the domain of another. But, if it be true that far the most important passage in the history of Private Property is its gradual separation from the co-ownership of kinsmen, then the great point of inquiry is identical with that which lies on the threshold of all historical law - what were the motives which originally prompted men to hold together in the family union? To such a question, Jurisprudence, unassisted by other sciences, is not competent to give a reply. The fact can only be noted.

The undirided state of property in ancient societies is consistent with a peculiar sharpness of division, which shows itself as soon as any single share is completely separated from the patrimony of the group. This phenomenon springs, doubtless, from the circumstance that the property is supposed to become the domain of a new group, so that any dealing with it, in its divided state, is a transaction between two highly complex bolies. I have already compared Ancient Law to Modern International Law, in respect of the size and complexity of the corporate associations, whose rights and duties it settles. As the contracts and conveyances known to ancient law are contracts and conveyinces to which not single individuals, but organised companies of men, are parties, they are in the highest degree ceremonious; they require a variety of symbolical acts and words intended to impress the business on the memory of all who take part in it ; and they demand the pres- 
rnce of an inordinate number of witnesses. From these peculiarities, and others allied to them, springs the universally unmalleable character of the ancient forms of property. Sometimes the patrimony of the family is absolutely inalienable, as was the case with the Stavonians, and still oftener, though alienations may not be entirely illegitimate, they are virtually impracticable, as among most of the Germanic tribes, from the neeessity of having the consent of a large number of persons to the transfer. Where these impediments do not exist, or can be surmounted, the act of converance itself is generally burdened with a perfect load of ceremony, in which not one iota can be safely neglected. Ancient law uniformly refuses to dispense with a single gesture, however grotesque; witl a single syllable, however its meaning may have been forgotten; with a single witness, however superfluous may be his testimony. 'The entire solemnities must be serupulously completed by persons legally entitled to take part in it, or else the conveyance is mull, and the seller is re-established in the rights of which he had vainly attempted to divest himself.

These various obstacles to the free circulation of the objects of use and enjoyment, begin of course to make themselves felt as soon as socicty has acquired even a slight degree of activity, and the expedients by which advancing communities endeavour to overcome them form the staple of the history of Property. Of such expedients there is one which takes precedence of the rest from its antiquity and umiversality. The idea seems to have spontaneously suggested itself to a great number of early societies, to classify property into kinds. One kind or sort of property is placed on a lower footing of dignity than the others, but at the same time is relieverl from the fetters which antiquity has imposed on them. Subsecuently, the superior convenience of the rules governing the transfer and descent of the lower order of property becomes generally recognised, and by a gradual course of innovation the plasticity of the less dignified class of valuable objects is communicated to the classes which stand conventionally higher. The history of Roman Property Law is the history of the assimilation of Res Mancipi to Res Nee Mancipi. The history of Property on the European continent is the history of the subversion of the feudalised law of land by the Romanised law of movables; and though the history of ownership in England is not nearly completed, it is visibly the law of personalty which threatens to absorb and annihilate the law of realty.

The only natural classification of the objects of enjoyment, the 
only classification which corresponds with an essential difference in the subject-matter, is that which divides them into Norables and Immovables. Familiar as is this classification to jurisprudence it was very slowly dereloped by Roman law, from which we inherit it, and was only finally adopted by it in its latest stage. The classifications of Ancient Law have sometimes a superficial resemblance to this. They occasionally divide property into categories, and place immovables in one of them; but then it is found that they either class along with immovables a number of objects which have no sort of relation with them, or else divorce them from various rights to which they have a close affinity. Thus the Res Mancipi of Roman Law inchided not only land but slaves, horses, and oxen. Scottish law ranks with land a certain class of securities, and Hindoo law associates it with slaves. English law, on the other hand, parts leases of land for years from other interests in the soil, and joins them to personalty under the name of chattels real. Moreover, the classifications of Ancient Law are classifications implying superiority and inferiority; while the distinction between movables and immovables, so long at least as it was confined to Roman jurisprudence, carried with it no suggestion whatever of a difference in dignity. The Res Mancipi, however, did certainly at first enjoy a precedence over the Res Nec Mancipi, as did heritable property in Scotland, and realty in England, over the personalty to which they were opposed. The lawyers of all systems have spared no pains in striving to refer these classifications to some intelligible principle; but the reasons of the severance must ever be vainly sought for in the philosophy of law: they belong not to its philosophy, but to its history. 'The explanation which appears to cover the greatest number of instances is, that the objects of enjoyment honoured above the rest were the forms of property known first and earliest to each particular community, and dignified therefore emphatically with the designation of Property. On the other hand, the articles not enumerated among the favoured objects seem to have been placed on a lower standing because the knowledge of their value was posterior to the epoch at which the catalogue of superior property was settled. They were at first unknown, rare, limited in their uses, or else regarded as mere appendages to the privileged objects. 'Thus, though the Roman Res Mancipi included a number of movable articles of great value, still the most costly jewels were never allowed to take rank as Res Mancipi, because they were unknown to the early Romans. In the same way chattels real in England are said 
to have been degraded to the footing of personalty, from the infrequency and rahuelessness of such estates under the fendal landlaw. But the grand point of interest is the continued degrarlation of these commodities when their importance had increased and their number had multiplied. Why were they not successively included among the faroured objects of enjoyment? One reason is found in the stubbormess with which Ancient Law adheres to its classifications. It is a characteristic both of uneducated minds and of carly societies, that they are little able to conceive a general rule apart from the particular applications of it with which they are practically familiar. They cannot dissociate a general term or maxim from the special examples which meet them in daily experience; and in this way the designation covering the bestknown forms of property is denied to articles which exactly resemble them in being objects of enjoyment and subjects of right. But to these influences, which exert peculiar force in a subjectmatter so stable as that of law, are afterwards added others more consistent with progress in enlightenment and in the conceptions of general expediency. Courts and lawyers become at last alive to the inconvenience of the embarrassing formalities required for the transfer, recovery, or devolution of the favoured commodities, and grow unwilling to fetter the newer descriptions of property with the technical trammels which characterised the infancy of law. Hence arises a disposition to keep these last on a lower grade in the arrangements of Jurisprudence, and to permit their transfer by simpler processes than those which, in archaic conveyances, serve as stumbling-blocks to good faith and stepping-stones to fraud. We are perhaps in some danger of under-rating the inconveniences of the ancient modes of transfer. Our instruments of conveyance are written, so that their language, well pondered by the professional draftsman, is rarely defective in accuracy. But an ancient conveyance was not written, but acted. Gestures and words took the place of written technical phraseology, and any formula mispronounced, or symbolical act omitted, would have vitiated the proceeling as fatally as a material mistake in stating the uses or setting out the remainders would, two hundred years ago, have vitiated an English deed. Indeed, the mischiefs of the archaic ceremonial are even thus only half stated. So long as elaborate conveyances, written or acted, are required for the alienation of land alone, the chances of mistake are not considerable in the trinsfer of a description of property which is seldom got rid of with much precipitation. But the higher class of property in the 
ancient world comprised not only land but several of the commonest and sereral of the most raluable movables. When once the wheels of society had begun to move quickly, there must have been immense inconvenience in demanding a highly intrieate form of transfer for a horse or an ox, or for the most costly chattel of the old world - the Slave. Such commodities must have been constantly and even ordinarily convered with incomplete forms, and held, therefore, under imperfect titles.

The Res Mancipi of old Roman law were, land, - in historical times, land on Italian soil, - slaves and beasts of burden, such ats horses and oxen. It is impossible to doubt that the objects which make up the class are the instruments of agricultural labour. the commodities of first consequence to a primitive people. Such commodities were at first, I imagine, called emphatically Things or Property, and the mode of converance by which they were transferred was called a Mancipium or Mancipation; but it was not probably till much later that they received the distinctive appellation of Res Mancipi, "Things which require a Mancipation." By their side there may have existed or grown up a class of objects, for which it was not worth while to insist upon the full ceremony of Mancipation. It would be enough if, in transferring these last from owner to owner, a part only of the ordinary formalities were proceeded with, namely, that actual delivery, physical transfer, or tradition, which is the most obvious index of a change of proprietorship. Such commodities were the Res Nec Mancipi of the ancient jurisprudence, "things which did not require a Mancipation," little prized probably at first, and not often passed from one group of proprietors to another. While, however, the lint of the Res Mancipi was irrevocably closed, that of the Res Nec Mancipi admitted of indefinite expansion; and hence every fresh conquest of man over material miture adeled an item to the Res Nec Mancipi, or effected an improvement in those already recognised. Insensibly, therefore, they mounted to an equality with the Res Mancipi, and the impression of an intrinsic inferiority being thus dissipated, men began to observe the manifold advantages of the simple formality which accompanierl their transfer over the more intricate and more venerable ceremonial. Two of the agents of legal amelioration, Fictions and Equity, were assiduously employed by the Roman lawers to give the practical effects of a Mancipation to a Tradition; and, thongh Roman legislators long shrank from enacting that the riglit of property in a Res Mancipi should be immediately transferred by bare delivery 
of the article, yet eren this step was at last ventured upon by Justinian, in whose jurisprudence the difference between Res Mancipi and Res Nee Mancipi disappears, and Tradition or Delivery becomes the one great conveyance known to the law. The marked preference which the Roman lawyers very early gave to Tradition caused them to assign it a place in their theory which has helped to blind their modern disciples to its true history. It was classed among the "natural" modes of acquisition, both because it was generally practised among the Italian tribes, and hecause it was a process which attained its object by the simplest mechanism. If the expressions of the jurisconsults be pressed, they undoubtedly imply that Tradition, which belongs to the Law Natural, is more ancient than Mancipation, which is an institution of Civil Society; and this, I need not say, is the exact reverse of the truth.

The distinction between Res Mancipi and Res Nec Mancipi is the type of a class of distinctions to which civilisation is much indebted, distinctions which run through the whole mass of commodities, placing a few of them in a class by themselves, and relegating the others to a lower category. The inferior kinds of property are first, from disdain and disregard, released from the perplexed ceremonies in which primitive law delights, and then afterwards in another state of intellectual progress, the simple methods of transfer and recovery which have been allowed to come into use serve as a model which condemns by its convenience and simplicity the cumbrous solemnities inherited from ancient days. But in some societies, the trammels in which Property is tied up are much too complicated and stringent to be relaxed in so easy a manner. Whenever male children have been born to a Hindoo, the law of India, as I have stated, gives them all an interest in his property, and makes their consent a necessary condition of its alienation. In the same spirit, the general usage of the old Germanic peoples - it is remarkable that the Anglo-Saxon customs seem to have been an exception - forbade alienations without the consent of the male children; and the primitive law of the Sclavonians even prohibited them altogether. It is evident that such impediments as these cannot be overcome by a distinction between kinds of property, inasmuch as the difficulty extends to commodities of all sorts; and accordingly, Ancient Law, when once launched on a course of improvement, encounters them with a distinction of another character, a distinction classifying property, not according to its nature but according to its origin. In India, where there 
are traces of both systems of classification, the one which we are considering is exemplified in the difference which Hindoo law establishes between Inheritances and Aequisitions. The inherited property of the father is shared by the chilitren as soon as they are born; but according to the custom of most provinces, the acquisitions made by him during his lifetime are wholly his own, and can be transferred by him at pleasure. A similar distinction was not unknown to Roman Law, in which the earliest innovation on the Parental Powers took the form of a permission given to the son to keep for himself whatever he might have acquired in military service. But the most extensive use ever made of this mode of classification appears to have been among the Germans. I have repeatedly stated that the allod, though not inalienable, was commonly transferable with the greatest difficulty; and moreover, it descended exclusively to the agnatic kindred. Hence an extraordinary variety of distinctions came to be recognised, all intended to diminish the inconveniences inseparable from allodial property. The wehrgeld, for example, or composition for the homicide of a relative, which occupies so large a space in German jurisprudence, formed no part of the family domain, and descended according to rules of succession altogether different. Similarly, the reipus, or fine leviable on the re-marriage of a widow, did not enter into the allod of the person to whom it was paid, and followed a line of devolution in which the privileges of the agnates were neglected. The law, too, as among the Hindoos, distinguished the Acquisitions of the chief of the household from his Inherited property, and permitted him to deal with them under much more liberal conditions. Classifications of the other sort were also admitted, and the familiar distinction drawn between land and morables; but movable property was divided into several subordinate categories, to each of which different rules applied. This exuberance of classification, which may strike us as strange in so rude a people as the German conquerors of the Empire, is doubtless to be explained by the presence in their systems of a considerable element of Roman Law, absorbed by them during their long sojourn on the confines of the Roman dominion. It is not difficult to trace a great number of the rules governing the transfer and devolution of the commorities which lay outside the allod, to their source in Roman jurisprudence, from which they were probably borrowed at widely distant epochs, and in fragmentary importations. 


\section{SECTION +}

\section{THE VILLAGE COMAUNITY AS A PRIMITIVE INSTITUTION ${ }^{2}$}

In order to understand properly what the village communities of Britain really represent in the history of our race, it is necessary we should start with a clear view of what a village community is. The term has become popular, and has lost somewhat of its more precise historical and archeological meaning. The two sourees of its popularity in England are the writings of Sir Henry Maine and Mr. Frederic Seebohm. Sir Henry Maine some years since drew attention to the traces of the village community in English loeal institutions and customs, basing his proofs upon the parallel which exists between some English and Indian phenomena. Mr. Seebohm, more recently, has chronologically traced back the existence of certain economical phenomena in English villages to a period which, speaking roughly, may be identified with the Roman oceupation of this island, and he seeks, in the events of this period, the origin of the village community in its English form. And it happens that, in the contrast between the village community as represented by each of these great scholars, the institution which the term connotes has become somewhat indefinite and obseure. A group of men cultivating their lands in common and having rights and duties in common is the typical form; but students are divided as to whether this institution is of historical origin and growth, or of primitive origin and growth.

It is just this question of origin which is of the first importance, and if, as I suggest, the village community can be proved to be a primitive institution, this must have a most important bearing upon its history in Britain. It means that the village community originated at a stage of social development long prior to the political stage, and that hence its appearance among the local institutions of Britain is of the nature of a survival from prehistoric times. If this riew is once fully understood and accepted, much of the difficulty arising from a conflict in terminology will vanish, beeause the whole methot of future research must be coloured by the evidence as to origin. If the village community is of primitive origin, and its later existence a surviral, we should be able to note its opposition to the political phenomena of eirilized history. If it arises out of the adranced political organization of the Roman

1 'By George Latrence Gomme, "The Village Community," (Ch. I), London. The Walter Scott Publishing Company, Limited, 1890; republished by permission.] 
Empire we should be able to note that it has developed into and forms part of the political and economical phenomena of civilized history, which, indeed, under this hypothesis it must have helped to form; for, with all the spur of Roman civilization, it must have so influenced English institutions as to make English institutions themselves but a continuation of Roman institutions. Thus the evidence as to origin is of great importance; and before we can properly examine the trpes in Britain, or ascertain what they really represent in English history, we must know something of the more primitive types, which alone can tell us anything of origin.

If the village community is a primitive institution, it must be granted that from the present position of the subject in the hands of those students who have dealt with it, there are some considerable obstacles to be got over in taking up this new position. In the first place, we must sooner or later come to the question of race in the formation of such an institution, because in Britain alone we have certain evidence of an Iberic, a celtie, and a Tentonic population, all of which lived in communities, and all of which have left their mark upon later British history. With the researches of Professor Boyd Dawkins and Mr. Elton before us, it is idle to attempt an investigation into any section of English institutions without taking count of the ethnic influences. Secondly, we have to disentangle ourselves from the notion that the form in which the village community is found in Britain could only have arisen from the influences of civilizing powers, a position forced upon us by Mr. Seebohm; we have to get rid of the idea that as an institution it is a special heritage of the Aryan race, a position forced upon us by sir Henry Maine. And, finally, we shall have to establish if possible that it is exactly similar in its wide extension to other ascertained phases of human society, and must, therefore, be reckoned with as one of the phases throngh which practically all mankind who have reached a certain stage of development must have passed. Thus it will be seen that in attempting to investigate the village communities of Britain our study is, in fact, a chapter in the science of comparative custom, not in the chronologieal history of a nation. What we shall be doing is to trace out the history of an institution, which may be said to be almost universal, during its existence in a special commtry, namely, Britain, where it has been subject to special influences; it is not the history of a British institution, but the history of a human institution in Britain. 
It seems remarkable that the early history of institutions in this country, and in the Western world generally, should have been so infrequently studied side by side with the monumental and other evidence of the existence of different ethmic stocks. Cave dwellers, hill men, lake dwellers, dolmen builders, have all left very important proofs of their lengthened occupation of this country, but their influences are never reckoned with when anything but monumental archeology is being considered. Mr. Elton was the first to point out that certain rude customs among the peasintry could best be accounted for by the theory of their survival from non-Aryan tribes; but, except to explain the prevalence of junior right in a certain well-defined tract of country, he does not suggest that this survival may possibly direct our attention to these race influences for an explanation of much that is obscure in our remarkably diversified local institutions. In the meantime Sir Henry Maine had put a more express limit upon the value of race influences in comparative jurisprudence. The tribes of men with which the student of jurisprudence is concerned, he tells us, are exclusively those belonging to the races now universally classed, on the ground of linguistic affinities, as Aryan and Semitic: besides these he has at most to take into account that portion of the ontlying mass of mankind which has lately been called Uralian, the 'Turks, Hungarians, and Finns. ${ }^{1}$

Now an appeal to comparative custom to unlock some of the hidden secrets of our own early life means that we must study not only the prehistoric monments and the barbaric customs of Aryan nations, but the very rude forms of life still existing; for, as Mr. McLemnan has well observed, the preface of general history must be compiled from the materials presented by barbarism. Rude stone monuments tell us something of the rude people who built them; philology tells us something of the archaic social conditions of Aryan man; but the knowledge gained from these two sources of scientific observation, however true as to general outline, is not rich in cletail. For this we ean only go to comparative custom; and it is in detail that an institution like the village community must be examined.

Comparative custom, not seeking for evidences of early man merely in the written records of ancient nations, does not define as old everything that is chronologically early. It has ascertained that man is an unchanging being under certain conditions which have been present over a large part of the globe; it there1 "Early History of Institutions," p. 65. 
fore seeks for eridence of early man from the unchanged representatives still living, and it defines as old that which has not advanced and become progressive. If we can find rude types of the village community in India and in Europe, we may conclude that these rude types are probably as old as the Indo-European race; and if we can go one step further and find rude types of the village community in still more backward races of the world, we may conclude that these rude types show us what early man was capable of doing in the matter of social and economical organization before there was any chance of his contact with any civilized or civilizing sirstem.

This seems to be the necessary starting-point in our researches. We must first note some of the details available from this source of information, in order to set forth as clearly as may be that the village community belongs essentially to the primitive and archaic stage of social development; and we can then see if there are any traces of continuity between the rudest forms of this institution and the forms found to exist in civilized Britain.

For this purpose I shall first of all turn to some examples of the village community among sarage races, and I shall choose the Fijians, the Basutos, and the Dyaks. Low down in the scale of humanity, it will be seen that these people have yet developer a system of village economy remarkably close to that surviving in India and Europe. The effect of such evidence is twofold. It shows that the mental efforts which called forth such a system did not serve to make the race other than savages; and it suggests that in these sarage institutions we have types of the early stages of our own history when the village community was first formed. It may seem a far-off ery from the Fijians of to-day to the inhabitants of our own island in prehistoric days; but while we know from the evidence of monumental remains that man in his most primitive condition lived in these islands long enough to impress his barbarism upon the successive waves of civilization, while we can trace evidences of that stage of barbarism in a race of people which must at least have extended from Central Asia to Britain, and while we know that modern savagedom retains habits and beliefs which best explain the silent monuments of ancient saragedom, ${ }^{1}$ it is abundantly clear that to understand the survivils of

1 A very good example of this is to be found in Dr. E. B. Tylor's comparison of the Digging Sticks as the earliest agrienltural implements, used both among the North Amerioan Indians and in sweden, and the system of shifting-brand tillage among the Basutos and in Sweden. See "Contemporary Review," vol. xxii, p. 64. 
early institutions in civilized countries, we must examine existing types of these self-same institutions in the rutest form in which they are to be found. And if authority is needed for such a course as I propose to take, I am content to stand by the great name of Dr. E. B. 'Tylor, who, in one of his most pregnant essays on primitive society, connects the various steps in the history of legal ownership of land by evidence which commences with the low sarages of Brazil, and leads up to the old Scandinarian and Teutonic communities. "The case is indeed plain," says Mr. Tylor, "showing us that while we have a land law modified from that of our barbaric ancestors, their law again had its origin in the simplest form of tenure still to be found among savages who have but just come to the agricultural stage." 1

But there is something more to be sait for such a comparison. I have suggested that an examination of the village community among the most backward races will go far to establish the widespread extension of this institution as a phase of development through which mankind must have passed to reach civilization. And let me note how necessary a complement this is to those other researches into the early history of man which are identified with the names of Tylor, McLennan, Morgan, and Lubbock. These scholars have established landmarks in the social, religious, and mental derelopment of man to which every day brings further research, cither confirming or varying the conclusions arrived at. But nothing, or very little, has been attempted to set out the landmarks of primitive economics. The totem tribes, with female kinship and exogamous marriages, in their progress towards male kinship and full tribal society, built their stone circles and their burial mounds, their rude habitations, their extensive defences against hostile tribes, and we are beginning more and more to trace out the connection between the monuments ant their builelers. But there also existed throughout all this period of early culture a system of economics which governed or marked the life of the tribes. Primitive economical conditions are just as important in tracing out the early history of man and the bearings of that early history upon all succeeding periods as other primitive conditions. They may be studied by the same methods, illustrated by the same types of modern barbarism, and traced along the same lines of development, which have been adopted in the corresponding studies of early man; and thus, when from the evidence of contemporary savagedom we for our 
present purposes come to select one or two instances to guide us to the earliest stages of primitive economics, we may allow this evidence to stand as typical of what further rescarch would bring forth upon the question of the widespread existence of the village community.

Proof of this widespread existence of a definite primitive economical sistem cannot now be undertaken, because it is a subject by itself, and needs immense research into some of the byways of the literature of travellers. But I may indicate some of the lines which such a study would proceed upon, and where such lines converge upon the examples I shall more particularly examine. It appears to me that the true way to study primitive economics is to commence with the structural details of primitive residences.

In prehistoric archeology a very considerable section is occupied by the remains - sometimes structural, sometimes consisting of mere deposits of domestic utensils - of early dwelling places. In savage archæology we meet with examples of early dwelling places peopled still by those who built or adapted them. If there is an overlapping of these two departments of archrology at any given point, they must illustrate and elucidate each other, because they both deal with the same phenomenon - the swarming of human groups into their shells during a vast period of time. It is important, therefore, to ascertain, if possible, whether such an overlapping does take place, and if so, at what point.

But to accomplish this task with anything like success it would be necessary to gather together the evidence, now almost hopelessly scattered, as to the dwelling places and home economy of the savage races. Only one authority, so far as I know, has paid close attention to this subject, namely, the late Mr. Lewis Morgan, but his book relates entirely to the evidence derived from the American Indians. His researches, however, into this branch of the human race are so true that it is not unimportant to note that they are confirmed in all essential particulars when we extend the area of research to other uncivilized peoples. For the rest, it would be necessary to pick our way among the recorded observances of travellers who have scldom noted the essentials of salvage economics.

Mr. Tylor has remarked that "thinking of the nests of hirds, the dams of beavers, the tree platforms of apes, it can scarcely be supposed that man at any time was unable to build himself a shelter." I That he does not do so is due to causes which are 1 "Anthropology." p. 22:9. 
inscparably connected, though how we cannot exactly say, with the form of the society in which he is living. In such types of society which may perhaps best be identified with the primitive human horde to which Mr. McLennan worked back, ${ }^{1}$ there is no room for artificially-built dwellings. Such, for instance, are the wild Bushmen of South Africa. "A cave with its opening protected by a few branches, or the centre of a small circle of thorn trees, round which skins of wild animals were stretehed, was the best dwelling place that they aspired to possess; if neither of these were within their reach they scooped out a bole in the ground, placed a few sticks or stones round it, and spread a skin above to serve as a roof, or sometimes nothing more than a reed mat on the side from which the wind was blowing: a little grass at the bottom of the hole formed a bed, and though it was not much litrger than the nest of an ostrich, a whole family would manage to lie down in it." 2 This is the indiscriminate squatting of a human horde, the atoms of which are kept together by forces which operate from outside, instead of by forces originating from the recognition and use of the ties of blood relationship, as among more advanced peoples. The use of constructed dwellings would not fit in with the mental attitule or with the unregulated individualism of this stage of human life, and accordingly it seems possible to date the rise of a permanent form of dwelling from the time when blood kinship began to be utilized in the building-up of society. Much profitless discussion has taken place upon Mr. McLennan's theory as to a period in human history when blood relationship was not recognized. That blood relationship has always de facto existed of course needs no proof ; that it has always to some extent been one of the means of calling forth the springs of natural affection in the human race, may be accepted also as a general fact; that it has not always been utilized as the foundation of political societies, that it has not always been made the cement which bound large groups of men and women together, are the points to which Mr. MICLennan has directed attention.

The stage when permanent forms of artificial dịellings were constructed seems to mark a definite point in the line of development; and we may proceed from it to fix upon such races as the Fijians, Basutos, and Draks as sufficiently indicative of the rudest forms of the village community. When we have examined the details presented by these examples we shall be

${ }^{1}$ Cf. my paper in "Journ. Anthrop. Inst.," vol. XVII, pp. 118-133.

2 Theal's "Compendium of South African History," p. 55. 
able to affirm that the formation of the village community as a human institution arose in the period of primitive economics, and that a reasonable conclusion may be drawn from this, namely, that its existence among economical conditions which were not primitive is not due to such conditions, but to a resistance which all primitive institutions actively exert when they are brought into antagonism with a sistem which must in the end overthrow them.

(a) Villages in Fiji are sometimes inhabited by land-owning tribes, and sometimes by people who have no land of their own. Our business is with the former of these two classes, but it is worth while pointing out that the existence of this distinction shows some advance in social derelopment. The village inhabited by landowners is surrounded by moat and mound and war-fence. It is divided into two sections separated by a ditch, which sections are subdivided into quarters. Apparently in some cases the sections do not appear, but the quarters generallỵ do.

The houses are thus arranged. Each family group has its own town lot. It is subdivided into smaller lots until each family or household has its own. 'This is the precinct, and may be surrounded by a fence at the will of its owners. Each family lot must be built upon so as to leave a pathway between it and the adjoining lot. It is sacred against all encroachments of any kind.

Each of the quarters belongs to a section of the community called a mataqali, a word which means literally a number of men who are twisted together, i.e., of common descent. It is composed of the descendants of a hand of brothers, from each of which is descended a minor division called a yavust, and each yavusa may be again subdivided into a number of vuvale, consisting of brothers with their families who inhabit either the same house or adjoining houses. The people of a village are theoretically of common desecut, thomgh they are not actually so.

The village has its own lands distinct from those of other villages. They are of three kinds: (1) the Iaru or town lot; (2) The Qele, or arable land; (3) the Veikau, or forest. The town lot, as we have noted, is that which is occupied by the house and the garden, and there seems to be a close connection between this town lot and the arable land, the ownership of one appearing to go far towards establishing that of the other. The arable land lies beyond the village. In some places it is clivided into lots, and subdivided into smaller lots, each having its owner 
or owners. Elscwhere it is not so divided, and all the joint owners appear to use any piece that may be convenient. Beyond the arable is the forest. It is not subdivided like the arable, but is common to all the matarali of the village. Its members have the joint right of felling timber for building and other purposes, but one community may not trespass upon the forest of another. ${ }^{1}$

(b) The villages of the Dykas of Borneo are mostly built along the banks of the rivers, thongh here and there are solitary houses hidden from view among the forests at a short distance from a stream or creek. The houses are from 80 to 100 feet in length, 20 to 30 feet in width, and with walls about 10 feet high, the ridge of the roof rising another 5 or 6 feet. The house proper has only one floor, raised about 15 to 20 feet from the ground on posts of hard timber. Under the actual habitation is a raised floor or platform of boards and bamboo poles, about 4 or 6 feet from the level of the ground, and open on all sides. Here the women pound their rice, the men hold bitcharas or councils, the infants are nursed, and the rising generation play or practise war-dances. The ground under and around these platforms is occupied by the pigs, cats, dogs, and fowls. The floor of the house proper is reached by a ladder consisting of a block of timber or thick board, in which deep notches are cut to form steps. The floor is composed of bamboo and the walls of mixed bamboo and timber boards. The roof is covered with wood or with the split leaves of the nipa palm. Internally the house is divided longitudinally by a bamboo partition. One of the long compartments so formed serves as a sleeping place for the unmarried youths and men, and as a general living room for all the occupants; the other compartment is subdivided into a series of smaller rooms for the married members of the family and the women.

Every Dyak has his rice-field, on which he grows sufficient rice for his own consumption. He selects a piece of forest land and begins, with the assistance of his family, to clear the ground. The large trees are cut down and the undergrowth fired, the ashes of which act as manure. Having sown their rice, they build small huts in the rice-fields, remaining there till the miniature plants are transplanted out into the newly-cleared field, on which the women have all the time been busily engaged.

Near the houses are plantations of maize, bananas, pisangs, a sort of turnip, sugar-cane, penang, and a few cocoa-nut palms. Their agricultural implements are the mandau and a peculiar

$$
1 \text { "Journ. Anthrop. Inst.," vol. X, p. } 332 \text { et seq. }
$$


axe or adze, the iron of which is fastened with cords made from the sinews of deer plaited in chequer fashion to a shaft made of a piece of hard wood. This again is stuck into a large handle, to which it is firmly fastened by means of gutta-percha. ${ }^{\text {? }}$

(c) The tribes of the Basutos are subdivided into groups, which form a number of little villages, motsis, placed unler influential men. The rillage settlement is nearly always in the form of a rast circle, the centre being occupied by the flocks, while the huts form the circumference. The site being chosen, the chief drives into the ground a peg covered with charms, in order that the village may be firmly nailed to the soil. The highest spot is reserved for the habitation of the chief. Near this is a large court, formed by a circle of rushes or boughs, which is the general place of resort for the men, but women are not allowed to enter. Here public affairs are discussed, lawsuits decided, and criminal causes adjudged. In the centre of the village are large enclosures, perfectly round, formed of branches of the mimosa, in which the cattle are shut in the evening: the ground is so holy that it serves as a burial-place for the chiefs and their families.

In the country of the Batlapsis, the Barolongs, and the Baharutsis, where the heat is excessive and wood abundant, the hut is high and well rentilated. It is in the form of a conical dome, round which is a little rerandah which serves to support the roof. The Basutos, who inhabit a mountainous country, endeavour to shut out the cold and wet, and their huts are in the form of a large oval oven, and are entered by creeping along a very narrow passage, which serves to prevent the wind from reaching the interior. The walls are perfectly well plastered, and often decorated with ingenious designs. The sleeping place is on the ground. The most remote part of the hut generally serves as a receptacle for the enormous vases of coarse carthenware, containing the provision of wheat, and other articles of food. The door by which they go in and out of the hut leads into a circular court surrounded by rushes or branches; in which place is the fire and where the family generally assemble. Each hut is occupied by a married couple and their children. A polygamist has the same number of huts as he has wives.

The land is understood to belong to the whole community, and no one has a right to dispose of the soil from which he derives his support. The sovereign chiefs assign to their vassals

1 Bock's "Head Hunters of Borneo," pp. 195-202; "Journal Ethnological Society" (New Series), rol. II, p. 2S. 
the parts they are to occupy, and these latter grant to every father of a family a portion of arable land proportionate to his wants. The land thus granted is insured to the cultivator so long as he does not change his locality. If he goes to settle elsewhere he must restore the fields to the ehief under whom he holds them, in order that the latter may dispose of them to some other person. The bounds of each field are marked with precision. The possession of pasture land is also subject to rules. It is understood that the inhabitants of one village should prevent their flocks from grazing on ground which belongs to another. Among the Basutos it is the duty of every petty village chief to see that a part of the adjacent territory is reserved for winter pasture.

The eultivated fields are generally situated at some distance from the village. When a piece of land is exhausted, another piece is cleared by its side.

The Basutos, Bechuanas, and Caffres use oval hoes. The blade is thick in the middle, and gets thinner towards the two sides and the lower part, which renders it at the same time solid and sharp. It is furnished at the top with a kind of elongated tail, which is inserted into a hole bored in the end of the handle. The hoe is raised perpendicularly over the head, and allowed to descend almost by its own weight. The Tembukis and Amakosas dig the ground with a little wooden spade.

The Basutos assemble every year to dig up and sow the fields appropriated for the personal maintenance of their chief and his first wife. Inundreds of men, in a straight line, raise and lower their mattocks simultaneously, and with perfect regularity.

The Basutos preserve their sorgho (a grain) in large straw baskets in the shape of a dome. The Caftres have recourse to pits. They make deep excavations in the enclosures where their cattle are pemned. The walls of these pits are carefully plastered. The opening, which is only large enough to admit a man, is even with the ground. When the subterranean granary is filled the opening is hermetically sealed, and the whole is covered with a thick coating of dung and earth.

Most of the flocks and herds captured in war become the property of the chief, and the subjects regard it as a favour to become the depositaries and guardians of these new acquisitions. The milk belongs to them; they use the oxen as beasts of burden, and from time to time obtain permission to kill an animal which is already old. ${ }^{1}$ 
It seems not difficult to trace in these three types of the primitive mode and condition of life, represented by modern savagery, the roots of the tribal and village communities which have been hitherto identified with Aryan races only. We have representatives of lake-dwellers in the Dyaks; of totem tribes in the Basutos; of the early crystallization of a village system in the Fijis. That lake-dwellers, totem-formed tribes, and settled villagers are represented in the archeological remains of early Britain is well known, and there is no scientific reason why we should not pursue the parallel in order to find out what we can of the economical system of the early inhabitants of our land. I have stated the details somewhat fully in order to show how frequently they conform to the evidence of archaology in Europe, but an analysis of the economical details presented by these examples will show at once where the real interest of this suggested parallel begins. We may tabulate such an analysis as follows:

1. The chief, actually present in the Basuto village, has been pushed upward into a caste, and bence disappears from the Fiji village tu form the Fiji state.

2. Common living is the basis of the Drak unit ; the possession of a wife that of the Basuto; common descent that of the Fiji unit.

3. Common descent brings with it the conception of the sacredness of the homestead among the Fijians.

4. The grouping of houses into a village among the Fijians.

5 . The homestead determines the right of user in the village lands among the Basutos and Fijians.

6 . The division of the tribal territory into homestearl, arable and pasture among the Basutos and Fijians.

7 . The houselands being carved out of the nnoceupied forest lands by the Draks, and the shifting of the arable lands by the Basutos.

8. The village council as the source of village rights.

If we strike out of this analysis the names of the savage tribes which have been the subject of our examination, we might use very nearly the same terms to describe the features of the village system of Britain as it survives in different parts of the country.

Such evidence enables us to say that the village community is of primitive origin; and that it is not stamped with the marks of adranced political progress. And it is significant that when we come to consider its position among the institutions of the Western world, we never see it as the dominant factor in the constitution of nations. In all the countries of Europe, including those occupied by the great classical centres of civilization, it is found to have existed during times which are well within the ken of history. But it is always subordinated to a more or lesis strong central governing power, and, according as it is interfered with by the central authority for purposes of govermment, so is the pro- 
portion of its completeness as a primitive institution. While almost every local institution of Great Britain - the parish, the manor, the borough - bears upon it the impress of its origin in the primitive village community, no local institution of any importance is an exalct representation of what might be expected to have resulted from a normal development of the primitive village community. There is always a twist somewhere. Most generally this may be discovered from the growing commercialism of post- Norman times when the customary law of England was being incorporated into the king's law. Where we can succeed in subtracting the commercial elements in English manorial and village history we come upon the remnants of the primitive village community. These are represented by practices and customs whose startling antagonism to anything appertaining to commercial economy or political progress is the one remarkahle phenomenon in English economical history which quadrates with those old faiths, belicfs, and usages, which, under the generic title of folklore, students have now shown to have existed side by side, but subordinated to, the established religion of the nation. This subordinate position of the village community in the Western work, contrasted with its prominent position elsewhere, is a feature in its history which has escaped notice, and which, when examined, helps us to understand many elements in its composition hitherto explained by an appeal to events of political history which do not seem to come into the question at all. It places it among the institutions of the land whose origin is lost in the unrecorded history of the past; it answers the question of those who suggest that, because the village community is never mentioner in the charters and liplomatic documents of advancing political times, therefore it is of modern origin; and, above all, it forces upon the student the recognition of a most important factor in its history, namely, the cause of its long continuance, after the era to which it essentially belongs had wholly passed away. The consideration of this point, indeed, forms a most material section of the history of the village community as a primitive institution.

The rillage community is thus presented to us as a primitive institution, having a prominent position among the backward ralces and a subordinate position among the advanced races of the world, and it is suggested that the latter of these two phases is a survival from the former. It shoukl, therefore, be marked by all the characteristics of a survival. One of these charac- 
teristics will be found in the traditional sanction given to local practices by long ages of ancestral usage. The evidence of folklore is very important at this stage. If there is any value in the contention of folklorists that the elements of folklore are survivals from primitive belief and 'ustom, they must lave belonged to some form of social organism. They were not always waifs and strays, but once helped to consolidate the social structure of which they formed a part. As Professor Sayce well says, the religion of the primitive villager "in its outward form was made up of rites and ceremonies which could only be performed collectively." ' I seems, therefore, that we may fairly classify the survivals of folklore and the survivals of the village community as belonging to the selfsame stage of primitive social development. This conclusion is considerably strengthened by the fact that the causes of the survival of folklore and of the survival of the village community are identical, namely, the persistence of traditional usage. Proof of this in the case of folklore is hardly needed, and this is not the place to set it forth. Proof of the traditional sanction for the customs belonging to the village community has never been set forth, and has never been sufficiently insisted upon as an important element in the question of origin. But it is overwhelming. Fortunately for science, the backward condition of agriculture in this country, during the last years of the eighteenth century and the first decade of the present, was so alarming as to arrest the serious attention of the government. Ender the able and indefatigable guidance of Arthur Young and Sir John Sinclair, the Board of Agriculture set to work to collect information, county by county, about the actual state of agricultural industry, the obstacles to improvement, and the best means of introducing something like scientific principles. The one answer which seems to have almost overwhelmed the inquirers was that the then existing system was carried on simply because it hat always been so from time immemorial - an answer which was backed up by deep-rooted aversion to change of any sort, especially when change meant an enclosure of lands and the allotment of several parcels, held in common by a group, to individual owners. Over and over again in the reports presented to the Boarul of Agriculture, and in contemporary literature dealing with the same subject, was this view of the case brought prominently before the economical reformers, and over and over again do they complain of the unreasoning folly of the peasant farmers, who loved to do 1 "Introduction to Science of Language," vol. II, p. 290. 
only what their fathers had done, and who looked upon the improvements at last gradually introduced as so extraordinary that they must have been the result of a disordered intellect. ${ }^{1}$

A fact of the highest importance has thus been obtained from the lips of the villagers themselves, namely, that the agricultural practices observed at the beginning of the century were not the result of known economical forces; but were, on the contrary, derived from immemorial usage, were therefore traditional methods of agriculture. Now, traditional methods of agriculture, like traditional methods of belief, are valuable to the scientific inquirer just because they are traditional, and this brings prominently before us an historical fact of some importance, namely, that the attitude of civilization towards primitive institutions, in tolerating them and keeping them alive even long after their meaning and usefulness have been lost, cannot be determined without taking count of primitive economics. The sanction of traditional reverence for habits and ways that have come down with men from that far-off time which memory and fancy hold so dear, transcends and keeps in check even the forces of political economy which we have been taught to look upon as so irresistible, and it is worth bearing in mind that some of the traditional features of the village community are not very far removed from the socialism of to-day. In the history of human thought it will be found that the influences of traditional ideas far outweigh the influences of philosophy.

Thus our preliminary examination of the village community by the light of comparative custom has led us first to see that it is a product of the backward races of the world, not of the foremost; secondly, that its existence amidst the more adranced institutions of civilization is due to survival, not to ereation; and, finally, that from its widespread existence, absolute proof of which has not however been undertaken, it represents a phase of economic development through which all progressive races must have passed.

${ }^{1}$ See Stevurt's "Highlanders of Scotland," vol. I, pp. 147, 228. 


\section{Chapter XXII}

\section{ORIGIN OF COMMERCIAL INSTITLTIONS ${ }^{1}$}

Is tracing the advances in civilization, made by the various peoples of the earth, one can seldom mark off with certainty the distinction between what is borrowed and what is independently devised. Certain typical features are repeatedly revealed to us in the most willely separated epochs, yet with a most astonishing likeness. These surprising similarities meet us alike in the infancy, ${ }^{2}$ the youth, and the maturity of nations so completely cut off from each other, that no influence of one by the other can explain what we find.

1. Barter, and Money; Peddling; Personal Sale: Foreigners and Broliers. Primitive men, as yet without a State or any other organized form of community, and lacking the advances which man in history shows us, lived without any exchange of goods. The development of the human race is fulfilled only in proportion to the constant increase of intercourse and association, supporting and stimulating material needs and assistance, both economic and intellectual. It is a notable stage when dwelling-places become fixed, and division of labor thus necessarily arises and separate occupations are formed. The habitual exchange of products presupposes that private ownership has been recognized; this appears already in the primitive period, at least for morables.

In its first stages, all exchange of products is marked by three features: the transaction is a barter (goods for goods); it is itinerant (house to house); and the producer is his own distributor.

1 ['This passage is a translation of pp. 19-16, $\$ 4$ (omitting a portion) of Levin Goldschmidt's "Universalgeschirhte des Handelsrechts," Part I. This work, of which no more was erer published, formed the first portion of the third edition of the author's projected "Handbuch des Handelsrechts," and appeared in 1891 (Ferd. Enke, Stuttgart), shortly before his death. The author was the greatest authority of his generation on the history of commercial law.

The translation is by John $I I$. Wigmore.]

2 Of course, we do not possess a linowledge of the infaney of certain peoples, - hardly any for the Germans and the Hellenes; and none at all for the Italies and for the extensive Semitic and Jamitic States of Asia and North Africa, which were destined early to attain a luxuriant growth. 
(1) Very early, as soon as a common medium of exchange is formed, i.e., money, this elementary barter develops into regular selling-trade. This appears first in the intercourse between members of clifferent nations or tribes. The "money" is some product held in greatest esteem (jewels, cattle, tool-materials, salt, etc.) ; but the substance does not matter, either economically or legally. If indeed the "money" is a substance valued only within a people's own territory, the external trade of that people will of course be barter. The wider the circle in which the particular medium is recognized, the more regular and extensive is the trade. In all the great peoples of civilization the metals have served as moner. Their order of succession has been generally (but not alway's): copper, silver, gold. At first, mere bars or ingots were used (measured by weight and fineness) ; later, coins were devised, the State stamp guaranteeing the weight and fineness. Yet, even at a highly developed stage, bar-money has remained, both for internal commerce (as in China) and for international commerce, a safest medium for exchange and payment.

(2) House-to-house peddling is replaced (but only gradually) by fixed places of trade; ret even in our own day the traveling pediller is found, in thinly populated districts and in the once highly civilized countries of Asia and Africa.

(3) Among the latest features to appear is trade through factors and brokers; for commereial rights must first have become established and a system of credit developed. In the earliest period, there is naturally little exchange of goods between members of the same community. Extensive and regular exchange arises through the effort of foreign dealers bringing into a country wares which both stimulate and satisfy some need - jewelry, metals, weapons, tools, wines, etc. In exchange for these desired articles, the foreigner takes away some surplus product of the place. The foreign trader may come merely from another district, or from another clan, or even people. To the mistrustful primitive mind, he is both welcome and hateful. Throughout the primitive period, and indeed even in every people's " Middle Ages," the skilled foreign trater, constantly getting the best of the native in the transaction, is regarded as a cheat. ${ }^{1}$

${ }^{1}$ Hence, apparently the Creek $\kappa a ́ \pi \eta \lambda$ os (trader) derives his name. Hence, too, Ulysses' precautions against being mistaken for a foreign trader ("Odyssey," VIII, $158 \mathrm{ff.}$ ); Ulysses at Phracia declines to take part in the athletic contests, whereon the Phracian champion sneers:

"Stranger, I well perceive thou canst not boast, As many others can, of skill in games. 
In the primitive stage, the chieftain decirles whether the visits of outsiders shall be permitted; thus, after the benefits of regular trade come to be appreciated, the chieftains often are found holding a monopoly of its exercise. At first, through mutual distrust and lack of common language, the bargaining is done by signs. In a later stage, a go-between, skilled in languages, is employed; ${ }^{1}$ henee the professional interpreter and the broker eome to play an important part in trade with foreigners; and the official broker is required to be employed. ${ }^{2}$

As domestic industry grew in strength, and competition beeame more keen, the domestic trader developed, though gradually only; finally, he becomes the important figure, displacing the foreigner. Retail trade is of course the only trade at first; as wholesaling grows, it becomes a separate occupation. Domestic industry and hand-labor develops at last the machine-factory srstem. The medieval features and their stages of development, viz., homeindustry, hand-labor, separation of the wholesale eontraetor from the retail seller of stocks on hand, seem in the main to hare been true of the ancient nations.

2. Markets, Caravans. The more toilsome and dangerous was trade, the less the competition, hence the more irregular and unsettled the methods of commerce; hence the higher the profit. The prices were virtually monopoly prices. Prices eame to be equalized as markets and fairs grew up, - culminating in the modern bourses and exchanges, erected at fixed places and kept continuously open. ${ }^{3}$

But thou art one of those who dwell in ships

With many benches, rulers o'er crews

Of sailors, - a mere r rader, looking out

For freight, and watching o'er the wares that form

The cargo. Thou hast dombtless gathered wealth

By rapine, and art surely no athlete."

1 At Dioseurias, on the Black Sea, three hundred languages could be beard, and the Romans there had one hundred and thirty interpreters (Strabo, XII, 498).

2 We find this in the first trade treaty (A.D. 5C9) between Carthage and Rome; and again, in the treaties of the $1260 \mathrm{~s}$, and later between Italy and the Moslem States, this personage is termed "turcimanus." the modern "dragoman." It is worth noting that the Roman term was borrowed from the Greek ; the medieval one ("sensalis") from the Arabic ("simsar"), and the middle High (ierman ("dollmeteh") from the Turkish through the Slavic or Hungarian. The inn-kefper of the Middle Ages was often at the same time the interpreter and the lawful lroker for the foreign merchants who lodged with him.

${ }^{3}$ 'The market price is based on substantially ronstant standards of value. From the merchant's professional point of view, goods and money cease to be simply consumable things: they hecome spendable things (capital); the merchant is thus the representative of capitalism. 
The market was a place where producer, trader, and consumer all met at appointed times. At first it was usually a tract of land placed specially under religious protection ("peace-girt") on the borders between two tribal or national territories. Between the peoples or tribes, or even villages, their nomal relation would be, primitively, one of mutual hostility ; and to make possible the desired exchange of goods, a "trade-peace" was agreed upon, expressly or implicitly, at least for the period of the treaty. This arrangement for the market, as well as for the usual tribal feastdays and the court-assemblies, was usually connected with the religious cults of the peoples, or itself developed a new one. Trade and religion found a common meeting point.' 'The market-trade came to be given protection by formal treaties of amity and commerce. Here we reach the beginning of international customary law; and the traditional readiness to overreach the foreigner becomes discountenanced.

For going to the market-day and the feast-day (holy-day), great travel caravans were formed, of pilgrims and merchants, usually both together. A system of regular transportation began. It involved huge expense, indeed, ${ }^{2}$ for the roads lay through the uninhabited deserts and plains of Asia and Africa and amidst regions of marauding nomads. These latter persons are the owners and breeders of the animals needed by the merchant for his transport; and for many nomad races the chief business became (and still is) the supply of earavans. ${ }^{3}$ The pilgrim-caravans, indeed (e.g. to Mecea), still were virtually traveling markets; the pilgrims forming a market community at the various stations. Little by little permanent roads develop. Towns grow up around or near the market-places, and become the permanent and extensive centers for regular trades, which gradually specialize. Thus the "marketpeace" becomes the "town-peace."

3. Sea-Traffic: Admiralty: Trade-Colonies. Meanwhile, sea carriage and sea-traffic, starting with fishery, was developing on the great rivers, the coasts, and the open sea. Originally, the

Among all the occupations the merchants' (or traders') is the earliest to cease to be an incidental home industry and to become a complete oecupation by itself.

1 Lamprecht tells us, in the Middle Ages, of the large towns which had " not only the largest trade, but almost always the hest relics of saints."

" Fven in modern times, for freighting a single caravan in India, 4000 ramels have been used. The burthen-animals earliest used were the ass, the liorse, the mule; the camel was introdnced elsewhere from Arabia. The wagon is first foind in Alexander's time.

${ }^{3}$ Anciently, letter organized than now. 
vessel was a tree-trunk hollowed out; then it was a framework of withes or beams covered with skins; mast, ruller, sails, were then added. The first voyagers kept in sight of land; and the devious lengths of the Mediterranean coast were, for a period, the usual limits to the sea-traffic of those peoples. But, as the art of seamanship developed, and the observation of the heavens increased their knomledge of astronomy (amounting in Babylon to a veritable science), the royages were made on the high seas, as early as the Phoenician period, and as distant as to the Red and the Persian seas, the Atlantic and the Indian oceans. Though the use of sails reached a complete development, nevertheless, the oar-boat (galley, etc.) remained the usual (though manifokl) type of vessel throughout all antiquity and till nearly the end of the Middle Ages. Hence in the winter months (until up to modern times) it was customary ${ }^{1}$ to cease sea-trips ("closed shipping season"). Piracy, well down into the Middle Ages, is closely connected with the history of sea-traffic. ${ }^{2}$ And just as convoyed protected caravans developed on land, so arose regular admiralties ("conserva ") to convoy the merchants' ships.

In the early Asiatic empires and in Africa, the land-commerce naturally was the greatest part. But with the rise of the Phœnician coast-towns, then of Hellas and of Italy (greater Greece, Etruria), sea-commerce came into the foreground; and this domination it preserved until very modern times - the era of railroads. Herodotus opens his history of the Greek world by a description. of sea-commerce: "The sea is a road, which unites the peoples of the earth to each other. He who dwells inland is as one shut off from the facilities and attractions of human intercourse and unacquainted with the progressive growth of the race." It was only through sea-commerce, in antiquity, that local industrial seclusion was overcome and the lines of organization for the world's trate were marked out. An important part of the principles of commercial law, in ancient times as well as in the Middle 1ges, had their origin in sea-commerce and thence ${ }^{3}$ were gradually imported into land-commerce. ${ }^{4}$

1 Rhodes was an exeeption.

2 The oldest hero-myths of the Greeks - the Argonauts and the Trojan expedition - turn upon feats of piracy. The Vikings of Skandinavia were both sea-merehants and sea-roblers. The Pisans in the 1200s still eoneeived of sea-rar and piracy as a business hringing wealth. Thr. Arab merehant of Africa was, even to modern times, primarily a robber of men to sell as slaves.

3 There were exceptions; $\bullet . g$. the law of general arerage ("lex Rhodia de jaetu").

4 This influence is mostly elearly revealed in the law of Rome and of 
The sea-coast eommunities (Phoenicians and Carthaginians, Hellenic, Romanic Mediterranean, North Germanic) came to open up permanent trading posts (" factories") in the foreign land itself, - usually after a considerable period of ordinary trading with that place. In some cases, colonies grew up, i.e., separate communities of their own members; Greece and Carthage were the first to ereate such colonies by design. In these trading-posts and colonies groups of foreign traders settled down (sometimes remaining for life) and managed their own affairs; usually preserving the religion and the law of their original home. Throughout antiquity and the Middle Ages (and in places even to-day, as in the Levant and the Far East of Asia) they formed a community of their own, alien in religion and in laws to the people in whose territory they abode. Here the most striking analogies re-appear between the oldest trade-settlements recorded in history, the Romanic and the Ianseatic traders of the Middle Ages, and the European instances of the present day in the Orient. Through these tradestations the network of commereial interests extended over the whole globe. The general method and aim was to exploit the wealth of the country of their settlement, and to control its commerce, or at least its distributing trade. As the native communities grew stronger and learned how to get along without the foreigners, they devised ways to drive out their now unwelcome teachers, or to assimilate them.

4. Credit: Interest; Banks; Commercial Paper. Along with barter and eash-sale there early appears the first form of credittransaetion, the loan. The charge of interest appears in the Orient at an early stage. ${ }^{1}$ In the more advanced stages, when money has become the universal medium, the use of eredit in commerce gradually expands to a vast extent; here again the peoples of the Orient are the earliest. ${ }^{2}$ The security of the eredit is found in personal suretrship and property-gages of various forms. The loan (as a business transaction) is a leasing-out of capital; hence it involves a charge for the use of the capital. In a community

the Romanic Mediterranean States ; for example, the "actio exercitoria," the "receptum nautarum," the "foenus nauticum," in the former law, and the "commenda," the insurance by premium, and the stock-company, in the latter law. Even the ordinary bill of exchange derives its essential features from the maritime-loan contract, borrowed into land-commerce.

1 With the Greeks, perhaps not yet used in Hesiod's time (though they had special penalties for delayed payment, etc.). With the Germans, it was unknown in Tacitus' time.

2 In the Germanic tribes, and in North Germany, even into the $1400 \mathrm{~s}$, transactions on credit were scanty. 
where fungible ${ }^{1}$ goods (gold, grain, eattle) re-paying the loan are not abundant, or where for any reason (personal or social) the prospect of repayment is uncertain, eredit is scanty. And the scantier is eredit, the higher will be the interest-charge. In early times the borrowing of eapital was an extremity unweleome and abhorrent. The very act of borrowing was often only the first step to commercial downfall." The habitual lender-on-interest, the capitalist (" usurarius") tends to exploit his advantage selfishly, often ruthlessly, and became a hated object. Popular opinion even stigmatized as usurious the ordinary interest-loan indispensable to commerce, if the borrower's results from its productive investment turned out to be seanty. The history of usury (i.e., interest on capital loaned) is one of the richest chapters in the legal and economic annals of all epochs. Only the greatest commereial peoples (Babylonians, Phøenicians, Athenians) disdained either to forbid interest-charges or to fix their maximum. Not until our own times was reached that view of usury which is alone tenable in ethics. economies, or law, viz., usury depends on whether the particular transaction is in fact an exploitation of one party by the other: "non quantitate pretii, sed qualitate facti restimatur."

In primitive times, this seantỹ resort to commercial credit goes along with another feature, the harshness of the law to the debtor.

As the use of credit and money increases, a special occupation derelops, the banking-trade. As early as in Phonicia and Babylonia the money-ehanger (banker) is regularly found with the other merchants. He tests the coins, reckons their equivalence, receives and takes care of investments of surplus money-eapital.

The idea of salable property, at first confined to tangible things, enlarges gradually, to include creditobligations, especially those embodied in documents (commercial paper). Finally it brings within the protection of the law those rclations of patronage for ideas which have come to be included (inadequately) under the term "intellectual property" - eopyright, trademark, and patents for inventions.

As oceupations of trade become specialized, and a commerce based on money-ralues develops, along with a credit-system also based on the use of money), the "capitalistic" organization of

1 ["Fungible," a good Roman law word, is the only term that expresses the idea of uniformity in the single pieces of an article, such that any" number of them is equivalent to anv other number.l

${ }^{2}$ Hesiod. "Works and Days," 647 , classes the fear of borrowing with the fear of being hungry. 
society - part and parcel of the division of labor comes into full existence.

5. Slarery. An institution universally found in primitive times is slavery. 'This, to be sure, itself marks a step of progress beyond the earliest customs, that of the destruction of all enemies, and even of aliens in general, as well of debtors and wrongdoers. Throughout the Middle Ages it persisted among the Christianized peoples, and to our own times among non-Christian peoples. In a mild and patriarchal form it was found in the Orient, and in the earlier Ifellenic and Roman period, as well as among the Germanic periods. Its harsher form marks particularly the later Roman period, and the still later Christian times of negro slavery. A related feature - not abandoned by even the Christian communities intil the $1700 \mathrm{~s}$ - was serfom (in various forms). The conditions of primitive slavery and serfdom varied, of course, according to the type of its economic life, and therefore of its laws of trade. As this element in the community gradually diminishes, the class of small traders becomes professionally stronger; the formation of a "middle class" (" third estate") is favored; and the principle of association (group organization) is fully developed; and the differentiation of types of commercial transactions is stimulated, so that each has its own group of practitioners and its distinctive legal rules, - wholesale dealers, carriers, and many others.

6. Wholesale. The economic principles underlying wholesale and rotail trade being different, and the social position of the capitalist wholesaler being naturally above that of the retailer, a difference was not uncommonly found (notably from the Middle Ages onwards) in the law's treatment of them, - in eligibility to high office, etc., in police regulations, and in tax methods. No principle, however, for drawing an exact line between wholesale and retail trade, or between machinery-factories and manual or houseindustry seems ever to have been attainable. And the modern tendeney is to go beyond mere negative abolition of the distinction, and to articulate anew the relations of industrial society.

7. Commercial Custom and Laus; Hercantile Honor; Status of Foreigners. The positive law of the State is merely' the external embodiment of some legal principle immanent in the life of any particular epoch and people. Each specific legal transaction or relation, sale or partnership, bcarer-bills or checks, marriage or filial status, eitizenship or trade with neutrals - has a distinctive purpose

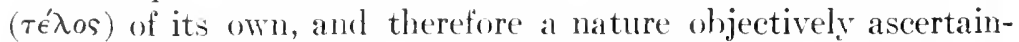
able ("Natura," " natura rei," "natura lis ratio"). The transac- 
tion or rule is variant, indeed, aceording to time and place, - the national traits and the changes in the course of eivilization. Thus develops a common consciousness of the principles just and suitable for these purposes. The principle may indeed be imperfectly earried out in law, or even perverted; for the irleal to be attained varies in law as in art, and the juristic gifts of different nations vary extremely (as with the Romans and the Hellenes, for instance).

In commerce, as in other relations, what we call law appears at first only as social custom; not until later does it take the form of legal enactment. The customs of commerce were formed chiefly in the various tradal occupations. Wholesale and retail dealers were grouped separately, and the former were international in character. In primitive times the State has but slender power and activity to protect trade by courts and police, and the treaties with foreign peoples, supplementing domestic law, are equally scanty; to this extent it was then the more natural and necessary that the mercantile groups should develop definite and inviolable eustoms, often under the sanction of religion, from whieh the individual trader departed at his peril. This growth of fixerl custom, gradually condensed into eustomary law, was furthered by the physical and social conditions of the times. Trade was restricted to certain seasons and places; land-roads were scantỵ and unsafe, and inns were few. Ship-convoys and land-earavans had fixed rules of the road. Moneys and their valuation, and indeed every tradal transaetion, even the simplest - and the simplest were those of widest observance among nations - became subject to these fixed " folkways." And here developed the great and indispensable mereantile principle of good faith (commercial honor). ${ }^{1}$ At the markets and fairs, especially, grew up the system of fixed terms and periods for parment and credit, of organized supervision, and of speedy court-procedure.

This principle of good faith was of special significance in its relation to foreigners. In primitive times, as in classic times, and even until late in the Middle Ages, the foreigner was without the pale of law and rights (except indeed when given temporary protection in the status of " guest-friend," long sanctionerl by religion)."

1 The Greek " riorss," the Roman "(lona) firles."

2 The view of some scholars, that the institution of "guest-friend" was devised (by the Phonicians) to assist eommercial intereourse. is open to much douht, in that it molervalues the ethical and the religious motive. In .Eschylus' "Eumenides" (v. 533 ff.), in the list of Roman moral duties, that of "hospitium" is named even hefore that of hood-relationship.

The primitive soriety is of course founded on an exelusive rommunity of religious cult; its law and rights are for its own memlers only. The 
But gralually, by treaty, or by custom, or by special enactment eonceding limited rights, he anme to receive the legal right known at liome as "commercium," i.e., to participate in trarle muler protection of law ; and a special procedure is later allowed, to speed the suits of forcigners, mainly in commereial cases.

Nevertheless, there obtained, even till modern times (with elaborate development in medieval Italy), a special discrimination in the principle of reprisal. The prineiple that one wronged by personal injury or by default in a debt might seek redress from the family or relatives of the wrongdoer, allowed him, when the wrongdoer was a foreigner, to resort to any fellow-countryman within the territory. Herein lay the kernel of a far-sprearling principle of soliclarity. Gradually certain customs of commerce, originally local to a tribe or territory, tended to become universal, when fitted to do so; while, conversely, certain general eustoms of nations became lotally accepted and differentiated, by statute or corle. IIere came into play the influence of the dominantly commercial peoples and cities. These left indelible marks upon commercial custom and law, while the other communities played chiefly a receptive rôle. In far antiquity, the Phoenicians stand out as the merchant-people; in the Midclle Ages, the Genoese, the Lombarls, the Hanse towns; in East Europe, often the Jews; in the Orient of to-day, the Greeks, the Armenians and the English. A special mark of such trade-supremacy is usually revealed in the wide currency of the coins of that people or town. ${ }^{1}$

8. Lines of Evolution. In human transactions, as well as in the laws that govern them, the double aspect of all evolution may be observed, i.e., the principle of successive stages of differentiation and integration (heterogeneity and homogeneity). The simple transactions of exchange, credit, association, - the medieval loan and joint-undertaking ("commenda"), - the Roman power of attorney ("mandatum"), - the Skandinavian jointtenure ("félag"), - these and many other typical transactions proslue gradually a number of distinct varieties. A transaetion originally having a simple and narrow use enlarges into a type, assimilating many similar species. Marine insurance, for example

Greek word for "guest," "gtuos," originally means "enemy," "alien" ; so also the (ierman "gast" ; and the Latin "lostes," which afterwards preserved this meaning in the hroader "peregrinus." And the Slavie "gosti" signified both "stranger" and "merchant," for the foreigner was gencrally a merehant.

IE.g., thise of BaJyton, Athens, Byzantium, the Arabian empires, Venice, Genoa, Barcelona, the Champagne markets, Cologne, and (in modern timess) England. 
- the carliest form develops into insuramese of various sorts; gromps of persons contributine jointly for varions purposes (joro-

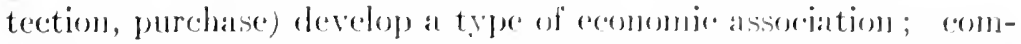
panies formed to earry on colonies, banks, and insurance, develope the general type of stock-ompany. ('omversoly, legal tramsaretions and relations orignally independent of each other, are ultimately recognized (b,y courts, lecrislators, and jurists) to lue moited in principle, as varieties of a single economie and legal tepe. For example, the dassification of all commercial assocoations into the three varjeties, viz., jartnership, limited partuership, and storelcompany, was first made in molern times, in the Frenede code of Commerce (1807). Sometimes the manifold forms originaly existing, or afterwards developed, fall gradually into disuse, and a single form replaces thens; for not every simplification, in evolution, signifies progress. For rexample, the original Roman transactions of "sponsio," "fidepromissio," " mandatum," " (o) debiti," " receptum argentarii," " fidejussio argentarii," erive place to a colorless abstraction, viz., warranty or suretylijp. So also the sundry primitive forms of joint obligation are replaced by the single idea of solidarity; and the immmorable kinds of marital property tenures are simplified into a few types.

The kernels, or even the defined principles, of important learal institutions can sometimes be traced in existence for centuries, before they come to their full development. Ilere the hindrance was perhaps some untavorable ecomomic condition, or some rival legal principle; until finally, under changed conditions, the principle reached its maturity. The arly classic times, for example, possessed the principle of insurance, of money-remittance by fill of exchange, of instruments transferable to orler or bearer; yet all of these, so far as can be learned, waited for a thousand years or more before they found general recognition.

9. Commercial Law as a Seporate Borly of Late. A specoial law of commeree, as a separate branch, bad not been known as arly as the times of the Oriental peoples. In classic antiquity, and among the Germanic peoples, it appeareal only in the nucleus. Nevertheless, a considerable part of private law in classic times, as well as in the Germanic period, after the rise of the great medieval cities, bears dominantly commoredal foatures, and is formed particularly to favor the needs of enmmerce, esperially the wholesale trade between nations and localities. The more or less wall defincel separation, mow obtainine in one form or another in alunost all civilized peoples, is a creation of the later Middle Iges in Italy 
and of modern codifications. But the further the division of labor progressed in occupational pursuits, the more distinctly the middleman's function of the merchant became separated from other callings - the greater became the economic scope of this service, so much the more extensive became the body of law specially applicable to it.

The distinguishing feature of commercial law may be sought either in the fact or in the idea ; i.e., we may emphasize either the commercial fact (and incidentally the legal idea applicable), or we may emphasize and formulate the controlling legal principle. The same group of commercial facts may be governed by distinct legal rules, and vice versa. The distinction is illustrated when we remember that in the ancient world we owe the origin of our commercial transactions (in great part) to the Babylonians and the Egyptians, the Phoenicians and the Greeks; but it was the Romans who first gave them definite legal principles. So again, in the Micklle Ages, the various commercial methods and institutions were contributed partly from the Germanic peoples, partly from the Orientals, partly from the inheritance of classic times; but they received their typical legal forms from the Romanic peoples, especially the Italians. 'This process of derising legal principles and forms for the commercial transactions can be traced from its earliest beginnings in the annals of the professional clerks and notaries.

If, now, we ask, which are the peoples whose contributions have been the vital ones in the continuous development of the body of universal commercial law, we may thus name them in the order of their historical rise ${ }^{1}$ 1, 2. The empires of Western Asia and the East Mediterranean, especially the Egyptians and the Phœenicians, form the great commercial region. The "merchant" is here preeminently the Phonician, whose trading-posts and colonies spread even to the Atlantic shores. 3. The Hellenes gradually took over the domination, in commerce as well as in civilization generally, of a large part of both East and West, and from Alexander's time assimilated to themselves the Orient more and more markedly. 4. 'The Romans, founding a world-empire, brought it into wellordered mastery in about five centuries, and gave it an everincreasing unity of law.

1 [The author here eliminates the far Eastern peoples; the Hindus and the Persians; the Finns and the Lithuanians and Slavic peoples; the Kelts; and the early Americans. He then groups the remainder for (1) ancient times, (2) medieval times, (3) modern times. Here the description of the first group only is reproduced.] 
The four great peoples of antiquity - the Egrptians, the Babylonians (and their Semitic relatives, the Syrians, I'honicians, etc.), the Greeks, and the Italians, - each (as Mommsen sars) in its own way built up a civilization of its own on a grand scale, and helped in manifold relations to each other to develop in a welldefined and ample way all the elements of human progress, until its destiny was fulfilled. It is a truism that in economics, as in legal life, innumerable rivulets and springs unite to form one great stream. But the universal features in the history of this merging were received only from those nations which were gifted with the talent of absorbing and infusing these elements with its own spirit and of preserving and transmitting them to its successors. It is in this sense that the economic and legal ideas of the Oriental peoples, of the Hellenes, of the Romans, and the Romanic Mediterranean region, of the Germanic peoples North and West, may be deemed universal, as well as national, in their significance.

And yet, it remains to say, the contrast between antiquity and modern times must ever be kept in mind. In the period between ancient Egypt in its industrial prime and the $1700 \mathrm{~s}$ our own era - a period of from two to three thousand years or so-- the technical features of industrial life underwent no radical alteration. And so also, for the technique of commerce and commercial law, it is equally true that in the more than fifteen centuries that witnessed the successive predominance of Phønicians, Hellenes, and Romans, progress and regress apparently alternate in the seales, without decisive gains maintained. No period of the later Middle Ages can be named which in all its aspects so surpasses the commercial life of the ancient world at its best period, especially that of the Roman empire, that we can speak of an absolute superiority in commercial and legal type. It would not be far wrong to assert that not until the last two centuries of our own era do we find the full development of all the principles which already existed profusely in embryo for the many thousand preceding years of commercial history. 


\section{Chapter XXIII}

\section{PRIMITIVE COMIIERCIAL LAW ${ }^{1}$}

IT may be taken as established by political economy that the most ancient commerce was of a migratory sort, and between different tribes, or peoples. ${ }^{2}$ The origin of commerce, therefore, is closely related to the actirities of peoples; and the beginning of commercial law is bound up with the laws of peoples and international law, as well as the most primitive form of international law - the law of strangers or aliens. It has been rightly emphasized by Post $^{3}$ and other investigators, ${ }^{4}$ that everywhere on the earth, it is the first principle of the law of aliens, that the stranger has no rights whatever. "Only a relationship to a social group provides any guaranties for life and property.", 5 Therefore, between peoples who are foreign to each other by descent and language, there is either no comnumication at all, or only intercourse of a positively hostile nature. Inasmuch, as the deatl or imprisonment of an alien is regarded not as a wrong, but as a praiseworthy act, ${ }^{6}$ so on a chance meeting, every person who is unwilling to meet a stranger as an enemy, takes to his heels as speedily as possible. $^{7}$ Yet, it would be a mistake to suppose that an utter absence of friendly communication among uncivilized peoples, is the rule. On the contrary, it may be regarded as demonstrated by ethnology and ancient history, that definite begimnings of commerce are not incompatible with the lower stages of culture; for even among such peoples there are found "implements and adornments which have come from thousands

1 [Br Carl Konhne, "Markt-, Kaufmanns-, und Handelsrecht in prinitiven Culturverhältnissen," VI, in "Zeitschrift für Vergleichende RechtsWissenschaft," Bd. XI (1895) pp. 196 scq.; and translated by Albert Kocourek.]

${ }^{2}$ Schmoller, Jahrb. XIII, pp. 10:33-5i, XIV, p. 1036; Roscher, "System der Volkswirtsrhaft," III, Ser. 16, pp, $99 \mathrm{krq}$.

3 "Alufgaben," p. 38, "Afr. Jur.," p. 176.

${ }^{4}$ Cf. Fulluti, "Z. f. d. ges. Staatsw.," VI (Tübingen, 1850), pp. 185,

201 ; Darqun, "Z. f. v. R.," V. p. S2; Roscher, "System," III, p. 111.

sPost, "Afr. Jur.," p. 175.

${ }^{6}$ Cf. Dargun, loc. rit., p. 82.

${ }^{7}$ Cf. Fallati, loc. cit., p. 175. 
of miles." 1 In fact, there may be extensive commerce among uncivilized races, based on the well-known custom of "silent trading," without diminishing the principle of a lack of rights in aliens, or the distrust which arises from it. One party places an article at the boundary, or at some other piace which is risited by the other, and withdraws; thereupon, the other party lays down, in return, an article, which, however, is not removed until it corresponds in worth to the offer. ${ }^{2}$ An advance is indicated, when the traders stand face to face, but ret at a distance which makes riolent acts, and especially seizure of the person, impossible. ${ }^{3}$

Notwithstanding the great interest of these kinds of commerce for ethnology, they are of no significance for jurisprudence. On the other hand, the various ceremonies by which different uncivilized peoples communicate their desire to engage in friendly commerce are the first germs of international institutions, and are equally of importance for the universal history of law. For this reason, such customs as gestures and touching which express friendly salutation, the smoking of the pipe of peace, entertainment in the home, bearing of twigs, etc., are significant not only for [the evolution of] commerce, but also for such international abjects, as for example, a treaty of peace. ${ }^{4}$ It may be recalled, therefore, that the frequently attested, and even to-day, here and there, existent custom of using twigs for the purpose of giving notice of the making of commercial agreements," has its origin in the usage which employed foliage as a token of peace. But this custom is not only a "common Germanic, and, presumably, a common Aryan" "institution (as has recently been stated by

${ }^{1} \mathrm{Cf}$. Schmoller, Jahrbuch, XIII, p. 10.33; Peschel, "Vökerkunde" (Leipzig, 1885), pp. 215-6.

2 Cf. Schmoller, loc. cit.; Roscher, "System," III, p. 112; “7. f. allg. Erdkunde" (Berlin, 1854), I, pp. 13-16" (Andréc), and II, p. 213 (Gumprecht).

${ }^{3}$ Such is the commerce of the Malays at the southern point of Timor" see George Windsor Earl, "The Native Races of the Indian Arelipelago," (London, 1853), p. 183.

${ }^{4}$ Cf. Fallati, loc. cit., pp. 201-210. That the smoking of the pracepipe is employed as a legal symbol for the estahlishment of (*mmmerer, is observed by Lafiteru, "Alours des Samvages Americains" (Paris, 17-4), p. 331 .

5 Cf. Richard Schröder, in Béringuier, "Die Rolande Deutschlands," (Berlin, 1890), pp. 20, 21. In addition to the evidence there nerted. it may be added that in Vienna, aceording to an ordinanee of 14.19 . the pullie criers of wine held a branch in their hands-("Ber. des Wienel" Alterthumsv." III, p. 286); and that "ren to-day, in Siluerian villages, the vodka tavern is made known by a branch - (Kennan, "Siberien" (trans. by Kirchner, Berlin, 1890), p, 203).

6 Schröder, loc. cit. 
an eminent investigator of German legal history), but has been found widely disseminated among the peoples. ${ }^{1}$ For the purposes of the present study, the branch as a symbol of peace comes particularly under consideration in those ceremonies in which it is used in connection with other simbols, for commercial transactions.

Examples of such legal symbols are found in various books of travel. When Captain ron Kotzebue, on his well-known voyage of discovery, was nearing the Penrhyn Istands in Polynesia, various boats of the natives approached his ship, and in each of the larger boats an old man adorned with a chaplet of palms in his hair, and a neck-piece of cocoa leaves, held aloft a palm branch. When the boats came within 20 fathoms of the ship, they stopped, and the islanders commenced a peculiar song. After the natives had completed these ceremonies, they came without fear to the ship, and showed themselves ready to engage in barter. ${ }^{2}$ In a similar way, the natives of Noatka Sound on the North-west coast of America [Kotzebue Sound(?)] rowed around the ship of Cook, "while on each ship a man provided with a mask spoke or called out a long time." When the circling of the ship was completed, the boat laid alongside of the ship, and then the natives began to barter. ${ }^{3}$ The Brazilian Indians also have a special legal symbol for the initiation of commercial transactions. They lay down "their arms in common, and alongside of one another; and when the transaction is completed, which is indicated by certain words frequently repeated on both sides, both parties at the same moment seize their weapons." 4 There we have one of the many cases where a legal solemnity is at the same time a legal symbol. ${ }^{5}$ The laying down and taking up of the weapons, in order that the possibility of attack may be made more difficult and lessened, signifies, (in that both acts are simultaneous on both sides), the renunciation of malevolence, and notice of it. It is noteworthy, that here the peaceable situation, so far as it may be inferred from the legal symbolism, exists only during the continuance of the legal transaction; the same persons who for the time being mutually grant peace, may, on meeting again,

${ }^{1}$ Especially, also, among the Australians, and South Sea Islanders; cf. Waitz-Gerland, "Anthropologie," VI, p. 750 ; Ratzel, "Völkerkunde," II (Lpz., 1S\$0), p. 210; Fallati, loc. cit., pp. 1S0-1.

2 I'on Kotzcbue, "Entdeckungsreise nach der Südsee und nach Beringstr." (Weimer, 1821), I, p. 124.

"'ook's "Third Voyage of Discovery" (trans. by G. Forster) (Berlin, 1789), III, pp. 12, 13, 1s, 19.

${ }^{4}$ Yon Martius, "Ton dem Rechtszustande unter den Einwohnern Brasiliens" (Munich, 1832), p. 44.

${ }^{5}$ C'f. Heusler, "Inst. d. deut. Privatrechts.," I, p. 72. 
consider each other as enemies. On the contrary, the ceremonies above described, of the natives of Noatka sound, appear to indicate a permanent peace between the parties. When Cook continued trading the next day with the natives, the same ceremonies were performed only by the occupants of such boats as had come to the ship the first day. ${ }^{1}$

As a rule, primitive law has another method for making permanent trade possible; some important societies have taken the foreign merchant under their special protection. Such relations are found developed, quite conspicuously, among various peoples of East Africa. Reference may especially be made to the so-called "Ashkerays," subjects of the \aib of Samhar, who regularly visit the land of the Bogos for commercial purposes. ${ }^{2}$ Each "Ashkeray" chooses among the Bogos a protector to whom he pays, by custom, yearly, a moderate sum of money. The protector is obligated to receive the "Ashkeray" at his home, to furnish his board for the first day, to assist him in his business, and especially in the collection of his claims, and he must also furnish him safe escort to the next tribe. If the "Ashkeray" is killed while in Bogoland, then the master has the right of bloodrevenge. If he prefers to take weregild, the same as for a Bogo, then he may keep the entire amount for himself; yet, he usually turns over a part of it to the relatives of the dead man. ${ }^{3}$ Similar protective relations are found developed among other African peoples; thus among the Wogo-Galla, the Somali, the Barea and Kumana; and such a relation is the only measure of safety for life and property of strangers in the markets in Berbera and Massua. Among the Kumanas the stranger must always be accompanied by a native; otherwise he would be considered an enemy and killed.5

The most complete information, in detail, concerning the protective relation among merchants comes from Somaliland; and it may be accepted, that in the essential features, it is the same there as among the peoples already mentioned. Protector and

${ }^{1}$ Cook, op. cit., p. 18. $72-75$.

2Munzinger, "Das Recht der Bogos" (Winterthur, 1859), p. 46, Nos.

${ }^{3}$. Hunzinger, op. cit.

${ }^{4}$ Cf. Krapf, "Reisen in Ostafrika" (Kornthal u. Stuttg., 1S58), p. 106; Burton, "First Footsteps in East Afriea" (London, 15.56), p. SG seq.; Haggenmacher, in Petermunn's "Mith. Ergänz." X. No. 47, pp. 36, 37; Hildcbrand, in "Verh. der Ces. f. Erdkunde zu Berlin," 187t, p. 27t; Munzinger, "Ostafr. Studion" (Schaffh., 1S64), pp. 121, 314, 315, 477; further, Post, "Afr. Jur.," I, p. 177; Andrée, "Welthandel," p. 213.

${ }^{5}$ Munzinger, op. cit., p. $4 \div 7$. 
protectce are ealled by the Somalis "Abban"; ${ }^{1}$ yet it is allowable according to the usage of books of travel to apply the term solely to the protector. The protective relation is ereated by an exchange of gifts; ${ }^{2}$ and with this, the merehant also permits the "Abban" to fortify the security of the relation by an oath." Protection consists in defence against all hostile attacks on the traveler and his property proceeding as well from the protector's tribesmen as from non-tribesmen. Furthermore, the "Abban" is the representative of the merchant before the courts. Finally, he furnishes him with a residence and subsistence, serves him as interpreter, and negotiates his business affairs, or executes them in his own name as commissioner." This office, called "el Tabaan," is bound up with unlimited power over the life and property of the stranger; so that he is entirely dependent on his "Abban." 5 For this service, the "Abban" receives a courtage, fixed by eustomary law, upon all the business done by the client, whether he took part in it or not, ${ }^{6}$ and oceasionally other compensation. $^{7}$ The relation ends as soon as the merchant leaves the tribal territory of the patron; and, also, as a rule, on the death of one of the parties. Yet, it is reported of the Somalis, that if the patron is killed, it becomes the duty of his kin to assume the undertaking of protection, and to assist the merchant in getting his goods, which, perchance, are out of his reach. ${ }^{8}$ If the relation is terminated by reason of the killing of the merchant, it may be assumed that among all these peoples, the protector becomes vesterl with the right of blood-revenge. ${ }^{9}$ Among the Barea and Kumana tribes, this right is employed in such manner that the protector of the murdered man lills a elient of the murderer. ${ }^{10}$ As to most peoples, there is no information whether the protective relation may be ended by the will of one of the parties. It is reported only of the market in Berbera in Somaliland, that there, no one may change his "Abban" without the approval of the judicial assembly." On the contrary, among the Bogos the

Burton, op. cit., p. S9, note.

- Haggenmucher, op. cit., p. 32.

${ }^{3}$ Itrid., pp. 7, S.

4 ('f. esp. Hagycnmacher, op. cit., p. 36 ; Hunzinger, op. cit., p. 121.

${ }^{5}$ Burton, op. cit., p. s9, note.

${ }^{6}$ Haggenmacher, op. cit., p. 37.

"In the market at Berbera, the "Ahban" has a claim secured by customary law to a garment of 16 ells of calico for each ship which arrives helonging to the rlient. Furthermore, when the merchant leares the marlint. the "Ahban" has a claim to the timbers of the lut ereeted by the merehant at the market; ef. Huggenmecher, op. cit.
Burton, op. cit.
10 Nunzinger, op. cit., p. 475.
${ }^{9}$ Ci. note 3, p. 423, supra.
${ }^{11}$ Heggenmacher, op. cit., p. 37. 
"Ashkeray" may change his protector at wili." The information is given, that this protective relation is of no value to the merchant, unless he selects an honest and skillful patron who is well recarded in his tribe; ret, frequently, unqualified persons present themselves for this office, to foreign merchants. ${ }^{2}$ The English traveler, Burton, therefore, in 1856 , proposed to establish a list of the best "Abbans" in Somaliland. ${ }^{3}$

The statement, here, of this point, is not to be regarded as superfluous, since in connection with the information affurded regarding the protective relation, it throws a strong light on the legal evolution of the institution of brokerage, in legal circles different from that of the somalis. What Burton proposed in 1856 for Somaliland was actually done, to a certain extent, in 1864 in Massua. Here, an exclusive class of persons, the so-called "Nesil," who serve the merchants as patrons, hosts, and commissioners, dominate the market to such an extent that it rould be "foolish" to expect "to engage them only as agents" for the purpose of cutting down their high courtage. " In another locality", where the function of host and broker is identical, among the south Arabians, these persons (dallâl) constitute a special guild under self-chosen directors; here the restrictions on the office of broker have gone so far as to limit the exercise of this calling to sons of brokers. ${ }^{5}$

These facts may now be considered with reference to the development of Germanic law. Here, also, at first, the stranger had no rights, and only the usages of hospitality. which the host observed with reference to his "patronus" or "senior," was able to secure him protection for life, liberty, and goods. ${ }^{6}$ That influential persons furnished hospitality to merchants is attested at least among the north Germans. It is to be remarked, however, that hospitality was not given to merchants for nothing, as to other persons, but only for compensation in goods or money. ${ }^{7}$

1 Munzinger (Bogos), p. 46, No. 72.

${ }^{4}$ Munzinger, "Ostafr. St.," p. 121. The absence of differentiation, sharply defined in our law, brtwen the roncept factor and broker, is not attributable to a defiriency of legal knowledge of the informant. As a matter of fact, it is easy to understand that the same persons who negotiate business affairs with their own people, in many cases also expcute the business of strangers in their own names. First. only, with the appearance of the sworn broker in Islamitic law, and among the (iermanic and Roman nations, is a clate distinction seen letween the functions of the broker and factor.

"Cf. Tan den Berg, "Le Harhhramount" (Batavia, 18s6), p. 7t.

${ }^{6}$ Heusler, "Inst.," I, p. 144; tichröler, "D. R. (;.," Pp. 37, 72, n. 7, p. 323 .

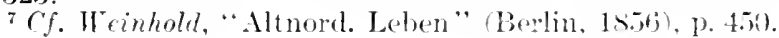


For the rest, it may be said that analogous relations corresponding to the same phase of culture of other peoples developed, so that frequently the same person was the protector, host, business intermediary, and interpreter of the alien merchant. ${ }^{1}$ From the time that a kingly protection of strangers grew up, ${ }^{2}$ this protection became limited in effect to support by testimony in the conrts. This was usually provided for by inviting the agent to join in the customary drink $^{3}$ with which a transaction was closed, whereby the agent became a witness to the business in question. It appears, also, that improper inducements entered to require the foreign merchant to rely on a business agent. In any event, the laws regulating commerce in the period from the 11 th to 13 th century - the regulations conferring commercial privileges on foreigners, as well as domestic Stadtrecht, which, for the greater part, designated as competent business agents, the "Unterkäufer" or "Litkäufer," " - were unfavorable. Their testimony was admitted only in unimportant matters, or when it agreed with that of persons of consequence. $^{5}$ Or, only those agents were competent to testify, who were also hosts of the stranger. ${ }^{6}$ Again, there were regulations which made their testimony wholly incompetent; and, here and there, remunerated agency was entirely prohibited. ${ }^{7}$ Yet, at the same time, men preferred to

${ }^{1}$ Cf. Pappcuhtim in "Z. f. Handelsrecht," XXIX (1884), pp. 440-444. He points out that among the north Germans those who served strangers as brokers or commissioners, were also frequently called interpreters (Dolmetscher). See, further, Schmoller, "Strassb. Tucher- und Weberzunft" (1SS1), p. 7S, concerning the commection between the function of host and business agent for aliens ; and Ehrenberg in "Z. f. Handelsrecht," XXX, p. 414 scq., concerning membership of the "Hosteliers" in Brügge in the guild of brokers, and the natural relation between these callings.

2 Cf. Hcusler, "Inst.," I, p. 145.

3 Cf. Schröder, "D.'R. G.," p. 54; Grimm, "Deutsche Rechtsalterthümer," p. 191

${ }^{4}$ Example of such provisions will be found in the citations entered below; also in Goldschmidt in "Z. f. Handelsrecht," XXVIII, p. 11S. The term "Unterkäufer" shows that in Germany a business ageney for aliens was connected with the termination of a business in the agent's name for account of the alien. 'T'he origin of the term "Litkäufer," however, is as follows: on the conclusion of a transaction where performance still remained to he made, a light repast was served to which the agent was invited. At first, there was used a home-made wine (lit); therefore the transaction was also called lîtkouf. Cf. Schrödcr, "D. R. G.," and also my "Hansgrafenamt" (1893), p. 58, note 75.

5 C'f. "Wiener Stadtrechtshch.," art 110 (ed. Schuster, Vienna, 1873), p. 106; Stdr. Leopold VI for Vienna c. 21 (Rechtsquellen der Stadt Wien, 1877. Bd. I, p. 13).

${ }^{6}$ Ibid., I, p. 2.

"Cf. the examples given by Laband in "Z. f. deutsches Recht," Bd. XX (1S61), p. 21, notes 65,66 ; also "Bremisches Urkundenbuch" (1873), I, p. 142 . 
swear in to a faithful performance of his duties an "Cinterkäufer" of good report, and avoided giving the function of business agency to others. ${ }^{1}$ In this manner, the institution of the sworn broker arose in Germany. It did not proceed from the authentication of officers commissioned in commercial matters, which first concerned itself with business agency per abusum." Neither is its origin attributable to a reception of Italian commercial law; since this law itself adopted the notion of the "Sensale" [licensed broker] from Oriental commercial usages. ${ }^{3}$ Here, as elsewhere, the same necessity has, in an entirely different locality, brought forth a similar institution. Thus, it is possible to supply the vacancies in the evolution of this important commercial institution in German legal history, by comparison of related forms in entirely foreign countries.

The same is true with respect to the origin of the market law of the Middle Ages. Eminent investigators represent the view that, primarily, Germanic market law must be referred to the King's Peace which has a connection with Market Peace." But, if the notion is permitted to assert itself, that economic necessities must be considered as peculiarly decisive of these questions, then it will seem probable that a special Market Peace has existed even among peoples not living under a monarchical constitution. Indeed, originally, the market did not involve territorial power, and

I See examples in Schmoller, "Strassb. Tucher- und Weberzunft," p. 78, n. 2, and Gengler, "Stadtrechtsalterthümer" (Erlangen, 18\$2), p. 464, n. 48 . Since it was desired, in the interest of other merchants, not to give the sworn broker an actual legal monopoly in the eonsummation of the affairs of strangers, it was necessary at the same time to prohibit them from executing a transaction in their own names. Thus is explained the prohibition considered, as an essential in the legal conception of the sworn broker, and also the complete separation of this funetion from that of the factor. (f. Laband, oc. cit. (note 7, p. 426), pp. 25, 26, and the parallel in Islamitic law (note 3, below).

2 As is well known, Laband represents this view (sce note 7, p. 426), which is followed by struck, "Die Effectenbörse" (Lpz., 1SS1), pp. 1SS-9.

${ }^{3}$ One might erroneously arrive at this notion from the article above cited (p. 426) of Goldschmiclt. Yet, it will appear from the discussion, taken in connection with Goldschmidt's sourees, that there was an extraordinary similarity of development with reference to the commercial broker in German, Italian, and Islamitic law. Touching the last, compare, also, Behrnauer, "Mémoires sur les institutions de police chez les Arahes" (Paris, 1S61), p. 187. Aceording to this work, in the states of Islam in the 13th century, brokers were nominated and rontrolled by the chief of Police (Muhtasib). They were rigidly prohibited from doing business on their own arcount.

"Sohm, "Entstehung des deutschen Städtewesens" (Lpz. 1S90), and Kuntzc, "Die deutschen Stadtgrünclungen" (Lpz.. 1891). The latter even attempts to prove that market freerlom first arose out of kingly municipal peace which itself is reforable to Roman connections; $c f$. my recension of the book in "Z. f. v. R." 
the market visitors themselves, in the beginning, provided for the maintenance of the Market P'eace. 'The marketers were not united in any kind of association except the interest of maintaining the peace.

Thus, by way of example, in central Africa, periodical marketday's are held "on neutral territory in the heart of the primitive forest." The otherwise hostile tribes, the Boluas, Balubas, and Baketes, meet here together in amity. ${ }^{1}$ In Bogelo in the northern part of East Africa a daily market is held in a large inclosed place outside the village. 'This place is regarded as neutral, and not as belonging either to the inhabitants of the village or to the other visiting tribes. ${ }^{2}$ Various North-American Indian tribes also met in market commerce at a place on the Mississippi, resarded as neutral territory. ${ }^{3}$ Furthermore, ancient mythology points out similar conditions in the founding of European peoples. At any rate, two eminent investigators, Lubbock and Maine, explain the well-known fact that the Helleno-Italic god Hermes or Terminus was at once the god of boundaries and merchants, by the circumstance that markets in these places, at first, were held on neutral territory. ${ }^{4}$ Finally an institution of the Kabyles, among whom, notwithstanding the acceptance of Islam, many primitive legal establishments maintained their integrity, ${ }^{5}$ is of the highest importance for the question of the origin of Market l'eace. Although there these markets were, as a rule, subject to the power and regulation of a definite tribe, ${ }^{6}$ yet punishment

'Ludwig llolf, in “Z. f. Ethnol.," XVIII (1886), p. 726.

2 Munzinger, "Ostafr.," p. 519.

${ }^{3}$ Carver, "Travels throngh the Interior Parts of North America" (London, 1778), p. 99. In connection with these observations it is shown l, $K 1 \mathrm{cmm}$, "Allg. Culturgesch.," II, p. 133, and after him by Kulischer, p. 352, that similar legal customs existed among the Indians of Chili. Here, the market, howerer, is for the Indians and Whites; cf. Pöppig, "Reise dureh Chile," ete. (Lpz., 1535), p. 37\%. On the other hand, reference may be made to the declaration of peace in the market assemhlies of Cuzula on the West African coast. Yet, of course, the tradition for this fart, for which Kulischer, loc. cit., gives Bastian, "Rechtsv. bei relschieltenen Völkern" (Berlin, 1872), p. lxix, n. 63, as authority, is little to be relied upon, since it is separated by a period of nearly two centuries from the occurpence reported.

"Lubbock, "Origin of Cirilization," 2d ed. (London, 1870), p. 220; Waine, "Village Communities" (London, 1876), pp. 192-3. It is noteworthy that Maine reconciles the fact that Hermes was also god of thieves, with the speedy conviction and severe punishment of thefts rommitted in the market; while this fact had frequently, and erroneously as well, heen explained as resting on the small trust put in the honesty of merchants; of., for example, Roschcr, "Srstem," III, p. 67, n. 14.

5 (f. Hanotern and Letourneux, "La Kabytie et les eoutumes Kabyles," (Paris, 1872), II, p. 135.5 seq.

${ }_{6}$ Ibid., II, p. 78 seq. Sometimes, also, two tribes establish a rommon market, and exercise in common the right of control over it (ibid., II, p. 75$)$. 
for violations of Market Peace was inflicted, frequently in the most primitive way, by the marketers themselves. ${ }^{1}$ When anyone ealls out that a murder has been attempterl, or theft, or an imposition committed against the peace of the market, then all the bystanders attempt to stone the real or supposed culprit. The market master of the tribe having the control of the market, as a rule, exerts himself to save the accused from this kind of justice. Sometimes he suceeeds, and then the aceused is tried by judicial procedure. Of course, the market master desists at onee in his attempt to rescue the eulprit, if he regards him as guilty, or thinks it improper to defend him. If the aceused is a person of influence, then his friends intervene, and the market becomes the field of a bloody fight.' Thus, this method of seeuring Market Peace by instantaneous blood punishment of all disturbanees, is the most primitive and completest methor of seeuring peace.

These eustoms conspieuously suggest the most aneient legal conditions known of the Greeks and Germans. Here, in the beginning, public criminal justice was limited to "intervention by the public as to offenses of special evil." But then the "community did not proceed by way of a defined" procedure, but acted as an "unregulated mob assisting the person injured in self-help" or considered it a duty to destroy the person who had set himself in opposition to the institutions of peace, the same as if he were a wild beast. ${ }^{3}$

Concerning protection of the Market Peace by the visitors to the market, which, of course, is brought about in a different way, we also have information from Berbera. 'There, if a stranger is murdered, the merchants all go away, and do not visit the place again until full settlement of the blood debt is made with the heirs of the murdered person. ${ }^{4}$

Also, when breaches of the Market Peace are not diseiplined by the market traders, by an immediate blood punishment, and regular measures govern such cases, even to-dar, in primitive countries, as in Germany in the Middle Ages, the same crime is more severely punished if eommitted at the market than outside the market. For instance, the local customary usages and statutes of the Kabyles, as a rule, provide for severer punishment

${ }^{1}$ Ibid., II, p. 81 ; III, 302 seq.

2 Ibid., III, p. 304 seq.

${ }^{3}$ Cf. Bernhöft in “.'. f. v. R.," I, p. 7; Brunner, "Z. d. Sar.-Stft. Germ. Abth.," XI (1890), pp. 6i3, (it.

${ }^{4}$ Haggenmacher, loc, cit. (see note 4, p. 4.23 supra), p. 37. 
of offences committed at the market, in providing for the jurisdiction of the market-master. Theft is punished not only by the customary money penalty, but also by the disgraceful discipline of burning the clothing and cutting the beard of the culprit. ${ }^{1}$ It is especially worthy of remark, that among the Kabyles the visiting stranger is considered as under the protection (ânaïi) of the tribe to which the market belongs, not only while he is visiting the market, but also in going and returning. ${ }^{2}$ Offences against visitors going or returning from the market receive the same punishment as if committed at the market; and such offences have frequently provoked bloody quarrels among the Kabyle tribes when the home tribe of the delinquent has refused to deliver him up to the market authorities. ${ }^{3}$ In the market of Berbera, also, breaches of Market Peace are more severely punished. If the peace is broken by a quarrel in the market-place, both sides must pay a penalty fixed by the common assembly of the home tribe. All grosser offences are punished by death. ${ }^{4}$ When a dispute arises, the parties at once withdraw from the market-place, and at some distance from the market, end the quarrel - often with knives and daggers. ${ }^{5}$

In addition to severer punishments for crimes committed at the market, the Market Peace also extends to give immunity, to those present at the market, for previous offences. In Berbera, no one may take blood-revenge at the market; ${ }^{6}$ and in the markets of the Kabyles any killing by way of blood-revenge is treated on the part of the market associates in the same way as any other crime. ${ }^{7}$ If a merchant in Berbera recognizes goods put up for sale as having been taken from him by robbery, he may not even so much as make claim to them against the robber. ${ }^{8}$ In the market in America, to which reference has been made, ${ }^{9}$ hostile tribes associate together on terms of peace.

The markets which have been so far considered are all either held in neutral territory or concern peoples still hiving under a primitive clan constitution. If we find, under these conditions, a Market Peace with all the essential attributes already developed,

1 Hanoteau and Letournenx. III, p. 303.

${ }^{2}$ Ibid., III, pp. 108-9. The same custom extending market protection to the coming and going of market visitors is well-known in German law ; ef. Wraitz, "Deutsche Verfassungsgesch.," VII, pp. 378-9.

${ }^{3}$ Hanoteau and Letourneux, III, p. 109.

${ }^{4}$ Haggenmacher, p. 37. ${ }_{5}$ Burton, op. cit. (note 4, p. 423 supra).

${ }^{6}$ Haggenmacher, p. 37.

${ }^{7}$ Cf. Honoteau and Letourneux, III, p. 303.

${ }^{8}$ Haggenmacher, p. $37 . \quad{ }_{9}$ Carver (see note 3, p. 428 supra). 
it seems incorrect, therefore, to refer it to a people with a monarchical constitution - where a special peace obtains near the king, ${ }^{1}$ and where at the market the king's presence is fictitionsly assumed. ${ }^{2}$ When the market is altogether under territorial authority, then so long as the clan constitution ${ }^{3}$ prevails, the village community maintains the peace of the market and collects the revenues therefor, but as soon as a competent kingly power arises with the rudiments of state organization, then the maintenance of peace and the revenues appertain to it.

It has already been pointed out, that in Berbera the common assembly fixes the penalties for the lesser offences against the Market Peace, and that the consent of this authority is necessary in order that an "Abban" may be changed." This assembly also has jurisdiction over eapital crimes, and levies on each mooring vessel a definite money tax. ${ }^{5}$ It consists of all male adult members of the Somali tribe, Rer Achmet Noh; in which tribe only those persons are regarded as adults who have killed an enemy. ${ }^{6}$ At Emberria, also, in the land of the Wanikas in East Africa, the village community is the protector of the Market Peace; it receives the oath of the captains of the visiting caravans that they will respect the peace. ${ }^{7}$ As has already been observed, the markets of the Kabyles are subject to the authority of a definite tribe, which selects the master of the market, fixes the punishments for breaches of the Market Peace, and regards all visiting strangers at the market as under its protection. The marketmaster, however, is vested only with police and criminal jurisdiction. ${ }^{8}$ When disputes arise in civil matters, the parties resort to the "Alem" (the sage) of the market, a Marabout (priest) who resides at some distance from the market. ${ }^{9}$ He, likewise, is appointed by the tribe which controls the market; but every visiting Marabout may claim the privilege of participating in the judgment, with an advisory voice. ${ }^{10}$ The jurisdiction of the Alem is not, however, exchusive; the parties may resort to a

1 The same phenomenon is found, moreover, in German and AngloSaxon law, also in Celtic, Polish, Chinese, and aneient Peruvian law; cf. Post, "Bausteine," II (Oldenb., 1881), p. 249.

2 The view of Sohm (see note 4, p. 427, supra).

3 Thus appropriately called by Post ("Aufgaben," p. 38), to distinguish it from conditions when there appear the rudiments of a state constitution in which "a people lives in a small community essentially independent of others, or conneeted with others only by agreement."
${ }^{4}$ See above, p. 424.
7 Krapf, pp. 273-4.
${ }^{5}$ II aggenmacher, p. 37.
${ }^{6}$ Ibid., p. 36.
${ }^{8}$ Hanoteau and Letourneux, II, pp. 80-1.
9 Ibid., p. 82. ${ }_{10}$ Ibid., III, p. 37. 
referee; and when they are from the same village, they may take the law of the home court. ${ }^{1}$ On the other hand, disputes may be adjudicated before the Alem, of matters not originating at the market. ${ }^{2}$

The procedure is usually brief. The plaintiff' and defendant speak; the witnesses are heard, who either appear voluntarily, or are produced by the master of the market; and then follows the judgment which as a rule makes the final decision dependent on an oath of the parties judicially administered. The judgment is executed not by the Alem, but by the marketmaster. $^{3}$ If the judgment debtor camnot or will not pay at once, execution follows, by means of which his goods, and contingently his clothing, are attached in favor of the judgment creditor.

It is worthy of note, that the tribe to which the market belongs establishes special officers for the measuring and weighing of merchandise. These officers are compensated by fees paid by the traders. ${ }^{4}$ Sometimes, these offices are sold by the masters of the market. ${ }^{5}$ Otherwise no taxes are levied, except that, when the tribe with dominion over the market has a school, a small portion of meat of all animals killed at the market must be delivered to it. ${ }^{5}$

Thus, among the peoples considered, so far as there do not appear remnants of the protection of the peace by the assemblage of the traders themselves, the Market Peace is controlled by all the members of a primitive village or tribal community and the officers appointed by it. On the contrary, it may be regarded as an universal legal phenomenon that where a vigorous chieftain or kingly power has developed, it assumes the function of regulating the markets. Kingly market sovereignty existed to some extent, perhaps as early as in time of the dispersion of the peoples, ${ }^{6}$ and in developed form, at all events, as early as the Carolingian period. ${ }^{7}$ Royal protection of Market Peace is found very early, in fact before the influcnce of Germanic law, among

${ }^{1}$ Hanoteau and Letourneux, III, p. 38.

${ }^{3}$ Ibiel., III, p. 38.

${ }^{4}$ Ibid., II, p. 79.

${ }^{2}$ Ibid., III, p. 39.

5 Ibid., II, p. 82.

${ }^{6}$ Cf. Eugippius, "Vita S. Severini," e. 22 ("Mon. Germ. Auct. Ant.," II, p. 19), according to which residents of a Roman city desired to go to a neighboring German prince to receive permission to trade in his domain. Against the view that "there were no markets in ancient Germanic society" (Dahn, "Deutsche Geschichte," Bd. I, Th. 2, p. 707), cf. Eugipp., op. cit., ce. 6,9 .

" Cf. Rathgen, "Entstehung der Märkte in Deutsehland" (Darmstadt, 1S\$1), p. 9 seq.; Schröder, "D. R. (G.," p. 186. 
the Slars' ${ }^{1}$ and Magyars. ${ }^{2}$ Among the Chinese ${ }^{3}$ and the peoples of Islam, ${ }^{*}$ officers of the ruler are found caring for the regulation and law of market commeree. In primitive cultural conditions there may be found a dereloperl market-police; thus, especially, in the capital city of the Bautshi in Sudan, living under a monarchical srstem of government. The Ssersi-n-kurmi, in all probability a royal officer, is seen daily at the market. He decides all barter disputes, and sees to it that only unadulterated milk, and that only flesh separated from the bones, are offered for sale. ${ }^{5}$ In the kingdom of the Bomas on the Loango coast, a special royal officer was vested with supervision over the market as early as the previous [18th] century; it was his function to orersee all the commerce between the natives and the Europeans, and to prevent trading between native-born slaves and Europeans. ${ }^{6}$ Lastly, reference may be made to the conditions in the kingly territory, Whydah, in Guinea. It was already reported ${ }^{7}$ in the previous century that there a special royal officer heard all complaints between buyers and sellers at the market, and decided by summary procedure. The still primitive medium of exchange was also under the control of a roval officer in Whydah.?

Just as in the case of the public (State) law and criminal law foundations of the regulation of market commerce, so also in the construction of the standards of private commercial law, there is seen a surprising similarity among widely separated peoples. It must be conceded, that for the lowest stages of culture there is almost an entire absence of information concerning private commercial law, if we except the institution of the broker, discussed above, who is also a protector of the alien, and the special form of company law of the caravans, ${ }^{8}$ where certain elements of public law still play a part. It is certain that this is due in no small degree to the fact that under such conditions civil law and commercial law are nearly synonymous. But it requires to be men-

1 Cf. Tomaschek, "Deutsches Recht in Oesterreich" (1959), p. 71.

"Fessler, "Gesch. ron Lngaru" (Lpz., 1867), I, 1) 192.

${ }^{3}$ Biot, "Le Tscheou-Li" (Paris, 1si1). p. 309 seq.

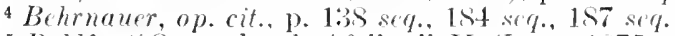

"Rohlfs. "Quer dureh Arika," II (Lpz., 1S75), p. 160, and in Petermann's "Mitth. Ergänzungsh.," VII, No. 33. p. 236.

"Proyart. "Histoire rle Loange" (Paris, 1776), p. 124; ef also Bastian, "Die deutsche Expedition an der Loangoküste" (Jena, 1s゙̈4), BA. II, p. 40 .

"Labat, "Toyage du chevalier des Marchais en Guinée" (Amsterd., 1731), II, pp. 162, 163.

8 This phenomenon is better treaterl in another commetion: of. Kulischer, p. 385 seq., Haggemmacher, p. 32, Wunzinger, p. 124, Kohler, "Rechtsvergl. Studien" (1Ss9), p. 171. 
tioned that among the Kabyles there existed local commercial usages. In a period now left behind, in the markets of the tribes, Ait Yahia, and Akbil, the actio redhibitoria on account of latent defeets in goods sold, was not admitted in the sale of cattle. ${ }^{1}$ It hardly needs to be suggested, that, also, in Germany, notwithstanding the existence of a general commercial law, special commereial usages, and many special commercial statutes, for a long time governed the markets.

Much greater analogies are found in the private commercial law of developed legal systems, even when full allowance is made for the wide reeeption of foreign law, and the leveling process in commercial legislation of modern peoples. It will here suffice to point out the similarity between Germanic commercial law of the later Middle Ages and Indian law. According to the code of Manu, one aequires "ownership of an objeet who buys it at the market before witnesses," whether the seller himself was the owner or not. This corresponds fully with the fact that, in the liter Mildle Ages, "whoever buys a stolen article in the open market, is protected against the elaim of the true owner." 3

These examples, however, lie outside our field, in that they do not any longer represent the theme of primitive law. For this reason, the writer forbears to diseuss the other analogies of this and later stages of legal development. ${ }^{4}$... In any event, it may be apparent from the faets introduced by this study that the field of commercial law involves a fulness of problems, of interest for ethnological jurisprudence, as well as universal legal history.

${ }^{1}$ Hanoteau and Letourneux, II, pp. 79, 390.

2 Book $\mathrm{T}$. See. 201 (trans. by Jolly); cf. also Maine, "Early Law and Custom," pp. 194, 195.

${ }^{3}$ He'usler, II, p. 215; Sehröder, “D. R. G.,”p. 664.

${ }^{4}$ It may be added, that in China, the raising and lowering of a flag was a signal for the beginning and ending of Market Peace. precisely as was the case in many German places; ef. Biot, p. 213, No. 5, with Schröder, "Rolande," pp. 16, 23 seq. 


\section{Chapter XXIV \\ BARTER AND TRANSFER}

\section{SeCtion 1}

\section{BARTER ${ }^{1}$}

1. Barter is based on the idea of equalizing values. A man gives something and receives something in return, and this relation of giving and receiving is not governed by chance; rather, the persons stand in an economic relation to each other, a relation in which values are equalized. The tertium comperationis of both acts is the equivalence of their value.

2. The barter value is not the same as the value in use; for it is not the value that is determined by the individual's need, but the value that is fixed by the social function of the article in general commerce. Uuder value in this sense, we understand the extent of the economic wortb of an article, which is determined by its comparison with other wares and their econonic uses. It is incorrect to say (with Marx) that value always corresponds to the labor that the article represents. Value is rather determined by a whole series of social factors: the demand for the article, the effort to obtain it, the greater or lesser frequency with which it is offered for sale, the facility with which it is obtained and its greater or lesser rarity, which is by no means only a matter of labor conditions but is rooted in natural cireumstances. All these factors will affect value, and will cause the thing - even though it may always represent the same amount of labor - to assume sometimes a greater, sometimes a lesser social importance.

3. It is not only need that is of importance in barter. 1 number of other, mainly psychic circumstances come under consileration, especially the human love of variety which is strongly developed, particularly in nations that have little self-control and

${ }^{1}$ [Reprinted, by permission, from Josef Kohler. "Philosophy of Law" (Albrecht's trans.), Boston Book Company, 191.t (Philosoplyy of Law Series, Vol. XIl).] 
little mental culture. Men grow tired even of what is best and most beautiful and want something else. Then, too, the psychic needs that are esthetic or partly esthetic in their nature have to be consilered. People want what dazzles and attracts them, what appeals at the time to their sense of beauty, or rather their mental aspirations. 'The sudden, unaccountable popularity of a thing, the immeasurable attraction that some article has for people, often plays a great part.

4. It is a misconception to assert that barter grew out of the division of labor. The division of labor naturally increased the need of harter; for whereas, formerly, it might have been possible for the individual to satisfy his own needs and longings himself, it ceased to be so as soon as the individual was limited to the production of certain definite wares. It is true only, that while otherwise the tendency favoring barter transactions was based more or less on chance, the whole system of economic production made it essential.

5. The backbone of barter is, as has been said, the equalization of value. This idea of equalization increases, as soon as articles are produced which are not regarded as a means of satisfying personal neels, but are intended to represent values. While, otherwise, value is an $x$ which is contained invisibly in the objects $a$ and $b$, value now, at least on one side, appears openly. It is no longer an $x$ but a certain quantity, $v$, and the question of value which otherwise comes unter consideration in respect to both the objects $a$ and $b$ (because in both value lies invisibly dormant), need now be considered only in connection with the article $a$, since the exchange value of the value-representative, $v$, is given, representing clearly and unmistakably to everyone a definite value. In this way money originates. This not only means great progress in the valuation of things, it being possible to reduce the value of everything to a money unity, just as when we bring all fractions under one denominator; ${ }^{1}$ but a second advantage is involved, - an advantage with the most momentous consequences, - that the value-representative, money, is not, at the same time, a means of satifying any one special human purpose. If one who wishes to dispose of article $a$, wants to obtain article $b$, he must, in a period in which barter is the only means of commerce, seek a person who wants article $a$, and at the same time has article $b$ to dispose of. In other words, the transaction as regards $a$ and $b$ depends upon chance - chance 1 "Einführung in die Rechtswissenschaft," p. 69. 
on both sides, in fact - for the sale can only take place if one individual wishes to dispose of $a$ and obtain $b$, and the other wishes to obtain $a$ and dispose of $b$. This is, of course, a powerful obstacle, and not only imposes difficult conditions on the barter transaction, but necessitates a great deal of human effort, till finally, an opportunity is found that combines both requirements.

It becomes necessary to eliminate this chance, and one of the principal means of accomplishing this is the introduction of money ; for if one wishes to dispose of article $a$ and obtain article $b$ he has only to find a person who wants $a$, and will give him the value-representative, moner, for it. With this value-representative, he can now seek some one else who wishes to dispose of article $b$, and in this way he succeeds in acquiring article $b$ instead of the article $a$ which he possessed. Here the contingency is only on one side; the sole chance is, that some one wishes to acquire article $a$, and further that some one else wishes to dispose of article $b$. Separated in this way, the contingency is much more easily overcome than when it is combined. If the simple chance occurs in perhaps fifty per cent of the cases, the combined chance occurs in only about ten per cent of the instances.

6. In order that moner may come into use, things must enter into commerce that are most generally used, and which are fairly uniform in value. When this is the case, the custom will gradually grow up of giving an article for such an article of general use. which is much easier to find and circulates more freely in commerce than any other. When it has become usual, instead of satisfying one's wants directly by barter, to seek first for such an article, and then to find the man who wishes to dispose of the thing desired, the peculiar use of the article will be less and less considered, and it will become more and more a representative of value until finally. it comes to be regarded only in the latter aspect. Among peoples that live by hunting, such articles are chiefly animals' pelts, which everyone needs; among cattle-raising peoples, cattle. Different kinds of animals acquire a general value-significance; small cattle (calves, sheep, goats, and pigs) represent a certain value, large cattle another; and, as merlium sized animals are the standard, the size of the individual animals does not matter. This is marle especially easy among pastoral tribes, by the fact that one shepheril has all the animals of the place in his keeping; so that the transfer can be made simply by re-branding those that have changed hands.

The disadvantages of using animals in this way appear as soon as the institution of money becomes more developed; for then 
moncy must not only be a representative of value, but also a means of keeping or storing value, and a means of dividing it. This presupposes that the articles have a certain permanency, and do not decay after a time; also that they do not require constant attention, as is the case with animals. 'Thus, instead of pelts or animals, leather money comes to be used. Hence, also, some nations use shells and other permanent objects of value. But it should also be possible to represent different degrees of value, from the smallest to the greatest, for if the objects $a, b, c$, having different degrees of value, are exchanged, the value-representative must be such that the value of $a, b, c$, can be represented. This is only possible if it is divisible, which is not the case with animals, but is with leather and shells, inasmuch as a larger or smaller number can be strung together.

But metals have all these qualities in a much higher degree; hence, it soon occurs to peoples that have metals to give up all other value-representatives, and to use only metallic money; ore, of course, at first, and then, when the production of gold and silver is sufficiently developed, these metals too.

The division of value, when metals are used, presupposes of course that weighing scales are always at hand, on which the quantity can be weighed that corresponds to the value; until at last, the new idea arises of marking on a piece of metal the amount of metal it contains, and in such a way that it is universally credited. Thus coined money originates. Coined money has two qualities: it is a vahue-representative in itself, and it is a value-representative with a publicly announced metal content.

In this way, the public offices that mark the pieces of metal gain a tremendous influence over money. Soon the idea of allowing semblance to take the place of reality appears more and more persistently. The State begins to make out false certificates, to coin or mint money, that is, to stamp the coin with a higher value than the true value of the piece of money. If this is done secretly, and in order to deceive the people, it is immoral and leads to the destruction of public confidence. Whenever it has been done in this way, it has always ended in a period of confusion and disorder. It is entirely different, however, when the semblance is not intended to deceive, when the stamp is not supposed to convey the irlea that the coin contains a certain amount of metal, but only that it is to be used as if it contained that amount. In this way fractional eurrency and paper money arise.

7. Even after the introduction of money one clement of con- 
tingency still remains, and this element the intermediaries of commerce seek to eliminate as far as possible. This kind of commerce consists of acquiring goods not for one's own use but in the expectation that others will need them. They are kept in stock on the chance of their being wanted. The result of this is that if some one wishes to sell article $a$, it is not necessary for him to find a person who needs this article; he has merely to go to the midclleman: and similarly, if he wishes to buy the article $b$, he need not seek a person who happens to have such an article, and is willing to sell it; he need only apply to the middleman who, without himself being in need of any special article, disposes of the object $b$ for money. The progress of culture can be perceived in this process, inasmuch as chance is eliminated as far as possible, and man overcomes the obstacles that nature and society throw in his path.

8. At first all barter transactions were promptly and immediately completed, particularly barter between rlifferent tribes, which developed as private commerce. But, even among members of the same tribe, a thing was given for a thing receiverl at the time. To give something for a thing that is to be received in the future presupposes an economic mind that is directed toward the future, which primitive peoples did not possess, and which some peoples never attain. When sale takes the place of barter, the idea of credit will arise much more easily ; though, even then, the mind is not able to renounce the idea of a bargain for ready money. Thus, if a man wishes to buy something and pay for it later, he does it indirectly by paying the price "constructively," and then receiving it again as a loan. By this method two transactions are combined that gradually become one: the "constructive" payment is no longer taken into account, and the return of the loan is treated as a part of the original transaction.

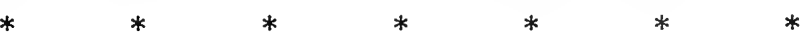

\section{Section 2 \\ PRIMITIVE TRANSFER OF GOODS 1 \\ 1. Tribes among whom Commerce is supposed to be unknoun}

The fundamental fact from which we must start out is that among all the tribes here investigated, there was commerce not

${ }^{1}$ By Felix Somló, Professor in the Lniversity of Kolozsrár. Translated hy Albert Kocourel from "Dor Güterverkehr in der Crgesellschaft" ("Travaux de l'Institut de Sociologie" [Solvay Institution], I, Notes et 
only within the tribes but also between tribes. We must, however, hear the recitals concerning tribes which are supposed to have known nothing of trade. Grierson has collected a small number of such assertions. Cook found that the Australians had no idea of barter. 'The same fact is deposed by Dampier also, for the Australians; by Le Vaillant for the Iottentots; by Wallis for the natives north of the Magellan Straits; by Herrera for the aborigines of America with whom Alonso de Ojeda and Amerigo Tespueci first came into contact; and by Labillardiere for the natives of the Solomon Islands. ${ }^{1}$ It has been shown, however, for all of these tribe's, that these statements are untrue. It has been the misfortune of many authors, such as Herbert Spencer, and Ch. Letourneau, ${ }^{2}$ to be misled by such superficial assertions. A. Coste also maintains that of all social phenomena, barter was the last to appear and to develop. ${ }^{3}$ So far as social development can be traced back, we also find a circulation of goods. This activity goes parallel with all other activities of social life.

We have come very near to the same conclusion that Grierson arrives at in his book ("The Silent Trade") where he states that the custom is almost universal of expecting an equivalent in return in making gifts ; and that there are many cases where there is an understanding between the giver and taker that a return gift is to be marle. It is, of course, reported of various tribes that they hat no idea of trade; yet, it is to be remarked, that in many cases these assertions are contradictory, and that such an assertion for all cases, does not mean any thing more than that certain Europeans were not able to trade with certain savage peoples. It is entirely possible that these instances do not show a lack of knowledge of trade, but are due to fear, mistrust, or misunderstanding. A savage may be quite ready to trade with a tribesman when he would decline any association with a foreigner. ${ }^{4}$

Mémoires, Fasc. S, Brussels, 1909), p. 155 seq. The primitive societies examined in this work are the following: The aborigines of Tasmania, the Botocudos, the Fuegians, the Andaman Islanders, the Negritos, the Bushmen, the Seri Indians, and the Veddahs.]

1 Grierson, "The Silent Trade," pp. 20-21 (where the respective references are entered); $c f$. also A. Sartorius, "Die Entstehung des Tauschhandels in Polynesien," "Z. f. Sozial u. Wirtschaftsgeschichte," IV, 1896 , pp. 5-9.

2 Spencer, "The Principles of Sociology." London, 1897, III, 380-1 ;

Letourneau, "L'évolution du Commerce," Paris, pp. 6, 10, 24.

3 Adolphe Coste, "L'Expérience des peuples," Paris, 1900, p. 197.

${ }^{4}$ Grierson, "The Silent Trade," 39, 40. 


\section{Exchange of Ciifts}

We find not only that barter is known to all these primitive peoples, but that there is also considerable commerce between the tribes and, likewise, among the individuals of these tribes. This circulation of goods is not always based on the juristic plan of barter familiar to us. Yet the juristic form of these transactions is only of secondary importance. Too much weight has heretofore been ascribed to juristic form. Because the legal form of harter, as we know it, has not been found among these peoples, it has been conchuded that the fact of exchange of goods did not exist. The gift, it is true, was found, but since in our economic life it has no great importance, it was supposed, in like manner, that it also had no importance as an idea of primitive peoples. Incidentally, it may be observed, that to denominate these primitive transactions as gifts is not aceurate. Such a transaction is neither our form of gift nor our form of barter, but lies intermediate between them. It is a legal transaction rigilly eireumscribed by definite rules and is the primitive form of gift and barter in the modern sense. Both have erolved out of this original undifferentiated institution. It is a mistake, therefore, to call these primitive transactions gifts. They resemble gifts in this, that at first there is a one-sided giving corresponding to a one-sided taking, and that the amount of the gift, as well as the gift itself, depends on the one-sided act of the giver. They resemble barter, however, in so far as the gift is made with the expectation of a gift in return which return gift is one of the most stringent customary duties. Custom regulates the value of the gift and the return gift by strict rules. It is therefore proper to eall this legal transaction barter-gift. ${ }^{\text {? }}$

More important than the form, is the fact that the legal transaction is widely disseminated among primitive peoples, and has great economic significance as a means for the interchange of goods.

\section{Origin of the Caste System}

The fact of tribal barter, and the division of labor resulting therefrom, as well as the reciproeal dependence of the tribes on

1 Berolzheimer, "System der Rechts- und Wirtschaftsphilosophie," Munich, 1907 , Bd. IV, p. 223, aceurately states that "the foundation of commerce is the offer of a gift with the expertation of a gift in return.". II. Panckow, "Betraehtungen über das Wirtschaftsleben der Naturvölker" in "Z. d. ges. Erdk.," Berlin, XXXI, 181, on the eontrary inaceurately draws the conclusion that "in this stage, harter entirely misses any direct connection between performance and counter-performance, and, also, any concept of its value." 
each other, attain significance when combined and connected with another fact generally known. We know that it is a world-wide phenomenon which regularly appears, for primitive social organizations to integrate into higher forms. Spencer has even been able to demonstrate that the higher social organizations never result from simple extension or development of primitive forms, but that a combination of lower organizations is always necessary in this process. ${ }^{1}$ The ways in which this integration is brought about may be very dissimilar. In one locality it may result from an amicable union of neighboring tribes in perpetual wars of defense against an overpowering enemy ; in another, such a new construction may follow permanent subjugation. Let us see what are the necessary consequences of such an integration between tribes which during their independence had developed various tribal industries, and had attained a tribal division of labor; like those of Australia, Central Brazil, and the North American Indians; and which, likewise, is an universal phenomenon. At one stroke, the tribal industries turn to a variety of industries of the new social unity; and the different tribes become differentiated into elements of a greater society with an internal division of labor now sharply defined, and inknown in the earlier stages of development. The enlarger social entity, together with the differentiation of function which it conditions, is already in existence in the independent tribes with different tribal industries, and only awaits an incidental, external circumstance which, now, in one form, and then, in another, brings about an integration. ${ }^{2}$

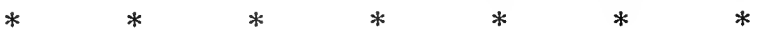

\section{Silent Trade}

According to a view widely accepted so-called "silent trade" is the primitive form of barter. ${ }^{3}$. .

We are unable to share this conclusion. We have seen that silent trading even among the most primitive tribes is very little diffuserl. Of those discussed [in the original work] only the Teddahs know this kind of barter. We learned also that silent trading in Ceylon is an ancient institution which has stood thousands of years and is thoroughly established. Greeks, Persians,

1 Spencer. "The Principles of Sociology," London, 1904, I, 543.

2 Ratzel, "Tölkerkunde," I, s1 ; Parcliow, op. cit. [p. 441 note], pp. 186-7 ; René Maunier. "Vie religieuse et vie éronomique," Paris, 1908.

3 Thus Post. "Grundriss der Ethnolog. Jur.,"'II, 628; and Letourneau, "L'érolution du Commerce," Paris, 1897, p. 529. The latter even derives the barter-gift from silent trading. 
Arabians, and Chinese have had commercial relations with Ceylon, and have used the silent trading method as a custom of the country. It is highly probable that silent trading among the Veddahs is not an original institution with them but has been adopted from neighboring tribes. We may, therefore, assert that silent trade among the most primitive tribes which we have examined is not an autochthonous form of barter. In support of our view that silent trade cannot be regarded as a rudimentary form of barter, it is significant that while this institution is not found as a general autochthonous usage among the most primitive tribes, yet otherwise it is very widely disseminated. Grierson in his comprehensive examination of this question has demonstrated that silent trading is not an exceptional peculiarity of this or that people, but is an institution of the widest diffusion. He collects accounts of forty tribes which employ this form of barter. . . If the data assembled by Grierson also relate to entirely primitive tribes - aside from the Veddahs only the Kubus of Sumatra and the Akkas of the Belgian Congo come here under considerationyet it is to be observed that these are tribes which have come into commercial touch with peoples of higher development. Among the great mass of data, on the contrary, which inform us of barter transactions of the most primitive tribes among themselves, silent trade is wholly unknown. This is sufficient to prove that silent trade is not the original basis of barter, but that it belongs to a higher stage of development in the exchange of goods. ${ }^{1}$

This shows the vice of the prevailing ethnological method which chooses to proceed without a classification of social tryes and simply assumes that that which appears to be primitive is the token of the earliest form of society. Thus, it is believed that nothing can be more primitive than when two persons want to barter with each other, that they should not meet face to face, but that they should lay down their wares and run away ; ${ }^{2}$ and the conclusion is reached, regardless of the people who adopt this form of barter, that this is the starting-point of barter relations. One sees how necessary it is for the reconstruction of primitive society which is still accessible to us to confine our investigation to the most inferior tribes.

* $* * \quad * \quad * \quad * \quad * \quad *$

${ }^{1}$ See Grierson, "The Silent Trade," pp. 41-50; II. Schurtz, "Grundriss

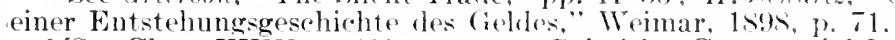

2[See Chap. XXIII, p. 421, supra-"Primitive Commercial Law."] 
We may incidentally indicate the only explanation which it seems can be given of silent trating in primitive ages, by calling to mind the Nuia-mgiampe in Australia. ${ }^{1}$ Two ehildren of different tribes are mutually estranged by certain ceremonies. They may not speak together, touch each other, or come near each other. Such persons take great pains to remain apart from another. As soon as they reach maturity they beeome agents through whom the tribes in question carry on their barter transactions. Grierson, to whom this faet was not unknown, has nothing to say of it, except that this kind of barter has nothing to do with silent trade. He inclines, moreover, to the view that silent trade is an invention for securing the safety of foreign tribes in their dealings. The practiced eye of Durkheim perhaps does not deceive itself when he says, contrary to the views of Grierson, that the ceremonies of silent trade "are visibly of a religious origin." 2 . . .

Durkheim appears to have hit the right path with this statement of the problem, and by taking the Australian Ngia-ngiampe for illustration of the origin of silent trading, to have made a distinct advance. For the religious ceremonies in the barter transaction of Neia-ngiampe are entirely the same as those which are typical of silent trade. . .

\section{The Payment of Tribute}

The various forms of compulsory tribute are well known. Iusband and wife each owe certain material performances to the other; the same is true between parents and children; also, on the part of the son-in-law to the father- and mother-in-law, and, less frequently, in the reverse order. In general, every one must make these performanees in favor of a strictly defined order of relatives, sometimes even to the entire group association. Frequently, also, the tribal associates owe these duties to prominent individuals, and, in turn, the most prominent and wealthy to the tribal members. Very often, a rigidly defined class in the tribe must make performances in favor of another elass; and lastly the younger people to certain elders. These duties of giving tribute are all of a compulsory eharacter, and may appear in the most diverse juristic forms. It may be a duty of liberality which, however, may be in performance of an external preseription, as well as an inner compulsion. Again, it may be a parental or a

${ }^{1}$ Cf. Howitt, "The Native Tribes of South-East Australia," p. 181.

2 Durkheim, "L'année Sociologique," Paris, 1905, VIII, 485. 
filial duty. Furthermore, tribute may be given in the form of religious ceremonies. The oecasion may be nuptial, pre-nuptial, or post-muptial. Many forms of tribute rclate to the event of death; others are due to the taking of booty, or are occalsioned by certain meetings or eeremonies, or are made obligatory in some other way through usage casuistically defined for the case.

A phenomenon of primitive cireulation of goods of special interest, and hitherto wholly umoticed on the part of sociology, is that which developed about the chieftain. Among the Dieri, individuals collect a large amount of property in all kinds of weapons and adornments, which they present to the leading chiefs in order in this way to promote their own position. Especially in the more developed tribes of Southeast Australia, who also have a more developed form of chieftainship, there is a lively giving and receiving of goods among the ehieftains. We learn eren of the miserable Fuegians that they often have feasts where the host serves, and shows himself to be very generous. . . The fact which confronts us, in view of these usages of giving presents, and tributes, whatever the juristic form may be, is that these peoples have a dereloped tribal and intra-tribal system of transferring goods, and that we can attain no proper idea of their economic situation without taking this fact into account.

\section{Circulation of Goods without Division of Labor}

It is generally assumed that distribution of property must be based on division of labor. Where there is no division of labor, where all persons produce the same things, there is nothing to barter; and there is no oeeasion for the eirculation of goods. Inasmuch as among the most primitive peoples, division of labor, and, especially, intra-tribal division of labor on the whole, is limited only to a sexual distinction, it is supposed that here there can be no movement of goods except between man and woman.'.

On the contrary, the facts show that circulation of goods is not exelusively connected with division of labor, but rather that a development of individualized labor cannot come about without antecedent exchange of property. It is only when exchange has become a durable practice that the varying phenomena of special-

${ }^{1}$ Karl Bücher, "Die Entstehung der Volkswirtschaft," 5e Auflagr, Tübingen, 1906, p. 62; Berolzheimer, "System der Rechts- u. Wirtschaftsphilosophie," IV, 221-3. 
ization of production are seen. Barter is the primary phenomenon, and division of labor secondary.

* $* \begin{array}{llllll}* & * & * & * & * & *\end{array}$

\section{Individual Satisfaction of II'ants}

Aceording to the prevailing view, primitive society shows us an economic situation without barter. Differenees of opinion first arise in laying a foundation for this view. One extreme has it, that there is no exchange of goods in primitive society beeause there was no economic association between individual persons; each one standing cconomically apart from the others. According to the other extreme, primitive society has no room for a eirculation of goods, and especially none for barter, because the primitive group was the most exelusive economic society. Primitive communism had no nced for exchange of goods.

One extreme is represented by Bücher: ${ }^{1}$ "If we eliminate from the life of the Bushmen or the Veddahs the use of fire, and the bow and the arrow, there will be nothing left except individual eftort to provide the means of subsistence. Each one consumes raw what he is able to lay his hands on, or seratch out of the earth with his nails - small animals, roots, and fruits. At one time men gather in small troops or in larger companies; at another time they break up their crowds according to the productiveness of the country or the hunting ground. But these gatherings are not societies; they do not mitigate the lot of the individual." "Each individual eonsumes immediately what he finds, and there is no such thing as a common household or home." For proof of this supposed stage of individual satisfaction of wants, Bücher relies on the fact that among many tribes there are no common meal hours "in the family." "Each person is separated from the rest and it is considered unbeeoming to disturb another when eating or to take food in the presence of a stranger." Furthermore, within the family nearly every object is individually owned by a member of the family. "So certain is it that, as to such things, the first thought is of mine and thine, and so numerous are the observances which point in that direction, that this idea of ownership becomes attached to the individual and suceumbs with him. Possession sinks into the grave with the possessor." 2 . . .

1 "Der wirtschaftiche Urzustand" and "Die Wirtschaft der Naturvölker" in his "Entstehung der Tolkswirtschaft."

'See, also, H. Schurtz, "Crgeschichte der Kultur," Leipzig u. Trien, 1900, pp. 212-3; H. Panckow, "Betr. ii. d. Wirtschaftsleben d. Naturvölker" in "Z. d. Ges. f. Erdk. zu Berlin," XXXI, 178-S0. 
It is perhaps not necessary to say much on the insufficieney of this description of primitive society. Others have already done this. ${ }^{1}$ I may conveniently limit my discussion to the question of the stage of individual satisfaction of wants.

Of such a stage of evolution we know nothing at all, and we have no right to assume it. Truly, there is a sharply defined scparation of work between the sexes. Women everywhere have provided the man with plant food and frequently share to some extent in the animal food gotten by the man. The youths are obliged to make provision for the elders. Division of the spoils of the ehase is a matter strictly regulated. Various tribute duties are paid to the families of women, to the members of the individual's own family, to the members of certain tribal classes, etc. 'The pursuit of means of subsistence is everything, but it is not limited to the individual.

It must be admitted that the primitive family is not found to be an exclusive eonsuming unity. Yet, this is not proof of an anterior individualist economy. Husband and wife are usually of different clans. That in many places they do not have a eommon meal time is perhaps easier explainable as a condition of exogamy than as a survival of individual sceking of subsistence. This is most clearly shown by the fact that not all the members of the tribe are required to shun each other at meal times. In Australia a great deal of food must be eaten in public and not by each individual for himself. ${ }^{2}$. . .

* $\quad * \quad * \quad * \quad * \quad * \quad * \quad * \quad * \quad * \quad * \quad *$

One may see how unprofitable is the customary ethnological method of which we have already spoken, and which Biicher con-

${ }^{1}$ L. IFodon, "Sur quelques Erreurs de Méthode dans l'étude de l'Homme Primitif" ("Trav. d. l'Inst. Solvay," Fase. 4), Bruxelles, 1906; S. R. Steinmetz, "Classification des types sociaux" in "L'année Sociologique," III, 1900 , p. 101.

2 Lumholz, "Réponse au Questionnaire" in "Bulletin de la Société d'Anthropologie," Bd. XI, p. 649. [For further examples, from the omitted text, see:] Ehrenreich, "Ueber die Botokudos," in "Z. f. Ethnologie," 1SS7, Bd. XIX, p. 31; Ph. M. Rey, "Etude anthropologique sur les Botocudos," Paris, 1880, p. 79: Hyades et Deriker, "Mission scientifique du Cap Horn," 1882-:3, Tome VII, Anthropologie, Ethnographie, 1891, p. 243; M. Iyades, "Ethnographie des Fuégiens," in "I3ull. te la Soc. d'Anth. de Paris," 1887, X, 32S; Man, "Aboriginal Inhah," 327, 344-54; P. Felipe Calayag y Clemente, "Vida de los Aitas o Negritos," 1877 ; L. Wetschmikoff, "Bushmen et Ifottentots," in "Bull. de la sor". Neuchâteloise de Géog." 1S\$9-90, V, \$1; Passarłe. "Die Buschmämnè der Kalahari," Berlin, Ig07, 57, 5s; Fentherman, "Social History of the Races of Mankind," First Div., "Negritians," London, 18S., .iz9; MCGee, "The Seri Indians" [ser Vol. I of this compilation] ; Tennent, "Ceylon," II, 441, 444, 445. Cf. Thanuar, "Essai sur le système cronomique des primitifs," pp. 9-12; F. Simiend, in "L'Année Sor." VI, 4S.j. 
scionsly follows. If it is allowable to select at random from the great mass of ethnological data what appears to be primitive, or to declare facts so selected to be survivals of a hypothetical primitive stage of evolution without reference to a precedent general classification of the peoples, then it is possible to prove anything with ethnologr. In such case, it will make no difference what the facts themselves show, but our conclusions will depend on what we hold to be true a priori. It is certain, that when we trace back the course of economic development, the distance traveled from the production of goods to their consumption, becomes progressively shorter. It is easy then to represent a primitive situation where the distance between production and consumption has been wiped out; a situation where production and consumption coincide in the same individual; where there is no movement of goods at all; and where there is only individual satisfaction and seeking of necessities, as Bücher has outlined it. What can be simpler, what can be more primitive than that situation where every indiviclual eats raw food, and where only animal instinct governs to satisfy necessities limited to the individual and to the moment? This picture of a primitive cconomy is, however, purely speculative; it is not the simplest economic situation which actually has existed; but is the simplest, the most primitive arrangement which can be thought out. But the most primitive economic state cannot, by any means, have had its basis on what has been thought to be most primitive. ${ }^{1}$

* $\quad * \quad * \quad * \quad * \quad * \quad * \quad * \quad * \quad * \quad *$

\section{Beginmings of Inheritance Rights}

It is likewise widely accepted that in the lowest stages of culture, inheritance of private property does not obtain. The concepts, mine and thine, cleave, as Bücher assumes, to the individual, and perish with $\lim ^{2}$...

I [Bücher argues that to limit ethnological investigation to the lowest stages of culture has the undesirable effert of narrowing the point of view, and that a reconstruction of institutions is possible by taking into account social phenomena appearing among developed peoples which "can only have arisen from the earliost conditions among prinitive peoples." The anthor olyjerts, in the concluding paragraphs of this division, that this method leads to the areeptance of eonchusions regarding primitive society which can not be demonstrated. One of such conclusions is the theory of individual satisfaction of wants which is not discovered in fact among the most undevaloped peoples.|

"Bücher, "Fntstehung der Volkswirtschaft," p. 10. [See to the same mupos:] Wilutzliy, "Vorgesehichte des Rechts," II, 166. 
According to the method which we have adopted, the question arises, what is the situation as to inheritance rights in the lowest stages of social development, an inspection of which development is still possible? We may here recall that among the central Australian tribes, the Warramunga, Walpari, Wulmala, Tjingilli, Lmbaia, and Binbinga, all the things of a dead man pass to the possession of men, the brothers of his mother, or the husbands of his daughter. In other words, everything is inherited by that half of the tribe to which his mother belongs. 'The wives inherit only the digging-sticks. It is customary for the heirs to divide the goods among others. We may also recall that there is a regular movement of goods between different tribal groups based on the event of death. In the Warramunga tribe, for example, the goods of a Tjunguri go to a Thakomara; those of a Thakomara to a Thapanunga; those of a Thapanunga to a Tjambin; and those of a Tjambin to a Tjunguri. ${ }^{1}$

Among the Botocudos, the weapons and effects of the dead are not consigned to the grave. ${ }^{2}$ Among the Fuegians the relatives of the dead divide everything which he possessed, among his friends. ${ }^{3}$ The property of an Andaman Islander goes to his nearest relatives who within a short time divide it among his friends. ${ }^{4}$ Among the Negritos the wife and children inherit. ${ }^{5}$...

Under these circumstances, may we not question whether the termination by death of private ownership is a part of primitive society and the antecedent of the right of inheritance? It seems, rather, that the widespread fear of death which reached its full development in later times with the belief in spirits, brought with it the entire renunciation of the goods of the dead, and that this situation belongs to a somewhat higher stage of development.

'Speneer and Gillen, "The Northern Tribes," etc. pp. 615-618; [see ante chap. VII, vol. I, p; 234 seq. — "The Urabunna Tribe"].

'See, Ph. M. Rey, "Etude anthropologique sur les Botocudos," Paris, 1880, p. 79 ; Louis Agassiz, "Scientifie Results of a Journey in Brazil," Boston, 1870, p. 598.

"Hyades et Denilier, "Mission seientifique du Cap Horn," 18s2-3, Tom. VII, "Anthropologie," "Ethnographie," 1891, p. 379; Bridges. "Mneurs et Coutumes des Fuégiens" in "Bull. de la Soc. d'Anthrop. de Paris," 1884, VII, 175; Myades, "Ethmographie des Fuégiens" in "Bull. de la Soc. d'Anthrop. de Paris," 18s7, X, 335.

"Man, "On Andamanese and Nicobarese Objects" in "Journ. of the Anthrop. Inst." XI, London, 1882, 2\$6; and, by the same author. "On the Aboriginal Inhabitants of the Andaman Islands," l. c., XII (18S3).

5 Montano, "Voyage aux Philippines," 1886, p. 71. 


\section{Primitive Communism}

According to the view which we have rejected, there can be no such thing as a transfer of property in primitive society by reason of the fact of communism. 'Thus Engels speaks of "the primitive communal household of a number, often many families." "In earlier stages of development, there could only be occasional transfers of goods. Special skill in making weapons or tools might lead to a transitory division of labor. But, in no event, in this stage, could there be any exchange of goods, except that within the tribe, and this sort was exceptional." The development of pastoral tribes first leads to inter-tribal barter. ${ }^{1}$...

'The term communism is not a happy designation of the earliest economic stage known to us. We find rather, simply, strictly regulated, but not always uniform, distribution of articles of food in certain tribes, whereby wide scope is left for undivided private ownership of other objects. This so-called communism is by no means an obstruction to the movement of goods in the tribes considered; but, on the contrary, is a conspicuous example of primitive circulation of goods. Indeed, it sometimes results in barter transactions which are made obligatory by custom. Still the interpretation of primitive economic life as communism, even though highly inexact, strikes nearer the truth than the view of a stage of pure individualism.

Naturally, when we compare the beginnings of the transfer of property with the commerce of modern societies, we arrive at a very extended meaning of the idea of barter. Modern man produces almost exclusively to satisfy the wants of others, and exchange of goods is effectuated by means of a long chain of intermediate exchange transactions. The distance between producer and consumer is a great one. On the contrary, in rudimentary society man produces more largely for his own needs, and where there is exchange, the chain from producer to consumer is usually short. Products usually go directly from the producer to the consumer. Yet, it is not allowable to project this tendency any farther in order to create a basis of construction where there is

${ }^{1}$ Engels, “Der Ursprung der Familie, des Privateigentums und des Staats," 2 Aufl., Stuttgart, 1886 , pp. 20, 122. For the error of the notion of prinitive communism, ef. Pancliou, "Betr. ü. d. Wirtsehaftsleben d. Naturvölker," in "Z. d. Ges. f. Erdkunde zu Berlin," 1896, XXI, 185-90. See also to the same effect as Engels, Letourneau, "L'évolution du Commerce," Paris, 1897, (Préface), 25, 527; Lafargue, "The Evolution of Property," London, 1905, p. 43. 
no transfer of goods, and where it is assumed that pure individual satisfaction of wants is the exclusive situation. . . .

$* \quad * \quad * \quad * \quad * \quad * \quad * \quad * \quad *$

In that it is impossible to dispose of the production of gonds by the group with the label communism, so, also, we camnot disregard the movement of goods within the group between incliriduals. The group which appears externally as a more or less isolated economic unity, and which various authors call by the name tribe, clan, kindred, and most frequently, the family, is a romplicated structure made up of a variety of producing and consuming unities. First are the individuals from which the higher economic form of the group is formed. Next is the family in the morlern sense (i.e. man, wives, and small children) which is an addition by way of a special economic unity. The family is an exclusire economic institution in affairs of the household, but it has a choser economic connection and a narrower economic dependence on individuals than the group which circumscribes the family as a superior economic unity.

It is not legitimate even to speak of collective production in the family; for also within the family the indiriduals are individual producers who owe duties strictly fixed by custom of giving parts of what they produce to certain family associates.

The primitive economic situation, therefore, cannot be disposed of, either with the acceptance of the proposition of individual satisfaction of wants, or ret with the catch-word, communism or collective production. We can assent neither to an economically isolated individual, nor to a group of individuals economically fused together, as the first stage of social development. In the earliest period of society we alrearly have to do with a compound economic group, constituted of mutually dependent economic individuals and smaller economic groups, which represents the primitive system of transfer of property. 


\section{Chapter XXV}

\section{PLEDGE}

\section{SECTION 1 \\ FORMS OF PLEDGE RIGHTS ${ }^{i}$}

1. The pledge may be interpreted in two ways, and has taken on two fundamentally different forms in the legal systems of the nations. The object of the pledge may serve to satisfy a debt, inasmuch as the creditor's claim is settled with it. As yet, however, nothing final has occurred; for the debtor still has the power to redeem the pledge, and until the question of redemption is settled, the matter remains pending; but this does not prevent the pledged object from amounting to a satisfaction. It is so, if it is the aim of the pledge that the thing shall by the operation of time, become the property of the creditor. The change of ownership takes place as soon as the redemption term has passed. The pledge relation may, however, assume the opposite form, the object becoming immediately the property of the creditor, and the redemption being considered an act of re-purchase. The matter is developed still somewhat differently if, on the expiration of the term of redemption, the object is, indeed, to be kept by the creditor, but that he is to make settlement with the debtor for its surplus value. In this case, the delivery of the pledge is, everwhere, the satisfaction of the claim.

2. This form learls to the second fundamental interpretation; according to which the delivery of the pledge is not in itself satisfaction, but merely the means of satisfaction. If the creditor turns the pledge into money and pays himself with it, the idea is that the delivery of the pledge does not discharge the debt, but that only the acquisition of the money obtained from the pledge operates as a discharge. Whereas, according to the pre-

1 [Reprinted, by permission, from Josef KoHLer, "Philosophy of Law" (Albrecht's trans.), Boston Book ('ompany, 1914 (Philosophy of Law Series, Tol. XII).] 
vious view, the intrinsic value of the pledged object corers the creditor, so that afterwards, at the most, an equalization has to be made. This interpretation requires a sale, before there is satisfaction.

This latter interpretation has become so predominant, and is so general in modern law, that we scarcely ever think of the former interpretation until studies of comparative lan remind us of it. It was, indeed, distinctly present in the Germanic law, but it was not found possible to include it under a larger principle.

3. The practical difference between the two riews is this: according to the principle of satisfaction, the creditor at once takes the risk, and if the thing is clestroyed, he cammot make a second demand on the debtor; for the surrender of the thing has settled his claim, just as parment would have done. The thing is the creditor's satisfaction; and, if, after being taken it is destroyed, he must of course bear this loss; just as he would the loss of money that the debtor had paid him.

The second view is entirely different; for even though the creditor holds the means of satisfying himself, ret he has not the satisfaction itself. Thus, if the means perishes, the debtor must give him another means of satisfaction. The possibility of satisfaction is not the same as satisfaction.

At most it may be asserted that the creditor to whom the pledged object is delivered is the depositary of the pledge, and is liable as such; and this liability can then be more or less extended, accorling to whether he is regarded as a remunerated or unremunerated depositary. It accords with the nature of the transaction to regard him as a remunerated depositary, as the delivery of the pledge is made in his interest.

Although to-day this last standpoint is universal, a few fragments of the former principle have remained, as, for instance, the principle of our bankruptcy law, that whoever has a plerge cannot bring forward his whole claim at the meeting of the creditors, but only the amount not covered by the pledge; and, also, the principle in eivil procedure, that whoever has a pledge right eannot proceed against the debtor in as far as the pledged object affords him satisfaction, etc.

4. A second important division of pledges is into pledges delivered into possession ("Besitzpfand"), and pledges not delivered into possession ("Nichthesitzpfand"). In the first case, the pledge is delivered into the creditor's keeping, so that he is not merely legally but actually secured. In the latter, the debtor 
retains possession of the thing, and the creditor is more or less dependent on his honesty.

It is easy to understand that, in early times, the pledge was commonly delivered into the ereditor's keeping, because the measures of the law were weak, and confidence in dealing was not yet firmly established. This arrangement was also desirable, because the transaction was then made public to a certain extent.

On the other hand, it has the great disadvantage that the debtor is thus reprived of the use of the thing: this may possibly bring his business to a complete standstill. Take, for instance, the case of agricultural implements given in pledge, without which the work of the farm camnot be carried on.

And this is not only a disadvantage to the debtor, but a universal economic disadvantage; for, as the debtor camot, and as the creditor will not, use the thing - and the latter is, perhaps, unable to use it in most cases - it is impossible for it to be used at all, and thus hmanity is deprived of the service of often very important wealth.

5. This can be remedied by allowing the creditor to use the thing, thus making it a usufructuary pledge ("Nutzpfand"). This presupposes, to be sure, that the creditor has a business or establishment in which the pledge can be used, and this requisite obstructs one of the main advantages of the pledge: the abstract nature of its value. Nevertheless, in earlier times, when all the subjects of the State were very similarly engaged, this was more easily accomplished; and, in particular, where agriculture predominates, it is very appropriate, if a pledge consists of land that it be given over to the use of the creditor; in which case, of course, the use of his own land is simply extended to include the pledged property.

This usufructuary pledge has played a great part, and has served to make money fruitful, and to weaken somewhat the prohibition of taking interest: the creditor had the use of the thing, without the profits of this use being deducted from his capital, or only a part was derlucted, and the remainder compensated him for being deprived of his capital.

This form of the pledge is less practieal with movable things; at least, when there is a great differenee between the occupations or establishments of individuals, so that it is more or less a chance whether the creditor can make use of the thing pledged.

6. All these cireumstances have contributed to bring about an arrangement whereby the debtor retains possession of the 
pledge, and the creditor is not actually but only legally secured. When the State has attained a firm derelopment so that the faithful conduct of the debtor is legally assured, no great obstacle will oppose this arrangement; hence it developed in the Orient, in Greece and Rome, as well as in Germany. It is the Roman "hypotheca," and the newer principle of German law.

Nevertheless this form has its considerable disadvantages, because a man's financial condition is thus more hidden than formerly. No one knows what is pledged and what is not, and thus a wild chaos of legal relations arises, from which escape is only possible by the adoption of the principle, that when a person acquires a pledged thing in good faith it is freed from the pledge. But the financial condition of the debtor also becomes nore and more uncertain. The man who is supposed to be well off is perhaps already overburdened with pledges; one evil involves another, and as each creditor seeks to cover himself as far as possible, each will endeavor to obtain a pledge of the debtor's whole property; in this way the economic relations become more and more entangled.

'The attempt was made to remedy this by publicity, so that everyone could see from a public record how the debtor's credit stood. This proved very effective in respect to land; hence the publication of mortgages ("Hypotheken") was adopted in Egrpt, Greece, and later in Germany and in all Germanic comtries. It has not been found as practical with movable things, however. Two systems have been used, either the system of keeping public books, which, however, can only suffice where movables of a certain durability are concerned, such as agricultural, or manufacturing implements; or the șistem of "marking" pledgeobjects by sealing, etc.

Another disadrantage that arises when the pledge remains in the debtor's possession cannot, however, be avoided in this way: this arrangement furthers the debtor's recklessness, and he is led to overstrain his credit, and pledge everything that can be pledged, as he suffers no inconvenience at the moment, and the "day of reckoning" does not come till afterwarls.

7. The pledge is not now turned into money by being first given into the creditor's possession, but is sold, and the proceceds are given to the creditor, or divided among them, if there are more than one, according to their priority. The manner of sale, whether by private sale or public auction, is a matter of legal technic and belongs to the civil law. 
8. A later development displays the following tendency: A distinction may be made between the original thing and the thing as it exists after an improvement has been made upon it. The improvement (amelionation) ean only become separate property when it is actually separable; as, for instance, a structure built on a piece of laurd. But, if, for example, the land has gained in value owing to irrigation, or drainage, the improvement cannot be distinguished from the rest; in this case, the improvement is not an addition but an internal alteration. On the other hand, security rights ("Wertrechte") may attach to the improvement, though not in such manner that the right of security embraces a component part of the thing, while another component part remains unaffected; but in such a way that in the exercise of the right of security, that part of the value which corresponds to the improvement, falls to the holder of the security. This is the case with mortgages on improvements ("Ameliorations-hypotheken"), and they exemplify the great advantages of security rights which are much more mobile, and conform much better to the interests of humanity, than the more rigid rights of servitude.

\section{SECTION 2}

THE PLEDGE IDEA: A STUDY IN COMPARATIVE LEGAL IDEAS ${ }^{1}$

* $\quad * \quad * \quad * \quad * \quad * \quad * \quad * \quad * \quad * \quad *$

The pledge-idea - briefly expressed, that of collateral security - is familiar enough in modern law. But it is distinctly an idea of modern times. The various known systems of law recognize it with various degrees of definiteness, according to the social stage which their development has reached, or had reached when arrested. The idea familiar to us has grown, in the history of the law, out of a very different one. The attempt here will be to go back to the primitive notion of that transaction, and notice its development and the traces it has left on the law as handed over to us in its later stages.

'To realize the root notion of the transaction, we may put ourselves in the place of the primitive traders and try to reconstruct the conditions of their traffic. In the ordinary case of barter between passing travellers, or at the monthly or half-yearly markets, I will find what he wants in B's hands, but the equivalent

1 By John H. Wramore, editor; reprinted, by permission, from "Harvard Law Review," Tol. X, No.6 (1897), p. 321 seq. 
which A has to give may be either not to B's liking in lind or not of proper value. They must and will make a provisional trade or parment, B taking something of A's that will induce him to sell, but $A$ having the privilege of substituting later an equivalent not now arailable. So, too, when $A$ has injured $B$, and $B$ seeks selfredress by his own hands, A may be able to buy off $B$ by handing over whatever he has that is available, but subject to the right of subsequent substitution of something more nearly an equivalent. In short, all transactions of the sort must be cash transactions, because there is no eredit. We know that the absence of credit is a feature of the times, both from the ethnological sturly of primitive surviving communities, and from the fact that credit presupposes a use, legal or moral (customary), of the force of the community, which is wholly inconsistent with the private redress notions of primitive times. ${ }^{1}$ One must try, moreover, to realize this absence of credit subjectively; i.e. to remember that the seller or claimholder is not willing to go away from the spot learing the matter unsettled, and trusting to (crediting) the other's future action; he is going to get something then and there in satisfaction, and the best allowance that the would-be borrower or the tortfeasor can obtain is that the settlement shall be provisional in his favor, i.e. the res given over shall be open to future redemption. The cardinal feature of the transaction is, then, that the party whom we should call the creditor goes away with nothing left to claim, though the (as we call him) debtor has a right of redemption against the other.

We shall be better able to appreciate the primitive state of mind if we remember that in at least four important bodies of law and language the primitive worl for the irleas of "pledge," "bet" (or "forfeit"), and "promise," was substantially the same. In the Scandinavian we have vaed, red." In the Germanic we have wetti, wette, wedde, vadi-um, guadi-um., and (by shiding the di into ji) wage, guage, gage. ${ }^{3}$ In the Latin we have pignus in the first two

${ }^{1}$ Goldschmidt, "Handelsrerht," I, 29, 20): "In its first stages all rirenlation of goods is done by barter. . . . In the (iermanir tribes. in North Germany even into the 15th century, trade on credit is scanty." Compare the foltowing recital of 1150 " A.D.: "Timm mithi vendiclit. . . Non habens igitur arlmanum per'nniam, rensum quendam . . in varlimonio ei deposui" (Kohler, 120). ("ompare the ways in whirh both Franken (21:3) and Hoster (II, 13i) posit this. $\$ 22$.

2 Amira, "Nordgermanisches Ohligationen-recht," I, \$\$ 2--31; II,

${ }^{3}$ Meibom, "Dentsehes Pfandrerht," 24: Fal de Liome. "Lannegild und Wadia," 97 ff.; Diez." Wörterbureb dor Romanisehen sprarthen." s. v. "Gaggio." Our modern word "forfeit" (romedju) preserves dosely. 
meanings, and from the same root $(\pi \dot{\gamma} \gamma \nu v \mu \iota)$ pango, pag, pact-um, in the third meaning. In the Greek, the rerb-stem $\theta \epsilon \tau-$ (put) has all three meanings. It is not mercly that the words for the three ideas were the same; it is much more than that; there was only one idea for what we now distinguish as three. That is, the transactions which we now distinguish as pledge, forfeit, and promise, were then not distinguished at all, and only differentiated themselves later and gradually. We may get some slight notion of the unity by noticing how to-day we ourselves say, "I pledge you my word," and "He pledged his wateh" (thus using one word for the first and third notions) ; or, "I stake my honor upon it," and "He held the stakes" (using thus one word for the second and third notions); or how the Germans say "pfand" for the first notion, and "pfandspicl" for a game of forfeits. But of course with us the ideas are still different, though the words may coincide; while with the primitive speaker the one root represented the same general notion. We can, however, describe the past only in terms of our own notions; and, in fixing on the idea which most nearly represents to us the essence of the primitive notion, we find the second one to be the chief and suggestive one, i.e. "bet," or, more closely, "forfeit." The "forfeit" idea is the important one, because, first, out of it the other two seem to have developed, and, next, it brings out most clearly the contrast between the original and the modern idea of the transaction which we now call "pledge." The "promise" idlea developed by transferring the moral emphasis from the fact that the transaction was settled to the fact that it was only provisionally settled ; the "forfeit" itself was used as a mere form, and was subordinated in idea to that which it came to mark, i.e. the debtor's duty. ${ }^{1}$

the ped and the wette form, as does "bet" (pace the Century Dietionary) less rlearly; while "wager" follows the guagium development. In Scotland, in the 1600 's, wed-setten was still the generie word for a mortgage: Skene, "De Verhormm significatione,"s. v." Vadium" (1641). Curiously enough, there is a similar coincidence in the verb used, which is usually a symonym of "put"; sactia in Gothic and Icelandie, setzen in

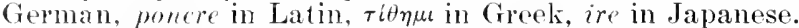

1 The connection of the wadium with the promise idea is no part of the present subjert; but a remincler of the probable features of its development will perhaps make more clear the unity of the primitiveroot-notion. Te may assume (though this has been disputed) that it is the infrajudicial wadium promise which was first reognized, and therefore is the process to be explained. This puts before us the case of a defendant against whom judgment is giren by the assembly ; he finds himself ordered to pay. IJow shall he pay? There is no credit; present satisfaetion, provisional or final, is all that creditors of that time take. There are three primitive ways of giving satisfartion. One is by handing over property ; this is simple enough. Another is by self-surrender, working out the debt if possible. A third is by hauding over the body of a rela- 
On the other side, the "pledge" or "collateral security" idea developed by a similar transfer of emphasis where the res handed

tive; this is natural enough from the debtor's point of view, such is the solidarity of family responsibility; from the ereditor's point of view it is equally natural, for his ultimate hold on the family property or the corporal servitude of the surety (geisel, pleige, fidejussor) is ample; and it is even a question whether this payment by corporal surety was not the most natural early form. At any rate, it would be so where a judieial sentence of the assembly was to be satisfied; for property enough the debtor has probably not with him, and his own freedom he needs in order to collect what will pay his creditor. He therefore offers one or more of his relatives as provisional satisfaction. A common form (now accepted as authentic) for this was: the debtor hands a stick, a glove, etc., as his wadium, to the ereditor, bringing forward at the same time the fidejussor, and the creditor passes the wadium to the firlejussor. The problem is to explain this process. A question which all the theories have to answer, viz. how the wadium came to be a mere valueless article, is here answered by pointing out that the fidejussor was the real payment, - not a surety in our modern sense, but the substantial substitute for present payment, and the real reliance of the creditor. Another question next ocrurs: Why have the stick-wadium at all? Why not merely hand over the pleige without the other formality? In fact, we do not find the intervening stick-wadium in all primitive laws, - not in the Roman, for example, although we do find the human pledge. But there seem to be two good reasons which account for it in the Cermanic law. One is, that, as the typical transaction of provisional payment in every-day life involved the handing over of some res on the spot to the creditor, it was entirely natural that this part of the process should persist in form at least. Another is that the handing of the wadium to the pleige made it possible for him to get redress against the original debtor if he subsequently left the pleige to suffer. The debtor could not be thought of as subject to a levy from another unless the other had some mark of a creditor; and the surety would be content with a uadium of nominal value (as the creditor would not), because family feeling would compel the debtor to redeem. Thus, the wadium was handed to the creditor as a formal, though worthless payment, freeing the rlebtor; then the pleige surrendered himself to the creditor, and thus liberatit wadium, taking it himself. In later times, the personal surety dropped out of the transaction, because it was no longer in harmony with social ronditions, and because credit had developed, while the wrdium stick or glore remained associated in form with the idea of plighted faith.

Three facts in particular seem to narrow down the explanation of the process to something like the above: (1) The wadium was the regular and proper accompaniment in judgment promises, but was casual only in extra-juclicial promises, - indieating the former as the home of the form; (2) the debtor had to give a substantial substitute for payment, either property or self or relative; he was primitively never let off" with a mere form, - indieating that the wadium would never have been allowed to become a res of trifling value if it had not been accompanied by other sufficient value; and (3) in the judgment-promise with wrotium the pleige always accompanied it, indicating that it was the presence of the substantial pleige, which allowed the wadium to beeome of mere nominal value and paved the way for its beoming a conrentional form.

The foregoing attempt to restate the origin of the wadium promise is of course based only on the material that has been published by the valrious workers in that field (Sohm. Brumner, Stohhe. Heusler, Franken, Val de Lière, Esmein. Wodon, ete.); but none of the theories hitherto (except Heusler's) seem to have taken into aceount the original unity of the wed-idea, from which the three branches developed, and a restatement from that point of view seems to explain certain faets otherwise unaccounted for. The above statement is substantially Heusler's. 
over remained of substantial value; i.e. the idea that it was provisional led to the disappearance of the "forfeit" iclea; the original claim became ultimately the measure of the parties' rights, and therefore the debtor could no longer throw the creditor exclusively on the res for satisfaction, nor could the creditor keep it all in case of default. It is this progress from the idea of forfeit to the idea. of collateral seeurity which we are to keep in mind as the general feature of our present subject; and we may now proceed to the evidence that this was in fact the course of development of this legal idea.

The varied aspects of the subject and the richness of the material make it necessary to keep within narrow bounds. . . . It is enough to trace the main idea, and to distinguish the various transactional forms that throw light on it. The topics will be:-

I. The Forfeit idea, in general, as the forerunner of the Collateral-Security idea. II. The Hypothec (pledgor's possession) as distinguished from the ordinary Pledge (pledgee's possession). III. The Sale for Re-Purchase, as distinguished from the Pledge. IV. The Vifgage as distinguished from the Mortgage.

After noting the development of the idea in the legal systems which furnish the richest materials for examining different stages of the law, the Germanic and the Scandinavian, we may then examine what evidence there is in other systems, - Jewish, Mohammedan, Egrptian, Chaldean, Slavic, Hindu, and Japanese ; leaving to the last the Greek and the Roman, as presenting peculiar difficulties, and the French, as involving an acquaintance with the Roman. ${ }^{1}$

1 Until IIcusler, the true significance of the Germanic pledge law, in spite of much research and discussion, seems not to have been appreriated. In 1867, en Meibom had established the ehief data so as to clear away most previons errors of fact; but he saw in the transaction only an "exchange," and this prevented him from understanding the complete relation of the facts and their historical changes, and it particularly misled him as to the hypother. In 1852, von Amira clearly worked out the rhief data for Swedish Scandinaria. But Heusler (in his Institutionen, 1886) was the first to alvance the forfeit-theory for Germanic law, and to state all its hearings, and his analysis (though accompanied hy little evidence) is irresistible in its plausibility and its harmony with the evidence elsewhere abundant. The statement in the following pages is substantially an arlaptation of Heusler's theory ; though the mode of presentation is different, and his theory is not to be held responsible for all the arguments here advanced in its support (especially as to the relation between the anflassung-rlause and the evasion of the duty to restore the surplus, which does not seem to have attracted his attention). Almost all of the passages quoted in illustration have been culled for the present purpose from earlier publications whose authors knew nothing of the forfeit-theorr.

In 1S95, con Amira (in his second rolume), writing in the light of 


\section{Germaxic and Scandinaviax Law ${ }^{1}$}

\section{The Forfeit Idea, in general}

If the idea above described was that which marked the transaction of primitive times, - the idea of forfeit or provisional satisfaction, - what would be some of the legal consequences in the relations of the two parties? Certain main features would surely be found.

A. 1. If the pledgor chooses not to pay (redeem), the pledgee cannot compel him; he looks exclusively to the res for parment; it is a provisional parment. Hence: $a$. the pledgee cannot sue the pledgor, inasmuch as the res is his parment; $b$. the pledgee has no redress if the res perishes by accident; $c$. the pledgee has no redress if at the maturity of the period the res has become less in value than the original claim, or on being sold leaves a deficit.

2. The pledgee, while thus having the detriment arising from the res being a parment, has also the advantage; for on default the res becomes his in toto, i.e. he is not bound to restore the surplus value.

B. Along with these features, but not peculiar to this transaction, is another, whose steps of development have to be noted in order to distinguish them from the preceding features, and to explain later problems, i.e. the feature of defect of absolute title, due to the fact that the transfer of the res, being provisional only, lacked the auflassung or final abandonment of right by the

Heusler's published view, found it amply confirmed and proved it to be the key to the West Scandinavian development. But outside of these two fields, the forfeit-idea as the key to the history of the pledge-idea seems never to have been advanced for any system of law, not even for the Roman; and it will be the purpose of a later article to test its validity for other systems.

1 The references that follow are to these works: 1S55, Stobbe. "Deutsches Vertragsrecht"; 1875. Id., "Deutsches Privatrecht," II, 1; 1865, Neumann, "Geschichte des Wuchers in Doutschland"; 1867 r. Meibom. "Deutsches Pfandrecht"; 1S67, sohm. "Prozess der" Lex Salica" (tr. Thévenin); 1875, Id., "Rerht der Fheschliessung"; 1S7:3, Schulte, "Lehrb, der Deutsches Reichs- und Rechtsgesrhichte"; 1ST4, Endemann, "Roman.-Kanon. Wirthsch.- u. Reehtslehre" [really" Die Wucherlehre"]; 1877, Fal de Lière, "Launegild und Wadia" ; 1s79. Franken. "Französisches Pfandrecht im Mittelalter" ; 1SS0, Brumer, "Rechtsgesehirhte der Römischen und Germanischen Urkunclen", $16 !)_{2}^{2}$.Id.. "Deutsche Rerehtsgeschichte"; 1881, Weisl, "Deutsches Pfandrecht his zur Reception;" 1882, Kohler, "Pfandrerhtliche Forschungen"; 1s\$3, Esmein. "Etules

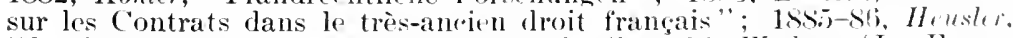
"Institutionen des Deutschen Privatrerhts": 1893 , Worlon, "La Forme" et la Garantie dans les rontrats franes" ; 1852-9.5," Amirn. "Norderrmanisches Obligationenrecht: I. Altschwedisches R.: II. We'stnordisches R." 
pledgror. Even after default at the time appointed for redemption, the pledgee's title still has this defect; and while the other features are passing into their later stages, we here find the pledgee successfully endeavoring to remedy this defect; it is this process that has to be carefully distinguished from the others.

To take up the eridence.

A. 1. a. No personal action for the pledgee against the pledgor. ${ }^{1}$ In the first place, the documents usually do not (as our modern ones do) mention any obligation of debt as arising from or accompanying it; ${ }^{2}$ e.g. "we have pledged the manor of Blackacre for 100 marks." Furthermore, the early documents expressly speak of the transaction as a "payment," i.e. extinction of a claim. ${ }^{3}$ Finally, some laws particularly mention the pledgee's inability to treat the claim as surviving. ${ }^{4}$ Strong light is also thrown by the analogy of the transaction which we now call personal suretyship. The fidejussor (as already mentioned) comes to the front in the development of the legal promise through the wadia, and the notable thing about his function is that the wadia is first given, and then the giving of the fidejussor pays and frees the wadia; as in the much discussed passage of Liutprand, 37 (Lombard): "si wadiam dederit, et antequam eam per fidejussorem liberit," etc. Furthermore, the whole notion of the fidejussor was that he freed the debtor, and stepped into his place just as a res would; thus, in the Frankish law, the debtor "liber erit, si fidejussor moritur";

1 Heibom, 274 ff. ; Heusler, II, 132, 133; Kohler, 99, 100, 137.

2 Ibid., 276.

${ }^{3}$ "Cum in solutionem dictarum 500 marcarum .. . tum in recompensationem damnorum . . . eastrum . . . pro 1000 mareis obligavimus" $(1 /$ cibom, 27S $)$; "pro ipsa eausa solidus tantus in pagalia mihi dare debueras, quos et in praesenti per wadio tuo visus es transolsisse" (Wodon, 122); "per suum wadium ipsas res . . . reddidit" (Id. 108), and of course the phrases "per wadium meum eomponere" and "cum uno wadio enendare" were common ones for the process of payment by wadium; "ducentas libras Hollandenses ad [dotem] dicte Aleidis promisimus conferendas, et pro solutione dicte pecunie eidem obligavimus decimas segetum et minutas decimas" (Kohler, 52; this is as late as 1269).

4 "When one man sues another for a sum of money and the other answers, "I deny him not the sum which he elaims, but he has a pledge from me [for it],' . . . the former shall use it [the res], and the latter shall remain harmless, and the former shall sell the pledge, as is right" (Bäyr. Landr. 240; quoted Meibom, 422). A Lombard commentary on the following formula, "Cujus placiti vadimonia (per usum) debent esse cum fidejussoribus tacita pena," sars : " If the debtor does not come to trial as thus pledged,] non est intelligendum . . . is rem unde agitur debeat amittere; immo... intelligendum est quod penam wadie debeat solvere" ( $\mathrm{ral}$ de Lière, 142); and the pains thus taken by the later seribe to assert that the debtor could not get off by letting his pledge be forfeited show that the contrary notion had prevailed and was to be eombated. 
the creditor could not sue the original debtor, ${ }^{1}$ and it was only in later times ${ }^{2}$ that he had his choice between the debtor and the fidejussor; while the question whether he must first seek the debtor before suing the surety is an essentially modern one. Again, the fact that, in later times, when other debts were inherited, the liability of the fidejussor was not, ${ }^{3}$ (witness the maxim, "le pleige mort, la pleigerie meurt,") is apparently best explained by the notion that his person was simply paid over to the creditor, like a res, in liberation. ${ }^{4}$

The progress to the later stage, in which the liability is recognized as independent of the pledge, came through express contract, i.e. if there had been an express promise (gelobet) of liability, the res became merely collateral to that. ${ }^{5}$

1. b. No claim for the pledgee if the res perishes by accident. This feature was long a matter of dispute; but the work of Meibom and of Heusler has explained all the difficulties, and settled berond a doubt the question of fact. ${ }^{6}$ The fact is equally clear

1 Esmein, 85; Heusler, II, \$ 126. Sohm ("Eheschliessung," 35, n. 38) offers the forced explanation that "the surety, because he last received the wadium, is thus the first in liability"; but it is clear that he admits in effect the fact of the liberatory function, for he had already said ("La Procérture de la Lex Salica," ed. "Thévenin, App. I, and § 5): "La contrainte procédurale, à laquelle donne lieu le refus, sexerce principalement contre le fidéjusseur, et non contre le lébiteur" ; when, moreover, he sars, "Le débiteur principal reste lié vis-à-vis du créancier; mais l'action ilu créancier est dirigée contre le firléjusseur," the first statement can hardly be correct if the second is, and the law indorses the second. As late as the "Schwabenspiegel" (2S5 b, quoted in Stobbe) we find a rule that if a pledged animal dies, the creditor has no claim for the debt, unless there is a surety; which shows how the surety was assimilated to a res substituted for the elaim.

2 Stobbe, 124-126. $\quad{ }^{3}$ Esmein, 145; Stobbe, "Vertr." 132, 195.

"Another significant notion of the Middle Ages is the "tavern right"; by which the tavern keeper was obliged to set out drink not only for money offered, but for pledges offered, provided they exceeded the drink ralue by a certain ratio; the pledge is payment, and the tavern keeper "may re-pledge it for the elaim, and shall notify the debtor that he may redeem it, if he wishes, at the place where it has been re-pledged" (Kohler, 13).

5 In the later records, the independent survival of the debt is of course fully recognized, although this does not neeessarily indicate that the ereditor could look to the pledgor personally. Roughly, there are three stages: (1) to pay off, per wadium eomponere, the pure forfeit idea, and no notion of debt survival; (2) to pay provisionally, the debt surviving, but the res being the creditor's sole resort for payment; (3) to secure in a purely collateral way. See post.

6Significant passages: "Sachsenspiegel," III, 5, \$ 5: "[If a pledged animal dies without the creditor's fault, the creditor] ne gilt s nicht; he hevet aber ver]oren sein gelt, dar it ime' vor stund, [for it stood in its plare to him]"; "Prague Rechtsb." 166 : " Fr gilt seim nicht; er hat aber verloren sein gelt" ; "Ledebach I'rivil.": "[lf a pledged house burns down,] si vero domum suam redificare [s'. pledgor] non voluerit, quod remansit de igni cum possessione dat illi cujus vadimonium prius fuerat, ot sic se absoluat; creditor postea, quantumeumque deliti superest, nihil amplius 
in Scandinavian law. ${ }^{1}$ This rule points clearly to the notion that the res is provisional payment. If the pledgee had been merely compelled to deduct its value from his claim, this result might well have been explainable on some theory of a counter-liability on his part as bailee of the res. But the treatment of the res and his claim as equivalent shows clearly how the res is regarded as measuring the claim, as representing it, as having in effect paid it by forming the sole resort of the pledgee for satisfaction. ${ }^{2}$

$b^{\prime}$. The next stage is reached by the aid of an express contract; i.e. the pledgee can claim nothing, unless the debtor has otherwise promised (in the common phrases, "ere vorwort ne sy anders," "ire gelovede ne stunde [settle] den anders"). This is the first step towards getting away from the primitive rule; the step being taken, of course, at different times in different communities. ${ }^{3}$

$b^{\prime \prime}$. Finally, that which at first needed to be expressly provided for in the contract becomes the general rule without express provision, and the accidental loss of the res does not bar the pledgee's action. ${ }^{4}$

* $\quad * \quad * \quad * \quad * \quad * \quad * \quad * \quad * \quad * \quad *$

ab eo extorquere, secundum nostram justitiam, possit" (Schulte, 500); "Statuta Susatica": ". . . relinquet creditori reliquias incendii vel ruine et fundum pro pignore, sic creditor nil amplius potest petere" (Kohler, 114). The passages are collected in Meibom, 283, 426; Kohler, 19, 111115; Heusler, II, 202; Weisl, 61; Stobbe, "Vertr." 263-5. "Ein Haus, ein Brand"' was a proverb implying that the risk of fire was on the pledgee: Chaisemartin, "Proverbes et Maximes du droit germanique," 223 (1891). For an explanation of the difference between this risk of loss of his claim through provisional payment and the creditor's burden of risk as a bailee, see post.

1 Amira, I, $213 ;$ II, \& 22.

2 This notion occasionally finds express mention in the documents: "Veloren se [pledgee] aver edder ere ammechtlude dat slot [castle] van wanhnede edder van unlukke, des god nicht en wille, so scholden se ere gheld in deme slote unde we dat slot verloren hebben" (Kohler, 114); in another document the pledgor promises to help the pledgee recover the castle if he should be spoiled of it, but if the castle should not be recovered, "so scholet ze [pledgee] dat ghelt verloren hebben, dar id en vore satet was van uns, unde vor der scholet ze dar nene nod umme liden" (Kohler, 114).

${ }^{3}$ 'The just-quoted passage from the "Prague Rechtsbuch" ends: "jr geluhdesteezwissen in den andere" ; so also the "Sachsenspiegel" passage, "ire gelovede stunde den anders." A clause in a document of 1344 reads : "Wore ouch daz se [creditor] das... hus verloren in unseme . . dinste, so solde wir [dehtor] en er phenninge weder geben" (Stobbe, "Vertr." 269). The passages are collected in the following places: Weisl, $61 ;$ Heibom, 290 ; Stobbe, "Vertr." 269; Heusler, 11, 204; Kohler, 115, 315; and for Scandinavia, in Amira, I, 213; $11,822$.

"Heibom, 290: Stobbe, "Priv." 625, "Vetr." 256. In this stage by express agreement the risk is often thrown back on the pledgee; thus: "and if any hamm comes to the castle [pledged,] of whatever sort it be, that shall they [pledgee] not demand of us [pledgor] or our successors, . . nor have any elaim or action therefore against us in any way" (document of 1435, iohler, 332 ). 
1. c. No claim for a deficit. If at the time for redemption the res is not redeemed, and proves deficient in value, by rleterioration or otherwise, the pledgee has no redress; the res is his forfeit, and he cannot look besond it for payment. ${ }^{1}$ The significance of this rule for the forfeit idea seems clear.

$* \quad * \quad * \quad * \quad * \quad * \quad * \quad * \quad * \quad *$

$c^{\prime \prime}$. Later still we find the next step taken, and the law expressly authorizes pledgees to collect the deficit from their pledgors. ${ }^{2}$

2. a. No return of surplus by the pledgee. If the res is really a forfeit, standing for and in place of the claim, the pledgee grets the benefit as well as the detriment, and if, when the pledgor fails to redeem, the res is worth more than he would have neederl to pay for redeeming, the pledgee cannot be looked to for the surplus; and this is equally true whether the res is merely kept by the pledgee or is sold and turned into moner. ${ }^{3} a^{\prime}$. The transition comes first through a contract clause requiring restoration of the surplus ; ${ }^{4}$ and, $a^{\prime \prime}$, then this settles into the fixed custom. ${ }^{5}$ It seems (where careful chronological tracing is possible) to have come first for personal property ${ }^{6}$ Moreover, the notion (2 $a$ ) that the pledgee need not restore the surplus seems (often or

${ }^{1}$ Lübeck Stadtrecht: "Brickt eme ock, dat is des scharle deme dat erve vorpandet is [But if it falls short for him, that is the loss of him to whom the land is pledged]" (Stobbe, "Vertr." 261). The passages are collected in the following places: Heibom, 280; Weisl. 61; Schulte, 500; Stobbe, "Priv." 271, 623; "Vertr." 260; Neumann, 202; and for Seandinavia, Amira, I, 213 ; II, \$ 22.

${ }^{2}$ See the same citations. The development is neatly seen in the successive revisions (quoted Meibom, 424) of the Hamburg Stadtrecht. The text of 1270 read : "Umbreke eme ok wat, de schade is sym" ; while the revision of 1292 left it, "Unthreke eme och wat, dhat sca cme dhe volden des dat goet oder dat erve was."

3 This we notice most clearly in the form of the judgment which the creditor (as explained later) oltained. There is no talk of returning the surplus value; it is simply ordered that "he take the pledge to his own use and be from the other man quit and free" ; it is his forfeit, and its ralue is immaterial. The authorities are found in Veibom. 230; Heusler, II, 204; Schulte, 500; Stobbe, "Priv." 270, 627; "Vertr." 260; Kohler, 137; and for Seandinavia, Amira, I, 203, 213; II, 22.

${ }^{4}$ Example of a document clause (IJesse, 1248): "eo parto, ut . . . si quid superest, ant restituat," ete. (. Heibom, 29.7) ; for other passages, see the citations of the preceding note.

${ }^{5}$ Lübeck Stadrecht: "Wat dat erve [land] mer gelt, wan dit it rervolget [forfeited] is, dat schal he ime wedrler geven" (Stoblise. "Vertr." 261) ; Ditmars Landrecht, 1541 A.D. : "Wumneth he arerst mit clarumme, also be gelaveth heft; dat overighe gheldt schall hr dem rechten sar.kwolt wedergeren" (Neumann, 202). In the Stadtrecht of Freiberg we see another shade of transition: "Was die pfant bezzer suit, wi si sten, daz mag he hehalden; he mue $i z$ ouch widergeben ob er wil" (Weisl). For authorities, sce those of the preceding note, and Neumann, 204: Ireisl, 25,39 .

${ }^{6}$ Amira, I, 203, 213. 
usually) to have suffered the change earlier than the correlative notion $(1 c)$ that the pledgor need not pay the deficit ; ${ }^{1}$ perhaps the explanation of this is, first, that the pledgee usually took care to obtain a res much in excess of his claim, and hence the case of a surplus was forced oftener than the reverse case upon the community's thoughts; and, secondly, the fairness of the pledgee's returning the surplus could be worked out on the theory merely of the pledgor's right to redeem (i.e. if he had paid cash to redeem, he would have got back this surplus value; hence, why not assume a redemption per rem ipsam, and give back the surplus, leaving the pledgee no worse?), while the pledgor's duty to make up a deficit could not be appreciated until the independent survival of an obligation, alongside of the pledge, had been fully recognized in thought.

These four features, then, just described, seem to mark as clearly as anything can the theory of the transaction of ved, wette, satzung, as that of a redeemable forfeit or provisional payment. In all four there is a gradual change to the notion of modern times which looks on the debt as continuing in full force, and the res as handed over purely as an auxiliary resource for the creditor. ${ }^{2}$ We are not to seek in the law of pledge itself for the reasons of the change. The change came about as soon as the community recognized credit widely and developed varieties of obligation and forms of action for them; but this was an independent process. As soon as there were many ways of creating a principal debt, and of enforcing it without a wette, then it could be seen that the wette need only be collateral and not substitutive. But this would take

1 Amira, I, 205, 213; II, § 22; Stobbc, "Vertr." 260; Meibom, 331.

2 It should be noted here, as to the feature 1 a above, that the views of Heusler and rom A mira differ. The view of the latter (I, 206) is that after receiving the red the creditor has no claim (forderungsrecht) of any kind left against the debtor; and this is also the doctrine of von Meibom (274). The former thus answers it, and states his own view (II, 133): "It is here overlooked that the pfund is only a potential [eventuelles] equivalent for the elebtor's performance, i.e. is given on the condition that payment do not ensue. But this assumes in itself the survival of the creditor's claim. . . It does not alter the matter that he cannot bring an action for parment; the reason that he cannot is, not that he no longer has a claim, int that he has already in hand his potential means of satisfaction, and thus can of course no longer demand that which already he has provisionally received." Kohler $(99,100)$ takes the same view. "The solution of this difference seems to be that ach lays stress on a different stage of development. In the primitive notion of wette, there is no more of a surviving debt or obligation than there is to-day in our bet with stakes; lont in the course of development the independent survival of the debt hecomes more and more emphasized; and one of these stages of transition (and an (arly one) might undoubtedly be expressed in the language of Henster, though the view of zon Amira more arenately represents the prinitive stage. 
time to see, and meanwhile the old traditional rules of uette would persist by mere inertia. Thus it is that we find some of them eren in the late Middle Ages long after a fully developed sistem of debt had arisen; and even in the last century it was necessary in some of the codes in Germany to declare that the loss of the res did not deprive the creditor of his claim. ${ }^{1}$

B. a. Along with the features of the development just described, there are also constantly mingled certain other phenomena that have to be carefully separated and accomted for. They are the product of the limited nature of the pledgee's property right in the res aiter default, and their transition stages are the result of his effort to make that right absolute. The key to their explanation is the part played by the auflassung (resignatio, abdi-

1 The primitive doctrine above explained $(1 \mathrm{~b})$, that the creditor could not recover, even though the res has aceidentally perished, would probably never have been doubted by scholars as an historical fact if it had not been for the concurrent prinitive doctrine that the pledgee was, as bailee, absolutely responsible even for accidental loss. Thrse two doctrines were sometimes, in the legal records, merged into a rule of thumb which has been misint erpreted by some scholars. It can best he xplained by taking the troublesome "Sachsenspieg(l" passages. This first says (III, 5, \$ 4), that the pledgee-bailee is absolutely liable: "Svat man aver deme manne liet [lets] oder sat [pledges] dat sal he [the bailee] unverderft wederbringen, oder gelden na sime werde." Then it makes an exception (\$5) for animals pledged: "Stirft aver en perd oder ve, bimnen sat unge, ane jenes scult [without the pledgee's fault], bewiset he dat und darn he dar sin recht to dun, he ne gilt es nicht." So much as to his liability as bailee to the pledgor offering to redeem. But suppose the pledgor does not redeem, and the pledgee claims the debt (which he would try to do if the res were lost); this the law next calls to mind: "He heret arer verlorn sine gelt, dar it ime vorstunt." Thus, there is an alleviation made for him from his generic liability as bailee to a redeeming pledgor; but the forfeit idea - i.e. as regards his claim against the pledgor - is strictly maintained. The oath of innocence which he takes has to do only with his getting the benefit of the former, and does not affert the latter at all. In the later Magdeburg law the situation is thus described: "der schade ir beide schade sein"; i.e. the res is at the risk of the pledgor so far as he is bailor, and is at the risk of the pletgee so far as he has taken it. in lieu of his claim as a pledge. The distinction in Sweden (Amira, 1, 213) and elsewhere by which "both bear the loss" (i.e. the pledgor can hold the pledgee by an offer to redeem) if the res has been burned with the pledgee's own goods, though he must roplace it if it is stolen, involves a modification of the pledgee's bailere-liability, and does not affert his loss of his claim against the pledgor, whirh it assumes as unquestioned.

It is thus useless to lay down simply the proposition (as certain earlier scholars did) that in pledges the "risk" primitively was, or was not, the pledgee's; only by taking the above distinetion can the situation he aceurately describel. The two situations may arise separately: for it is only when the perished res was worth more than the debt that the plederor will ever offer to redeem and thus raise the question of the pledgew"s liability as bailee: while if the res was worth less, the pledgor will not try to redeem and tho pledge will try to make the pleflgor pay, and will thus raise the single question of the nature of the pledge-transaction.

Stobbe "Vertr." 260) and Yr ibom (367) lave fully "xplainerl, in substantial harmons, the correset signifirance of the passage's; Heusler (1I, 203) expresses the same conclusion hriefly. 
(atio, "se exitum dicere") of the Germanic law. It is enough to call to mind that the Germanic notion of a complete transfer of a property-right involved three distinct elements, - the sale or traditio, the gewere or investitura, and the verzicht, uplaten, werpitio, dewerpitio, auflassung, or resignatio. The first two dealt with the transfer of possession or control over the res, and were later symbolically merged in a transaction which was in effect single, and is sufficiently indicated by the one word traditio. The third, however, remained essentially separate; it signified the final and complete abandonment of all right or interest in the res. One would, for example, give traditio equally in a sale, a life-estate, a pledge; but in the first there would also be aufiassung, in the last two there would not.' To the Anglo-American lawver the idea presents no difficulty, for it is already familiar to him throughout the history of his own law; it is in essence and in historical continuity the remittere and quietum clamare of the 1200's and the "release" and "quitclaim" of later times. ${ }^{2}$. . .

Now, when the primitive Germanic pledgor defaulted, the pledgee was not hampered by any question of a duty to appraise or sell the res and hand back the surplus value; on the contrary, the res, so far as it was now his, came to him as a whole and undiminished. But the res was not his absolutely; that was his difficulty. It was not that he had a duty to sell; such a notion was then unthought of; it was that he had not the right to sell. He had only a defective title to give, and even if he disposed of that, the ultimate possessor might (in the case of personalty) hold the res successfully against the pledgor by the doctrine of hand muss hand wahren, ${ }^{3}$ and then the pledgor might come against the pledgee for wrongfully disposing of the goods. The fact that the pledgor was in default by not redeeming at the due time did not help the matter; the trouble was that a defect existed in the very property-right of the pledgee, i.e. he had never had an auflassung from the pledgor. ${ }^{4}$ This defect prevents him from doing as he

1"Auflussung" was sometimes used by older German scholars in a sense inclusive of traditio. The true doctrines of Germanic law, in particular the significance of auflassung, are here assumed to be those established hy Heusler in his "Gewere," and expounded in their latest form in his "Institutionen," II, \$\$ $92-94$.

${ }^{2}$ Pollocli and Maitland, "Hist. Eng. Law," II, 90.

3 Heusler, II, 10, 212.

"Ibid., II, 141: "If any doubt could exist on this point, it would be removel by the fact that the documents in a satzung never speak of resignare; that the laws always place setzen and auflassen in antithesis, using the former for pledge-giving, the latter for ownership-transfers; that the land-register's were classed into libri resignationum and libri 
pleases with the res; usually, he pleases to sell; hence he must get a good right to sell.

Furthermore, the process of curing this defect of title after default must be distinguished from the process of reducing to a term the unlimited period for redemption which the pledgor had if no period had been expressed for redemption. The wette without any' fixed period was (primitively at least) as common, if not commoner than the other, ${ }^{3}$ and in such case the right of redemption might go on through generations." This, too, the tribe of pledgees were interested in changing. But notice that two steps would here be necessary : first, a period must be supplied for redeeming, and then the situation is as if there had been a limit originally; but, next, after a default at maturity of the period, the defect of title also remained, and this, too, had to be remedied, as in the general case above described.

$a^{\prime}$. This being so, it is easy to see that the sale of the res, about whieh so much is said in the earlier sources, has nothing whaterer in common with our modern compulsory sale. It is simply an incident, and the commonest, in the pledgee's efforts to cure the defect in his title by cutting off the pledgor's outstanding right and thus curing the lack of auflassung. Let us examine the unmistakable marks of this.

(1) He is always spoken of as asking for or receiving a "libertatem vendendi" or "distrahendi"; i.e. he wants to sell, and some obstacle to a sale has been removed. ${ }^{3}$

(2) In the stage reached by some of the laws, the permission to realize is confined to a re-pledge by the plerlgee for the amount of his claim, and a sale by him is expressly disallowerl." Another stage is represented by laws permitting the sale only where a repledge is not practicable. ${ }^{5}$ Still others give an option either to re-pledge or to sell. ${ }^{6}$

impignorationum; and that after a sale the regular entry is "coram. consulibus resignavit,' which is wholly lacking for pledges."

1 Neumann, 192.

${ }^{2}$ Meibom, 380; Amira, II, $\$ 22$; hence the proverb, "versatz verjähret nicht."

${ }_{3}$ "Potest venumdare de licentia" is another phrase. See instances in Meibom, 331; Kohler, 7 ff.; Weisl, 25, 39, 63; Amira, I, 213.

${ }^{4}$ E.g.: "[When the pledgee wants to realize on default,] daz [the res] sol er dem andern ansagen [notify], und wann der daz nit zu lössen hat, so sol er daz nit höcher versetzen als um sein schult, aher rerkaufen soll ers "nit" (Kohler, 11).

${ }^{5}$ E.g.: "Wel her [pledgor] is denne nicht loszen, so rorseczte her [pledgee] is vor sin gelt, ob her mae; kan her is nicht vorsecze. so mag her is vorkouffe" (Kohler, 6).

${ }^{6}$ Kohler, 7,14 . The reason for the pledgee's rearliness to re-pledge 
(3) The proceeding which he took was the generie one for cutting off outstanding clams. The pledgee or other person applies to the judge to summon all who may have any claim to the res to come and make it known; then the judge appoints a period for this, and at its end, by the expedient of mittere in bammum, declares the petitioner's title absolute. ${ }^{1}$. . .

(i) That the cut-off proceedings had in essence nothing to do with sale, and in particular that the sale had nothing to do with any duty to restore the surplus to the pledgor (our modern idea, which is apt to be associated with this older process), is further clearly seen from the facts that (a) the pledgee was allowed to employ the cut-off process, and to get permission to sell or to keep, long before he was compeiled to restore the surplus, ${ }^{2}$ and $(b)$, conversely, the duty of restoring the surplus, when that stage is reached, is found even where the pledgee keeps the res, and quite independent of sale by him. ${ }^{3}$

$a^{\prime \prime}$. This proceeding, then, by means of aufbietung and mittere in bamm supplied the defect of title which arose from the lack of the auflassung, resignatio, or "release" element. But why

seems to have been, as Kohler suggests (19), that as the risk of loss (both as bailee and as ereditor) was upon him, he would naturally be anxious to get ricl of the risk in any way.

${ }^{1}$ Heusler (II, 85) describes the process; examples of terms of delay, ete., are given in Kohler, $10 \mathrm{ff}$. This ufbiten, aufbietung, or offering to the debtor for redemption, is not to be confused with the same process when made to eut off the claims of the heirs (or other persons having the retraktrecht, retrait lignager, or right of preferment in buring). In the periods and places where this survived, the eutting-off process might also have to be cmployed as against such persons; yet by some customs the debtor was bound to have offered the res in pledge first of all to those persons, and thus there was no need for cutting off the right which they had previously renounced. The different varieties of situations are illustrated in Amira, I, 221; Kohler, 116; Weisl, 42.

${ }^{2}$ E.g. in Lübeck, as late as 1325 , he might sell without accounting for the surplus: Meibom, 332, see also Amira, I, 203. A eustom of Noyon, in 1181, shows clearly the process: "Si quis terram vel domum in vadimonio posuerit, rel aliquid aliud, et determinato tempore non reddiderit [paid], ille qui radimonium habet, si voluerit illud assignare sibi et ad se trahere, judices et scabinos illue adducat, et si post infra quindecim dies redemptum non fuerit, perpetuo sili jure possident" (Kohler, 138).

${ }^{3}$ E.g. in Freiberg, it was provided by law "doch das dieses pfand geschätzt sey durch das gerichte, und die bessernng an dem das guth gewest [i.c. pledgor] geweiset werde" (.Meibom, 338). So for an express clause in a document of 1077 in Salerno: "Et si ipsi tari [golden money] minime nobis [pledgee] retdere potuerit de propria sua causa, et illud nobis dandum venerit, atjungamus [hand over] ei pretium a super [over and above] ipsi tari, sicut ipsa rebus abpretiata fuerit per doctos omines et deum timentes, et firma nobis carta entionis secundum legem facta et cum pena obligata" (Kohler, SS); on default the pledgee is to restore the surplus "quanto tres justi hominis existimarerit," and the pledgor is to execute a deed of sale (Id. S6). See also Amira, I, 205. In many laws the pledgee is expressly said to have his choice hetween keeping the res and selling it: Weisl, 199; Stobbe, "Priv." 623, 627; Amira, I, 205; II, \$22. 
could not this be supplied by the pledgor himself? It could be. It might be done by actual aufassung or resignatio after default; ${ }^{1}$ but this was rare, of course, being dependent on the pledgor's good will. Instead of this the customary method came to be the embodiment of an auflassung clause in the original document, this being done at a time when the debtor would be more ready to concede any terms demanded.

$a^{\prime \prime \prime}$. Abuse of the resignatio-clause. So far all was well; the thought of the community was that the pledgee should have his cut-off, and he was allowed to get it either by the judicial proceeding or by the deed clause. If the primitive rule as to non-restoration of surplus had continued, and, even then, if the judicial process had remained the sole or usual cut-off method, no new problem would have arisen. But the old rule had been left behind, and the pledgee was by this time bound to restore on default the surplus value to the debtor (whether he kept or solk the res). So long as he resorted to the judge for achieving his cut-off, the duty of restoration was managed easily enough ; the judge declared the title of the pledgee absolute, either for keeping or for selling, on the terms, in the former case, that the res was appraised and the excess value paid to the debtor, and, in the latter case, that the surplus money received was so paid over. But when the cut-off came to be attainable (for landed property) by a resignatio-clause in advance, the pledgees soon found that this was an excellent method of evading the new rule about surplus restoration; for the res on default became the absolute property of the pledgee without his going to court, and he could keep it all, which he could not do if he had had to apply to the court; hence the popularity of the clause.

It will be seen that, in the examples cited in the preceding note, the clauses all provide that the res shall go in toto to the pledgee, without any provision for surplus restoration. Now until the old notion of forfeit or equivalency had been thoroughly cast aside, and until the rule about surplus restoration had become a solid and instinctive element in the legal thinking of the community. (which in some places lid not come till the 1400 's), the community would not be prepared to protest against this ingenious evasion of the rule by the use of the resignatio-clause. But when

${ }^{1}$ Heusler gives an example (II, 139): "Predium meum ahbati pro C marcis exposui et statuto die cum memorata pecunia solvere proposui; cum vero prefixus dies advenisset ot ahbas argentum milhi dudum datum requisisset, minime illud recompensare valens, predium abbati in perpetuam possessionis institutam obtuli.' 
that time did come, the evasion would have to be stopped. It was not that there was anything to be said against the resignatio-clause in itself, i.e. as a cut-off; for this very cut-off was that to which the courts themselves had been accustomed for several centuries to aid pledgees. It was the abuse of this particular cut-off process in evading the surplus-restoration, that made it vicious. Now the enabling circumstance for the pledgee was that he got absolute title by operation of the deed, without going into court; and thus the obvious thing, by way of remedy, was to oblige him to do just what he had been used voluntarily to do under the old mittere in bammm proceeding, viz. come into court to get a complete title; for then the court itself could see that he accounted for the surplus. Thus the difference between his coming into court in the 900 's and his coming into court in the 1500 's was radical; then, he came voluntarily to get justice and have a defect of title cured; now, after he had found out another way of curing that defect, and was using it to abuse a principle of justice that had grown up in the meantime, he came into court compulsorily to be made to do justice; the two situations being wholly distinct. ${ }^{1}$

This, then, is the stage at which the pledge transaction emerges into what we call modern history. . . . The imperial prohibition of the lex commissoria in Roman law, which has served as the theme of much fruitless discussion, is nothing more or less than the same feature in the development of another legal system. . . .

For the form in which the problem was presented to modern law, then, we were indebted to two distinct principles, operating together to cause confusion and misinterpretation in the modern student's mind. First (A) the forfeit notion which had primitively prevailed, and had then given way to the notion of collateral security ; and, next (B), the necessity of a resignatio or auflassung, which left a defect in the pledgee's title, and led him to strive to cure it, and revealed to him, in curing it, a way of erading the other principle; so that it became necessary for the law, in maintaining the former principle, to deal with that form of the latter through which the abuse was perpetrated. Only by keeping clear the history and separate workings of these two principles can we understand the form which, by their collision, they gave to the

1 So that such a provision for sale or forfeiture as the following, which would fairly represent in its terms one of the earlier medieval town laws, exists on modern statute books for wholly different reasons; Code Civil, art. 2078: "le ereancier ne peut, à defaut de paiement, disposer du gage; sauf à lui à faire ordommer en justice que ee gage lui demeurera en parément ot jusqu'a due concurrence d'après une estimation faite par experts, ou qưil sera vendu aux enchères." 
transaction and the problem as it came before modern Germanic courts.

\section{The Pledge without C'reditor's Possession}

Neither etymology nor usage furnishes us in our language with terms exactly expressing the antithesis between the giving and the not giving of possession of the res to the pledgee; for the purposes of discussion, however, it is necessary to have a term that implies merely this antithesis; and accordingly the word "hypothec" will be here employed as indicating a pledge of which the custody is not given to the pledgee, but is retained by the pledgor.

The problem, of course, is to ascertain why that form of the transaction was in a given case chosen instead of the other, - to account for its existence as a distinct legal expedient. Not until we have learned this shall we be able to interpret and to harmonize its peculiarities, whaterer they may be, and to understand its development.... This natural relation which is found in the legal thought of the modern community that peculiarly represents in its law the continuity of Germanic tradition will to us suggest a priori the plausibility of a wholly different view of the hypothec's history, which has been championed by Heusler and ron Amira,the view that it is historically of a piece with the generic wed (or sutzung) already described; that it was simply a variety of that transaction, adapted to a special purpose; that it bore features and followed in the main the development of the wed; and that it had no connection with the peculiar expedient of judicial execution until fairly modern times. This view we may now consider ; first setting out the evidential marks of identity between the hypothec and the generic wed or satzung already explained; next, examining the raison d'être of the former; and then noticing its ultimate fate.

1. The hypothec, or "neue satzung," as identical in purpose and features with the generic wed, satzung, ved.

a. In the first place, the name is identical; this alone starts the probabilities in faror of an identity of institution.' 'They are en-

1 Satzen, rersetzen (verb idea), and red, wed, weddeschaft (the res idea), were the generic terms for both: lieibom, 36; stobbe. "Priv." 273: Amira, I, 193, 216; II, $\$ \$ 22,23$. Interpfand (perhaps a translation of subpignus) and subpignus (the Roman term) rame to designate the hypothec form: Meibom, 36, 263; Neumann, 197; Hensler, 1I, 148. (Subpignus in modern German writers is often used to mean a pledge upon a pledge, or afterpfand, i.e. by a pledgee himself; but it did not mean this either in Roman or in (iernanie law: Sohm, "Jehre der Subpignus," 1.) Faustpfand, handhabendes pfand, denoting the pledgee's possession of 
hanced, moreover, when we find that the phrases in the other line of doctrines about private redress - pledge-taking, etc. - and about the later judicial execution are constantly contrasted with the terms indicating a voluntary pledge. ${ }^{1}$

personalty, were later phrases hased on the false etymology (pugnus, fist) of the Roman pignus: Heibom, 37. Vorkummern or bekummern (our English "encumber") ("ame to be, so far as anything was, the term for hypothec; and the terms versetzen and vorkummern are in later times of ten grouped as covering all kinds (see examples in Heibom, 429), much as pignus vel hypothect were in Roman law, the former being the generic term and the latter a species. Kistenpfand in some regions was used to denote the hypother; "posuit domum suam pro cistoli pignare," "sette sin hus to eyme listenpande": Meibom, 423 ; Amira, I, 216. Fürpfand, or eontingent pfand, was another name used in Bavaria: Heusler, II, 148; Kohler, 234.

1 The contrast of ideas appears in the two words nam and set, nehmen and setzen ("seize" and "hand over"): Meibom, 24; Amira, I, \$\$15-21. Other words in some places used instead of nam have the same idea: badian (force), raf (raub, seize): Brunner, II, $\$ 110$. This antithesis in the verb idea of the transactions lasts till modern times. The development of one is a part of the history of procedure; of the other, a part of the history of substantive law; and all the associations of the hypothec transaction are with the latter, not with the former.

But there is one confusing circumstance; pfand, pant, is used for both transactions; and this must be accounted for. Now the sourees of the later law of execution were, roughly speaking, two (Heusler, II, \&117; Brunner, I1, \$110-112; Amira, I, \$ 15-21, 2\$; I1, \$\$11-16). (1) The ereditor or injured person could primitively, in limited cases and following certain rule's, go himself and carry off (nam) movable goods of the debtor sufficient to pay; they then became to him a forfeit-payment of the ordinary sort, i.e. they were at his risk till redeemed, and if not redeemed they were forfeited to him absolutely without regard to any surplus value; in Scandinavia the thing thus taken was designated (from the verb idea) as nam, while in Germanic tribes the thing taken was called usually pant (a word of uncertain origin, but probably having the same force). (2) Where the dehtor's ontlawry had occurred, the injured person might hy a strules legitima or "legal rape," go and get satisfaction from the outlaw's confiscated personalty; and, much later, the doctrine of missio in bannum regis olstained for him a similar satisfaction out of the confiscated realty, - the phrases being missio in vorbannum, fronbote, fromung, and the like. Now these two processes worked towards each other, so that they came to share the common feature of securing satisfaction from any defaulting lebtor subject to the control of the court. But the distinctive feature of the former process was still that the creditor got the res as a redeemalle pledge only; while in the latter he got a true payment on execution. Hence the former process had bonds of relation with both the ordinary wed transaction and with the execution or vorbannung process; and for the one relation the pant word came to serve, while Por the other the nam or nehmen idea was emphasized. Moreover, since what the creditor almost always got by nam was personalty, personalty pledges came naturally to be called pant generically, and the wed term was thus largely driven ont of usage for personalty (though wadium originally covered both personalty and realty, and though the process itself - the nam - from which pant was horrowed, had a history independent of the trd ); moreover, the original state of things is further shown by the fact that in Seandinavia ved was not thus driven out, though pant when borrowed from the German in later times covered, as in Germany, pledges both nem and set. Later still, pfond partly extends to realty also, - in surh componnd words as kistenpfand, pfandschaft. The case is much like that of our "pledge" ; originally pleige, a personal surety, it 
$b$. The pledge without creditor's possession is found quite as early as the other form ; ${ }^{1}$ which indicates that it cannot have made its first appearance through the development of the missio in banmum.

$c$. The documents indicate its nature to be simply that of a postponed or contingent wed.2 This characteristic is the key to its origin, and will be explained later. . . .

* $*$ * * * * * * * *

d. The unmistakable marks of the forfeit idea, which we have seen to belong to the ordinary wed, are found also in this form. In the first place, the res, if default occurs, in primitive times, pays the pledgee regardless of its deficiency of value, and the pledgor cannot be looked to for the deficit; ${ }^{3}$ while (as we saw above) the later law finds this departed from, and the debtor made liable for the deficit. ${ }^{4}$ In the next place, the res was forfeited, in the sense that the ereditor took the whole, without any duty to return the

practically drove out gage for personal property and restricted it (as "mortgage") to realty; ret the old law of personal suretyship is no more to be looked to as the source of our "pledge" doctrines than is the process of nam for the Germanic doctrines of wed and pfand. It should be added that as most hypothees were of realty, ant as pfand was chiefly applied to personalty, the hypothee is almost always (except in kisten$p$ fand) dealt with in medieval Germanic law in the terms wed, satz, satzung; and thus there is ample evidence from etymology that the hypothee is quite distinct historically from the process of execution, independently of whether we are able or not to account for the use of $p$ fand. Nevertheless, that use, though confusing, seems quite capable of explanation in the above manner.

1 Stobbe, "Priv." 272; Heusler, II, \$ 104; Amira, I, 216. Kohler, 24 , gives a capitulum as early as $\$ 66$, dealing with it.

2 A Scandinavian example (Amira, II, $\$ 23$ ): After selling a piece of land with warranty: "That this sale may be more firm and trustworthy, $J$. [the seller] has put us [the buyer] his farm of five aeres, in M., in full liability, so that we are to take it if the above piece of land should be sued away from us." Germanic examples: After selling a mill and engaging to get the lord's consent to the sale: "quod si negligentia vel culpa prepediti non fecerimus, curias duas in M. ecclesiae loco molendini contulimus perpetuo possidenda" (IIcusler, II, 145, also 152); after stating a debt: "Predictam autem villam tibi ohligo et in pignore pono, ut si minime fecero te ad deliberandum ad suprascriptum terminum eo hordine et racione ut supra legitur, tune tribuat tibi potestas acedere et intromittere sive at proprium dominare ipsa vestra pignora, et tamquam legitimum documentum possidere, nullo volsis homine rontradicente" (Kohler, 353); "Nos . . subpignoramus curiam nostram . . ., et si in solucione... negligentes extitimus, . . . immediate, cum ipsis [creditors] placuerit, . . accipiant subpignora nostra" (1Teibom, 22, 261).

3 Stobbe, "Priv." 276-278; Amira, I, 216; II, 23. Moreover, the same general but indescribable evidences of the equivaleney-idea run through the documents, which give the reader a clear impression of the identity of the wed idea in both.

4 Stobbe, Ib.: Amira, Ib. (in the first passage, the Wishy law represents the more adranced or later stage). 
surplus, ${ }^{1}$ - as in the ordinary wed or satzung; but here, too, the later law gets gradually away from this, and we find a valuation and return of the surplus. ${ }^{2}$ As before, in the ordinary wed, the latter development - the pledgee's duty to restore the surplus comes before the former, - the pledgor's liability for the deficit. ${ }^{3}$ Parallel with this development of the forfeit-idea went also, of course, the development of the pledgee's efforts to cure the defect of his title, as already described for the ordinary wed with pledgee's possession.

$e$. The pledgee obtained a title to the res, good against third persons. This, if true, militates strongly against the theory that the debtor has merely promised the creditor a general right of lery and sale on default which he would otherwise either not have at all or have only by legal proceedings. This, if true, is more in harmony with the notion that the specific res is now the creditor's, subject to the contingency of default. . . .

$f$. The debtor who gave a hypothec could not, by primitive law, during its life give another one to a third person. ${ }^{*}$ This is a nota-

1 Stobbe, Ib.; Amira, Ib.; Meibom, 435.

2 Stobbe, Meibom, Amira, ubi supra. A clause from a document in Meibom, 261, 262, shows how the auflassung or commissoria clause was used to dispense with the duty of restoration which the later law ordinarily placed on the piedgee; upon default, the pledgees "cum placuerit, immediate accipient subpignora nostra, facientes cum hiis omnibus, secundum formam proprietatis tituli, quitquit ipsis videbitur expedire", again, "Si non redederemus . . licentia aveatis tu aut tuos heredes supradicta terra avire et clominare in vestra potestate" (Kohler, 85). In Norway, the different stages appear very distinctly; the pledgee takes the whole res in forfeit, unless there is a special agreement that he is to take the equivalent of his claim only; in the next stage, he is to take the exact equivalent of his claim, unless by special agreement he may take the whole. In Iceland an intermediate stage appears, in which he is to take double the amount of his claim, by measuring off for himself the land required, according to a valuation of the neighbors, - unless other creditors would suffer owing to the debtor's insolvency, in which case he takes only the exact equivalent; in the later law, he takes always the exact amount only.

3 Stobbe, Amira, ubi supra. This is neatly to be seen in the laws mentioned by Stobbe; in some of them the stage of handing over the surplus is not yet reacherl; but in most of them a sale is to be made and the surplus handed over; within this latter group, however, are still some which do not require the pledgor to make up a deficit. So in Amira's records, the Wisby law, representing the later stages, requires the pledgee to restore the surphus, and the pledgor to make good any defieit; but an earlier text of the Hamburg law, on which the Wisby law was founded, does not contain a clause making the latter requirement.

${ }^{4}$ Meibom, 429; Stobbe, "Priv." 274, 283; Amira, II, \$ 23 (in Iceland the pledgee might take possession immediately upon the pledgor's transferring to the third person); Kohler, 23. A later but transitional stage is seen in the rule that a second could be given only for the surplusamount orer the first; but as soon as the forfeit-irlea disappears, and the pure notion of collateral security lecomes established, it is perceived that 
ble feature of other systems of law, and it seems to be explainable on only one theory, viz. that since the res has been dedicaterl specifically as contingent parment for a possible default, and since (as we have just seen) the creditor-pledgee obtains a title to it pursuable in the hands of a third person, and since on default the pledgee will obtain the whole res as the equivalent of his claim, regardless of any surplus value that may exist, it is impossible to conceive of any other creditor as having a concurrent interest in that res. In short, this well-proven rule is not only consistent with, but is the inevitable consequence of the fundamental forfeit-idea in the wed or satzung.

2. The hypothec then, being originally in legal nature nothing but a form of wed or satzung in which the pledgee was not given possession, what were the circumstances to which this form of satzung would be appropriate? Why and when would this form be used instead of the other? The answer has already been pointed out, viz. wherever the existence of a claim is not yet certain, i.e. a default is only contingent. The chief cases of this sort, as enumerated by Heusler (147) are: (1) Warranty of title in a sale of land; (2) Rent from a lessee or other rent-grantor; (3) Liability of a debtor to a surety for possible default; (4) Liability of a guardian on account of an infant's revocation of a sale at majority, of a husband for a wife's claim of dower in property sold, and the like. In such cases, as Heusler remarks, "it would be unreasonable to make a satzung which would transfer the enjoyment of the property immediately to the creditor, for that would be wholly unnecessary and quite beyond what the creditor could have any pretext for demanding." The res was to be the wed, if there should be a default; but as there might not be any default, it was enough assurance for him to have the res legally dedicated in advance to cover that default, while remaining in the meantime in the obligor's hands. This explanation is a priori wholly natural and harmonious with the forfeit idea. ${ }^{1}$. .

any number of ereditors are welcome to take their chances with the res, even though their united rlaims exceed its value; and so we find (Stobbe, 283) the codifications of the 1500 's providing expressly that additional hypothees are allowable.

${ }_{1}$ [In later chapters of the original work, the author traces a corresponding development in Egyptian, Babylonian, Jewish, Japanese, Greek, and Roman law.] 


\section{Cinapter XXVI}

\section{SLRETYSHIP ${ }^{1}$}

1. Suretyship originally meant the giving of a hostage, the debtor being released by a new debtor, either at once or when the need arose. Not until later did suretyship change its character so that it implied an addition to the debtor's credit instead of an attachment of the person.

The principle of giving pledge of a hostage is based on the idea of representability, one person being considered as fitted as another to assume the liability for the debt and thus to satisfy the creditor. This applied not only to obligatory relations of an economic kind, but also to penal obligations, a surety taking the place of the guilty subject. Here, too, we find the idea of equivalence, resting on the view which at that time dominated criminal justice, and did not necessarily connect the punishment with the perpetrator, but even extended it to other persons.

2. To act as surety was considered the special duty of the members of the family; this was an outgrowth of the earlier idea of the collective liability of the family. While formerly, by virtue of the law, the family was liable for the individual, the later form reversed this, so that the individual took upon himself the liability for other members of his family.

3. Suretyship does not, of course, aim at subjecting the surety to the debtor's difficulties; rather, it is understood that he is to be released by the debtor's doing what is necessary to satisfy the creditor either economically or by undergoing the penalty. Not to protect the surety against liability was a reprehensible breach of faith, and whoever was guilty of it not only incurred the blame of society, but the surety was allowed to proceed against him rigorously. At first, this so-called recourse developed within the family, and the State paid little attention to it originally ; because

1 [Reprinted, by permission, from Josef Kohler, "Philosophy of Law," (Albrecht's trans.), Boston Book Company, 1914 (Philosophy of Law Series, Tol. KII).] 
the family kept order in its own eirele, and of its own accord revenged all negligences and failures on the part of its members to perform their duty.

4. Suretrship was a liability of the person. It was not a trade obligation but a personal intervention for another; hence the principle that suretrship expires with the surety; it is not handed on to the heirs.

5 . But this leads to serious evils, for the debtor is freed from the creditor by virtue of the surctrship, and then the ereditor loses the surety also.

Of necessity, then, the rule developed, that in such cases the debtor must produce a new surety, or must again offer himself, and this brings about a far-reaching change in the institution. As long as obligations existed only for a short time, this condition of affairs either did not occur at all, or had no effect deep enough to influence the institution to any consilerable extent. But, when long-continued obligatory relations arose, it was necessary to provide for the creditor in the way mentioned; and this gave rise to the rule, that by proeuring a surety the prineipal debtor is indeed freed, but not completely ; he must again beeome answerable if the guaranty of the surety fails. This conditional, further liability of the debtor gradually grew to be unconditional; and so it came to be that both the debtor and the surety were liable to the creditor - a condition that would have been impossible, according to the views held in earlier times; for then the principle was maintained: one debt, one debtor. Gradually the debtor's liability became so conspicuous that some systems of law have forced the surety entirely into the background; so that he is answerable only if the debtor fails in some way to perform. What is called the beneficium excussionis, according to which the surety may require that the creditor first proceed against the debtor and resort to the surety only if this attempt is unsuceessful, is a very meager institution and one that discourages eredit, for it makes the creditor's security unstable. The security of credit requires not only full, but also easy satisfaction to the creditor; in order that credit may be easily obtainable, it is necessary not only that the creditor be paid, but also that he attain his object quiekly. and without trouble. Henee the idea, that appeared in Germany in the Middle Ages, that the surety may require the ereditor to proceed punctually against the principal debtor, so that the latter may not beome insolvent and thus ast the burlen on the surety, is entirely at variance with the meaning of the institution 
and deprives it of a great part of its value. The only proper course, in such a case, is to allow the surety to proceed against the debtor, and to leave it to him, whether he will do so; so that the debtor may be compelled to give the surety security, or to release him (either by finding another surety or in some other way). 


\section{Chapter XXYiI}

\section{EVOLUTION OF THE LAW OF CONTRACT}

\section{SECTION I}

\section{THE FIDES COMMANDMENT ${ }^{1}$}

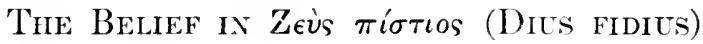

The belief in two powers - gods and the spirits of ancestors who stand in a certain contrast to each other, is the basis of the ancient Aryan system. Among the south Aryan tribes, the worship of the "parentes" of the first three grades [father, grandfather, and great grand-father] differed in a peculiar manner from the general cult of more distant ancestors, especially famous heroes. Out of this, the Greeks and the Latins developer the precept of obedience to the fatherland. A fourth idea has been annexed to this cult - aid to fellow-creatures needing protection, who if despised have the power of the curse. Accorting to the ancient fundamental ideas, sacrifices are made to these four powers. The commandments to honor them are religious. These four commandments are unmistakably found in ancient Roman "fas." In contrast to them are the five moral injunctions - [physical and moral cleanliness, not to defame, not to inflict physical injury, not to steal, and not to lie.]

Four peoples which will be more closely consirlered here, have a clear connection with these five moral precepts - the Indians, Iranians, Greeks, and Latins. But in the use of these precepts, these peoples finally drew far apart. The seeds of these five rules already lay in the first religious commandments: one must

1 [By Dr. B. W. Leist, Professor of Law at the Cniversity of Jena. Translated from "Alt-Arisches Jus Civile," Erste Abtheilung, Jena, 1892 (pp. 420-450), by Albert Kocourek. The translator is glad to ackinowledgo the use, for purposes of comparison, of a preliminary translation of the same material, courteously made at his request. by $M i H . R$. Juergensen of Chicago, a former student of law at the University of Munirh. The present translator, lowever, is solely responsible for whatever may have missed the mark in the rendering now made.] 
keep oneself pure towards the gods and be loyal and true. These rules then shaped themselves in the form of general precepts of conduct towards other men. In that these rules were unified by basic moral ideas, they were alike in calling for expiations when violated. These expiations were established for physical uncleanliness as well as for intentional injuries, and also for the three chief wilful offenses of the ancient world - defamation, killing, and theft. For the latter violations (as well as other offenses altogether apart from the question of purity) revenge on the part of those entitled to it by authority or by reason of their own injuries, prevailed. Lastly, these expiations were provided for untruths and faithlessness.

With reference to the three intentional misdeeds, the historical development among the Indians, Iranians, Greeks, and Italians took quite different courses. In India, a kingly system of penal justice was added to the Prīyaçcitta system which at first had a wide extension; but this addition did not accomplish a unified legal establishment. In Persia, a real system of public justice in the beginning far superior to that of other nations took the plan of the ancient Lpäzana system. Here the substitution of the principle of civil legal protection, for priestly revenge and individual retribution, was first clcarly expressed. This principle became equally effective in private concerns against the ancient method of self-help. In Grcece and Latium, however, the transformation from the system of personal revenge and self-help to the stage of civil legal protection was much more tardy and complicated. But especially for this reason, Rome brought forth a product which will always be the standard of all real progress for the whole civilized world. In any event, with this development, the whole question was once and for all removed from the domain of the ancient ideas of "fas" law into the sphere of civil law.

Thus, it came to pass that with the dropping out of the three middle rules of the five moral precepts, the first and fifth drew closer together. This occurred most conspicuously among the Iranians. These two injunctions constitute the substance of the Zoroastrian teaching. A similar combination, however, is not discovered either among the Greeks or the Romans. But the rules themselves are found in perfect clearness. The form which they took, especially among the Latins, is the object of this inquiry. Having already, with this purpose, [in previous pages of the original work] considered the precept of cleanliness, it remains only to examine further the "fides" commandment. This inquiry 
falls into three divisions: the elements of the "fides" concept; the relations which especially are based on "ficles"; and, lastly" and chiefly", the acts by which the obligation of "fictes" is effected.

\section{Elements of the Fides Concept}

The Latin idea of "fides" is entirely the same as the Greek

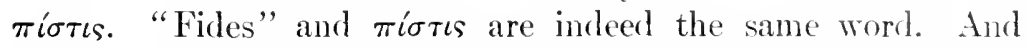
yet it is not even conceivable that the "fides" concept of the Latins and Romans was borrowed from the Greeks. It was for the Latins an ancient, deeply-rooted ethical precept which, in their own way, they formed and cultivated with more energy than the Greeks who were more easily moved by the impulses of the moment. We have already seen that the primitive Aryan injunction against lying (the fifth Minnara precept) had been absorbed in a characteristic way by the Iranians in the Zarathustra teaching with the commandment of cleanliness, of which traces may be found in the Indian sutras. The Greeks and Romans of a later age, of course, were familiar with the Zarathustra teaching, but it is not to be believed that they were acquainter with this doctrine from the beginning. The conclusion, therefore, alone remains that the ancient Aryan injunction not to lie, without its special Zarathustrian color, had already been a fundamental ethical possession of the fore-fathers of the Greeks and Latins in pre-ethnic ages; and that they developed from it much the same detailed rules found in the Indian suitras. This conclusion also fully agrees with the fact. In connection with the question of truth, there stands out conspicuously in the parallel series of Semitic commandments, fashioned in a similar manner, the only proposition of the kind reduced to a formula: "thou shalt not bear false witness against thy neighbor."

One of the most important institutions of Themis and "fas" law was that which required in matters of dispute, before resort could be had to self-execution, that a judicial judgment must be invoked, which had to be supported by witnesses. The precept that, here, the witness must speak the truth, accordingly vindicates among the Greeks and Romans a primitive situation; even though the statutory provision in Rome of punishment first dates from the Twelve 'Tables. But not only in procedure, but generally in public and in private matters, it was always a commonly recognized ethical postulate of the Latins, that one must keep " firdes." It was precisely in accord with the Latin character to require a 
particularly strict observance of this commandment. A certain mutuality was involved in the illea, as shown in the saying: "da et accipe fidem" . . . ; "accipe daque fidem." On one side, it is presupposed that what is declared conforms to the truth. Whoever may not be trusted to speak the truth is not fitted to be a witness; he is "intestabilis"; . . . "intestatus est, cuius verbis fides non habetur." On the other sicle, confidence is to be reposed in him who is trustworthy ; one is not only to give "ficles," but also to accept it; . . . "credere" est fidem habere dictis et factis." Thus, "fides" appears to be an objective totality of principles of faithfulness governing mankind in a mutually obligatory "fidelitas."

The principles of faithfulness are called to the attention of one's adversary where it is perceived that they may be violated ; and their observance is especially expected in those of mature years. . .

If we regard "fides" as an objective standard, yet clearly this does not mean that it originates in the State, or in the force of legislation or customary law. It had to do rather with one of the ancient Aryan Themis or "fas" law commandments. Therefore the basis of its coercive force is the belief in the gods. The gods know whether truth is in the hearts of men; they protect and reward the faithful, and punish the breach of "fides." The protection of "fides," accordingly is committed to the will of the gods. Thus it was, both among the Greeks and the Romans. The

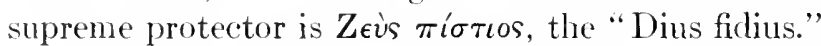

In comnection with the extent of the "dharma-Themis-fas" legal commandment under discussion, we may state its further historical development among the various Aryan peoples. The fifth Minnava command deals only with veracity, and for that reason the detail of the sutras is limited essentially to the viewpoint: "speak the truth, not untruth"; even though it is accompanied by the maxim: "deal justly, not unjustly." In the Iranian Zarathustra teaching and the Persian magi doctrine, the truth conception, on the contrary, has an extraordinary extension. The Greek "pistis" and the lioman "fides" idea has much narrower boundaries, but still reaches beyond the Indian formula of truthfulness.

The highest obligation of "fides" is expressed by "jurare"; and this may be either declarative or promissory; . . . "jus jurandum apud Romanos inviolate sancteque habitum serratumque est"; . . " "juro' tunc dici debere cum confirmamus aliquid aut promittimus." "The keeping of "ficles" therefore signifies not 
simply the maintenance of truth in what is asserted, but also faithful conduct in what is promiserl. The "firles" idlea has even extended beyond the sphere of assertion and promise. One may be placed in a position of trust, where, without either assertion or promise, the situation itself uncquirocally demands the duty of faithfuhness. A single concept of fidelity, however, runs tirough all these forms, which has a clear connection with the nirrower idea of veracity. 'This idea of veracity and firlelity may be said to be a characteristic Aryan element, however rude it may appear in the begiming, and however diversified its use and development among individual Aryan peoples. It will not be said that nonAryan peoples have not possessed and do not possess the notion of fidelity as a parcel of their growing ethical ideas; but closer inspection will show that this idea among non-Aryans is in essence of different complexion than that prorluced by Aryan bloorl. Still, from another side, the Latin idea of "fides" requires examination. I have already observer that the ancient Aryan commandments of clcanliness and truthfulness were combined in a peculiar manner among the Iranians. One should be pure and true in thought, in word, and in deed. Nothing similar to this is found in Latium. But here a certain combination of the commandments of purity and fidelity with more general ethical postulates, was, however, effecter. The Roman, also, combined the requirements of morality in a harmonious picture - that of the "vir bonus." He is the man who is honored by his fellow men for his virtue (honestus) which he practices, not for external gain, but for its own sake. 'This moral character, according to Roman views, also had a rlouble aspect - negative and positive. The negative side was in being clean of fault; the positive side was lifelong proof of integrity or trustworthiness, which was especially expressed in the keeping of "firles," "dictorum conventorumque constantia et veritas." ... In particular his integrity and "fides" must be manifested in such wise that he holds aloof from all treachery, that crime which can be traced back to the most ancient times, and the punishment of which fell to the revenge of the $\beta a \sigma i \lambda \epsilon$ 's as well as the "animadversio" of the king.

According to the Latin viewpoint, the consequences of riolations of the commandments of purity and truthfulness, may be considered as resting on the same fundamental idea. In the first instance such a violation is against the gods. They are injured by unclean and unfaithful behaviour. In both eases in order to be made clean and whole again, it was necessary to make expia- 
tion in faror of the gods; just as among the Indians, atonement for such offences lay in the domain of the Prạyaççita system. Kingly punishment could not remain exchded, as already appears, as to some of these violations, in the sintras; and in greater measure among the Grecks and Romans as the particular laws of cities and states developed; whereupon the commandments of purity and truthfulness of "fas" law came to be recognized in the most varions ways in civil law. . . .

The commandment "thou shalt not bear false witness" which we found to be of great antiquity may be regarded as the central point of the commandment of veracity. In Rome it was provided with civil legal punishment in the provision of the Twelve Tables that "qui falsum testimonium dixisse convictus esset, e saxo Tarpcio leiiceretur" (Gell. 20, 1).

Another proposition concerns the oath. The Greek and the ancient Roman world regarded it as an institution lending security to the civil law as well as indispensable to "fas" law. In a highly characteristic way, the oath is described in Roman legend as a pact with the gods, attributed to Numa as the final representative of "fas." The oath of ancient times took a great variety of forms ; it was a means for invoking the greatest diversity of gods. At the time when the whole important sphere of the religious system was exclusively set apart with rigid boundaries from the State, it was nccessary that the manifold forms of the oath should have a unified operation. Tiolation of the oath brought down the revenge of all the gods. Thus it was said, that Numa by giving a rotum, through which the judgment of the gods is obtained, was directed, onee and for all, that every oath, even one addressed to an indivichal god, stood under the combined protection of all the gods; ("Incert. ad .En.," XII, 234:) "Granius Flaccus seribit Numam Pompilium, cum sacra Romanis conderet, voto impetrasse, ut ommes dii falsum juramentum vindicarent." 1

The general prineiple, however, arising from the combination of the two "fas" law commandments, of freedom from guilt and the integrity of "fides," which contimued to be a permanent fact and also persevered under the dominion of civil law, is the following. He who lives in aceord with these commandments is the "vir bonus." The individual rules into which these commandments break up in the manifold eonditions of life are not newly

${ }^{1}$ [For a full discussion of the procedural importance of the oath in ancient law, see Part IV of this volume, post (Chapter XXXI, Section 4) - " The Ordeal and the Oath."] 
thought out by each "vir bonus." They become, by progressive development, a complex of principles which, in the long course of generations, the totality of a unifier people become accustomed to follow. There is, therefore, a complex of "boni mores" which may be called the residue of ancient "fas." But the "fas" element has never been eliminated by "jus" (civile). It still survives as the foundation of the latter. Thus the principle still prevails that what is "contra bonos mores" is not permitted. Accordingly. the ancient "fas" law standard of the old Aryan moral corle will always have a place in the domain of "jus civile" ; with conditions, of course, dependent on the circumstances of particular cases.

\section{Fides Relations}

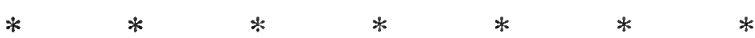

"Fides" duties are owed: 1, to parents; 2, to wards: 3, to clients; 4, to guests: 5, to cognates and affines. There have been differences of opinion as to the order of succession of these relations. Many place No. 4 before No. 3; but I shall let the question pass. My problem is to discover how this series arose at all "ex moribus Romanorum"; and to me it seems that these five divisions themselves clearly furnish the answer.

We have already demonstrated what follows concerning the ancient household organization. The ancient Aryan household establishment ["koinonie"] in Latium and Rome underwent far-reaching changes. The "paterfamilias" took the place of the master and mistress of the household ["pati" and "patni"]. This substitution of authority was effecter with great energy and in vigorous conception; it resulted in an entirely new Roman family sistem governed by particular law - the agnatic family. But the Romans were not able to make of it more than a governing institution; they could not eradicate the ancient Aryan sistem of household authorities. Important residues continuel to exist; and certain of these survivals at last again orerthrew the agnatic system.

Upon what elements dirl these five duties, to parents, to wards, to clients, to guests, and to cognates and affines, rest? It is beyond question that they all belonged to the ancient Aryan "jus gentium." As to the second of these duties also, in which ats we have already seen, there were definite seeds of the agnation concept, it can by no means be asserterl that it was simply the product of the Roman agnation principle. These five duties clearly show 
their ancient Aryan origin if we disregard in the comparison the "potestals" of the house-lord (and the house-mistress). The "potestas" itself is not a duty in favor of the members of the houschold. Each one has a different position in the house, but all are subject to the "ditio" of the house-lord ; and this "ditio" is something quite different from a duty. For the rest, these five duties furnish a distinct picture of the unified special relations according to which the Aryan house-lord owed a variety of duties shortly expressed by the term "ficles-performanee." The wife does not bear an "officium" [duty] relation to the husband; according to the ancient view she is a co-ruler of the house. The "officium" of the child, however, to both parents, stands out conspicnously. 'This duty survives the lives of the parents, and after their death continues as a solemn obligation to render them "obsequium."

Closely conneeted (to consider the next form) is the ancient relation of fidelity which the house-lord owes to the children of his brothers; if these brothers had maintained separate establishments, and one of them died leaving minor children. Again this relation has a near likemess to the protection of clients, which also goes back to the most ancient times. A kindred system such as then existed is hardly to be thought of without clients. For there were always persons reduced by necessity or diminished by war who would desire for security to ally themselves as clients to a powerful family. A similar relationship likewise was created when a settlement was made in a conquered country, if the former inhabitants were not enslaved, but were attached as free persons to the various families of the ruling tribe. And, precisely, because, in such client-relationships, the strong ones dominate the weaker ones, the more intensive is the duty of "fides." The Latins restored the ameient client relationship by means of the sacral ceremony of manumission.

Next in order, eomes the "fides" duty to the guest. The guest relation is usually temporary, while the client relation presupposes life-long duration. The eoncluding "fides" relation, that toward the cognates and affines, springing from the ancient Aryan root of socicties of "propinqui" for defense and offense, has elsewhere been discussed in detail. We may, therefore, be permitted to observe that these "officia" transmitted to the Romans by the "majores," and reaching back to ancient Aryan times, fare similarly with other faets which were not found to belong to the dominating agnatic srstem. All the more the necessity was felt to 
intrust them to the memory of succeeting generations in a fixed form of numbers and in a studied order.

* $\quad * \quad * \quad * \quad * \quad * \quad * \quad * \quad * \quad * \quad *$

\section{FIDES ACTS}

\section{Marriage}

It remains to examine the Latin acts which operate to ereate the obligation of "fides," and to show to what extent they are connected with pre-ethnic ages. Since it is eertain that such acts may be discovered not only in Latium, but also in Greece, and even farther away, in the Indian sintras, there is langer that the institutions in question will be incompletely understoor or even misunderstool, if we restrict our investigation solely to the Roman sources. We must serutinize that which is found to be one and the same institution, with its local variations among flifferent peoples, in its entire historical development in a common race element, as well as its special developments. We must not comfortably limit the inquiry to the written Roman sources which contain many gaps, and which in other things give too narrow a point of view. Where the sources of other Aryan peoples make possible a more extended horizon, the effort is not to be avoided which a broader view requires. We must be content to meet inconvenience in order that an enlarged vision may make comprehensible what now cannot otherwise be explained. First of all, it is our object to deal with that which is capable of being made certain.

Four institutions come under consideration in connection with acts of "fides," which unmistakably appear, not only among the Latins, but also among other Aryan peoples, and especially among the Greeks, in such manner that we are compelled to regard them as historieally coherent. These are marriage, the allianee, the "sponsio," and various real acts. We shall consider them in detail ; not exhaustively, but with the purpose of attaining established points of view.

Marriage is an allianee ("foedus"). The worl itself tells us that its fundamental prineiple involves "fides." The Greelss say" the same thing in that they designate marriage as the leading $\pi i \sigma \tau \omega \mu \alpha$. . . . We may at once call marriage the balsie "foedus" of the Aryan legal system. So far as the peoples here reviewed are concerned, we do not find mother-right. And also in a survey of 
the marriage concept, despite all that is crude and rough in this race, we find a constant effort to assign to woman a higher position than she has attained, even to this day, in marriage, among many non-Aryan peoples.

In Aryan marriage three stages recognizable even in later days are found, which have been derived from the manner of constructing the physical seat of the matrimonial life. The foundation of the house is first constructed; then the building is erected on it; and lastly it is inhabited. The three stages of marriage were not created cither by legislation or yet by customary law. They are the product of ancient Aryan recognition of the "rita" of the separation of the sexes. The effort to establish marriage on a higher ethical plane is supported by the belief that it is regulated by divine authority ("charma," "Themis," "fas"); and that it has its model in the marriage of Jupiter (Tellus) and Juno. Ancient marriage law is not founded on organized "popular consciousness," but on a precedent "rita" sı́stem and divine principles based thereon revealed through the wisdom of exegetes. The ancient Aryan marriage therefore is a holy "fides" institution for the orderly propagation of the human race. Its basis is the order establishing the course of legitimate descent ("aurasa," $\gamma \nu \eta$ б "causa liberorum (legitimorum) quarendorum."

The wife has a high position of honor in the house, because she is the means whereby man attains his highest wish to beget legitimate children, especially sons, who at some time can take his place. The marriage relation presupposes the legitimacy of the children arising therefrom. It is manifest then that the husband has to provile for the support of the wife and the children. But more important yet than physical maintenance is the spiritual and moral training. In ancient times all instruction and education of the growing generation were provided in the heart of the householl. It is the highest aim of the husband to make his sons like himself, that they may grow up in the fear of the protecting "dii patrii" as strong, able, and clever members of the tribal community. In this the mistress of the house has a part as well as the lord; but in order to develop the ethical powers, it is necessary that the marriage be of life-long duration. Even when the children have become independent the counsel of the parents is necessary ; and when the parents become feeble, it is the purpose of Aryan marriage that the father and mother be cared for in the homes of the children. Therefore as the Aryans understood this "naturale rita" of marriage, it is a "fides" relation . . . enduring 
until death. There was no temporary marriage among the Aryans. And since marriage was governed by " rita," it did not rest solely on the will of man and wife like an association in proprietary matters.

In each of the three stages of marriage, there is involved a "fides" obligation. In the first there is a binding of the purity of the maiden as well as the will of the groom; but not by virtue of a contractual willing, but through a betrothal of the maiden by him who has power over her, to him who is the suitor ["Freier"]. But this act of betrothal on the part of the person in authority does not proceed out of his pure free-will. According to the "rita" he is bound, in order to avoid the punishment of the gods, to arrange a marriage as soon as the girl is of marriageable age. According to ancient ideas it is the duty of the wife to bear children as soon as she is able. This duty is so firmly implanted in the maiden that her own independent will does not come into question. . . .

The second stage of marriage is likewise not explainable on the theory of contract. It is a unilateral exercise of "potestas" by the husband with the consent of the person in authority. The seizing with the hands in the matrimonial ceremony does not disclose in any of its operations the "datio" of the person in authority" over the maiden, but still the "datio" is included. It is an act of forcible establishment of power according to "fas" which is not explained away by an existing "jus" which is based on contractual ideas...

Lastly, in the third stage, in the founding of the household, man and wife are united to a common domicile, but again not by a special contract, but through the definite fact of cohabitation which makes them as one.

$\begin{array}{lllllll}* & * & * & * & * & * & *\end{array}$

The manner in which the Aryans formed the institution of marriage, in large measure was the cause of the wonderful power and vitality which distinguished this race above others. For the reason that in its Aryan originality it was the leading gromnd element of the legal system, it is necessary to reconstruct it first of all from its pure "fas" law elements. Then only will we be able to understand its continuance in the succeeding ages of civil law. We will then perceive that marriage as the original and most important of all other "firles" institutions, is the source of categories, ideas, and regulations met in later periods of the hegemony 
of civil law, which appear to lie far apart from, and to be foreign to the marriage institution.

\section{International Fodus}

The second ancient foundation of the concepts, agreement, legal transaction, sale, converance, etc., is the "fœedus" entered into between different clans, especially Aryan societies which worship the same Zeus-Jupiter. In the "fordus" the "fides" expression is verbally adhered to. In a narrower technical sense it is designated the "foerlus," while in the marriage relation it is called $a$ "focdus." In any event, they occur together as distinctive basic Aryan institutions which rest on a "fides" act, and accordingly in thcir content are treated as "fides" relations. While they have a common foundation, yet in other respects they are essentially different. One rests upon the principle "naturalis ratio," - the other on a vohuntary element.

The fact is well established of all Aryan (as well as non-Aryan) peoples that various tribes unite for the purpose of protecting each other in their perpetual wars. 'Testimony of this is furnished among the Indians by the battle of the ten kings; among the Greeks, by the Trojan war; and among the Italians by the ancient "fodus Latinum." The characteristic method of sanctioning such a "foerlus" is the oath in its most solemn form. . . .

An essential condition of this "fides" transaction is the making of a sacrifice whereby the gods are invoked to participate in the entire solemnity. Alliances with non-Aryan peoples are possible where each of the parties calls upon its own gods. But, as it is casy to see, an alliance mutually sanctioned by the same Aryan gods, especially the king of the gods, Jupiter, had a particular holiness and obligation.

* $\quad * \quad * \quad * \quad * \quad * \quad * \quad *$

\section{The Sponsio}

In the marriage "foedus" based on "naturalis ratio," and in the international "foedus" which discloses the voluntary element, we have before us beyond doubt the most ancient "fides" acts of Themis and "fas" law. We now approaeh a very important third type also of pre-ethnic ages, the "sponsio." An investigation of this institution is surrounderl by the greatest difficulties, but yet it is a subject of the highest historical interest. We 
shall approach it from the standpoint of what is securely established by the sources.

When we found among the Indians, Persians, Germans, Greeks, and Romans, three stages in the consummation of marriage the foundation, installation, and performance - no doubt was left that we had discovered the fundamental basis of this ancient Aryan institution. From this port of safety we may without peril go a little farther. In the middle phase of the three stages in the evolution of marriage where we found the ceremony of forcible seizure, lies the germ of the whole marriage "foelus." Indic as well as Iranian sources accordingly shortly express a valid marriage by the term "hand seizure." I have therefore considered it justifiable to identify the Roman marriage mancipation (which only later developed the general institution of mancipation) with the similar ancient Aryan ceremony of "hand seizure" as being historically coherent; in like mamer as, without question, the "domum deductio," of the third stage, among the Indians, Persians, Greeks, and Romans, may be regarded as one and the same historically connected usage. We are furthermore constrained to connect the peculiar coemption mancipation of Latin particular law (where the thought enters more and more that the consensus of man and wife constitutes the basis of marriage) with the "dextrarum conjunctio" of the Greeks which was thought to fortify the consensus; and to regard them as common survivals of the ancient ceremonies of "hand seizure." . . .

In the same way that the marriage "fœedus" is supplemented by a "sponsio," so also we find a similar element in the international "foedus." This is discovered of the Greeks as well as the Latins. In Homer the $\sigma \pi 0 \nu \delta a i$ are still a complete constituent in the solemn oath of the "fœdus." But in Greece as in Latium, the international "sponsio" became detached from the "foedus." It takes an inferior place as a "fides" act alongside the supreme solemnity of the sworn agreement of alliance in a similar way that in the celebration of marriage by "dextrarum conjunctio", the independent and preliminary "sponsalia" of "dare" of the maiden are subordinate to the marriage itself. And, again, the Latins injected a general proprietary legal idea into the original conception - " dare spondes," "spondeo" - in the same manner that the general institution of mancipation attached itself to the ancient matrimonial mancipation. They gave it a technical meaning which could not be constructed out of the Greek language for a similar legal transaction. But they always acknowledged that 
the Greeks also had a general "sponsio juris gentium." The Laws of Gortyn bave furnished the most convincing proof for the Greck é $\pi \iota \sigma \pi \epsilon ́ \nu \delta \epsilon \iota \nu$.

We may, therefore, assert that the sponsio, the libation solemnity (and, only later, the declaration that one undertakes the solemnity - the verbal act) is a "fides" act which has appeared among the Indians, Greeks, and Latins; even though in varying form, yet in such manner that it can be traced back to pre-ethnic tribal society. In Latium it was a weaker form of "fides" obligation by the side of the precise central act of the marriage alliance, and alongside of the international alliance which was entered into with the fullest solemnity of the oath. But in Latium it developed, as in Gortyn, into a special formal act for undertaking proprietary performances. With the declaration $\epsilon \pi \iota \sigma \pi \epsilon ́ \delta \omega$, "spondeo," a man pledged his word to carry out a promise. A residue of the time when the "sponsio" was a sacral act, a libation to the gods, is found in the fact that the condition of being "reus" sprang from the Latin "sponsio," and also from the "votum." Being "reus" signifies a sacral legal obligation of a special kind. But in other respects the obligation of the rotary is something quite different from that of sponsor. As soon as the gods have done their part, the votary by reason of the real act of the gods becomes a "voti damnas"; and no "fides" relation subsists between him and the gods. The obligation of "fides" through the pledge of one's word can obtain only between persons, and not between gods and men.

Such an obligation by pledging one's word, however, appears in Latium in still other forms than that of "sponsio." Especially important in this regard is the use of the word "vas," and besides and of yet greater importance, the word "præs." In the sense of wager, "vas" has had a far-reaching extension in Indo-Germanic speech to indicate an obligatory relation. It is indispensably necessary to investigate closely the wager transaction from every side. Linguistically "vas" and "pres" are related; but the actual connections between them remain to be explained. Since in Latium a plurality of formal acts was employed, so also do we find in Grortyn five methods of creating an obligatory relation enumerated . . . the individual relations of which to $\epsilon \pi \iota \sigma \pi \epsilon ́ \delta \delta \omega \nu$ remain undiscovered. Again, however, all formal acts also require explanation as to their exact connections with the law of slavery for debt.

Large provinces of this domain are still unexplored. Inasmuch, however, as we are able to distinguish the leading land-marks of these inquiries, and even though in detail our explanations may be 
wholly defective, yet we may hope that in time we may make progress in knowledge of individual institutions. For the present, we may venture a generalization. Aryan antiquity, groumled on the ethical command of fidelity, already recognized promises ("nudæ pactiones") as having a certain binding force. The compositions for debt arising from defamation, battery, and theft ("pacta de non petendo") especially are very ancient. But pacts of a positive content did not have a position sufficiently fixed to be considered as generally obligatory. They were open to the objection that they need not be considered as binding by the debtor. It was otherwise, however, when in answer to a formally worded question, one used the definite technical term "spondeo," "vas," or "pres," and thus gave his word the same value as a pledge of a thing. In this way the formal contract arose. In different countries a great diversity of such forms, of course, could come into being; but in the Aryan countries there would still be historical connections between these different terms which can be traced out.

\section{Real Acts}

... In the age when Themis and "fas" law dominates, the real act has, as is self-apparent, a high importance. Where there is no judge appointed by the State to protect one's claims, the security which one has for the phrsical taking and holding of things is all the more valuable. The transaction of sale, for example, apart from all legal protection, has its guaranty in that it is a cash operation, where the thing is not delivered until the price is paid. On the other hand, where one delivers the object of sale without receiving the price, then there is involved a relation of trust, as where a thing is leased to another; in which case, upon the expiration of the appropriate time, the thing may be taken back by force according to "fas" law. It is not my object to follow the dominion of real relations in all their points of view. But it is my purpose to enter in the inquiry, how in pre-ethnic GrecoItalic ages one is able to obtain real security apart from formal transactions. Undoubtedly the giving of pledges already served the purpose. But I shall examine this point more in detail later. However, reference must be made here to the pledge of the hand as a real act for the creation of a "fides" obligation, and its relation, on one side, to the giving of a pledge, and, on the other, the pledge of one's word already noticed, in a formal act.

The question as to what meaning the pledge of one's hand, the 
$\delta \in \xi \iota a$, the "data dextra," has had since aneient Aryan times, will seem to many als quite umprofitably raised. It is thought to be an alet so simple and so natural as to make any effort to extract from it a special meaning a mistaken labor. But the extending of the hand (like kising) is not so natural that it had the same meaning among all the peoples of the earth. And, with reference to those peoples which know the custom, it cannot be said that it also involves a special juristic significance. What has elsewhere [in the original work] been brought forward from Persian sources with regard to the Ancient Iranian contract doctrine is of great interest. It appeared there that the hand-pledge as a tie of "fides" had the same function as the giving of a pledge. The only difference is that in an actual pledge the thing which the pledgee receives for his security speaks for itself; and he can always make it plain by showing the pledge, that the debtor at the time of making the pledge acknowledged himself as under a duty to pay. In a hand-pledge the pledgee, of course, does not take with him the pledge; it is not chopped off. But this is no counter argument for the primitive legal mind. The hand even though it remains with the pledgor is none the less pledged. Ideally it is just as much pledged as if it were an independent object. In fact, the ideal sense of obligation is so firmly established that the pledgee, even when he is agent for another, can deliver the pledge in an ideal sense to his principal.

But the need of providing the hand-pledgee with a permanent token, as in the case of a real pledge, by which he can prove that at a certain time the hand was pledged, developed the practice of placing in the extended hand of the pledgee an object which the hand-pledgee retained as evidence of the obligation of "fides." I have already shown [elsewhere in the original work] that this ancient Iranian legal theory of contractual obligation coincides at all points with the Greek and Latin principles concerning the creation of the guest relation. Here, also, the purpose is to establish the bond of "fides" even though not involving a single proprietary" performance. It is always founded on $\delta \epsilon \xi \iota a$, , "data dextra." But a guest-present is also added as a permanent token of the concluded friendship, and it is also possible to establish an "hospitium " with an absent person by sending a guest-present. The similarity of the Iranian contractual obligation by means of a hand-shake and the Graeco-Italic guest-contract raises the supposition that the interpretation of the "dlata dextra" as a giving of pledge also rests on the same ancient Aryan legal conception. 
This supposition is in fact confirmed by our Roman sources. Even in later Rome this interpretation was not lost - giving the hand means giving consent; it involves the bond of "ficles"; one gives his hand as a pledge of performance; and the "dextra" is the embodiment of "fides." . . . And, again, since the "dextra" is the incarnation of "fides," the Greeks and Romans rearlily employed the "data dextra" in the highest form of "fides" obligation, the international alliance. . . . Furthermore, the hand is extended in salutation to indicate a friendly disposition when no alliance or contractual obligation is in question, beeause the "dextra" is the symbol of "fides."

We have found, despite the thick obscurity which hangs over the pre-ethnic contract doctrine, important connections between the Iranian contract theory, especially in its descent from the idea of giving pledge, and between the Roman conceptions of real acts. We have now to add to this discussion of ancient Arran formal and real acts two negative propositions which may be laid down with considerable assurance.

The first proposition is that even though the Romans carried along the ancient "fas" law ideas of the obligation of "fides" by means of "data dextra," still they did not adopt it in their system of civil contract law. They did not recognize any principle, such as that of the Persians, that invested every contract fortified with a hand-pledge with legal protection. Still, an important exception must be noted. The ancient Aryan usage of hand-seizure in the matrimonial ceremony is in itself the taking hold of "potestas," which the Romans earried as a survival into their matrimonial mancipation. But we have seen that from early times in the matrimonial ceremony of hand-seizure, there was visible the seed of the idea that it inrolved a mutual obligation of "fides." The farther the thought developerl that "consensus facit nuptias," the more clearly the notion was receiver among the Greeks and Romaus that the "dextrarum conjunctio" was the corporal expression of this consensus. To this extent we may say, also, that the "dextra data" as a "fides"-obligation act became a parcel of Roman civil law.

The second negative proposition relates to the formal act of pledging one's word, as we found it distinctly formulated in the Iranian contract theory. In my exposition of the elements of the formal act, I have intentionally dwelt on the word-pledge, because it corresponds with ideas of Germanic law. It is not eren entirely foreign to our present-day ideas to speak of "pledging 
one's word," or of "redeeming the given word." I But in the Loman sources I think no trace of such a conception can be found. The Roman interpretation of this matter - "spondeo," "vas," "pres" - rests on original foundations. We may accordingly draw the conclusion, that notwithstanding the wide extension of the "sponsio" act as well as the wager act throughout the various Aryan peoples, the Latin-Roman treatment of these contract forms developed under the preponderant influence of strictly national tendencies.

\section{SECTION 2}

\section{EARLY HISTORY OF CONTRACT ${ }^{2}$}

Neither Ancient Law nor any other source of evidence discloses to us society entirely destitute of the conception of Contract. But the conception, when it first shows itself, is obviously rudimentary. No trustworthy primitive record can be read without perceiving that the habit of mind which induces us to make good a promise is as yet imperfectly developed, and that acts of flagrant perfidy are often mentioned without blame and sometimes described with approbation. In the Homeric literature, for instance, the deceitful cumning of Clysses appears as a virtue of the same rank with the prudence of Nestor, the constancy of Hector, and the gallantry of Achilles. Ancient law is still more suggestive of the distance which separates the crude form of Contract from its maturity. At first, nothing is seen like the interposition of law to compel the performance of a promise. That which the law arms with its sanctions is not a promise, but a promise accompanied with a solemn ceremonial. Not only are the formalities of equal importance with the promise itself, but they are, if anything, of greater importance; for that delicate analysis which mature jurisprudence applies to the conditions of mind under which a particular verbal assent is given appears, in ancient law, to be transferred to the words and gestures of the accompanying performance. No pledge is enforced if a single form be omitted or misplaced, but, on the other hand, if the formscan be shown to have been accurately proceeded with, it is of no avail to plead that the promise was made under duress or deception. The transmuta-

${ }^{1}$ [Compare here the etymologies for " promise" and "pledge" eited in Chapter XXV (supra) Sec. 2-"The Pledge [dea."]

2 [By Sir Henry S. Maine. Reprinted from "Aneient Law," by permission of Henry Holt and Company, New York.] 
tion of this ancient view into the familiar notion of a Contract is plainly seen in the history of jurisprudence. First one or two steps in the ceremonial are dispensed with; then the others are simplified or permitted to be neglected on certain conditions; lastly, a few specific contracts are separated from the rest and allowed to be entered into without form, the selected contracts being those on which the activity and energy of social intercourse depend. Slowly, but most distinetly, the mental engagement isolates itself amid the technicalities, and gradually becomes the sole ingredient on which the interest of the jurisconsult is concentrated. Such a mental engagement, signified through external acts, the Romans called a Pact or Convention; and when the Convention has once been conceived as the nucleus of a Contract, it soon becomes the tendeney of adraneing jurisprudence to break away the external shell of form and ceremony. Forms are thenceforward only retained so far as they are guarantees of authenticity and securities for caution and deliberation. The idea of a Contract is fully developed, or, to employ the Roman phrase, Contracts are absorbed in Pacts.

The history of this course of change in Roman law is exceedingly instructive. At the earliest dawn of jurisprudence, the term in use for a Contract was one which is very familiar to the students of historical Latinity. It was nexum, and the parties to the contract were said to be nexi, expressions which must be carefully attended to on aecount of the singular durableness of the metaphor on which they are founded. The notion that persons under a contractual engagement are connected together by a strong bond or chain, continued till the last to influence the Roman jurisprudence of Contract; and flowing thence it has mixed itself with modern ideas. What then was involved in this nexum or bond? A definition which has descended to us from one of the Latin antiquarians describes nexum as omme quod geritur per as et libram, "every transaction with the copper and the balance," and these words have occasioned a good deal of perplexity. The copper and the balance are the well-known accompaniments of the Mancipation, the ancient solemnity described in a former chapter, by which the right of ownership in the highest form of Roman Property was transferred from one person to another. Mancipation was a conveyance, and hence has arisen the difficulty, for the definition thus cited appears to confound Contracts and Conveyances, which in the philosophy of jurisprudence are not simply hept apart, but are actually opposed to each other. The jus in re, right in rem, right "availing against all the world," or Proprietary 
liight, is sharply distinguished by the analyst of mature jurisprudence from the jus al rem, right in personam, right "availing against a single individual or group," or Obligation. Now Conveyances transfer Proprietary Rights, Contracts create Obligations - how then can the two be included under the same name or same general conception? This, like many similar embarrassments, has been oceasioned by the error of aseribing to the mental condition of an unformed society a faculty which pre-eminently belongs to an advanced stage of intellectual development, the faculty of distinguishing in speculation ideas which are blended in practice. We have indications not to be mistaken of a state of social affairs in which Conveyances and Contracts were practically confounded; nor did the discrepance of the conceptions become perceptible till men had begun to adopt a distinct practice in contracting and convering.

It may here be observed that we know enough of ancient Roman law to give some idea of the mode of transformation followed by legal conceptions and by legal phraseology in the infaney of Jurisprudence. The change which they undergo appears to be a change from general to special; or, as we might otherwise express it, the ancient conceptions and the ancient terms are subjected to a process of gradual specialisation. An ancient legal conception corresponds not to one but to several modern conceptions. An ancient techuical expression serves to indicate a variety of things which in modern law have separate names allotted to them. If, however, we take up the history of Jurisprudence at the next stage, we find that the subordinate conceptions have gradually disengaged themselves, and that the old general names are giving way to special appellations. The old general conception is not obliterated, but it has ceased to cover more than one or a few of the notions which it first included. So too the old technical name remains, but it discharges only one of the functions which it once performed. We may exemplify this phenomenon in various ways. Patriarehal Power of all sorts appears, for instance, to have been once conceived as identical in eharacter, and it was doubtless distinguished by one name. The Power exercised by the ancestor was the sime whether it was exercised over the family or the material property - over flocks, herds, slaves, children, or wife. We cannot be absolutely certain of its old Roman name, but there is very strong reason for believing, from the number of expressions indieating shades of the notion of pouer into which the word manus enters, that the ancient general term was manus. But, when Roman 
law has adranced a little, both the name and the illea have become specialised. Power is discriminated, both in word and in conception, according to the object over which it is exerted. Exercised over material commodities or slaves, it has become dominium - over children, it is Potestas - over free persons whose services have been made away to another by their own ancestor, it is mancipium - over a wife, it is still manus. The old word, it will be perceived, has not altogether fallen into desuetude, but is confined to one very special exercise of the authority it had formerly denoted. This example will enable us to comprehend the nature of the historical alliance between Contracts and Converances. There seems to have been one solemn ceremonial at first for all solemn transactions, and its name at Rome appears to have been nexum. Precisely the same forms which were in use when a conveyance of property was effected seem to have been employed in the making of a contract. But we have not very far to move onwards before we come to a period at which the notion of a Contract has disengaged itself from the notion of a Converance. A double change has thus taken place. The transaction "with the copper and the balance," when intended to have for its office the transfer of property, is known by the new and special name of Mancipation. The ancient Nexum still designates the same ceremony, but only when it is employed for the special purpose of solemnising a contract.

When two or three legal conceptions are spoken of as anciently blended in one, it is not intended to imply that some one of the included notions may be not older than the others, or, when those others have been formed, may not greatly predominate over and take precedence of them. The reason why one legal conception continues so long to cover several conceptions, and one technical phrase to do instead of several, is doubtless that practical changes are accomplished in the law of primitive societies long before men see occasion to notice or name them. Though I have said that Patriarchal Power was not at first distinguished according to the objects over which it was exercised, I feel sure that l'ower over Children was the root of the old conception of Power; and I camnot doubt that the earliest use of the Nexum, and the one primarily regarded by those who resorted to it, was to give proper solemnit. to the alienation of property. It is likely that a very slight perversion of the Nexum from its original functions first gave rise to its employment in Contracts, and that the rery slightness of the change long prevented its being appreciated or noticed. The old 
name remained because men had not become conscious that they wanted a new one; the old notion clung to the mind because nobody had seen reason to be at the pains of examining it. We have had the process clearly exemplified in the history of Testaments. A Will was at first a simple conveyance of Property. It was only the enormous practical difference that gradually showed itself between this particular conveyance and all others which caused it to be regarded separately, and even as it was, centuries elapsed before the ameliorators of law cleared away the useless encumbrance of the nominal mancipation, and consented to care for nothing in the Will but the expressed intentions of the Testator. It is unfortunate that we cannot track the early history of Contracts with the same absolute confidence as the early history of Wills, but we are not quite without hints that contracts first showed themselves through the nexm being put to a new use and afterwards obtained recognition as distinct transactions through the important practical consequences of the experiment. 'There is some, but not very violent, conjecture in the following delineation of the process. Let us conceive a sale for ready money as the normal type of the Nexum. The seller brought the property of which be intended to dispose - a slave, for example - the purchaser attended with the rough ingots of copper which served for money - and an indispensable assistant, the libripens, presented himself with a pair of seales. 'The slave with certain fixed formalities was handed over to the vendee - the copper was weighed by the libripens and passed to the vendor. So long as the business lasted it was a nexum, and the parties were nexi; but the moment it was completed, the ncrum ended, and the vendor and purchaser ceased to bear the name derived from their momentary relation. But now, let us move a step ouward in commercial history. Suppose the slave transferred, but the money not paid. In that case, the nerum. is finished, so far as the seller is concerned, and when he has once handed over his property, he is no longer nexus; but, in regard to the purchaser, the nexum continues. The transaction, as to his part of it, is incomplete, and he is still considered to be nexus. It follows, therefore, that the same term described the conveyance by which the right of property was transmitted, and the personal obligation of the debtor for the unpaid purchasemoney. We may still go forward, and picture to ourselves a proceeding wholly formal, in which nothing is handed over and nothing paid; we are bronght at once to a transaction indicative of much higher commercial activity, an cxceutory Contract of Sale. 
If it be true that, both in the popular and in the professional view, a Contract was long regarded als an incomplete Conreyance, the truth has importance for many reasons. The speculations of the last century concerning mankind in a state of nature, are not unfairly summed up in the doctrine that "in the primitive society" property was nothing, and obligation everything"; and it will now be seen that, if the proposition were reversed, it would be nearer the reality. On the other hand, considered historically, the primitive association of Converances and Contracts explains something which often strikes the seholar and jurist as singularly enigmatical, I mean the extraordinary and uniform severity of very ancient systems of law to debtors, and the extravagant powers which they lodge with creditors. When once we understand that the nexum was artificially prolonged to give time to the debtor, we can better comprehend his position in the eye of the public and of the law. His indebtedness was doubtless regarded as an anomaly, and suspense of parment in general as an artifice and a distortion of strict rule. The person who had duly consummated his part in the transaction must, on the contrary, have stood in peculiar favour; and nothing would seem more natural than to arm him with stringent facilities for enforcing the completion of a proceeding which, of strict right, ought never to have been extended or deferred.

Nexum, therefore, which originally signified a Converance of property, came insensibly to denote a Contract also, and ultimately so constant became the association between this word and the notion of a Contract, that a special term, Mancipium or Mancipatio, had to be used for the purpose of designating the true nexum or transaction in which the property was really transferred. Contracts are therefore now severed from Converances, and the first stage in their history is accomplished, but still they are far enough from that epoch of their development when the promise of the contractor has a higher sacredness than the formalities with which it is coupled. In attempting to indicate the charaeter of the changes passed through in this interval, it is necessary to trespass a little on a subject which lies properly beyond the range of these pages, the analysis of Agreement effeeted by the Roman jurisconsults. Of this analysis, the most beautiful monument of their sagaeity, I need not say more than that it is based on the theoretical separation of the Obligation from the Convention or Pact. Bentham and Mr. Austin have laid down that the "two main essentials of a contract are these: first, a signification by the promising party of his intention to do the acts or to observe 
the forbcarances which he promises to do or to observe. Secondly, a signification by the promisee that he expects the promising party will fulfil the proffered promise." This is virtually identical with the doctrine of the Roman lawyers, but then, in their view, the result of these "significations" was not a Contract, but a Convention or Pact. A Pact was the utmost product of the engagements of individuals agrecing among themselves, and it distinctly fell short of a Contract. Whether it ultimately became a Contract depended on the question whether the law annexed an Obligation to it. A Contract was a Pact (or Convention) plus an Obligation. So long as the Pact remained unclothed with the Obligation it was called mude or naked.

What was an Obligation? It is defined by the Roman lawyers as "Juris vinculum, quo necessitate adstringimur alicujus solvenda rei." This definition connects the Obligation with the Nexum through the common metaphor on which they are founded, and shows us with much clearness the pedigree of a peculiar conception. 'The Obligation is the "bond" or "chain," with which the law joins together persons or groups of persons, in consequence of certain voluntary acts. The acts which have the effect of attracting an Obligation are chiefly those classed under the heads of Contract and Delict, of Agreement and Wrong; but a variety of other acts have a similar consequence which are not capable of being comprised in an exact classification. It is to be remarked, however, that the Pact does not draw to itself the Obligation in consequence of any moral necessity; it is the law which annexes it in the plenitude of its power, a point the more necessary to be noted, because a different doctrine has sometimes been propounded by modern interpreters of the Civil Law who had moral or metaphysical theories of their own to support. The image of a vinculum juris colours and pervades every part of the Roman law of Contract and Delict. The law bound the parties together, and the chain conld only be undone by the process called solutio, an expression still figurative, to which our word "payment" is only occasionally and incidentally equivalent. The consistency with which the figurative image was allowed to present itself, explains an otherwise puzzhing peculiarity of Roman legal phraseology, the fact that "Obligation" signifies rights as well as duties, the right, for example, to have a debt paid as well as the duty of paying it. The Romans kept, in fact, the entire picture of the "legal chain" before their eyes, and regarded one end of it no more and no less than the other. 
In the developed Roman law, the Convention, as soon as it was completed, was, in almost all cases, at once crowned with the Obligation, and so became a Contract; and this was the result to which contract-law was surely tending. But for the purpose of this inquiry, we must attend particularly to the intermediate stage - that in which something more than a perfect agreement was required to attract the obligation. This epoch is srichronous with the period at which the famous Roman classification of Contracts into four sorts - the Verbal, the Literal, the Real, and the Consensual - had come into use, and during which these four orders of contract constituted the only descriptions of engagement which the law would entorce. The meaning of the fourfold distribution is readily molerstood as soon as we apprehend the theory which severed the Obligation from the Convention. Each class of contracts was in fact named from certain formalities which were required over and above the mere agreement of the contracting parties. In the Verbal Contract, as soon as the Convention was effected, a form of words had to be gone through before the "vinculum juris" was attached to it. In the Literal Contract, an entry in a ledger or table-book had the effect of clothing the Convention with the Obligation, and the same result followed, in the case of the Real Contract, from the delisery of the Res or Thing which was the subject of the preliminary engagement. The contracting parties came, in short, to an understanding in each case; but, if they went no further, they were not obliged to one another and could not compel performance or ask redress for a breach of faith. But let them comply with certain prescribed formalities, and the Contract was immediately complete, taking its name from the particular form which it had suited them to adopt. The exceptions to this practice will be noticed presently.

I have enumerated the four Contracts in their historical order, which order, however, the Roman Institutional writers did not invariably follow. There can be no doubt that the Verbal Contract was the most ancient of the four, and that it is the eldest known descendant of the primitive Nexum. Several species of Verbal Contract were anciently in use, but the most important of all, and the only one treated of by our authorities, was effected by means of a stipulation, that is, a Question and Answer; a question addressed by the person who exacted the promise, and an answer given by the person who made it. This question and answer constituted the additional ingredient which, as I have just explained, was demanded by the primitive notion over and 
above the mere agreement of the persons interested. They formed the ageney by which the Obligation was annexed. The old Nexum has now bequeathed to maturer jurisprudence first of all the conception of a chain uniting the contracting parties, and this has become the Obligation. It has further transmitted the notion of a ceremonial accompanying and consecrating the engagement, and this ceremonial has been transmuted into the Stipulation. The conversion of the solemn conveyance, which was the prominent feature of theoriginal Nexum, into a mere question and answer, would be mere of a mystery than it is if we had not the analogous history of Roman Testaments to enlighten us. Looking at that history, we can understand how the formal conveyance was first separated from the part of the proceeding which had immediate reference to the business in hand, and how afterwards it was omitted altogether. As then the question and answer of the Stipulation were unquestionably the Nexum in a simplified shape, we are prepared to find that they long partook of the nature of a technical form. It would be a mistake to consider them as exchusively recommending themselves to the older Roman lawyers through their usefulness in furnishing persons meditating an agreement with an opportunity for consideration and reflection. It is not to be disputed that they had a value of this kind, which was gradually recognised; but there is proof that their function in respect to Contracts was at first formal and ceremonial in the statement of our authorities, that not every question and answer was of old sufficient to constitute a Stipulation, but only a question and answer couched in technical phraseology specially appropriated to the particular occasion.

But although it is essential for the proper appreciation of the history of contract-law that the Stipulation should be understood to have been looked upon as a solemn form before it was recognised as a useful security, it would be wrong on the other hand to shut our eyes to its real usefulness. The Verbal Contract, though it had lost much of its ancient importance, survived to the latest period of Roman jurisprudence; and we may take it for granted that no institution of Roman law had so extended a longevity unless it served some practical advantage. I observe in an English writer some expressions of surprise that the Romans even of the earliest times were content with so meagre a protection against haste and irreflection. But on examining the Stipulation closely, and remembering that we have to do with a state of society in which written evidence was not easily procurable, I think we 
must admit that this Question and Answer, had it been expressly devised to answer the purpose which it served, would have been justiy designated a highly ingenious expedient. It was the promisee who, in the character of stipulator, put all the terms of the contract into the form of a question, and the answer was given by the promisor. "Do you promise that you will deliver me such and such a slave, at such and such a place, on such and such a day?" "I do promise." Now, if we reflect for a moment, we shall see that this obligation to put the promise interrogatively. inverts the natural position of the parties, and, by eflectually breaking the tenor of the conversation, presents the attention from gliding over a dangerous pledge. With us, a verbal promise is, generally speaking, to be gathered exclusively from the words of the promisor. In old Roman law, another step was absolutely required; it was necessary for the promisee, after the agreement had been made, to sum up all its terms in a solemn interrogation; and it was of this interrogation, of course, and of the assent to it, that proof had to be given at the trial - not of the promise, which was not in itself binding. How great a difference this seemingly insignificant peculiarity may make in the phraseology of contractlaw is speedily realised by the beginner in Roman jurisprudence, one of whose first stumbling-blocks is almost universally created by it. When we in English have occasion, in mentioning a contract, to connect it for convenience' sake with one of the parties, - for example, if we wished to speak generally of a contractor, it is always the promisor at whom our words are pointing. But the general language of Roman law takes a different turn; it always regards the contract, if we may so speak, from the point of view of the promisee; in speaking of a party to a contract, it is always the Stipulator, the person who asks the question, who is primarily alluded to. But the serviceableness of the stipulation is most vividly illustrated by referring to the actual examples in the pages of the Latin comic dramatists. If the entire seenes are read down in which these passages occur (ex. gra. Plautus, Pseudolus, Act I. sc. 1; Act IV. sc. 6; Trimmmns, Act V. se. 2), it will be perceived how effectually the attention of the person meditating the promise must have been arrested by the question, and how ample was the opportunity for withdrawal from an inprovident undertaking.

In the Literal or Written Contract, the formal act by which an Obligation was superindueed on the Convention, was an entry of the sum due, where it could be specifically ascertained, on the 
debit side of a ledger. The explanation of this contract turns on a point of Roman domestic manners, the systematic character and exceeding regularity of book-keeping in ancient times. There are several minor difficulties of old Roman law, as, for example, the nature of the Slave's Peculium, which are only eleared up when we recollect that a Roman household consisted of a number of persons strictly accountable to its head, and that every single item of domestic receipt and expenditure, after being entered in waste books, was transferred at stated periods to a general household ledger. There are some obscurities, however, in the descriptions we have received of the Literal Contract, the fact being that the habit of keeping books ceased to be universal in later times, and the expression "Literal Contract" came to signify a form of engagement entirely different from that originally understood. We are not, therefore, in a position to say, with respect to the primitive Literal Contract, whether the obligation was created by a simple entry on the part of the creditor, or whether the consent of the debtor or a correspondent entry in his own books was necessary to give it legal effect. The essential point is however established, that, in the case of this Contract, all formalities were dispensed with on a condition being complied with. This is another step downwards in the history of contract-law.

The Contract which stands next in historical succession, the Real Contract, shows a great adrance in ethical conceptions. Whenever any agreement had for its object the delivery of a specific thing - and this is the case with the large majority of simple engagements - the Obligation was drawn down as soon as the delivery had actually taken place. Such a result must have involved a serious innovation on the oldest ideas of Contract; for doubtless, in the primitive times, when a contracting party had neglected to clothe his agreement in a stipulation, nothing done in pursuance of the agreement would be recognised by the law. A person who had paid over money on loan would be unable to sue for its repayment unless he had formally stipulated for it. But, in the Real Contract, performance on one side is allowed to impose a legal duty on the other - evidently on ethical grounds. - For the first time then moral considerations appear as an ingredient in Contract-law, and the Real Contract differs from its two predecessors in being founded on these, rather than on respect for technical forms or on deference to Roman domestic habits.

We now reach the fourth class, or Consensual Contracts, the most interesting and important of all. Four specified Contracts 
were distinguished by this name: Mandatum, i.e. Commission or Agency ; Societas or Partnership; Emptio Venditio or sale; and Loeatio Conductio or Letting and Iliring. A few pages back. after stating that a Contract consisted of a Pact or Convention to which an Obligation had been superadded, I spoke of certain acts or formalities by which the law permitted the Obligation to be attracted to the Pact. I used this language on account of the advantage of a general expression, but it is not strictly correct unless it be understood to include the negative as well as the positive. For, in truth, the peculiarity of these Consensual Contracts is that no formalities are required to create them out of the Paet. Much that is indefensible, and much more that is obscure, has been written about the Consensual Contracts, and it has even been asserted that in them the consent of the Partie: is more emphatically given than in any other species of agreement. But the term Consensual merely indicates that the Olyligation is here annexed at once to the Consensus. The Consensus, or mutual assent of the parties, is the final and crowning ingredient in the Convention, and it is the special characteristic of agreements falling under one of the four heads of Sale, Partnership, Agency, and Hiring, that, as soon as the assent of the parties has supplied this ingredient, there is at once a Contract. The Consensus draws with it the Obligation, performing, in transactions of the sort specified, the exact functions which are discharsed, in the other contraets, by the Res or Thing, by the lerba stipulationis, and by the Literce or written entry in a ledger. Consensual is therefore a term which does not involve the slightest anomaly, but is exactly analogous to Real, Verbal, and Literal.

* $\begin{array}{lllllll} & * & * & * & * & * & *\end{array}$

The Consensual Contracts, it will be observed, were extremely limited in number. But it cannot be doubted that they constituted the stage in the history of Contract-law from which all modern conceptions of contract took their start. The motion of the will which constitutes agreement was now completelyinsulated, and became the subject of separate contrmplation: forms were entirely eliminated from the notion of contract, and external acts were only regarded as symbols of the internal act of volition. The Consensual Contracts harl, moreover, been elassed in the Jus Gentium, and it was not long before this classification drew with it the inference that they were the species of agreement which represented the engagements approved of be 
Nature and included in her corle. This point once reached, we are prepared for several celebrated doetrines and distinctions of the Roman lawyers. One of them is the distinetion between Natural and Civil Obligations. When a person of full intellectual maturity had deliberately bound himself by an engagement, he was said to be under a natural obligation, even though he had omitted some necessary formality, and even though through some technieal impediment he was devoid of the formal eapacity for making a valid contract. The law (and this is what the distinction implies) woukl not enforee the obligation, but it did not absolutely refuse to recognise it; and natural obligations differed in many respects from obligations which were merely null and void, more particularly in the ciremimstance that they could be civilly confirmed, if the capacity for contract were subsequently acquired. Another very peculiar doetrine of the jurisconsults could not have had its origin earlier than the period at which the Convention was severed from the technical ingredients of Contract. They taught that though nothing but a Contraet could be the foundation of an action, a mere Pact or Convention could be the basis of a plea. It followed from this, that though nobody could sue upon an agreement which he had not taken the precaution to mature into a Contract by complying with the proper forms, neverthcless a claim arising out of a valid contract could be rebutted by proving a comter-agreement which had never got beyond the state of a simple convention. An action for the recovery of a debt eould be met by showing a mere informal agreement to waive or postpone the payment.

The doetrine just stated indieates the hesitation of the Præetors in making their advances towards the greatest of their innovations. Their theory of Natural law must have led them to look with especial favour on the Consensual Contracts and on those Pacts or Conventions of which the Consensual Contracts were only particular instances; but they did not at once venture on extending to all Conventions the liberty of the Consensual Contracts. They took advantage of that special superintendence over procedure which had been eonfided to them since the first beginnings of Roman law, and, while they still declined to permit a suit to be launched which was not based on a formal contract, they gave full play to their new theory of agreement in direeting the ulterior stages of the proceeding. But, when they had proceeded thus far, it was inevitable that they should proceed farther. The revolution of the ancient law of Contract was consummated when 
the Pretor of some one year announced in his Eilict that he would grant equitable actions upon Pacts which had never been matured at all into Contracts, provided only that the Pacts in question had been founded on a consideration (causa). I'acts of this sort are always enforced under the adranced Roman jurisprudence. The principle is merely the principle of the Consensual Contract carried to its proper consequence; and, in fact, if the technical language of the Romans had been as plastic as their legal theories. these Pacts enforced by the Pretor would have been styled new Contracts, new Consensual Contracts. Legal phraseology is, however, the part of the law which is the last to alter, and the Pacts equitably enforcel continued to be designated simply Prætorian Pacts. It will be remarked that unless there were consideration for the Pact, it would continue mude so far as the new jurisprudence was concerned; in order to give it effect, it would be necessary to convert it by a stipulation into a Verbal Contract.

The extreme importance of this history of Contract, as a safeguard against almost innumerable delusions, must be my justification for discussing it at so considerable a length. It gives a complete account of the march of ideas from one great landmark of jurisprudence to another. We begin with the Nexum, in which a Contract and a Converance are blended, and in which the formalities which accompany the agreement are even more important than the agreement itself. From the Nexum we pass to the Stipulation, which is a simplified form of the older ceremonial. The Literal Contract comes next, and here all formalities are waived, if proof of the agreement can be supplied from the rigid observances of a Roman household. In the Real Contract a moral duty is for the first time recognised, and persons who have joined or acquiesced in the partial performance of an engilgement are forbidden to repurliate it on account of defects in form. Lastly, the Consensual Contracts emerge, in which the mental attitude of the contractors is solely regarded, and external circumstances have no title to notice except as evidence of the inward molertiling. It is of course uncertain how far this progress of lioman ideats from a gross to a refined conception exemplifies the neecessary progress of human thought on the subject of contract. The Contract-law of all other ancient societies but the Roman is either too scanty to furnish information, or else is entircly lost: and modern jurisprudence is so thoroughly leavened with the Roman notions that it furnishes us with no contrasts or parallels 
from which instruction can be gleaned. From the absence, however, of everything violent, marvellous, or unintelligible in the changes I have described, it may be reasonably believerl that the history of Aneient Roman Contracts is, up to a certain point, typical of the history of this class of legal eonceptions in other ancient societies. But it is only up to a eertain point that the progress of Roman law can be taken to represent the progress of other systems of jurisprudence. The theory of Natural law is exclusively Roman. The notion of the vinculum juris, so far as my knowledge extends, is exclusively Roman. The many peculiarities of the mature Roman Law of Contract and Delict which are traceable to these two ideas, whether singly or in combination, are therefore among the exclusive products of one partieular soeiety. These later legal conceptions are important, not because they typify the neeessary results of advancing thought under all conditions, but because they have exercised perfectly enormous influenee on the intellectual diathesis of the modern world.

\section{Section 3}

\section{SPONSIO AND PRIMITIVE CONTRACT 1}

In the early history of the "stipulatio," or rather of the "sponsio," one point appears to be now settled, viz., its religious nature. Its form, to be sure - which would have been originally an oath - is still in dispute. A recently advanced hypothesis of the correct translation of "stipulatio" — that this early word of religious usage signified "to complain on oath," i.e. to challenge the opponent and to make an offering ("stips," "stipula," some small object) to the deity ${ }^{2}$ - would give to it the same religious character, involving plainly the "sacramentum," the early sanction for the "sponsio."

But none of the scholars (so far as we are aware) has pursued the inquiry whether the rôle of the "sponsio" was in primitive times the same as we find it in the developed Roman law, viz. a form for giving obligatory effeet to all rarieties of legal relations by the utterance of the simple words, "Spondesne etc.? Spondeo." It is conceivable that the "sponsio" was not always

1 [Translated from an essay by Pol Collinet, Professor of the History of French Law in the University of Lille, and published in the "Mélanges Gérardin." a volume in honor of the 70th birthday of Professor Gérardin (Paris, 1907, Larose \& Tenin). The translation is by John H. Wigmore; some portions on the technique of Roman Law are onitted.]

"P. II unelin, "Stipulatio, stips, et sacramentum" (Naples, 1906, "Studi in onore di Carlo Fadda"). 
a generic "contract-factory" ; and its primitive purpose is what we now propose to inquire into.

\$1. Scantiness of Contract Transactions in Primitive Lau. It is difficult to believe that the primitive Italic peoples invented the "sponsio" as a general form of validity applicable to all varieties of simple agreements.

In the first place, the psychology of primitive peoples makes against this. Modern legal practice and theory is used to this method of using legal ideas. But primitive peoples do not begin by devising a general rule or principle capable of application to ail unlimited or numerous variety of situations. Every legal institution makes its first appearance in a single aspect only ; it is a species, not a genus. It is like a bacillus, which enlarges and propagates itself. Primitive men, like simple-minded moderns, are concrete. Whenever it was that they devised the broad verbal form of the "sponsio," they did not conceive of it as a general "contract-factory." Rather must we suppose that, when aiming to ralidate some specific agreement, they employed a formula which was concrete in their thought, though generic in its terms. It was reserved for their descendants, more advanced in legal ideas and more addicted to generalizations, to profit by this form of words.

In the second place, the "sponsio" could not have been invented to cover a group or species of transactions, but only to cover a single kind of promise. We must remember the rudimentary conditions of the Italic civilization as it existed before the foundation of Rome, and even into the fifth and sixth centuries of the Roman era. They did not need a generic legal form as a cloak for numerous kinds of simple contracts. We know that contract-transactions are few in all primitive communities. And in Italy there were already enough forms, scanty as they were, for the legal needs. They possessed the "nexum" and the "mancipatio," - these two reducible to the form of "per res et libram" ; this was little, but it was enough. The "mancipatio" was a sale for cash. Primitive peoples have not reached the sale on credit; as they emerge from the stage of barter, they devise the sale, but for cash, - a natural mode of transferring title. The archaic form for this was the transaction "per as et libram," - again, a natural enough form, as soon as money comes to be used, in the shape of ingots, measured by weight not by number. The sale for cash, then, was one of the oldest transactions. The moneyloan, which was perhaps not so old, was also practiced by the 
Italiots with this same form "per as et libram," and for the same necessary reason. But these two types of transaction sufficed, it would seem, for these primitive peoples. Why? Because most of the linown forms, real and consensual, of contract are not prchistoric, nor even "protohistoric," but are known to be of later date, - at Rome, specifically about the serenth century. 'This is true of sale (as a contract), letting, mandate, partnership, deposit, etc. We may go even further, and say that, among the contracts known to primitive Roman law, the one that is generally stated to be earliest, viz. the "nexum," cannot in our opinion be regarded as a true contract at all. ${ }^{1}$

In short, the view here advanced is that there was, in primitive Roman law, but one species of contract, viz. the "sponsio."

The Italiots were not making contracts. Their family chiefs had no commercial transactions with each other, except the sale and the money-loan; or, if there were such transactions, they were not recognized by any law; "fictes" alone controlled them. The main and suffieient explanation of this is the conditions of primitive life. Each family within its own circle satisfied its needs (few enough at that), and such transactions within the family were not within the purview of the tribal law, which aimed principally at regulating the relations between "patresfamilias," who were aliens to each other's family and perhaps to each other's gens. The same reasons also explain why (in our opinion) the "nexum" originally applied only to money-transactions; for though money might be had from another member of the same family, yet it would also often be necessary (especially when the family was poor or straitened) to resort to the head of another family to borrow; whereas such resort would seldom be had for borrowing products of the soil, because one's own family would be able to supply them, or if not, this would be because of bad harvests, which would probably have affected other families as well. ${ }^{2}$

1 This point, the precise nature of the "nexum," has been much discussed of late years; but it need not here be examined. See Girard, "Manuel élémentaire de droit romain," 4th ed., 1906, p. 480, n. 2. In our opinion, the "nexum" is a peculiar transaction which has no corresponding one in the developed law and therefore no term that exactly describes it. But that it is not a contract, i.e. does not create an obligation, in the strict sense, is plain. The "damnas esto" of the nexum does not generate a "dare oportere"; and it is not easy to see how the term "contract" can be applied to a transaction for which the procedural right of action lacks the technical "oportere." The latter word is indispensable to the idea of obligation; and it appears for the first time in the "sacramentum," which is the sanction for the "sponsio" and not for the "nexum."

2 The large land-owners, witl whom we later hear of " nexi" being made, did not exist in the primitive period. 
To sum up, the Italic community (as we must conceive it) had no need of the "sponsio" as a "contract-factory," because people did not make contracts.

\$2. The "Sponsio" as originally made in lieu of composition for a feud. - There was, however (we believe), one contract; and it must have been in frequent use. This transaction was the subject for the "sponsio."

Now the sources themselves tell us nothing directly as to the subject of the "sponsio"; there is extant only one passage (as also for the "litis contestatio") of a grammarian, - a passage vague and perhaps mutilated." But it is easy to construct an hypothesis, - solid enough, in that it is merely a deduction from the system of ideas now indisputably proved to have characterized the early history of law. It is this:

The subject of the "sponsio" must have been the promise to pay a sum of money representing the amount of a composition due to a person for a tort (feud).

The situation was this: After committing a tort, the wrongdoer owed a "pœna"; the amount was always fixed, either by the tariff of the law, or by a settlement with the injured party. If payment was made, well and good. But suppose that the wrongdoer had no money? Was the feud (which the settlement stopped) to recommence between the two families? No doubt it did, in the earliest times. But as the wholesome effort for social peace gained ground, in the early communes, then the mediators ("peace-makers," in the phrase of the old French custumals of the North) - elders, or priests, or soothsayers, or kings - would naturally seek a means of restraining that mutual destruction which would shed the blood and deplete the strength of their citizens. And the guilty party himself would naturally wish for a truce (like that of the "communes jurées" in the Middle Ages) until he could procure the money needed. At this point, would he not make a promise, when asked by the injured person or his chief of family? "Spondesne mihi centum dare?" "Spondeo."

And here we would have the "sponsio," the earliest true contract, and the only primitive one, - the promise to pay the pecuniary composition to stop a feud.

This simple idea readily explains (in our view) several features:

1. In the first place, the relation between the "sponsio" and the other two earliest transactions of Roman law - the "nexum"

1 See my article on "The Original Nature of the Litis Contestatio". ("Nouv. revue hist. de droit fr. et étr.," 1902, XXVI, 529). 
and the "mancipatio" - is now easy to detect. The wrongdoer who is to pay cannot obtain the money (from others than his own fimily) except by one of two means, viz. by selling some property of his own and paying his liability with the price received - in which case he will use the "mancipatio": or, by borrowing the sum needed, - in which case he must use the "nexum." We may even venture further, and assert that these two transactions would in general be needed only when it was a tort for which the familychief needed this money. For what other purposes could the money be needed? In primitive times, the other occasions for such expense are limited; agriculture calls for no investment of capital. The need of money in those primitive communities is exceptional.

2. The province of the Roman "cautio," or suretyship contract, was at the beginning no more specific, in our opinion, than that of the "stipulatio." The two contracts bore the same name, "sponsio." I It seems to us clear that the primitive surety-contract served solely to guarantee the promise of a wrongdoer liable for a composition. What other purpose it could serve is not apparent. Not that of a sale; for at liome the price of a sale, primitively, was paid in cash. Not that of a "nexum"; for the "cautio" by its very definition was accessory to some other obligation, and the borrower in the "nexum" incurred no obligation, in the technical sense ; moreover, the consequences of the "nexum" were positive enough not to need a surety. Looking at facts, we must conclude that, at Rome as clsewhere, the situation of the wrongdoer called for some mode of insuring payment to the victim; and to take a third person as surety was the natural expedient. Family solidarity placed upon the relatives the burden of taking up the feud either as attackers or defenders; what more natural than to bring about a peace, by either helping to pay the required sum or by joining in the promise to pay it?

3. Furthermore, our hypothesis serves to explain how the primitive subject of the "sponsio" and of its remedial action the "legis actio per sacramentım" (leading to the "legis actio per manus injectionem"), was a sum of money." This "legis actio"

"It would not he impossible that the "sponsio" was employed at first, as a species of "cautio," to furnish a third person's guarantee of the obligation of a wrongdoer, and as a well-rlefined instance of family solidarity, without having the wrongdoer himself enter into a "stipulatio." [Compare here the (iermanio: use of the "wadia" = promise, noted supra, Chap. XXY., 2, p. 45s, note 1.]

2 "This part is proved for the "manus iniectio," and probably also for the "sacramentum." 
developed, in historic times, an application to a "certa res" ; but in its origin it probably applied only to a money-claim, i.e. the amount of the "pœna" required to settle for a wrong. The later change would be explainable by" the corresponding enlargement in the province of the "stipulatio."

4. Finally, the immominate (generic) feature of the "sponsio" formula, as developed in later times (like that of the "sacramentum" and also of the "condictio"), would be perfectly compatible with its primitive rôle. For the "sponsio" formula, "mihi centum dare" etc., mentioned no "causa," or purpose, of the obligation, for the simple reason that this was needless; there was but one normal "causa," the purpose of settling the composition for a feud. ${ }^{1}$. . .

§3. Conclusion. - Our hypothesis, then, though not as firm as though it could be rested on specific texts, is nevertheless plausible enough. For it squares with the concerlerl features of primitive law and the important part played by the fanily feud and the composition. It satisfies our natural curiosity to complete the situation. The researches of those scholars who have sought to discover the origins of the Roman law of obligations, from the point of view of comparative archaic law, have neglected to trace into all its consequences this case where the wrongdoer or his family does not pay on the spot the composition demanded by the victim. 'These authors had in their mind's eye only the legal proceeding as replacing the private feud, and the primitive mode of enforcement by "manus injectio." The other alternative they did not work out, viz. the primitive contractual alternative, in which the wrongdoer promises to pay, if the victim is willing. This truce would suspend the legal proceeding. If this question had been raised, those authors conld not have failed to reply that the recourse here would have been to the "stipulatio"; for by their assumption it was from the very first a "contract-factory." We have here tried to show that the "sponsio" hard originally no other purpose than to embody this specific kind of contract. And this theory serves to complete our understanding of the primitive Roman svistem of composition for wrongs.

1 [The author here enlarges on certain details of Roman law theory and later history, as being not inronsistent with this hypothesis of the origin of the "sponsio." The extension of usage to a generic form he places at about the 5 th or 6 th century of Rome.] 


\section{Chapter XXviII}

\section{SALES AND LOANS AT ROME ${ }^{1}$}

\section{The Tuelve Tables}

The characteristics of early Roman law, as we find it, or suppose it to have existed, in the Twelve Tables, are formalism and rigidity.

All private dealings between man and man are, at this time, governed by two juristic acts: (1) 'mancipatio'; (2) 'nexum.'

1. Mancipatio.

Mancipatio is the solemn sale of early Roman law. In the presence of five witnesses (cives Romani puberes) a skilled weighmaster (libripens) weighs out to the vendor a certain amount of uncoined copper (aes, raudus, rauduseulum) which is the purchasemoner, and the purchaser, with solemn words, takes possession of the thing purchased as being his property.

Before the Twelve Tables, when there was as yet no coined money, the weighing out of the aes by the libripens constituted or, at any rate, might constitute the actual payment of the purchasemoney. Maneipatio was not an 'imaginaria venditio,' but a genuine sale. But the decemviri introduced coined money into Rome. 'The first coin used was the copper 'as,' the silver denarius not being introduced till 269 B.c. 'These changes, however, did not affect the formalism of mancipatio. The libripens and the weighing still remained, in spite of the fact that the weighing out of uncoined aes had ceased to constitute parment. For the payment implied in the ceremonial of mancipatio was now a purely fictitious one, and the actual payment was a matter quite independent of the mancipatio. Hence the enactment of the Twelve Tables that no mancipatio should be legally operative unless the price were actualy paid or, at least, security given for it. Thus mancipatio continued to be a real sale, and on principle it was a sale for ready

${ }^{1}$ [By Rudolph SoHm. Reprinted by permission from "The Institutes of Roman Law" (Ledlie's trans.), Oxford University Press, 1392.] 
money, a narrowly circumscribed transaction clothed in rigid formalities and only available for a single economic purpose. The mancipatory sale was the only valid form of sale which was known, and was thus at the same time the only private legal transaction by which, at this stage of the jus civile, property could be convered. No alienation of property, therefore, was legally valid unless it satisfied the following conditions: it must be for valuable consideration; it must be done in the presence of five witnesses and the libripens; the thing to be alienated must be before the parties, and only so many things ean be alienated in any one transaction as the purchaser can take hold of (manu eapere) at one and the same time. Thus if more things are to be mancipated than the alienee can take hold of at once, the whole eercmony of mancipatio must be repeated anew each time. ${ }^{1}$ Such was as yet the clumsy and backward condition of the law which governed the ordinary dealings between man and man.

2. Nexum.

Next to mancipatio we have, in the second place, the 'nexum,' or solemn loan. In the presence of five witnesses the libripens weighs out to the borrower the eorresponding amount of raw metal, and the lender at the same time declares in solemn words that the borrower is now in his debt (dare damnas esto). The borrower is now under an obligation to repay. He is saill to be 'nexus' to his creditor, i.e. he has directly pledged his own person for reparment of the loan, and thus stands already in precisely the same position as a judgment debtor. Here, again, the effect of the introrluction of coinert money is that the loan, as executed in the nexum itsclf, is a mere form, the actual loan being an independent matter. Nevertheless, as in the case of maneipatio, so here, the material character of nexum as a transaction subserving one definite purpose onl $y$, remains intact. For nexum cannot be employed to ereate any kind of debt, but solely a debt based on a loan. ${ }^{2}$ Thus we see that the law of contraet, too, is narrow and meagre, like the whole life of this early period.

1 It appears from a document recently discovered in Pompeii that eren in the first rentury of our era it was necessary, in mancipating several slaves, to repeat the whole manripatio ceremony specially for earlo separateslave. Cp.Eck, vol. 1, p.ST (Romanist. Abt.) of the "Zis. der Sav. St."

2 This follows from the legal rules ahout nexi liberatio. It appears. therefore. that in nexum as well as in mancipatio the material character of the transaction must have been hrought out in the eeremonial in some way or other, so that just as the purchaser did net acquire ownership by the bare form of mancipatio alone, so liere the debtor did not ineur an obligation by the hare form of the nexum alone. 
We have stated that mancipatio is a ready money transaction. It does not, as such, bind the purchaser to pay the price, but only makes such payment a condition precedent to the passing of ownership. Nexum, on the other hand, is a transaction on credit. Its effect is to place the borrower under an obligation to repay. If he fails, the debt will be followed by execution.

Execution proceeds directly with inexorable rigour against the person of the debtor. He falls into the power of his creditor, who may bind him and cast him into chains. After having thrice publicly invited some one to come forward and release him, the creditor may - in default of any one appearing, and after the lapse of sixty days - regard the debtor as his slave, and may either kill him or sell him 'trans Tiberim,'i.e. into a foreign country, say, Etruria. If several creditors have claims upon one and the same debtor, the law allows them to cut the debtor into pieces, and provides that a mistake in the division shall in no wise prejudice their rights.

The rigour of the private law finds its counterpart in the rigour of the family power. Within his family the paterfamilias is an absolute sovercign; he has power over the life and liberty of any member of the household. The only external checks on the exercise of his legal rights are furnished, not by the law, but by religion and custom.

\section{The Interpretatio}

The Twelve Tables had exhibited early Roman law in a form corresponding to its tendency, the form, namely, of a popular statute.

In the original stages of its development the law of Rome, like that of other nations, was of the nature of customary law. The Romans, however, looked upon customary law as an inferior kind of law. Their innate sense of form conld not rest satisfied with a speeies of law which is comparatively intangible, formless, and difficult of proof. True, there were some rules of customary origin which possessed the full force of law (legis vicem), rules resting on immemorial usage which the legal habits of the nation had gradually shaped into precision. But, generally speaking, it was held that the magistrate in administering justice was not absolutely bound by rules of mere customary law, and that in dealing with such rules he was justified, within certain limits, in exercising his free liscretion. But a Lex (publica), i.e. a rule of law which magistrate and people had agreed upon by means of a solemn dec- 
laration of consensus, was a different matter. ${ }^{1}$ The authority of a lex was irrefragably binding on the magistrate.

In the Twelve Tables, Roman law had, to a considerable extent, received the form of a lex. ${ }^{2}$ It is to this fact that the suceess and popularity of the decemviral legislation is due. So far as it was codified, at any rate, the law was now secure from the arbitrary powers of the magistrate who alministered it.

The decemviral legislation being accomplished, the energies of the three succeeling centuries were concentrated in the task of thoroughly working out its eontents. During the Republic, changes by statute, in matters of private law, were exceptional, and the function of interpreting and, at the same time, developing the laws of the Twelve Tables was left, in the main, to the operation of the existing legal agencies. The periot of legislation was followed by the period of interpretation.

The exigeneies of commerce demanded new regulations. How to represent these new regulations as virtually eontainet in, and covered by the statutory foree of, the law of the Twelve Tables, was thus the problem to be solved. The notion of formally superseding the law of the Twelve Tables, which was statutory, by conflicting rules of law, which were merely customary, would, at that time, have appeared well-nigh inconceivable to the Romans. For

${ }^{1}$ Lex (Icelandic: lag, lög; Frisian: laga, lag, log; Anglo-Saxon : lagu, lah; Saxon: lach; English: law) means literally that which is 'laid' or 'fixed,' in other words, 'a statute.' In the language of the Romans lex means anything which is 'laid down' or 'settled,' and which, being proposed in a certain form by one party, is accepted by the other (e.g. the 'lex commissoria '). A 'lex publica,' then, is a covenant, or statute, proposed by the magistrate and accepted by the people, which linds the community in virtue of this reciprocal declaration. Cp. Hommsen. "Röm. Staatsrecht," rol. 3, pp. 303, 309; A. Pernicc, "Formelle Gesetzo in Römischen Recht" (Festgahe für Gneist), 18SS.

${ }^{2}$ Some isolated laws were made as early as the regal period. Servius Tullius, for instance, is credited with some laws on contracts and delicts. The 'leges regiae,' however, which were collected in the so-called 'jus civile Papirianum' (probably a private compilation dating from the close of the Republic), owe their name, in all probability, merety to the fact that the regulations they contain were plared under the immediate protertion of the kings (in precisely the same way as the name of 'royal laws' was applied to early Attic regulations of ceremonial ritual, merely berause their administration was the official duty of the Archon Basileus; $"$. R. Scholl, pp. 8S, 89 of the "Sitzungsberiehte der Bärerischen Alialemis" d. Wissensehaft," ISS6). These 'leges regiae' are conecrned, in the main. with 'sacred' matters, i.e. they are essentially of a loligious and moral charaeter, and hear clear testimony to the closeness of the original connextion between law and religion. It is probable that, in substaner, the majority of them actually date back to the time of the Kings. Brums. "Fontes," p. I ti.; ilommson. "Röm. Staatsrecht," rol. "Bd rod.).

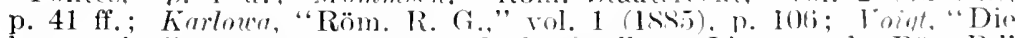
leges regiae" (1sti); P. Krüger. "C̈. der Quellen u. Literatur des Röm.R." (1SS8), pp. 4-S; Jörs, "Röm. RW." (1SSS). p. 59 ff. 
throughout the long period of one thousand years, extending down to the final stage in the development of Roman law, i.e. down to the Corpus juris civilis of Justinian, the legal force of the Twelve Tables, as the source of all Roman law, was all along regarded as remaining, in theory, unimpaired, in spite of the fact that, when the end came, there was not a stone in the entire structure of the decemviral laws but had long been displaced from its original position. And this was quite in kecping with the conservatism of the Romans and the extreme caution with which they proceeded in all matters of law. Not one letter of the Twelve Tables was to be altered, and yet the new spirit was to be infused into the old letter. The decemviral legislation being complete, the time had arrived for an 'interpretatio' which should develop and even alter the law, but should, at the same time, leave the letter of the law intact.

The period of interpretation covers the later centuries of the Republic. At the outset the work of interpreting the law, i.e. of carrying on, in its initial stage, the development of the jus civile, was performed by the pontiffs. It was regarded as the special professional duty of the pontiffs to preserve the knowledge of the laws of the Kings. In consequence more particularly of the knowledge they thus possessed and also of their general scientific learning, it became their office to assist with legal advice not only magistrates in regard to the exercise of the jurisdiction vested in them, but also private parties in regard to the steps to be taken in concluding contracts and carrying on lawsuits. Thus it happened that the business of interpreting the subsisting law, and thereby developing the civil law, fell under the control of the pontiffs.

It was by' means of such interpretation that the so-called 'In Jure Cessio' was now developed. In jure cessio was a new way of conferring a legal title by means of a fictitious lawsuit before the magistrate. The beginnings of in jure cessio probably date back to a time anterior to the laws of the Twelve Tables, but its full development belongs to a period subsequent to these laws. The Twelve Tables provided that whenever one party to an action, at the suit of the other, at once admitted his opponent's title in person before the magistrate ('in jure'), no judgment should be required, and the party confessing should be regarded as already condemned (confessus pro judicato est). 'The confession before the magistrate had the force of a judgment. Thus, in a suit about ownership, the magistrate could at once proceed to award the thing to the plaintiff (the 'adclictio'). In other worls, if a person confessed before the magistrate that his opponent in the action was the owner, he was 
divested of his ownership, if at the moment of the confessio he was still owner. This suggested a general method for transferring ownership. If A desired, on any legal ground whatever, to transfer his ownership in a thing to $\mathrm{B}, \mathrm{A}$ and $\mathrm{B}$ would go before the magistrate, $\mathrm{B}$ (the intended transieree) would claim ownership), $\mathrm{A}$ (the intended transferor) would admit his title, and the magistrate would then pronounce his award (addictio) in favour of the transferee. Thus the transferor was divested of his ownership and the transferee was invested with it. A rule of procedure (confessus pro judicato est) had been utilized for developing a new kind of private juristic act, the act of transferring ownership by means of a fictitious vindicatio (in jure cessio), and one the validity of which could be represented as resting on the Twelve Tables. The same process could be utilized for the purpose of establishing patria potestas and effecting the manumission of a slave by means of a fictitious vindicatio 'in patriam potestatem' and 'in libertatem' respectively. Thus in jure cessio became the medium through which a whole host of new juristic acts were introduced into the working system of Roman law.

Another juristic act was developed in a similar manner by utilizing a penal provision of the Twelve Tables. This was the 'emancipation' of the filiusfamilias. The Twelve Tables enacted that, if a father sold his son thrice into bondage, he should suffer the penalty of forfeiting his patria potestas.

The 'interpretatio' utilized this rule. The father might sell his son, by a purely imaginary sale, thrice repeated, into the bondage of another who would manumit the son after each sale by means of in jure cessio. The effect of this transaction was the 'emancipation' of the filiusfamilias, i.e. he was discharged from the paternal power ; for the conditions required by the Twelve Tables had been complied with. The father had thrice sold his son into bondage, consequently the son was now free from the paternal power. A different adaptation of the same penal rule led to the development of the 'datio in arloptionem.'

Of all the changes the most important was the transformation which mancipatio underwent in the course of the century subsequent to the Twelve Tables. The Twelve Tables enacted: XII Tab. VI. I: Cum nexum faciet mancipiumque, uti lingua nuncupassit, ita jus esto.

That is to say, the formal juristic act was to operate in the manner defined by the solemn oral declaration (nuncupatio). Utilizing this rule, the interpretation changed the nature of 
maneipatio. It was the intention of the Twelve Tables that mancipatio should be a genume sale, and it was essential for its validity that the purchase-money, as specified in the mancipatio, should be actually paid down. But there was nothing to prevent the parties from naming in the ceremony of mancipatio, not the real price, but a fictitious one, and the parment of this price would suffice to eall into play the operation of mancipatio as a legal converance, and thus, at the same time, to evade the rule as to the necessity of paying the price. And this is what actually happened at a later stage. The outcome of this device was the so-called 'mancipatio sestertio nummo uno.' In the mancipatio a declaration was made that the thing was being sold for 'one sesterce,' and, the alience having paid his sesterce, ownership passed to him in virtue of the Twelve Tables. So far then as mancipatio took the form of a 'mancipatio sestertio nummo uno,' it had passed from a genuine to a purely fictitious sale (imaginaria venditio).

The result was that mancipatio developed into a general mode of conveying ownership as such, quite irrespective of the legal ground on which such converance took effect. It could now be employed for a variety of purposes. It was, for instance, available for the purpose of making a gift. But there was another and a more important use to which it could be turned: the so-called 'mancipatio fiduciae causa' had now become practicable. This mancipatio fiduciae causa, or, brieflyr, 'fiducia,' was a qualified mancipatio which imposed a duty on the transferee, and it was a transaction, the nature of which rendered it conveniently available for economic purposes of the most multifarious kinds. Thus the change from the old mancipatio to the new was the change from a transaction narrow in character and circumscribed in application, to one free from inward restrictions and capable of adaptation to an indefinite variety of uses.

'Fiducia' is an agreement of trust, whereby the transferee in a mancipatio undertakes, to divest himself of the ownership which has been conveyed to him, and more especially - in certain circumstances - to remancipate the thing he has received.

Suppose, for instance, that a debtor desired to give his creditor a pledge. A transaction by which a person made his property simply liable for an existing debt, in our sense (a 'hỵpothec'), was unknown to early Roman law. But mancipatio in its new shape would meet the necessities of the case. The debtor mancipated the thing to the creditor 'for one sesterce,' and thus constituted him owner by means of an imaginary sale. But the creditor held the legal owner- 
ship subject to a 'trust' (fidei or fiduciae causa), and the fiducia was to the effect that on parment of the debt the creditor should reconvey ('remancipate') the thing to the debtor. The creditor thus got his security, and meanwhile he was the owner of the thing pledged. But as soon as the debtor discharged the elebt, the firlucia or trust-clause gave him a right to claim the thing back agan. Other agreements could be concluded in the same way. In the case of the pledge just described there was a "fiducia cum creditore contracta.' In precisely the same manner the so-called 'fiducia cum amico contracta' could be used for the purpose of effecting a depositum, commodatum, or mandatum in accordance with the forms of the civil law. Thus, whether the thing were delivered for safe custody - as in the case of depositum - or for specific use, as in the case of commodatum; or, again, were delivered on terms that the transferee should, for instance, sell it, or give it to a third party, or (if the object were a slave) should manumit such slave - as in the case of mandatum - in all such cases the transferor (deponens, commodans, mandans) made the transferee (depositarius, commodatarius, mandatarius) formally owner of the thing delivered, but the ownership was held subject to a trust, 'fiduciae causa'; it was purely formal, and involved an obligation to abide by the terms of the agreement on which the mancipatio was based.

There was no reason why the agreement that ownership should pass subject to a trust, should not be set forth in the formula used in the mancipatio (the 'nuncupatio'). The existence of a fiduciary duty was thus clearly established by the solemn act itself, but to embody the entire agreement in the nuncupatory formula was scarcely feasible. The mancipatio itself, therefore, said nothing about the terms of the trust; for these it was necessary to look to the 'pactum conventum,' a formless collateral agreement. But, according to early Roman law, no action can be taken on a formless pact. Is then, a 'pactum fiduciae' actionable or not? The early. jurists argued this way. Inasmuch as the pactum conventum as such is not actionable, that which is promised in the pactum cannot, as such, be enforced by an action. But the duty to deal with the object 'in good faith' is actionable. Haring been clearly set forth in the solemn mancipatio this duty falls, of course, under the protection afforded by the rule of the Twelve Tables: "utilingua nuncupassit, ita jus esto.' The transferee thus became liable to an 'actio fiduciae.' It is important to observe what it was precisely that the plaintiff in this action conld require the defendant (i.e. the transferee in the mancipatio) to do. He could not call upon him to do 
what he had promised in the pact, because the pact had not been 'nuncupated.' But he could call upon him to do that which any honourable and trustworthy man could be reasonably expected to do having regard to the circumstances of the case, the most important of which was, of course, the pactum conventum itself. In other words, what the judge had to find out was not whether the defendant had acted up to the precise terms of the pact - for the pact being formless, its terms were still quite unenforceable - but whether the defendant had conducted himself in such a way, 'ut inter bonos bene agier oportet et sine fraudatione.' Since the pactum conventum lay outside the solemn mancipatio, the fiducia did not give rise to an actio stricti juris, but to a so-called 'actio bonae fidei,' i.e. the extent of the obligation which it produced was not fixed by any hard and fast line, but rather by the judge exercising, within fairly wide limits, his free judicial discretion. In fiducia we have the first recognized instance of a contract different in kind from the legal transactions which had been handed down from olden times. For the extent of the obligation engendered by these transactions was rigorously determined by the letter of the agreement; in fiducia, on the other hand, it was equitably determined in accordance with the free discretion of a 'bonus vir,' taking into account all the circumstances of the case. It was a contract which placed the existence of a liability beyond all doubt, but which was neither designed nor able to fix, in set terms, its precise contents.

Thus the interpretation of the Twelve Tables, in dealing with mancipatio, the formal, rigorous, ready-money sale of the early law, had produced a twofold result:

(1) It had developed a formal method for conveying ownership for any purpose whatsoever ;

(2) It had developed a whole series of transactions (negotia bonae fidei) based upon credit, being the various cases of fiducia, which were concluded 're,' by performance, that is, by mancipation (sestertio nummo uno).

With regard to Nexum, no corresponding development took place. Nexum remained what it had been, a loan-transaction, and was subsequently superseded as such by the formless loan called 'Mutuum.' The sole trace of the original severity of the formal contract of loan is to be found in the fact that mutuum was a negotium stricti juris. It was reserved for 'Stipulatio' to supply a type for all agreements in which the solemn promise of the debtor gives rise to a rigorously unilateral obligation quite irrespective of 
the legal ground on which such obligation is based. Stipulatio was the outcome of the ancient 'sponsio,' and resembled nexum in so far as the underlying idea in both was originally a kind of selfpledge; but it differed from nexum in that the pledge implied in stipulatio could only be enforced by the gods. ${ }^{1}$

As the mancipatio fiduciae causa supplied the foundation for the negotia bonae fidei of a later period, so nexum is the type and basis of the negotia stricti juris, i.e. transactions which generate a rigorously unilateral obligation and leave no latitude to the discretion of the judge.

\section{The Beginnings of the Jus Gentium}

From the earliest times there must, of course, have existed in Rome, side by side with the formal juristic acts which alone enjoyed the sanction and force of the jus civile, a countless variety of transactions which were despatched without any form whatever. It happened, as a matter of course, that many a sale was made by simple delivery of the article and payment of the price, many a loan, too, contracted by simple handing over of the money, and so on. In other words, there were informal sales, loans, deliveries (with a view to transferring ownership in things), and so forth. But according to the early civil law all these informal proceedings were totally devoid of legal validity. That which was effected by an informal sale was, of course, a transaction, but not a juristic transaction. Thus if $\mathrm{A}$ sold and delivered something to $\mathrm{B}$ which did not belong to him, and B were evicted by the true owner, he had no action against $A$. There was no question of law at all; the whole relationship between $\mathrm{A}$ and $\mathrm{B}$ was purely one of fact, and might, in this respect, be compared to our position in dealing with savage tribes. We may sell to them, and barter with them, but no legal relations, no actionable rights, are called into existence.

1 Sponsio was the name originally given to a contract which was concluded by a libation, i.e. by a formal self-denunciation, to the following effect: - Even as this wine now flows, so may the punishing gods cause the blood of him to flow who shall be the first to break this covenant. (Cp. Leist, "Gräco-italische Rechtsgeschichte" (1S84), p. $457 \mathrm{ff}$.$) . The$ original obligation created by such a promise was a purely moral, or religious one, partaking largely of the nature of an oath. It was not till later that it assumed a legal character. When Cicero says that to 'spondere, promittere' is to 'obligare fidem,' his words seem to point to some surviving notion of a pledge of one's moral self (cp. A. Pernice, "Laheo," vol. i. (1873), p. 408). German law confirms the vien that all the oldest contracts originated in some kind of pledge (obligatio), whether of one's person or of portions of one's property. ('p. e.g. J. Kohler, "Shalispeare vor dem Forum der Jurisprudenz," vol. i. (18\$3), p. 52 fi.: Heusler, "Institutionen des deutsehen Privatrechts," vol. i. (1585), p. 104. 
There was, however, one element which was bound, in the long run, to secure the legal recognition of these formless transactions. This element was the foreign trade, in so far as it was carried on within the confines of Rome. Every alien, i.e. non-citizen, was, as such, absolutcly debarred from the use of any of the formal juristic acts of early Roman law. Mancipatio as well as nexum was, on principle, null and roid, if one of the parties, nay, if one of the witnesses, were without the Roman civitas. Thus, even though a foreign merchant, i.e. one who did not enjoy the privileges of Roman citizenship, were quite willing, in doing business in Rome, to observe the forms, say, of mancipatio, it would have been useless, because the mancipatio would have been none the less void. The result was that the commercial dealings of aliens in Rome, including therefore, the dealings of aliens with Roman citizens, were at all times confined, without option, to the formless transactions just referred to. For aliens these were the only juristic acts. Of course such a srstem could not last. 'The commercial transactions of the foreign merchants could not remain permanently outside the pale of the law, and some method had to be devised by which they should obtain legal validity not only if both parties were aliens, but also if one of them were a Roman citizen. Inasmuch, moreover, as even Roman citizens, among themselves, were making daily and habitual use of these informal acts, it was quite obvious that their gradual recognition by the law was a matter of pressing importance to citizens and aliens alike.

At a subsequent period the law under which aliens traded in Rome assumed a shape which served to bring out the full significance of the process with which we are here concerned. In the course of the first centuries of its history (down to about 250 B.c.), the lioman community frequently concluded international and commercial treaties with other states (as, for example, Carthage), members of which were permitted to engage in commerce in the Roman market. By these treaties legal protection and legal capacity were reciprocally guaranteed to members of the communities concerned, the legal protection being secured in Rome by means of the courts of 'recuperatores.' . . . In Rome a special judge for foreigners, a 'praetor peregrinus,' was appointed in 242 B.c. This marks the final victory of the movement. We have now a law for the citizen, as such, the jus civile, and, beside it, a law for the alien, as such, the jus gentium. Thus there sprang from the intercourse with foreigners thesecond great power in the workingsistem of Roman law, viz. the jus gentium, and it was the very exclusion 
of aliens from the privileges of the jus civile which rendered the birth of the new force possible. It is certain that the contents of the jus gentium were largely determined by the example of such laws as had come to regulate the rights of aliens in other commercial centres of the age. The legal convictions of foreign nations struck root in Rome itself and appeared in the form of the jus gentium. In addition to this, we must not fail to bear in mind that from this same time onwards the ancient national character of Rome was steadily yielding to the inroads, increasingly powerful, of foreign, more especially Greek, elements bearing within them the whole accumulated force of Hellenic culture. The whole world came, so to speak, to make Rome its capital, and with it came the jus gentium, a law, not for any particular state, but universal; a law not merely for the citizen, but for the private person as such. The jus gentium came to fulfil its twofold rocation. It was destined not only to shape and determine the legal rights of aliens in Rome, but also to guide and direct the Roman civil law itself. For by securing the legal recognition of formless transactions, i.e. such as depend for their effect not on any form, not on something visible, external, or tangible, but rather on the will of the parties themselves, the jus gentium was laying down the lines of a new development for the law governing the ordinary dealings between Roman and Roman.

In this way it gradually came to be acknowledged that legal ownership (in res nec mancipi) could be validly acquired by means of a formless traditio. The only qualification seems to have been that such traditio, in order to pass ownership, must take place in pursuance of a sale, and the purchaser must have actually paid the price. For the rule of the Twelve Tables that no ownership conld pass to the vendee unless he actually paid the price or were given credit for it by the vendor, was deemed to apply, in an equal measure, to the transfer of ownership by traditio. The principle that, in sales, ownership could pass by traditio, was then extended from sales to traditio in general, provided only the parties had concluder some transaction which placed the intention to convey ownership berond doubt. Thus the necessity for a solemn mancipatio was, in the end, confined to certain classes of things only, viz. those comprised under the collective name of 'res mancipi' in dealing with which it seems probable that, from the oldest times, mancipatio was, as a matter of fact, almost universally employed. Those 'res' comprised all such things as constituted, properly speaking, a farmer's stock-in-trade: lis land (fundus Italicus), his slaves, 
his live-stock (beasts of draught and carriage). All other things were 'res nec mancipi,' so that simple delivery (traditio) was sufficient for the purpose of conveying ownership. Such would be, e.g. money, articles of dress, tools, etc., in short, all such things as were intended not so much for permanent possession as for commercial intercourse.

In the same way as informal traditio thus obtained the sanction of law, so informal sales, loans, etc., gradually secured legal recognition.

Theold-fashioned formalities of the Roman jus civile found themselves confronted with the exigencies of a world-wide commerce. The new demands which had thus arisen had won their first victory towards the close of the Republic by securing the recognition of a number of formless juristic acts. The whole future course of development was virtually involved in this recognition. Thus the end of the Republic marks the commencement of that process by which the local law of the city of Rome was gradually converted into that which Roman law was destined, at a future time, to be, viz. the general law of the civilized world. 


\section{Chapter XXix}

\section{INTEREST ${ }^{1}$}

1. Just as in the law of things there is a right of security as well as a right of servitude, so too in the law of obligations there is a barter of value ("Werttauseh"), that is to say, a value, a money value being given for a money value. But as value and value are naturally equivalent, the exchange can only take place with a difference in time: one and the same value takes on a different significance when present value and future value stand opposite each other. Thus, all business that has to do only with money values is a business that exchanges a present for a future value.

2. In the closest relation to the use of capital stands the theory of interest. In the life of primitive peoples, where the production of value is generally agricultural and little free or available capital is found, the loan is nearly always consumable in its nature: it is given either in moments of dire need, or in moments of recklessness. In this case, it is comprehensible if it is thought to be hard if neighbors and members of the same tribe require the return not only of the capital, but of something more as well. A man should aid his neighbor, and not make his necessity a source of profit; and if he abets his recklessness, the matter should be so arranged that he suffers by it as little as possible. This is the origin of the rule that forbids the taking of interest. The prohibition accords with the times in which the use of free capital was rare.

3. But it continued in later periods, and in this, two motives were concerned. First, a speculative one, the idea that the future is still a zero, and cannot be made the object of agreements ; something that is now present should not be given for something that thus belongs to the future. This idea has been carried out

"[Reprinted, by permission, from Josef KoHLEr, "Philosophy of Law" (Albrecht's trans.), Boston Book Company, 1914 (Philosophy of Law Series, Vol. XII).] 
by the nations even in regard to interest; and they have assumed, that in this respect, tralling with future values is still less admissible than where physical products are eoncerned. For, even if free capital brings advantages, yet these are not as tangible as products; they are profits that appear sometimes in one way, sometimes in another; profits that are difficult to separate from the results of work and the success of speculation. Hence, they are less the subject of agreements than are future physical products; and, thus, the idea of the sterility of money develops, an illea which the Scholasties of the Middle Ages spun out to great lengths.

4. In additional motive was the inherent impulse to increase individual activity, and to prevent the individual from retiring with the proceeds of his principal. In this respect, the prohibition of taking interest long exercised a fayorable influence. Anyone who has available capital should seek to make use of it himself, in agriculture, industry, or trade; the division between capital and labor that exists to-day would have been impossible at that time. Whoever wanted to live on his capital was obliged to pay some attention to its employment, and could not simply draw the interest on it without considering what was being done with it. One kind of investment was the usufructuary pledge, the capitalist taking a piece of land into his possession in return for money lent. He was allowed to use the proceeds of the land, as these were not interest but the results of the use of the land, and for this land he had given his capital. But this method gradually fell under suspicion, and it was difficult to refute the idea, that the capitalist should really credit the proceeds of this land to his capital; and so it happened, that in time even this method of applying capital was declared to be usury, and it was looked upon as if interest were taken instead of merely what the land produced.

Another transaction of this kind, was the purchase of an annuity ("Rentenkauf"), which consisted in a man's receiving for his capital a perpetual ineome from a piece of land. The capitalist might not demand the return of his money, but the debtor, on the contrary, was allowed to redeem the sums paid as part of the annuity. 'These sums were not regarded as interest, because a capital debt ("IIauptgutschuld") was necessary to a debt that bore interest. That there was much disapproval of this transaction is easy to understand.

These two arrangements made it possible to circumvent the 
prohibition against interest, though not entirely ; for after all, the usufructuary pledge creditor was obliged to occupy himself with the cultivation of the soil, and whoever lent his capital for a perpetual annuity could not prosper unless he kept an eye on the man who paid the annuity and the condition of his land. It was sometimes necessary for him to provide for the further cultivation of the land, so that he might not suffer himself.

5. In trade, too, the capitalist had to take part in the business, if he wanted his money to be productive. But it was possible for him to have an associate who performed most of the active duties, so that he was little more than a supervising spectator. This is the form of partnership ("Kommenda-Geschäit") which dereloped equally in the Orient and in the Occident, and by which a capitalist provided a man engaged in commerce with the opportunity of gaining money in an agreement for a division of the profits. Thus, the partnership relation was a deviation from the rule, and it was possible to draw proceeds from capital, even if the economic labor was left to some one else. It was, of course, adrisable for the capitalist to exercise a certain amount of supervision and care in the matter; and even to-day, a man who invests his fortune in stocks is not alive to his interests if he pars no attention whatever to the business, and does not at least take part in the annual meeting, or in some other way acquaint himself with the manner in which the business is carried on.

6. This necessity of combining labor and care with capital, in order to be able to draw income from it, is characteristic of certain periods. With a people that has to be trained to regular oecupation, it helps to develop the inclination to labor, and prevents the individual from being overwhelmed by the tide of profit, and working only until he can retire and live on the interest of his capital. This is all changed as soon as the acquisitive instinct is so far developed that even the capitalist wants to have more and more, and seeks to heap up treasures. However much Stoic philosophy may despise such a course, however strongly it may be represented to the individual, that he will achicre more by moderating his desire for aequisition, the striving for gain will still continue, and the ambition to outclo some one else will rule. The result will be, perhaps, feverish haste and rush, but it will also be an impulse to use the earth's forces in all directions, and to obtain more and more mastery over nature. The mastery of nature is the source of acquisition; for nature is the goddess who pours the fruits of industry into our laps. 
7. At this point, the exchange of capital becomes of the greatest importance; because now the first concern is that capital should reach the person who can do the most with it, and this exchange of capital presupposes, of course, the charging of interest; for, whoever dispenses with money, only to receive it back again after a time, will find this no profitable undertaking. Philanthropy may indeed lead to this, but philanthropy is generally a defective spring, not to be compared to the tremendous driving power of egoism; hence, everything that promotes healthy egoism must be recognized to this extent as also promotive of culture, and this inchudes the charging of interest. Therefore, among all industrial peoples, it has proved necessary to allow the taking of interest; and this interdiction of interest was either directly violated, or circumvented, in every possible way ; it had been outlived and could no longer exist.

One other point of view contributed to the abolition of the interest prohibition. The speculative assertion that money was unfruitful was met by the statement, that when a man has to do without his capital for a time he suffers damage; hence, it is only just that he should receive compensation. So it followed, that even though interest was unjustified from the borrower's point of view, it was yet justified from the lender's standpoint; for he camnot be required to do without his money, and without compensation renounce the profits that it might bring him. Thus, even the Canonists have long recognized, at least conditionally, the admissibility of interest; and, to-day, there is no longer any doubt about it, even in ecelesiastical circles.

8 . In the lives of nations, a system frequently develops according to which legal rates of interest are established. This is not an isolated phenomenon; in a similar way, certain rates are determined for the purchase of provisions, for contracts of service, and other things. The idea that underlies all this is, that when commerce does not regulate itself, it must be regulated by definite rules; so that no one can take advantage of another's necessitous condition, need of provisions, or of employment, and thus introduce needless contingencies into economic life. It is the same as regards money; for, it was long before competition among those who granted credit forced the price of credit down to a just basis. It was not until then that a certain average current interest arose, which of itself bccame a standard, and helped would-be borrowers in acute situations and difficulties.

Such conditions in fact lasted very long; hence it is compre- 
hensible that the establishment of a rate of interest became widespread and has continued for centuries. Nor are we eoneerned here with the absurdities that have prevailed, or periods of economic ignorance, but the definite conditions of human culture through which the nations had to pass, and whose peculiar needs required peculiar legal forms. 


\section{Cinapter XXX}

\section{SUCCESSION}

\section{SECTION 1}

\section{SURVEY OF THE LAW OF SUCCESSION 1}

\section{(A) In General.}

1. Inheritance is based on the idea of the continuity of the indivilual property after the death of its owner, through a person who is connected with this owner in a definite way, either by reason of family or a similar relationship, or by reason of a legally effective testamentary provision that creates a new relationship.

2. The right of inheritance, therefore, does not exist in any of the following cases:

(a) If after the owner's death the property reverts to the community. Hence when, in Rome, property fell to the "gentiles," or when as to-day, in the absence of heirs, it falls to the fiscus, it is improper to designate this an inheritance. It is merely called inheritance, because the technical juristic principles governing inheritance law have been extended to include such cases.

(b) Neither is it inheritance if the proprietary rights of the deceased cease, and another, unrelated to him, acquires the property ; for instance, by new investiture ("Nenverleihung").

(c) It is not inheritance if a man is a joint owner, and on his death his share either is merged in others, or another takes his place as a joint owner, but not by virtue of the dead person's disposition of his property, but owing to the special principles governing rights held jointly.

(d) It is not inheritance if the property of a juristic person, after the dissolution of the juristic person, falls to an individual, or another juristic person; although this, too, is often treated technically as an inheritance.

"[Reprinted, by permission, from Josef Kohler, "Philosophy of Law" (Albrecht's trans.), Boston Book Company, 1914 (Philosophy of Law Series, Vol. XII).] 
3. As inheritance rests, above all, on family relations, the principles of family organization are mainly determinative for the inheritance, and this in two respects: first according to the lind of organization and then according to the degree of exclusiveness. If we ask who stood nearest to the decased person, the first thing to be considered is whether the family organization conforms to matriarchy or patriarchy ; in the one case, the nephew, in the other the sons, will suceed. But, also, in another respect, the family organization must be considered. If each family is distinct in itself, and sharply separated from the other, so that, possibly, they are at odds with each other, then, the individual must belong exelusively to one family or the other, since one could not be, at the same time, a member of both the families $A$ and $B$. In this ease, the succession conforming to matriarchy will be exclusively matriarchal, and that conforming to patriarchy exclusively patriarchal; and in the latter case, the child will be able to inherit only from the father and his family, not from the mother and her relatives.

Not until families are less sharp!y divided from one another, and are merged in the unity of the State to which they leave the guiding functions of eulture, and when there ean no longer be any question of struggles between families, does the time come when a person can belong to several families as regards the right of inheritance.

The whole development of the law of inheritance among modern peoples is filled with this idea; and Roman law, in particular, labored for five centuries before it finally forsook the agnate right of inheritance, that is to say, the right to inherit exchusively from the paternal family, and established the right to inherit from both the paternal and the maternal families, which is called the cognate right of succession. The Germanic law also developer in the same way; largely, it is true, under the influence of Roman law.

4. The position of women, as regards the law of inheritance, is also closely connected with the family system; as appears, for instance, in the treatment of daughters. Patriarchy does not indeed prevent both sons and danghters from inheriting from the father, but the daunhter's right of inheritance leads to an undesirable result; for if the daughter marries, her property, according to the principles of patriarchy, is transferred to her husband, and the property of her family is thus considerably reluced. If the daughter of family $A$ marries into family $B$, her possessions will fall to family $B$, and thus be lost to family $A$. This idea of itself 
led to the result that the daughter was deprived of her heritage and restricted to her dowry.

From this standpoint, there could, of course, be no question of a woman's children's inheriting from her, as by her marriage she herself had been deprived of her property ; and, if a widow, she became dependent on annuities and usufructuary rights.

All this was changed when the principles of patriarchy became weakened and a woman retained her property in spite of her marriage. No logical reason then any longer existed for excluding daughters from the right of inheritance, although, on other grounds, many restrictions were laid upon their inheritance rights. It followed, that the children of a mother who, as a wife or widow, possessed property, would inherit from her; for it was no longer in accordance with the principles of family organization that a woman's brothers or more distant paternal relatives should inherit from her to the exclusion of her own children. This gave rise to the right of children to inherit from their mother, which can be traced in various forms in the laws of nations that were governed by patriarchy, as, for instance, the Romans and Jews.

5. With this development, a characteristic change took place in family life. Whereas, in the time of family property, the various branches of the family lived, worked, and earned together, the different brothers and their branches of the family now struck out for themselves. This brought about a significant new formation.

Formerly, if one of the brothers died before his parents and left children, these children inherited nothing; the remaining brothers inherited everything, and were, of course, obliged to care for their dead brother's children as for their own. It would have been considered monstrous for these children to have contended against their uncles and claimed anything for themselves. But, when once the fraternal branches of the family were separated, so that even during their lifetime, the brothers with their children had separate property, then the opposite course must have appeared monstrous ; for it is umnatural, that if the head of the family dies, and leaves descendants, the main line shall suddenly be erased. If the other bearers of the family name, that is to say, the brothers, are still alive, it may indeed long appear that because of their near relationship to the head of the family, they have superior rights in his property. But this idea soon conflicts with another, that the children of a dead son stand quite as near to the head of the family ; in fact, that the relationship of grandehildren to their grandfather is usually an especially intimate one. 
Thus originates what has been called the right of representation, which in reality is nothing but the principle of trunk distribution ("Stammteilumg"), as I termed it thirty years ago. The maintenance of the opposite principle in some systems of law, among others in that of Islam, is merely a defect in development, and shows that these systems have, in this respect, remained arrested.

The same applies when there are no sons living, but only grandsons; in this case, the idea of treating all the grandsons equally, without regard to the number of family branches and the number of children in each line, is also a defect which stands in open contradiction to the usual separation of the lines; for which reason, all the nations of the European continent have accepted the division into family lines.

(B) Indivisible and Dirisible Inheritance ("Einheits- und Mehrheitserbrecht"').

1. The struggle between individualism and the social tendencies of humanity is also seen in the law of inheritance. On the one hand, the individual demands consideration, and, if there are several persons of equal position, he demands the same measure and amount of consideration as they receive. On the other hand, social life often demands that a deviation be made, and that one or more individuals be forced into the background.

This struggle is especially pronounced in the treatment of children. That for a long time women were less favored than men, that is, the daughters less than the sons, was due to the speeial law governing the sexes. Yet, even among persons of the same sex, although the individual urges equal treatment, the social aspects of the family and of property frequently require another course.

2. The social mission of the family often demands, in particular, that the estate remain intact, and not be divided among several children. This may be the ease for various reasons; especially if a division of the estate would mean that its power would be destroyed or weakened; the portions into which it would be separated not having the same economie significance as the unified whole. Religious reasons often oppose such dirision, when the estate is also dedicated to the gods and to their service, and religious observances in the family are to remain uniform.

3. This disagreement may be avoided if the estate remains intact, and the children live together in mity ; so that the property of the head of the family belongs to all the children and their 
descendants, while the fact that its management remains in the hands of one person does not prevent the various members of the family from pursuing different interests. But, from what has already been said, we have seen that it is not possible for the family to continue in this kind of life permanently; for not only clo the interests of the different members clash, but also their fundamental differences of character, and this must necessarily break up the unity.

4. If the individual's claim to a division, and the social claim to unity, of the estate, cannot be reconciled in this way, one of the two claims is forced into the background. And here, it is self-erident that the social interest must come before the individual claim; for under the stress of social decay, the individual also wonld be ruined; whereas if social interests are maintained, it is still always possible for the individual to make his way, and find his proper course. This has led to various solutions. The whole estate may go to only one child as, for instance, in East Asia, in China, and Japan, or at least one child may receive far the greater part of it, and at the same time be obliged, more or less, to provide for the others. A more detailed discussion of the subject lies within the province of legal history. It need only be said here, that philosophically all these institutions sustain the social endeavor to comterbalance the exaggeration of individual activity. The special question whether the oldest or the youngest child, or one chosen by the family, or by the father himself, is to be the manager of the whole, cannot be generally solved, but must depend on the conditions of life, and on national views and customs. It may be said, however, that the right of the eldest would seem to be the most natural and appropriate; for the eldest son is thus placed somewhat in the position of a parent, as regards the younger children, and this gives him a certain support. The right of the roungest som, on the contrary, can only be justified by certain peeuliar family conditions; as, for instance, if the older sons have left the home, and the roungest devotes himself to the care of his parents, and hence takes over their house and property. The practice of permitting either the family or the father to make the choice will lead to favorable results only if the others have so much confidence in the one entitled to choose, and if the family feeling is so strong, that all immediately submit to the choice made, and also if their faithfulness to duty, and to the welfare of the family, is unquestionable; so that it need not be feared, that those with whom the choice rests will allow themselves to be in- 
fluenced by personal motives - a proceeding that would mean psychic ruin and the decline of the family. With us such a right of choice has therefore been generally exchuded.

(C) Disposal of Property after Death.

1. The question whether it is proper to accord to the holder of property the capacity to determine the fate of the inheritance after his death has occupied the nations much. The discussion of those particular conditions that led to the introduction of the will belongs to the history of the law. There it appears, that quite different motives, which were partly religious, partly of a family nature, and partly also connected with statesmanship, led to the granting of such a right of disposition in greater or less measure.

2. The legal philosophical significance of the will lies in the increased importance of the individual, as opposed to the family, and in the insistent claims of the members of the family to the property left. The claims of the family as regards the different portions of the property are not always equally powerful; not seldom, a distinction is made between property which the owner has inherited from his family, and property which he himself has accuuired. The inherited property is regarded as an indivisible portion of the family property ; and this view frequently brings the efforts of the individual to naught. Of acquired property, on the other hand, the individual has the free capacity of disposition, even after death. Here, too, we see the conflict between individualism and sociality, and the question is whether the welfare of society is to be expected from the triumph of the one or of the other element.

3. The predominance of individualism to such an extent that the holder of property has the power of disposition corresponds to human development; for it is promotive of culture, if property does not always take a certain course, but may be derised by the owner to certain purposes, and thus making it possible that great undertakings of mankind may be considerably advanced. 'This gains added significance from the fact that it also increases the instinct of acquisition, and causes a man to strive with all his might to obtain the means of carrying out his will, even after death. In this way, the possibility of disposing of property after death is a powerful incentive; it increases the individual's devotion to his work and to his business life, and this, of course, advances cultural life in a high degree. 


\section{SECTION 2 \\ RELIGIOUS BASIS OF INHERITANCE ${ }^{1}$}

\section{Nature and Principle of the Right of Succession among the Ancients}

The right of property having been established for the accomplishment of an hereditary worship, it was not possible that this right should fail after the short life of an individual. The man dies, the worship remains; the fire must not be extinguished, nor the tomb abandoned. So long as the domestic religion continued, the right of property had to continue with it.

Two things are elosely allied in the ereeds as well as in the laws of the ancients - the family worship and its property. It was therefore a rule without exception, in both Greek and Roman law, that a property could not be acquired without the worship, or the worship without the property. "Religion prescribes," says Cicero, "that the property and the worship of a family shall be inseparable, and that the care of the sacrifices shall always devolve upon the one who receives the inheritance." 2 At Athens an orator claims a succession in these terms: "Weigh it well, $O$ judges, and say whether my adversary or I ought to inherit the estate of Philoctemon, and offer the sacrifices upon his tomb." 3 Could one say more directly that the care of the worship was inseparable from the suecession? It was the same in India: "He who inherits, whoever he may be, is bound to make the offerings upon the tomb." ${ }_{4}$

From this principle were derived all the rules regarding the right of succession among the aneients. The first is that, the domestic religion being, as we have seen, hereditary from male to male, property is the same. As the son is the natural continuator of the religion, he also inherits the estate. 'Thus the rule of inheritance is found; it is not the result of a simple agreement made between men; it is derived from their belief, from their religion, from that which has the greatest power over their mind. It is not the personal will of the father that causes the son to inherit. The father need not make a will; the son inherits of full right, - ipso jure heres existit, - says the jurisconsult. He is even a necessary

1 [By Fustel de Coulanges, "The Ancient City"; translated by Willard Small; 11th ed., Lothrop, Lee, and Shepard Co., Boston; reprinted hy permission.]

2 Cicero, "De Legib.," II. 19, 20. Festus, v. "Everriator."

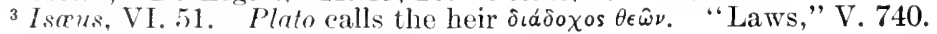

" "Laws of Manu," IX. 186. 
successor - heres necessarius. ${ }^{i}$ He has neither to accept nor to reject the inheritanee. The continuation of the property, like that of the worship, is for him an obligation as well as a right. Whether he wishes it or not, the inheritance falls to him, whatever it may be, even with its eneumbrances and its debts. The right to inherit without the debts, and to reject an inheritance, was not allowed to the son in Greek legislation, and was not introduced until a later period into Roman law.

The judicial language of Rome calls the son heres suns, as if one should say, heres sui ipsius. In faet, he inherits only of himself. Between his father and him there is neither donation, nor legacr, nor change of property. There is simply a continuation - morte parentis continuatur dominium. Already, during the life of the father, the son was eo-proprietor of the field and house - vivo quoque patre dominus existimatur. ${ }^{2}$

To form an idea of inheritance among the ancients, we must not figure to ourselves a fortune which passes from the hands of one to those of another. The fortune is immorable, like the hearth, and the tomb to which it is attaehed. It is the man who passes away. It is the man who, as the family unrolls its generations, arrives at his hour appointed to eontinue the worship, and to take care of the domain.

\section{The Son, not the Daughter, inherits}

It is here that ancient laws, at first sight, appear whimsical and unjust. We experience some surprise when we see in the Roman law that the daughter does not inherit if she is married, and that, according to the Greek law, she does not inherit in any case. What concerns the collateral branches appears, at first sight, still farther removed from nature and justice. This is beeause all these laws flow, according to a very rigorous logic, from the creed and religion that we have deseribel above.

The rule for the worship is, that it shall be transmitted from male to male; the rule for the inheritance is, that it shall follow the worship. The daughter is not qualified to continue the paternal religion, sinee she may marry, and thus renounce the religion of her father to adopt that of her husband; she has, therefore, no right to the inheritance. If a father should happen to leave his property to a daughter, this property would be separated from the worship, which would be inadmissible. The daughter could not

1"Digest," XXXYIII. tit. 16, 14.

2 "Institutes," III. 1, 3; III. 9, 7; III. 19, 2. 
even fulfil the first duty of an heir, whieh was to continue the series of funeral repasts; since she would offer the sacrifices to the ancestors of her husband. Religion forbade her, therefore, to inherit from her father.

Such is the ancient principle: it influenced equally the legislators of the Ilindus and those of Greece and Rome. 'The three peoples had the same laws; not that they had borrowed from each other, but because they had derived their laws from the same belief.

"After the death of the father," say's the Code of Manu, "let the brothers divide the patrimony among them ;" and the legislator adds, that he recommends the brothers to endow their sisters, which proves that the latter have not of themselves any right to the paternal succession.

This was the case, too, at Athens. Demosthenes, in his orations, often has occasion to show that daughters cannot inherit. ${ }^{1}$ He is himself an example of the application of this rule; for he had a sister, and we know, from his own writings, that he was the sole heir to the estate; his father had reserved only the seventh part to endow the daughter.

As to Rome, the provisions of primitive law which excluded the danghters from the inheritance are not known to us from any formal and precise text; but they have left profound traces in the laws of later ages. The Institutes of Justinian still excluded the daughter from the number of natural heirs, if she was no longer under the power of the father; and she was no longer under the power of the father after she had been married according to the religious rites. ${ }^{2}$ From this it follows that, if the daughter before marriage could share the inheritance with her brother, she had not this right after marriage had attached her to another religion and another family. And, if this was still the case in the time of Justinian, we may suppose that in primitive law, this principle was applied in all its rigor, and that the daughter not yet married, but who would one day marry, had no right to inherit the estate. The Institutes also mention the old principle, then obsolete, but not forgotten, which prescribed that an inheritance always descended to the males. ${ }^{3}$ It was clearly as a vestige of this old rule, that, according to the civil law, a woman could never be constituted an heiress. The farther we ascend from the Institutes of Justinian towards earlier times, the nearer we approach the rule that woman

1 Demostheres, "in Breotum." Iscus, X.4. Liysias, "in Mantith.," 10. 2"Institutes," II. 9, 2.

'Ibid., III. 1, 15; III. 2, 3. 
could not inherit. In Cicero's time, if a father left a son and a daughter, he could will to his daughter only one third of his fortune ; if there was only a daughter, she could still have but half. Te must also note that, to enable this daughter to receive a third or half of this patrimony, it was necessary that the father should make a will in her faror; the daughter had nothing of full right. ${ }^{1}$ Finally, a century and a half before Cicero, Cato, wishing to revive ancient manners, proposed and carried the Voconian law, which forbade, - 1. Making a woman an heiress, even if she was an only child, married or unmarried. 2. The willing to a woman of more than a fourth part of the patrimony.2 The Voconian law merely renewed laws of an earlier date; for we cannot suppose it would have been accepted by the contemporaries of the scipios if it had not been supported upon old principles which they still respected. It re-established what time had changed. Let us add that it contained nothing regarding heirship ab intestato, probably because on this point the old law was still in force, and there was nothing to repair on the subject. At Rome, as in Greece, the primitive law excluded the daughter from the heritage; and this was only a natural and ineritable consequence of the principles which religion had established.

It is true men soon found out a way of reconeiling the religious prescription which forbade the daughter to inherit with the natural sentiment which would have her enjoy the fortune of her father. The law decided that the daughter should marry the heir.

Athenian legislation carried this principle to its ultimate consequences. If the deceased left a son and a daughter, the son alone inherited and endowed his sister; if they were not both children of the same mother, he had his choice to marry her or to endow her. ${ }^{3}$ If the deceased left only a daughter, his nearest of kin was his heir; but this relative, who was of course also a near relative of the daughter, was required, nevertheless, to marry her. More than this, if this daughter was already married, she was required to abandon her hushand in order to marry her father's heir. The heir himself might be already married; in this case, he

"Cicero, "De Rep.," III. 7.

2 Cicero, "in Verr.," I. 42. Liv"y, XLI. 4. Sit. Augustine, "City of God," III. 21.

${ }^{3}$ Demosthenes, "in Eubul.," 21. Plutarch, "Themist.." 32. Isaus, X. 4. Corn. Nepos, "Cimon." It must he noted that the law did not permit marrying a uterine brother, or an emancipated hrother; it could he only a brother by the father's side, because the latter alone could inherit of the father. 
obtained a divorce, in order to marry his relative. ${ }^{1}$ We see here how completely ancient law innored nature to conform to religion.

The necessity of satisfying the requirements of religion, combined with the desire of saving the interests of an only daughter, gave rise to another subterfuge. On this point Hindu law and Athenian law correspond marvellously. We read in the Laws of Manu, "He who has no male child may require his daughter to give him a son, who shall become his, and who may perform the funeral ceremonies in his honor." In this case the father was required to admonish the husband to whom he gave his daughter, by pronouncing this formula: "I give you this daughter, adorned with jewels, who has no brother; the son born of her shall be my son, and shall celebrate my obsequies." 2 The custom was the same at Athens; the father could continue his descent through his daughter, by giving her a husband on this special condition. The son who was born of such a union was reputed the son of the wife's father; followed his worship; assisted at his religious ceremonies; and, later, guarded his tomb. ${ }^{3}$ In Hindu law this child inherited from his grandfather, as if he had been his son; it was exactly the same at Athens. When the father had married his daughter in the manner we have described, his heir was neither his daughter nor his sonin-law; it was the daughter's son. ${ }^{4}$ As soon as the latter had attained his majority, he took possession of the patrimony of his maternal grandfather, though his father and mother were still living. ${ }^{5}$

This singular tolerance of religion and law confirms the rule which we have already pointed out. The daughter was not qualified to inherit; but, by a very natural softening of the rigor of this principle, the only daughter was considered as an intermediary by whom the family might be continued. She did not inherit; but the worship and the inheritance were transmitted through her.

${ }^{1}$ Iscus, III. 64; X. 5. Demosthenes, “in Eubul.," 41. The only daughter was called $\dot{\epsilon} \pi \hat{i} \kappa \eta \eta \rho$ s, wrongly translated heiress; it signifies the daughter who goes with the inheritance. In fact, the daughter was never an heiress.

2 "Laws of Manu," IX. 127, 136. "Vasishta," XVII. 16.

${ }^{3}$ Isceus, VII.

${ }^{4}$ He was not called the grandson; they gave him the particular name of $\theta v \gamma a \tau \rho l \delta o u s$.

5 Isaus, VIII. 31 ; X. 12. Demosthenes, "in Steph.," II. 20. 


\section{Of the Collateral Succession}

A man died without children; to know who the heir of his estate was, we have only to learn who was qualified to continue his worship.

Now, the domestic religion was transmitted by blood from male to male. The descent in the male line alone established between two men the religious relation which permitted one to continue the worship of the other. What is called relationship, as we have seen above, was nothing more than the expression of this relation. One was a relative because he had the same worship, the same original sacred fire, the same ancestors. But one was not a relative because he had the same mother; religion did not admit of kinship through women. The children of two sisters, or of a sister and a brother, had no bond of kinship between them, and belonged neither to the same domestic religion nor to the same family.

These principles regulated the order of succession. If a man, having lost his son and his daughter, left only grandchildren after him, his son's son inherited, but not his daughter's son. In default of descendants, he had as an heir his brother, not his sister, the son of his brother, not the son of his sister. In default of brothers and nephews, it was necessary to go up in the series of ascendants of the deceased, always in the male line, until a branch of the family was found that was detached through a male; then to re-descend in this branch from male to male, until a living man was found; this was the heir.

These rules were in force equally among the Hindus, the Greeks, and the Romans. In India "the inheritance belongs to the nearest sapinda ; in default of a sapinda, to the samanodaca." 1 Now, we have seen that the relationship which these two words expressed was the religious relationship, or the relationship through the males, and corresponded to the Roman agnation.

Here, again, is the law of Athens: "If a man dies without children, the heir is the brother of the deceased, provided he is a consanguineous brother; in default of him, the son of the brother; for the succession always passes to the males, and to the descendants of males." 2 They still cited this old law in the time of Demosthenes, although it had already been modified, and they had commenced at this epoch to admit relationship through women.

In the same way, the Twelve Tables ordained that, if a man died

1 "Laws of Manu," IX. 186, 187.

2 Demosthenes, "in Macart." ; "in Leoch." Isaus, VII. 20. 
without his heir, the succession belonged to the nearest agnate. Now, we have seen that one was never an agnate through females. The ancicnt Roman law also specified that the nephew inherited from the patrums, - that is to say, from his father's brother, and did not inherit from the avunculus, his mother's brother. ${ }^{1}$

By returning to the table which we have traced of the family of the Scipios, it will be seen that, Scipio Amilianus, having died without children, his estate could not pass either to Cornelia, his aunt, or to C. Gracchus, who, according to our modern ideas, was his cousin-german, but to Scipio Asiaticus, who was really his nearest of kin.

In the time of Justinian, the legislator no longer understood these old laws; they appeared unjust to him, and he complained of the excessive rigor of the laws of the Twelve Tables, "which always accorded the preference to the masculine posterity, and excluded from the inheritance those who were related to the deceased only through females." 2 Unjust laws, if you will, for they made no account of natural affection; but singularly logical laws, for setting out from the principle that the inheritance was attached to the worship, they excluded from the inheritance those whom this religion did not authorize to continue the worship.

\section{Effects of Emancipation and Adoption}

We have already seen that emancipation and adoption produced a change in a man's worship. The first separated him from the paternal worship, the second initiated him into the religion of another family. Here also the ancient law conformed to the rules of religion. The son who had been excluded from the paternal worship by emancipation was also excluded from the inheritance. On the other hand, the stranger who had been associated in the worship of a family by adoption beeame a son there; he continued its worship, and inherited the estate. In both cases ancient law made more account of the religious tie than of the tie of birth.

As it was contrary to religion that one man should have two domestic worships, so he could not inherit from two families. Besides, the adopted son, who inherited of the adopting family, did not inherit from his natural family. Athenian law was very explicit on this point. The orations of Attic orators often show us men who have been adopted into a family, and who wished to inherit in the one in which they were born; but the law was against them.

$$
\text { 1 "Institutes," III. 2, } 4 . \quad \text { "Ibid., III. } 3 .
$$


The adopted son could not inherit from his own family unless he re-entered it; he could not re-enter it except by renouncing the adopting family; and he could leave this latter only on two conditions: the one was, that he abandoned the patrimony of this family; the other was, that the domestic worship, for the continuation of which he had been adopted, did not cease by his abandonment; and, to make this certain, it was necessary for him to leare this family a son, who should replace him. This son took charge of the worship, and inherited the cstate; the father could then return to the family of his birth, and inherit its property. But this father and son could no longer inherit from each other; they were not of the same family, they were not of kin. ${ }^{1}$

We can easily see what was the idea of the old legislator when he established these precise rules. He did not suppose it possible that two estates could fall to the same heir, because two domestic worships could not be kept up by the same person.

\section{Wills were not knou'n originally}

The right of willing - that is to say, of disposing of one's property after death, in order to make it pass to other than natural heirs - was in opposition to the religious creed that was at the foundation of the law of property and the law of succession. The property being inherent in the worship, and the worship being hereditary, could one think of a will? Besides, property did not belong to the individual, but to the family; for man had not acquired it by the right of labor, but through the domestic worship. Attached to the family, it was transmitted from the dead to the living, not according to the will and choice of the dead, but by virtue of superior rules which religion had established.

The will was not known in ancient Hindu law. Athenian legislation, up to Solon's time, forbade it absolutely, and Solon himself permitted it only to those who left no children." Wills were for a long time forbidden or unknown at Sparta, and were authorized only after the Peloponnesian war. ${ }^{3}$ Aristotle speaks of a time when the case was the same at Corinth and at Thebes. ${ }^{4}$ It is certain that the power of transmitting one's property arbitrarily by will was not recognized as a natural right; the constant principle of

IIsaus, X. Demosthenes, passim. Gaius, III. 2. "Institutes," III. 1, 2. It is hardly neressary to state that these rules were modified in the pretorian laws.
2 Plutarch, "Solon," 21.
4 A ristotle, "Polit.," II. 3, 4.
${ }^{2} I d$., "Agis," 5. 
the ancient ages was, that all property should remain in the family to which religion had attached it.

Plato, in his treatise on the Laws, which is largely a commentary on the Athenian laws, explains very clearly the thought of ancient legislators. He supposes that a man on his death-bed demands the power to make a will, and that he cries, "O gods, is it not very hard that I am not able to dispose of my property as I may choose, and in faror of any one to whom I please to give it, leaving more to this one, less to that one, according to the attachment they have shown for me?" But the legislator replies to this man, "Thou who canst not promise thyself a single day, thou who art only a pilgrim here below, does it belong to thee to decide such affairs? Thou art the master neither of thy property nor of thyself: thou and thy estate, all these things, belong to thy family; that is to say, to thy ancestors and to thy posterity.". 1

For us the ancient laws of Rome are very obscure; they were obscure even to Cicero. What we know reaches little farther back than the Twelve Tables, which certainly are not the primitive legislation of Rome; and of these only fragments remain. This code authorizes the will; yet the fragment relating to the subject is too short, and too evidently incomplete to enable us to flatter ourselves that we know the exact provisions of the legislators in this matter. When they granted the power of devising property, we do not know what reserve and what conditions they placed upon it. ${ }^{2}$ We have no legal text, earlier than the Twelve Tables, that either forbids or permits a will; but the language preserved traces of a time when wills were not known; for it called the son the self-successor and necessary - heres suns et necessarius. This formula, which Gaius and Justinian still employed, but which was no longer in accord with the legislation of their time, came, without doubt, from a distant epoch, when the son could not be disinherited or refuse the heritage. The father had not then the free disposition of his fortune. In default of sons, and if the deceased had only collateral relatives, the will was not absolutely unknown, but was not easily made valid. Important formalities were necessary. First, secrecy was not allowed to the testator during life; the man who disinherited his family, and violated the law that religion had established, had to do this publicly, in broad daylight, and take upon himself, during his lifetime, all the

¿Plato, "Laws," XI.

2 " Iti legassit, ita jus esto." If we had of Solon's law only the words

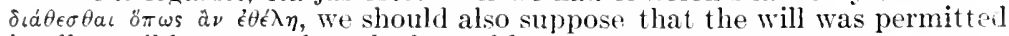
in all possible cases; but the law adds, $\ddot{a} \nu \mu \dot{\eta} \pi a \hat{\imath} \delta \in \hat{\omega} \sigma \iota$. 
odium attached to such an act. This was not all; it was also necessary that the will of the testator should receive the approbation of the sovereign authority - that is to say, of the people assembled by curies, under the presidency of the pontiff. ${ }^{1}$ We must not imagine that this was an empty formality, particularly in the early ages. 'These comitia by curies were the most solemn assemblies of the Roman city ; and it would be puerile to say that they convoked the people under the presidency of the religious chief, to act simply as witnesses at the reading of a will. We may suppose that the people roted, and we shall see, on reflection, that this was absolutely necessary. There was, in fact, a general law which regulated the order of succession in a rigorous manner; to modify this order in any particular, another law was necessary. This exceptional law was the will. The right of a man to devise by will was not, therefore, fully accorded, and could not be, so long as this society remained under the empire of the old religion. In the belief of these ancient ages, the living man was only the representative, for a few years, of a constant and immortal being - the family. He held the worship and the property only in trust; his right to them ceased with his life.

\section{The Right of Primogeniture}

We must transport ourselves beyond the time of which history has preserved the recollection, to those distant ages during which domestic institutions were established, and social institutions were prepared. Of this epoch there does not remain, nor can there remain, any written monument; but the laws which then governed men have left some traces in the legislation of succeeding times.

In these distant dars we distinguish one institution which must have survived a long time, which had a considerable influence upon the future constitution of societies, and without which this constitution could not be explained. This is the right of primogeniture.

The old religion established a difference between the older and the younger son. "The oldest," said the ancient Aryas, "was begotten for the accomplishment of the duty due the ancestor:; the others are the fruit of love." In virtue of this original superiority, the oldest had the privilege, after the death of the father, of

1 Ulpian, XX. 2. Gaius, I, 102, 119. Aulus Gellius, XV. 27. The testament calatis comitics was doubtless the oldest in use. It was no longer known in Cicero's time. ("De Orat.," 1. 53.) 
presiding at all the ceremonies of the domestic worship; he it was who offered the funcral repast, and pronounced the formulas of prayer; "for the right of pronouncing the prayers belongs to that son who eame into the world first." The oldest was, therefore, heir to the hymns, the continuator of the worship, the religious chief of the family. From this ereed flowed a rule of law: the oldest alone inherited property. Thus says an ancient passage, which the last editor of the Laws of Manu still inserted in the code: "The oldest takes possession of the whole patrimony, and the other brothers live under his authority as if they were under that of their father. The oldest son performs the duties towards the ancestors; he ought, therefore, to have all." 1

Greek law is derived from the same religious beliefs as Hindu law; it is not astonishing, then, to find there also the right of primogeniture. Sparta preserved it longer than other Greek cities because the Spartans were longer faithful to old institutions; among them the patrimony was indivisible, and the younger brothers had no part of it." It was the same with many of the ancient codes that Aristotle had studied. He informs us, indeed, that the 'Theban code prescribed absolutely that the number of lots of land should remain unchangeable, which certainly excluded the division among brothers. An ancient law of Corinth also provided that the number of families should remain invariable, which could only be the case where the right of the oldest prevented families from becoming dismembered in each generation. ${ }^{3}$

Among the Athenians we need not expect to find this old institution in full vigor in the time of Demosthenes; but there still existed at this epoch what they called the privilege of the elder. ${ }^{4}$ It consisted in retaining, above his proportion, the paternal dwelling - an advantage which was materially considerable, and which was still more considerable in a religious point of view; for the paternal house contained the ancient hearth of the family. While the younger sons, in the time of Demosthenes, left home to light new fires, the oldest, the true heir, remained in possession of the paternal hearth and of the tomb of his ancestors. He alone also preserved the family name. ${ }^{5}$ These were the vestiges of a time when he alone received the patrimony.

1 "Laws of Manu," IX. 105-107. 126. This ancient rule was modified as the old religion became enfeebled. Even in the code of Manu we find articles that authorize a division of the inheritance.

"2 "Fragments of the Creek Historians," Didot's Coll., t. II. p. 211.

3 A ristotle, "Polit.." II. 9; II. 3.

"II $е \epsilon \sigma \beta \epsilon i a$, Demosthenes, "Pro Phorm.," 34.

${ }^{5}$ Demosthenes, "in Bøot. de nomine." 
We may remark, that the inequality of the law of primogeniture, besides the fact that it did not strike the minds of the ancients, over whom religion was all-powerful, was corrected by several of their customs. Sometimes the younger son was adopted into a family, and inherited property there; sometimes he married an only daughter; sometimes, in fine, he received some extinct family's lot of land. When all these resources failed, younger sons were sent out to join a colony.

As to Rome, we find no law that relates to the right of primogeniture; but we are not to eonclude from this that the right was unknown in aneient Italy. It might have disappeared, and even its traces have been effaced. What leads us to believe that before the ages known to us it was in force is, that the existence of the Roman and Sabine gens eannot be explained without it. How could a family reach the number of several thousand free persons, like the Claudian family, or several hundred combatants, all patricians, like the Fabian family, if the right of primogeniture had not maintained its unity during a long series of generations, and had not increased its numbers from age to age by preventing its dismemberment? This aneient right of primogeniture is proved by its consequences, and, so to speak, by its works. ${ }^{1}$

\section{Section 3}

\section{EARLY HISTORY OF TESTAMENTARY SUCCESSION 2}

It is not difficult to point out the extreme difference of the conclusions forced on us by the historical treatment of the subjeet, from those to which we are conducted when, without the help of history, we merely strive to analyse our prima-facie impressions. I suppose there is nobody who, starting from the popular or even the legal conception of a Will, would not imagine that certain qualities are necessarily attached to it. Ile would say, for example, that a Will necessarily takes effect at death only - that it is secret, not known as a matter of eourse to persons taking.

1 The old Latin language, noreover, has preserved a restige which, feeble as it is, deserves to be pointed out. A lot of land, the domain of a family, was called sors; sors patrimonium significat, says Festus. The word consortes was applied then to those who had among them only a single lot of land, and lived on the same domain. Now, the old language designated hy this word hrothers, and even those fuite distantly related. This bears witness to a time when the patrimony and the family were indivisible. (Festus, v. "Sors." C'icero, "in Verrom," II. 323." Liry, XLI. 27. Velleius, I. 10. Lucretius, III. 722; VI. 1.280.)

${ }^{2}$ [By Sir Hexley S. Mane. Reprinter from "Ancient Law," hy permission of Henry Holt and Company, New York.] 
interests under its provisions - that it is rerocable, i.e. alwars capable of being superseder by a new act of testation. Yet I shall be able to show that there was a time when none of these characteristies belonged to a Will. The Testaments from which our Wills are directly descended at first took effect immediately on their exceution; they were not seeret; they were not revocable. Few legal agencies are, in fact, the fruit of more complex historical agencies than that by which a man's written intentions control the posthumous disposition of his goods. Testaments very' slowly and gradually gathered round them the qualities I have mentioned; and they did this from eauses and under pressure of events which may be ealled casual, or which at any rate have no interest for us at present, except so far as they have affected the history of law.

* $\quad * \quad * \quad * \quad * \quad * \quad * \quad * \quad * \quad * \quad * \quad *$

The conception of a Will or Testament cannot be considered by itself. It is a member, and not the first, of a series of conceptions. In itself a Will is simply the instrument by which the intention of the testator is declared. It must be elear, I think, that before such an instrument takes its turn for diseussion, there are several preliminary points to be examined - as for example, what is it, what sort of right or interest, which passes from a dead man on his decease? to whom and in what form does it pass? and how came it that the dead were allowed to control the posthumous disposition of their property? Thrown into technical language, the dependence of the various conceptions which contribute to the notion of a Will is thus expressed. A Will or Testament is an instrument by which the devolution of an inheritance is prescribed. Inheritance is a form of universal succession. A universal succession is a succession to a universitas juris, or university of rights and duties. Inverting this order we have therefore to inquire what is a miversitas juris; what is a universal suceession; what is the form of universal succession which is called an inheritance? And there are also two further questions independent to some extent of the points I have mooted, but demanding solution before the subject of Wills can be exhausted. These are, how eame an inheritance to be controlled in any ease by the testator's rolition, and what is the nature of the instrument by which it eame to be controlled?

The first question relates to the universitas juris; that is a university (or bundle) of rights and duties. A universitas juris 
is a collection of rights and duties united by the single circumstance of their having belonged at one time to some one person. It is, as it were, the legal clothing of some given individual. It is not formed by grouping together any rights and any duties. It can only be constituted by taking all the rights and all the duties of a particular person. The tie which so connects a number of rights of property, rights of way, rights to legacies, duties of specific performance, debts, obligations, to compensate wrongs which so connects all these legal privileges and duties together as to constitute them a universitas juris, is the fact of their having attached to some individual capable of exercising them. Without this fact there is no university of rights and duties. The expression universitas juris is not classical, but for the notion jurisprudence is exclusively indebted to Roman law; nor is it at all difficult to seize. We must endeavour to collect under one conception the whole set of legal relations in which each one of us stands to the rest of the world. These, whatever be their character and composition, make up together a universitas juris; and there is but little danger of mistake in forming the notion, if we are only careful to remember that duties enter into it quite as much as rights. Our duties may overbalance our rights. A man may owe more than he is worth, and therefore if a money value is set on his collective legal relations he may be what is called insolvent. But for all that the entire group of rights and duties which centres in him is not the less a "juris universitas."

We come next to a " universal succession." A universal succession is a succession to a univcrsitas juris. It occurs when one man is invested with the legal clothing of another, becoming at the same moment subject to all his liabilities and cntitled to all his rights. In order that the universal succession may be true and perfect, the devolution must take place uno ictu, as the jurists phrase it. It is of course possible to conceive one man acquiring the whole of the rights and duties of another at different periods, as for example by successive purchases; or he might acquire them in different capacities, part as heir, part as purchaser, part as legatee. But though the group of rights and duties thus marle up should in fact amount to the whole legal personality of a partieular individual, the acquisition would not be a universal succession. In order that there may be a true universal succession, the transmission must be such as to pass the whole aggregate of rights and duties at the same moment and in virtue of the same legal capacity in the recipient. The notion of a universal succession, like that 
of a "juris miversitas," is permanent in jurisprudence, though in the English legal system it is obscured by the great variety of capacities in which rights are acquired, and, above all, by the distinction between the two great provinces of English property, " realty" and "personalty." The succession of an assignee in bankruptey to the entire property of the bankrupt is, however, a universal succession, though, as the assignee only pays debts to the extent of the assets, this is only a molified form of the primary notion. Were it common among us for persons to take assignments of all a man's property on condition of paying all his debts, such transfers would exactly resemble the universal successions known to the oldest Roman Law. When a Roman citizen adrogated a son, i.e. took a man, not already under Patria Potestas, as his adoptive child, he succeeded universally to the adoptive child's estate, i.e. he took all the property and became liable for all the obligations. Several other forms of universal succession appear in the primitive Roman Law, but infinitely the most important and the most durable of all was that one with which we are more immediately concerned, Hereditas or Inheritance. Inheritance was a universal succession, occurring at a death. The universal successor was Hæres or Heir. He stepped at once into all the rights and all the duties of the dead man. He was instantly clothed with his entire legal person, and I need scarcely add that the special character of the Hreses remained the same, whether he was named by a Will or whether he took on an intestacy. The term Hæres is no more emphatically used of the Intestate than of the Testamentary Heir, for the manner in which a man became Hæres had nothing to do with the legal character he sustained. The dead man's universal successor, however he became so, whether by Will or by Intestacy, was his Heir. But the Heir was not necessarily a single person. A group of persons, considered in law as a single unit, might succeed as co-heirs to the Inheritance.

Let me now quote the usual Roman definition of an Inheritance. The reader will be in a position to appreciate the full force of the separate terms. IIcreditas est successio in universum jus quod. defunctus habuit " an inheritance is a succession to the entire legal position of a (leceased man"). The notion was that, though the physical person of the leceased had perished, his legal personality survived and descended unimpaired on his Heir or Coheirs, in whom his identity (so far as the law was concerned) was continued. Our own law, in constituting the Executor or Administrator the representative of the deceased to the extent of his 
personal assets, may serve as an illustration of the theory from which it emanated, but, although it illustrates, it does not explain it. The view of even the later Roman Law required a closeness of correspondence between the position of the deceased and of his Heir which is no feature of an English representation; and, in the primitive jurisprudence everything turned on the continuity of succession. Lnless provision was made in the will for the instant devolution of the testator's rights and duties on the Heir or Co-heirs, the testament lost all its effect.

In modern Testamentary jurisprudence, as in the later Roman Law, the object of first importance is the execution of the testator's intentions. In the ancient law of Rome the subject of corresponding carefulness was the bestowal of the Lniversal Succession. One of these rules seems to our eyes a principle dictated by common sense, while the other looks very much like an idle crotchet. Yet that without the second of them the first would never have come into being, is as certain as any proposition of the kind can be.

In order to solve this apparent paradox, and to bring into greater clearness the train of ideas which I have been endeavouring to indicate, I must borrow the results of the inquiry which was attempted in the earlier portion of the preceding chapter. We saw one peculiarity invariably distinguishing the infancy of society. Men are regarded and treated, not as individuals, but always as members of a particular group. Everybody is first a citizen, and then, as a citizen, he is a member of his order - of an aristocracy or a democracy, of an order of patricians or plebeians; or, in those societies which an unhappy fate has afflicted with a special perversion in their course of development, of a caste. Next, he is a member of a gens, house, or clan ; and lastly, he is a member of his family. This last was the narrowest and most personal relation in which he stood; nor, paradoxical as it may seem, was he ever regarded as himself, as a distinct individual. His individuality was swallowed up in his family. I repeat the definition of a primitive society given before. It has for its units, not individuals, but groups of men united by the reality or the fiction of blood-relationship.

It is in the peculiarities of an undereloped society that we seize the first trace of a universal succession. Contrasted with the organisation of a modern state, the eommonwealths of primitive times may be fairly described as consisting of a number of little despotic governments, each perfectly distinct from the rest, each absohutely controlled by the prerogative of a single monarch. 
But though the Patriarch, for we must not yet call him the Paterfamilias, had rights thus extensive, it is impossible to doubt that he lay under an equal amplitude of obligations. If he governed the family, it was for its behoof. If he was lord of its possessions, he held them as trustee for his children and kindred. He had no privilege or position distinct from that conferred on him by his relation to the petty commonwealth which he governed. 'The Family, in fact, was a Corporation; and he was its representative or, we might almost say, its Public officer. He enjoyed rights and stood under duties, but the rights and duties were, in the contemplation of his fellow-citizens and in the eye of the law, quite as much those of the collective body as his own. Let us consider for a moment, the effect which would be produced by the death of such a representative. In the eye of the law, in the view of the civil magistrate, the demise of the domestic authority would be a perfectly immaterial event. The person representing the collective body of the family and primarily responsible to municipal jurisdiction would bear a different name; and that would be all. The rights and obligations which attached to the deceased head of the house would attach, without breach of contimuity to his successor; for, in point of fact, they would be the rights and obligations of the family, and the family had the distinctive characteristic of a corporation - that it never died. Creditors would have the same remedies against the new chieftain as against the old, for the liability being that of the still existing family would be absolutely unchanged. All rights available to the family would be as available after the demise of the headship as before it - except that the corporation would be obliged - if indeed language so precise and technical can be properly used of these early times - would be obliged to sue under a slightly modified name.

The history of jurisprudence must be followed in its whole course, if we are to understand how gradually and tardily society dissolved itself into the component atoms of which it is now constituted - by what insensible gradations the relation of man to man substituted itself for the relation of the individual to his family, and of families to each other. The point now to be attended to is that even when the revolution had apparently quite accomplished itself, even when the magistrate had in great measure assumed the place of the Pater-familias, and the civil tribunal substituted itself for the domestic forum, nevertheless the whole scheme of rights and duties administered by the judicial authori- 
ties remained shaped by the influence of the obsolete privileges and coloured in every part by their reflection. There seems little question that the devolution of the Lniversitas Juris, so strenuously insisted upon by the Roman Law as the first condition of a testamentary or intestate succession, was a feature of the older form of society which men's minds have been unable to dissociate from the new, though with that newer phase it had no true or proper connection. It seems, in truth, that the prolongation of a man's legal existence in his heir, or in a group of co-heirs, is neither more nor less than a characteristic of the family transferred by a fiction to the individual. Succession in corporations is necessarily miversal, and the family was a corporation. Corporations never die. The decease of individual members makes no difference to the collective existence of the aggregate bodr, and does not in any way affect its legal incidents, its faculties or liabilities. Now in the idea of a Roman universal succession all these qualities of a corporation seem to have been transferred to the individual citizen. His phrsical death is allowed to exercise no effect on the legal position which he filled, apparently on the principle that that position is to be adjusted as closely as possible to the analogies of a family, which, in its corporate character, was not of course liable to physical extinction.

* $\quad * \quad * \quad * \quad * \quad * \quad * \quad * \quad * \quad * \quad * \quad *$

When a Roman citizen died intestate or leaving no valid Will, his descendants or kindred became his heirs according to a scale which will be presently described. The person or class of persons who succeeded did not simply represent the deceased, but, in conformity with the theory just delineated, they continued his civil life, his legal existence. The same results followed when the order of succession was determined by a Will, but the theory of the identity between the dead man and his heirs was certainly much older than any form of Testament or phase of Testamentary jurisprudence. This indeed is the proper moment for suggesting a doubt which will press on us with greater force the further we plumb the depths of this subject - whether wills would ever have come into being at all if it had not been for these remarkable ideas connected with universal succession. Testamentary law is the application of a principle which may be explained on a variety of philosophical hypotheses as plausible as they are gratuitous; it is interwoven with every part of modern society, and it is defensible on the broadest grounds of general expediency. But 
the warning can never be too often repeated, that the grand source of mistake in questions of jurisprudence is the impression that these reasons which actuate us at the present moment, in the maintenance of an existing institution, have necessarily any thing in common with the sentiment in which the institution originated. It is certain that, in the old Roman Law of Inheritance, the notion of a will or testament is inextricably mixed up, I might almost say confounded, with the theory of a man's posthumous existence in the person of his heir.

The conception of a universal succession, firmly as it has taken root in jurisprudence, has not occurred spontaneously to the framers of every body of laws. Wherever it is now found, it may be shown to have descended from Roman law; and with it have come down a host of legal rules on the subject of Testaments and Testamentary gifts, which modern practitioners apply without discerning their relation to the parent theory. But, in the pure Roman jurisprudence, the principle that a man lives on in his Heir - the elimination, if we may so speak, of the fact of death - is too obviously for mistake the centre round which the whole Law of Testamentary and Intestate succession is circling. The unflinching sternness of the Roman law in enforcing compliance with the governing theory would in itself suggest that the theory grew out of something in the primitive constitution of Roman society; but we may push the proof a good way beyond the presumption. It happens that several technical expressions, dating from the earliest institution of wills at Rome, have been accidentally preserved to us. We have in Gaius the formula of investiture by which the universal successor was created. We have the ancient name by which the person afterwards called Heir was at first designated. We have further the text of the celebrated clause in the Twelve Tables by which the Testamentary power was expressly recognised, and the clauses regulating Intestate Succession have also been preserved. All these archaic phrases have one salient peculiarity. They indicate that what passed from the Testator to the Heir was the Family, that is, the aggregate of rights and duties contained in the Patria Potestas and growing out of it. The material property is in three instances not mentioned at all; in two others, it is visibly named as an adjunct or appendage of the Family. The original Will or Testament was therefore an instrument, or (for it was probably not at first in writing) a proceeding, by which the devolution of the family was regulated. It was a mode of declaring who was to 
have the chieftainship, in succession to the Testator. When Wills are understood to have this for their original object, we see at once how it is that they came to be connected with one of the most curious relics of ancient religion and law, the sacra, or Family Rites. These sacra were the Roman form of an institution which shows itself wherever society has not wholly shaken itself free from its primitive clothing. They are the sacrifices and ceremonies by which the brotherhood of the family is commemorated, the pledge and the witness of its perpetuity. Whatever be their nature - whether it be true or not that in all cases they are the worship of some mythical ancestor - they are everywhere employed to attest the sacredness of the family relation; and therefore they acquire prominent significance and importance, whenever the continuous existence of the Family is endangered by a change in the person of its chief. Accordingly, we hear most about them in connection with demises of domestic sovereignty. Among the Hindoos, the right to inherit a dead man's property is exactly co-extensive with the duty of performing his obsequies. If the rites are not properly performed or not performed by the proper person, no relation is considered as established between the deceased and anybody surviving him; the Law of Succession does not apply, and nobody can inherit the property. Every great event in the life of a Hindoo seems to be regarded as leading up to and bearing upon these solemnities. If he marries, it is to have children who may celebrate them after his death; if he has no children, he lies under the strongest obligation to adopt them from another family, "with a view," writes the Hindoo doctor, "to the funeral cake, the water, and the solemn sacrifice." ...

In Hindoo law there is no such thing as a true Will. The place filled by Wills is occupied by Adoptions. We can now see the relation of the Testamentary Power to the Faculty of Adoption, and the reason why the exercise of either of them could call up a peculiar solicitude for the performance of the sacra. Both a Will and an Adoption threaten a distortion of the ordinary course of Family descent, but they are obviously contrivances for preventing the descent being wholly interrupted, when there is no succession of kindred to carry it on. Of the two expedients Adoption, the factitious creation of blood-relationslip, is the only one which has suggested itself to the greater part of archaic societies. The Hindoos have indeed advanced one point on what was doubtless the antique practice, by allowing the widow 
to adopt when the father has neglected to do so, and there are in the local customs of Bengal some faint traces of the Testamentary powers. But to the Romans belongs pre-eminently the credit of inventing the Will, the institution which, next to the Contract, has exercised the greatest influence in transforming human society. We must be careful not to attribute to it in its earliest shape the functions which have attended it in more recent times. It was at first, not a mode of distributing a dead man's goods, but one among several ways of transferring the representation of the household to a new chief. The goods descend no doubt to the Heir, but that is only because the government of the family carries with it in its devolution the power of disposing of the common stock. We are very far as yet from that stage in the history of Wills in which they become powerful instruments in modifying society through the stimulus they give to the circulation of property and the plasticity they produce in proprietary rights. No such consequences as these appear in fact to have been associated with the 'Testamentary power even by the latest Roman lawyers. It will be found that Wills were never looked upon in the Roman community as a contrivance for parting Property and the Family, or for creating a variety of miscellaneous interests, but rather as a means of making a better provision for the members of a household than could be secured through the rules of Intestate succession. We may suspect indeed that the associations of a Roman with the practice of will-making were extremely different from those familiar to us nowadays. The habit of regarding Adoption and Testation as modes of continuing the Family cannot but have had something to do with the singular laxity of Roman notions as to the inheritance of sovereignty. It is impossible not to see that the succession of the early Roman Emperors to each other was considered reasonably regular, and that, in spite of all that had oceurred, no absurdity attached to the pretension of such Princes as Theodosius or Justinian to style themselves Cresar and Augustus.

When the phenomena of primitive societies emerge into light, it seems impossible to dispute a proposition which the jurists of the seventeenth century considered doubtful, that Intestate Inheritance is a more ancient institution than Testamentary Succession. As soon as this is settled, a question of much interest suggests itself, how and under what conditions were the directions of a will first allowed to regulate the devolution of authority over the household, and consequently the posthumous distribution of 
property. The difficulty of deciding the point arises from the rarity of Testamentary power in archaic communities. It is doubtful whether a true power of testation was known to any original society except the Roman. Rudimentary forms of it occur here and there, but most of them are not exempt from the suspicion of a Roman origin. The Athenian Will was, no doubt, indigenous, but then, as will appear presently, it was only an inchoate Testament. As to the Wills which are sanctioned by the bodies of law which have descended to $u$ s as the codes of the barbarian conquerors of imperial Rome, they are almost certainly Roman. The most penetrating German criticism has recently been directed to these leges Barbarorum, the great object of investigation being to detach those portions of each system which formed the customs of the tribe in its original home from the adventitious ingredients which were borrowed from the laws of the Romans. In the course of this process, one result has invariably disclosed itself, that the ancient nucleus of the code contains no trace of a Will. Whatever testamentary law exists, has been taken from Roman jurisprudence. Similarly, the rudimentary Testament which (as I am informed) the Rabbinical Jewish law provides for, has been attributed to contact with the Romans. The only form of Testament, not belonging to a Roman or Hellenic society, which can with any reason be supposed indigenous, is that recognised by the usages of the province of Bengal; and the Testament of Bengal, which some have even supposed to be an invention of Anglo-Indian lawyers, is at most only a rudimentary Will.

The evidence, however, such as it is, seems to point to the conclusion that Testaments are at first only allowed to take effect on failure of the persons entitled to have the inheritance by right of blood genuine or fictitious. Thus, when Athenian citizens were empowered for the first time by the Laws of Solon to execute Testaments, they were forbidden to disinherit their direct male descendants. So, too, the Will of Bengal is only permitted to govern the succession so far as it is consistent with certain overriding claims of the family. Again, the original institutions of the Jews having provided nowhere for the privileges of 'Testatorship, the latter Rabbinical jurisprudence, which pretends to supply the casus omissi of the Mosaic law, allows the power of Testation to attach when all the kindred entitled under the Mosaic syrstem to succeed have failed or are undiscoverable. The limitations by which the ancient German codes hedge in the testamen- 
tary jurisprudence which has been incorporated with them are also significant, and point in the same direction. It is the peculiarity of most of these German laws, in the only shape in which we know them, that, besides the allod or domain of each household, they recognise several subordinate kinds or orders of property, each of which probably represents a separate transfusion of Roman principles into the primitive body of Teutonic usage. The primitive German or allodial property is strictly reserved to the kindred. Not only is it incapable of being disposed of by testament, but it is scarcely capable of being alienated by conveyance inter vivos. The ancient German law, like the Hindoo jurisprudence, makes the male children co-proprietors with their father, and the endowment of the family cannot be parted with except by the consent of all its members. But the other sorts of property, of more modern origin and lower dignity than the allodial possessions, are much more easily alienated than they, and follow much more lenient rules of devolution. Women and the descendants of women succeed to them, obviously on the principle that they lie outside the sacred precinct of the Agnatic brotherhood. Now, it is on these last descriptions of property, and on these only, that the Testaments borrowed from Rome were at first allowed to operate.

These few indications may serve to lend additional plausibility to that which in itself appears to be the most probable explanation of an ascertained fact in the early history of Roman Wills. We have it stated on abundant authority that Testaments, during the primitive period of the Roman State, were executed in the Comitia Calata, that is, in the Comitia Curiata, or Parliament of the Patrician Burghers of Rome, when assembled for Private Business. This mode of execution has been the source of the assertion, handed down by one generation of civilians to another, that every Will at one era of Roman history was a solemn legislative enactment. But there is no necessity whatever for resorting to an explanation which has the defect of attributing far too much precision to the proceedings of the ancient assembly. The proper key to the story concerning the execution of Wills in the Comitia Calata must no doubt be sought in the oldest Roman law of intestute succession. The canons of primitive Roman jurisprudence regulating the inheritance of relations from each other were, so long as they remained unmodified by the Edictal Law of the Protor, to the following effect:- First, the sui or direct descendants who had never been emancipated succeeded. 
On the failure of the sui, the Nearest Agnate came into their place, that is, the nearest person or class of the kindred who was or might have been under the same Patria Potestas with the deceased. The third and last degree came next, in which the inheritance devolved on the Gentiles, that is, on the collective members of the dead man's gens or House. The House, I have explained already, was a fictitious extension of the family, consisting of all Roman Patrician citizens who bore the same name, and who on the ground of bearing the same name, were supposed to be descended from a common ancestor. Now the Patrician Assembly called the Comitia Curiata was a Legislature in which Gentes or Houses were exchusively represented. It was a representative assembly of the Roman people, constituted on the assumption that the constituent unit of the state was the Gens. This being so, the inference seems inevitable, that the cognisance of Wills by the Comitia was connected with the rights of the Gentiles, and was intended to secure them in their privilege of ultimate inheritance. The whole apparent anomaly is removed, if we suppose that a Testament could only be made when the Testator had no gentiles discoverable, or when they waived their claims, and that every Testament was submitted to the General Assembly of the Roman Gentes, in order that those aggrieved by its dispositions might put their veto upon it if they pleased, or by allowing it to pass might be presumed to have renounced their reversion. It is possible that on the eve of the publication of the Twelve Tables this vetoing power may have been greatly curtailed or only occasionally and capriciously exercised. It is much easier, however, to indicate the meaning and origin of the jurisdiction confided to the Comitia Calata, than to trace its gradual development or progressive decay.

The 'Testament to which the pedigree of all modern Wills may be traced is not, however, the Testament executed in the Calata Comitia, but another 'Testament designed to compete with it and destined to supersede it. The historical importance of this early Roman Will, and the light it casts on much of ancient thought, will excuse me for describing it at some length.

When the Testamentary power first discloses itself to us in legal history, there are signs that, like almost all the great Roman institutions, it was the subject of contention between the Patricians and the Plebeians. 'The effect of the political maxim, Plebs Gentem non habet, "a Plebeian cannot be a member of a house," was entirely to exclude the Plebeians from the Comitia Curiata. 
Some critics have accordingly supposed that a Plebeian could not have his Will read or recited to the Patrician Assembly, and was thus deprived of Testamentary privileges altogether. Others have been satisfied to point out the hardships of having to submit a proposed Will to the unfriendly jurisdiction of an assembly in which the Testator was not represented. Whatever be the true view, a form of Testament came into use, which has all the characteristics of a contrivance intended to evade some distasteful obligation. The Will in question was a converance inter viros, a complete and irrevocable alienation of the Testator's family and substance to the person whom he meant to be his heir. The strict rules of Roman law must always have permitted such an alienation, but when the transaction was intended to have a posthumous effect, there may have been disputes whether it was valid for Testamentary purposes without the formal assent of the Patrician Parliament. If a difference of opinion existed on the point between the two classes of the Roman population, it was extinguished, with many other sources of heartburning, by the great Decemviral compromise. The text of the Twelve Tables is still extant which sayss, "Pater fumilias uti de pecuniâ tutelâve rei suce legâssit, ita jus esto" - a law which can hardly have had any other object than the legitimation of the Plebeian Will.

It is well known to scholars that, centuries after the Patrician Assembly had ceased to be the legislature of the Roman State, it still continued to hold formal sittings for the convenience of private business. Consequently, at a period long subsequent to the publication of the Decemviral Law, there is reason to believe that the Comitia Calata still assembled for the validation of Testaments. Its probable functions may be best indicated by saying that it was a Court of Registration, with the understanding, however, that the Wills exhibited were not enrolled, but simply recited to the members, who were supposed to take note of their tenor and to commit them to memory. It is very likely that this form of Testament was never reduced to writing at all, but at all events if the Will had been originally written, the office of the Comitia was certainly confined to hearing it read aloud, the document heing retained afterwards in the custody of the Testator, or deposited under the safeguard of some religious corporation. 'This publicity may have been one of the incidents of the Testament executed in the Comitia Calata which brought it into popular disfarour. In the early years of the Empire the Comitia still lseld its meeting, but they seem to have lapsed into the merest 
form, and few Wills, or none, were probably presented at the periodical sitting.

It is the ancient Plebeian Will - the alternative of the Testament just described - which in its remote effects has deeply modified the civilisation of the modern world. It acquired at liome all the popularity which the Testament submitted to the Calata Comitia appears to have lost. The key to all its characteristics lies in its descent from the mancipizm, or ancient Roman conreyance, a proceeding to which we may unhesitatingly assign the parentage of two great institutions without which modern society can scarcely be supposed capable of holding together, the Contract and the Will. The Mancipium, or, as the world would exhibit itself in later Latinity, the Mancipation, carries us back by its incidents to the infancy of civil society. As it sprang from times long anterior, if not to the invention, at all events to the popularisation, of the art of writing, gestures, simbolical acts, and solemn phrases take the place of documentary forms, and a lengthy and intricate ceremonial is intended to call the attention of the parties to the importance of the transaction, and to impress it on the memory of the witnesses. The imperfection, too, of oral, as compared with written testimony necessitates the multiplication of the witnesses and assistants berond what in later times would be reasonable or intelligible limits.

The Roman Mancipation required the presence first of all of the parties, the vendor and vendee, or we should perhaps rather say, if we are to use modern legal language, the grantor and grantee. There were also no less than five witnesses; and an anomalous personage, the Libripens, who brought with him a pair of scales to weigh the uncoined copper money of ancient Rome. The Testament we are considering - the 'Testament per as et libram, "with the copper and the scales," as it long continued to be technically called - was an ordinary Mancipation with no change in the form and hardly any in words. The Testator was the grantor; the five witnesses and the libripens were present; and the place of grantee was taken by a person known technically as the familia emptor, the Purchaser of the Family. The ordinary ceremony of a Mancipation was then proceeded with. Certain formal gestures were made and sentences pronounced. The Emptor familia simulated the parment of a price by striking the scales with a piece of money, and finally the Testator ratified what had been done in a set form of words called the "Nuncupatio" or publication of the transaction, a phrase which, I 
need scarcely remind the lawyer, has had a long history in Testamentary jurisprudence. It is necessary to attend particularly to the character of the person called familix emptor. There is no doubt that at first he was the Heir himself. 'The Testator conveyed to him outright his whole "familia," that is, all the rights he enjoyed over and through the family; his property, his slaves, and all his ancestral privileges, together, on the other hand, with all his duties and obligations.

With these data before us, we are able to note several remarkable points in which the Mancipatory Testament, as it may be called, differed in its primitive form from a modern Will. As it amounted to a converance out-and-out of the Testator's estate it was not revocuble. There could be no new exercise of a power which had been exhausted.

Again, it was not secret. The Familix Emptor, being himself the Heir, knew exactly what his rights were, and was aware that he was irreversibly entitled to the inheritance; a knowledge which the violences inseparable from the best-ordered ancient society rendered extremely dangerous. But perhaps the most surprising consequences of this relation of Testaments to Converances was the immediate vesting of the Inheritance in the Heir. This has seemed so incredible to not a few cirilians, that they have spoken of the Testator's estate as vesting conditionally on the Testator's death, or as granted to him from a time uncertain, i.e. the death of the grantor. But down to the latest period of Roman jurisprudence there was a certain class of transactions which never admitted of being directly modified by a condition, or of being limited to or from a point of time. In technical language they did not admit conditio or dies. Mancipation was one of them, and therefore, strange as it may seem, we are forced to conclude that the primitive Roman Will took effect at once, even thougl the 'Testator survived his act of Testation. It is indeed likely that Roman citizens originally made their Wills only in the article of death, and that a provision for the continuance of the Family effected by a man in the flower of life would take the form rather of an Adoption than of a Will. Still we must believe that, if the Testator did recover, he could only continue to govern his household by the sufferance of his Heir.

Two or three remarks should be made before I explain how these inconveniences were remedied, and how Testaments came to be invested with the characteristics now universally associated 
with them. The Testament was not necessarily written: at first, it seems to have been invariably oral, and, even in later times, the instrument deelaratory of the bequests was only incidentally connected with the Will and formed no essential part of it. It bore in fact exactly the same relation to the Testament which the deed leading the uses bore to the Fines and Reeoveries of old English law, or which the charter of feoffment bore to the feoffment itself. Previously, indeed, to the Twelve Tables, no writing would have been of the slightest use, for the Testator had no power of giving legacies, and the only persons who could be advantaged by a will were the Heir or Co-heirs. But the extreme generality of the clause in the Twelve Tables soon produced the doctrine that the heir must take the inheritance burdened by any directions which the Testator might give him, or, in other words, take it subject to legacies. Written testamentary instruments assumed thereupon a new value, as a security against the fraudulent refusal of the heir to satisfy the legatees; but to the last it was at the Testator's pleasure to rely exclusively on the testimony of the witnesses, and to declare by word of mouth the legacies which the familix emptor was commissioned to pay.

The terms of the expression Emptor familice demand notice. "Emptor" indicates that the Will was literally a sale, and the word "familia," when compared with the phraseology in the Testamentary clause in the Twelve Tables, leads us to some instructive conclusions. "Familia," in elassical Latinity, means always a man's slaves. Here, however, and generally in the language of ancient Roman law, it includes all persons under his Potestas, and the Testator's material property or substance is understood to pass as an adjunct or appendage of his household. Turning to the law of the Twelve Tables, it will be seen that it speaks of tutela rei suc, "the guardianship of his substance," a form of expression which is the exact reverse of the phrase just examined. There does not therefore appear to be any mode of escaping from the conclusion, that even at an era so comparatively recent as that of the Decemviral compromise, terms denoting "household" and "property" were blended in the eurrent phraseology. If a man's household had been spoken of as his property, we might have explained the expression as pointing to the extent of the Patria Potestas, but, as the interchange is reciprocal, we must allow that the form of speech carries us back to the primeval period in which property is owned hy the family, and the family is governed by the citizen, so that the members of the community 
do not own their property and their family, but rather own their property through their family.

At an epoch not easy to settle with preeision, the Roman Pretors fell into the habit of acting upon 'Testaments solemnised in closer conformity with the spirit than the letter of the law. Casual dispensations became insensibly the established practice, till at length a wholly new form of Will was matured and regularly engrafted on the Edictal Jurisprudence. 'The new or Protorian Testament derived the whole of its impregnability from the Jus IIonorarium or Equity of Rome. The Prætor of some particular year must have inserted a clause in his Inaugural Proclamation declaratory of his intention to sustain all Testaments which should have been executed with such and such solemnities; and, the reform having been found advantageous, the article relating to it must have been again introduced by the Prretor's successor, and repeated by the next in office, till at length it formed a reeognised portion of that body of jurisprudence which from these suceessive incorporations was styled the Perpetual or Continuous Edict. On examining the conditions of a valid Prætorian Will they will be plainly seen to have been determined by the requirements of the Mancipatory Testament, the innovating Præetor having obviously prescribed to himself the retention of the old formalities just so far as they were warrants of genumeness or securities against frand. At the execution of the Mancipatory Testament seven persons had been present besides the Testator. Seven witnesses were aceordingly essential to the Pretorian Vill; two of them corresponding to the libripens and familice emptor, who were now stripped of their symbolical character, and were merely present for the purpose of supplying their testimony. No emblematic ceremony was gone through; the Will was merely recited; but then it is probable (though not absolutely certain) that a written instrument was necessary to perpetuate the eridence of the 'lestator's dispositions. At all events, whenever a writing was read or exhibited as a person's last Vill, we know certainly that the Pretorian Court would not sustain it by special intervention, unless each of the seven witnesses had severally affixed his seal to the ontside. This is the first appearance of sealing in the history of jurisprudence, considered as a mode of authentication. The use of seals, however, as mere fastenings, is donbtless of much higher antiquity ; and it appears to have been known to the Hebrews. We may olserve, that the seals of the Roman Wills, and other documents of importance, did not only 
serve as the index of the present or assent of the signatary, but were also literally fastenings which had to be broken before the writing could be inspected.

The Edictal Law would therefore enforce the dispositions of a Testator, when, instead of being symbolised through the forms of mancipation, they were simply evidenced by the seals of seven witnesses. But it may be laid down as a general proposition, that the principal qualities of Roman property were incommunicable except through processes which were supposed to be coeval with the origin of the Civil Law. The Protor therefore could not confer an Inheritance on anybody. He could not place the Heir or Co-heirs in that very relation in which the Testator had himself stood to his own rights and obligations. All he could do was to confer on the person designated as Heir the practical enjoyment of the property bequeathed, and to give the force of legal acquittances to his payments of the 'Testator's debts. When he exerted his powers to these ends, the Pretor was technically said to communicate the Bonorum Possessio. The Heir specially inducted under these circumstances, or Bonorum Possessor, had every proprietary privilege of the IIeir by the Civil Law. He took the profits and he could alienate, but then, for all his remedies for redress against wrong, he must go, as we should phrase it, not to the Common Law, but to the Equity side of the Pretorian Court. No great chance of error would be incurred by describing him as having an equitable estate in the inheritance; but then, to secure ourselves against being deluded by the analogy, we must always recollect that in one year the Bonorum. Possessio was operated upon by a principle of Roman Law known as Usucapion, and the Possessor became Quiritarian owner of all the property comprised in the inheritance.

We know too little of the older law of Civil Process to be able to strike the balance of advantage and disadrantage between the different classes of remerlies supplied by the Pratorian Tribunal. It is certain, however, that, in spite of its many defects, the Mancipatory Testament by which the unixersitas juris devolved at once and unimpaired was never entirely superseded by the new Will; and at a period less bigoted to antiquarian forms, and perhaps not quite alive to their significance, all the ingenuity of the Jurisconsults seems to have been expended on the improvement of the more venerable instrument. It the era of Gaius, which is that of the Antonine Caesars, the grcat blemishes of the Mancipatory Will had been remored. Originally, as we 
have seen, the essential character of the formalities had required that the Heir himself should be the Purchaser of the Family, and the consequence was that he not only instantly acquired a vested interest in the 'Testator's Property, but was formally made aware of his rights. But the age of Gaius permitted some unconcerned person to officiate as Purchaser of the Family. The Ifeir, therefore, was not necessarily informed of the succession to which he was destined; and Wills thenceforward acquired the property of secrecy. The substitution of a stranger for the actual Heir in the functions of "Familix Emptor" had other ulterior consequences. As soon as it was legalised, a Roman Testament came to consist of two parts or stages, - a Conveyance, which was a pure form, and a Nuncupatio, or Publication. In this latter passage of the proceeding, the Testator either orally declared to the assistants the wishes which were to be executed after his death, or produced a written document in which his wishes were embodied. It was not probably till attention had been quite drawn off from the imaginary Conveyance, and concentrated on the Nuncupatio as the essential part of the transaction, that Wills were allowed to become revocable. 


\section{PART IV \\ PROCEDURE}

\section{Chapter XXXI}

Section 1. Survey of the Law of Procedure By Josef Kohler

\section{Section 2. Ancient Magistracy}

By Fustel de Coulanges

Section 3. Primitive Forms of Legal Remedies By Henry S. Maine

Section 4. The Ordeal and the Oath By Gustave Glotz

Section 5. Ancient Formalism

By Andreas Heusler

Section 6. Ancient Semitic Procedure By Stanley A. Cook

Section 7. Ancient Roman Procedure By Rudolph Sонм

Section 8. Eyolution of Procedure By Gabriel Tarde 



\section{Chapter XXYI}

\section{PROCEDURE}

\section{SECTION 1 \\ SURVEY OF THE LAW OF PROCEDURE ${ }^{1}$}

1. Peaceable regulation is prineipally furthered by the worship of the divinity. The divinity is often the goddess of peace; she resists force and hates disputes and quarreling. So it happens that the efforts to obtain the settlement of legal claims and disputes without violence cling about divine service, and that the law of procedure is divine and ecclesiastical, before it becomes secular. The further exposition of this belongs to the universal history of the law; but here the part that worship played in the development of procedure must be explained.

2. Already on the plane of pure legal order, the priesthood attains great eminence; for even the law is not a human but a divine law. The ereation of the law is a formation of the conditions as they conform and are agreeable to the divinity; and the exercise of the law corresponds to the divine will - at least as soon as religion has advanced to the point where many gods are merged into one unified divine authority.

Hence it is comprehensible that even at that time the law is made mainly by the priests, and that they endeavor to develop the divine will in all directions.

3. But this activity will become still more pronounced when society reaches a basis of peaceable adjustment, and when it is a question of opposing the individual assertion of the law. Here, of course, people will turn first to the priesthood when arbitration courts are desired; for they have the best knowledge of the law. But another reason is also combined with this. The priesthood represents the lighest power; it possesses the authority to eurse

1 [Reprinted, by permission, from Josef KoHLer, "Philosophy of Law" (Albrecht's trans.), Boston Book Company, 1914 (Philosophy of Law Series, XII).] 
and expel the individual who resists. This is a power that exceeds all others, and extends into eternity. Thus, of course, the intervention of the priesthood camnot be avoided, when quarrels and disputes arise, and it will fall more and more to the lot of the priests to solve legal questions, whether it be a matter of the realization of justice or the establishment of the law.

4. Moreover, the people of that time believed in the constant activity and intervention of the divinity for the individual; they assumed that the divine powers would never forsake the innocent; that they would not permit the wrong to triumph. Such a man, therefore, believed that the question of right and wrong was unconditionally solved with absolute certainty by divine intervention; so that all doubt disappeared, and man bowed to the infallible divine decision. This of course strengthened the priestly procedure; for it was just the priesthood that acted as the mediator in the individual's relation to the divinity, and appealed to him to reveal the celestial decision. Thus arose what is called the judgment of god ("Gottesurteil").

5. The judgment of god is not unique. In other matters also the priesthood acted as the medium through which the divinity spoke; thus, for instance, in important State affairs, when responsible decisions were to be made, enlightenment was sought of the divinity; and it was supposed that the divine power could reveal to men the future. Thus arises the augury, that is, the totality of means used to discover the mystery of the future. It did not appear to the same extent in all the nations, but was pronounced among the star-interpreting Babylonians, the Etruscans, and consequently among the Romans; also among the Chinese.

Just as the future was spied out in this way, so too were the present and the past; the divinity said what was right; it announced the circumstances that were determinative for justice; especially who had committed an evil deed and who was guilty of some crime was learned in this way.

6. Thus an abundance of divine judgments arose. They were, first, those that were closely connected with the augury; like the judgment by lot or the seer's power, the priest believing that in some manner he could discover the evil doer. Second, there were the divine juidgments connected with the worship of the dead; it being supposed that a murdered man would point out his murderer, a belief which appears in various forms in the life of the nations: the wounds bleed if the murderer comes near, the bearers of the body suddenly become paralyzed at sight of 
the murderer, etc. 'Then there were the divine judgments proper: the aceused, or sometimes the accuser, or both, were placed in relation to some material object so that this deified object might in some way make known their guilt or innocence; thus, for instance, there were the ordeals by fire, by water, and many others.

It is unjust to suppose that lying and deception, or even mere chance, played a large part in these judgments. There was certainly no intentional deception until all these institutions reached a state of decay, and the priesthood began a rapid decline. But even the effect of chance was limited; for frequently the elements of reason were also involved. The consciousness of guilt or innocence was an important factor in these tests; they assumed more and more the character of allowing the pstchic emotions of the suspected person to appear, when he was confronted with the deified things of nature. Thus, for instance, the fact that the accused trembled, or in some other way expressed inward excitement, might be interpreted as arising from the consciousness of guilt. As regards prophetic vision and the belief in the power of the dead, it may also be assumed that the reasonable motives that led to the conviction that one or another was guilty, so overcame the priests and the bearers of the dead that the cultural phenomena appeared just when consideration of the facts made one or another seem guilty ; for it is a well-known psychic experience that such convictions affect our imaginative activity beneath the surface of our consciousness, and often we are as if possessed by reasonable ideas that grow up in us more or less unconsciously.

But, eren if we must assume that the element of chance was large - and this can scarcely be doubted - yet, it must be taken into consideration that the sacrifice of the individual secured the peace of society ; for the belief in the correctness of the divine judgment was so great that even the imocent man believed himself guilty, and thought that he had been caused to murder by some evil magic spell, or had attracted murderous spirits to himself.

Universal history often requires the individual to be thus sacrificed: the iron tread of progress tramples thousands under foot. This is a terrible phenomenon which we must moderate and ameliorate, as far as possible, in the course of the development of culture. But here we must simply aceept the ways of Dirine Providence, in the conscionsness that thus the progress of the world is accomplished; and we must realize that our modern criminal procedure also demands thousands of innocent rictims, so liable to error are our methods of proof and conviction. 
7. Procedure must advance beyond this stage, and become a Ireccolure of reason, as soon as humanity ccases to believe in the hasis of the earlier procedure; that is, as soon as men no longer assume that the divinity intervenes in the government of the world for every individual, and gives him a good or bad testimonial. When once this belief has ceased, proeedure must be along entirely different lines: the essential thing is, not that it should actually lead to objectively right results, but that society should recognize the dominion of the law in the administration of justice. Hence, as long as people believe in a divine procedure, it can be retained; but when once this belief is shaken, procedure must be built up on another foundation.

This eannot be done, however, until education has advanced so far that it is possible to obtain fairly sound results with the procedure of reason; and this is only possible if judges possess a certain degree of insight, if the impartiality of those who find the judgment is beyond doubt, and also if the conditions of life are such that it is possible, in the main, to reach a reasonable establishment of the necessary facts.

Until man has reached this point, the religious method of proof will continue to live in certain off shoots. It does not die easily, and can still be traced even today in certain institutions.

S. One of its outgrowths, for instance, is the oath, which means in reality that a man curses himself in the expectation of drawing dorn upon himself the curse of the divinity should he be in the wrong. 'This institution can maintain itself for a long time; for even if men no longer believe that the curse of God can be brought down upon us by the will and power of men, yet the belief that it is possible for a man, by appealing to the divinity, to place himself under the divine power of vengeance, is not so remote even from the man of today. In addition, compurgators were called; originally they were relatives; later, any persons of untarnished reputation.

The institution of divine judgment had one very evil result the torture - one of the worst institutions that the erring human mind ever devised. The original idea was that, just as the divine judgment leaves the innocent persons untouched, so too they will be able to bear torture without suceumbing. But even after this idea had gradually declined, torture still remained as a means of extorting testimony which was considered necessary, whether it was to extract a confession, or a statement, or to discover where a treasure was buried or the identity of accessories and confederates. 
Also this institution, eating like a canker into mankind, had to be overcome before modern procedure could arise.

9. In the procedure of today, however, we have first of all the far-reaching division between civil and criminal procedure. In earlier times there was no conception of this difference. Anyone with a grievance simply presented himself before the jurlge, whether he demanded the punishment of another, desired to have his property returned, or was anxious in one way or another to have some disagreement settled. Only gradually, after the State had properly grasped the criminal idea, was the great difference perceived in the activity of the State, whether it prosecuter an evil doer in the name of society, or whether it made it possible for the individual to establish and realize his rights.

10. Courts were originally either priestly courts, popular courts, or chieftains' courts. The priestly courts made an effort in favor of scientific form, and it is not by chance that the science of the law was first developed mainly in religious colleges. Sometimes the chieftains' courts imitated the priestly courts, and possibly competed with them as regards legal education. The popular courts, on the other hand, always maintained a certain degree of informality, and their administration of the law was more or less simple and naïve, proceeding from the midst of the population that practised the law, without careful working out, and more mconsciously than on the basis of principle. Nevertheless, such courts sometimes rose to considerable eminence under the influence of certain unusually learned persons: take, for instance the office of "law-man" in the Scandinavian law. Sometimes, too, the popular court developed into a court composed of persons from among the people who were considered to have special knowledge of the laws; and thus the popular court became an assessors' court ("Schoffengericht").

11. With the growth of the priestly and chieftains' courts, in contrast to the popular courts, a law as understood by jurists ("Juristenrecht") was developed as against the popular law ("Volksrecht"). Both belonged to customary law ("Gewohnheitsrecht"), but the juristic law grasped the matter with a logically trained understanding, the popular law with an instinctive general view of life ("Weltanschauung").

12. As the development of the law is partly teleological, partly logical, no one kind of court will be the only right one; the proper court can only be formed by a combination of the popular court and the technical court. Both can contribute to the advance of 
the administration of justice. Technical law has an easily understood tendency toward exaggerated logic, unwholesome elaboration, sophistry, and quibbling. Popular law, on the contrary, is inclined to lose its balance, and to be so dominated by practical consitlerations that it goes to pieces. It is also in danger of losing itself in circumstantials, and since in it a firm core is lacking, to become the shuttlecock of momentary moods and passions.

\section{SECTION 2}

\section{ANCIEN'T MAGISTRACY 1}

The union of the political authority and the priesthood in the same person did not cease with royalty. The revolution which established the republican régime, did not separate functions whose comnection appeared natural, and was then the fundamental law of human society. 'The magistrate who replaced the king was, like him, a priest, and at the same time a political chief.

Sometimes this annual magistrate bore the sacred title of king. ${ }^{2}$ In other places the title of prytane, ${ }^{3}$ which he retained, indicated his principal function. In other cities the title of archon prevailed. At Thebes, for example, the first magistrate was called by this name; but what Plutarch says of this office shows that it differed little from the priesthood. 'This archon, during his term of office, was required to wear a crown, ${ }^{4}$ as became a priest; religion forbade him to let his hair grow, or to carry any iron object upon his person - a regulation which made him resemble the Roman flamen. The city of Platrea also had an archon, and the religion of this city reculired that, during his whole term of office, he should be clothed in white ${ }^{5}$ - that is to say, in the sacred color.

The Athenian archons, when entering upon their duty, ascended the Acropolis, their heads crowned with myrtle, and offered a sacrifice to the divinity of the city ${ }^{6}$ It was also a custom for them, in the exercise of their duty, to wear a crown of leaves upon their heads. ${ }^{7}$ Now, it is certain that the crown, which in the course of time became, and has remained, the symbol of power, was then

1 B By Fustel de Coulanges, "The Ancient City"; translated by Willard Small; 11 th ed., Lothrop, Lee, and Shepard Co., Boston; reprinted hy permission.] 1052.

${ }^{2}$ At Megara, at Samothrace. Livy, XLV. 5. Boeckh, "Corp. Inser.,"

"Pindar, "Nem.," XI.

4 Plutarch. "Rom. Quest.," $40 . \quad 5 \mathrm{Ibid} .$, "Aristides," 21.

${ }^{6}$ Thueydides, VIII. 70. A pollorlorus, "Fragment," 21 (coll. Didot).

"Demosthene's, "in Meidian," 33. Eschines, "in Timarch.," 19. 
only a religious emblem, an exterior sign, which accompanied prayer and sacrifice. ${ }^{1} \quad$ Among the nine archons the one called king was especially a religious chief ; but each of his colleagues had some sacerdotal function to fulfil, some sacrifice to offer to the gods. ${ }^{2}$

The Greeks had a general expression to designate magistrates;

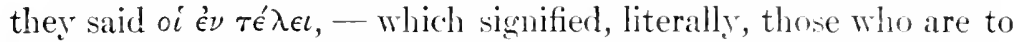
accomplish the sacrifice: ${ }^{3}$ an old expression, indicating the idea that was entertained of the magistrate in early times. Pindar says of these personages that, by the offerings which they make to the sacred fire, they assure the safety of the city.

At Rome the first act of the consul was to offer a sacrifice in the forum. Victims were brought to the public square; when the pontiff had declared them worthy of being offered, the consul immolated them with his own hand, while a herald enjoined a religious silence upon the multitude, and a flute-player somded the sacred air. ${ }^{4}$ A few days later, the consul repaired to Lavinium, whence the Roman penates had come, and offered another sacrifice.

When we examine the character of the magistrate among the ancients with a little attention, we see how slightly he resembles the chief of state of modern societies. Priesthood, justice, and command are confounded in his person. He represents the city, which is a religious association, as much, at least, as a political one. He has in his hands the auspices, the rites, prayer, the protection of the gods. A consul is something more than a man; he is a mediator between man and the divinity. To his fortune is attached the public fortune; he is, as it were. the tutelary genius of the city. The death of a consul is calamitous to the republic. ${ }^{5}$ When the consul Claudius Nero left his army to fly to the succor of his colleague, Livy shows us into how great alarm Rome was thrown for the fate of this army; this was because, deprived of its chief, the army was at the same time deprived of its celestial protection; with the consul, the auspices have gone - that is to say, religion and the gods.

The other Roman magistracies, which were, in a certain sense, members successively detached from the consulship, like that office, united sacerdotal and political attributes. We have seen the censor, on certain days, with a crown upon his head, offering a

1 Plutarch, "Nicias," 3; "Phocion," 37. Cicero, “in Verr.," IV. 50.

"Pollux, VIII. ch. IX. Lycurgus (coll. Didot), t. II. p. 36.

${ }^{3}$ Thueydides, I. 10; II. 10; III. 36; IV. 65. Comp. Herodotus, I. 133; III. 18; Eschylus, "Pers.," 204; "Agam.," 1202; Euripides, "Trach.," 238 .

${ }^{4}$ Cicero. "De Lege Agr.," II. 34. Liny, XXI. 63. Macrobius, III. 3.

${ }^{5}$ Livy, XXVII. 40. 
sacrifice in the name of the city, and striking domn a victim with his own hand. The pretors and the curule ediles presided at religions festivals. ${ }^{1}$ There was no magistrate who had not some sacred act to perform; for, in the minds of the ancients, all authority ought to have some connection with religion. The tribunes of the pcople were the only ones who had no sacrifice to offer; but they were not counted among the real magistrates. We shall see, farther along, that their authority was of an entirely exceptional nature.

The sacerdotal character belonging to the magistrate is shown above all, in the manner of his election. In the eres of the ancients, the rotes of men were not sufficient to establish the ruler of a city. So long as the primitive rovalty lasted, it appeared natural that this ruler should be designated by birth, by virtue of the religious law which prescribed that the son should succeed the father in every priestly office; birth seemed sufficiently to reveal the will of the gods. When revolutions had everywhere suppressed this rovalty, men appear to have sought, in the place of birth, a mode of election which the gods might not have to disavow. The Athenians, like many Greek peoples, saw no better way than to draw lots; but we must not form a wrong idea of this procedure, which has been made a subject of reproach against the Athenian democracy; and for this reason it is necessary that we attempt to penetrate the view of the ancients on this point. For them the lot was not chance; it was the revelation of the divine will. Just as ther had recourse to it in the temples to discover the secrets of the gods, so the city had recourse to it for the choice of its magistrate. It was believed that the gods designated the most worthy by making his name leap out of the urn. This was the opinion of Plato himself, who say's, "He on whom the lot falls is the ruler, and is dear to the gods; and this we affirm to be quite just. The officers of the temple shall be appointed by lot; in this way their election will be committed to God, who will do what is agreeable to him." The city believed that in this manner it received its magistrates from the gods. ${ }^{2}$

1 Tarro, "L. L.," VI. 54. Athenare, XIV. 79.

2Plato, "Laws," III. 690; VI. 759. Comp. Demetrius Phalereus, "Fragm.," 4. It is surprising that modern historians represent the drawing of lots as an invention of the Athenian democrary. It was, on the contrary, in full rigor under the i'ule of the aristoeracy" (Plutarch, "Pericles," 9 ), and appears to have been as old as the archonship itself. Nor is it a democratic procedure: we linow, indeed, that even in the time of Lrsias and of Demosthenes, the names of all the citizens were not put in the urn (Lysias, "Orat., de Invalido," e. 13; "in Andocidem," c. 4): 
Affairs are substantially the same at Rome. The designation of a consul did not belong to men. The will or the caprice of the people could not legitimately create a magistrate. This, therefore, was the manner in which the consul was chosen. A magistrate in charge - that is to say, a man already in possession of the sacred character and of the auspices - indicated among the dies fasti the one on which the consul ought to be named. During the night which preceded this day, he watched in the open air, his exes fixed upon the hearens, observing the signs which the gods sent, whilst he pronounced mentally the name of some candidate for the magistracy. ${ }^{1}$ If the presages were favorable, it was because the gods accepted the candidate. The next day the people assembled in the Campus Martius; the same one who had consulted the gorls presided at the assembly. He pronounced in a loud roice the names of the candidates concerning whom he had taken the auspices. If among those who sought the consulship there was one for whom the auspices had not been favorable, his name was omitted.' The people voted upon those names only which had been pronounced by the president. ${ }^{3}$ If the president named but two candidates, the people necessarily roted for them; if he named three, they chose two of them. The assembly never had the right to rote for other men than those whom the president had designated; for the auspices had been for those only, and for those only had the consent of the gods been assured.

This mode of election, which was scrupulously followed in the first ages of the republic, explains some peculiarities of Roman history which at first surprise us. We see, for example, that quite frequently the people are unanimous for two men for the consulship, and still they are not elected. This is because the president has not taken the auspices concerning these two men, or the auspices have not been favorable. On the other hand, we have

for a still stronger reason was this true when the Eupatrids only, or the Pentakosiomedimni could be archons. Passages of Plato show clearly what idea the ancients harl of the drawing of lots; the thought which caused it to be employed for magistrate-priests like the arrhons, or for senators charged with holy duties like the prytanes, was a religious idlea, and not a notion of equality. It is worthy of remark, that when the democracy gained the upper hand, it reserved the selection by lot for the choice of archons, to whom it left no real power, and gave it up in the choice of strategi, who then had the true authority. So that there was drawing of lots for magistracies which dated from the aristocratic age, and election for those that dated from the age of the democracr.

1 Valerius Maximus, I. 1, 3. Plutarch, "NIarcelhus," 5.

${ }^{2}$ Livy, XXXIX. 39. Velleius, II. 92. Valfrius liaximus, III. 8, 3.

${ }^{3}$ Dionysius, IV. 84; V. 19 ; V. 72; V. 77 ; VI. 49. 
seen the people elect to the consulship men whom they detested. ${ }^{1}$ This was because the president pronounced only these two names. It was absolutcly necessary to vote for them, for the rote was not expresised by "yes" or "no" ; every vote was required to contain two names, and none could be written except those that had been designated. The people, when candidates were presented who were orlious to them, conld indeed show their displeasure by retiring without a vote; but there always remained in the enclosure citizens enough to make up a quorum.

Here we see how great was the power of the president of the comitia, and we no longer wonder at the expression, Creat consules, which referred not to the people, but to the president of the comitia. It was of him, indeed, rather than of the people, that it might be sairl, "He creates the consuls ;" for he was the one who discovered the will of the gods. If he did not ereate the consuls, it was at least through him that the gods created them. The power of the people went no farther than to ratify the election, or, at most, to select among three or four names, if the auspices had been equally favorable to three or four candidates.

Doubtless this method of procedure was very advantageous to the Roman aristocracy; but we should deceive ourselves if we saw in all this merely a ruse invented by them. Such a ruse was never thought of in the ages when they believed in this religion. Politically it was useless in the first ages, since at that time the patricians had a majority in roting. It might even have turned against them, by investing a single man with exorbitant power. The only explanation that can be given of this custom, or, rather, of these rites of election, is, that every one then sincerely believed that the choice of the magistrates belonged, not to the people, but to the gods. The man in whose hands the religion and the fortune of the city were to be placed, ought to be revealed by the divine voice.

The first rule for the election of a magistrate is the one given by Cicero: "That he be named according to the rites." If, several months afterwards, the senate was told that some rite har been neglected, or badly performed, it ordered the consuls to ahdicate, and they obeyed. The examples are very numerous; and if, in case of two or three of them, we may believe that the senate was very glad to be rid of an ill-qualified or ill-intentioned consul, the greater part of the time, on the contrary, we cannot impute other motives to them than religious scruples.

${ }^{1}$ Livy, II. 42 ; II. 43. 
When the lot or the auspices had designated an archon or a consul, there was, it is true, a sort of proof by which the merits of the newly-eleeted officer were exammed. But even this will show us what the eity wished to find in its magistrate; and we shall see that it sought not the most courageous warrior, not the ablest and most upright man in peace, but the one best loved by the gods. Indeed, the Athenian senate inquired of the magistrate clect if he had any bodily defect, if he possessed a domestic god, if his family had always been faithful to his worship, if he himicelf had always fulfilled his duties towards the dead. ${ }^{1}$ Why these questions? Because a bodily defect - a sign of the anger of the gods - rendered a man unfit to fill any priestly office, and consequently to exercise any magistracy ; because he who had no family worship ought not to have a national worship, and was not qualified to offer the sacrifices in the name of the city ; because, if his family had not always been faithful to his worship, - that is to say, if one of his ancestors had committed one of those acts which affect religion, - the hearth was forever contaminated, and the descendants were detested by the gods; finally, because, if he himself had neglected the tomb of his dead, he was exposed to their dangerous anger, and was pursued by invisible enemies. The city would have been very daring to have confided its fortunes to such a man. These are the principal questions that were addressed to one who was about to become a magistrate. It appeared that men did not trouble themselves about his character or his knowledge. They tried especially to assure themselves that he was qualified for the priestly office, and that the religion of the city would not be compromised in his hands.

This sort of examination was also in use at Rome. We have not, it is true, any information as to the questions which the consul was required to answer. But it is enough to know that this examination was made by the pontiffs.?

${ }^{1}$ Plato, "Laws," VI. Xenophon, "Mem.," II. Pollux, VIII. 85, 86,95 .

Dionysius, II. 73. 


\section{SECTION 3}

THE PRIMITIVE FORMIS OF LEGAL REMEDIES ${ }^{1}$

* $\quad * \quad \begin{array}{llllll}\mathrm{I} & & & & \\ & * & * & * & * & *\end{array}$

The value of the precious discovery made by Niebuhr, when he disinterred in 1816 the manuscript of Gaius, does not solely arise from the new light which was at once thrown on the beginnings of the legal system which is the fountain of the greatest part of civilised jurisprudence. There are portions of the treatise then restored to the world which afford us glimpses of something older than law itself, and which enable us to comnect with law the practices dictated to barbarous men by impulses which it has become the prime office of all law to control. At the head of the passages in the work of Gaius which allow the mind's eve to penetrate some little way into the chaos out of which social order sprang, I place the fragmentary and imperfect account, given near the commencement of the Fourth Book, of the old Legis Actiones, ${ }^{2}$ which in the age of Gaius himself had ceased to have more than an historical and antiquarian interest.

Legis Actio, of which the exact meaning does not seem to have been known to Gaius, may be conjectured to have been the substantive form of the verbal expression, legem or lege agere, and to have been equivalent to what we now call Procedure. It has been several times observed that among the Legis Actiones are included several proceedings which are not of the nature of Actions or Suits, but are rather modes of executing decrees. The fact seems to be that, by a course of change which may be traced in the history of Roman law, one portion, 'Actio,' of the venerable phrase 'Legis Actio' has been gradually disjoined from the rest, and has come to denote that stage of the administration of justice which is directly conducted by the Court, together, in some judicial systems, with the stage immediately preceding it. I suppose that originally lex, used of the assumed written basis of Roman law, and legis actio, corresponded roughly to what many centuries afterwards were called Substantive and Adjective Law, the law declaring rights and duties and the rules according to which the law declaring rights

${ }^{1}$ [By Sir Hexry S. Maine. Reprinted from " Early History of Institutions," by permission of Henry Holt and Company, New York.I

${ }^{2}$ [This passage is given in Vol. I of this Series " Sources of Ancient and Primitive Law"), Part IV, Chap. XXIII, See. 4, No. 1.] 
and duties is administered. . . A As a fact, it is only in the most recent times or in the most highly developed legal systems that remedies have lost importance in comparison with rights and have ceased to affect them deeply and variously.

The first and in many respects the most interesting of these ancient modes of proceeding is the Legis Actio Sacramenti, the undoubted parent of all the Roman Actions, and consequently of most of the civil remedies now in use in the world. Several years ago I pointed out ('Ancient Law'), that the technical formalities appeared plainly, upon inspection, to be a dramatisation of the Origin of Justice. 'Two armed men,' I said, 'are wrangling about some disputed property. The Prætor, vir pietate gravis, happens to be going by and interposes to stop the contest. The disputants state their case to him, and agree that he shall arbitrate between them, it being arranged that the loser, besides resigning the subject of the quarrel, shall pay a sum of money to the umpire as remuneration for his trouble and loss of time.' 'This interpretation,' I then added, 'would be less plausible than it is, were it not that, by a surprising coincidence, the ceremony described by Gaius as the imperative course of proceeding in a Legis Actio is substantially the same with one of the two subjects which the God Hephæstus is deseribed by Homer as moulding into the First Compartment of the Shield of Achilles.' Since these passages were written, the labours of more recent enquirers enable us to class this judicial picture of the origin of one great institution, Civil Justice, with other pictorial or dramatic representations of forgotten practices which, in various parts of the world, survive in the forms attending institutions of at least equal importance. It may be seen, for example, from Mr. McLennan's work on 'Primitive Marriage,' that a large part of mankind still simulate in their marriage ceremonies the carrying off the bride by violence, and thus preserve the memory of the reign of force which, at all events as between tribe and tribe, preceded everywhere the reign of law. It is not at the same time to be supposed that these long-descended dramas imply or ever implied any disrespect for the institutions with which they are associated. In all probability they intentionally commemorate not the evil but the remerly for the evil: and, until they degenerate into meaningless usages, they are enacted, not in honour of brute foree, but in honour of the institutions which superseded it, Marriage and Civil Justice.

Almost every gesture and almost every set of formal works in the Legis Actio Sacramenti symbolise something which, in some 
part of the world or another, in some Aryan society or another, has developed into an important institution. The claimant places his hand on the slave or other subject of dispute, and this grasp of the thing claimed, which is reproduced in the corresponding procedure of the ancient Germans and which, from them, was continued in various modified forms far down into the Middle Ages, is an early example of that Demand before action on which all cirilised systems of law insist. The wand, which the claimant held in his hand, is stated by Gaius to have represented a spear, and the spear, the emblem of the strong man armed, served as the symbol of property held absolutely and against the world, not only in the Roman but in several other Western societies. 'The proceedings included a series of assertions and reassertions of right by the parties, and this formal dialogue was the parent of the Art of Pleading. The quarrel between plaintiff and defendant, which was a mere pretence among the Romans, long remained a reality in other societies, and, though its theory was altered, it survived in the Wager of Battle which, as an English institution, was only finally abolished in our fathers' day. The interposition of the Pretor and the acceptance of his mediation expanded into the Administration of Justice in the Roman State, one of the most powerful of instrumentalities in the historical transformation of the civilised world. The disputants staked a sum of money - the Sacramentum, from which the proceedings took their name - on the merits of their quarrel, and the stake went into the public exchequer. The money thus wagered, which appears in a singularly large number of archaic legal systems, is the earliest representative of those Court-fees which have been a more considerable power in legal history than historians of law are altogether inclined to admit. The very spirit in which a Legis Actio was conducted was that which, in the eyes of laymen, has been most characteristic of lawyers in all historical times. If, says Gaius, you sued by Legis Actio for injury to your vines, and called them vines, you would fail; you must call them trees, because the text of the Twelve Tables spoke only of trees. The ancient collection of Teutonic legal formulas, known as the Malberg Gloss, contains provisions of precisely the same character. If you sue for a bull, you will miscarry if you describe him as a bull ; you must give him his ancient juridical designation of 'leader of the herd.' You must call the forefinger the 'arrow'-finger, the goat the 'browser upon leeks.' There are lawyers alive who can recollect when the English sy'stem of Special Pleading, now just expiring, was applied 
upon principles not remotely akin to these and historically descended from them.

The description given by Gaius of the Legis Actio Sacramenti is followed by a lacuna in the manuscript. . . . The text of the treatise begins again with a description of the Condictio, which is saicl by Gaius to have been created, but which is believed to have been only regulated, by two Roman statutes of the sixth century before Christ - the Lex Silia and the Lex Calpurnia. The Condictio, which afterwards developed into one of the most useful of the Roman actions, originally derived its name from a notice which the plaintiff gave the defendant to appear before the Prætor in thirty days, in order that a Judex or referee might be nominated; and immediately (as I myself think) on this notice being given, the parties entered into a 'sponsio' and 'restipulatio,' that is, they' laid a formal wager (distinct from the stake called Sacramentum) on the justice of their respective contentions. The sum thus staked, which was always equal to a third of the amount in dispute, went in the end to the successful litigant, and not, like the Sacramentum, to the State. Lawyers wondered, Gaius tells us, that such an action should be needed when property could have been recovered by the older and unmodified procedure. Many technical answers to this question have been given by modern commentators on Roman law, but we will see whether a better explanation of it camot be obtained by approaching it from another side.

Gaius, leaving the Condictio, proceeds to discuss two of the Legis Actiones, the Manus Injectio and the Pignoris Capio, which cannot be made to square in any way with our modern conception of an action. The Manus Injectio is expressly stated to have been originally the Roman mode of execution against the person of a judgment debtor. It has considerable historical interest, for it was undoubtedly the instrument of the cruelties practised by the Roman aristocracy on their defaulting plebeian debtors, and thus it gave the first impetus to a series of popular movements which affected the whole history of the Roman Commonwealth. The Pignoris Capio also possibly under a slightly altered name, was a mode of execution in later times against property after decree; but this was not its original purpose ats a Legis Artio. It was at first a wholy extra-judicial proceeding. The person who proceeded by it seized in certain cases the goods of a fellow-citizen, against whom he had a claim, but against whom he had not instituted a suit. The power of seizure could be exercised by soldiers. against public officers bound to supply them with pay, horse, or 
forage; and it could also be resorted to by the seller of a beast for sacrifice against a defaulting purchaser. It was thus confined to claims of great urgency or of highly sacred obligation: but it was afterwards extended to demands for overdue arrears of public revenue. I am indebted to Mr. Poste for the observation that the ideal institutions of Plato's Laws include something strongly resembling the Roman Pignoris Capio ; and here again it is a remedy for breach of public duties connected with military service or religious observance.

I take the Pignoris Capio as the immediate starting-point of all which I am about to say on the subject of Ancient Civil Procedure. First of all let us ask whether Gaius himself gives us any hint of its meaning and significance in the primitive Roman system. The clue is slender, but it seems to me sufficiently traceable in the statement that the Pignoris Capio could be resorted to in the absence of the Pretor and generally in that of the person under liability, and also that it might be carried out even when the Courts were not sitting.

Let us go back for a moment to the parent Legis Actio - the L. A. Sacramenti. Its venerable forms presuppose a quarrel and celebrate the mode of settling it. It is a passing arbitrator whose interposition is simulated by the Prator. But suppose there is no arbitrator at hand. What expedient for averting bloodshed remains, and is any such expedient reflected in that ancient procedure which, by the fact of its existence, implies that the shedding of blood has somehow been prevented?

I dare say I shall at the outset appear to be making a trivial remark when I say that one method of gaining the object is to lay a wager. Even now this is one of the commonest ways of postponing a dispute as to a matter of fact, and the truth is that the tendency to bet upon results lies extremely deep in human nature, and has grown up with it from its remote infancy. It is not everybody who, when his blood is hot, will submit to have a quarrel referred to a third person present, much less to a third person absent; but he will constantly do so, if he lays a wager on it, and if, besides being found in the right, he has a chance of receiving the amount staked. And this I suppose - differing, I own, from several high authorities - to be the true significance of the Sponsio and Restipulatio, which we know to have been of the essence of the ancient Roman Condictio, and of the agreement to appear before the Prætor in thirty days. The Legis Actio Sacramenti assumes that the quarrel is at once referred to a present arbitrator ; the Con- 
dictio that the reference is to the decision of an arbitrator after thirty days' interval, but meantime the parties have entered into a separate wager on the merits of their dispute. We know that the liability to an independent penalty attached to the suitor by Condictio eren when it had become one of the most important Roman actions, and that it was still exacted in the age of Cicero.

There is yet another primitive contrivance by which, in the absence of a present arbitrator, a quarrel may be prevented from issuing in bloodshed. The claimant willing to go to arbitration may, in the absence of his adversary, or if he be the stronger, in his presence, take forcible possession of his moveable property and detain it till he too submits. I believe this to have been the true primitive office of the Pignoris Capio, though the full evidence of my opinion will not be before you till I have tracked the same institution through the twilight of other legal systems. Among the Romans, even at the date of the Twekve Tables, it had become (to employ Mr. Tylor's phrase) a meie survival, confined to cases when the denial of justice was condemned by superstition or by a sense of the sternest public emergencr; and this was a consequence of the exceptionally rapid development of Roman law and procedure, and of the exceptionally early date at which the Roman tribunals became the organs of the national sovereignty. You will see hereafter how much reason there is for thinking that the progress of most societies towards a complete administration of justice was slow and gradual, and that the Commonwealth at first interfered through its various organs rather to keep order and see fair play in quarrels than took them, as it now does always and everywhere, into its own hands. To this period, long forgotten among the Romans, those peculiar rules pointed back which survived along with the Pignoris Capio, and which provided for its exercise out of court and during the judicial vacation.

I turn to the Teutonic societies for vestiges of a practice similar to that which the Romans called Pignoris Capio. Ther seem to be quite unmistakeable in that portion of our own English law which is concerned with the power of Distraint or Distress and with the connected legal remedy known as Replevin. The examples of the right to distrain another man's property which are most familiar to you are, I dare say, the landlord's right to seize the goods of his tenant for unpaid rent, and the right of the lawful possessor of land to take and impound stray beasts which are damaging his crops or soil. The process by which the latter right is made effectual retains far more of the ancient institution than does 
distress for rent. For the peculiar power of the landlord to distrain for rent, while it remains an extrajudicial remedy, has been converted into a complete remedy of its kind by a series of statutes comparatively modern. It has always, however, been the theory of the most learned English lawyers that distress is in principle an incomplete remedy ; its primary object is to compel the person against whom it is properly employed to make satisfaction. But goods distrained for rent are nowadays not merely held as a security for the landlord's claim; they are ultimately put up for sale with certain prescribed formalities, the landlord is paid out of the proceeds, and the overplus is returned to the tenant. Thus the proceeding has become merely a special method by which payment of rent, and certain other payments which are placed on the same footing, are enforced without the help of a Court of Justice. But the distraint of cattle for damage still retains a variety of archaic features. It is not a complete remedy. The taker merely keeps the cattle until satisfaction is made to him for the injury, or till they are returned by him on an engagement to contest the right to distrain in an action of Replevin.

The practice of Distress - of taking nams, a word preserved in the once famous law-term withernam - is attested by records considerably older than the Conquest. There is reason to believe that anciently it was resorted to in many more cases than our oldest Common-Law authorities recognise; but about the reign of Henry the Third, when it was confined to certain specific claims and wrongs, the course of the proceeding was as follows: The person assuming himself to be aggrieved seized the goods (which anciently were almost always the eattle) of the person whom he believed to have injured him or failed in duty towards him. He drove the beasts to a pound, an enclosed piece of land reserved for the purpose, and generally open to the sky. Let me observe in passing that there is no more ancient institution in the country than the Village-Pound. It is far older than the King's Bench, and probably older than the Kingdom. While the eattle were on their way to the pound the owner had a limited right of rescue which the law recognised, but which he ran great risk in exercising. Once lodged within the enclosure, the impounded beasts, when the pound was uncovered, had to be fed by the owner and not by the distrainor; nor was the rule altered till the present reign. The distrainor's part in the proceedings ended in fact with the impounding; and we have to consider what courses were thereupon open to the person whose cattle had been seized. Of course he 
might submit and discharge the demand. Or he might tender security for its acquittal. Or again he might remain obstinate and leave his beasts in the pound. It might happen, howerer, that he altogether denied the distrainor's right to distrain, or that the latter, on security being tendered to him for the arljustment of his claim, refused to release the cattle. In either of these cases the cattle-owner (at least at the time of which we are speaking) might either apply to the King's Chaneery for a writ commanding the Sheriff to 'make replevin,' or he might verbally complain hinself to the Sheriff, who would then proceed at once to 'replery.' The process denoted by this ancient phrase consisted of several stinges. The Sheriff first of all demanded a view of the impounded cattle; if this were refused, he treated the distrainor as having committed a violent breach of the King's peace, and raised the hue and cry after him. If the cattle (as doubtless constantly was the case) had been driven to a distance and out of his jurisdiction, the Sheriff sought for cattle of the distrainor and seized them to double the value of the beasts which were not forthcoming - the 'taking in withernam' of old English law. In more pcaceable times, however, and among law-abiding people, the deputy of the Crown was allowed to see the cattle, which he immediately returned to their original owner on a pledge to abide by the decision of a Court of Justice. A day was then appointed for the trial, which took place with the proceeding well known to lawyers as the Action of Replevin. A great deal of technical learning has clustered round it, but for our purposes it is enough to say that the plaintiff in the action was the owner of the distrained cattle and the defendant was the distrainor.

The comparative antiquity of the various steps in the procedure are not, I think, difficult to detect. Nothing can be more archaic than the picture presented by its more venerable details. The seizure of the cattle, the rescue and the counter-seizure, belong to the oldest practices of mankind. We were carried back, by the Legis Actio Sacramenti of the Romans, to a sudden fight over disputed property barely stopped by a easual passer-by. Here, not in a city-community, but among the ancient legal forms of a laalfpastoral, half-agricultural people, we come upon plain traces of a foray. But the foray which survives in the old Law of Distress is not, like the combat of the ancient Roman Aetion, a mere dramatic representation. Up to a ecrtain point it is a reality, and the most probable aecount of its origin is that it is a genuinely disorderly proceeding which the law steps in to regulate. You will see 
presently that there are other independent reasons for thinking that some of the earliest interferences of the power which we call the Law, the State, or the King, with high-handed violence consisted, neither in wholly forbidding it nor in assuming active jurisdiction over the quarrel which provoked it, but in limiting it, prescribing forms for it, or turning it to new purposes. 'Thus the next series of incidents in the practice of distraint - the impounding, the stress laid upon pledge or security, and the acknowledgment of continuing ownership which is implied in the liability of the person distrained upon to feed the cattle, and in the rule that the distrainor shall not work them - belong to a newer range of ideas which dictate the first attempts to moderate reprisals and regulate revenge for wrong. Distress now becomes a semi-orderly contrivance for extorting satisfaction. Many vestiges of this ancient function remain. It has been observed by Blackstone and others that the modified exemption of certain classes of goods from distraint - plough-oxen, for example, and tools of trade - was not in its origin the least intended as a kindness to the owner. It was entailed by the very nature of the whole proceeding, since without the instruments of tillage or handicraft the debtor could never pay his debt. A passage in the 'Dialogus de Scaccario' (ii. 14), prescribing the order in which the goods of the King's debtors are to be sold, strongly bears out this view.

Latest in the order of proceeding, and latest probably in date, came the direct interposition of the State. The King steps in, first, in what we should now eall his administrative capacity. His administrative deputy, the Sheriff, on complaint made by their owner, follows up the cattle, demands a sight of them, raises the hue and cry if it be refused, and seizes twice their number if the bcasts have been driven away. Even when he obtains his view, he can do nothing unless the cattle-owner, denying the right of his adversary to distrain, is prepared with security that he will try the question between them in a Court of Justice. Thus tardily' does that power make its appearance which according to our notions should long since have appeared on the scene, the judicial power of the Commonwealth. Its jurisdiction is obviously acquired through the act of the Sheriff in restoring the cattle upon pledge given. The distrainor has lost his material security, the cattle. The owner of the cattle has become personally bound. And thus both are placed under a compulsion which drives them in the end to a judicial arbitration.

*

*

$*$

*

$\dot{*}$

*

* 
The information furnished to us respecting this primitive procedure by the various bodies of Continental Teutonic law known collectively as the Leges Barbarorum is of a very interesting kind. Almost all of them contain references to Pignoratio or distraint of goods. The Visigothic law expressly prohibits it; and, at the other end of the scale, the Lombardic law has a trace of that licence of distress which has survived in the English Common-Law and permits it after simple demand of parment. But the Salic law, which the most learned Germans now believe to have been drawn up at some period between the time at which Tacitus wrote and the time at which the Franks broke into the Empire, contains a series of very peculiar and instructive provisions on the subject, which have been for the first time fully interpreted by sohm. Under this system, Distress is not yet a judicial remedy ; it is still an extrajudicial mode of redress, but it has been incorporated with a regular and highly complex procedure. A succession of notices have to be given in solemn form by the complainant to the person of whom he complains, and whose property he proposes to seize. Nor can he proceed to seizure until he has summoned this person before the Popular Court, and until the Popular Officer of the Court, the Thunginus, has pronounced a formula licensing distraint. Then, and not till then, he can make what we should call a distress upon his adversary. It seems quite clear that, before the Conquest, attempts were made in England to narrow the liberty of distraint by the same class of restrictions which we find in the Salic Law and the allied Teutonic bodies of usage. These provisions have their close counterpart in the ordinance of Canute that no man is to take nams unless he has demanded right three times in the Hundred; if he obtain no justice the third time, he is to go to the Shire-gemot; the shire is to appoint him a fourth time, and, if that fails, he may take the distress.

It is to be remarked that the process of the Salic Law which answers to our distress is especially a remedy in certiun cases of breach of contract. Distraint, the seizing of names, was certainly employed to enforce a similar class of demands under old English law before the Conquest; and the practice scems to have been known in Bracton's day, though the brevity of his notice does not permit us to understand fully its course and character. In this respect the Pignoration of the Continental Teutonic law is more archaic than the distress with which we are familiar in England, since the fragment of the system which has survived in onr Common-law (and it is to this that it probably owes its survival) was from the first pre- 
eminently a remedy by which the lord compelled his tenants to renter him their services. But on the other hand it is interesting to observe that our English distress is in some particulars of a more archaic character than the corresponding compulsory process of the Leges Barbarorum. Thus notice of the intention to distrain was never in England essential to the legality of distress (Trent $v$. Hunt, 9 Exch. Rep. 20), although statute-law renders it necessary to make a sale of the distrained property legal; and again, in the oldest ancertainable state of our Common-law, though distraint sometimes followed a proceeding in the lord's Court, yet it did not necessarily presuppose or require it.

It should be understood that the Frankish procedure was completely at the disposal of the complainant. It is not a strictly judicial procedure, but rather a procedure regulating extrajudicial redress. If the complainant observes the proper forms, the part of the Court in licensing seizure is purely passive. Even after the exhaustive examination which this part of the Salic Law has undergone from Professor Solnm, it is very difficult to say whether at any point of the procedure the defendant had the opportunity of putting in a substantial defence; but it seems certain that, whenever he could do this, he appeared virtually as a plaintiff like the distrainee in our Action of Replevin, and there is no doubt that, if he submitted or was unsuccessful in attacking the proceedings of the other side, he paid not only the original debt but various additional penalties entailed by neglect to comply with previous notices to discharge it. Such a procedure seems to us founded on the now monstrous assumption that plaintiffs are always in the right and defendants always in the wrong. Yet the assumption would not perhaps have struck the earliest authors of legal improvement as altogether monstrous, nor could they have quite comprehended the modern principle which compels the complainant to establish at all events a prima facie case. With them, the man most likely to be in the right would appear to be the man who faced the manifold risks attending the effort to obtain redress, the man who complained to the Popular Assembly, the man who cried for justice to the King sitting in the gate. It is only when violent wrong has ceased to be rife, when the dangers of contesting the oppressions of powerful men have become insignificant, when the law has heen long and regularly administered according to technical procedure, that unjust claims are seen to be at least as common as unjust refusals to satisfy them. In one particular case, the complaint of the King, the old assumption that complainants are pre- 
sumably in the right was kept long alive among us, and had much to do with the obstinate dislike of lawyers to allowing prisoners to be defended by Comsel.

Gaius, speaking of the Leges Actiones generally, observes that 'they fell into discredit, because through the excessive subtlety of the ancient lawyers, things came to such a pass that he who committed the smallest error failed altogether.'

Blackstone, many centuries afterwards, has the following remark on the English Law of Distress: "The many particulars which attend the taking of a distress used formerly to make it a hazardous kind of proceedings; for, if any one irregularity was committed, it vitiated the whole.'

I quote these passages, not only on aceount of the curious similarity of language between two writers of whom the later could not possibly have read the earlier, but because the exeessive technicality of ancient law which they both notice goes some way to explain the severity and onesidedness of the old Tentonic procedure. The power of seizing a man's property extrajudicially in satisfaction of your demand was, as Professor Sohm justly remarks, a sort of two-edged sword. You might bring your adversary to the ground by it, but you were extremely likely to injure yourself. For, unless the complainant who sought to distrain went through all the acts and words required by the law with the most rigorous aceuracy, he in his turn, besides failing in his object, incurred a variety of penalties, which could be just as harshly exacted as his own original demand. The difficulty of putting the procedure into operation thus at once made disputants cautious in resorting to it, and seemed to men in general to compensate for its inherent inequitableness. This consideration, howerer, though it explains in part how the harsh ancient law reconciled itself to the sense of right, is not by itself sufficient to account for the form which it assumed in the Teutonic Codes, or for the vitality of a portion of it amid our own institutions.

I cannot doubt that the practice which I have called by the general name of Distress kept its place in ancicnt Teutonic law partly as a mere 'survival.' I have already insisted that one great characteristic of the primitive ages was the fewness of human ideas. Societies, just emerging from the savage state, had been used to associate redress of wrong with the seizure of a wrongdoer's goods, and they were unable mentally quite to discomect the two even when they began to regulate the practice. They did not, therefore, supersede distress by a wholly new system, 
but engrafted it on a later procedure, which occasionally took the form so curiously preserved in its main features to our own day by the English Common-law, but which at a relatively later date and more generally may be believed to have shaped itself on the model of the rules observed by the Salian Franks.

It is not possible to explain all survivals by some convenience which they incidentally serve. Some have undoubtedly been continued by superstition, some by mere habit. But those relies of ancient thought and conduct which have been kept alive longest have generally had an usefuhness of their own. Here the private redress of wrong, taken into the legal procedure, served to compel the appearance of the defendant and his submission to jurisdiction at a time when judicial authority was yet in its infancy, and when Courts of Justice could not as yet completely and regularly command the aid of sovereign power. Gradually, as the public force, the arm of the State, was more and more placed at the disposal of tribunals, they were able more and more to dispense with extrajudicial assistance. In the state of Teutonic law represented by the Frankish Code, we find a specific class of cases tried throughout judicially (in our molem sense of the word) from the initial stage to the judgment; but the judgment is not by its own force operative. If the defendant has expressly promised to obey it, the Count or royal deputy, on being properly summoned, will execute it; but if no such promise has been made, the plaintiff has no remedy except an application to the King in person. No long time, however, after the Franks have been settled within the Empire, we find that another step has been taken towards the administration of justice on modern principles, and now the royal deputy will execute the judgment even though there has been no promise to submit to it. At this point Distress is wholly taken out of the hands of private litigants and extrajudicial seizure becomes juticial seizure. The change is obviously a result of the growing vigour of Courts, greatly due in our own country to the derelopment of royal justice at the expense of popular justice. Still English judicial proceedings long savoured of the old practices. Every student of our ancient English forms of proceeding will recollect on what small apparent provocation the King constantly took the lands of the defendant into his hands or seized his goods, simply to compel or perfect his submission to the royal jurisdiction.

The comparison of the various Teutonic bodies of law suggests then to my mind, as regards those systems, the following conclu- 
sions respecting the historical development of the remedies which grew out of the savage practice of violently seizing property in redress for supposed wrong. Two alternative expedients were adopted by nascent law. One of these consisted in tolerating distraint up to a certain point ; it was connived at so far as it served to eompel the submission of defendants to the jurisdiction of Courts, but in all other eases it was treated as wilful breach of the peace. The other was the incorporation of distraint with a regular procedure. The complainant must observe a great number of forms at his peril ; but if he observes them he can distrain in the end. In a still more adranced eondition of legal ideas, the tribunals take the seizure of land or goods into their own hands, using it freely to eoerce defendants into submission. Finally, Courts of Justiee resort to coereion before judgment only on the rarest oecasions, sure as they at last are of the effectiveness of their process, and of the power which they hold in deposit from the Sovereign Commonwealth.

\section{II}

I pass from the early law of procedure in the Roman and Teutonic soeieties to the corresponding branch of another ancient legal șrstem which has been only just revealed to us, and which, so far as its existence was suspected, was supposed until lately to be separated by peculiarly sharp distinctions from all Germanic bodies of usage.

Rather more than half of the Senchus Mor is taken up with the Law of Distress. The Senchus Mor pretends to be a Code of Irish law, and indeed to be that very Code which was prepared under the influence of St. Patriek upon the introduction of Christianity into Ireland. In the present state of our knowledge, no theory can be very confidentiy advaneed as to the date of this Brehon eompendium. It may be that some such revision of the pre-Christian law did take place; it may be that the Brehon lawyers only eonjectured that it must have taken plaee; it may be that a traet of unusual dimensions and proportionately valued by the Brehon lawschool whieh happened to possess it, came gradually to be associated with a name held in pre-eminent honour or pre-eminently sacred, a process of which there are believed to be several examples in the history of Eastern jurisprudence. These doubts, however, as to the true date of the Senchus Mor do not take away from the signifieance and instructiveness of the faet that in a volume of great antiquity, of undoubted genuineness, and eridently thought by 
its possessors to contain all that was important in the law, the Law of Distress, now an extremely subordinate branch of our legal system, occupies a space so extraordinarily large.

I borrow from the Editor of the First Tolume of 'Ancient Laws of Ireland,' the following epitome of the old Irish law of distress as laid down in the Senchus Mor:-

'The plaintiff or creditor, having first given the proper notice, proceeded, in the case of a defendant or debtor, not of chieftain grade, to distrain. If the defendant or debtor were a person of chieftain grade, it was necessary not only to give notice, but also to "fast upon him." The fasting upon him consisted in going to his residence and waiting there for a certain time without food. If the plaintiff did not within a certain time receive satisfaction for his claim, or a pledge therefor, he forthwith, accompanied by a law-agent, witnesses, and others, seized his distress. The distress, when seized, was in certain cases liable to a Stay, which was a period varying according to fixed rules, during which the debtor received back the distress, and retained it in his own keeping, the creditor having a lien upon it. Such a distress is a "distress with time"; but under certain circumstances and in particular cases an "immediate distress" was made, the peculiarity of which was that during the fixed period of the Stay the distress was not allowed to remain in the debtor's possession, but in that of the creditor, or in one of the recognised greens or pounds.

'If the debt was not paid by the end of the Stay, the creditor took away the distress, and put it in a pound. He then served notice of the distress on the debtor whom he had distrained, letting him know where what was distrained was impounded. The distress remained in the pound a certain period, fixed according to its nature (dithim, translated "delay in pound," is the name of this period). At the end of the delay in pound, the Forfeiting Time began to run, during which the distress became forfeited at the rate of three "seds" per day, until entirely forfeited. If the entire value of the distress thus forfeited was exactly equal to the original debt and the subsequent expenses, the debt was liquidated; if it was less than this, a second distress was taken for the difference; and, if more, the overplus was returned. All this proceeding was managed by the party himself, or his law-agent, with the several witnesses of the various steps, and other necessary parties.

'But if, instead of allowing his cattle to go to pound, the debtor gave a sufficient pledge, e.g., his son, or some article of value, to the creditor, that he would within a certain time try the right to the 
distress by law, the creditor was bound to receive such pledge. If he did not go to law, as he so undertook, the pledgre becane forfeited for the original debt. At any time, up to the end of the "dithim," the debtor could recover his cattle by paring the debt and such expenses as had been incurred. But, if he neglected to redeem them until the "ditim" had expired, then he could only redeem such as were still unforfeited.'

The very existence in ancient Ireland of the law thus summarised is almost enough by itself to destroy those reckless theories of race which assert an original, inherent difference of idea and usage between Teuton and Celt. The Irish system of Distress is obriously, in all essential features, the Germanic sistem. It wears, on its face, a very strong general resemblance to the corresponding branch of our Common Law ; and I have seen some very ingenious attempts to account for the differences between the two by suggestions that the primitive contour of the English law of Distress has been impaired. The object of such speculations is to argue for the direct derivation of the English set of rules from the Celtic; but it does not appear to me necessary to resort to a supposition which has great and special difficulties of its own. The virtual identity of the Irish law of Distress with the Teutonic law is best brought out by comparing it with the Teutonic sistems of procedure collectively. Thus the Distress of the Senchus Mor is not, like the Distress of the English Common Law, a remedy confined in the main to demands of the lord on his tenants; as in the Salic and other Continental Germanic Codes, it extends to breaches of contract, and indeed, so far as the Brelion law is already known, it would appear to be the universal method of prosecuting claims of all kinds. The Notice again to the person whose goods are to be distrained which it strennously insists upon, though not found in the surviving English Common Law, fills an important place, as I stated, in other Teutonic collections of rules. So too the attendance of witnesses is required by the Continental Corles; and, though the presence of the Brehon law agent is peculiar to the Irish system and very characteristic of it, certain persons having much the same duties are required by some of the Teutonic sistems to be present during the process of distraint. Further, the Stay of proceedings, which has been compared to an Attachment, seems to me better explained by certain provisions of the 'Leges Bar'barorum.' Lnder some of them when a person's property' is about to be seized he makes a minic resistance; under the Salic law, he protests against the injustice of the attempt; under the 
Lipuarian law, he goes through the expressive formality of standing at his door with a drawn sword. Thereupon, the seizure is interrupted and an opportunity is given for enquiring into the regularity of the proceedings and, probably also, into the justice of the claim. The Lien or charge upon the distrained property, which the Irish law confers on the creditor during the currency of the Stay, is not found in the Continental Teutonic law in this exact shape; but, at a particular stage of the Salic proceedings, the creditor has the power of interdicting the debtor from selling or mortgaging any part of his property until the debt has been satisfied. On the other hand, several features of the Irish system, which are wholly absent from the Continental Teutonic procedure, or very faintly marked in it, belong conspicuously to the English law. Among these may be placed the impounding, and the 'taking in withernam,' but the great resemblance of all, and the common point of dissimilarity from the most ancient of the Leges Barbarorum, lies in the fact that the Irish procedure, like the English, requires neither assistance nor permission from any Court of Justice. In all the Teutonic bodies of custom except the English and the Lombardic, even when the greatest latitude of seizure is allowed to litigants out of Court, some judicial person or body must be applied to before they proceed to extremities. With us, however, the entire seizure is completed before authority is called in ; and the Irish law has exactly the same peculiarity. Not only so, but the Irish law corresponds to the English law of Distress in a very advanced stage of development. It does not employ the seizure of cattle merely as a method of extorting satisfaction. It provides, as you have seen, for their forfeiture in discharge of the demand for which they were taken; and thus is distinguished by an improvement which was only added to the English law by statute after the lapse of several centuries.

The true difficulty in estimating the place of this Irish procedure in the historical development of law arises from doubts as to the part really played by the legal proceeding in: which it terminated. The English process of Distress, wherever it was felt to be unjust, led up to, and ended in, the action of Replevin, and the Court, which ultimately tried the action, practically acquired its jurisdiction through the interposition of the Sheriff in restoring the cattle upon security given. No such interference with a high hand as that of the Sheriff appears to be contemplated by the Irish law; but the Brehon lawyer who ought properly to accompany the distrainor is expressly stated by the Senchus Mor to aid him 'until the deci- 
sion of a Court.' ('Ancient Laws of Ireland,' i. 8.5.) What was the proceeding thus referred to? What authority had the Irish Courts at any time at which the Brehon law was held in respeet? What were these Courts" 'To what extent did they command the public force of the sovereign State? Was there any sovereign power at any time established in any part of Ireland which could give operative jurisdiction to Courts of Justice and operative force to the law? All these questions - of which the last are in truth the great problems of ancient Irish history - must in some degree be answered before we can have anything like a confident opinion on the actual working of the Law of Distress set forth at such length in the Senchus Mor.

The learned Editors of the varions Introductions prefixed to the official publications of Ancient Irish Law are plainly of opinion that such jurisdiction as any Irish Courts possessed was, to use the teehnical phrase, voluntary. The Law of Distress, in this riew, was clearly enough conceived by the Brehon lawyers, but it depended for the practical obedience which it obtained on the aid of public opinion and of popular respect for a professional caste. Its object was to force disputants to submit to what was rather an arbitration than an action, before a Brehon selected by themselves, or at most before some recognised tribunal advised by a Brehon. At the same time, it would seem that there are ancient Irish tracts or fragments of tracts in existence which describe the ancient Irish as having had a most elaborate public organisation, judicial as well as legislative. . . . There are analogies to many of the tribunals described among the rudimentary institutions of several communities. Such tribunals might further be highly developed and yet their jurisdiction might be only voluntary. Sohm appears to me to have proved that the Frankish Popular Courts did not execute their own decrees; if the defendant had promised to submit to an award, the local deputy of the King might be required to enforce it, but, if there had been no such promise, the plaintiff was forced to petition the King in person. There is much reason in fact for thinking that, in the earliest times and before the full derelopment of that kingly authority which has lent so much vigour to the arm of the law in most Aryan communities, but which was virtully denied to the Irish, Courts of Justice existed less for the purpose of doing right miversally than for the purpose of supplying an alternative to the violent redress of wrong. Even then if we suppose that the Ireland which is said to have enjoyed an chaborate judicia! organisation was greatly ruder and wilder than Irish patricts 
wonld probably allow it to have been, there is no such inconsistency between the prevalence of disorder and the frequency of litigation as would make them exclude one another. The Norse literature, which Mr. Dasent has popularised among us, shows that perpetual fighting and perpetual ligitation may go on side by side, and that a highly technical procedure may be scrupulously followed at a time when homicide is an everyday occurrence. The fact seems to be that contention in Court takes the place of contention in arms, but only gradually takes its place; and it is a tenable theory that many of the strange peculiarities of ancient law, the technical snares, traps, and pitfalls with which it abounds, really represent and carry on the feints, stratagems, and ambuscades of actual armed strife between man and man, between tribe and tribe. . . The simple explanation is that the same natural impulse is gratified in a new way ; hasty appeals to a judge succeed hurried quarrels, and hereditary law-suits take the place of ancestral blood-feuds. If the transition from one state of society to another in modern India were not sudden but gradual and slow, as it universally was in the old Aryan world, we should see the battle with technicalities going on in Court at the same time that the battle was waged out of Court with sword and matehlock.

When, however, we are considering the place in legal history of the old Irish Law of Distress, the point to which we have to attend is not so much the mere existence of Courts of Justice as the effectiveness of their process, or in other words the degree in which they command the public force of the Commonwealth. I think I have shown it to be probable that, in proportion as Courts grow stronger, they first take under their control the barbarous practice of making reprisals on a wrongdoer by seizing his property, and ultimately they absorb it into their own procedure. Now, the Irish Law of Distress belongs in one respect to a very early stage in this course of development, since it is even more completely extrajudicial than is that fragment of the primitive barbarous remedy which has survived among ourselves. On the other hand, there are several particulars in which it is not more but distinetly less archaic than the English Common Law. The 'Notice' to the defendant, for which it provides - the 'Stay,' or temporary retention of the goods by the owner, subject to a lien - the witnesses who have to be present, and the skilled legal adviser who has to attend throughout the proceedings - belong to a range of ideas greatly more advanced than that under which all these precautions are dispensed with. Even stronger evidence 
of maturity is furnished by the almost inconceivable multitude of rules and distinctions which the Senchus Mor applies to every part of the proceedings; and our own experience shows that the most remarkable feature of the old Irish law, the forleiture of the property taken in distress when the original debt and the expenses of custody come up to its full value, has its place among the latest improvements in jurisprudence.

* $\quad * \quad * \quad * \quad * \quad * \quad * \quad * \quad * \quad * \quad * \quad *$

Among the writers who have recognised the strong affinities connecting the English and Irish Law of Distress, I find it difficult to distinguish between those who believe in the direct derivation of the English law from pre-existing Celtic customs common to Britain and Ireland, and those who see a sufficient explanation of the resemblances between the two sets of rules in their common parentage. . . The true rival of all these theories of the derivation of one body of custom from another is, of course, the theory of the common descent of all from an original basis of usage which we must, provisionally at all events, call Aryan. Confining ourselves to the practice which we have been investigating, the remedy for supposed wrong by distress, if there could be a doubt of its being a legacy from the primitive Aryan usages, it would be removed by the remarkable detail which connects the Irish with the Hindoo law. The Irish rules of distraint very strongly resemble the English rules, less strongly resemble the Continental Teutonic rules, but they include one rule not found in any Teutonic Code, almost unintelligible in the Irish system, but known to govern conduct even at this hour all over the East, where its meaning is perfectly clear. This is the rule that a creditor who requires parment from a debtor of higher rank than himself shall 'fast upon him.' What possible explanation will cover all the fact except that the primitive Aryans bequeathed the remedy of distress to the commmitie: which sprang from them, and that varieties of detail have been produced by what Dr. Sullivan, in his Introduction, has happily called dynamical influences?

Here is the leading provision of the Senchus MIor on the subject (i. 113):-

'Notice precedes every distress in the case of the inferior wrades except it be by persons of distinction or upon persons of distinction. Fasting precedes distress in their case. He who does not give a pledge to fasting is an evader of all ; he who disregards all things shall not be paid by God or man:' 
Mr. Whitley Stokes was the first, I believe, to point out that the institution here referred to was identical with a practice diffused over the whole East, and called by the Hindoos 'sitting dharna." . . But perhaps the most striking examples of the ancient custom are to be found at this day in Persia, where ( $\mathrm{am}$ told) a man intending to enforce parment of a demand by fasting begins by sowing some barley at his debtor's door and sitting down in the middle. The symbolism is plain enough. The creditor means that he will stay where he is without food, either until he is paid or until the barley-seed grows up and gives him bread to eat.

'The corresponding Indian practice is hnown, I before stated, as 'sitting dharna' - dharna, according to the better opinion, being exactly equivalent to the Roman 'capio,' and meaning 'detention' or 'arrest.' Among the methods of enforcing payment of a debt described in the collection of rules attributed to the semi-divine legislator, Manu (viii. 49), is one which Sir William Jones renders 'the mediation of friends;' but more recent Sanscrit scholars assert that the expression of the original text signifies 'hdarna.' And in the 'Tyavahara Mayukha,' a Brahminical law-book of much authority, Brihaspiti, a juridical writer sometimes classed with Manu, is cited as enumerating, among the lawful modes of compulsion by which the debtor can be made to pay, 'confining his wife, his son, or his cattle, or watching constantly at his door.' This remarkable passage not only comnects Hindoo law with Irish law through the reference to 'watching constantly at the door,' but it connects it also with the Teutonic, and among them with the English bodies of custom, by speaking of the distraint of cattle as a method of enforcing a demand. We have not in the Western world, so far as I am aware, any example of so strong a form of distress as seizing a man's wife or children, but it is somewhat curious that we have evidence of its having been common in ancient Ireland to give a son as a pledge to the creditor for the purpose of releasing the distrained property.

Lord 'Teignmouth has left us a description (in Forbes' 'Oriental Memoirs, ii. 25) of the form which the 'watching constantly at the door' of Brihaspiti had assumed in British India before the end of of the last century: "The inviolability' of the Brahmin is a fixed principle with the Hindoos, and to deprive him of life, either by direct violence or by causing his death in any mode, is a crime which admits of no expiation. To this principle may be traced the practice called dharna, which may be translated caption or arrest. It is used by the Brahmins to gain a point which cannot be accom- 
plished by any other means, and the process is as follows: The Brahmin who adopts this expedient for the purpose mentioned proceeds to the door or house of the person against whom it is directed, or wherever he may most conveniently arrest him; he then sits down in dharna with poison or a poignard or some other instrument of suicide in his hand, and threatening to use it if his adversary should attempt to molest or pass him, he thus completely. arrests him. In this situation the Brahmin fasts, and by the rigour of the etiquette the unfortunate object of his arrest ought to fast also, and thus they both remain till the institutor of the dharna obtains satisfaction. In this, as he seldom makes the attempt without the resolution to persevere, he rarely fails; for if the party thus arrested were to suffer the Brahmin sitting in dharna to perish by hunger, the sin would for ever lie upon his head. This practice has been less frequent of late years, since the institution of the Court of Justice at Benares in 1793; but the interference of the Court and even of the Resident has occasionally proved insufficient to check it.'

You will observe that the old Brahminical writer merely speaks of confining a man to his house by 'watching constantly at the door' as one among several modes of extorting satisfaction. He classes it with forms of distraint more intelligible to us - the seizure of the debtor's cattle, of his wife, or of his child. Though the ancient rule has not descended to us along with its original context, we need not doubt that even in the earliest times it was enforced by a supernatural sanction, since every violation of the Brahminical Code was regarded by its authors not only as a civil offence but as a sin. Thus a Brahmin might quite well be conceived as saying with the writer in the Senchus Mor, 'He who does not give a pledge to fasting is an evader of all; he who disregards all things shall not be paid by God or man.' Many centuries then elapse, which it would be vain to calculate, and almost in our own day we find the ancient usage practised in India, but with modifications corresponding to a great deal of change which is suspected to have occurred in Hindoo theology. The indefinite supernatural penalty has become the definite supernatural penalty incurred by destroying life, and particularly human life. 'The creditor not only 'watches at the door,' but kills himself by poison or dagger if the arrest is broken, or by starvation if payment is too long delayed. Finally, we have the practice deseribed by Lord Teignmouth as one peculiarly or exclusively resorted to by Brahmins. The sanctity of Brahminical life Kus now in fact pretty much taken, 
in Ilindoo idea, the place once occupied by the sanctity of human life, and 'sitting (tharna,' when the English law first endeavoured to suppress it, was understood to be a special mode of oppression practised by Brahmins for a consideration in money. . . .

* $\quad * \quad * \quad * \quad * \quad * \quad * \quad * \quad * \quad * \quad *$

It seems to me that a reasonable explanation may be given of the origin of these practices which now seem so strange. Let us not forget that all forms of Distress, the seizure of wife, child, or cattle, even when wholly unregulated by law, were improvements on older eustom. The primitive proceeding was undoubtedly the unceremonions, unamounced, attack of the tribe or the man stung by injury on the tribe or the man who had inflicted it. Any cxpedient by which sudden plunder or slaughter was adjourned or prevented was an advantage even to barbarous society. Thus, it was a gain to mankind as a whole when its priests and leaders began to encourage the seizure of property or family, not for the purpose of permanent appropriation, but with a view to what we should now not hesitate to call extortion. Similarly, it was a step forwards when men learned to pause before attacking instead of attacking at once. We are told, in the 'Compendium of Kafir Laws and Customs' ' published by Mr. Dugmore and other missionaries (p. 38), that the regular procedure of a Kafir law-suit simulates an expedition in force of the plaintiff and his friends against the village to which the defendant belongs. 'On their arrival they sit down together in some conspicuous position and await quietly the result of their presence. This . . . is the signal for mustering all the aduit male residents that are forthcoming. These accordingly assemble and also sit down within conversing distance.' After long silence a conversation ensues, and the procecting, which is a perfectly peaceable one, is continued by a long series of technical formalities and intricate pleadings. This silent pause of the attacking party is an early form of Notice, in itself onc of the most valuable of institutions; and with it is connected another primitive contrivance, shutting a man up in his house till he gives satisfaction, instead of setting on him at once. A very striking illustration of it is found in a law of Alfred, familiar to historical seholars (Kemble, 'Saxons,' i. 272; Thorpe, 'Ancient Laws,' i. 91) :-

'Let the man who knows his foe to be home-sitting fight not

1 [See Vol. I. Chapter XI ("Sources of Aneient and Primitive Law") for this report.] 
before he have demanded justice of him. If he have power to beset his foe and besiege him in his house, let him keep him there for seven days but not attack him if he will remain indoors. If then, after seven dars, he be willing to surrender and give up his weapons, let him be kept safe for thirty days, and let iotice be giren to his kinsmen and friends. But if the plaintiff have not power of his own, let him ride to the Ealdorman, and, if the Ealdorman will not aid him, let him ride to the King before he fights.' The passage ends with a provision of which the spirit, strange to say, survives in the modern Code making the loudest claim to civilised principle, the Code Napoleon (Code Pénal, s. 32t), to the effect that if the man who is homesitting be really shut up in his house with the complainant's wife, daughter, or sister, he may be attacked and killed without ceremony.

The object of the Law of Alfred is plainly the same with that aimed at by the ancient rule of Brihaspiti. The man who, if nature had her way, would be slain at once, is shut up in his house but left otherwise unharmed till he or his kinsmen par the debt or compound for the money. The English rule is to be enforced by the civil power, the Ealdorman or the King; the Hindoo Brahminical rule by the fear of punishment is another world. The Irish law-tract retains the Brahminical rule as an alternative in certain cases to Notice. But an institution which was perfectly intelligible in a society which included an order of lawyers who were also priests has lost all meaning when this society has been introduced by Christianity to a wholly new set of religious ideas.

\section{Section 4 \\ THE ORDEAL AND THE OATH ${ }^{1}$}

\section{TiIE ORdeiL}

\$1. Universality of the Decision of God. The Ordeal in Primitive Greek Legend. The ordeal, or decision of God - the decision, preëminently - is one of those institutions which have an attraction, not only for the legal historian, but also for historians in general and for every one who is interested in studving the

1 ['This extract is Chapters II and III (in part) of "Etudes sociales ot juridiques sur l'antiquité grèrque," l,y Gustave Glotz (1906, Librairit Hachette et Cle, Paris). MI. Glotz is professor of history at the Lyreeum of Louis le Grand, Paris, and is widely known also for other works on Greek manners and customs, notably "La solidarité de la famille dans le droit criminel en Grèce." The trafslation is by John H. Wigmore.] 
germinal ideas of civilization in primitive peoples. Ordinarily the ordeal is associated by us especially with the medieval practices of Christian peoples. But fo: the thorough understanding of its spirit, as well as of its later forms, we shall do well to study it in a period and an enviromment further removed from our own belicfs. Some effort is required, of course, to enter into a type of thought so alien to our own developed notions. But it is worth our while; for this eustom of the ordeal is one of those which had a potent influence in primitive societies and have contributed largely to the first fruition of legal ideas, - customs destined to perpetuate themselves in fertile variety by continual differentiations.

From France to Polynesia, from Scandinavia to farthermost Africa, there is perhaps no country in the world which has not made use of some test of mortal import, imposed upon him who would enforce his elaim or demonstrate his imoeenee. Trial by boiling water or by cold water, trial by fire or by poison, - whatever the method and whatever the era, the belief is always found, at a certain stage of a people's social and religious growth, that the best mode of ending a eontroversy is to place one (at least) of the disputants in some position of serious peril, and thus to force the divine beings to take sides for the sake of doing justice.

The idea inspiring this procedure - at once religious and awful - may be clearly seen in the preliminary ceremony. At the crueial moment, the petitioner for divine intervention generally the one whose body is to undergo the trial - utters a prayer, a rlirect and formal appeal to Divine Providence. In communities where the priesthood forms a caste, the professional man of God is the one who comes forward to make the solemn invocation. This ntteranee, for example, of the Hindu priest, was as follows: ${ }^{1}$ "O Fire! thou seest, eren as a witness, into each human being's heart. 'Thou alone knowest that which mortals eannot know. The aceused man stands before Thee, seeking exoneration. Let him escape the harm which impends in the test now to be applied to him." Or, again, the Christian priest, approaching the stream into which the accused was to plunge, spoke thus: "I adjure Thee, Water of trial, in the name of God, that Thou give no good reception to this man, if he be guilty in aught."

1 A number of these formulas may be found collected in Kovalewsky's "Coutume contemporaine et loi ancienne," pp. 397-398. [For a collection of Germanic formulas see Vol. I, Ch. XXIII, No. 5.] 
In communities where no priestlood obtained, the party himself uttered the appropriate formuli. At Rome, for example, the restal virgin sentenced to submit either to death or to safety. by a miracle. praved: "O Vesta! guardian of Rome"s city, if I have fulfilled towards thee for nearly thirty years all my religious duties with strictness, if my soul is pure and my boly spotless, appear now and help me; let not thy priestess perish in dishonor. If I have acted sinfully, punish me, and let my death atone for the cicy." I

ind so, whether it be Hindus, Romans, or medieval Christians (and among other peoples the same is true), they all exhibit the firm conviction that Gorl himself will pronounce the truth either by letting the party perish or by saving him from an otherwise certain destruction.

And ret this conception of a justice made visible upon earth by ${ }^{\mathbb{f}}$ a divinity, master of fates, is in fact the conception of a relatively advanced epoch. It presupposes that the primitive hman hordes ${ }^{\text {is }}$ have already formed social groups of governed communal life ${ }^{\text {at }}$ before they can have attained a belief in superior deities wher watch over those common interests and dispense justice. Thi inception, which is an adranced one, has been applied to a crude and earlier procedure; it dit not create that procedure. And so, is we ask, what were those more primitive ideas which themselve ${ }^{\text {nin }}$ gave rise to the ordeal?

To answer this question, we must go far behind the period of written laws and codified srstems. It is a safe general canon that every custom has undergone important changes before it comes to be reduced to a formal document. And the primary significance of the ordeal must ordinarily be expected to appear only in the customs of those tribes which are still more or less meivilized and are known only to the occasional explorer of distant lands. And yet, on the other hand, it is full of risk, after all, to base our inferences on a comparison of peoples differing not only in their stages of civilization but also in their social habits. Some scholars, and sound ones, have declined to trace the evolution of a trait by shifting from one country to another; they insist on a strieter method. If one could point to two successive conceptions of the ordeal in the same community, there need be no hesitation in deeming that the phenomenon in question exhibited a genuine principle of evolution.

Such an instan se can be found. We have it in Greece. Finough

${ }^{1}$ Denis of Halicarnassus, II, 68. 
data are there extant to exhibit to wis both the decision of God in its dassical mode, and the ordeal in its primitive conception.

The Greeks of the advanced period had not forgotten the use of ordeals. In Sophocles" "Antigone," the guards set to watch the body of Polynices, denying neglect of their duty, converse thus: "We were ready to take up the red-hot iron, to walk through the flames, and to make oath before the gods that we were neither guilty nor privy to it." I Again, in sicily, where there werecraters of boiling liquid, emitting poisonous gases, and consecrated to the goods I'aliei, it was customary on the brink of these craters to take oaths which would bring death to perjurers; for the gods spared the innocent and destroyed the guilty. ${ }^{2}$. .

We need not be surprised at the abundance of evidence of ordeals in pre-historic times in Greece. That country teemed with legends. Scholars were long accustomed to explain these myths as the dramatic imagination of reasons for natural phenomena. "3ut to-day we do not concede that entire communities, especially " $n$ the crude childhood of humanity, were so absorbed in the conta emplation of sum and moon, storm and lightning, as to know no mor themes for their recitals. These stories are in truth history, $d$ - the history of real men, who loved and hated, triumphed anc. suffered, lived and died. These fantastic shadows of divine 'Ippets, viewed close at hand, become beings of flesh and blood, who breathe and move. Even in Nature's forces the primitive man saw manifestations of beings like himself. He explained the relations of the elements by the same relations, hostile or friendly; which he saw among other men around him. Thus, even in those myths which are open to a naturistic interpretation, we see rerealed the minds of those who invented them, as well as the phenomena which they were meant to explain. But, in the case of an infinite number of myths, they were certainly not meant to mask cosmic forces or divine beings in a human guise. They are merely the ingenuous memorials of early beliefs and primitive (ustoms. They served to transmit the law and the religion of a rudimentary social condition.

If, then, we eull from them the details added by later generations, they become indisputable evidence and rank as historical sourees. 'The collections of the Greek myth-writers contain virtually a custumal of primitive law. Among the institutions therein depicted, the ordeal is prominent.

1 "Antigone," 264-266.

2 Polemon, in Macrobius, "Saturnalia," V, 1', 15 ff. 
\$2. The Ordeal in the Crenos. Its principal Lues. Its E.tfects. The communities in which the ordeal appeared harl not ret become city-states. 'They were the "genoi," or family wapus, clans, or patriarchal families. In these small wroups, the later distinctions growing out of a complex social life were not ret known. Civil and eriminal law, public law - all these divisions formed but a single subject; and law was as pet undistinguisted from religion. Even religion was not yet imbued with that ethical spirit which was later to dominate as the eommunity grew more numerous and extensive. The gods were not di-pensers of justice. They are beings who wield the supreme forces of the world. They are hostile and malevolent to all who do not belong to the group protected by the gods: and they are the erer-ready champions of all who share their own blood or race.

Amidst such beliefs, when quarrels arise, it is not a question of deciding which party has the law on his side. It is not even a question of finding the moral truth or the justice of the case, as between the disputants. To settle it, what is wanted and wha suffices is that the party shall be able to invoke some magical power and thus to overcome the dangers which in the natural course of things would subject him to destruction. This power he cas set from the gods; it belongs only to the race of the gods. His blood-connection is what vindicates his high lineage and thms his innocence; for the gods will implacably destroy the worthles creature who invokes them without any claim to be of their blood.

Who, then, were the persons who could thus vindicate themselves when in peril of life or limb? Here we must remember that the sturdy warrior supported by a following of other warriors had no need to demonstrate his lineage with the grods; for this was apparent to all men. But the humble being who existerl in obscurity on the fringe of the community, - he it was who needed this help, and conld save his life and his honor only by the posiession of some secret talisman. Who were these, the discarted class in primitive society? 'They were the aliens, the ontsider: and particularly also the women and the children. Although the ordeal was used in an imnumerable variety of canes, it was preeminently the weak who were liable to be called upon to furnish this proof of worthy origin, of a right to life and to saffety. We can even say that the weaker elass, instead of being sometimes: complainants and sometimes defendants, were always put upon the uginsive. The use of the ordeal has this general feature rumning 1. it. 
A typical case was that of the woman whose delivery or pregnancy of a chilel revealeel her misconduct. She was culpable, if she had introduced into the group of relatives a being not of their blood. She was not gruily, if she had been intimate with a scion of the gods; for the blood of the child woukt be that of the gods. Often and often, in the legends, the woman cxcuses herself by as erting that she hat been visited by a celestial being. But this she must prove; ant the proof would be that, on subjecting her to the risk of death, the god would reveal his interest and would save her. Danaë's legend is the most typical case. ${ }^{1}$ Her father Acrisius had immured this maiden in a cave, that she might never become a mother. After several years, he heard the cry of a child, in the hollow of the earth. He brought her out, with the boy, placed her before the altar, and demanded that she name the father. "Zeus," she replied. But Acrisius believed her not. What proof shoult he require? He subjected the unfortunate girl to a dreadful test, and set her afloat on the sea. This same idea, in legends almost identical, reappears in all parts of Greece and even in Rome. The Vestal virgin, Rhea Silvia, when she gave birth to Romulus and Remus, named Mars as their father, and the infants were set afloat in a cradle. In all of these legends, when the social group grants to the virgin-mother her life without dishonor, it concedes thereby that her lover was a man of pure race, a seion of the gods. This helps us to understand how it is that in the mythologies so much is sait about the gods having to do with the daughters of mortals. ...

This mote of treating the woman herself was applied, naturally, to her chilfl also. Perseus was subjected to the test with his mother I)anaë; Telephus with Auge; Dionysus with Semele. But sometimes, too, the child alone is exposed to the ordeal, while the erring mother is kept alive in the clan, reserved for dishonor ant a harsh fate. Numerous are the heroes who entered upon life through the test of exposure to death; the legends abound in them. Almost always the circumstances point unmistakably to an ordeal as the interpretation. In most of the instances, the test was that of water. The story of Romulus and Remus is familiar; it runs the same as the story of the twins Neleus and Peleus, in Greece; of Moses, among the Hebrews; of Sargon of Agade, king of Chaldea. Was all this nothing more

1 In the narration of Pherekydes, preserved hy the scholiast A pollon $\mathrm{dc}^{+}$ of Rhodes, IV, 1091 ("Fragmenta historicorum græcorum," J frag. 26 ). , If. 
than an imaginative fable, transmitted from country to country? On the contrary; it reveals a custom of primitive peoples, reappearing everywhere, from age to age. I'roof enough of this feature is found in the fact that it appears also among the primitive Celtic and Germanic peoples, at the close of the lioman empire; for the emperor Julian, and many others, report that the married women of those tribes, when they bore a child of suspected ardulterous origin, were sent afloat on the surface of the lhine; if the child drowned, the woman was deemed guilty; if it survived, it was deemed legitimate and the mother imocent. ${ }^{1}$

The ordeal, then, in primitive times, served to decide, not only questions of guilt, but also questions of personal status. Hence it was well suited for deciding competing claims to a succession; that is (inasmuch as a system of collective and undivided property could hardly give rise to a property succession in the molern sense), when competitors claimed the succession to the chieftainship and the inheritable priesthood. The chief must be a scion

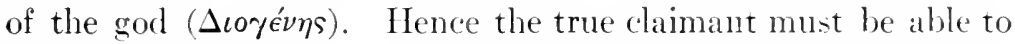
prove his origin, and to demonstrate his poteney, so that none could doubt his superhuman traits. This would be a case of the ordeal applied to persons of high degree. Both parties might be subjected to it, but its import was the same. It signified the triumph of the one who was acceptable to the gods, and his investment with the chieftain's insignia, as being of divine race.

In the primitive ordeal, it remains to note, the consequences were decisive. The method was simple (or complex, aceording to the point of view). But whether the party offers his own body for the test; or whether he accepts an adversary's challenge; or whether he is summoned to it by a third person; the dispute is terminated by the ordeal. If the subject of it survives, he is rictorious; if he dies, then this simply shows that the evil influenees have been more potent than the talismans. The esiential principle is that the event of the ordeal serves both as a proof and and as a judgment without recourse. In place of a jurdgment pronounceable by men, we have a judgment accorded by the gods. And better than a human judgment, the gods execute their judgment in pronouncing it. It is all one act. They are both judges and exeentioners. They vindicate the immoeent by saving his life, and they condemn the guilty in killing him.

And so in the primitive ordeal, the proof is not yet distinguished li

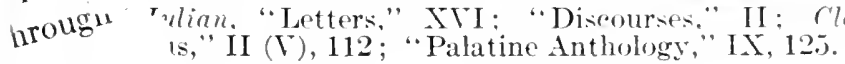


from the julgment, nor eren from the penalty. In one aspect it is procedure; in another aspect punishment; its notion is that by placing the subject of it at the discretion of the gods, he is given a chance, more or less likely, of survival. From the most painless test to the capital penalty, from safety to almost certain death, the various ordeals form a series of finely graded risks and sufferings. In short, the ordeal of primitive peoples forms by itself a whole system of penal law and procedure, in spite of its lack of any of the categories which at a later day the human mind was destined to evolve.

\$3. Relation of the Ordeals to Religious Beliefs. The Ordeals by Sea. The Mouths of IIell. Coincident Tariances in Ordeals and Beliefs. The Greek legends reveal to us, not only the legal side of the primitive ordeal, but also, and strikingly, its essential relation to religious ideas. It can be shown that the Greeks, in their usual ordeals, while adhering to practices and beliefs common to primitive humanity, nevertheless gave to these beliefs an expression more modern, more national, and more original.

In all primitive peoples, the subject of the ordeal is required to make visible to the observers his ability to approach in safety the all powerful Beings or to take them into his own body - to face and oppose their terrible presence or to absorb their power of destruction, to send safely the death-bearing fluid over his body or into his body. Thus the ordeals might be applied either externally or internally. The subject might immerse himself in cold water, or thrust his hand into boiling water, or walk through a fire or over glowing coals, or hold out red-hot irons. Or he might partake of those foods or liquids which were reserved in popular belief for the gods and were thus indued with magical qualities, - substances both sacred and accursed, able to give immortality or death; for to the primitive mind it was the god's presence which alike accounted for the lethal and the benignant powers.

All these forms of ordeals were known to the Greeks, even in the classic age.... But their choice ran to others. Ordeals had naturally showed marks of the popular beliefs as to the future fate of the wrongdoer; for the ordeal was to demonstrate whether the man was stronger than death. He was placed between life and death, at the very boundary between the world of men and the workl of spirits, so that he would naturally be forced into the latter, and yet by the magic of a divine birth or by the protection of a god he could be retained on earth. Thus the method and the place of the test varied according to the local conception of 
a future life. In primitive communities, the ordeals reveal sometimes a whole eschatology.

The Greeks, then, being born sailors, and susceptible alike to the fascination and the terror of the sea, pictured the country of the dead as lying far away, beyond the countries of the living, on the other side of the great river Ocean, where the sun sank from sight beneath the waves. And so, to put a human being in the presence of death, it was enough to set him afloat on that seat which led to the fateful Ocean. One of two issues there must be; the subject was borne off to the coasts whenee no mortal returned; or he was saved by the waves, vindicatcd and consccrated by a miracle.

Such is the explanation of all those legends in which the hero is shut up in a coffer and cast into the sea. Sargon, in Chaldea, was placed in a chest coated with tar; Moses, in the Hebrews, is placed in a basket; Romulus and Remus in a cradle; among the Celts, the infants of doubtful paternity were set afloat on a shiekd and so the god who decides, in all these instances, is the river. In Greece, the subject was usually placed in a $\lambda a \rho^{\prime} \nu a \xi$, or box with a lid, and committed to the decision of Poseidon.

The same beliefs explain the leap into the sea, a variant from the usual form of the cold-water ordeal. The subject was taken out to the deep in a boat, and was then to plunge into the waves. A valuable instance is revealed in the recently discovered poem of Bacchylides. The hero of the ordeal is Theseus. He has embarked on the ship taking the youths and maidens to be sacrificed at Crete to the Minotaur; and as the tragic royage approaches its end, king Minos attempts to embrace the beautiful maiden Eriboia. Theseus, running up, interferes to save her, and justifies his attack on the king, the son of Zeus, by proclaiming his own sonship to Poseidon; and to prove his divine origin he proposes a duel by miracle. "Let us display our powers, and the god shall determine

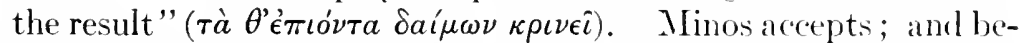
gins by asking Zeus for an $\mathrm{cmphaticsign}$ of recognition ; \%eus answers with a clap of thunder. 'Then it is 'Theseus' turn to show that he is protected by his father. Minos tosses a ring into the sea ; let Theseus go and recover it from the depths of his father's home. He falters not, utters not even a prayer, leaps in, and the waves cover him. Straight passes the hero into the palace of l'oseidon; there he finds Amphitrite, who clothes him in purple and places her own erown on his head. Now he can return to the surface of the waters; for he holds proof which will confound those who 
believed him an impostor. ${ }^{1}$ Except for the ending, which the poet idealized, this legend is replete with reality. . . .

Another variant of this form was the leap from a cliff. The Greeks believed that the border of the land of the dead was marked by a lofty cliff, the white or Leucadian Cliff, ${ }^{2}$ - the cliff already bathed in the pale light that envelops the souls of the dead. A cliff of that name could be found on almost any part of the Greek coasts. Wherever some unfortunate one had sought death by leaping from the eliff into the vortex, this was enough to make one more Leucadian Cliff. The leap might have been taken in expiation, or it might have been done as an ordeal. All along the Mediterranean one can trace the cult of Ino-Leucothea, the erring wife who leaped into the sea and became the White Goddess; or the cult of Britomartis-Dictrnna, the virtuous maiden who cast herself into the sea to save her innocence from the wicked pursuer, and became the "mailen of the net," the maiden of safety. In that whole region these two heroines typify and consecrate the leap from the white eliff, the leap into death, the leap to punishment or glorification. Before it dwindled to a mere religious ceremony on the island of Lencadia, the Leucadian leap had this broad relation to a proceeding which involved both law and religion.

Thus the impression produced on the Hellenic mind by the ordeals of the sea was deep and enduring. That mystic notion in their geography - the Ocean leads to the realm of the dead came also to import the ethical idea: There is a Justice of the sea. From Thetis to Themis is not a long step; in forms more or less variant, the two godklesses are frequently brought together in the legends. The primitive superstition was in time transmuted into a dogma. The miracles of justice ascribed to the sea never lacked believers in Greece. Long after the popular courts had ceased to employ these terrible ordeals, popular opinion still looked upon the safe return from a sea-royage as a strong presumption of imnocence; towards the end of the 5th century B.c., an accused person (it is recorded), arguing before the Athenian judges upon "the best and most credible tests," appealed to the signs given by the gods, and urged in proof that he had many times traversed the sea without shipwreck. ${ }^{3}$. .

And so, in the variety of their ordeals, as well as in their predilection for the justice of the sea, the Greeks of the primitive age reveal to us the most striking features of their legal, social, and even

\footnotetext{
${ }^{1}$ Bacohylides, XVII.

2 Odyssey, XXIV, 11.

3 Antiphon, "On the Murder of Herodes," $81-\$ 3$.
} 
economic life, s well as their rooted beliefs in the life after death. And these same sources enable us to perceive how the methods of the ordeal could and must alter in accordance with the beliefs as to the hereafter. Among almost all the peoples who have left behind them documentary sources, the ordeal by cold water is deemed favorable to the accused when he sinks to the bottom, but condemnatory when he floats on the surface; archbishop Hincmar of Rheims, for example, a Frank of the 9th century, says of it (as also did the Hindu law of Manu) : "Innoxii submerguntur aqua, culpabiles supernatant." 1 And yet at Babylon, by the Cocle of Hammurabi, it is the guilty one who is retained below by the god of the river, while the innocent is restored to the surface. $^{2}$ Whence this contrariety? Is it due to the mere eaprice of chance? Or does it mark some distinctive trait of two races, the Indo-Europeans and the Semites? Neither. A resort to Greek annals demonstrates that we have here, not a difference between racial traits, but merely a differenee in the stages of civilization. For a long period they left it to the divine forces to determine whether the subject of the ordeal should be released unto life or retained for death. This was the primitive solution, simple and realistic; it attributed the disappearance to death, and the death to dishonor. King Minos and the judge Themison ${ }^{3}$ make their decision in the same way as does the Code of Hammurabi. But later, in the period made known to us in the newer parts of the Odyssey, when the idea had developed that the gods would keep among themselves the worthiest men, to bestow upon them a share in their own deathless happiness, the Greeks liked to believe that, in the ordeal by immersion, the god of the water kept to himself those who were dear to him and repudiated the others. This solution, more idealized and more refined in its moral element, was also that of Manu. In Greece, it finally served as a principle for divination, and was found in all consultations of the oracles. ${ }^{4}$ The ehange is signifieant. This simple detail of the procedure, altering beneath our eyes, is not an arbitrary and purposeless change in the rule of the game. It reveals the soul of a people in its deepest beliefs, - its conception of the other world.

${ }^{1}$ Hincmar, "De divortio Lotharii et Tethergie," 6 (Migne, "Patrologia," vol. CXXY, col. 665).

2 "Code of IIammurahi," pol. V, 1. 33.

3 Scholia of Euripides, "Hippolytus," 1200; Apollodorus, III, 15, 8, 3; Herodotus. IV, 154.

4 At Epidaurus Limera, the threw eakes into a pool (as formerly they threw the erring wom in), and if the calies floated, it was a sign of misfortune (Pausanias, III, 23, S). 
\$. Changes of the Ordeals in II istoric Times. Teath Penalty, Oath, and Torture. These ordeals, with their variety of uses, what became of them in the historie period of Greece? If we concede that this custom of law and religion took its origin in a time when law and religion were one, and when the State was still restricted to the narrow circle of the family, we shall not be surprised to find that as justice, religion, and government become more and more separate, they preserve the primitive customs while adapting them to uses more and more distinct.

When the State's justice attained authority enough to formulate judgments and to give them effect, the proof and the penalty would no longer be merged. And so the ordeal in its primitive form is not found in the amnals of Greek courts. So far as we find it still used, in the classic period and up to the end of the Greek era, its persistence is explained simply by the circumstance that the parties to a dispute - even in a criminal case - could always scttle it without recourse to the courts. But in the courts themselves, the ordeals luad ceased to be both proof and penalty in one, and had become cither a proof or a penalty. The most formiclable - those which imported death, unless a miracle interposed - now servel as capital punishments; for in Greece, as in Rome, the party condemned to death was cast into the sea in a sack (if his crime had been specially atrocious) or hurled into an abyss (for an ordinary crime). As a proof, it had degenerated, for the most part, into a mere form, or even a symbolic utterance; the oath had replaced the ordeal, and preserved its memory in the terrible imprecation which it contained; it was merely an ordeal in words. Nevertheless those persons - the "capite minores" - who were not permitted to take oath, were still subjected to an actual ordeal. This was the inquisitorial torture.

How did it come to pass, in the history of so many peoples, and not only among the Greeks, that we find everywhere, in the beginnings of probative procedure, the compulsory alternative of wath and torture? The only logical bond between these two methods is the imprecation. Their common origin, the source of their lethal potency, is none other than the primitive ordeal. . . .

\section{THE OATH}

\$1. The Oath in (icmeral. ${ }^{1}$ [The oath (öpкos) is, in Greek traditional etrmology, a moral " b " limiting freedom of a [This first sertion is summari " OHerodes," $s$ thor's text.] 
man's words and actions. Over this barrier the gorls keep watch. By invoking the gorls in an oath, a man binds himself to another

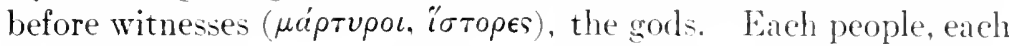
town, had its appropriate gods to invoke: and different purposes and different men might have different gods by whom to swear. The form also varied. A sacred stone usually marked the appropriate spot. In the Areopagus there were the stones "of erime" and "of accusation." And the place ordinarily must be a sacred one, - a temple in general, or some special temple.

The oath-taker stood ereet, his hands stretched towards heaven, his eyes looking upwards. Sometimes one hand was placed on the altar, - as if touching the god. And generally a sacrifice must be performed. Probably the dramatic sacrifices of the Greeks originated in the Orient. In the most solemn ones, the oath-taker stood upon the dismembered rictims; this was the custom preserved at Athens in the antique proceeding for homicide; here the sacrifice must be a triple one, - not less than a boar, a ram, and a bull. For the sacrifice, sometimes, might be substituted some other ceremony; the Phocians cast a mass of iron into the sea ; the parties to a treaty grasped hands.

The oath-formula was not complete without an imprecation $\left(\dot{a} \rho a^{\prime}\right)$; this was the sanction which made it binding. The simplest was: "If faithful, may much good come unto me; if false, may evil come in place of good." A grandiloquent form in Crete ran thus: "For those who swear in good faith and keep their oath, may" children bring joy, may the earth produce in plenty, may the herds be fruitful, and may all other blessings deseend on them and their children. For the false, may neither lands nor herds be fruitful ; may they perish miserably, they and their whole tribe."

Innumerable were the oceasions for which oaths were used. Citizens, soldiers, officials, took the oath in all important undertakings. The Athenians, before entering on the political and judicial duties of the assembly of the Heliasts, took a special oath. The arthons swore to govern justly and aceording to the laws. The citizen pleading an excuse for not assuming a public duty must verify it by an oath ( $\dot{\epsilon} \xi \omega \mu \sigma \sigma i a$, swearing off). And the citizen who gave notice of a prosecution acrainst a member of the assembly for introdueing an illegal proposal must pledge his faith to this by

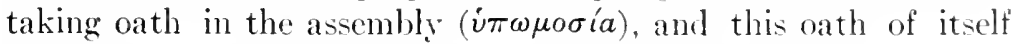
served as a veto suspending proceedings on the bill.]

In judicial procedings, we distinguish the oath of the judges, the oath of the parties, and the oath of the witnesses. 
\$2. The Judges' Oath. The right of pronouncing upon the life and property of other men was regarded by the Greeks as a function of divine origin. It must be delegated from the gods. The judge must swear to be responsible before their sight for the use made of the right. ${ }^{-}$Even in the imaginative tale of Atlantis, Plato depicts the ancient kings, assembled in a court of justice, taking oath at a table which bears, together with the laws, a formula of oath and imprecation.

This need for giving to the judge's decision some superhuman support is seen in two distinct aspects. At the beginning, the judge is merely an arbitrator, even when the king is the judge. Ire directs the proceeding, and proposes some settlement. But only when the proceeding leads to nothing and the parties reject all compromise, - only then does he pronounce a judgment sanctified by an oath. And the oath has only a limited effect; it avails only for the particular case. But in later times, when community-justice has come to have a solid position, the judges who embody it in their office receive their general power from the gods by an oath taken at their installation. That they may become once for all invested with judicial authority, they take the oath once for all. And this oath gives validity to all their judgments to come; it is an oath of investiture, unlimited in its effects. Plato draws this precise distinction between the special oath, to be administered to the judge "at the moment when he is about to render judgment," and the general oath which he takes for all purposes, promising to ober the laws."

In the heroic age, Aristotle tells us, ${ }^{3}$ "the kings judged sometimes without an oath, sometimes with one." That is, in the former case, they followed the procedure conformable to primitive custom; in the latter case, they attested the source and the bindingness of their decision as inspired by Zeus.

This early practice appears in the laws of Gortyn. The judge is to render his decision ( $\delta \iota \kappa \delta^{\delta} \delta \epsilon \nu$ ) according to the witnesses' testimony or the parties' oaths, in the cases for which that mode was specified; in other cases, he is to decide upon his oath (ó $\mu \nu v \dot{\nu} \tau a$ $\kappa \rho i \nu \epsilon \iota \nu)$, that is, he is to furnish proof and corroborate his decision by his oath. Even in those cases where the ordinary modes

${ }^{1}$ Perrot, "Essai sur le droit public d'Athènes," pp. 293, 294: "The oath was a solemn and religious act, establishing a strict bond between gods and man; thus it was necessary for the judge. It raised him out of the crowd and above it, and gave him prestige. It compelled even the malcontents to accord to his decisions an involuntary respect."

2 Plato, "Critias," p. $119 \mathrm{E}$; "Laws," XII, p. 948 E.

${ }^{3}$ Aristotle, "Polities," III, ix, 7. 
of proof were preferred, ret if they were lacking or were insufficient, the judge could supply their place by his oath. The foregoing instances throw a clear light on the oath of the "diaetetes," or arbitrators, at Athens. The public arbitrators, Aristotle tells us explicitly, took an oath before pronouncing their lecision; thus not differing on this point from private arbitrators. Both classes, in other words, at the moment of rendering a formal judgment, needed the oath to give it executory force; the public arbitrators must take oath upon the city's "oath-stone," while the private arbitrators could take it at any altar. But an essential difference was that the oath of the public arbitrators was no obstacle to an appeal to a higher court; while the oath of the private arbitrators (selected by the parties) settled the case beyond appeal. The latter method is clearly exemplified in a clause in some contracts found at Delphi; "the decision which they shall render

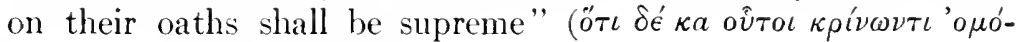

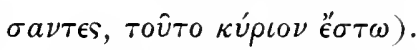

By the classic period, the oath taken by the regular judges is the oath of investiture of office. That of the heliasts is well known. If we may believe the orators, it was thought to have a real influence on the conscience; for the pleaders are continually referring to it to show that the judges have a personal interest in demonstrating their respect for the gods, in deciding according to justice and honor, and in escaping the fate that will torture them for a broken oath. Whenever, in Athenian history, special tribunals were constituted, the members took the same oath as the heliasts. After Cylon's insurrection, the three hundred Eupatrids, who were to pronounce the fate of the murderers, were placed under oath. And when a committee of fifteen was empowered (about 332 B.c.) to fix by judicial decision the boundaries of the land sacred to Eleusis, they swore "to rote without favor and without malice, in all justice and honor."

Throughout Greece, the exercise of judicial functions carried the same requirement. The judges of Egina swore "to rote according to the laws." The assembly of Eresos, when it resolved itself into a court of eight hundred and eighty-three persons to sit in judgment on the trrants, took this oath: "I will judge this charge, so far as the law has provided, according to the laws; and in other respects I will strive to judge as well and as justly as I am capable. If I convict, I will allot a penalty that is right and just: So will I perform, by Zeus and by Helios." And the Amphictyons of Delphi, before judging a dispute, were to bind 
themsclves in these terms: "Called to deeide upon the goods and estate of Apollo, I will judge the whole ease, so far as possible, according to the truth, without faror and without malice, and in no way will I judge falsely ; if I condemn, I will cause the fines to be paid as fully and ats speedily as I can, and will place them honestly to the god's account. I will aceept no presents, either direetly or indirectly; I will neither give nor take from the sacred treasures. So will I perform. And if I keep my oath, may I receive all kinds of blessings! If I break it, may Themis, the Pythian Apollo, Lato, and Artemis, Hestia, and external fire, and all the gods and goddesses send me to a miserable death and withhold all salvation! May they leave me no happiness, neither of children, nor of seed-time nor harvest, nor of prosperity, neither to me nor my descendants! May they deprive me of all that I possess, if I forswear mrself !" I

The oath of the judges, as a security for their impartiality, was deemed so important by the suitors that pleaders whose conseience was not entirely at ease would manœurre to induce the inadvertent omission of the most formidable phrases of the oath, or would erase the names of the judges from the pillar where the oath was inseribed. The orators several times mention these attempts; e.g. that of Midias, with the judges of the choregi, and that of Euboulides' followers, with the judges of a ward eourt.

\$. The Parties' Oath. At the outset of the proceeding, the two parties must take oath. This was known as the contradic-

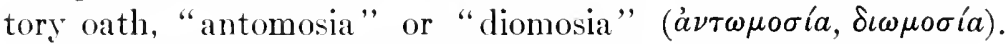
It was obligatory, without exception on either side; no other course would have been thought possible. But it was by no means a promissory oath, with a moral purpose. It was a declaratory oath, analogous to the Roman "litis contestatio," - a sort of declaration of legal war. In this oath the adversaries join in the struggle. They define, irrevocably, the subject of the dispute, not only to bind themselves as against each other and as against the judge, but also to bind the judge in relation to them.

The early form of this oath is explained by the trial seene depicted in the Iliad on Aehilles' shield. 'The demandant declares before the people that he has not received the composition price for a blood-feud, the opponent deelares that he has paid it, and they agree to lay the dispute before the arbiter. Complete these declarations by an oath, and we have the "antomosia." Far

1"Bulletin de correspondance hellénique," Xxvil (1903), p. 107, B, 1. 10-16. 
from being a restraint on the perjurer, or from showing (as some German scholar has suggested) that the Athenian people were not a "Rechtsvolk" ; far from being a purely religions institution (as others have believed), destined to substitute ultimately the justice of the gods for the fallible justice of men; an! far from being a mere degenerate relic of the decisory oath, -- this introductory oath, on the contráry, is merely a remnant of primitive procedure, sharply defined in its own special field of legal icleas, and distinct in the very beginning from the decisory wath tendered by way of proof. When the State's justice was as yet in its first stages, a dispute at law had necessarily to be preceded by a bilateral agreement, an agreement to arbitrate, confirmed by an oath. Later, this part of the proceeding no longer answered that actual need; but it continued to serve as an acknowledgment of the authority of the judge or to create the authority of the arbitrator, and at the same time to define the position taken by each of the parties....

At thens the "antomosia" was indispensable in every lawsuit; it gave its name to the document containing the claims of the parties, and it was required even in controversies where there was strictly neither plaintiff nor defendant. It signified that each pleader was required to state in advance, under oath, how he presents his case and in what sense he understands the proceeding. Only one formula of the "antomosia" is extant; it occurs in the law of Gortyn concerning unlawful distraint. Before suit begun, this oath must be taken: "The seizure was made without wrongful intent and lawfully, but without touching the person against whom it was directed.". . .

But in addition to this introductory oath, primitive procedure used an oath also as a means of proof. This probative and "decisory" oath originated in the ordeal, the "decision of God." The ordeal was an oath in action; the oath, an ordeal in words. The Hellenes had certainly once emploved the decision of Cod: but so primitive a mode of proof (ame to be early repugnant to them. In place of the moral concept that a god would protect the right, they developed by preference the legal concept of the oath of purgation. In its later stage, this oath could be tendered to a party by his opponent; but at the outset it was required of him by the "themis" of the gods, the judge being their monthpiece. Such was the oath imposed by Rharlamanthus, which "ends all, quickly and rightly." I In the Iliarl, Menelaus, the "Plat", "Laws," NiI, p. 948, B, C. 
king, tenders the oath to Antilochus; but his defiance is uttered, not as party, but as ling and judge; and Antilochus takes the oath as a defendant.

Such are the two primitive ideas in the oath-procedure. They appear in use, from time to time, throughout a long period, and in criminal as well as in eivil actions. In the Homeric Hrmns, the bold thief of the bullocks, Hermes, seeks to extricate himself by proposing, first to Apollo, who threatens him, and then to Zeus who is chosen as arbiter, to take "the great oath." In a famous painting of Polygnotus, Ajax, under accusation by Cassandra, and summoned by the Fates to exonerate himself by oath, is advancing to the altar, to save himself by a perjury. The poet Theognis records his indignation against those who invoke the name of the gods to repudiate a debt. Herodotus recounts at great length the story of the Spartan Glaucus who was tempted by the treasures left in his charge and went to ask the oracle of Delphi whether he might appropriate them and escape by a false oath.

In almost all these well-known instances, the accused perjures himself ernically ; and, in all, the defeated accuser remains convineed of his own righteous claim. An unfortunate and fruitless proceeding, one might say. And to remedy that shortcoming, means were sought by the law-makers to determine which of the parties ought to have the exclusive right to make oath; or, if both were to take it, which should have the prior right to take it and be eredited.

The best illustration of this stage of the development is found in the law of Gortyn. 'The judge's deeision must be determined by the party's oath in eertain elasses of eases, viz. when the ordinary method of proof by witnesses is inapplicable or inadequate. Sometimes only one of the parties is obliged or allowed to take the decisory oath; sometimes both are allowed, but one of them is

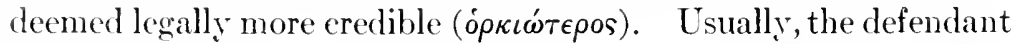
alone makes oath or has the right of superior credibility. The

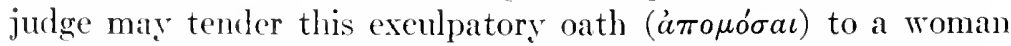
divorced, on a charge of sequestration of property or any other claim and to a merehant denying a debt to a co-merchant. The plaintiff, on the other hand, is the one to take the decisory oath (óóral) when he sceks to renew an instrument of defendant after the death of the debtor, or when he sues an adulterer and rebuts the plea of collusion. The defendant, again, has the right of superior credibility, when a woman is charged with having faile 
to make formal declaration of a child born after divoree, or when a judge is charged with exeeeding the lawful term for a judgment. The demandant, on the other hand, has the right of superior credibility when a female slave complains of rape by her master, or when the owner of an animal killed or maimed claims damages after demand made on the opponent. But the general rule, apart from such special cases, was for the defendant to make the deeisory oath. "Noreover, in that ease, the exculpatory oatl of itself sufficed; whereas the plaintiff's oath always, and the defendant's when he was merely privileged as the more credible, must be supported by the oath of compurgators or of the attesting witnesses to a document (the only exception here was that of the female slave complaining against her master, but then obviously. there could be no compurgators nor doeumentary witnesses). All these rules are reminiseent of the earlier spirit; but the sign of the future was the rule that, in suits between co-merchants the exculpatory oath was tendered to the defendant by the plaintiff.

In this transitional stage belong also other documents (none of which are Athenian). One of them tells us that certain followers of Pythagoras had only to take oath, to escape a fine, i.e. as defendants they were to take the exeulpatory oath. Again, a law of Halicarnassus, passed in the 5th century 13.c., after some civic disturbances, allowed a period of eighteen months for the exiled citizens to reclaim their landed property; pending this period, they were still presumed owners, and thus the disseisor would virtually be demandant, though nominally the exile-claimant took that rôle; hence the privilege given him by this law of taking the decisory oath, confirming it by a decharation of the record-elerks, was an exeeption to the general rule; but after the expiration of the term, the possessor of the land beeame the presumptive owner, and so was entitled, in case of claim by the exile, to take oath as defendant, on the usual principle, and this oath (to be exacted by the judges, in the opponent's presence, immediately upon receiving their fees) was of itself deeisory. Again, the documents of Ptolemy Philadelphus, dealing with fiseal affairs, reveal to us the officials of the oil department called upon to defend certain official conduet by making oath.

In the law between nations and between private associations, we find again the party's oath, recalling the primitive methods. :A treaty between Athens and Lacedamon provides that all dif"erenees that may rise shall be settled "by way" of law and oaths" iкаф 
a sacrifice which the latter leemed not due, it was agreed that the oath should be tendered first to the respondent city, and if it declined, then to the elainant city. And again, in the regulations of the Labyarls at Delphi, any member of the fraternity who disputed the lawfulness of a fine imposed upon him was to go quit, if he exonerated himself by formal oath; the ordinance thus phrasing

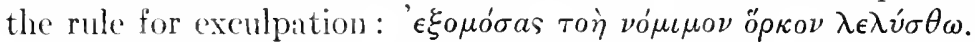

The Athenian laws show us the last stage in the parties' decisory oath; for Solon no longer gave it a place in his legislative reforms. Only in total lack of witnesses or documents was there to be any recourse to the parties' oaths; and even then, neither party was obliged to take oath; either was at liberty to do so, and

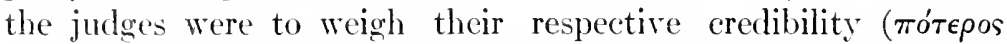

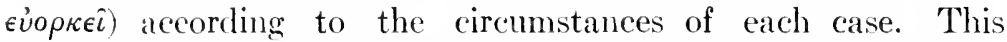
adranced stage (which may be contrasted with that of the Roman "legis actio sacramenti") is a long remove from the oath compulsorily tendered and made decisive. The decision here is made, not by the party's performance of the oath, but by the judge's persuasion. The party tenders or refuses the oath, when called upon, at his own risk of the inferences therefrom. It might even happen that one party would ask for the opponent's oath and also tender his own oath, thus either forcing the opponent to refuse, or at least getting the benefit of the contrasting oaths. And the two oaths might thus leave the case no better than before. The pleaders developed to perfection the various inferences to be drawn from one party's offering his own or demanding the opponent's oath, and from the acceptance or refusal of this challenge by the opponent. In general (it would seem) one could without losing one's cause decline the oath when demanded by the other party ; but, as in such a case the refusal was equivalent to a confession, the refusing party would have to restore the balance by ehallenging the first party to take the oath himself. Sometimes the oath-taker must deposit security. But on the whole the law gave entire liberty of conduct to the parties and entire liberty of decision to the judges.

There were, to be sure, one or two classes of eases in which the party's oath was actually decisory, because any other rule would have been plainly unfair. In these exceptional cases the oathceremony was of special solemnity, and the opponent, who phrased the formula, watched carefully to detect any evasion. Such a case was that of a claim for the restoration of goods informally bailed or of an ordinary loan made without writing; all the Gresk 
systems of law here preserved the rule. ${ }^{1}$ But the Athenian law, when in such cases it provided for putting the defendant to his oath, did not oblige the plaintiff to rely solely on the divine punishment for perjury ; for it allowed the plaintiff a special exit, by

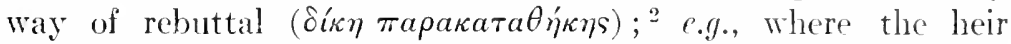
was sued for his ancestor's liabilities, and no other proof was a railable, the heir might exonerate himself by an oath of ignorance; yet the claimant was entitled to refuse to consent to this oath, provided he was willing to risk the inferences. Thus, eren in these exceptional cases, ${ }^{3}$ the Athenian law remained faithful to its general spirit, viz. to concede as little importance as possible to the parties' oath. And Solon allowed it to remain in form only ; for he desired not to break too roughly with inherited institutions, nor to shock too rudely the eustoms of Athenian life. . . .

$\$ 4$. The "'itness' Oath. - In primitive law, the oaths of parties and witnesses are not distinguished. The witnesses take sides with the parties. They do not testify to their knowledge; they merely express their favor for one side or the other; and they are to do this publicly and formally. In other words, they are relatives and friends who act as sworn partisans, i.e. co-swearers. compurgators. This custom was found in early Greece as weli as among the Germanic tribes. It represents the transitionai period in procedure, when the private clan-feud has passed away, but the method of proof by disinterested witnesses has not yet arrived; in this interim stage the members of the respective families and clans support their relative by appearing with him in eourt.

The compurgation procedure was in rogue in the Homeric period. ${ }^{4}$ And Aristotle mentions the existence at Krme, in . Eolis,

${ }^{1}$ Under similar circumstances the exenlpatory oath appears naturally in Egypt under the rule of the Greek Ptolemies. Here is a complaint deciphered from the papyri of Magdola: "To king Ptolemy, hail! I, Theonides, of the village of Apollonias, an wronged by seuthes, of the same village. I had lent him without writing five measures of barley, and he had promised to repay them when the harvest was gathered; that time has passed, and he has not repaid me, though of tell demanded. Therefore I ask you, ol king, if it seems proper, to order the judge Diophanes to write to the bailiff Agathocles to send Seuthes to him, and if I speak truth, to have Diophanes make him pay me what is due; and if he swears that he owes me nothing, lo discharge him; so that I suffer no wrong, but obtain justice by resorting to you, oh king, benefartor of all. Farewell." ("Bulletin de rorrespondance hellenique." XXVII, 1903. p. 178.)

2 Isocrates composed the "Oration against Euthynos" and the ".Trapeziticus" for cases of this sort.

${ }^{3}$ Which were so restricted that e.g. a wife was allowed to swear as witness to the paternity of her children but not as party to prove her own marriage.

${ }^{4}$ Although no one passage clearly exhibits it; the rourt scene in the Iliad, for example, mentions the helpers (apwroi) for calch pleader; but 
of a ha "of antique simplicity" by which a person charged with homicide is declared guilty if the accuser produces from among his relatives a certain number of witnesses. And an ancient law of Athens, sanctioned by Draco, reveals the same feature; on the trial of a homicide, the chief accuser is to be joined by his farthest relatives and the members of his phratry, the relatives making oath of their status. At Kyme as at Athens, these relatives, of course, were originally co-swearers, party-witnesses. As time passed, they took on the special character either of ordinary witnesse's ( $\mu \alpha \dot{\rho} \rho \tau \nu \rho s)$, as at Kyme, or as joint party-complainants $\left(\sigma \nu \nu \delta \iota \omega_{\kappa} \epsilon \iota \nu\right)$ as at Athens. Their original technical name is disclosed to us in some fragments of private law found at Crete:

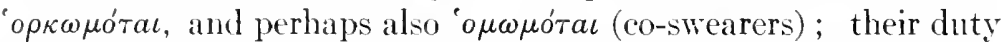

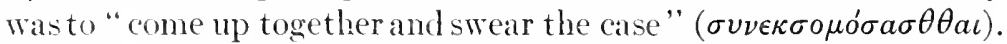
Again, the law of Gortyn required that the party should in certain cases appear with co-swearers in number proportioned to the penalty involved (virtually, according to the rank of accuser and accused). In a charge of adultery, if the defendant, taken in the act, pleaded a collusive trick of the husband as his defence, the husband took oath affirming the detection in the act and denying any trick, and this oath he took "five-handed" (i.e. with four others) if he belonged to a brotherhood, or "three-handed," if a free man of inferior rank, or two-handed, if a serf; the oath (including the imprecation) being the same for the co-swearers as for the parties. So, too, in the treaty between Chaleion and

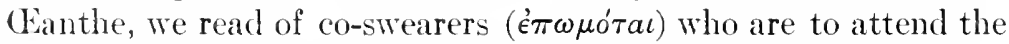
resident aliens, - fifteen or nine, according to the amount involved. And in all of these instances, there was no question of weighing the testimony, but merely of counting the witnesses; at Gortyn, for example, the law expressly says that "the party

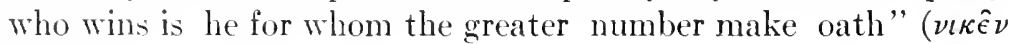

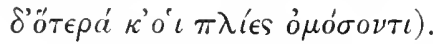

The development of co-swearing into ordinary witness-proof naturally and gradually lessened the importance of the oath itself. The change can be seen in two features especially; (1) the oath follows, instead of preceding, the witness' statement, and (2) it becomes optional, not obligatory.

(1) In the ancient town of Ascra (Hesiod's birthplace), the witness is recorded as begimning with the oath. And in the

they are not rompurgators: they mix with the crowd, and are kept hark by the heralds; they do not take part in the proceedings, and the judge: do not aret upon their oaths. 
antique homieide proceeding surviving at Athens, the oath is required first of all from the witnesses; and the name itself, "co-

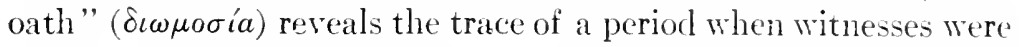
mere partisans. At Gorțn, on the other hand, the oath is no longer promissory in form, and the witnesses take oath after their testimony is given; the oath is still the important thing, but it is merely declaratory of the truth of the testimony already given.

(2) At Gortyn, furthermore, we find a transition stage between required compurgation and optional testimony. The oath is required only for special classes of cases; but in these the witnesses, though no longer strictly co-swearers, are either attesters of a document or other required witnesses who make oath with the party. Thus, when a creditor sues to revive an instrument of debt, the judge and the record clerk are called to prove the doculment ; to certify that the owner of an animal killed or maimed has performed all the formalities, two documentary witnesses must be produced; to prove that the child of a divorced woman has been presented for acknowledgment to the husband, documentary witnesses must be produced (varying in number with the woman's status). In all these cases the witnesses make oath with the plaintiff (or, in the woman's case, with her relatives or guardian). Thus the law of Gortyn, like that of Draco, preserved the compulsory oath, but in limited cases only. And both of them exhibit the transition from compurgation to optional witnesses.

But the last stage of this development was to be seen at Athens, in the procedure of the popular courts. There the witness' oath had become merely a warranty of the testimony, optional and supplementary, or perhaps a special proof accepted by the parties. Usually the oath was administered, on the preliminary hearing, after taking the depositions, by the witnesses on one side, on demand by the other side. Sometimes it was taken at the trial, after reading the depositions. Sometimes the witnesses themselves offered to confirm their testimony by their oath, - as when they were directly interested in the case or related to the parties. The judge's discretion was theoretically free; ret in some cases the oaths practically carried the decision with it, - as where the parties had by contract made it decisory, but this would have an extrajudicial basis. In essence, the witness-oath was optional.

But how often was it employed, in practice? As late as the 5th century B.c., testimony and oath were still inseparable. But by the th century this was so no longer. In the ordinary trials of that period at Athens, the witness' cenfirmatory oath was 
reduced to a minimum, - mostly, a mere signature at the bottom of a deposition. Athens had gone, in its system of proof, almest to the end of the road leading from partisan eompurgation to a purely rational probative testimony, freed from all religious element. The procedure of the Areopagus Senate had stopped with the oath as compulsory and promissory ; the procedure of Gortyn had gone as far as the oath declaratory but still compulsory; the Ieliaea made the oath both declaratory and optional. ${ }^{1}$. . .

\$5. The Contract-()ath. [The Greeks employed the oath, in inmmerable ways, in the affairs of private life. The phratries and other associations made use of it for admitting their members ; a father, for example, presenting his ehild to a phratry (a form equivalent to our registration of eivil status) must make oath "that the child here presented was born in lawful marriage of himself and a citizeness." And, notably, oaths of peace and alliance between individuals eommon enough in primitive and legendary times (for example, between Achilles and Agamemnon) developed the promissory or contract-oath.] . . This served to give authenticity and validity to ordinary eontraets, and was widely used in Greece, as well as in Assyria and Egypt. This contraetoath might eonfirm a promise of marriage, or a partition of an estate, a baiment, a loan, or a lease. At Thebes, the eustodian reeeiving in charge an abandoned ehild took oath formally to bring it up. In Egypt, under the Greek Ptolemies, the farmers and their sureties bound themselves to the treasury-offieial by a "royal oath"; as did also the shipmasters who contraeted to deliver their eargo at destination."

"The contract of sale and purchase," said Theophrastus, in his lost treatise on Greek law, "is eomplete, as regards the buyer, when the price is paid and the lawful formalities performed, . . . such as the oath." It does not appear that this practice obtained at Athens; . . . but it is recorded at Haliearnassus; for there the purehaser of goods sold by a temple would take a covenant of perpetual possession, not merely from the gods as guarantors, but also from the temple officials, who took oath as co-warrantors with the gods. At Enos, to prevent impersonation of the vendor and to give publicity to the transfer, the vendee of the land must offer a sacrifice (proportionate to the value of the estate), and must

${ }^{1}$ [The author then deseribes three exceptional cases where the compulsory oath was preserved, viz., women-witnesses, in certain cases; witnesses who are unable to appear at the trial to confirm their depositions; and witnesses alleging an exeuse for not testif ying.]

2 Kenyon, "Papyrus of the British Museum," II, No. 301. 
take oath, before the altar, in the presence of a recording official and three residents, as follows: "I am buring this lawfully, without collusion, or trick, or fraud of any sort : "and the vendor must swear, "I am selling without fraud." Withont this formality the officer must refuse to record the sale, and his oath of office imposed on him this duty. This explains why the Cnidians termed their

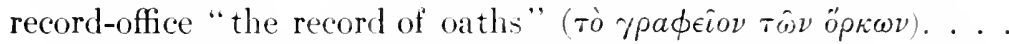

In contracts for public works, the contract-oath played a larese part. When the Athenians set about repairing their Long Walls, the successful bidders for the molertaking were obliged by the terms to take oath before the Council. In an inscription of Eretria, a contract for draining the marsh is accompanied by an ordinance fixing the procedure and the formulas for the oaths; all the citizens and youths bound themselves to the contractor and his heirs by this oath, to be pronounced after the officers: "I swear, by Apollo, Lato, and Artemis, to leave to Chairephanes the possession of the lands gained from the marsh, on the terms assented to by the city ; if any one tries to violate the contract made with Chairephanes, I will oppose him with all my power, in accordance with our common oath; if I keep my oath, may much good fortune come to me ; if I break it, may I be destroyed, I and my property." And the contractor, on his part, was to give sureties who should make oath that the work would be performed.

The oath served also to warrant a recital of fact inserted in a contract. For example, in a contract of lease, the lessee must affirm on oath before the lessors that he had spread on the lands the agreed quantity of manure. This application of the oath, while unusual in Greece itself, was frequent in the later Greco-Egyptian contracts. Under Ptolemy Philadelphus, the farmers who sold their oil-crop to the government made oath, in their contract of sale, how much seed they had put in; in the duplicate contract between the tax-officers of the vinevards and the vine-dressers, both parties' recitals must be confirmed by the "royal oath" ; and the statements made upon the recording of a transfer must be verified by oath, the documentary recital of the oath serving to give validity to the transaction.

\$6. False Oaths. Inabitual oath-taking leads soon to perjury. And the Greek, only too often, behaved as if (in a phrase proverbial in his country) "the old gods had been supplanted by new gods." The Romans, we know, were scandalized by "Greek honor." Was this rice a feature of their decarlent period" By no means. As early as the Odysey, we learn that it wil 
esteemed meritorious to be skilful in profiting as much fromttom oath as from a theft. And sophocles dramatizes a falsmcst without a word of censure. ${ }^{1}$ The rhetoricians and the sito a served as a manual of perjury, at the service of litigants. . ele-

Nevertheless, the practice did not come entirely easy. "th had to deceive one's conscience. One must use the gods as gently as might be. The object was to observe the letter of the oath while evading its spirit. Nowhere more than in Greece has wider use been made of the oath of double sense, or sophistical oath. A sly fellow (one anecdote runs) refuses to restore a sum of money left in trust; he hides it in the hollow of his staff; at the moment of taking the oath of exculpation, he hands the staff to the plaintiff to hold; thus he truly swears that he has delivered to the plaintiff what is due him; and yet he can keep it all, - even the favor of the gods. ${ }^{2}$ Or, again, a rascal who has stolen a fish in the market slips it deftly into another's basket; now he can swear with a safe conscience that he has it not, nor knows of any other person who took it. And Chillon, faithiul strictly to his oath as judge, cast his own vote for the death penalty against a friend of his on trial - but persuaded his two colleagues to vote for acquittal. ...

These hypocritical practices led to a reaction. The distinction between the letter and the spirit came to be emphasized. But this itself gave rise to quibbles equally dangerous. Euripides, the master of Greek casuistry, expressed the principle in the celebrated line: "The tongue has sworn, but not the mind." And some of the moral philosophers discussed the conditions requisite for the bindingness of oaths, in manner of the jurists concerning contracts. ...

The Athenians, to be sure, imagined themselves to be notably superior to the other Greeks, in their strict adherence to their pledged word; they boasted of "Attic honor." They were piqued with Euripides for having turned an epigram on the excuse of false swearers, even though he did make the-hero Hippolytus perish as a victim of his own perjury. In private affairs, they conceder (with Pericles) that a man should stand by his friends "up to the very foot of the altar"; while in public affairs they maintained that they were bound, even as are heirs by the oaths of their ancestors. The Spartans they accused of a deplorable

${ }^{1}$ Odrssey, XIX, 395; Sophocles, "Electra," 47.

2 [This aneedote may be found again in :"Don Quixote,". c. LXXVII.]

3 "Hippolytus," 612. 
take oait for perjury... The Thessalians likewise they reand th as perjurers. As for the Cretans, their reputation as liars out cong been made. . . .

swear inst this abuse of the oath, the highminded Greeks, and the officers of philosophy, sought to devise a remedy. Many persons, moved by rehigious scruple or by more practical considerations, adopted the custom of substituting for the invocation of the deity some expletive which signified nothing. Rhadamanthus, according to the legend, had recommended to swear by some animal or plant; and accordingly we hear of Lampon, the priest, swearing "by the goose"; of Zeno, the philosopher of Citimu, "by the caper"; of others, "by the cabbage." When Socrates swore "by the dog" and "by the plane-tree," he was not showing contempt for the national religion (as his enemies asserted); on the contrary, he showed his real respect for the gods.

Such protests are found at a much earlier period, as early as the 6th century b.c. Yenophanes (570-480?), founder of the Eleatic sect, rejected entirely the oath as a means of proof, because it was in partnership with inpiety. Pythagoras (582-500?) argued against the practice of oaths, even in the most weighty cases; and his followers professed that they would rather lose a lawsuit than gain it by taking an oath. "Swear not at all "was the motto of this school. And the principle spread to others. Eschylus, the dramatist $(525-456)$, in the trial scene of Orestes, represented the tribunal as rejecting proof by oath, as a travesty of justice, too often insuring the triumph of injustice; and he put these words into the mouth of one of his characters: "The oath does not warrant the man, but the man the oath." Choirilos and Menander, the poets, invented or repeated the proverb, "Swear not, for a good cause any more than for a bad one."

And so Plato was not a pioneer, but only a timid imitator, when he proposed to banish from his liepublic the whole oath-procedure, and to reserve the oath only for situations involving no direct and temporal advantagc. In Plato's view, the oath-procedure was something too fine for the men of his own times. He regarled it as practicable only in the days long past, in a primitive community, still moulded by morality and religion. Rhadamanthus, he said, had been convinced that the power of doing justice must be entrusted, not to human judges, but to the gods; whence the

1 Aristotle, "Rhetorie," I, 15; I amblichus, "Life of Pythagoras," 47, 144, 150; Sosiades, in Stobée, "Florilege," III, s0: Exchulus, "Wumenides," 426 and fragm. 369; Choirilos, in Stobée, ib. XlI1, 114 ; Menander, fragm. 441 . 
simplicity and promptness of his decisions; for he merely tendered an oath to the parties, "and so it is all settled quickly and rightly." But this excellent methor of settling disputes presupposed necessarily a deep and universal religious belief.

"And to-day," continued Plato, "when men either do not believe that the gods exist or believe that the gods to not interfere in human affairs, or, most of all and worst of all, believe that the gods, on receiving petty sacrifices and flatteries, will become their accomplices in chicanery and will save them from punishment, - no, for the men of to-day the method of Rhadamantlus is no longer suitable. And so, since men's beliefs about the gods have altered, the law too must be altered To-day, when a suit is begun, the law, if intelligently framed, should not require an oath from either party. It should merely require the acenser to put the points of his rharge in writing and the defendant to do likewise, without allowing either of them, on filing the documents, to make oath. And indeed, when we think of the multitude of lawsuits in our State, we cannot for a moment douht that perhaps a half of our citizens are perjurers, who nevertheless do not hesitate to sit at table with the rest nor to associate with them in pulblic assembly and in private homes." 1

But the philosophers' utterances had little effect. Without the help of the law they could do nothing; and the law gave no help. Some writers have supposed that there was a eriminal

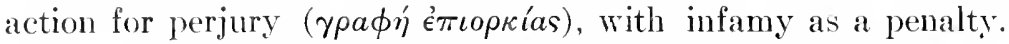
But no document mentions it, either at Athens or elsewhere. There is no question, to be sure, that discovered perjury was visited with disgrace. ... But the only punishment of the perjurer was that which the gods might have in reserve.

And this belief in the gods' enmity for the false swearer never weakened in the soul of the Greeks. Centuries apart, we find it expressed with equal validity. Two instances of this will serve to bring us to an end.

Herodotus tells us (not without a suppressed horror) of what happened to Glaucus the Spartan. This man had reached the highest position in his town, by force of his many virtues and particularly his uprightness, when Fate subjected him to a baleful test. A rich Milesian sought him out and left with him a large sum of money in trust. Years passel. One fine day there came to Glaucus the sons of the Milesian, showed their tokens from him, and asked for the return of the treasure. Glaucus could not resist the temptation. He replied that he remembered nothing about it; would look for it; and told them to return in four months. Meanwhile he sought to get the gods on his side. Betaking himself to Delphi, he asked the oracle if he might appropriate the deposit by making oath. The reply of the priestess of 
Apollo was like a thumderbolt: "Glaucus, son of Epikydes, yes! For the time, thou may"st gain thy suit and secure the treasure, by taking the oath. Take it, then! Death indeed awaits some day all mortals, alike those who keep and who break their oaths. But Horkos, the god of oaths, has a nameless son, who, having nor hands nor feet, will none the less pursue relentlessly until he has destroyed thee and thy whole family, root and branch. But the honest man will leave after him a posterity more and more prosperous." The wretched Claucus, stunned by his doom, begged for mercy. But the implacable priestess replied that to solicit the god to assist his crime was as great a fault as the crime itself. In vain was it for Glaucus to send for the Milesians and restore the money. In due time there remained not a scion of the house of Glaucus, not the least trace of his place among men; root and branch, his race had disappeared. The grod was avenged. ${ }^{3}$

With this story of Herodotus may be compared the evidence of an inscription which was found in a temple at Delos. Five centuries had passed since Glaucus' day, ret the beliefs as to the punishment of a faithless trustee had not altered. The inscription reveals to us a humble slave, Theogenes by name, who had entrusted to a certain woman the money saved by him for the purchase of his freedom. The faithless trustee kept it all, and swore that she had received nothing. For the unfortunate victim of her wickedness there was no human recourse, - no resort but to divine justice; and he carred on a stone this accusation, which he committed to the care of the gods: "Theogenes, with uplifted hands, implores the aid of the Sun and the Maiden Godkless against - She had made oath not to wrong or deceive me about my treasure which she received to keep in trust for me, nor to deprive me of it. And I, confiding in the Maiden Goddess, believed in that oath, nor did I do her any wrong. But she, after receiving in trust the money destined to purchase my freedom, now has despoiled me of it. May she not escape the power of the goddess: I ask and pray all the votaries of this temple to declare against her the curses of religion." 2

And so, throughout the whole epoch, the gods who are involed in false oaths see to it that rengeance follows the insult to their name and the wrong done to the immutable order of things.

${ }^{1}$ Herodotus, VI, 86.

2"Bulletin de correspondance hellénique," VI, 1S52, p. 500, No. 24. 


\section{SECTION 5}

\section{ANCIENT FORMALISMI}

\section{The Stages of Internal Evolution of the Law}

1. . . The legal activities of every civilized people show a movement through three stages of development. One might denominate them as the divinatory, formalistic, and intellectual stages, in the sense about to be explained. In order to operate effectively and to accomplish their mission, all three stages must be supported by the belief that the law is of divine origin and of a higher power, realized in a worldly existence; and that it is not a human product to be mastered by the will. In purest form, this belief is found in the earliest childhood of a race; for, the more that reason enters into the law, the less pronounced this belief becomes. It cannot, however, disappear entirely ; except that the law itself should fall into a decrepit trifling with dead ideas.

A people and a productive law first come into being with an emergence from the condition which may be called the patriarchate. By no means, however, must it be thought that the purely patriarchal condition of society is one wholly devoid of legal ideas. The statement is made, constantly, that so long as the patriarch, the head of the family, determines everything within the family, and that his will is supreme, there is no law, and only might. It is said, also, that the members of the house are subject to the house-father but not by virtue of legal rule; that the housefather is in no way obligated to his dependents, or bound to them by legal compulsion; that when he decides a quarrel in the household he does not utter the sentence of law, but acts according to convenience in the plenitude of his power, granting to one what under the same circumstances he denies to another; and that while the house-father embodies within himself all law, he also displaces all law. True, but it is still the idea of law which maintains order in the extensive domestic concerns of the patriarch, and which restrains the servants and bondmen from asserting their superior strength and rising up in rebellion. Nevertheless, the legal idea here is still restricted ; it manifests itself only in a passive relation, and is not yet active and productive. It first becomes active in the tribe, from that moment when the relations of the

1 [By Dr. ANDreas Heuster, translated by Albert Kocourek from "Institutionen des deutschen Privatrechts" (S'rstematisches Handbuch der. deutschen Rechtswissenschaft, herausgegeben von Dr. Karl Binding), Erster Band, Leipzig, Duncker \& Humblot, 18S5.] 
tribal associates among themselves are no longer subject to the arbitrary will of an over-lord, but are regulated in a definite way by an arrangement established by the will of law and for the purpose of its realization; even though this arrangement involves also the harsh despotism of a chieftain.

During this early period, a people enters a healthy state of things in which arbitrary despotism does not repress all sense of legality through a solemn dread of law, but allows it free scope to grow and thrive, that is to say, to reveal itself in the conscionsness of the people. The people is the judge, but it does not legislate; and, as judge, it does not know that its mission is not only to declare the law, but rather to awaken among litigants a consciousness of law, which itself approves or condemms. As the apostle, Paul, says (Romans, ii, 14, 15), "for when the gentiles, which have not the law, do by nature the things contained in the law, these, having not the law, are a law unto themselves. Which show the work of the law written in their hearts, their conscience also bearing witness, and their thoughts the meanwhile accusing or else excusing one another." The law exists, but it is brought into consciousness by the fact of strife, wherein the defeated party goes away feeling his own self-condemmation. This is the way the Cadi of an Oriental nomadic tribe proceeds, whose administration of justice, on superficial view, appears to exhaust its jest, in that he sets a trap by which the guilty party ensnares himself, and by which he shows that he is more acute than the culprit who has been eircumvented. Deeper comprehension of these aneedotes, however, compels the belief, that the judge desires to avoid giving a decision as the product of his own reasoning, but rather seeks to have the law express and realize itself through its own form and irresistible influence on the parties themselves; he merely opens the way whereby the law may manifest itself to the conscionsness of the litigants - a species of divine judgment of the greatest purity, the most ideal instance of which is the judgment of solomon. All that the judge in such cases has to do with the matter is to discover the ways and means by which the law, foreshadowed to him and recognized by divination, may be declared; and he subordinates his own augury to a method of eonfirmation through an aroused sense of lecality in the minds of the parties. In this sense, we speak here of the divinatory attitude of the law.

2. The next phase of erolution is logal formalism. The human mind strives to attain definite knowledge of the idea of legality, it seeks forms in which the law manifests itself and declares its 
existence; it does not any longer rely on divination as a test of conscience, but attempts to make legality obvious by an external appearance. In its earliest manifestation, it has an inflexible quality, but the very fact of its unbending rigidity gives to formalism the appearance of a divine institution which is not subject to the manipulation of human will. This is the age when the law appears as a constituent part of religion; the priesthood unites the application of law and judicial judgments with the forms of divine worship. The law precedes formalism in the same way that it preceded divination. The task of both is to permit it to come to consciousness and be realized. In the words of Pomponius (Dig., de orig. juris, 2, 1, 2, 6), "omuium tamen legum et interpretandi scientia et actiones apud collegium pontificum erant." That also among the Germans the law was sustained in its earliest form by a priesthood is less clearly shown by 'Tacitus than by isolated tokens elsewhere.

The rigid form in which the law is clothed protects it against arbitrary manipulation; and the formalism which surrounds the law is like a sheltering wall, in an age when the intellectual power of the people has not yet sufficiently developed to permit it to understand the internal value of the law. Objective things are comprehensible, but the abstract is not intelligible. The law is unified with precisely circumscribed sensible phenomena, and is therefore protected from arbitrary perversion and demoralization. Fixed legal concepts are first expressed in formalism, and they are progressively understood and developed, in the abstract, as they separate from their original forms.

3. The course just mentioned characterizes the third phase of legal development in which an intellectual domination of the abstract materials of the law is brought to function. 'This is the period of true jurisprudence whether as manifested in the activity of courts or by juristic efforts. But this activity is limited by a constantly regenerating perception of legality implanted in the people and in the national spirit. Of itself, it cannot generate law, and every activity in legislation or legal science which disregards this limitation fails to produce a true legal development, but results in legal aberration. In such case, it either remains impotent by the side of the true idea of law, when the legal consciousness of the people is still strong enough to maintain its legal concepts; or it breaks down the integrity and soundness of legal life, if the vital force of the spirit of legality among the people is unable to resist the assault. 
The transition from one stage of lemal development to anotier is not sudden and abrupt. For this reason, the ordeal in it: historicaliy transmitted form, as well as the institution of the oath, which in their deepest meaning and nature bclong to the first stage, are suited to the second phase of development, legal formalism. The extent to which legral formalism is still a part of the stage of intellectual derelopment of law needs no mention. Nevertheless, the transition time is always a critical moment. It may well be said, that Germanic law ran aground in its evolution from legal formalism to an intellectual conception of law; and that on this account the reception of Roman law to so great an extent became possible. Rigid formalism ruled Germanic law far into the Middle Ages; but since the capacity for abstract juristic construction had not yet evolved, when form no longer sufficed, it resulted that formalism either was entirely abandoned before there was a workable substitute therefor, or it became degraded to the point of caricature. Both consequences led to insecurity in the legal situation, whereupon Roman law presented itself as a deliverance.

\section{Scope of Legal Forinlisit}

In accordance with the foregoing explanation, I shall discuss the term legal formalism as that phase of legal development where objective perception is the sole or preponderant generative force of the law, and where internal processes of a spiritual nature such as mental dispositions, will, reason, etc., are either excluded or are subordinate. This wide sense is not the customary usage. Legal formalism is rather taken to mean the principle according to which acts and transactions become valid as legal acts or legal transactions - a prescribed legal form of words, or acts foreign to the usages of ordinary life. This external formalism is only half of what is here under consideration; the other half, we may say, is internal formalism which has the function of measuring, aceorling to a pattern established by the law, the material operation, the internal processes of legal life. We thus speak of a formal and material theory of proof, when in connection with formal proof the rule is established that a single witness is not sufficient for complete proof, but that two competent witnesses are neersaly. Wherein is the formalism? The rule has nothing to do with form in the narrow sense. 'The formalism lies in this, that bascd on many hundreds of years of experience with the unreliability of 
witnesses an average rule is made which deprives the judge of a free hand, which easily becomes arbitrary, in the valuation of testimony, and prevents, by an external standard, the giving of an often false credit to the veracity and character of men. We may therefore speak of legal formalism as indicating that plan of the law which excludes consideration of internal character, motives, processes of the will, and the like, and which is based on the external phenomena of legal regulation. One of the leading aspects of this formalism is the subordination of all particulars to a general rule, the establishment of an iron roadway upon which everything which concerns the law must move, and across which, or alongside of which, there is no other path. The individuality of the particular case must give way to an average; and a substantial valuation of the details of a special instance, especially personal qualities, internal processes of the will, and the like, is excluded; and the emphasis is placed upon what is objectively perceptible, upon the external phenomenon, and therefore upon a formal foundation. A contract does not bind a twenty-year-old person, because he is a minor. That, in spite of this he may be an astute business man, does not come into consideration. This is formal law.

Law camot be thought of as entirely divested of such formalism; all time limitations are formal law, and are indispensable in any system of law. Germanic law began with pronounced internal and external formalism, and this quality still held the upper hand, even in the classical period of the Middle Ages, although at that time it was already on the defensive against more liberal views. This situation was not peculiar to Germanic law. No early law could make shift without this characteristic; not so much because juristic technic was too little developed, as because it was sought to avoid the necessary peril of a rbitrariness and the demoralization of all fixed legal values resulting from an individualization of cases. In the words of Jhering, "form is the sworn enemy of unlimited discretion, and the twin sister of freedom"; not, indeed, so much in the sense intended by Jhering, that it provides the counterbalance against the temptation to lead freedom to the limits of license, as that it establishes an unchanging and controllable standard by which the degree and force of the law may be accurately measured; and, especially, in that it deprives the judge, also, of discretionary power. When one stops to look more closely into modern legislation where the meaning of entire chapters is left to a free judicial discretion, one can hardly resist the feeling that we are no longer ruled by fixed law, but are subject 
to the will of the judges; and one might almost wish to see a system of formal law. There is no doubt, that our forefathers would not submit to a kind of law which rested on the will of the judge. They desired to be able, themselves, to measure accurately their expectations before going into court; they desired to know all the factors out of which judicial decision was to be constructed, in order that a trial might not be, as to-day, a lottery where one has an equal chance to win or lose.

Agreeably to this requirement, the most cursory glance at the Folk-laws shows, from the point of view of modern legislation, a striking, and likewise avoidable characteristic - the extraordinary minuteness and detail of crimes and their amercements. In our modern criminal codes a few paragraphs dispose of corporal injuries; still briefer is the treatment of property damage. A pair of large rubries is quickly done away with, and the judge may impose a sentence of one day in jail or ten years in a penitentiary, at discretion. We may compare with this the long catalogue of crimes and penalties in the Folk-laws. The German who had a splinter of bone knocked out of his cranium wanted to know the result before he went into a law-suit, and the Folk-law told him exactly what he would get, if the splinter made a sound thrown against a shield at a distance of twelve feet. There was no room here for judicial aberration or discretion. The degree of liability also was much more simple and external than in Roman law and in modern law with its modifieations of culpa.

A law of procedure set in motion by the parties themselves, and maintained by formalism of procedural steps must, if possible, substitute for the exclusion of judicial discretion a srstem of criminal law rich in the detail of delicts, and with the greatest possible external criteria of liability. Ancient Germanic procedure, in a manner entirely foreign to the practice of the present day, was dominated by the parties. When a man submitted his rights to the verdiet of his fellows, he wanted to know precisely how this verdict was to be obtained, and what share he was to have in the construction of the foundations of the decision. Just as when he took up the feud, where he considered and employed every means by which he could wage his fight, so also in the battle of law, he desired to struggle on his own account; not, of course, by independent measures, but as preseribed by the law; but he wanted to know all the conditions of the struggle, and he would not be deprived of measures proper for him, or permit his antagonist to have any others. He wanted to fight his own legal battles - should it not rather be 
said that he must? Is not this personal representation in procedure rather a heavy duty and burden than a right? It is not here in question that one conditions the other; that right and duty are coördinate. One must always be the starting-point, the principal and limiting factor, and the other the accessory and limited element. Te moderns, without doubt, would regard the duty as the chief thing, and the right as only a badly disguised adulterant which we would gladly renounce if the duty were only done away with. But the ancient German thought otherwise; for him the right was the first consideration. Whoever "nihil neque publice neque privatre rei nisi armatus agit," whoever is prepared each day and each hour to draw the sword, and to give his life for revenge of injuries, - such a man is possessed by an intensity of spirit, which would lead him to the greatest exertion of his mental forces in a struggle before a court. For him a trial is not a thing to be delegated to an attorney, but is a matter where success in the assertion of rights secures the honor and esteem of his fellows, and where defeat would bring shame and disdain. Therefore he desired to understand as thoroughy the weapons of procedure as the method of the sword.

The formalism of Germanic law, therefore, fully emphasized party participation, and confined it according to definite models. The summons was sent by the plaintiff to the defendant. The various steps of procedure and even the decision itself were proroked in a formal manner by a ritual of question and answer of the parties. The decision was in the highest degree a formal verdict upon the meight of the evidence. The oath and if need be the most formal method which conld be conceived, the ordeal, were the sources of proof. The hostility of the German to the innovations introduced by a system of roval justice, and also to those attempted in Folk courts, may be comprehended; since he would not tolerate the method of inquisitorial proof, and preferred to absent himself from the court, and suffer the consequences of contumacy, rather than submit voluntarily to a procedure which permitted free scope to the judge in a valuation of the evidence. It may also be understood how the ancient German fought against a method of proof by documents; since that he could neither read nor write, he saw here a factor, opposed to him, upon which he could not calculate.

Our special task is to deal with the formalism of private law. For this purpose, we separate the two divisions which above were denominated as internal and cxternal formalism; but inas- 
much as these terms are not suitable for technical purposes, we may substitute therefor the terms "legal forms" and "legal plastics.” . . .

\section{LEgal Foris}

\section{a. Limitations of Time}

All legal limitations of time have a profound and indispensable connection with legal formalism. That a person attains his majority with his twenty-first year at the midnight hour, and that the validity of a juristic act depends on whether it was done one minute before or after the hour; and that a claim may be atinerted up to a definite day, and after that day may not be urged - this is formal law. No legal sistem, not even one the farthest remored in abstraction from external concerns, can avoid this legal formalism. Limitations fixing the time of majority, actionability of claims, etc., cannot ever be dispensed with in the law. It frequently happens, though, that the law makes it possible to orercome the rigidity and want of consideration of a temporal limitation, where the individuality of the circumstances is such that it appears desirable. Thus a minor may, if he is capable of diligent management of his own proprietary affairs, be vested with the capacity of a person of full age. But curiously, so strong is the inclination to formal law, that a new form is easily imposed, in that while one form is put aside, the concession in faror of venia atatis is itself made dependent on a new age limitation. ${ }^{1}$ Such is the difficulty of the law in ridding itself of formalism. . . .

\section{b. The I'alue of Word and Act as against the I'ill}

Strictly formal law recognizes no opposition between will and word, and no possibility of their being inconsistent. For the will can only be known by the word which has given it expression. Therefore, the word is the measure of the legal content of intention. A man is not held liable beyond the seope of his word, but, however, he is held remorselessly to it.

This is completely in accord with the ideas of Germanic law, where the word is plastic law - neither more, nor less, than what is

1 [Thus B. C. B. - "a person is incapable of disposing who has not eompleted his screnth year of agr" (sere lot); "a minor who has aompleted his seventh rear of ago is limited in disposing raparity," ote. (Sec. 106); "a minor requires for a derelaration of intention wherehy he does not merely acquire a legal andrantage, the approval of his statutory agent" (Sec. 107). - Trans. of C'hung Hui H'ung.] 
uttered - absolves or binds. This explains the minute exactness with which obligations are paraphrased, especially in relation to their transfer to the heirs, whether of the debtor or creditor. How painfully tiresome it seems to read in a code of the tenth century : "quod si Johannes vel eius filiis et eredes omnia mihi vel ad meis eredibus noluerit adimplere, tune hobligavit se et suis filiis et eredes ad componendum mihi vel ad meis eredibus," ete. But the creditor found it necessary, or at least expedient, to secure to his heirs the right of asserting the claim without objection, by express agreement, in order that nothing might be overlooked in their faror. Even the Longobard edict (Ahistulph 16) mentions as a particular requisite of a convention effective for or against the heirs, that the contracting parties "heredes vel successoribus suis conlingaverint." Since, on the one hand, the law does not add anything to the spoken word, on the other hand, it takes nothing away. The word is inflexible, and in a period of formal law, it is unthinkable that a definite expression of intention upon which a legal transaction is based, could still not be willed; and that the act might be attacked on account of a conflict between the actual will and the word of one of the parties. The will is embodied in the word. Epon this maxim are based the legal proverbs - "the man, the word," "the word stands," and "words make trade," etc.

A necessary consequence is that error in contractual relations hardly comes under consideration. "Whoever closes his eyes opens his purse"; "Whoever buys foolishly must pay wisely"; and "Whoever buys damaged goods, let him keep them." Not error, but only fraud of a party, especially in sale, gives freedom from the obligation of an agreement. The sources show this clearly, especially with reference to the commercial action for defects in goods sold. Apparent defects do not relieve the buyer under any circumstances; latent defects relieve him only when the seller cannot affirm under oath that they were not within his knowledge. In the course of trade particularly in horses and cattle this burden on the buyer was found to be too heavy in the case of latent defects; but a remedy was not given at once through a full and free individualization of cases. Relief came by a formal process of thought which singled out certain principal defects, which when they existed, relieved the buyer without anything further, from the obligations of the contract of sale.

\footnotetext{
*

$*$

*

*

$*$

$*$

$*$

1 "Codex diplomaticus Canensis," ed. Morcaldi, ete. II, No. 213, p. 4.
} 
The formal character of the law is still more decisively shown in its disregard of the factors of the will in the consequences of acts in private law. Everything that a man does was judger by external appearance and economic effect and not aceording to internal motive. The law made no allowance either for bona ficles or for guilt when it sought to determine the legal operation of an act. Whoever acted so as to disturb a legal relation was made fully accountable. The law recognized only rights and wrongs, and the civil consequences of that which appeared as a wrong were laid against the person acting.

The two chief applications of this rigidity were that a person was liable for damages to person or property eren though of defeetive mental capacity or even though acting in self-defense, and that liability in case of things deposited or owed in a contractual relation, was absolute, and was not ammulled even though an accident intervened. In the field of obligations there is no such thing as excusable error ; every error is regarded as " necligentia." In Longobard law the terms "negligent" and "voluntary" appear to furnish the same contrast and to be identical with "per errorem" and "asto animo." It is the contrast between " bona" and "mala fides" ; "ignoranter" or " per errorem " means lack of knowledge of wrong; " asto," on the contrary, means knowledge of illegality. But even the lack of knowledge of a wrong does not relieve from civil liability for damages; and the opposite has significance only in criminal law where ignorantia camnot be penalized. In the same sense that "ignoranter" is employed in the Longobard edict, the Sachsenspiegel uses the word "unwetene" which means without knowledge of wrong; thus, "whoever cultivates 'unwetene' the land of another, shall still lose his labor." ...

\section{c. Damages}

Modern law has given free rein to the judge especially in the field of damages, and in order that this liberty may prosper has made use of the civil jury. Aneient Germanie law did not individualize in this department, but fixed absolute standards which regulated the greatest and the least of culpable aets which resulted in damage. We frequently read in the Folk-laws, of the capital which the criminal must pay in addition to a compositio. This means in general the value of the thing stolen or damaged, - the compensation. But, how is this ascertained? Wals it not left to the judicial judgment? If we sather from Lex salica 60 that the 
solidus is measured by cattle and grain, then we may retrace our steps and conelude that every object had its fixed price which exchuded individual valuation. This was in truth an average valuation which might not in certain cases, cover the actual damage, but the person injured received in addition a penalty which abundantly ontweighed any difference. . . .

\section{Legal Plastics \\ a. Modes of Legal Thought}

It is characteristic among all peoples in the beginnings of the law, that the law and legal rules should be thought out and expressed plastically ; that is to say, in such manner, that out of concrete, objective forms and appearances, an original image is created which remains graven in the memory. This method finds its greatest enemy in a writing down of the law; it thrives only in naîve Folk-life and with the transfer of the law from mouth to mouth, where abstract rules, which are at once forgotten, cannot be employed. Even the first efforts to reduce law to writing are far more lacking in spirit, and more directed to the understanding, than primitive law which is the direct expression of the Folk-soul. We would have no notion of the plastic method of thought peculiar to ancient Germanic law if we were restricted to the Folk-laws, the law-books, and the provincial and municipal codes, and if we did not have in the precedents of the peasantry and in the legal proverbs one of the most valuable treasures of ancient law. For the Folk-laws are already the product of reflection. As the prologue of Lex Salica says, the causes of strife were considered by men skilled in the law, and suitable provision was made for decisions. The Folk-laws are no longer the pure, unconscious product of customary law; this is found in objective form only in the legal rules contained, often in fragments, in the sayings of the peasantry [such as have been collected by Jacob Grimm].

One will hardly venture to be eontent to explain these methods of thought and expression (which are objective and generally sensible and rarely (umbrous), solely as the product of a naïv Folk-soul, and to base them exelusively on the practical consideration that something thought of in a vigorous image is better retained by the memory than an abstract principle. Thus, for example, that the throw of a hammer to fix the limits of a farmstead, or that a spear laid square alcross a saddle to mark the width of road, could be more easily remembered, than a plain measure in numbers. Just such 
acts, which are intended to take the place of a plain measuring in paces or feet, are often complicated enough to confuse the memory. Such, perhaps, is the measure for finding the limits in which chickens may range on the land of a neighbor; where the peasant, standing on the ridge of the roof, holding his ear with his right hand, threw a sickle held by the point with his left hand, behind him, under the right arm. Even an appeal to humor and poetry, here, does not suffice. Grimm has already pointed out that the throwing of a hammer has a religious meaning, the consecration of boundaries. A religious connection may also be affirmed with more or less certainty regarding the shooting of an arrow, and other acts. We may therefore assume, in general, a deeper explanation for all these phenomena, which frequently is of a religious character; since the forms in which the law appears were originally religious forms. Law was a parcel of religion, and its protection was given over to religion in the same way that there was committed to it the manifestations of Goll. Apart from a religious connection it was still necessary to distinguish legal acts as such from other acts of no legal significance, and to express their importance by an external force. The act of throwing a sickle, which, for us, approaches tomfoolery, is, in its transmitted form, perhaps an already ridiculous distortion of what was originally a very solemn performance, which not only expressed the legal significance of the transaction, but also protected the neighbor against a vexatious and improper extension of a power. When legal consequences were in question, the manner in which the sickle was to be thrown was not a matter of discretion. . . .

* $\quad * \quad * \quad * \quad * \quad * \quad * \quad * \quad * \quad * \quad *$

\section{b. Solemnities and Symbols}

The plastics of ideas and expressions and the plasties of legal acts and transactions are inseparably connected. Germanic law in its external appearance is uncommonly plastic, that is to say clothed in forms which in the highest degree accurately denote the objective sense of its materials. Every species of formalism, however, is not plastic. The requirement that certain contracts shall be in writing is an example of the exception. In this instance the content and essence of the contract are in no manner externally represented; on the other hand, the form is the same for the most dissimilar contracts. The greatest monument of modern formalism, the bill of exchange, and especially its more important form, 
the draft, cloaks in its external appearance, substantive law; for one does not gather from reading the document itself that the drawer becomes liable to the payee or the indorser. One must first know the law to understand the form. The form indicates nothing; it is the converse of plastics, because it will lead everyone astray, who without understanding the nature of a bill signs a bill believing from the form that he is giving a direction, and not that he is subscribing an obligation.

In contrast to this modern formalism which in its legal foundations is an independent product of artificial legal development, we may turn to the legal formalism of early law which is characterized by an objective representation of its processes in which solemnities and symbols play the leading part. Solemnity potentializes the form of ordinary life. Instead of the freely chosen words of current speech, certain prescribed words, or entire formulas must be uttered; and instead of an inconspicuous act, a ceremonial must be performed. Symbols come into being when there is no place for a natural form, or when a natural form is impossible. An emblematic form, therefore, is created in order to bring the abstract process to expression.

The origin of solemnities and symbols has often been ascribed to an imnate, unconscious impulse of a people toward imagery, and it has been supposed that primitive Folk customs have developed without design or purpose; in other words, that they have not been made, but that they have grown. It would be umprofitable to quarrel with this view, but yet the opposite notion seems to me more likely. All formalism of this kind is created by deliberate refiection by the priesthood which in the infancy of the law is the guardian of the law. Only that which is bound up with law and religion is under the dominion of this formalism. There solemnity prevails while here symbolism preponderates. The latter especially (and in large past also the former) is never naïve, the result of a free impulse of the people, but is always reflected and artificially thought out. In this connection, we may refer to the rich symbolism of the Mosaic legislation and worship, where each precious stone in the robe of the high-priest and each part of the priestly restments had a symbolical meaning. The spirit of the people does not generate it; it is discovered by the priestly leadership; but yet it fits in accurately with the feelings of the people in order that it may become acceptable. The original purpose was not directly to make the people dependent on the priesthood, or to secure to themselves power and influence through the possession of 
strongly fortified secrets; although in later times formalism may have been employed with this end in view. Rather, formalism sprang from the effort to make law and religion holy to the people. Law and religion were permeated with ceremonial acts and symbols; in fact, they were completely embodied in solemnities and symbols, in order that there might be instilled into the people a holy respect and honor for them; that the easily susceptible nature of a young people might be favorably disposed by them ; and that they might be made receptive to the law at a time when the mind did not grasp its meaning and was unable to understand its necessity. Without formalism, the law would have been a hidden treasure to the people. Therefore according to the nature of the form it is itself the law; and the form is employed for its own sake because the people see the law only in the form.

Inasmuch as we cannot carry ourselves back to this stage of mental development, the unyielding dominion of form may too easily appear as an insufferable hindrance to a free expression of will; but, in its flourishing time, it is not, however, regarded as such in any sense. For, on one hand, there is more earnestness in the law than at the present day, and legal transactions are entered into with an increased spirit comparable to the devotional ardor of religious worship; and, on the other hand, the feeling of seeurity and stability of law guaranteed by formalism which requires foresight, attention, and the striving for certainty is too strong not to make the exactions of formalism acceptable to all persons who undertake the concerns of the law. One, perhaps, may say, that formalism is not even regarded as formalism; for without it there is no law, and all law is known and exerted solely through formalism. The strict formalism of the bill of exchange does not oppress and limit us, for precisely the same reason, that by it the law of bills of exchange is first of all maintained.

If the interrogation is put whether Germanie law required for legal transactions the use of definite words or formulas, one, on first impression, would be inclined to answer in the negative. A verborum obligatio, like the stipulatio of elassical Roman law, never as much as existed; there was no form by which the law preseribed a fixed phrasing for the creation of a legal relation. Therefore, in Germanic law, there was no formal contract whereby any agreement could be chothed in words formally uttered, wherchy thenceforth by virtue of the foree of the words used, and without reference to the content of the agreement, its validity was established. Still it may be accepted that in the finishing of a legal 
transaction, the content could be expressed by the parties in a definite ceremonial manner by a solemin, fixed formula. This is shown by the Cartularim Langobardicum. This collection sets out the formula which was to be employed on the occasion of completing a legal transaction concerning the execution of a document.

* $* \begin{array}{llllll}* & * & * & * & *\end{array}$

The thing which, heretofore, has diverted attention from this side of the question is chiefly the circumstance that nearly all juristic acts, at any rate those especially characteristic in Germanic law, to which the leading interest has attached, are surrounded by a great luxuriance of solemn and symbolical acts. The importance of the form of words has not been observed, although it is to beadmitted, at the outset, that solemn and symbolical acts naturally are also connected with solemn words.

Solemnity and symbolism, and solemn and symbolical acts, are not mutually exclusive. Frequently, symbols are used for solemn precautions; in fact, symbolical acts are generally also solemn, although not necessarily. 'Thus, the shield, symbol of judicial power, and its suspension on the tree of the court, preserves the necessary solemnity of the tribunal. Or when the vendee of land is led around the boundaries of the land, or grasps the portals of the house, or when the rendor hands over to the vendee a broken twig or a clod of earth - all these acts are at once symbolical and solemn.

A symbol is a concretely sensible perception, an objective realization of an idea or concept. A symbolical act, therefore, is one which embodies in an external act a process which is not objectively perceptible. The twig and clod of earth in the examples given are not symbols, because they do not externalize any idea, but represent the land. They represent property, but the transfer of a twig and a clod of earth may be used as a symbolical act in that they objectify the transfer of possession (Gewere), with all its legal incidents, to the new owner. This, in fact, is the essence of a symbolical act, - that an abstract process is visualized; for example, when the transfer of omnership is represented by handing over a glove which is put on by the new owner. Feigned acts, therefore, are not to be regarded as srmbolical acts. The transfer of an arrha is not symbolical payment; a hanging in effigy is not a symbolical execution. The reason is, that payment and hanging are not abstract, but highly encrete and perceptible processes, the ideas of which are incapable of being symbolized. . . A A 
seller is not paid with an arrha, nor is a criminal executed by a hanging in effigy ; but the delivery of a twig is sufficient to transfer possession. Solemnities, funally, are precautions which legal acts alone are unable to represent, and which are designed only to provide an act with a special ceremonial and ralue, with the result that the act becomes legally valid only through the observance of its solemnity. Examples of this are the calling in of solcmn witnesses, the tweaking of the ears of witnesses, and the like. As already observed, symbolical acts (and likewise colorable acts) are frequently also solemn, as the act of investiture by delivery of a twig and a clod of earth before witnesses in a ceremonial performance. There ceremonials answer the purpose of the dignity of the symbol, but are not, however, indispensable.

Solemnities and symbols are so frequently encountered in Germanic law, that a detailed examination of the matter must be passed over. Grimm has done the most to collect them. I draw attention only to the great number of applications where the calling upon solemn witnesses, "testes" in contrast with " adstantes," was necessary. Reference may be made only to the two titles 46 and 50 of Lex Salica, according to which for the single transaction of Affatomie three witnesses are three times required in three different acts to set it in motion, and the transaction is completed by a series of purely solemn acts with witnesses. That these witnesses are also proof witnesses does not change the solemn character of the proceeding.

Symbols, however much they may differ, always objectify the concept of dominion and power, and symbolical acts make the admission of this dominion externally perceptible. Thus, assistance, in the institution of commendation, is symbolized by the vassal laying his folded hands into the open palms of the lord, indicating submission to the feudal tie; in Saxon law the dipping and snapping of a finger indicates the cession of every claim to a parcel of land conveyed ("digitis ineurvatis abnegationem facere"); the offer of a twig and turf signifies the induction into possession of land; the touching of an altar-cloth or the bell-rope declares the taking possession of a chapel; the laying down of the house-keys or a mantle upon the bier or grave of a husband expresses relinquishment of the matrimonial property to the creditor of the late husband; the cutting off of the beard and hair means surrender to a servile condition; the giving up of a hat or a glove, a transfer of ownership; and the bestowal of a staff, sceptre, spear, or small military flag, feudal sempice. 
The fourishing-time of this symbolism was the Frankish period. In this age, every symbol still had spirit and life, and this was chiefly made evident by the fact that it was not a benumbed and dead form, but had a living connection with the spoken word. As all things are created by the word (John i, 3) so also the form, the symbol, receives its vitality through the word, in order that, in turn, it may give to the abstract word an objective meaning. Both are equally essential for the foundation of the right, and both are of service in giving stability $\ell . g$. to the legal transaction of manumission, "ut rata haberi posset libertas," which Paulus Diaconus $(I, 13)$ designates as the symbol of the delivery of an arrow, but adds, "immurmurantes nihilominus ob rei firmitatem quaedam patria verba." This is not mere ornamentation, not even in the transfer of lands where symbolical acts are conspicuous by their number. How eareful the Cartularium Langobardicum is to remind that when the vendor is a Frank there should not be forgotten the knife, staff, clod, twig, and glove; when he is an Aleman, the hand ligature; while when he is a Burgundian or Bavarian, the knife may be omitted. In the period of the law-books this symbolism had already become a ruin.

* $\quad * \quad * \quad * \quad * \quad * \quad * \quad * \quad * \quad * \quad * \quad * \quad *$

\section{Section 6}

\section{ANCIENT SEMITIC PROCEDURE ${ }^{1}$}

Babylonians and primitive Senites - Tribal custom the foundation of law - Blood-revenge - Judicial anthorities - Institution of judges in Israel - Centralisation of justice - Divine decisions - Resort to a deity - Oaths of purgation "before God" - Semitic ordeals - Procedure in Babylonja - Laws relating to judges and witnesses.

TuE existence of a lengthy code, which, as we have seen in chap. $i,{ }^{2}$ covered a great variety of legal topics, is sufficient proof that in Hammurabi's age law and justice had reached an extremely advanced stage of development. It presupposes regularly instituted courts of law with duly qualified judges, and it requires us to conclude, further, that this stage had long been in existence, and that the Code was intended to fix once and for all certain judicial decisions which, if not new, at least required the authority of royal approval to make them general.

$1^{-}$[By Stanley A. Cook. Reprinted hy permission from "The Laws of Moses and the Code of Hammurahi," Adam and Charles Black, London, 1903. See list of abbreviations at the end of this section, p. 667.]

2 [Not reprinted.] 
The Babylonian Semites and the Semites of the desert lived under entirely different conditions, and whilst the latter, particularly in districts removed from the regular trade-routes, have remained throughout all ages practically untouched by the influence of the surrounding seats of culture, Babylonian society in the time of Hammurabi was a fusion of Semitic and pre-Semitic stocks of obscure origin. ${ }^{1}$ What Robertson Smith has said of the religious ideas of Babylonia in their relation to those of the primitive Semites ${ }^{2}$ may be applied to its laws. The fusion of races in Babylonia leads to the expectation that the principles of law and justice were an artificial combination of the most diverse elements. and it is therefore obvious that our inquiry must start with the less complicated types from the other regions of the Semitic world.

Here we are at once brought face to face with the fact that among primitive Semitic communities there is, properly speaking, no law and no law-givers. But it would be a mistake to infer that there was lawlessness. ${ }^{3}$ Tribal custom - and with it is involved religious custom - is the strongest of laws. A thing is lawful because it has always been considered lawful; things that are unlawful are things that are not wont or ought not to be done. ${ }^{4}$ Within the tribe all men are on a footing of equality, and under a communistic system petty offences are unreasonable. Serious misdemeanour is punished by expulsion; the offender is excluded from the protection of his kinsmen, and the penalty is sufficiently severe to prevent its being a common oceurrence. The man who is wronged must take the first step in gaining redress, and when it happens that the whole tribe is aroused by the perpetration of any exceptionally serious crime, the offence is fundamentally regarded as a violation of the tribe's honour, rather than as a personal grievance on the part of the family of the sufferer. Courts, as in Babylonia, for the adequate punishment of offences and legally ordained punishments are not yet in existence. This essential distinction between primitive Semitic and Babylonian procedure comes out most clearly in the case of blood-revenge.

The familiar Semitic conception of the sacredness of blood -

1 That the so-called Accadians or Sumerians were not Semites seems to be conclusively proved, but of their nationality and life there is little certain information. Under these circumstances it is searrely necessary to attempt to discover in what respects the Code is indebted to nonSemitic legislation.

2 "Rel. Sem." $\left({ }^{2}\right)$ p. $13 s q$.

${ }^{3}$ Cp. Benzinger in EBi. "Law and Justice," \$ I, "Government," \$ 9.

${ }^{4}$ Gen. xx, 9, xxix, 26 (a reference to local custom); $c p$. Gen. xxxiv,

7 ; 2 Sam. xiii, 12. 
whether human or animal - must have long been forgotten among the Babylonians, whose code is characterised by the frequent application of the death penalty. It is unnecessary to point out in detail how the Semites have been influenced by this conception. The inviolable nature of the blood-tie which makes kinsmen brothers, and the responsibility attached to the shedding of blood, lie at the very root of the almost ineradicable system of bloodrevenge. If a man has killed one of his own group, he has committed an offence for which he camnot expect to obtain protection from the members of his tribe. He may be solemnly put to death, and this was primarily effected without the spilling of blood, or he may be formally expelled, in which case he becomes an outlaw. ${ }^{1}$ In any case the community must be purged of the presence of the impious member. On the other hand, when the slayer and the slain are of distinct groups, the principle of the sacredness of blood reacts in a different manner. The group of the slain, on the one side, are bound in point of honour not to leave their kinsman's death unavenged; the slayer's group, on the other, so far from being under an obligation to surrender the guilty one, regard it as equally a point of honour to unite to protect him. There is blood-fend between the two groups. Any member of the aggrieved group may retaliate upon any of the slayer's group, and until satisfaction is obtained this state of feud continues. Naturally, under the circumstances, there may be indiscriminate slaughter, and the blood-feud is prolonged indefinitely. So deeply rooted is the practice that blood-revenge holds good among the wilder Bedoun tribes of to-day. Certain modifications, however, were sradually introduced, with the object of preventing the fierce internecine fights and the insecurity of life which the feud entailed. Blood-wit was offered and accepted, the responsibility for murder was confined within limits, and retaliation restricted to the guilty party and immediate relations. ${ }^{2}$ The development of the system in Israel will require separate consideration later, where we shall find that as late as the seventh century the murderer is solemnly

${ }^{1} \mathrm{Cp}$. Gen, iv, 12. In ancient Arabia the formula varied: we pronouncerd so-and-so to be a hali", "God put away this man," or "We are dean (innocent) of him" (I Procksch, "Über die Blutrache bei den vorislamischen Arahern," p. 31 sq.). For the principles of blood-revenge, see Robcrtson Smith, "Kinship and Marriage," $\left.{ }^{2}\right)$ pp. 25-27; cp. also IV. M. Patton, "Bloorl-revenge in Arabia and Israel," American Journal of Theology," Octoher 1901, pp. 703-731.

"Jaussen ("lierue Biblique," 1903, p. 253) mentions the story of a modern Bedonin who, to protect his kin from blood-fend and to confine a quarrel to his adversary and himself, solemnly repudiated his family. Henceforth he alone became responsible for what followed. 
delivered over into the hands of the slin man's nearest linsman, "that he may die," and that in other cases where the death penalty has to be enforced it is carried out by the community in general. Even the responsibility of judiciai blood-shedding must needs be borne by as many as possible.

It is characteristic of primitive Semitic orcanisations that there are no specified officials to pronounce or earry out legal decrees. In every tribe there were, and are, certain leading families, often hereditary, whose heads enjoyed certain privileges, ${ }^{2}$ in return for which they performed particular duties - the entertaining of guests, the protection of widows and orphans, ete. but except when the tribe is organized for defence or offence, the office is one of dignity rather than anthority. The sheikh may be called upon to settle differences within the tribe, or, if he be of repute, men from outside may appeal to his decision. But he has no judicial powers, and if either of the parties is dissatisfied he cannot enforce obedience. Much less ean he himself inflict punishment even upon the poorest man of the tribe. He is not supported by subordinate officers appointed to carry out his decrees; his weapon is persuasion rather than compulsion. ${ }^{3}$

Such tribes, held together by the bond of blood, in course of time united with their neighbours, and became knit together by common interests and practical necessity, and when the occasion arose for joint action, the leading sheikhs of each community consulted together and took the reins of these half-dereloped states. These steps on the road to kingship ${ }^{4}$ were trodden by the Israelites, whose conditions, in the earliest periods of their history, can scarcely have been very different from the pre-Islamic Arabs and modern Bedouin. How utterly removed they were from the advanced organisation of Hammurabi's age needs no demonstration.

On entering Canaan, the Israelites found themselves in the presence of a culture superior to their own, through whose influence their primitive tribal constitution in course of time became entirely lost. But the superior culture of the Canatanites rested solely in the fact that they were a settled people, who lived in towns and were familiar with agriculture, and the excavations in

1 "Rel. Sem." $(2)$ pp. 284 sq., 304 sq., 417 sqq.

2 Thus the sheikh, in ancient Arahia also called sayyid, "counsellor" (cp). Heb. sōd), receives one-fourth of all booty.

3 See Robertson Smilh, "Prophets," p. 381, "Kinship," $\left(^{2}\right)$ p. 68; Doughty, "Arabia Deserta." i. 145 (and possim): Procksch. op . cil. pp. 7 sqq.: Lady Anne Blunt, "Bedouin Tribes of the Euphrates," ii, 231 sqq.

" Rel. Sem." $\left.{ }^{2}\right)$ p. 33 sq.; Blunl, op. cil. p. $23.3 \%$ 
Solithern Palestine, at all events, do not lead us to infer that the stage of civilisation which they had reached was as high as the presumed influence of Babylonia would have led us to expect. The Cananite communities consisted of cities around which were grouped "daughters," villages which stood in a subordinate relation to them. We are as ignorant of the details of their constitution as we are of that of their northern ncighbours, the Phonicians, although several considerations tend to make it probable that their government was in the hands of an aristocracy, the princes (sārim), elders (zĕl:ēnim), or lords (bë älïm) of the Book of Judges, ${ }^{1}$ who controlled all matters affecting the interests of the city (Judg. viii sq.). That they held legislative powers is doubtless true, in so far as might makes right. Professional judges were not known in the carlier period of Israelite history; even in Egypt it is questionable whether they existed before the New Kingdom. ${ }^{2}$ Of the Hebrew terms for "judges," the šstêr is primarily a military official, and it is not until post-exilic literature that it is applied to one with judicial powers. ${ }^{3}$ The méhokel. is a commander or ruler, and the same appears to be true of the kiasin (the familiar Arabic lia ad i). ${ }^{4}$ The šophettim in the Book of Judges are the champions or deliverers of Israel ; the term is synonymous with mélel, "king," in Hos. vii, 7, Ps. ii, 10, and as an official title of the chief magistrate or consul in Phonician cities is interpreted "king" by the Greeks." A noteworthy exception to these terms is the specific designation dayyān (Heb. and Aram.), corresponding to the Babylonian da-a-nu, da-ia-nu; it is, however, extremely rare, and appears only in Ps. lxviii, 5 (6) and 1 Sam. xxiv, 15 (16); even in the latter passage it is questionable whether it belongs to the original text. ${ }^{6}$

That a professional class of judges did not exist is also borne out by the fact that we find no mention of them in the oldest

${ }^{1}$ Cp. Meyer, EBi. "Phoenicia," \$ 16.

2 Spicglberg, "Studien und Materialien zum Rechtswesen des Pharaonenreiches", (Hanover, 18:2), p. 63.

"See iriver's note, "Dent." p. 17.

"From Judg. v, 14, Sayce " Early History of the Hebrews," p. 121 sf.) wrongly argues that there were lawgivers in the oldest period of the Hehrew settlement. There would be no object in lawgivers coming to a military assembly. The lis sin is a petty ruler; $c p$. Is. iii, $6 s q .$, xxii, 3 (in Mic. iii, 1, 9, parallel with "head," rōss),

5 .Heycr, EBi. "Phenicia," \$ 16; Moore, it. "Judges," \$ 1.

"The LXX. reads, "May the Lord be a judge and arbiter," and Budde (Stamuel, ad loe.) rightly suspects that dayyan is an addition. Fol the sake of completeness niention must also be made of pillēl, to mediate, arlitrate; $c p$. pêtlilăh, an umpire's work, Is. xvi, 3, in late Hebrew, a matter for judgment (i.q. Hebr. pĕlīlì). 
Israel law-book, the Book of the Covenant (Exod. xxi-xxiii), ${ }^{1}$ and the story of Naboth (1 Kings xxi) shows that in the middle of the eighth century judicial functions still lay in the hands of the aristocracy and elders. Appeal could be made to the head of the state, and the readincss with which a complainant could gain the king's ear is illustrated by the story of the woman of Tekoa (2 Sam. xiv, $4 s q q$.), and the judgment of Solomon (1 Ki. iii. 16-2s). ${ }^{2}$ But as long as judicial powers continued to be exercised by the nobles and highest of the land, there was no higher authority to whom to appeal against injustice, and the passionate outcry of the prophets against the unjust dealings of the roval families of the land (Is. i, 23, Jer. xxi, 11 sq. Mi. iii, 9) stands, in unpleasant contrast with Babylonia, where Hammurabi, as his letters show us, investigated the suits of his poorest subjects, and dicl not hesitate to reverse the decisions of his governors.

The sistem of electing subordinate judges under the control of a supreme central authority was an innovation in Israe!. Tradition itself realised that it mas not part of the desert heritage, and ascribed its initiation to the Midianite Jethro, the father-inlaw of Moses (Ex. xviii), or to Moses himself (Deut. i, 9 sqq.). The system is practically one adapted for administrative purposes, ${ }^{3}$ and whereas, according to the Elohist in the former passage, Moses chooses the officers, the Deuteronomist leaves the choice to the people, and Moses only charges them with their duties. The practice of referring difficult or contested cases to a supreme head is similar to that which the Chronicler ascribes to Jehoshaphat (2 Chron. xix), and it is upheld by the Deuteronomist, who emphatically insists upon the sanctity of the priests' decisions (Dent. xvi, $18-20$; xvii, $8-13$ ). The actual date of its introduction is nuncertain. At all events, the "elders" (zĕliēnim) had been in possession of a certain amount of judicial authority, which they still partly" retain in the time of the Deuteronomist (Deut. xix, 12 ; xxii, $15 . s q$ ). It is about the period of Josiah's reformation, or a little later, that

${ }^{1}$ In Ex. xxi, 22 the text is corrupt. The judges do not appear in $v$. 30 , where some reference to them would certainly be expected. 1 sam. vii, $16 \mathrm{sq}$., viii eannot be taken as evidence for judicial authorities in early times; the passages are late.

${ }^{2} \mathrm{Cp}$. also $2 \mathrm{Sam}$. xr, 2 sqq., $2 \mathrm{Ki}$. xv, 5. In the Amarma Tablets $\mathrm{xxv}, 30-34,45$ ) the king of Alasia (Cyprus) uses his good offires for the return of the property of one of his eitizens who had died in Egrpt.

3 The traces of a parallel aecount in Nu. xi are 100 obsenre to build apon with eertainty. The divisions into thotsands, hundreds, fifties, and tens scarcely originated in Bahylonia, where the unit wats sixty; Assirian texts, howerer. acoording to Sayce, spock of captains of fifty and ten ("Early History of the Helrews," p. 191). 
the priests, who are the natural intermediaries whenever a divine decision is required, begin to receive greater powers. In Deuteronomy they investigate legal cases, and the evident attempt to place them upon equal footing with the judges (xix, $17 s q$.), together with the emphasis laid upon the inviolability of their decrees (xvii, 9b, 10a, 11b), and the consequent weakening of the authority of the elders, suggest that a change in Israelite legal procedure is introduced, which is not,improbably foreign to the original scope of that lam-bock. ${ }^{1}$

In Babrlonia, in addition to the judges, it would appear that law could be dispensed by the civil governors and the priests, and Sayce remarks that in certain cases, where foreigners were inrolved, "the elders" of the eity take their place among their judges." According to the same authority, the judges probably went on circuit, but this appears to be only an assumption from the allusion to Samuel's activity in 1 Sam. vii, 16, and the "royal judges" of Persia ; in Egrpt, however, the circuit system appears to be vouched for in Ptolemaic times, and Moret finds indications of this early attempt to centratise justice as early as the twelfth dynastr. ${ }^{3}$

Difficult cases are referred to a divine authority. The god is a "giver of decisions." 4 The Arabs of different clans sank all differences, and accepted Mohammed's decisions by reason of his divine authority ; in Israelite tradition, the Hebrews of the twelve tribes came to Moses for the statutes and laws of God; and when written laws are introduced, they receive their authority by being ascribed to an Ea, the god of culture, or a Šamaš, the god of law and justice. In Babylonia, from the earliest times, we find that the "gate" was the place where justice was administered. One contract-tablet speaks of litigant parties repairing to the judges, who bring them to the gate $(b \bar{a} b)$ of the goddess Nin-marki, where they duly give evidence; elsewhere the scene is the gate of the god Nin-gal, the house of Samaš or the gate of Šmaš, and the house of Marduk. ${ }^{5}$ The sanctuary is specifieally an appropriate place, since the solemn oath, taken in doubtful cases or for the

1 See "The Hexatelleh" (ed. Corpenter and IIarford-Battersby), vol. 2, notes on Deut. xvii, \&; xix, 17 sq.; xxi, 2, 5.

2 "Babylonians and Assyrians," p. $198 \mathrm{sq}$. On the sibutu (KB iv, 23, 1. 25, 1.28).

3 Mnspero, "Rec. de Travaux," new series, i, 44-49 (1895). According to Ermun ("Life in Ancient Egypt," p. 87), the administration of justice was thus contralised even under the old Empire.

" Rel. S'em." $\left.{ }^{2}\right)$ p. 70); $c p$. n. .2.

5 Whissur, op. cit. (below), nos. 43, 78 sq., 100, 110. 
confirmation of the evidence, is made before the deity or his representative. 'Similarly in Israel the place of resort for judgment might be a sacred site - the three places visited by samuel had the reputation of sanctity ( $1 \mathrm{Sam}$. vii, $16, \mathrm{cp}$. LXX.) - but in ordinary cases the presence of witnesses was all that was required, and the city gate, then as now the scene of business activity, served the purpose of a law-court (Job xxix, 7 sq\%). It was not difficult to collect ten men of repute and standing to act as witnesses (Puth iv, 2), and legal contracts were unnecesiary. It strikes one as quite in accordance with the business instincts of the Babylonians that out of the primitive system of administering justice at the gates in the presence of witnesses, the evidence being attested by an oath, ther should have developed the practice of building temples at these places, in order that the oath might be taken under the most sacred surroundings. The primitive Bedouin of to-day considers a solemn attestation sufficient in ordinary disputes - mercantile pursuits, one inagines, had seriously corrupted the inherited simplicity of the Babylonians.

The Code of Hammurabi is quite in touch with early Semitic custom when, under certain circumstances where independent evidence is not available, it lars down that a man must appear "before God" (maliar ilim), or undergo an ordeal. 'To be more specific, the solemn attestation applies to a man who has been robbed and the thief remains at large ( 23$)$, to a shipowner whose ship is lost ( $\$ 240)$, to a merchant who would regain the price he paid for slaves (\$281), to depositors whose deposits have been lost whilst in the keeping of another $(\$ 120,126)$. In every case the man who would recover his property (money or goods) must assess his loss "before God." A similar procedure is to be observed when a man would clear himself of a charge. Thus, a man from whom a fugitive slave has escaped $(\$ 20)$, an agent who is robbed of his merchant's goods (\$ 103), the herdsman who has hired an ox, which dies by a "stroke of God" whilst under his care $(\$ 249)$, the wife who is falsely accused of adultery $(\$ 131)$ these may protest their innocence and go free. Analogous to the above are the cases where an agent who accuses a merciuant of

${ }^{1}$ So, in $C I I, \& 9$, where stolen property is found in the hands of another, the witnesses for the areuser (who know the lost property) and for the accused (who testify that the article was bought in their presence) say out "before God" what they know, and the judge gives his decision. The disputed ol,ject is usually brought and deposited with the god (.Me issner, "Beitr. z. althab. Privatrecht," p. 5). For illustrations of modern procedure amone the Bedouin. sre l'almer, "Desert of the Fxodus," i, 87 (1871); Jaussen, "Revuc Biblique," 1903, pp. 252 sq., 2.59 sqq. 
wronging him puts him to account "before God and witnesses" (\$ $106 s(t)$, and where the shepherd, whose sheep are killed by a "stroke of God" or a lion, "declares his innocence (or purges himself) before God" (\$266). Here also may be mentioned the two instances where the man who has wounded another, or the brander who has made an indelible mark upon a slave, may swear that the act was not done "wittingly" 1 ' $(\$ 206,227)$.

In early Hebrew law, in the Book of Covenant, we may also distinguish two methods. The man from whose keeping a neighbour's deposit is stolen ean resort "to God" (ělōhìm) to clear himself (Ex. xxii, $7 s q$ ), and in like manner a suspected herdsman can take the "oath of Yahwè" (šĕbü'ath Yahwè) that he has not put his hands to his neighbour's goods, and go free (Ex. xxii, 10 sq.). These correspond to the seeond series in the $\mathrm{CH}(\mathrm{cp}$. especially $\$ \$ 120,266$ ), and are evidently different from the law in Ex. xxii, 9, which is couched in the most general terms, and possibly does not refer to deposit, but to stolen property. Here, it is not the aceused alone who comes to Elōhīm to elear himself of suspicion, but the passage deals with a dispute between two parties whose case is brought to the "god of decisions" for his judgment ( $c p$. 1 Sam. ii, 25a). It is the procedure which underlies the ordeal.

In the old contract-tablets the depositions are made before (mahar) witnesses, and the parties to the suit swear by (nis) the principal deities and the reigning sovereign. ${ }^{2}$ In Egrpt, a similar oath by the name of the Pharaoh was frequent. A man swore, "by Amon, by the prince whose spirits are dead, by Pharaoh my lord," and the "king's oath," as it was called, was usually followed by an impreeation. "Nay I have a hundred strokes, or give me over to the crocodile," maiming, and exile to the mines of Ethiopia, figure among the oaths sworn by Egyptian suspects. ${ }^{3}$ The old Hebrew methods of oath-taking are too well known to need repeating. At the present day, point may be given to an

\footnotetext{
${ }^{1}$ ina $i-d u-u$, "with knowledge"'; $c p$. bi-bĕlì da'ath, Deut. iv, 42, etc. (the later equivalent being vi-sĕgägah).

${ }^{2}$ E.g., by Nannar, Marduk, and Hammurabi ( $K B$ iv, 21), or even by the king alone (ib. iv, 25). Aceording to Meissner ("Beitr. z. altbab. Privatrecht," p. 5) the oath is taken by the name of the tutelary deity of the city, the principal deity of the land, and other gods, sometimes eren by the name of the native city of the contracting parties. The practice is found as late as the time of Darius.

3 Spiegelberg, "Studien u. Materialien z. Reehtswesen d. Pharaonenreiches" (Hanover, 1892), pp. 70-77 (p. 75, "To him was the king's oath given to say no lies, he [sajd] Ethinpia"); "Arbeiter und Arbeiterbewegung im Pharaonen-reich unter den Ramessiden" (Strassburg, 1895), p. 20.
}

${ }^{4}$ See EBi. art. "Oath." The later post-biblical usages are illustrated 
oath by the addition of such a wish as, "He who lies may none be born to him.' I

The oath of puration, which thus allows the accused to clear himself of an imputed crime by swearing that the charge is false, is regarded as entirely efficacious, since the deity in whose presence it is taken is confidently expected to arenge himself upon the perjurer. ${ }^{2}$ Primarily the ceremony is performed in a holy place before the god himself, or it may be in the presence of the priest, the authorised intemerliary of the god. The practice recorded by a writer of the Deuteronomic age, in accordance with which a man could swear his innocence before Yahwe's altar at Jerusalem (1 Kings viii, 31 sq.), in earlier days, before the institution of the central sanctuary, must have been customary at every shrine or holy place. To take the name of Yahwe falsely, therefore, was to perjure one's self. Under the Deuteronomic reformation the oath of purgation would be taken before the authorised officials (Deut. xix, 17), even as among the Bedoums of the present day it may be made before the sheikh. ${ }^{3}$ From this oath we must of course distinguish the curse which the rictim of a theft calls down upon the thief, or the adjuration, equally based upon a belief in the efficacy of the curse, which solemnly calls upon any man who has knowledge of the offence to say all that he kinows.

The belief that the deity punishes the guilty one who swears that a charge is false is intimately connected with the theory of the ordeal where it is left to him to indicate in some recognisable manner whether a man is guilty or not. Instead of the oath of purgation a test is employed. The Code of Hammurabi uses it only in two cases, and on each oecasion it is by water. The rivergod (ilu Nàmu) has to decide whether a man upon whom a spell has been cast has suffered unjustly (\$2), and whether a wife who

in the Mishnah (tract. Shebuoth), where some of the formule are given. An accused protests his innocence. The accuser says, "I adjure thee." If the man replies "Amen," and is proved guilty, he is culpahle. "Amen" is thus the legal term with which the acoused expresses his readiness to accept the adjuration (cp. Hogg, "Jewish Quarterly Review," 1896, p. 17).

1 Ewing, PEFQ, 1895, p. 172 sq.

2 "Rel. Sem." p. 480; cp. Jausen, "Rev. Biblique," 1903, p. 259 (a guilty Bedouin agrees to talie an oath [halifa] at a holy tomb, but on his way, fearing the possible consequenres, is filled with terror and eonfesses).

3 An interesting development of the nath taken in a holy place is recorded by Baldensperger, where two parties arranged to setul. a disputs and agreed to swear by St. George (I'EFQ, 1897. p. 131). To avoid the trouble of dressing in festival rothes and repairing to his shrine. it was decided to make a mark on the gronurl to represent the saint's abode: ("He is over against us but can be present just as well"). 
has fallen under the suspicion of unchastity is innocent ( $\$ 132)$. The rictim must plunge into the sacred element, which overpowers the guilty and saves the imnocent.' 'The revenge taken upon the impious finds analogies in the waters of the Asbamean lake, the springs near Tyana, and the Stygian waters in the Syrian desert - not to speak of the striking parallel of the "waters of Jealousy" in Israel - which harmed only the perjured." But the river-god, instead of punishing the wicked, may repudiate them, on the principle that impurity and guilt must not come in contact with sacred things. So in Arabia, those who were suspected of witchcraft - not their victims, as in Babylonia - were thrown to the water, and since the god would only receive the innocent, the guilty ones were those who floated: the procedure that has prevailed in dealing with suspected witches down to modern times. Arguing from the same point of view, the Laws of Manu allowed a man to justify his oath of purgation by remaining under water a certain length of time (viii, $114 s q$.), and - to go still further away from the Semitic world - in Burmah the parties to a suit keep their heads under water, and the one who emerges first is reckoned guilty. ${ }^{4}$

Although the laws in $\mathrm{CH}$ relating to judges and witnesses are few, the contract-tablets reveal, as might be expected, a very advanced system of procedure. ${ }^{5}$ Evidence was drawn up in legal form and written upon tablets, ${ }^{6}$ and each case was examined with commendable thoroughness ( $c p . C H, \S 9$ ). The general principle not to pervert judgment, accept bribes, or to show favouritism and the frequency with which these exhortations appear in the Old Testament is an indication of the prevalence of injustice in Israel 7 - if not expressed in so many words, at all events lies at the bottom of CH, $\$ 5$. Here, if a judge has judged a judgment (sum-ma da-a-a-num, di-nam $i-d i-i n)$, has decided a decision (pu-ru$u z-z a-a m$ ip-ru-ušs), and delivered a sealed sentence (ku-nu-uk-kam), and subsequently his judgment is annulled (di-in-šsu $i-\hat{i} e-n i)$, he is

1 Darrste ("Journal des Savants," 1902, p. 519, n. 1) notes the same principle in the old German custom of testing the legitimacy of children by throwing them into the water; one may compare also the Sicilian oracle, where the tablet hearing the oath of the accused floated if true and sank if false (Pscudo-Aristotle" "Mir. Ause." 57).

" "Rel. Sem." $\left({ }^{2}\right)$ p. 179 sq.

${ }^{3}$ Cp. Wellhausen, "Arab. Heid." ${ }^{(2)}$ p. 160 (on p. 189, however, those unjustly suspected of witeh(raft float).

"Frazer, "Pausanias," iii, 388 (other" water-oaths and tests, iv, $253 \mathrm{sq}$.).

"Cp. Sayce, "Tabylonians and Assyrians," chap. 9.

"Written evidence appears to he unknown in Israel until the time of the hook of Job (xiii, 26; xxxi, 35).

${ }^{7}$ Ex. xxiii, 3, 6-8; Deut. xvi, 19, xxiv, 17, xxvii, 19; Lev. xix, 15, ete. 
ordered to pay twelve times the penalty he had ordained in his decision, and is openly (properly, "in the assembly," puhm) thrust from the bench; he camnot be reinstated, and is not allowed to sit in judgment with the judges. There are two disputed phrases in the law as it stands. In the first place, the judgment is presumably annulled by an appeal, either to a fresh court or to the king himself. In the contemporary letters of Hammurabi and his dynasty, the king is frequently appealed to cither directly or after a case had been tried at the local courts. In one instance the litigants, having failed for two years to obtain justice at Sippar, apply to the king, who gives orders for the defendant and the "witnesses yho have knowledge of his case" to be bronght to him at Babylon for judgment. In another we find Hammurabi investigating a charge of bribery against one of his officials; he confiscates "the money or whatsoever was offered as the bribe," and commands the men who had taken it and the witnesses to be sent to him for trial." On the other hand, Scheil and Johns render, "if . . . he has ammulled (altered) his judgment," which seems hardly natural, since the judge, however much of a partisan, would scarcely go back from his written verdict. It is possible that the law refers to judicial error, but the penalty and subsequent punishment would be excessively serere. ${ }^{2}$ In the second place, the "twelve-fold" ( $a-d u \quad 12 \breve{s} u$ ) penalty has been disputerl, and Winckler, in his edition of the Code, understands it to mean that the penalty consists of the sum (in the judgment) together with $\frac{12}{60}$, that is to say, an additional 20 per cent. The addition of a fifth — as in late Israelite law (Lev. vi, 5, Xxvii, 15-19; Num. v, 7) is suggestive, but there are serious objections against this view. ${ }^{3}$

Next, attempts to intimidate the witnesses, or the giving of evidence which cannot be proved, is severely pmished, and if it

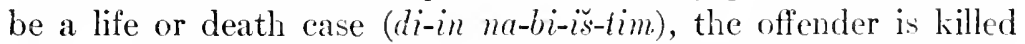
( $\$ 3)$. Bribery is rigorously discountenanced, and the man who has offered corn or money is punished by being made to bear the penalty of the judgment (a-ra-an di-nim, $\$ 4)$. In Isracl, false witness, prohibited among the additions to the Book of the Covenant (Ex. xxii, 3) and in the Decalogue, is punished under the Deuteronomic code in the same manner as in $\mathrm{CH}$ : "You shall do unto him as he purposed to do to his brother" (Deut. xix, 19); but one

1 King, "Letters of Hammurabi," iii, 21 sq., 136.

${ }^{2}$ In the case of a judge who has not acted in good faith, later. Jewish law required a sacrifice ("Mishnah," "Horaioth," i, 5, etc.).

3 See Joh. Jeremias, "Moses und Hammurabi," p. 25, n. 2; Orelli, "Gesetz Hammurabis," p. ':- 
can scarcely conclude that the law which is aimed at repressing false accusations (denounced in general terms in Ex. xxiii, 1) owed its origin to Babylonia. The same ruling held good in Egypt, and, indeed, the principle of the talio has prevailed in all primitive judicial systems. The Deuteronomic law is preceded by one in accordance with which serious crimes required the concurrent evidence of "two or three" witnesses as proof of guilt (v. 15), particularly in all capital cases ( $(p)$. Num. xxxv, 30 ; Deut. xvii, 6). The procedure is frequently referred to in the New Testament (Matt. xviii, 16, xxvi, 60; 2 Cor. xiii, 1; 1 Tim. v, 19), and must have been general, since it finds a place in the Syro-Roman law-book of the fifth century, which actually preserves the same loose wording, "two or three." 1 In the last-mentioned collection of laws, the penalty for unjust accusation is, as is to be expected, based upon the talio: "As he (the accuser) would do unto his companion, so shall it be done unto him.." 2

Legal disqualifications of certain persons to act either as judges or witnesses, and the more minute details of judicial procedure, do not appear to be codified before the time of the Mishnah. ${ }^{3}$ The Syrian law-book requires witnesses to be freedmen and trustworthy, not slaves, men who have never been convicted of misdeeds - theft, robbery, sorcery (Syr. harrāšnthā), and the like — "who have not been guilty of objuration" (? $\dot{\epsilon} \xi \omega \mu o s i ́ a)$, and are not relations, friends, or business associates of the parties. In Babylonia witnesses appear to have formed an official class; ${ }^{4}$ since every act of business, legal or otherwise, had to be set down in contracts, reputed and qualified men were doubtless in frequent demand as witnesses.

The Babylonian system of judicial procedure, it would appear, did not leave its stamp upon early Israelite institutions. Both share, it is true, the sacred oath and the ordeal, but these are common Semitic property, and are by no means confined to the Semitic field. The denunciation of false witness does not become

1 Bruns and Sachau, "Syrisch-Römisches Rechtsbuch aus dem fünften Jahrhumbert" (Leipsie, 1880), p. 106.

${ }^{2}$ () p. cit. p. 70 (110.75). Examples of the minuteness of the postbiblical Jewish rules relating to false evidence may be seen in the "Jewish Encreloperlia," i, 394 a.

${ }^{3}$ ('p. also the fulness of detail in the Mohammedan systems (abstract by Kohler. "Rerhtsvergleich. Stud." pp. 149-161). Aceording to Josephus ("Ant." IV, viii, 15), there must be three or at least two witnesses, reliable men; neither women nor slaves are admitted.

$4 \bar{s} \bar{\imath} \bar{u}(t i)$, "witness" (abstract sĩbūtu), properly the elders or "grey-

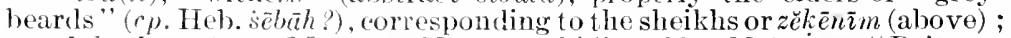
cp. Joh. Jeremias, “Míses 11. Manmurabi," p. 29; Meissner, "Beitr. z. altbab. Privatr." pp. 5, sq., 95). 
codified until the time of Denteronomy, at a period when the administration of justice was reconstructed and centralised. On the other hand, the precautionary rule that "two or three" witnesses are required in criminal cases, although fairly widespread, does not find a place in Babrlonian law.

Procedure, as we learn from the legal documents of the great law-suit under Rameses IX. (twellth rentury B.c.), was no less developed in Egypt. Officers, appointed by the government, sat in judgment daily, and received their salary from the fees paid by litigants. The evidence, as in Babylonia, was in writing, and could be extracted from unwilling lips by torture - a method apparently unknown in Babylonia. ${ }^{1}$ Under the New Empire the courts of justice differ in name and constitution from those of the Old. The judges were largely priests, supported by permanent officials, including a scribe, but the composition of the court varied considerably. The contrast between the methods that prevailed in Egypt and Babylonia and the simple primitive "courts" of the early Arabians and Israelites is thus sufficiently striking. ${ }^{3}$

* * * * * * * * * *

1 Torture is rarely practised among the Bedouin of the desert (ep., however, Doughty, "Ar. Des.," i., 14).

${ }^{2}$ Erman, "Life in Ancient Egspt, pp. 130 sqq.

3 List of Abbreviations.

"Encyclopædia Biblica," I-IV (London, 1S99-1903) = EBi.

Robertson Smith, "The Old Testament in the Jewish Church" (second edition: London, 1892).

"The Prophets of Israel" (second edition : London, 1895).

"Lectures on the Religion of the Semite" (second edition; London, 1894) $=$ Rel. Sem. $\left({ }^{2}\right)$.

"Kinship and Marriage in Early Arabia" (second edition; London, 1903) = "Kinship " (2).

"Keilinsehriftliche Bibliothek" (ed. Sehrader, Vol. IV - Assyrian texts; ed. Peiser (Berlin, 1S96) - Legal and business texts) $=K B$.

Wellhusen, "Die Ehe bei den Arabern" (Nachrichten v. d. kgl. Gesellseh. d. Wissensehaft, Göttingen, 1s93; No. xi).

"Reste Arabischen Heidentums" (second ertition; Berlin, 1897).

"Palestine Exploration Fund, Quarterly Statements" (London, 1869 - ) $=P E F Q$.

"Zeitschrift des deutschen Palästina-Vereins" (1S7s- ) $=Z D P V$.

"Zeitschrift der deutschen morgenländischen Gesellschaft" $(1846-)=$ $Z D . M G$.

Bruns and Sachau. "Syrisch-Römisches Rechtsbuch aus dem fünften Jahrhundert" (Leipzig, 18S0).

J. Kohler, "Reohtsvergloichende Studien über" islamitis"hes Recht," et». (Bertin, 18s9).

J. Estlin Carpenter and G. Harforl-Battersby. "The Ihexateuch . . arranged in its eonstituent documents. . with introrluction, notes. marginal refereness and symoptical tables." Two rols. (Oxford. 190().

JE. The oldest Hebrew documents aseribed to the Jahwist and Elohist schools respectively.

P. The writings of the Priestly school.

Code of Hammurabi $=C l 1$. 


\section{SECtion 7}

\section{ANCIENT ROMAN PROCEDURE 1}

\section{Roman Civil Procedure}

The fundamental characteristic of Roman civil procedure in the classical period is the division of all judicial proceedings into two sharply distinguished sections, the proceedings 'in jure,' and the proceedings 'in judicio.'

The proceedings 'in jure' are the proceedings before the magistrate, that is to say, before a judicial officer, the organ and representative of the sovereign power of the state. And since the introduction of the praetorship the 'magistrate' means, as a rule, the praetor. The object of the proceedings in jure is, firstly, to ascertain, whether the plaintiff's claim is admissible at all, i.e. whether there is any form of civil procedure by which it is enforceable; secondly, to determine the nature of such claim, and, at the same time, to fix the conditions subject to which it can be asserted. In the absence of a 'confessio in jure' the proceedings in jure culminate in, and terminate with, the so-called 'litis contestatio,' i.e. the formulating of the legal issue, the object of which is to supply a foundation for the 'judicium' and thus to obtain a final decision of the issue. The name litis contestatio is due to the original practice of coupling with this stage of the proceedings a solemn appeal addressed by each party to his witnesses. The granting of the litis contestatio by the magistrate is tantamount to a decision (decretum) on his part, that the plaintiff's claim is admissible in itself and must be enforced, subject to such limitations as result from the contents of the litis contestatio.

The proceedings in jure however can never lead to a 'sententia,' i.e. a judgment, in the legal sense of the term. The issue having been formulated and declared primâ facie admissible by means of the litis contestatio, it is necessary, for the purpose of obtaining judgment, that the proceedings should pass out of the hands of the magistrate into those of a private individual, or, in some cases, of several private individuals adjudicating as a collegiate body. ${ }^{2}$

${ }^{1}$ [By Rudolph Sohm. Reprinted by permission from "The Institutes of Roman Law" (Ledlie's trans.). Oxford University Press, 1892.]

2 All actions touching the liberty of a person were, during the republic, tried by a standing college of ten sworn judges (decemviri stlitibus judicandis). Actions concerning vindications, especially the hereditatis vindicatio, were referred to the college of centumviri consisting of 105 , and later of 180 members, who were gromped in several committees (con- 
A sententia, in other words, a judgment, in the legal sense, can only be pronouncer by a private person who cannot exercise any sovereign discretion, because he in no way represents the alsolute power of the state, but is bound, by the oath under which he i.s acting, to adjudicate in strict conformity to the law as already established. Thus no one but a private person can be a jurlex in the true sense of the term, i.e. an organ of the positive law For every decision of a magistrate is formally (even in civil (ases) an assertion of his sovereign imperium (a decretum or interdictum). It is, legally speaking, not a verdict, but an imperative order. ${ }^{1}$ On the other hand, the decision of a judex, i.e. of a private person acting under oath and under an authority based, not on imperium, but on officium, - such a decision, and it aloie, is a judgment, a veraict, a 'sententia,' and not an order, an imperative command. And this is the reason why the law of civil procedure in Rome required that the magistrate should abstain from deciding the legal issue, and should refer such decision to a private person who is thereby appointed judex for purposes of the action. The

silia). If the praetor wisher to have a matter speedily decided, he was able, by virtue of his imperium, to appoint an extroordinary college of, usually, three or five 'recuperatores' who were directed to find a rerdict within a speeificd timie. Such cases of urgency arose especially in actions coneerning personal liberty (vindiratio in lihertatem), with the result that the jurisdiction of the decemvini was de facto displaced by the court of recuperatores - a circumstance which explains why, since Augustus, the decemviri ceased to ar.t in this capacity. Recuperatores were also appointed in actions to whirh aliens were parties. - Like the single judges, the recuperatores (who were always appointed for the nonce) and the centumviri were, as such, private jersons. Although three centumviri were seleeted from earls of the thirty-five tribes, there is nothing to show that they were chosen by the romitia tributa. The decemviri however had, towards the close of the repullic, to be elerted by the comitia tributa, so that formally they belonger to the magistratus (minores) populi Romani, a fact which however dirl not alter their position as arainst the litigant parties. Ail sworn judges whatsoever, including the deremviri, stand to the parties solely in the position of private individuals (judex privatus), and not in the position of magistrates equipped with compulsory powers; r. Pernice, "ZS. der Sav. St." vol. v. p. 4.5.

1 This is the ieason why a magisterial derision, even in eivil matters, could be annuller by the intercession of a roördinate or a superior magistrate, i.e. by means of a counter-orter of equal imperative forces imperium). One ordar simply anmulled the other. It was this fart that gave rise to the srstem of appoal as dercloperl in the older Roman law, one magistrate being 'appealed to' to intercede against the other. The practice of appealing to the emperer, who was authorized to withdraw any suit in the empire from the ordinary rourts for the parpose of hringing it before his own rourt, led, during the principatus, to the dowlopment of the modern system of appeals. under which as in the nla protocatio') the rourts are ranged in a series of ligher and lower instanre, a higher rourt trying the rase over again with a view of pronomoneing a new jurlgment. C"P. J. Herkl. "Nhliandlungen aus dem Gebiete des römischen Rechts," Ileft 2 : "Uber die Geschichte fler classischen Appellation" (1SS3). 
principle of the division of all civil procedure into the two stages of proceedings in jure and proceedings in judicio is the elimination of the magisterial power from the domain of private law.

The issue, then, having been admitted and formulated in jure (litis contestatio), the next step is to pass it on for trial to a private judge, or judges, acting under oath. The proceedings before the judex are called the proceedings 'in judicio.' The object of these proceedings is, as we have already stated, to obtain a decision of the legal issue by means of the judgment (sententia) of the judex. The judge's first business will be to ascertain the facts of the case and receive such evidence as he deems necessary; after which he will proceed, according to the best of his knowledge and good faith (ex animi sententia), to pronounce judgment, i.e. to give his verdict on the legal relationship submitted to him.

While the procedure in judicio did not, as far as we can see, undergo any material alteration from the time of the Twelve Tables down to the end of the classical cpoch, an important reform had been effected in the procedure in jure towards the close of the republic. The system of legis actiones was superseded by the formulary procedure.

\section{The Legis Actio}

The litis contestatio, with which the proceedings in jure terminated, was, in the early Roman procedure, a solemn act of the parties. When the arguments betore the magistrate had concluded and the latter was about to grant a judieium, both parties, having solemnly called upon witnesses to testify to the issue between them, proceeded, in the presence of these witnesses, to formulate the issue in an unequirocal manner by means of their own formal act, using for this purpose, certain fixed traditional terms (litis contestatio). The formulae to be pronounced were determined either by the wording of a popular statute, the statute namely on which the action was based, or by old traditional custom which was regarded as possessing the same force as a law (lex). Hence it was that the act of performing the litis contestatio, nay, even the entire procedure of which the litis contestatio was the centre and pivot, was called a 'legis actio,' i.e. a proceeding according to the law. And by an action, in the true, the normal, the proper sense of the term, was understood a proceeding which led to a litis contestatio of this lind, and, through it, to a judicium and the judgment of a sworn judge, as opposerl to the decision of a magistrate. But there was yet another sense in which such a procedure could be called a 
'legis actio,' in the sense namely that not only the form of the litis contestatio, but the very right of the party to claim a judicium in any such case on the ground of the litis contestatio, was deterinined by the lex, or custom having the force of lex. The Roman actio, in other words, represents a right of the plaintiff not only as against the defendant, but also as against the magistrate, a right, namely, to have a judicium, i.e. a right to have the judicial, as opposed to the administrative machinery, placed at his disposal, in a word, a right to have a private individual appointed for the purpose of deciding by his judgment the question at issue between him and his adversary. This title to a judicium, i.e. the actio, rests in early times on lex, or custom with the force of lex. And for this reason it was called legis actio.

Of legis actiones we have five - (1) the L. A. sacramento, (2) the L. A. per judicis postulationem, (3) the L. A. per condictionem, ( 4 ) the L. A. per manus injectionem, (j) the L. A. per pignoris capionem.

\section{The Legis Actio sacramento.}

The ordinary and most important form of the legis actio procedure was the so-called 'legis actio sacramento.' Both parties, with a view to the litis contestatio, solemnly affirm their legal claim. The plaintiff declares: 'ajo hanc rem meam esse ex jure Quiritium,' \&c., and the defendant answers with the same formula. Thereupon both deposit a sum by way of wager, the so-called 'sacramentum,' which amounted, according to the matter in dispute, either to 50 or 500 asses, and which each party dectares shall be forfeited, if his contention proves to be false. This wager supplied the formal basis for the judicium, i.e. the formulating of the issue, and, when once entered upon, may be presumed to have, at the same time, formally established, as regards the magistrate, the right to a judicium (i.e. the actio). If a man challenged another to a wager (sacramentum) in reference to some legal clam primâ facie possible, he was thereby enabled not only to compel his opponent to lay a comter-wager, but also to require the magistrate to appoint a judex. This legis actio was thus, in the truest sense, a legis actio sacramento, for the judicial wager was the basis both of the decision of the judicium and of the formal title to the judicium. The private right secured its actio by means of the sacramentum. ${ }^{1}$

${ }^{1}$ It is probable that the compulsory fore of the sarramentum as against the magistrate is haserl on the fact that, originaliy, it was not merely a matter of money lad against momey, bul oath against wath (i.r. sacramentum, in the ordinary seiss of the word). 'The person temelering tho 
II. Legis Actio per judicis postulationem.

There were, however, some farticular cases where the law annexed to the existence of certain facts, facts, namely, constituting contracts and delicts of a specified lind, an immediate actio or right to a judicium. There was no need to lay a wager (sacramentum) and incur the consequent perils of a law-suit. In order to compel the magistrate to direct a judicium, all that was required was that the plaintiff should affirm in jure the existence of the particular facts, whether a contract or a delict, and should, on the ground of such facts, in solemn words claim to have a judex appointed. But it was indispensable that the facts of the case should tally precisely with those indicated by the verba legis, and that therefore, in setting forth these facts, the exact verba legis should be employed. Inasmuch then as, in these cases, the application for a judex inmediately bound the magistrate to grant the judicium, this legis actio was called the L. A. per judicis postulationem. ${ }^{1}$

oath pledges, for the truth of his oath, either his own person (i.e. he consecrates himself to the gorls), or he only pledges some portion of his property which he thereby ronsecrates to the gods, which he, in other words, agrees shall he forfeited to the gods, if the decision goes against him. In eivil procecdings, the latter kind of oath, where a man merely stakes some portion of his property (the "Vieh-Eid' of German law), is suffieient. Even it, moreover, was enough to raise a question whieh recuired to be defided by an objective judgment; in other words, ras enough to deprive the magistrate of all power to reserve the matter for his own decision (deeretum), and to compel him to appoint a sworn judge (judex), on a rollege of sworn judges (e.g. the centumviri), to decide it by means of a verdict, or sententia. The oath, in a word, establishes the actio, i.e. the claim to a judicium. Subsequently the oath was dropped, and the consecrated sum of money, (sacramentum, in this sense) alone remained, though, as a matter of faet, the actual depositing was, in later times, dispensed with, the money being merely promised. Sehultze ("Priv. R.," ete. p. 455) regards the sacramentum as a judgment given by the party on his oath. Of course it is a judgment in the logieal sense of the term, but searcely a judgment in the sense of civil proeedure, i.e. in the sense of deciding the question at issue.

In my opinion the 'legis actio de arboribus suceisis,' instaneed by Gujus, bk. iv. $\$ 11$, refers to this legis actio per judieis postulationem. There secms to be no doubt that the original artion, as based on the Twolve Tables, really only lay for cutting trees and nothing else. The extrnsion of the action to other cases, especially to the ease of vites succisae, was due to the intrrpretatio of a later time; but even when thus applied, the words used in the litis contestatio had still to he those preseribed by the statute, viz., "de arboribus saceisis." 'This was the source of the formalism of which (aijus speats. For it is of eourse out of the question that, in spealing 'de arboribus surcisis, the Twelve Tables intended, from the outset, to include also vites. The rule then that an action should only lie de arboribus succisis, meant originally that an aetio should lie on facts precisely rorresponding to the words of the statute and no other. In the comise of the subsequent development this rule, though really abamioned by the admission of the actio de vitibus sueeisis, was nevertheless maintained by a fietion, the aretion being still formally taken de arboribus suceisis only. The absurities of the formalism noted in Gajus must, threfore, be considered the result of a subsequent devel- 


\section{Legis Actio per condictionem.}

The L. A. per judicis postulationem had been designed for the enforcement of claims in personam. Actions for the enforcement of such claims received a further development by means of the L. A. per condictionem, which was first introduced by the lex Silia for the recovery of a fixed sum of money (certa pecunia), and afterwards extended by the lex Calpurnia to claims for a certa res. ${ }^{1}$ Wherever the plaintiff in an action in personam undertook to fix his claim against the defendant precisely at some liquidated amount (certam pecuniam dare), or to specify a particular object ownership in which should be conveyed to him (certam rem dare), he could, as in the L. A. per judicis postulationem, claim from the magistrate the immediate appointment of a judex. This condictio had its danger as well as its advantage. Its danger was that the plaintiff, though entitled to something, was nevertheless cast in his suit, if he had not claimed the precise amount due to him. Its advantage lay in this that it applied also to such cases the facts of which did not in themselves entitle a person to the judicis postulatio; nay even to cases where, possibly, there was no indisputable legal claim at all, as, for example, when the only feature of the case was that A had been enriched at the expense of $B$. In the L. A. per judicis postulationem the litis contestatio merely formulated the facts of the case without in any way indicating the nature of the claim deduced therefrom (legis actio in factum concepta), and, conversely in the L. A. per condictionem the litis contestatio merely formulated the legal claim without mentioning the facts from which it was deduced (legis actio in jus concepta). It was an abstract action where the concrete facts, on which the claim rested, were not referred to in the solemn act of formulating the issue (litis contestatio).

For cases falling under this second legis actio, the law required that the judicis postulatio should be made in a manner differing from the practice traditionally observed in the case of the L. A. per judicis postulationem. For in this latter action, the magistrate, in accordance with ancient usage, appointed the judex at once. The L. A. per condictionem had this characteristic of the later procedure - a characteristic which was connected with the general arrangements of a later period for the appointment of judges -

opment. The legis artio fiduriae supplies another example of the $\mathrm{L}$. A. per judicis postulationem (sup. p. 36, note 11). For further cases. $t$. Voigt, "Die zwölf Tafeln," vol. i, p. $5.66 \mathrm{ft}$. On the L. A. per juelic is postulationem, cp. A. Schmilt, "ZS. der Siv. St." vol. ii. (1881), p. $155 \mathrm{ff}$.

${ }^{1}$ Gaj. iv. $\$ \$ 1 \mathrm{~s}-20$. 
that, instead of a judex being appointed at once, the parties agreed to reappear in jure before the praetor in thirty days for the purpose of selecting and appointing a judex (ad judicem capessendum). The plaintiff at the same time gave the defendant formal notice to reappear within thirty days before the magisterial tribunal for the purpose of appointing the judicium. This notice was called 'condictio,' which means literally an 'agreement' or 'convention,' and hence the name legis actio per condictionem. It is to be observed, that the force of the qualifying words 'per condictionem' is precisely analogous to that of the words 'per judicis postulationem' in the other legis actio. In either case the plaintiff's application for a judex is directly binding on the magistrate.

IV. Legis Actio per manus injectionem.

In certain extraordinary cases the actio arises from a completed act of execution, in the same way as, in the L. A. sacramento, it arises from an act of affirmation.

The normal form of execution is judicial execution, i.e. the act of laying hands on one's adversary in jure in the presence of the magistrate (manus injectio). ${ }^{1}$ It means the attachment of the defendant for the purpose of making him the bondsman of his creditor. The party attached is disqualified from making any defence limself, because the effect of the manus injectio is to place him ipso jure in the position of a slave (servi loco). ${ }^{2}$ A third party, however, may intervene as a vindex and counteract the

${ }^{1}$ Extra-judicial manus injectio is never a real act of execution. It means either the taling possession of an unfree persion (as, in Livy iii. 44. Claudius applies the manus injectio to Virginia, with a view to taking her to his home as a slave), or it is an act of summons. If the defendant disregarded the in jus vocatio, i.e. the solemn oral summons addressed to him by the plaintift, the latter could always lay hands on him (manus injectio), with a view to bringing him before the Court (Twelve Tables, i. 2). In some eases the plaintiff could proceed to manus injectio at onee without any previous in jus vocatio. He could thus arrest, e.g. a judgment debtor (judicatus), in order to take him before the praetor for the purpose of there carrying out the judicial manus injectio; or again a 'fur manifestus,' or other person who had committed a delict partaling of a criminal nature (Demelius. "ZS. für RG." vol, i. p. 362 ff.). But extrajudicial manus injectio of this kind, though it serves the purpose of introducing legal proceedings, is, in itself, totally immaterial as far as the course of procedure itself is concerned; it is always merely preliminary to, never productive of, an action at law. Judicial manus injectio, and it alone, can beget an action. Thus, though there are several forms of manus injectio - judicial or extra-judicial manus injectio, and of the latter again several kinds - there is nevertheless but one legis actio per manus injectionem, that actio namely which springs from the judicial manus injectio or act of execution.

2 The fact that the manus injectio ipso jure debarred the person attached from making any defence confirms the supposition that, in the early law, the efficacy of manus injectio was independent of any addictio on the part of the praetor; ; p. Jhering, "Geist des Röm. R.," vol. i. p. 152. 
effect of the 'manum injicere' by means of 'manum depellere.' The manum depellere operates to annul the preceding manus injectio, in other words, the debtor is free once more and cannot be attached again for the same cause. But, on the other hand, the vindex is now bound to indemnify the creditor whose act of execution he has nullified. He must give immediate satisfaction for the debt to recover which manus injectio had been resorted to. If, however, he refuses to pay the debt on the ground that he challenges the legality of the manus injectio, the law-suit commences and the rindex, if defeated, is cast in double damages. 'The suit has to be decided by the ordinary procedure, a judex being appointed for the purpose. It is in this sense that manus injectio bescets an actio, viz. the L. A. per manus injectionem. Judicial manus injectio (i.e. the act of execution) implies a right to have any issue that may arise in the event of the claim being contested, tried by a judicium.

Judicial manus injectio ean only be used in the case of a liquidated money claim. The regular instance of this kind is the judgment-debt, i.e. a fixed sum which a person has been condemned to pay by the sententia of a sworu judge ('in judicio'). An 'aeris confessus,' i.e. a person who had admitted a money-debt in jure before the magistrate, was regarded as occupying the same position as a judgment-debtor, and was thus liable to 'manus injectio pro judicato.' It is probable that originally a debt incurred by nexum, i.e. the formal obligation of the early civil law was treated in the same way as a judgment-debt. Several later statutes assimilated other debts to judgment-debts, the harsh effects of the manus injectio, however, being in most cases mitigated in such a manner as to allow the debtor to be his orn vindex, to 'manum sibi depellere' himself, so that he (the debtor) became the defendant in the resulting action, if any, and was himself liable in duplum in case of condemnation. Thus there were two species of this form of actio, firstly, the L. A. per manus injectionem pro judicato (where the debtor could only defend himself through a vindex), and, secondly, the L. A. per manus injectionem pura (where the debtor might defend himself in person). But in any case the manus injectio which had been carried out in jure remained the formal subject of the law-suit as well as of the decision, because in point of form the actio (i.e. the claim to a judicium) did not spring directly. from the private law, but from the manus injectio.

$V$. Legis Actio per pignoris capionem.

Pignoris capio is a process akin to manus injectio. The law 
invested debts of a particular kind with special privileges by allowing the creditor to obtain satisiaction for them by an extra-judicial seizure of portions of the debtor's property. Every such authorized pignoris capio was characterized by the use of certain prescribed words (certa verba) which had to accompany its execution. The distrainee was bound to redeem the property seized within a prescribed interval, with the addition, probably, of a penalty ; in default of which we may presume that the ownership in the goods distrained passed to the distrainor. The latter generally exercised his right of ownership by destroying the things (pignora caedere), because the primary object of the distraint was not to satisfy the creditor, but to punish the refractory debtor.

The distrainee must have had the right, in some form or other of protesting before the magistrate in jure against the distraint which had taken place. Just as, in the preceding instances, the proffering of an oath (saeramentum) by one party, compelled the other to tender a counter-oath, and the manum injicere by one compelled the other to manum depellere, so here the pignoris capio compelled the distrainee, if he wished to make any defence, to enter a protest. Here, then, was another special issue which the magistrate had no power to reserve for his own decision, but was bound to send for trial before a judex. It was in this way that pignoris capio begot an action, viz. the L. A. per pignoris capionem.

The cases in which pignoris capio was available, were not, as far as we can see, sufficient in themselves to give rise to ordinary civil proceedings. They were partly claims of a public nature, e.g. a soldier's claim for his pay, for money to buy a horse, or for barley to feed his horse, or again the claims of farmers of the publie revenue for arrears of taxes due to the state; partly they were cases of a private law liability, which we may describe as not having given rise to any legal obligation in the early times. Thus if a victim had been sold for sacrificial purposes by means of an informal contract of sale, or again, if a beast of burden had been let out under an informal contract of letting with a view to investing the consideration money in the purehase of a lamb to sacrifice to Jupiter, the guardian deity of harvests - in neither case did the purchaser or hirer respectively incur any legal liability. It is possible also that pignoris capio was resorted to in the case of 'damnum infectum'; that is to say, where a man's property was in danger of being injured, though not yet actually injured, by the state of his neighbour's property (e.g. by the dilapidated condition of his house), he 
was perhaps allowed to seize some of the neighbour's land by way of pignoris capio.

In none of these cases was there any action at law. Nor was the legis actio sacramento availahle, because the sacramentum had to affirm a dare or facere oportere, in other words, the existence of a liability fully enforceable at civii law. But by the circuitous method of pisnoris capio the creditor's claim wats either satisfied in such a way as to put a penalty on the distrainee, if he sulmitted to the pignoris capio, or else was brought to trial (actio), if he (the distrainee) protested.

The right of pignoris capio was said to have 'instar actionis,' i.e. to grant a right of distraint was virtually to grant a right of action.

TI. Recapitulation.

To sum up. Private law grants a legis actio either directly (L. A. per judicis postulationem, per condictionem), or indirectly. The means by which a private right, which is not directly enforceable by the ordinary civil procedure, can nevertheless secure a trial or actio, are either a solemn affirmation (sacramentum) or a solemn act of execution, which latter can be either personal (manus injectio) or real (pignoris capio).

The legis actio sacramento is the general form of action; the remaining legis actiones are restricted to such cases as are determined by statute (lex) or ancient custom with statutory force.

These special legis actiones are, each and all, modes of enforcing obligatory rights; in other words, they are forms of so-called 'personal' actions. Thus we have an abundance of actions whose object it is to protect the rights of creditors. A creditor, however, may also proceed by legis actio sacramento, not only when his claim is for a 'certum,' but also where it is for an 'incertum' ( $c . g$. pro fure damnum decidere oportere), provided only the existence of his claim was disputed, and the peculiar form of trial by wager, which required two mutually exclusive allegations, thereby became practically applicable. But whenever the clam was not personal, but real, i.e. Whenever it sprang from some relation of power, whether a power over things (ownership), inheritance, servitude) or over persons (marital, paternal, tutelary power). in all such cases the legis actio sacramento was the sole form available. Having seized the object in dispute, ${ }^{\mathrm{I}}$ both parties had solemnly to

1 Corresponding to the 'ancfang' in the German form of rindicatio. Cp. Gajus, iv. 16. The scizing of the objeet was coupled with the ceremony of festueam imponere, the staff being the symbol of poiver. 
affirm their title to it sacramento (vindicatio and contravindicatio). ${ }^{1}$ In this way the litis contestatio was arrived at and the foundation for the judicium laid. I'ending the judicium, the praetor, acting on his own discretion, regulated the interim possession (vindicias dare).

We have thus, on the one hand, only one form for actions of ornership, in fact, only one form for real actions of any kind; on the other, a profusion of actions for the enforcement of obligations. From the very outset the productive genius of the Roman law of procerlure, like that of other departments of Roman law, characteristically exhibits itself within the sphere of the law of obligations. ${ }^{2}$

\section{The Formulary Procedure}

The solemn act by which the parties themselves, at the conclusion of the proceedings in jure, formulate the legal issue (litis contestatio), constitutes the pith and climax of the legis actio pro-

1 The sacramento provocare, i.e. the affirming of one's own word, involved the impeachment of the other party's word (injuria vindicavisti), which was thereby, legally speaking, anmulled, the party himself being thus compelled to make his reply by means of a counter-sacramentum. (Compare the precisely similar effect which resulted in German law from the fact that one party, by his deed or oath, impeached the deed or oath of his adversary.)

2 From an historical point of view, the legis actiones are divided into two yroups, those of an older and those of a later type. The legis actiones of the first group, which are antique in character, are marlied by the prominence in their procedure of the element of private force, which is the source and fountain-head of all actions whatever. To this class belong the L. A. per manus injectionem and the L: A. per pignoris capionem. The ancient civil procedure hoth of the Romans and Germans is nothing more than a form of self-help sanctioned by the law. And even the vindiratio sacramento hears clear traces of a similar character. In the proceedings in jure both parties are seen exercising force; they are struggling for the possession of the object in dispute, they both lay hands on it. At this moment the judge steps in and commands peace: mittite ambo hominem! Both parties must let go the object (e.g. the slave who is 'vindicated'). The judge alone has now power to deal with it; he is free to act as he pleases in awarding possession (vindicias dare). A wager is then laid with regard to the preceding act of force, and the judge is required to decile which of the parties was acting in the exercise of legitimate force, of justifiable self-help. The second group of actiones, on the other hand, the L. A. per judieis postulationem and the L. A. per condictionem, bear the impress of a later age. Everything is done peacefully. The parties morely ask to have a judex. The action is no longer a mere disguise thinly veiling what is really a hold exercise of self-help; the state itself dominates the legal system and the execution of the law, and the whole procecdings in jure merely represent an application by the parties for jurlicial proceedings. Cp. Beklier, "Actionen," vol. i. p. $18 \mathrm{ff}$. and Bechmonn's recent "Studie im Gebiet der legis actio sacramenti" ("Festschrift f. Windscheid"), 1SSS; Grudewitz, "Zwangsvollstreckung u. Urteilssicherung" ("Berliner Festschrift f. Gneist"), 1SSS; Matthiass, "Die Fntwirkelung des römischen Schiedsgerichts" ("Rostocker Festgabe f. Windscheid"), 1Sss, pp. 5-1S. 
cedure which we have just described. The oral formula of the parties, framed in strict alherence to, and operating by rirtue of, the letter of the law, begets the 'actio,' i.e. the concrete, formal right to a judicium, and, at the same time, slipplies the foundation upon which the judicium proceeds.

This solemn act of procedure camot be repeated. It necesiarily follows, therefore, in the first instance, that the solems litis contestatio of the legis actio procedure operates ipso jure to destroy the right of action. That is to say, in the same moment when the litis contestatio gives birth to the actio in the formal sense of the term (i.e. to the right to claim a judex for the dispute in ciuestion), in the very same moment the actio in its material sense (i.e. the right to the litis contestatio) is anihilated. The litis contestatio can only be carried out once and no more. Its effect is to consume the right of action.

It follows, moreover, in the second place, from the same rule that, if a mistake has been made in the formula, there is no way of correcting it and saying the formula over again in an amended form. A faulty formula entails the loss of the action, for the oral formula admits neither of repetition nor amendment. The reason why the use of the formula is attended with the risks incident to an action is because it is itself an act which operates to consume a right of action.

It was however ineritable that the oral formula should soon prove inadequate for the purpose for which it was designed, the purpose namely of formulating the dispute for the decision of the judex. The oral formulae were immutable, because the wording of the statutes on which ther were founded was immutable. But the law which was developing on the basis of these words was none theless changeable. True, the letter of the law frequently received, in practice, a sufficientiy liberal interpretation. On the strength of a section of the Twelre Tables dealing 'de arboribus succisis, the practice of the courts subsecuently admitted an action 'de vitibus $\beta$ us succisis.' But the worling of the Twelve Tables, and consequently also the wording of the spoken formula, remainerl the same. The words of the litis contestatio had to be de arboribus sucejsis, even when, as a matter of fact, the plaintifi intended to sue de

${ }_{1}$ Precisely the same irlea is to bo found in the old German procedure where the rule a man a word was applied, i.e. every math has only one word which, once uttered, "an neither be retracted nor rejeated nor amended. I might suggest that this rule. itself an expression of the formalism which dominates all rarly procedure, supplies the desired explanation (v. Irlassak. "Litis ront.," p. $\pi$, note 1 ) of the "consuming etfect incident to the old solemu act of litis contestatio. 
vitibus succisis. But how was the judex to find out the real meaning of the parties from a litis contestatio framed in that manner? The result, inevitable in such circumstances, was, that the litis contestatio became a mere mask for covering a variety of cases of a widely different character. Thus it happened, often enough, that the formulating of the legal issue, as carried out in the litis contestatio was a mere pretence. In order therefore to pierce the mask and discover the true nature of the issue before him, the judge had to resort to other expedients.

To all this must be added one other circumstance. The legis actio procedure was, so to speak, cut down and restricted to a definite number of statutable claims. It was a difficult matter (as we see in the case of the arbores and vites) to force a new law into the old moulds. But from about the middle of the third century B.C. onwards, as the inroads of the jus gentium became stronger and stronger, a large number of fresh claims arose, such as the bonae fidei judicia, the claims on informal sales, letting and hiring, and others, not based on, nor recognized by, any Roman statute, and lacking therefore the necessary credentials without which the procedure by legis actio remained closed to them. A new law for which there was no room within the narrow confines of the old legis actio was pushing its way into the Roman system. ${ }^{n}$ New skins were needed for the new wine."

And so it happened that at the same time when the forms of legal redress supplied by the legis actio began to fall short of the material requirements of the law, the necessity for a reform in Roman civil procedure (the legis actio procedure) became more pronounced.

It is characteristic of the tendency which marks the development of Roman law that a remedy by means of legislative enactment was not resorted to. It was time enough to invoke the interference of so melastic an agency, when the aim and method of the desired reform had been clearly ascertained. Meanwhile the judicature was left to its own resources. The task of reforming Roman law thus naturally devolved on the praetor.

The praetor was enabled to act the part of a reformer by means of his imperium, i.e. by means of that regal power - formally unrestricted and subject only to the intercession of a magistrate of equal or superior authority - which he wielded during his year of office. It was in the exercise of his imperium that he appointed a private person judex, i.e. compelled him by his order to lecide a legal dispute. Where the conditions of a legis actio existed, the praetor appointed the judex in accordance with the 
law, and in such cases the plaintiff had even a statutory right to the appointment. But the praetor had also the power to appoint a judex apart from the law, 'sine lege,' ' simply in virtue of his sovereign imperative power (judicium imperio continens). And this power he exereised in all those cases where there was no lecris actio, no statutable claim, but where the claim preferred was, nevertheless, such as to be, in lis cpinion, deserving of legal protection. The praetor, taking the responsibility on his own official authority, ordered the appointed judex, under certain conditions, to condemn or acquit, as the case might be. And since, in such cases, a legis actio, a formulating of the issue by solemn act of the parties, was quite foreign to the matter in hand, the task of formulating the issue, and in this respect of fulfilling the functions of the legis actio, was performed by the praetor himself in the written decree which he drew up in appointing the judex. This decree was called 'formula,' because it soon became the practice to frame it after the model of certain 'forms' or 'formulae' set out in the praetorian album. Thus two different kinds of procedure came to be opposed to one another: the legis actio procedure and the formulary procedure, the essence of the latter being that, under it, the issue was formulated for the judex, and the ground work and purpose of his functions as a judex were marked out, not by the legis actio (i.e. by the oral formula delivered by the parties), but by the decree of appointment (i.e. by the written formula delivered by the magistrate).

Of course the praetor would not use his imperium in this fashion unless, and as far as, there was occasion for him to do so, i.e. only where the exigencies of legal progress drove lim to such a course. And this was precisely what occurred when the recognition of the jus gentium became a matter of imperative necessity. At the outset the formulary procedure was nothing more than a new form of procedure according to the jus honorarium, and was designed above all things to supply a method by which claims resting on the jus gentium could be realized. In this way the jus honorarium and the jus gentium, mutually coöperating with one another, advanced, as it were, hand in hand.

If this view of the case be correct, it may be presumed that the praetor peregrinus was the first to find oceasion to proced $\mathrm{h}_{\mathrm{i}}$ means of the formulary procelure. Whenever a peresrinus pos-

${ }^{1}$ Cp. Cicero. "de Off." iii. 15, 61 : sime loge judiria, in quibus anditur. ex fide bona; "pro Q. Rosero." v. 1.,: arbitria honor"aria: "pro Flareo," 21,50: jurlicium lege non erat (Scil. in the provineo). ("p. Eisele, "Ahhandlungen," pp. ss, 17. 
sessed the Roman jus commercii, he stood under no disability either in regard to Roman private law or in regard to the Roman law of procedure, and in such cases therefore there was nothing to prevent the use of the legis actio even in the court of the praetor peregrinus. But the establishment of the foreign praetorship comcides precisely with the time when, as a matter of fact, the jus gentium had already become the law properly applicable to the great majority of aliens. [The legis actio, however, was juris civilis, not juris gentium. A new form of procedure was thus urgently demanded by the requirements of such non-privileged aliens. It was to satisfy this want that the formulary procedure was employed.

But in the court of the praetor urbanus the development of the law was rapidly leading to an identical result. His jurisdiction was confined to cases where both parties were Roman citizens. But Roman citizens as well as aliens acknowledged the jus gentium, and the existence of legal liabilities arising from sale, hire, and other such transactions. Thus exactly the same agencies were at work pressing the praetor urbanus to develop the formulary in addition to the legis actio procedure. Whenever the claim which it was sought to enforce in his cont admitted of legis actio, the legis actio procedure applied; in all other cases the formulary procedure was resorted to.

There is, however, no doubt that the formulary procedure steadily gained ground, and soon even began to dislodge the older procedure from its own peculiar domain. In the first instance the formulary procedure had only been resorted to juris civilis supplendi gratia, but it was not long before it proceeded a step further and boldly asserted its power to correct the civil or legis actio procedure. We have already pointed out that in many instances the mode in which the issue was formulated in the legis actio was inadequate and in no way indicative of the real facts of the case. In addition to this, the legis actio never got beyond an oral joinder of issue. And yet a single mistake in a single word entailed the loss of the whole suit. It is most probable that in a great many cases the evidence supplied by the mere statements of witnesses in regard to the words spoken in jure was felt to be obviously inadequate. All such inconveniences would be obviated, if the formula, the force and value of which the people had not been slow to appreciate, were used even in cases which, in themselves, admitted of the procedure by legis actio. The legis actio of the parties was tied to the verba legis and was thereby, in many cases, reduced to absolute unreality and hollowness. The magisterial formula, on the other 
hand, was unfettered; it contained the real matter at issue and not a mere empty form beneath which the truth lay concealerl. Accordingly, whenever the praetor addressed a witten order to the judex, there could be no doubt whatever, as far as the judex was concerned, as to the precise question upon which his verdict was required, and all the risks attending the use of a wromg word were, at the same time, avoided. 'Thus even where the procedure by legis actio was really available, there were sound practical reasons why the praetor should exercise his right to nominate a julge with a view to binding his nominee to act on the instructions (on the formula, namely) which he (the praetor) gave him.

Whether in such circumstances the formula and legis actio were used concurrently, or, as is more probable, the formula was substituted for the legis actio, in either (ase there was a distinct conflict between the civil law (which required legis actio) and the praetorian law (which gave the formula), a conflict, the sharpness of which must have been all the more noticeable, because at that time the praetorian power was as yet in the earliest stages of its revelopment, and the legis actio was associated with the powerful influence of the pontifices. It was the pontifices who created, developed and interpreted the legis actio. To assail the legis actio was to assail the influence which the pontifical jurisprudence exercised over civil procedure and consequently over the interpretation of the civil law itself. By giving preference to the formula, the practor thus came into collision with that influential college which till then had been the sole depositary of the civil law. It was at this moment that interference by legislative enactment became necessary.

The popular enactment which struck in at this point was the lex Aebutia (about 150 B.c.). Two other laws (the leges Juliae) followed at a later date, probably not till Augustus. The lex Aebutia was confined to legal proceedings before the praetor urbanus, i.e. to those cases where a judicium was appointed to try a cause between Roman citizens within the first milestone from Rome, in short, to those very proceedings to which the legis actio was most strictly applicable. It provided that a jullicium coukl be instituted in the city court (i.e. in the court of the prictor urbanus) without legis actio, merely by means of the formula or praetorian decree of appointment. The enceat controversy was thereby settled. Within the court of the prator urbanus the formulary procedure had been declared a civil law modus agendi. Formula and legis actio were thus, as far as the civil law wats concerned, placed on a footing of equality. In the city court the 
formulary procedure was now likewise a procedure 'ex lege,' and the judicium, which the praetor urbanus directed by means of his formula only, was now converted into a judicium legitimum. Henceforth the term judicia imperio continentia (judicia quae imperio continentur) was applied exclusively to the jurlicia appointed by the practor peregrinus or to those which were held outside Rome. With regard to these no change of procelure took place. The magisterial imperinm did not need any assistance from popular legislation, because its authority in these courts was unquestioned. The city court of the praetor urbanus, on the other hand, was, so to speak, the stronghold of the civil law and the legis actio, that peculiarly Roman form of civil procedure. The power of the praetor urbanus was, in truth, unequal to the task of ousting the legis actio from its strongest position. The assistance of the legislature was needed, and the method employed was to depreciate the legis actio - at once the product, and the source of power of, the pontifical jurisprudence - by investing the formula, for purposes of the city court, with a legal character. Thus the formulary procedure became legally available even in civil law causes. The legis actio procedure was not yet actually abolished. An option was left to the parties whether they would proceed by legis actio after the old fashion, or would avail themselves of the formula after the new method. The formula had, however, secured free scope for itself. It had now an opportunity of putting forth all its inherent capabilities. And in the competition between the two forms of procedure, there was, from the outset, no doubt which would win. In the legis actio procedure the formulating of the issue was an act full of pitfalls for the parties, inelastic and rigidly formal; in the formulary procedure the same act, stripperl as it was of all the old formalism, had acquired elasticity, a capability of indefinite expansion, and a ready adaptability to claims of all kinds. Everything, in short, was in favour of the formula. The natural result was that, in the practice of the courts, the formulary procedure came, by universal consent, to be substituted for the legis actio procedure in the vast majority of cases. The culminating point was marked by the two leges Juliae which, like the lex Aebutia, were concerned with the procedure of the court of the praetor urbanus, and provided that henceforth the appointment of sworn judges should only be effected by means of a formula, and not on the ground of a preceding legis actio. The effect was, practically, and with a few exceptions presently to be mentioned, to abolish the legis actio. The formulary procedure had now 
become the civil procedure of Roman law. The object of the proceedings in jure had been definitely changed, the place of the old litis contestatio being taken by the grant of the formula, which now constituted the principal and also the concluding act of these proceedings. Henceforth it was the question contained in the formula and no other which the judex was required to decide in judicio.

The so-called 'introduction' of the formulary procedure by' means of the above-mentioned enactments was, if our riew be the true one, a process of the kind we have just detailed. It was not, as we see, a sudden reform, a revolution, but merely the consummation of what had been gradually preparing itself. These laws were not the first to introduce the magisterial formula; what they did was merely to emphasize the final rictory of this formula over the oral formula of the parties, which had long existed side by side with it, a victory which itself was due to the logical necessities of the progressive evolution of the law.

There are two further facts which tend to corroborate and, at the same time, to illustrate our view of the character of that development of the formulary procedure which we have just endeavoured to render plausible.

The first of these facts is this, that whenever an action was to be decided in judicio by the judges of the so-called 'centumviral court,' a magisterial formula was not used, the proceedings being conducted in accordance with the forms of the ancient legis actio procedure (L. A. sacramento) - a practice which continued without break throughout the whole classical period of the empire at least as late as Diocletian. Actions concerning inheritances therefore, which in later times were certainly the most important subjectmatter for the jurisdiction of the centumviral court, were still conducted according to the old traditional forms of the legis actio sacramento. And the reason was simply this, that the centumriral court already constituted a standing college of judges which did not require to be called into existence in each separate instance by the written decree of the practor. In such cases there was accordingly no possibility of instituting a judicium, because a competent judicium, viz. the centumviral judicium, was already fortleoming. And inasmuch as this judicium was not called into existence by the decree of appointment (the imperium), the pratetor wats unable to bind the centumriri by instructions as to the conditions under which they were to eondenm or acquit respectird!. 'The absence of the praetorian decree of appointment thus explains 
evcrything; it explains why, in these cases, the formula did not come into use concurrently with the legis actio, and why the ancient litis contestatio was preserved; why, in short, in causes coming before the centumviral court the legis actio (sacramento) was not superseded by the formulary procedure. In the judicia privata, where a private individual had each time to be appointed judex for the nonce, the ancient ceremony of litis contestatio had found a rival in the praetorian decree of appointment; no such rivalry could spring up where there was no judex to appoint. ${ }^{1}$

'The second fact has reference to the so-called 'voluntary jurisdiction,' i.e. that kind of judicial procedure which serves the purpose, not of determining rights which are in dispute, but of establishing new rights. An example of this jurisdiction occurs in the case of in jure cessio, i.e. the transfer of a right by means of a confessio in jure. Inasmuch as, in this case, the allegation of title put forward by the fictitious plaintiff (the transferee of the right) is immediately followed in jure, before the magistrate, by the jural confession of the fictitious defendant (the transferor), no necessity, of course, arises for proceeding to a judicium, simply because there is no legal issue to decide. For the very same reason there is also no occasion for a formula, because there is no judex to appoint. The result was that in jure cessio, as long as it existed (i.e. throughout the whole classical period and even longer), retained the forms of the legis actio procedure, the particular legis actio employed being again the L. A. sacramento.

Both these facts signify one and the same thing, namely that where there is no occasion for instituting a judicium in any particular case by means of a decree of appointment, in every such case there is neither formula nor formulary procedure, and the ancient legis actio procedure holds its own.

The lex Aebutia and the leges Juliae did not simply abolish the legis actio procedure and substitute the formulary procedure in its place. What they did was rather this: wherever, as a matter of fact, the formulary procedure was already in practical use, in other words, wherever, as a matter of fact, the sententia of the judex already proceeded on the basis, not of the old litis contestatio, but

${ }^{1}$ The decemviral court was dissolved by Augustus; otherwise it is certain (as is very happily pointed out by Mommsen, "Staatsr." vol. ii. p. 592, note 1) that the old legis actio sacramento would have been preserved in cases coming before it (actions relating to personal freedom). Of course there was no more occasion for the use of a formula or decree of appointment for the decemviral court than there was for the centumviral court. 
of the magisterial formula, in those cases alone (and they formed, it is true, the great majority) the above-nentioned laws confirmed the formulary procedure, and at the same time swept away the fosilized relics of the concurrent legis actio procedure. But where the formulary procedure was not in use - as in the cases falling under the jurisdiction of the centumviral court and the cases of 'rolumtary jurisdiction,' and damnum infectum - the laws referred to did not introduce the formulary procedure.

Thus in matters coming before the centumviral court the old legis actio sacramento remained, but in all cases of judicia privata the formulary procedure henceforth prevailed. The change meant simply this, that henceforward the judex, in order to find an authoritative statement of the issue upon which he was to deliver his sententia, would have to look to the magisterial decree of appointment, i.e. the communication which the praetor convered to him in reference to the legal issue submitted to his decision. In other respects everything remained as before. The severance of jus and judicium remained, nor was the old rule altered that the magistrate's functions were restricted to introducing, allowing and formulating the issue, the final decision being reserved for the verdict of the judex. Nothing was changed except that the formal foundation of the judicium had been shifted. In effecting such a reform by means of the lex Aebutia and the leges. Juliae, it is quite possible that men merely imagined they were ridding themselves of some futile and antiquated formalities, and perhaps also (at the time of the lex Acbutia) of the predominant influence of the pontifices orer the legal procedure of the city of liome. The reform, such as it was, was probably not regarded as possessing any unusual significance, and it is hardly to be supposed that the Romans were conscious of having accomplished anything great, more especially as the idea of a fundamental reform of civil procedure never occurred to their minds, as we see from the manner in which they treated matters appertaining to the centumviral court.

In real truth, however, the reform which had thus been carried to its conclusion, was one of the utmost importance in its far-reaching practical results.

\section{The Formula}

The granting of the formula, i.e. the decree by which the judex, or the several recuperatores, were appointed, had now become the medium by which the litis contestatio was carried out. In other words, it formulated the legal issue for the purpose of a decision in 
judicio. ${ }^{1}$ The written formula of the magistrate superseded the oral formula of the parties.

In point of legal force this new lind of litis contestatio was theoretically inferior to the solemn act of the parties in the legis actio proccdure. An act of writing was, in the eye of the early law, an informal act devoid of all solemnity, and was therefore, in the legal sense of the jus civile, really no actio at all, i.e. it was not an act by which a person's statutable right of action was, at the same time, exercised and exhausted. As far as its nature and the law were concerned, the formula could, ipso jure civili, be retracted, repeated, or amended, if the decree of the practor so directed. For the civil law it had simply no existence, since it was a mere creation of the jus honorarium ; at civil law therefore it was not a litis contestatio at all, so that there was legally speaking (ipso jure) nothing to prevent the identical claim being brought before the praetor by action and carried on to the judicium twice over. The lex Aebutia and the two leges Juliae made the formulary procedure as applied in the judicium legitimum the only exception. In this particular instance the civil law had given its recognition to the formulary procedure. If a suit were commenced in the judicium legitimum with an actio in personam and an intentio juris civilis, the effect was ipso jure to consume the right of action and render any repetition of the proceedings impossible, just as had been the case with the old legis actio. In all other cases however - and they formed the great majority - the praetor was obliged, in each separate instance, to insert an explicit instruction, in the shape of an express 'exceptio rei judicatae vel in judicium deductae,' in order to prevent a cause which, under the formulary procedure, had already led to the institution of a judicium, or perhaps even been carried to the final judgment, from passing through every stage of the action a second time. From this it appears that it was not the action as such (neither the institution of the judicium nor the sententia of the judex) which operated to consume the right of action in the early law of procedure, but solely that solemn legal act by means of which the party himself brought about the appointment of a judex, in other words, the legis actio in the strict sense of the term, the old formal litis contestatio. And this very act had been dropped in the formulary procedure. In contemplation of law, the operative force of the granting of the formula was - apart from

${ }^{1}$ The formula granted by the praetor was either handed to, or occasionally dictated to, the defendant by the plaintiff. 
the exception adverted to - inferior to that of the old litis contestatio.

Nevertheless this modest formula, this written notice so bald and succinct, which the praetor convered to the judex, contained potentially the entire ifuture development not only of the law of Roman civil procedure, but also of Roman private law and, with it, of Roman law in general.

The ancient legis actio procedure, with its litis contestatio tied to set traditional words, offered but an extremely limited choice of way's in which to formulate the legal issue. If none of these traditional forms was strictly appropriate, the only remedy supplied by the civil law was to have recourse to the so-called "procedure by sponsio' (agere per sponsionem). A made a formal promise (sponsio) to his opponent $B$ that, if the allegation of fact or law put forward by B were true, he (A) would pay a sum of money. This sponsio could be enforced by a legis actio sacramento in personam, and the judicium on the sponsio would involve a judicium and sententia on the question of law or fact which formed the basis of the promise. The amount of the sponsio was never actually paid, because a sponsio of this kind (a so-called 'sponsio praejudicialis') was not designed for the recovery of a sum of moner, but was merely intended to bring on an action; to serve, so to speak, as a device for forcing on legal proceedings. ${ }^{1}$

On the other hand, there was no tradition to fetter the formula of the praetor. In the old litis contestatio the issue was formulated in narrowly prescribed terms; in the new formula the terms used were informal and freely chosen by the magistrate. The formula was thus well adapted as a means for directly submitting to the decision of a judex in judicio any question, or complex of questions, which the praetor deemed actionable. The praetor himself was now in a position, while formulating the legal issue, to give the judex at the same time direct instructions in reference to the decision of such issue. For whether the judge condemned or acquitted depended now solely on the manner in which the prater formulated the question in dispute.

The formula was bound to become, and did in fact become, the

${ }^{1}$ It was different with the so-called 'sponsio poenalis,' whirll was a sponsio on the result of an artion, the parties themselves contemplating the payment of the money. On thedefonrlant tendering a sponsio poenalis. the plaintiff had to reply with a 'repromissio, i.e. a promise to pay the same amount if defeated in the artion. No repromisso was required in the ease of the sponsio maejudiojalis. Gaj. Ir. \$\$ 1\%, 94, 171; Bekker, "Actionen," vol. i. p. $213 \mathrm{fir}$. 
instrument by means of which not only the worling, but also the decision of the legal issue was cmancipated from the trammels of the ancient statute-law and the exclusive influence of the civil law. The formula, in a word, was the weapon by which the praetor and his jus honorarium were enabled to assert their dominant influence over the whole development of Roman law.

The legis actio and everything comnected with its development and interpretation was in the hands, not of the praetor, but of the pontifices. In the legis actio procedure the judex was independent of praetorian instructions. Officially he was only bound to abide by such instructions regarding his judicium as were contained in the solemn litis contestatio of the parties, and in giving his decision on the issue thus joined, he was obliged to act in accordance with the civil law, and more especially in accordance with the pontifical interpretatio. In jure the magisterial power was paramount, in judicio, however, the old civil law, preserved and handed down by statute and pontifical tradition, and operating through the judex as its organ, held absolute sway. But now the relation between the jus praetorium and jus civile was altered. The praetorian decree of appointment (formula) had come to be binding even in civil law matters. That is to say, even in civil law cases, it was now not enough that the judex should simply decide in accordance with the civil law; he was obliged, in the first instance, to decide on the basis of the praetorian formula, having regard always to such limitations and instructions as were conveyed in that formula. Thus within the domain of the civil as well as the praetorian law the judex became dependent on the praetor. He was bound by the instructions (formula) of the praetor to acquit the defendant even where, according to the civil law, he ought to have condemned him. In other cases he was bound conversely, in virtue of the praetor's instructions again, to condemn the defendant where the civil law would have required his acquittal. With one stroke the judex had been converted from an organ of the civil law into an organ, in the first instance, of the praetorian law.

Through the medium of the formula the praetor was now master of the whole legal procedure, including the procedure in civil law causes, and the edict began henceforth to dominate the practice and development of the law. Apart from the centumviral causes, the enforcement, in the courts, of the civil law was now entirely subject to the limitations which the praetor in his edict thought fit to impose on it.... 
The judiex ceases to be, even for the jus civile, an independent private individual, bound by nothing but the positive law. He becomes an organ of the magisterial power and is already beginning to assume the character of a subordinate official. Thus the development of the formulary procedure was a deeisive element in paring the way for the subsequent elimination of the distinction between jus and judicium. And while this seeuring full control over the judex, the praetor at the same time definitely appropriated to himself a predominant influence over the whole evolution of Roman law. The formulary procedure marks the beginning of that vigorous derelopment of the jus honorarium, so momentous in its consequences, which resulted in the metamorphosis of the jus civile and the birth of classical Roman law. A reform of procedure was followed by a reform of the law itself.

\section{Section $S$}

\section{EVOLUTION OF PROCEDURE ${ }^{1}$}

Procedure, criminal and civil, exhibits to us a full crop of interesting similarities between the different historic systems.

$\S 1$. Methods of Proof. - In criminal procedure, we naturally find proof by witnesses and by confession universally employed, though with prodigious variety of importance. One might be surprised, however, to discover that every primitive or barbarous people has made use of that mrstical expert testimony known as the ordeal, in which human life seems almost like the stake in a game of chance or skill. Still more surprising is it, howerer, to find that the forms of the ordeal apparently vary little from people to people. 'The judicial duel, or wager of battle, it is truc, was not everywhere practised ; it could only develop spontancously in a pugnacious tribe; no pacifie-minded people (and there are many such, even among so-called savages) could have devised it. Neither in the Brahmanic corles nor in the Arestal is it found ; but we meet it in the tribes of America, Australia, and Occanica, an well as in the Old World. The ordeals by boiling water and by red-hot iron were widespread; they appear in India, l'ersial,

${ }^{1}$ [By Gabriel Tame. Trans]ated by Iohn $I J$. Wigmore from "h. 11 of that author's "Les transformations di droit, eturle somologigne" (1:t ed. 1893, 7th ed. 1912, Paris), with the consont of NIme. Tiarde. M. Tarde, famous alike as jurist, socologist, and psowhologist, died in 190!?; an aceoment of his rareer will be fomml in the Preface to the translation of his "Penal Philosophy" (1913, Morlen (rimina! Scince Series)]. 
Georgia, Bohemia, Poland, Serbia, Sweden, Norway, Denmark, Germany, and elsewhere. Phanly this extension was due to imitation induced by contact. But what motive accounts for such a popularity? Te must infer that wherever this superstitious resort to divine intervention was acclimatized from without, it served as a substitute for even more irrational or cruel practices which hat preceded it.

As a general truth, there appears to have been a certain logieal and irreversible order (not however a constant one) in the historical succession of the ordeats, at least wherever the judicial duel was employed. They seem to have followed each other with gradual mollification, - illustrating that general principle of minimum effort which dominates changes in industries, as well as in rituals, phonetics, and grammars. The inclination of our modern courts to treat the penal law from the point of view of correction and reform is an example of the same general tendeney. Thus the judicial duel - the most senseless and bloody of the ordeals, and the one least capable of popularization - gave place usually to the ordeals of water and of fire, - practices more humane than one might imagine, and more capable of evasion. And finally they are all supplanted by the oath, which may be regarterl (as M. Dareste well says) as a "milder and simplified form " of the judicial duel. ${ }^{1}$ The oath usually preceded all the others, and invariably survived them. As far back as we go, and even where no trace of the judicial duel is found, nor of any other ordeal, the primary proof is the oath.

In the Sutras, the carliest Brahmanic codes, the only proofs are those of water and of fire; as yet the parties' oaths do not appear; but we see the witness' oath beginning to be used, and it tends to predominate. In the code of Manu, later than the Sutras, which marked a new epoch in the Brahmanic system, proof was made by witnesses, and when necessary, by the party's oath. The Ossetes of the Caucasus (where many archaisms of law survive) make use to-day of only the oath and the usual sorts of proof; but there is evidence that the judicial duel and the other ordeals were formerly in use, and traces of them remain. In all the peoples of Germanic race, the judicial duel was the earliest procedure; those countries were the cradle of the method, and in them originated the various changes which it underwent, down

${ }^{1}$ From the oath of Merovingian times to our present-day oath, particularly to the parties" "dereisory" onth and to the witness-oath, is but a single step, and the transition is easy to trace. Our oath is itself, therefore (though only one form) a relic of the "decision of God." 
to the neo-chivalrie absurdities of the modern duel. Since the time of Tacitus they practiserl a divinatory duel, of which the jueliciat duel was the natural product. That they used (in the carly period) the ordeal by boiling water, is doubtful ; for 'Tacitus does not mention it; but it appears by the time of the Salic code, as also the oath of the party and his compurators. In swerlen, Norway, and Denmark, the judicial ducl wats abolisherl about A.D. 1000, under Christian influences, and the ordeal of rerl-hot iron replaced it. In the 1200 s the latter was in its turn suppressed (but not without popular opposition). With this climination of the "deeision of Gorl," there remained only the proof by oath of the party and his eompurgators. ${ }^{1}$

In Iceland also the duel was abolished, A.D. 1011, under the infuence of Christian ideas; then the ordeal of red-hot iron prevailed; and finally the oath, not taken by the party, but by a group of neighbors not unlike the Merovingian compurgators. In Ireland, the abolition of the judicial duel goes back to st. Patrick, in the $400 \mathrm{~s}$; it was supplanted by the orteal of boiling water, mentioned in the Senchus Mor; then by the oath of the party and his compurgators.

Among all the Slavic peoples - Czechs, Russians, Poles, cte. - the judicial duel was the primitive eustom. With the Czechs it was specially applicable to homicide, - a murderous proceeding suitable for a charge of murder. But in certain cases, the oath was substituted, viz. where the party was incapable of a combat; and this exception became the rule, - gradually, no doubt. If a house was attacked by night, the accused could exoneratc himself by taking oath, with two fingers resting on a red-hot iron, - an original combination of two morks of proof. But in case of injury to a crop, the accused exonerated himself by an oath corroborated by witnesses, and these witnesses, we are told, took the place of the boiling water formerly used. In l'oland, the judicial duel had been usual; but if the aceused proved that he was not fit to fight, they resorted to the ordcal of red-lot iron. The oath was also allowed, but was required only for wrongs of minor importance; these being the more numerous, it was natural that the oath should become finally the normal methorl; and in the statute of Wislica $(1300 \mathrm{~s}$ and $\mathrm{i} 400 \mathrm{~s})$, which abrograted many old customs, we read that neither ordeal nor judicial duel are any

${ }^{1}$ Plainly this parallelism in the order of sucression in these thres lingdoms, as well as anong the (Gsetes and the others, has nothing surprising in it; the same historic eause, viz. the preaching of the (iospel, naturally had the same effects. 
longer employed; the oath still plays a prominent rôle; and sometimes compurgators are required. The Lithuanian code, like the Polish code, which influenced it, provided for proof by the complainant's oath, in case of homicide, or wounding. In Russia, in the $900 \mathrm{~s}$, the judicial duel was widespread; whether the ordeals by fire or by water were used does not appear. But the dominant proof was the complainant's oath, together with circumstantial presumptions. In Dalmatia, in the $1200 \mathrm{~s}$, the oath was the most esteemed proof, - taken by the complainant, if he had witnesses, otherwise by the accused; when compurgators were required, and the required number were lacking, the party could make up the deficiency by repeating his own oath to the required number of times. In Hungary, the judicial duel is exceptionally found to survive the ordeal of the red-hot iron, which in the $1200 \mathrm{~s}$ was used for deciding nine-tenths of the eases. But the duel, in its later persistence, was much modified and had no mortal features; and while the ordeal was in favor, the clergy were allowed to substitute the oath for it. Finally, we note that, in the Serbian code of the $1300 \mathrm{~s}$, the favorite mode of proof was not the oath (as in the neighboring peoples), but the decision of God by boiling water and by red-hot iron. ${ }^{1}$

This rapid survey will suffice for allowing us to interpret the true nature of the similitudes observable between peoples most of whom have been in relations of successive contact with one another.

Note, first, that the formulas of invocation used for the ordeals of fire and of water were the same throughout Christendom. This little circumstance reveals plainly the important rôle played by Imitation in this point. And note also, as corroborative evidence, that among the Chinese and the Japanese there is no traee of ordeals; and that the acquaintance with them in Cambodia and Thibet, countries subject in all epochs to the influence of enlightenment from India and its imitative influenee, the ordeal there used was that of boiling oil, and probably of Hindu origin. In Madagascar, among the Hovas, and here and there throughout Afriea, the usual ordeal is that of a poisoned drink.

Note furthermore that though, in America and in Australia, as well as in the Old World, the judicial duel and some ordeals were practised, yet in the former the oath was not used; and that indeed the judicial oath is unknown among almost all wild tribes, ${ }^{2}$ while it is known among some peaceful and agricultural tribes. Here is

1 The foregoing data are taken from . .1 . Dareste's book.

2 Letourneau, "Evolution juridicue," p. 43. 
a difference which has its meaning, and which, taken with others, serves to restrict within their proper limits the similitules already observed. We have noticed that anong certain slavic peoples the complaint could be proved by the plaintiff or accuser, - an exception to the ordinary rule among primitive peoples. ${ }^{1}$ In both cases alike, to be sure - whether the accuser or the accused be allowed to settle the ease by his oath - we see the strength of the feeling of honor and of the holy horror attaching to the idea of perjury; but we certainly could not assert that the distinction between one party or the other taking the oath had no significance. The right of making proof by oath was regarded as a substantial advantage; and that is why, in all primitive legal systems, the "onus probandi" (nowadass become a "burden," but then a privilege) fell upon the accused or refendant. The truth is that the "burden of proof" was at one period generally" on the defenclant or accused, and afterwards in a later period passed to the complainant, until this latter principle, in our clay, has become an uirdisputed axiom. No one has cliscovered, so far as I am aware, an instance of the opposite transition, i.e. of the evolution of the duty of making proof from the complainant to the defendant. ${ }^{2}$ And this illustrates what I have above termed an irreversible process. And these instances of irreversibility, I confess, have to my mind much more value than the similitudes whose first impression is more striking; for they exhibit the working of the soeial logic."

Take another rule of proof, the rule "testis mus, testis nullus," which was universally in force in the European Middle Ages, and even in our day is still preserved in some of the Lnited States.

${ }^{1}$ I pass over minor differenees. Among the Aborigines of India, the judieial oath is taken on the skin of a tiger or a lizard; in Sumatra, on the grave of an ancestor; among the Cermans, originally, on a sword consecrated to the gods, and after their eonversion to Christianity, on the relies of a saint, as elsewhere upon the Gospel or the Koran. The women of Germany took oath "loy their breasts." Insignificant as these details may seem, they reveal none the less essential divergences of coneeptions as to the order of sanetity in the objects of their reverenee.

2 The causes for disqualifying witnesses exhibit an and logous inversion. Among the Arabs (Seignetle, loc. cit.), by the Musulman rode, the witness" relationship to the complainant, but not to the accused. authorizes the rejection of his testimony, - just the opposite of unr own rule. This difference is due to the aceusatury system; and as the growth of intercourse and the extension of the social group lod inevitahly to the sistem of official prosecution replaring that of private complaint. one may infer" here also that the transition from the Arab principle of disqualifieation of witnesses to our own principle is an irreversible proeess. - In our own law. even yet, when the injured party hrings a civil suit - the last rolic of the aceusatory system - he camot testify to the farets of his injury.

${ }^{3}$ [For the author"s theory of "sorial logie" in evolution, see the other passage from lis book, translated ante, in the Introduction, section III, $\S 1$, par. II.] 
One might suppose that this rule had its origin in human nature, and that its (relative) universality would be thus explained. But this rule requiring two witnesses is founded ${ }^{1}$ on the passage in St. John's Gospel: "In lege vestra scriptum est quod duorum hominum testimonium verum est"; and from that Gospel passage the Hebrew command spread over two worlds. Probably, also, this Jewish custom accounts for the Arab custom also requiring two witnesses. ${ }^{2}$

Take further the idea of compurgation. The Berbers of North Africa have always had compurgators; if fifty persons swear that he is innocent, he is acquitted. Is that an imitation of our analogous European institution? Perhaps, rather, it is a survival from a common body of tradition. Besides, the most natural expedient that would spontaneously occur to a man of the populace accused of a misdeed would be (if he lacked proof by witnesses or otherwise) to call upon his neighbors, relatives, and friends to bear witness formally to his good conduct and repute, his virtue and truthfulness. This idea is so natural that it must have given rise - in many countries simultaneously, and without any imitation - to an expedient analogous to our compurgation. Its almost universal use is easy to understand. Indeed, it can be said not to have wholly disappeared; for after the oath of compurgation had been abolished, the custom remained down into the $1700 \mathrm{~s}$ for the accused to be escorted to the courthouse by a long train of relatives and friends, whose mere presence was a silent and formal indorsement of his honorable character. And in our own day, the instinct to invoke such a popular indorsement is so strong that in most of the correctional tribunals and jury trials the accused parties get their counsel to read certificates of character fortified by interminable lists of names. And still more notably, when a popular personage happens to be publicly charged with misconduct reflecting upon his honor, and he happens thereafter to be a candidate for election to some office, do we not all believe (a few philosophers excepted) that his election by the majority is a sort of acquittal by the "vox populi," which passes always for the "vox Dei"? His electors are just so many compurgators. And we must admit that this proceeding, interpreted in its general principle, would take us straight back to primitive times. . . .

Let me now point out a general truth in the so-called evolution of law, applicable to the foregoing data, and illustrating the im-

1 Viollet, "Histoire du droit français," p. 26.

${ }^{2}$ But with this modification, viz. two men, or one man and two women. 
portant part played by imitation. ${ }^{1}$ If we take a jurilical invention all by itself - e.g. the judicial duel, the judicial oath, the ordeal by fire, the jury, proof by torture, or extradition, or for that matter, in other fields, adoption, lease on shares, etc. - and trace its course in history, nothing seems to show more dearly a process of Evolution; and the same is true when we trace a sperific wordroot or a myth or a machine or a method of art, thromgh its travels in space and time. But the moment we take sereral juridiral inventions together (even related ones) - such as the group of different ordeals or of different actions at law or forms of eivil procedure, or of sistems of relationship or succession, etc. - the moment we do this and attempt to describe as an "evolution" the gradual replacement of one by another, we then find that nothing is more obscure than this new sense of the word, - quite distinct from the former sense. And its obscurity is not due to the greater complexity of details (for they are not always more complex), but to something contradictory which makes itself felt, viz. a positive discontinuity and accidentality, concealed under that deceptive semblance of necessary continuity (or continuous necessity) which is inherent in the very notion of Evolution. Why, then, do we find this difference? Because, in the former of the two methorls of study, the changes observed consist principally in two things: 1 st, in the greater or less imitative propagation which has fallen to the lot of some juridical idea which was somewhere once invented by some ingenious brain (thanks to special (ircumstances) and spread gradually into new groups and was used for new purposes; $2 \mathrm{~d}$, in the greater or less belief in its efficacy which attended this imitative diffusion. These two phenomena are indeed continuous; and they constitute a gemuine Evolution, - an ascending or a descending one, a development or a decline, according as they fulfil themselves in an increase or a decrease of imitation and of faith in their efficacy.

As an example, take the judicial ducl. Once this idlea was born ${ }^{2}$ - in some corner of Gaul or Germany - of making the

${ }^{1}$ [For this author's exposition of his theory of Imitation as the hasis of most so-called Evolution, see the Introduction to the present volume, section III, \& 1 .]

2 It was suggested by a much olker idea, mentioned by Tacitus. vi\%. that of making a warrior of their own army fight with a prisoner taken from the enemy, so as to divine the issue of the general battlo from the issue of this particular one. Thus the divinatory duel gave rise to the judicial duel. Yet they are two separate inventions; for the latter required a new mental combination, viz. the application of the jdea of consulting the divinity, by means of a single combat, not to the issue of a battle of two armies, but to the issue of a lawsuit of two men. 
parties fight, to find out which one was in the right, it spread, first to the surrounding peoples; then, within each, from one social stratum to the other, from the great to the humble. And, naturally it spread with an increasing faith in its effieaey, in proportion as their bloody expedient was seen to be extending among others; for the Burgundian Code of king Gondebad ${ }^{1}$ and the fulminations of the Christian eouncils ${ }^{2}$ show us what a frenzy of favor this procedure enjoyed in the Merovingian epoch. And finally we see its eredit exhausted and its desuetude proceeding by degrees, from the $1300 \mathrm{~s}$, the time of king St. Louis.

Now this progress followed by this decline - this wave of faith and desire which rises and then falls, exhibiting first an extension and then a restriction in its imitation - is a phenomenon so gencral that it might be termed universal and therefore necessary. But this would be none the less an error. There are some juridical ideas - e.g. the will and the mortgage - whose success, once they are somewhere introduced, maintains itself indefinitely. ${ }^{3}$ And there are others - e.g. divorce and adoption - whose eredit is subject to fluctuations, and then to revivals after a diseredit of a short period or even of centuries. And there are exceptional cases in which, in place of stearly movement, the variations of faith in them and of imitation of them proceed in inverse ratio, - the jury, for example, which still continues to spread over the world with its aequired momentum, though the confidence in its verdicts is everywhere at its lowest. And furthermore, if one examined carefully, it would be found that the spread or the desuetude of a juridical invention (as well as of a word, a ceremony, an artistic form, a moral precept, or an industrial tool) is due to special circumstances - mostly accidental - which have favored or opposed it. However this may be, and leaving causes out of consideration, the truth remains that the variations of imitation and of faith form a natural sequence, like those of any quantity in matter; and that, like these, they lend themselves to the idea of a rational connection, formulable in a kind of theorems. And some day these formulas will be discovered by the seience of statistics, - the transcendental mathematics of society.

1 [About 500 A.D.]

2 For the opposition to the judicial duel, see a summary account in $\$ 120$ of Brissaud's "History of French Public Law" (Continental Legal History Series, 1914).]

" "Indefinitely" is too strong a word. Here too there are exceptions. Mahomet abolished the will, which before his time obtained in preIslamitic eustoms (teste M. Seignette, who offers strong evidence in support of his view). 
But how could we ever hope to formulate (at leasi with analogous precision) the law (if there were one) of a totally different phenomenon, viz. of a change in qualities substituterd suressively for each other, and not of the same quantity in variable degrees? When the prator's formulary actions at liome replaced the "actio sacramenti" and all other forms of action - wh'n torture in the 1200 s replaced the judicial duel, and then, a century ago, the jury replaced torture - are such facts capable of comparison with the variations which we have above survered? It would be useless to argue that the substitution was gradual, that the beginning of the later institution joined on directly to the end of the earlier one, -- as one passes gradually from one color to the other in a rainbow. For the obstinate fact remains that, at a certain time and place, a new germ. we implanted, - more or less fortuitous and unforeseen, and even impossible to foresee though explainable after we see it, - just as nothing could possibly have enabled us to predict that the yellow in the rainbow would come next to the blue and the red next to the sellow, if we did not know those colors.

All this is meant to make clear that there are tro senses of the term Evolution, profoundly distinct, when applied to society, and that the error or the unconscious and insidious method of the evolutionists consists in confusing them: 1st, Evolution, in the most precise sense, signifies "imitative propagation, more or less extensive, from an example supplied by a first inventor"; 2d, Evolution, in a sense much more confused, signifies, "a metamorphosis in the style of Proteus, a series of different initiatives, more or less imperfectly connected." And this ambiguity learls to another. For when they tell us of an evolution which is uniform for all societies, the "uniformity" thus meant inchudes two things, (a) uniformity whose cause is an imitation of the same model, thus the transmission of the same tradition; and (b) uniformity whose cause is the identity (to a certain degree) of the human organism and the human mind, producing a coincidence in certain principal inventions, independently of each other, but muler the same neerls, and producing them successively in an order often nearly alike, by virtue of logical laws.

$\$ 2$. Procedure and Courts in general. In many primitive systems of procedure, it may be conceded - even in that of Athens — the proceedings begin, as did the "actio salcranenti" of the early Romans, by the parties' leposit of a smom of money, required before any other formality, to insure the parment of the expenses 
of justice. ${ }^{1}$ Sir IIenry Maine has pointed out ${ }^{2}$ the striking analogies between the forms of the primitive Roman "pignoris capio" and of the distraining of cattle so important in early English law. . . One may easily concede that the analogy remarked by Maine is probably attributable to that common fund of common traditions and institutions which we know to have been the heritage of all Indo-Furopean peoples." In other words, its cause is the imitation of the father by the son. Another analogy noted by the same author is explainable in the same way, viz., the practice of "sitting dharna," used by the Hindus, and that of "fasting on a person," once practised in Ireland. In both practices, the ereditor, to compel payment from a debtor, places limself before the latter's doorway, there to remain fasting indefinitely, until the debt is paid $;{ }^{4}$ the expected payment seldom was delayed, for public opinion would have wreaked itself upon the debtor who allowed his creditor to become exhausted or to die of starvation before the door. I will only note that this method of compulsion illustrates the depth of the sentiment of compassion among primitive peoples, and in no way gives support to the insensibility commonly attributed to them. ...

1 It is umpleasant to have to note that, from earliest beginnings, justiee appears evervwhere as essentially something that costs. I am tempted to add that many of the numerous fatal teehnicalities devised in eodes of rivil procedure recall nothing more strongly than the Polynesian islanders' taboo. I do not dare to speak jocosely on so lamentable a subject; but one example from a thousand I cannot refrain from giving. Some years ago, a farner in my neighborhood, well-to-do and reputable, D. by name, sued one of his neighbors, and after a summary proceeding not permitting an appeal, obtained a judgment for fr. 700 against his opponent. In entering the judgment, the error was made of failing to record that the witnesses had been sworn. Observe that they had indeed been duly sworn, as everybody well knew, but the record failed to mention the performance of this archaic ceremony. The losing party, taking advantage of this mandatory rule, appealed. The upper court set aside the judgment and remanded the case to another court. While awaiting this trial, the opponent filed a claim against D. for the eosts of the appeal, some fr. 1800 . The astonished and indignant D. was levied upon; his farm, which was his sole subsistence, was sold at an absurdly low priee, searcely enough to pay the claim for costs. Here was a man ruined by winning a lawsuit, - by winning it twice, indeed; for after the sale the second trial again resulted in his favor. D., overwhelmed by his misfortune, is threatened with mental derangement. And no wonder!

${ }^{2}$ [See, in this volume, p. 586 seq., and p. 591 seq.]

3 And even of many others; for the item of raee is here very secondary. The Semites show surprising resemblances to the Aryans in primitive legal ideas.

${ }_{4}$ Among the Hebrews, and thus in a different race, $M$. Dareste finds a traee of this procedure; the creditor cannot enter the debtor's house to make a seizure; "thou shalt remain without," says Deuteronomy, "and he shall give thee what he las." 
But, seeking for generalizations, let us now ask whether it is indeed proverl: 1st, That procedure and courts have had, as a like point of departure, one and the same cmbryonic condition; 2d, Whether, though perhaps starting from different conditions, they have ererywhere in their derelopment passed through a like order of successive phases; $3 \mathrm{~d}$, Whether, though by difierent roads, they tend to converge towards the same ideal perfection.

1. In the first place, where do we see any evilence of this initial resemblance, which some have so readily conceded? What reason have we to believe that the resemblance is anything but that illusive simplification, that effacement of contours and colors, which is produced by distance in time and space, and forms the mirage of philosophic historians? The turther we proceed into the desert of the past, the further rcceles this picture of primitive life as one and uniform, glittering before our eyes in the deceptive distance. It is a common error to conceive of the single, the homogeneous, the undifferentiated, as located at the begiming and bottom of things. Tet wherever we take the trouble to dig down for this supposed homogeneous, we come upon a swarming progeny of characteristic differences. We have only to observe the wild tribes still extant. In some of them, e.g. the Kabyles, the judicial function is exercised by the entire village; in others, it centers in the chief, a patriarch or a despot; in others, it is shared between the chief and the assembly; and perhaps we should discover some tribe which called in a stranger to be the impartial judge for their quarrels, like the "podestà" of the medieral Italian cities.

Let us beware of hasty generalizations. Maine himself was here too hasty. Because the old Roman "actiones legis," like other early srstems observer by him in India, consisted in srmbolic combats disputing over some article, he drew the inference that this "juristic drama" must have been the universal primitive type in procedure. And Letourneau makes the same inference; "all this mimicry was evidently meant to aroid a violent struggle while calling it to mind; and the forms of a creditor's levy are drawn from the primitive foray of violence, while serving to replace it." This sounds very plausible. For symbolism in procedure is common enough - in primitive penalties, for example, where the rule of "an eye for an eye" and personal revenge mutually explain each other. A sort of natural simmetry of opposites leads often to one thing reflecting the inage of another. And the symbol may be drawn from preciscly that other thing which it 
opposes and replaces. ${ }^{1}$ But to universalize this feature (which of course woukl be confined to imaginative peoples) is to make a cardinal mistake, - the mistake of the philologians who seek to explain the origin of all languages by onomatopoeia, that is, by vocal mimicry.2 It would be as unreasonable to generalize the universal begimings of criminal procedure (which must have come before civil procedure) as a sort of lynch-law ; for this summary proceeding is found among many peoples; ${ }^{3}$ but nobody would go so far as to infer that therefore all primitive peoples began by lyruhing. 'The conchusion is that the greatest diversity must have reigned in primitive procerlures, as in primitive languages.

2. In the second place, I do not find - any more than in the first item - any great similitude in the succession of phases through which the various procelures and judicial systems passed in their development, - mless it be such similitude as is attributable to imitation, direct or indirect. Direct imitation is found, as where the institutions of an alien people are copied. Indirect imitation is where, without copving, but through the general diffusion and exchange of examples - tribes becoming cities, cities becoming kingdoms or empires or great nations, and thus more civilized, i.e. complex - this gradual enlargement and gradual complexity has forced the procedure and the judicial system to adapt itself thereto. The successive forms of this arlaptation, to some extent vague, present a certain analogy. For example, when the city became larger, of course, a ling's justice replacerl that of the family tribunals for certain kinds of offences or claims. So, too, this gradual enlargement of the social group explains why (in almost all legal systems) the original rule, forbidding the suitor to plead by attorney and requiring him to attend in person, ended finally in not only permitting the use of an attorney but in requiring it. So, too, in the very small democratic

${ }^{1}$ For what could be more opnosed than reconciliation and revenge? And yet the ceremony of reconciliation among the Bohemians, in the $1300 \mathrm{~s}$, as describerl to us in the Moravian eustumals (Dureste, p. 166), is a symbolie vendetta. And what eould be moro opposed to war than a sport? And yet the games of cards and of chess, to name no others, are symbolic combats.

2 This hypothesis, much too simplificative, and rejected moreover by most scholars, is applicable only to those phrases invented by exceptional persons belonging to what $M$. Ribot and other psrehologists term the "auditive type" ("Revue philosophique," Oct. 1591, article by Ribot, on "(ieneral ldeas").

${ }^{3}$ Notably in Israel, where, alongside of the judgments of the kings and the Levites, we find the "jurlgments of zeal," $i . e$. the spontaneous execution of a criminal by an indignant erowd. Indignation is a very old thing, and therefore also the moral sentiment. 
States, the laws had to be roted directly by the assembled people, while in the large States they could be roted only by representatives. And, furthermore, as invention led to the domestication first of animals, then of plants, diffusing and exchanging them, and the tribe passed from the hunting to the pastoral stage, and then to the agricultural stage, which permitted fixity of location and density of population, it is plain that legal procedure must have grown rich and complex in detail, and the jubicial function must have become regularized and specialized.

But I do not perceive that (apart from direct borrowings) two peoples who remained entire strangers to each other exhibited any similitudes that could not be explained by the foregoing ronsiderations. .. A All that can be generalized, as to the successive transformations of procedure, is that, contrary to the common opinion, it becomes more and more formal as it advances (at least up to a certain age), i.e. more and more precise, regular, and minute. And why? For the same reason that the orthography of language develops an ever-increasing meticulosity, - in spite of the reformers of the moment, and in proportion to the progress of literatures.

3. But though there is no common point of departure, and no common path imposed on the judicial methods of diverse peoples. may we not at least say that they tend to the same point of arrival? Thus far, this pole-star of hypothesis has not revealed itself to my eyes. I do indeed see, in proportion as the ficld of civilization expands, a small number of procedural sistems replacing numerous diversified ones. And it may be that this progressive elimination will lead finally to the reign of a single system, i.e. the procedural system (as well as the language) peculiar to that nation which proves most invasive, most obstreperous, most full of prestige. For it is beyond doubt that, by the laws of imitation. and just because we start with a diversity of original things each of which aspires to make itself universally imitated, some day a unity will come about by the trimmph of one of them. Thus it was that the Roman empire as a juridical unity was formed by the superposition of the law of the city of Rome upon the Etruscan law, the Celtie law, the Hellenic law, and the others. But that sort of uniformity is very different from the uniformity produced by inherent finality or purpose in nature, the necessiary effece of the concurrence of contacts, whether imitative, spontaneons. or foreed, - very different from the milormity caused ly that necessity that every system of law, developing in isolation, shall 
issue into a condition closely identical with that upon which all the others are converging (as if by some higher attractive force), and regardless of the various starting-points and of the diverse travels of each. ...

What need of further descending into concrete details? Does an ideal procedure imply necessarily the existence of barristers, attorneys, bailiff's? Clerks, yes, I concede that, since the invention of writing. ${ }^{1}$ But in ancient Eggpt, where trials were in writing, and though their juridical crolution was the longest, and reached the farthest point in its own type, of any in the whole world, there were no arguments and no lawyers. In China and in Japan there were no lawyers. In La Plata (and we all know that the peoples of South America are prond of their progressiveness) there are neither attorneys nor bailifis.

I do not say that that is the last word in perfection. But I believe that I am right in saying, No one can describe the Procedure of the Future.

It will be - what They will make it !

${ }^{1}$ Even among the Aztees, who used a sort of cursive painting for lack of a script, we find a clerk represented as "pictographing" the decisions. 



UNIVERSITY OF CALIFORNIA LIBRARY

Los Angeles

This book is DUE on the last date stamped below.

REC'

EEP \& 8 -

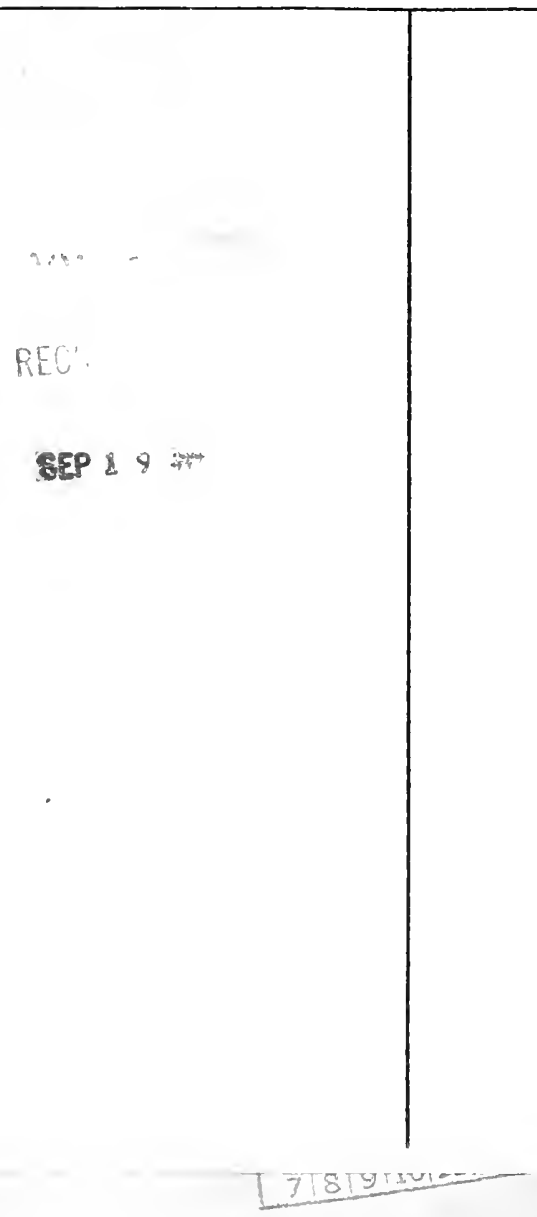


UC SOUTHERN REGIONAL LIBRARY FACILITY

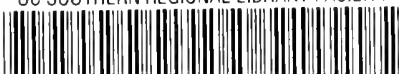

AA $000833768 \quad 5$
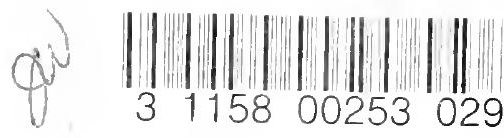
